National Water-Quality Assessment Program

\title{
Prioritization of Constituents for National- and Regional- Scale Ambient Monitoring of Water and Sediment in the United States
}

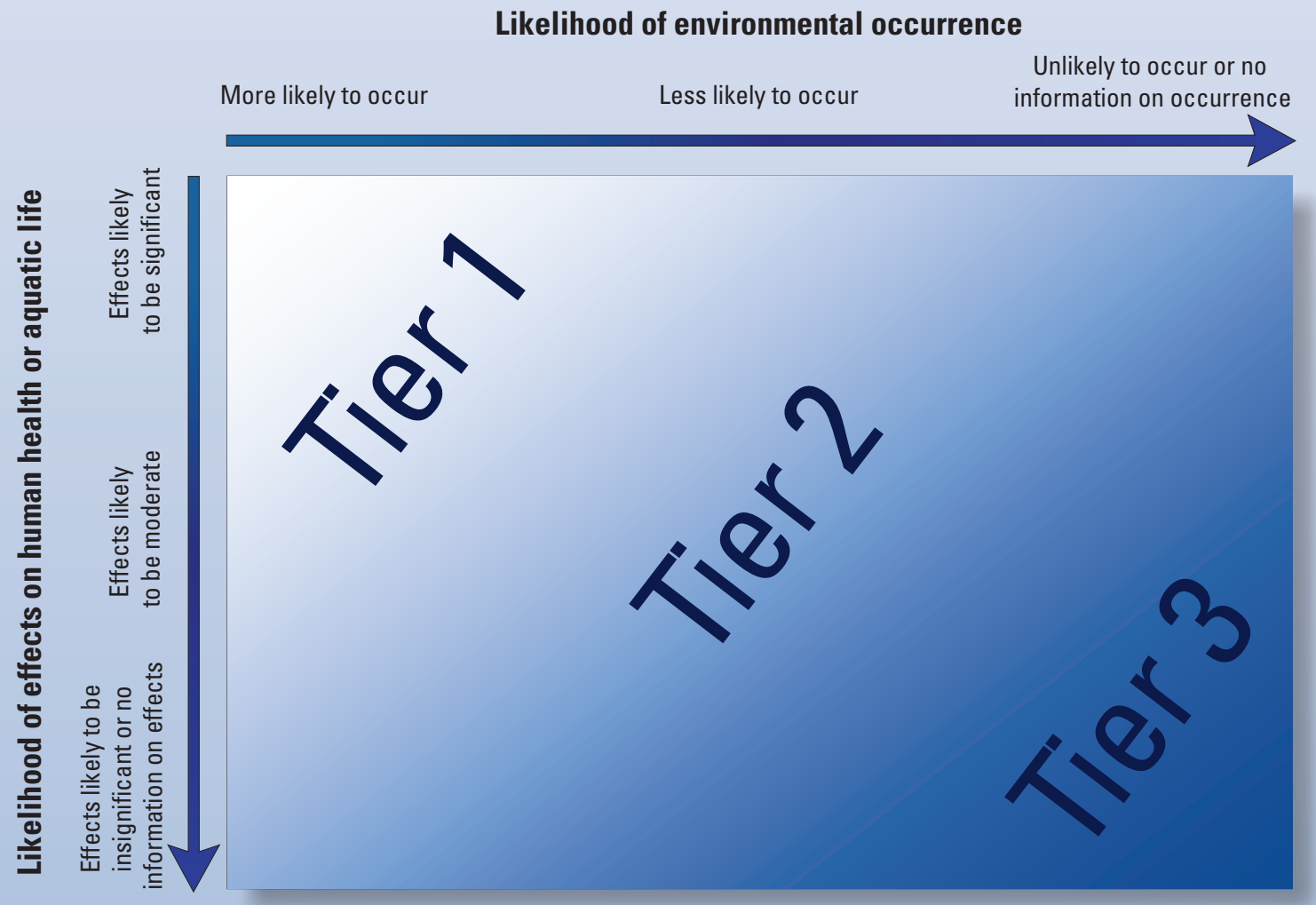

Scientific Investigations Report 2012-5218 



\section{Prioritization of Constituents for National- and Regional-Scale Ambient Monitoring of Water and Sediment in the United States}

By Lisa D. Olsen, Joshua F. Valder, Janet M. Carter, and John S. Zogorski

National Water-Quality Assessment Program

Scientific Investigations Report 2012-5218 


\title{
U.S. Department of the Interior SALLY JEWELL, Secretary
}

\section{U.S. Geological Survey Suzette M. Kimball, Acting Director}

\author{
U.S. Geological Survey, Reston, Virginia: 2013
}

For more information on the USGS - the Federal source for science about the Earth, its natural and living resources, natural hazards, and the environment, visit http://www.usgs.gov or call 1-888-ASK-USGS.

For an overview of USGS information products, including maps, imagery, and publications, visit http://www.usgs.gov/pubprod

To order this and other USGS information products, visit http://store.usgs.gov

Any use of trade, firm, or product names is for descriptive purposes only and does not imply endorsement by the U.S. Government.

Although this information product, for the most part, is in the public domain, it also may contain copyrighted materials as noted in the text. Permission to reproduce copyrighted items must be secured from the copyright owner.

Suggested citation:

Olsen, L.D., Valder, J.F., Carter, J.M., and Zogorski, J.S., 2013, Prioritization of constituents for national- and regionalscale ambient monitoring of water and sediment in the United States: U.S. Geological Survey Scientific Investigations Report 2012-5218, 203 p., plus supplemental tables, http://pubs.usgs.gov/sir/2012/5218/. 


\section{Foreword}

The U.S. Geological Survey (USGS) is committed to providing the Nation with reliable scientific information that helps to enhance and protect the overall quality of life and that facilitates effective management of water, biological, energy, and mineral resources ( $h t t p: / / w w w . u s g s$. gov/. Information on the Nation's water resources is critical to ensuring long-term availability of water that is safe for drinking and recreation and is suitable for industry, irrigation, and fish and wildlife. Population growth and increasing demands for water make the availability of that water, measured in terms of quantity and quality, even more essential to the long-term sustainability of our communities and ecosystems.

The USGS implemented the National Water-Quality Assessment (NAWQA) Program in 1991 to support national, regional, State, and local information needs and decisions related to waterquality management and policy (http://water.usgs.gov/nawqa). The NAWOA Program is designed to answer: What is the quality of our Nation's streams and groundwater? How are conditions changing over time? How do natural features and human activities affect the quality of streams and groundwater, and where are those effects most pronounced? By combining information on water chemistry, physical characteristics, stream habitat, and aquatic life, the NAWQA Program aims to provide science-based insights for current and emerging water issues and priorities. From 1991 to 2001, the NAWQA Program completed interdisciplinary assessments and established a baseline understanding of water-quality conditions in 51 of the Nation's river basins and aquifers, referred to as Study Units (http://water.usgs.gov/nawqa/studies/ study_units.html).

National and regional assessments are ongoing in the second decade (2001-2012) of the NAWQA Program as 42 of the 51 Study Units are selectively reassessed. These assessments extend the findings in the Study Units by determining water-quality status and trends at sites that have been consistently monitored for more than a decade, and filling critical gaps in characterizing the quality of surface water and groundwater. For example, increased emphasis has been placed on assessing the quality of source water and finished water associated with many of the Nation's largest community water systems. During the second decade, NAWQA is addressing five national priority topics that build an understanding of how natural features and human activities affect water quality, and establish links between sources of contaminants, the transport of those contaminants through the hydrologic system, and the potential effects of contaminants on humans and aquatic ecosystems. Included are studies on the fate of agricultural chemicals, effects of urbanization on stream ecosystems, bioaccumulation of mercury in stream ecosystems, effects of nutrient enrichment on aquatic ecosystems, and transport of contaminants to public-supply wells. In addition, national syntheses of information on pesticides, volatile organic compounds (VOCs), nutrients, trace elements, and aquatic ecology are continuing.

The USGS aims to disseminate credible, timely, and relevant science information to address practical and effective water-resource management and strategies that protect and restore water quality. We hope this NAWQA publication will provide you with insights and information to meet your needs, and will foster increased citizen awareness and involvement in the protection and restoration of our Nation's waters. 
The USGS recognizes that a national assessment by a single program cannot address all waterresource issues of interest. External coordination at all levels is critical for cost-effective management, regulation, and conservation of our Nation's water resources. The NAWQA Program, therefore, depends on advice and information from other agencies-Federal, State, regional, interstate, Tribal, and local—as well as nongovernmental organizations, industry, academia, and other stakeholder groups. Your assistance and suggestions are greatly appreciated.

William H. Werkheiser

USGS Associate Director for Water 


\section{Contents}

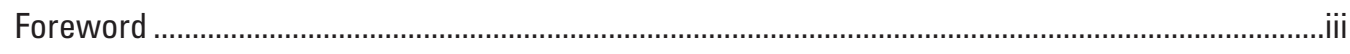

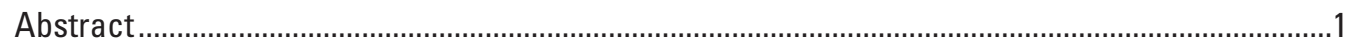

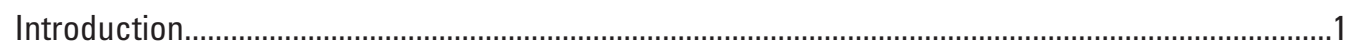

The National Target Analyte Strategy (NTAS) Work Group..................................................2

Composition and Structure of the NTAS Work Group ...........................................................

Selection of Constituents for Prioritization................................................................................

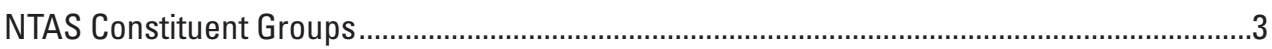

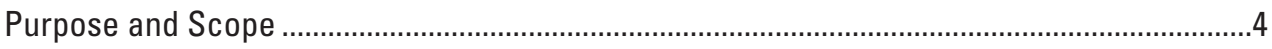

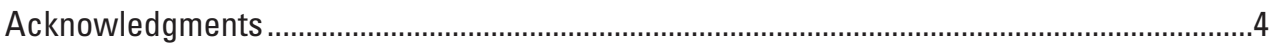

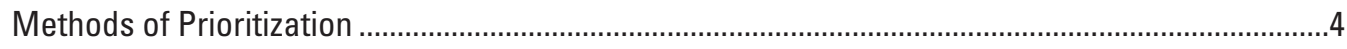

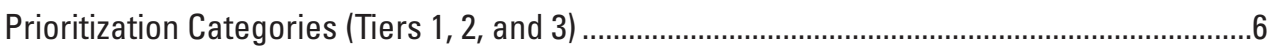

Sources of Information Used to Identify and Prioritize Constituents...........................................

Lists of Constituents of Human-Health Concern ............................................................

Lists of Constituents of Aquatic-Life Concern .............................................................

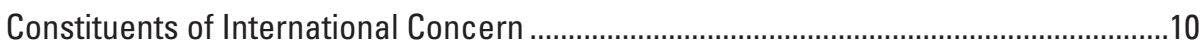

Human-Health Effects Information from the ACToR Database ........................................11

Aquatic-Life Effects Information from the ECOTOXicology Database ...........................11

Other Resources and Databases from the U.S. Environmental Protection Agency.......12

U.S. Geological Survey Programs and Publications ......................................................13

NTAS Prioritization Process................................................................................................14

Prioritization Methods for Volatile Organic Compounds in Water (Group A) .................15

Prioritization Methods for Pesticides in Water or Sediment (Group B)...........................16

Prioritization Methods for Pharmaceuticals and Hormones in Water or Sediment

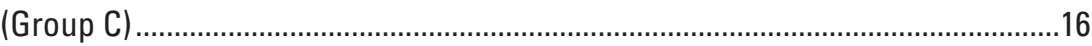

Prioritization Methods for Trace Elements and Other Inorganic Constituents in

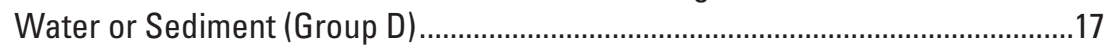

Prioritization Methods for Cyanotoxins in Surface Water (Group E) .............................17

Prioritization Methods for Lipophilic Organic Compounds in Sediment (Group F) .........17

Prioritization Methods for Disinfection By-Products in Water (Group G) .......................18

Prioritization Methods for High-Production-Volume Chemicals in Water (Group H).....18

Prioritization Methods for Wastewater-Indicator and Industrial Compounds in

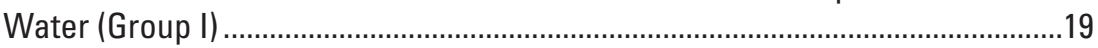

Prioritization Methods for Radionuclides in Water (Group J) .........................................19

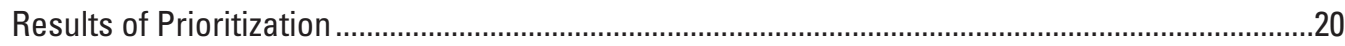

Constituents Identified as Having Highest Priority (Tier 1) for Ambient Monitoring ..............20

Constituents Identified as Having Intermediate Priority (Tier 2) or Low or No Priority

(Tier 3) for Ambient Monitoring ........................................................................................20

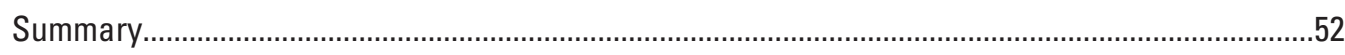

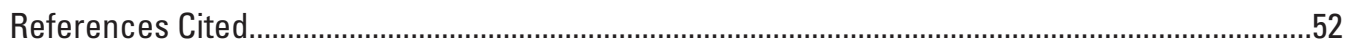


Supplemental Information A. Prioritization of Volatile Organic Compounds in Water

(Group A) .58

Prioritization of Volatile Organic Compounds in Water ............................................................5

Prioritization Methods for Volatile Organic Compounds in Water ..................................60

Results of Prioritization of Volatile Organic Compounds in Water ..................................60

Basis for Prioritization of Volatile Organic Compounds in Water ...................................62

Feasibility of Implementation for High-Priority Volatile Organic Compounds ........................62

Knowledge and Concerns of Volatile Organic Compounds as a Constituent Group...............62

References for Volatile Organic Compounds in Water (Group A) .........................................63

Supplemental Information B1. Prioritization of Pesticides in Water (Group B1).............................65

Prioritization of Pesticides in Water ..............................................................................66

Prioritization Methods for Pesticides in Water..........................................................66

Results of Prioritization for Pesticides in Water ...........................................................69

Basis for Prioritization of Pesticides in Water ..............................................................69

Feasibility of Implementation for High-Priority Pesticides in Water ........................................70

Knowledge and Concerns of Pesticides in Water as a Constituent Group..............................71

References Cited for Pesticides in Water (Group B1) .......................................................72

Supplemental Information B2. Prioritization of Pesticides in Sediment (Group B2)........................75

Prioritization of Pesticides in Sediment ...........................................................................

Prioritization Methods for Pesticides in Sediment.......................................................76

Results of Prioritization of Pesticides in Sediment ..................................................79

Basis for Prioritization for Pesticides in Sediment..................................................79

Feasibility of Implementation for High-Priority Pesticides for Sediment ................................81

Knowledge and Concerns of Pesticides in Sediment as a Constituent Group .......................81

References for Pesticides in Sediment (Group B2) ................................................................82

Supplemental Information C. Prioritization of Pharmaceuticals and Hormones in Water or

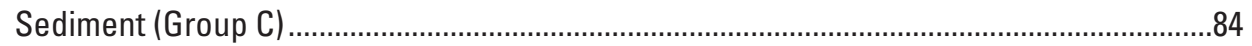

Prioritization of Pharmaceutical Constituents in Water or Sediment .....................................85

Prioritization Methods for Pharmaceutical Constituents in Water or Sediment.............85

Results of Prioritization of Pharmaceutical Constituents in Water or Sediment ............88

Basis for Prioritization of Pharmaceutical Constituents in Water or Sediment..............88

Feasibility of Implementation for High-Priority Pharmaceutical Constituents ........................89

Knowledge and Concerns of Pharmaceutical Constituents in Water or Sediment as a Constituent Group ...............................................................................................90

References for Pharmaceuticals and Hormones in Water or Sediment (Group C)...............91

Supplemental Information D. Prioritization of Trace Elements and Other Inorganic

Constituents (Group D) in Water (Group D1) or Sediment (Group D2)..............................100

Prioritization of Trace Elements and Other Inorganic Constituents in Water

(Group D1).

Prioritization Methods for Trace Elements and Other Inorganic Constituents in Water 101

Results of Prioritization of Trace Elements and Other Inorganic Constituents in Water 102

Basis for Prioritization of Trace Elements and Other Inorganic Constituents in Water 104

Feasibility of Implementation for High-Priority Trace Elements and Other Inorganic Constituents in Water. 
Knowledge and Concerns of Trace Elements and Other Inorganic Constituents in

Water as a Constituent Group .....................................................................................105

Prioritization of Trace Elements in Sediment (Group D2) .....................................................105

Prioritization Methods for Trace Elements in Sediment.............................................106

Results of Prioritization of Trace Elements in Sediment...............................................107

Basis for Prioritization of Trace Elements in Sediment ................................................107

Feasibility of Implementation for High-Priority Trace Elements in Sediment ........................108

Knowledge and Concerns of Trace Elements in Sediment as a Constituent Group ..............109

References for Trace Elements and other Inorganic Constituents in Water or

Sediment (Group D) ...........................................................................................109

Supplemental Information E. Prioritization of Cyanotoxins in Surface Water (Group E) ................112

Prioritization of Cyanotoxins in Surface Water (Group E)..................................................113

Prioritization Methods for Cyanotoxins in Surface Water ..............................................114

Results of Prioritization of Cyanotoxins in Surface Water............................................114

Basis for Prioritization of Cyanotoxins in Surface Water................................................114

Feasibility of Implementation for High-Priority Cyanotoxins in Surface Water.......................114

Knowledge and Concerns of Cyanotoxins in Surface Water as a Constituent Group ...........115

References for Cyanotoxins in Surface Water (Group E) ....................................................116

Supplemental Information F. Prioritization of Lipophilic Organic Compounds in Sediment

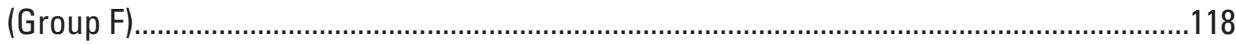

Prioritization of Lipophilic Organic Compounds in Sediment .............................................120

Prioritization Methods for Lipophilic Organic Compounds in Sediment........................121

Results of Prioritization of Lipophilic Organic Compounds in Sediment ........................123

Basis for Prioritization of Lipophilic Organic Compounds in Sediment ..........................123

Feasibility of Implementation for High-Priority Lipophilic Organic Compounds ....................127

Knowledge and Concerns of Lipophilic Organic Compounds by Subgroup ...........................128

Knowledge and Concerns of Polychlorinated Biphenyls (Subgroup F-1) .....................128

Knowledge and Concerns of Polycyclic Aromatic Hydrocarbons

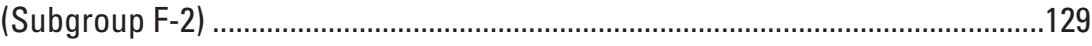

Knowledge and Concerns of Phthalates (Subgroup F-3) .............................................130

Knowledge and Concerns of Azo Dyes (Subgroup F-4) ...............................................132

Knowledge and Concerns of Brominated Flame Retardants (Subgroup F-5)...............132

Knowledge and Concerns of Chlorinated Naphthalenes (Subgroup F-6) ......................133

Knowledge and Concerns of Chlorinated Paraffins (Subgroup F-7) ...............................134

Knowledge and Concerns of Perfluorinated Compounds (Subgroup F-8) .....................135

Knowledge and Concerns of Alkylphenols, Alkylphenol Ethoxylates, and Other Phenols (Subgroup F-9) .........................................................................135

Knowledge and Concerns of Organophosphorous Compounds (Subgroup

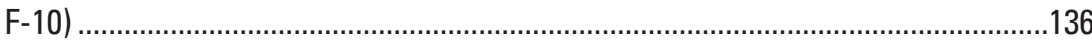

Knowledge and Concerns of Halogenated Dioxins and Furans (Subgroup

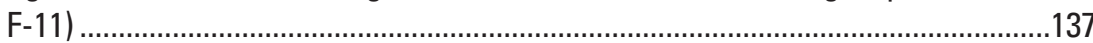

Knowledge and Concerns of Other Organohalogens (Subgroup F-12) ........................137

Knowledge and Concerns of Azaarenes (Subgroup F-13) .............................................138

Knowledge and Concerns of Siloxanes (Subgroup F-14) ............................................138

Knowledge and Concerns of Resin and Rosin Acids (Subgroup F-15) .........................139

Knowledge and Concerns of Miscellaneous Compounds (Subgroup F-16) ..................140 
References for Lipophilic Organic Compounds in Sediment (Group F) .................................140

Supplemental Information G. Prioritization of Disinfection By-Products in Water (Group G) .......148

Prioritization of Disinfection By-Products in Water ............................................................149

Prioritization Methods for Disinfection By-Products in Water .....................................150

Results of Prioritization of Disinfection By-Products in Water ....................................150

Basis for Prioritization of Disinfection By-Products in Water.....................................150

Feasibility of Implementation for High-Priority Disinfection By-Products ............................150

Knowledge and Concerns of Disinfection By-Products as a Constituent Group...................152

References for Disinfection By-Products in Water (Group G) .............................................153

Supplemental Information H. Prioritization of High-Production-Volume Chemicals in Water

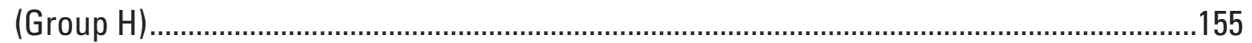

Prioritization of High-Production-Volume Chemicals in Water...........................................156

Prioritization Methods for High-Production-Volume Chemicals in Water ......................156

Results of Prioritization of High-Production-Volume Chemicals in Water .....................158

Feasibility of Implementation for High-Priority High-Production-Volume Chemicals in

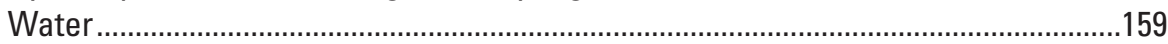

Knowledge and Concerns of High-Production-Volume Chemicals in Water ........................159

References for High-Production-Volume Chemicals in Water (Group H) .............................161

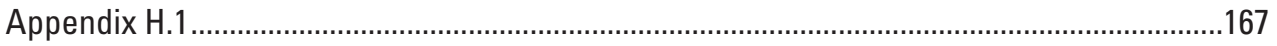

Supplemental Information I. Prioritization of Wastewater-Indicator and Industrial

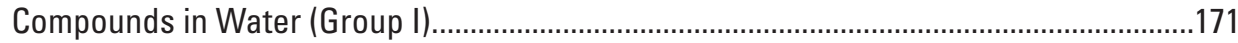

Prioritization of Wastewater-Indicator and Industrial Compounds in Water .......................172

Prioritization Methods for Wastewater-Indicator and Industrial Compounds in

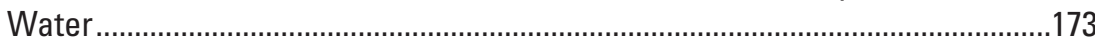

Results of Prioritization of Wastewater-Indicator and Industrial Compounds in Water

Basis for Prioritization of Wastewater-Indicator and Industrial Compounds in

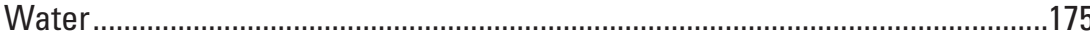

Feasibility of Implementation for High-Priority Wastewater-Indicator and Industrial Compounds in Water ............................................................................................176

Knowledge and Concerns of Wastewater-Indicator and Industrial Compounds in

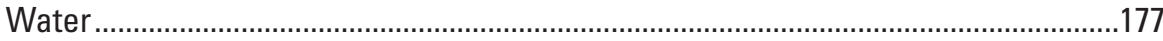

References for Wastewater-Indicator and Industrial Compounds in Water (Group I).........178

Supplemental Information J. Prioritization of Radionuclides in Water (Group J).........................190

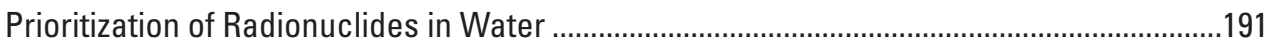

Prioritization Methods for Radionuclides in Water ......................................................191

Results of Prioritization of Radionuclides in Water........................................................193

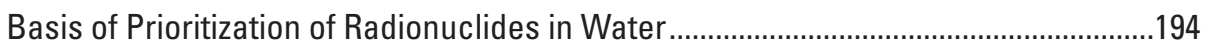

Feasibility of Implementation for High-Priority Radionuclides.............................................195

Knowledge and Concerns of Radionuclides in Water as a Constituent Group......................196

References for Radionuclide Elements in Water (Group J)...............................................199

Supplemental Information K. Constituents Identified as Having Intermediate Priority

(Tier 2) or Low or No Priority (Tier 3) for Water or Sediment .203 


\section{Figures}

1. Schematic of the categories (Tier 1, Tier 2, and Tier 3) used to prioritize constituents for national- and regional-scale ambient monitoring of water and sediment in the United States......

2. Schematic of the generalized National Target Analyte Strategy process used to prioritize constituents for national- and regional-scale ambient monitoring of water and sediment in the United States.

A.1. Flow chart for prioritizing volatile organic compounds (VOCs) for national- and regional-scale monitoring in water in the United States

B1.1. Flow chart for prioritizing pesticide constituents for national- and regional-scale monitoring of surface water (streams) and groundwater in the United States..

B1.2. Graph showing distribution of aquatic-life benchmark quotient values for predicted pesticide concentrations in surface water using the maximum of the 95th-percentile concentrations among stream sites for each constituent

B1.3. Graphs showing distribution of detection frequencies for surface-water and groundwater pesticide datasets collected for the National Water-Quality Assessment Program during 1993-2006.

B2.1. Flow chart for prioritizing pesticide constituents for national- and regional-scale monitoring of sediment in the United States......

B2.2. Simplified flow chart for prioritzing pesticide constituents of high priority for national- and regional-scale monitoring of sediment in the United States

B2.3. Graph showing detailed breakdown of pesticide constituents in sediment prioritized for National Target Analyte Strategy Tier 1 by prioritization pathway.

C.1. Flow chart for prioritizing pharmaceuticals and hormones for national- and regional-scale monitoring of water or sediment in the United States.

D1.1. Graph showing percentile concentrations of trace elements for public-supply wells sampled from 1991-94 and domestic wells sampled from 1993-2007 by the National Water-Quality Assessment Program.

D1.2. Graph showing 50th-percentile concentration benchmark quotients for trace elements and other inorganic constituents in water.

D1.3. Graph showing 99th-percentile concentration benchmark quotients for trace elements and other inorganic constituents in water..

F.1. Flow chart for prioritizing lipophilic organic compounds for national- and regional-scale monitoring of sediment in the United States.

G.1. Flow chart for prioritizing disinfection by-products (DBPs) for national- and regional-scale ambient monitoring of water in the United States.

H.1. Flow chart for prioritizing high-production-volume (HPV) chemicals for nationaland regional-scale monitoring of water in the United States

H.2. Graphs showing relation between vapor pressure $(\log p)$ and $\log K_{\text {ow }}$ for $A, 59$ high-production-volume chemicals from those ranked 1 to 100 , and $B, 49$ high-production-volume chemicals of human-health or aquatic-life concern from those ranked 101 to 379 , on the basis of equation 1 in the "Supplemental Information $\mathrm{H}^{\text {" section }}$

I.1. Flow chart for prioritizing wastewater-indic ator and industrial compounds for national- and regional-scale monitoring of water in the United States

J.1. Maps showing the distribution of uranium concentrations in surface-water samples at National Water-Quality Assessment and National Stream Quality Accounting Network sites in the United States . 
J.2. Graph showing comparison of polonium-210 activities and dissolved-oxygen concentrations for National Water-Quality Assessment data collected in the Mississippi Embayment study unit in 2009

J.3. Graph showing relation between radium-226 activity and $\mathrm{pH}$ for groundwater samples collected for the National Water-Quality Assessment Program in the Mississippi Embayment study unit in 2009 ...

J.4. Graph showing correlation between gross alpha-particle activity and the sum of uranium activity

\section{Tables}

1. Constituents identified as having high priority (Tier 1 ) for national- or regionalscale ambient monitoring of water or sediment in the United States

\section{Supplemental Tables}

Note: The supplemental tables are available online in Excel or PDF format at $h t t p: / / p u b s . u s g s$. gov/sir/2012/5218/downloads/ except tables D2.1 and D2.2, which are in the Supplement Information D section of this report. Page numbers in this section refer to first mention in text unless otherwise noted.

\section{NTASdatabase.xlsx}

Constituents identified as having any priority (Tier 1, 2, or 3) for national- or

regional-scale ambient monitoring of water or sediment in the United States

Supplemental Information A.

tableA.xls

A.1 Volatile organic compounds on laboratory schedules 2020 and 4024 (including custom addition 1,4-dioxane) that were identified as being of high priority (Tier 1) or intermediate priority (Tier 2) for national- and regional-scale ambient monitoring ofwater in the United States

A.2 Volatile organic compounds that were identified as being of low or no priority (Tier 3) for national- and regional-scale ambient monitoring of water in the United States

A.3 Selected information for volatile organic compounds on laboratory schedule 2020 that were placed into Tier 1 .

A.4 Selected information for volatile organic compounds on laboratory schedule 2020 that were placed into Tier 2

Supplemental Information B.

tableB1.xls

B1.1 Pesticides and pesticide degradates that were identified as being of high priority (Tier 1) for national- and regional-scale ambient monitoring of water in the United States

B1.2 Pesticides and pesticide degradates that were identified as being of intermediate priority (Tier 2) for national- and regional-scale ambient monitoring of water in the United States 
B1.3 Pesticides and pesticide degradates that were identified as being of low or no priority (Tier 3) for national- and regional-scale ambient monitoring of water in the United States

B1.4 Summary of U.S. Geological Survey analytical methods available for pesticides constituents in water samples

B1.5 Comparison of detection levels to human-health benchmarks for pesticide constituents in water for laboratory schedules available in 2011 for the determination of pesticides in water

tableB2_1-3.pdf

B2.1 Thresholds for National Target Analyte Strategy (NTAS) aquatic-life "bins" for prioritizing pesticide constituents for national- and regional-scale monitoring of sediment in the United States.

B2.2 Summary of screening pathways for prioritizing pesticide constituents for nationaland regional-scale monitoring of sediment in the United States

B2.3 Physical-chemical properties and thresholds used to predict likelihood of occurrence for pesticide constituents in sediment

tableB2_4-7.xls

B2.4 Pesticide constituents that were identified as being of high priority (Tier 1) for national- and regional-scale ambient monitoring of sediment in the United States.......79

B2.5 Pesticide constituents that were identified as being of intermediate priority (Tier 2) or low or no priority (Tier 3 ) for national- and regional-scale ambient monitoring of sediment in the United States.

B2.6 Summary of U.S. Geological Survey (USGS) analytical methods available for pesticide constituents in sediment samples.

B2.7 Analytical methods and reporting levels available in 2011 for the determination of pesticide constituents in sediment

Supplemental Information C.

tableC.xls

C.1A Pharmaceuticals and hormones identified as having high priority (Tier 1) for national- and regional-scale ambient monitoring of water in the United States

C.1B Pharmaceuticals and hormones identified as having high priority (Tier 1 ) for national- and regional-scale ambient monitoring of sediment in the United States.......87

C.2A Pharmaceuticals and hormones identified as having intermediate priority (Tier 2) for national- and regional-scale ambient monitoring of water in the United States.......87

C.2B Pharmaceuticals and hormones identified as having intermediate priority (Tier 2) for national- and regional-scale ambient monitoring of sediment in the United States

C.3 Pharmaceuticals and hormones identified as having low priority (Tier 3) for national- and regional-scale ambient monitoring of water and sediment in the United States.

C.4 Internet search strategy for obtaining information about pharmaceuticals and hormones in water or sediment (Group C)

Supplemental Information D.

tableD1.xls

D1.1 Trace elements and other inorganic constituents that were identified as being of high priority (Tier 1) or intermediate priority (Tier 2) for national- and regional-scale ambient monitoring of water in the United States

D1.2 Long-term method detection levels (LT-MDLs), benchmarks, and percentile concentrations for trace elements in groundwater collected from domestic and public-supply wells for the National Water-Quality Assessment Program 
Tables in report

D2.1 Percentages of streambed-sediment samples collected for Cycle 1 of the National Water-Quality Assessment Program from urban streams with traceelement concentrations greater than the probable effect level or probable effect concentration

D2.2 Median probable-effect-concentration quotient for selected trace elements in sediment deposited after 1990 in 13 urban lakes

Supplemental Information E.

tableE.xlsx

E.1 Cyanotoxin constituents analyzed in filtered water by the U.S. Geological Survey Organic Geochemistry Research Laboratory with supporting information.

E.2 Prioritization results for cyanotoxin constituents for national- and regional-scale ambient monitoring of surface water in the United States..

Supplemental Information F.

tableF1.pdf

F.1 The 16 subgroups used in the prioritization of lipophilic organic compounds in sediment (Group F) with example constituents, Chemical Abstracts Service Registry Numbers, and molecular structures.

tableF2.xIsx

F.2 Prioritization results for lipophilic organic compounds for national- and regional-scale ambient monitoring of sediment in the United States

tableF3.pdf

F.3 Summary of prioritization results for the 699 lipophilic organic compounds in sediment (Group F)

tableF4.xlsx

F.4A Statistical summary and comparisons to benchmarks for lipophilic organic compounds in streambed-sediment samples collected during 1992-2001 for the National Water-Quality Assessment (NAWQA) Program from streams with urban land use.

F.4B Statistical summary and comparisons to benchmarks for lipophilic organic compounds in streambed-sediment samples collected during 1992-2001 for the National Water-Quality Assessment (NAWQA) Program from streams with mixed land use

F.4C Statistical summary and comparisons to benchmarks for lipophilic organic compounds in streambed-sediment samples collected during 1992-2001 for the National Water-Quality Assessment (NAWQA) Program from streams with agricultural land use

F.4D Statistical summary and comparisons to benchmarks for lipophilic organic compounds in streambed-sediment samples collected during 1992-2001 for the National Water-Quality Assessment (NAWQA) Program from streams with undeveloped land use

tableF5.pdf

F.5 Analytical methods available or in development as of 2011 at the National Water

Quality Laboratory for lipophilic organic compounds in sediment (Group F)

Supplemental Information G.

tableG.xlsx

G.1 Prioritization results for disinfection by-products for national- and regional-scale ambient monitoring of water in the United States

G.2 Selected information for disinfection by-products that were prioritized for nationaland regional-scale ambient monitoring of water in the United States.. 
Supplemental Information $\mathrm{H}$.

tableH.xlsx

H.1 High-production-volume chemicals (HPVs) that were preliminarily identified as having the highest likelihood of occurrence in ambient water

H.2 High-production-volume chemicals (HPVs) that were identified as being of high priority (Tier 1) for national- and regional-scale ambient monitoring of water in the United States

H.3 High-production-volume chemicals (HPVs) that were identified as being of intermediate priority (Tier 2) for national- and regional-scale ambient monitoring of water in the United States

H.4 High-production-volume chemicals (HPVs) that were identified as being of low or no priority (Tier 3 ) for national- and regional-scale ambient monitoring of water in the United States

H.5 High-production-volume volatile organic compounds currently being tested as possible additions to laboratory schedule 2020 .

H.6 High-production-volume volatile organic compounds currently being tested as possible additions to laboratory schedule 4024 or 4025

Supplemental Information I.

tablel.xls

I.1 Reasons used to assign specific wastewater-indicator and industrial compounds to Tiers 1, 2, or 3 for national- and regional-scale ambient monitoring of water in the United States

I.2 Wastewater-indicator and industrial compounds that were identified as being of high priority (Tier 1) for national- and regional-scale ambient monitoring of water in the United States

I.3 Wastewater-indicator and industrial compounds that were identified as being of intermediate priority (Tier 2) for national- and regional-scale ambient monitoring of water in the United States

I.4 Wastewater-indicator and industrial compounds that were identified as being of low or no priority (Tier 3 ) for national- and regional-scale ambient monitoring of water in the United States.

I.5 Search strategy for for obtaining information about wastewater-indicator and industrial compounds in water (Group I)

Supplemental Information J.

tableJ.xlsx

J.1 Human-health benchmarks and information about U.S. Geological Survey (USGS) groundwater monitoring data for radionuclides and radioactivity collected from 1985-2009 and for National Water-Quality Assessment (NAWOA) Program Cycles 1 and 2

J.2. Radionuclides that were identified as being of high priority (Tier 1) for nationaland regional-scale ambient monitoring of water in the United States and status of analytical methods

J.3 Percentage of wells sampled for the National Water-Quality Assessment Program (NAWQA) during 1992-2003 for which one or more trace elements, volatile organic compounds, or pesticides had concentrations greater than human-health benchmarks by primary water use and land use

Supplemental Information K.

tableK.xIsx

K.1 Constituents identified as having intermediate priority (Tier 2) or low or no priority (Tier 3) for national- or regional-scale ambient monitoring of water or sediment in the United States 


\section{Conversion Factors}

\begin{tabular}{lll}
\multicolumn{1}{c}{ SI to Inch/Pound } & \multicolumn{1}{c}{ Multiply } & \multicolumn{1}{c}{ To obtain } \\
\hline \multicolumn{1}{c}{ By } & \\
\hline cubic meter $\left(\mathrm{m}^{3}\right)$ & \multicolumn{1}{c}{ Volume } & liter $(\mathrm{L})$ \\
liter $(\mathrm{L})$ & $1.000 \times 10^{3}$ & gallon (gal) \\
milliliter $(\mathrm{mL})$ & 0.2642 & fluid ounce \\
\hline & 0.03381 & \\
\hline gram $(\mathrm{g})$ & Mass & ounce, avoirdupois $(\mathrm{oz})$ \\
kilogram $(\mathrm{kg})$ & 0.03527 & pound (avoirdupois) $(\mathrm{lb})$ \\
\hline & 2.205 & \\
\hline kilometer $(\mathrm{km})$ & Length & mile (mi) \\
meter $(\mathrm{m})$ & 0.6214 & foot (ft) \\
\hline
\end{tabular}

Inch/Pound to SI

\begin{tabular}{lcl}
\hline \multicolumn{1}{c}{ Multiply } & By & \multicolumn{1}{c}{ To obtain } \\
\hline acre & Area & \\
acre-foot & $4.047 \times 10^{3}$ & square meter $\left(\mathrm{m}^{2}\right)$ \\
& $1.223 \times 10^{3}$ & cubic meter $\left(\mathrm{m}^{3}\right)$ \\
\hline pound (avoirdupois) (lb) & Mass & \\
\hline & 0.4563 & kilogram $(\mathrm{kg})$ \\
\hline mile (mi) & Length & \\
\hline
\end{tabular}

Temperature in degrees Celsius $\left({ }^{\circ} \mathrm{C}\right)$ may be converted to degrees Fahrenheit $\left({ }^{\circ} \mathrm{F}\right)$ as follows:

${ }^{\circ} \mathrm{F}=\left(1.8 \times^{\circ} \mathrm{C}\right)+32$

Temperature in degrees Fahrenheit $\left({ }^{\circ} \mathrm{F}\right)$ may be converted to degrees Celsius $\left({ }^{\circ} \mathrm{C}\right)$ as follows:

${ }^{\circ} \mathrm{C}=\left({ }^{\circ} \mathrm{F}-32\right) / 1.8$

Concentrations of chemical constituents in water are given in milligrams per liter (mg/L), micrograms per liter $(\mu \mathrm{g} / \mathrm{L})$, or moles per liter $(\mathrm{mol} / \mathrm{L}) ; \mathrm{mg} / \mathrm{L}$ is equivalent to parts per million, $\mu \mathrm{g} / \mathrm{L}$ is equivalent to parts per billion, and one mole contains $6.022 \times 10^{23}$ atoms or molecules of a substance. Concentrations or activities of radionuclide constituents are given in $\mu \mathrm{g} / \mathrm{L}$ or picocuries per liter ( $\mathrm{pCi} / \mathrm{L})$.

Horizontal coordinate information is referenced to the North American Datum of 1983 (NAD 83). 


\section{Abbreviations and Acronyms}

$\geq$

ACToR

AL

BO

CASRN

CCL3

CDC

CERCLA

$\mathrm{EC}_{50}$

ECOTOX

EPI Suite ${ }^{T M}$

HAL

HBSL

$\mathrm{HH}$

HPV

$\mathrm{LC}_{50}$

LOEC

$\log K_{\mathrm{ow}}$

LS

MAC

MCL

MCLG

NASQAN

NAWQA

NHANES

NIA

NOEC

NTAS

NWIS

NWOL greater than or equal to

Aggregated Computational Toxicology Resource (database, USEPA)

aquatic life

benchmark quotient (USGS)

Chemical Abstracts Service Registry Number ${ }^{\circledR}$ (American Chemical Society)

Contaminant Candidate List 3 (USEPA)

Centers for Disease Control and Prevention (U.S. Department of Health and Human Services)

Comprehensive Environmental Response, Compensation, and Liability Act median effective concentration (aquatic-life benchmark)

ECOTOXicology (database, USEPA)

Estimation Program Interface Suite (screening software, USEPA)

Health-Advisory Level (drinking-water-quality benchmark, USEPA)

Health-Based Screening Level (water-quality benchmark, USGS)

human health

high-production volume or high-production-volume chemical

median lethal concentration (aquatic-life benchmark)

lowest-observed-effect concentration (aquatic-life benchmark)

base-10 logarithm of the octanol-water partition coefficient

laboratory schedule (USGS)

Maximum Acceptable Concentration (drinking-water-quality benchmark, Health Canada)

Maximum Contaminant Level (drinking-water-quality benchmark; USEPA or California)

Maximum Contaminant Level Goal (drinking-water-quality benchmark; USEPA)

National Stream Quality Accounting Network (USGS)

National Water-Quality Assessment (USGS)

National Health and Nutrition Examination Survey; NHANES IV, Fourth NHANES (CDC)

no information available

no-observed-effect concentration (aquatic-life benchmark)

National Target Analyte Strategy (USGS NAWOA)

National Water Information System (USGS)

National Water Quality Laboratory (USGS) 
OEHHA

PBT

Toxics Program

UCMR

USEPA

USGS

VOC
Office of Environmental Health Hazard Assessment (California)

persistent, bioaccumulative, and toxic

Toxic Substances Hydrology Program (USGS)

Unregulated Contaminant Monitoring Rule; UCMR 2, second cycle of UCMR sampling; UCMR 3, third cycle of UCMR sampling (USEPA)

U.S. Environmental Protection Agency

U.S. Geological Survey

volatile organic compound 


\title{
Prioritization of Constituents for National- and Regional- Scale Ambient Monitoring of Water and Sediment in the United States
}

\author{
By Lisa D. Olsen, Joshua F. Valder, Janet M. Carter, and John S. Zogorski
}

\section{Abstract}

A total of 2,541 constituents were evaluated and prioritized for national- and regional-scale ambient monitoring of water and sediment in the United States. This prioritization was done by the U.S. Geological Survey (USGS) in preparation for the upcoming third decade (Cycle 3; 2013-23) of the National Water-Quality Assessment (NAWQA) Program. This report provides the methods used to prioritize the constituents and the results of that prioritization.

Constituents were prioritized by the NAWQA National Target Analyte Strategy (NTAS) work group on the basis of available information on physical and chemical properties, observed or predicted environmental occurrence and fate, and observed or anticipated adverse effects on human health or aquatic life. Constituents were evaluated within constituent groups that were determined on the basis of physical or chemical properties or on uses or sources. Some constituents were evaluated within more than one constituent group. Although comparable objectives were used in the prioritization of constituents within the different constituent groups, differences in the availability of information accessed for each constituent group led to the development of separate prioritization approaches adapted to each constituent group to make best use of available resources. Constituents were assigned to one of three prioritization tiers: Tier 1, those having the highest priority for inclusion in ambient monitoring of water or sediment on a national or regional scale (including NAWQA Cycle 3 monitoring) on the basis of their likelihood of environmental occurrence in ambient water or sediment, or likelihood of effects on human health or aquatic life; Tier 2, those having intermediate priority for monitoring on the basis of their lower likelihood of environmental occurrence or lower likelihood of effects on human health or aquatic life; and Tier 3, those having low or no priority for monitoring on the basis of evidence of nonoccurrence or lack of effects on human health or aquatic life, or of having insufficient evidence of potential occurrence or effects to justify placement into Tier 2 .

Of the 1,081 constituents determined to be of highest priority for ambient monitoring (Tier 1), 602 were identified for water and 686 were identified for sediment (note that some constituents were evaluated for both water and sediment). These constituents included various types of organic compounds, trace elements and other inorganic constituents, and radionuclides. Some of these constituents are difficult to analyze, whereas others are mixtures, isomers, congeners, salts, and acids of other constituents; therefore, modifications to the list of high-priority constituents for ambient monitoring could be made on the basis of the availability of suitable methods for preparation, extraction, or analysis. An additional 1,460 constituents were placed into Tiers 2 or 3 for water or sediment, including some constituents that had been placed into Tier 1 for a different matrix; 436 constituents were placed into Tier 2 for water and 246 constituents into Tier 2 for sediment; 979 constituents were placed into Tier 3 for water and 779 constituents into Tier 3 for sediment.

\section{Introduction}

Many thousands of chemical and biological substances are produced, created, or mobilized through human activities or natural processes, including more than 84,000 chemical substances (organic, inorganic, polymers, biological materials, and substances of unknown or variable composition) currently identified under the Toxic Substances Control Act (U.S. Environmental Protection Agency, 2010a). Many of these substances are thought to be harmless to human health and aquatic life, and many do not enter environmental waters or sediment in sufficient quantities to allow detection with existing technologies under ambient conditions. Others, however, are important because they are known to occur or have the potential to occur in environmental waters or sediment at concentrations that can adversely affect human health or aquatic life. Prioritization is necessary to ensure that limited resources allocated to ambient monitoring are directed toward those constituents with the highest likelihood of environmental occurrence and potential adverse effects. Human health and aquatic life represent two large areas of concern that intersect with many important issues facing water-resource managers, 
Prioritization of Constituents for National- and Regional-Scale Ambient Monitoring of Water and Sediment

including drinking-water quality, recreational water quality, emerging contaminants, stream habitat, ecosystem health, and the effects of land use and other stressors on the quality of ambient environmental waters and sediment. The prioritization of constituents presented in this report was performed in support of the U.S. Geological Survey (USGS) National WaterQuality Assessment (NAWQA) Program, in preparation for this program's third decade (Cycle 3; 2013-23) of monitoring; however, the priorities presented in this report could be used by other programs that plan to conduct national- or regionalscale ambient monitoring of environmental waters and sediment in the United States.

\section{The National Target Analyte Strategy (NTAS) Work Group}

The NAWQA Program strives to be a leading source of scientific information for the development of effective policies and management strategies to protect and improve water quality for human and ecosystem needs. The planned approach for the upcoming third decade of the NAWQA Program (Cycle 3) is built upon a foundation of 20 years (Cycles 1 and 2; 19912012) of monitoring, modeling, and understanding studies that describe linkages between contaminant sources and transport to receiving waters and is designed to make progress on forecasting how water quality responds to changing environmental conditions (U.S. Geological Survey, 2010a). Contaminants in water and sediment are among the leading causes of water-quality and ecosystem impairment (U.S. Environmental Protection Agency, 2009a); therefore, an evaluation of current and future priorities for contaminant monitoring at regional and national scales was identified as a key component of the Cycle 3 planning effort.

In April 2009, the NAWQA Leadership Team followed a recommendation from the Cycle 3 Planning Team and created the National Target Analyte Strategy (NTAS) work group to (1) evaluate constituents and associated analytical methods used during Cycles 1 and 2 of the NAWQA Program that should be retained or dropped during Cycle 3, and (2) develop priorities for emerging and traditional constituents, or constituent groups, that warrant consideration for Cycle 3 monitoring. These priorities were to be considered within the context of national- or regional-scale ambient monitoring of water quality in streams, rivers, lakes, reservoirs, and groundwater. Constituents monitored during previous NAWQA studies were to be evaluated within the context of available occurrence data and information on potential effects on human health or aquatic life. New constituents were to be evaluated using source information, fate and transport properties, input from external agencies and organizations, literature reviews, and best professional judgment to determine whether they are likely to occur in the environment and pose a significant risk to human or aquatic ecosystem health. The NTAS work group was asked to prioritize constituents for monitoring in water, sediment, and fish tissue; however, the prioritization of constituents for water and sediment was completed in advance of the prioritization for tissue, and constituents in water and sediment are the focus of this report. The work group was asked to seek input from scientists and laboratory staff within the USGS Water Resources Discipline, other USGS organizational units, and from external sources. The members of the NTAS work group were selected to take advantage of available expertise and linkages throughout the USGS.

\section{Composition and Structure of the NTAS Work Group}

Members of the NTAS work group were selected to represent expertise in water-quality monitoring, interpretative studies, and laboratory analyses. John S. Zogorski, Chief of the USGS National Water Quality Laboratory (NWQL) and former Chief of the NAWQA Volatile Organic Compounds (VOC) National Synthesis Project, was selected to lead the NTAS work group. Additional members included Michael J. Focazio of the USGS Office of Water Quality and USGS Toxic Substances Hydrology (Toxics) Program, Michelle L. Hladik and Kathryn M. Kuivila of the Toxics Program, Julia E. Norman and Lisa H. Nowell of the NAWQA Pesticide National Synthesis Project, Lisa D. Olsen of the USGS California Water Science Center, Michael R. Rosen of the USGS Nevada Water Science Center, Zoltan Szabo of the USGS New Jersey Water Science, James (Jim) F. Pankow of Portland State University, Joshua F. Valder of the NAWQA Source Water-Quality Assessment Program, Peter C. Van Metre of the NAWQA Contaminant Trends in Lake Sediments Project, and Duane S. Wydoski of the USGS NWQL. The NTAS work group also had assistance from staff associated with some of its members, including Wentai Luo, Bill Asher, Lorne Isabelle, and Cai Chen, who worked under the direction of Dr. Pankow, and Laura E. Garlie and Nathan Hersey, who worked under the direction of Julia Norman.

The NTAS work-group members consulted with additional staff within the USGS, including scientists in the Toxics Program, the National Research Program, the NWQL, the Columbia Environmental Research Center, the Kansas Organic Geochemistry Research Laboratory, the California Water Science Center Pesticide Fate Research Laboratory, the Geologic Discipline chemistry laboratories, the NAWQA Pesticide and VOC National Synthesis Projects, and the NAWQA Cycle 3 Planning Team. The work group also sought input from waterquality staff from the USGS Water Science Centers during the 2010 USGS National Water Quality Conference. The input received through these contacts represents an amalgamation of expertise from a large variety of water-quality studies, ranging from local to national in scale, and covering the leading current concerns about traditional and emerging contaminants.

Although the NTAS work group did not include members from external agencies, such as the U.S. Environmental Protection Agency (USEPA) or U.S. Department of Health and Human Services, the work group sought input from such 
agencies through technical briefings and written communications, as well as through external agency publications, Web pages, and databases. Resources from these agencies used by the NTAS work group are described in the "Methods of Prioritization" and "Supplemental Information" sections.

In prioritizing constituents for ambient monitoring, each NTAS constituent group was evaluated by a subset of the NTAS work-group members, sometimes in conjunction with additional staff from outside the work group. The persons responsible for prioritizing each constituent group are identified as the authors of the Supplemental Information chapter for that constituent group. Iterative feedback on prioritization methods and results was provided, and consensus was achieved through face-to-face meetings and conference calls within the NTAS work group. Each NTAS constituent group's prioritization methods and results were reviewed by other NTAS work-group members throughout the prioritization process.

\section{Selection of Constituents for Prioritization}

The number of candidate constituents that could be considered for ambient monitoring of water and sediment is quite large, but unfortunately, many constituents have little information about the likelihood of environmental occurrence or effects on human health or aquatic ecosystems. According to the USEPA, thousands of chemicals currently are in common use, including many industrial chemicals and pesticidal active and inert ingredients, with the potential for significant human exposures, but for which toxicity information is limited or nonexistent (Judson and others, 2009). For this reason, only a subset of this large number of constituents of potential interest could be evaluated in a meaningful manner. The 2,541 constituents evaluated by the NTAS work group were selected on the basis of their previous inclusion in USGS studies or because they were recognized by other agencies or organizations as being potentially important with respect to human health or aquatic life (or both), or because they were determined by other agencies or organizations to have the potential to occur in environmental waters or sediment. Constituents evaluated by the NTAS work group included hundreds of compounds with analytical methods already available through USGS laboratories or under development by USGS laboratories at the time of this prioritization. Additional constituents evaluated included high-production-volume chemicals (HPVs) identified on the basis of their production volumes, physical properties, and predicted persistence in the environment; new pesticides and pesticide degradates identified on the basis of information obtained through the USEPA Office of Pesticide Programs; constituents on lists of human-health or aquatic-life concern as compiled by other organizations; and additional compounds identified on the basis of literature reviews, including disinfection by-products, cyanotoxins, industrial compounds, agricultural compounds, pharmaceuticals, synthetic hormones, various endocrine system modulators or disruptors, and lipophilic organic compounds.

\section{NTAS Constituent Groups}

To facilitate prioritization, the 2,541 candidate constituents were first organized into 10 constituent groups by the NTAS work group:

A. Volatile organic compounds in water;

B. Pesticides in water or sediment;

C. Pharmaceuticals and hormones in water or sediment;

D. Trace elements and other inorganic constituents in water or sediment;

E. Cyanotoxins in surface water;

F. Lipophilic organic compounds in sediment;

G. Disinfection by-products in water;

H. High-production-volume chemicals in water;

I. Wastewater-indicator and industrial compounds in water; and

J. Radionuclides in water.

These NTAS constituent groups are referred to by the group letter (for example, Group A, Group B, Group C). Some constituent groups have subgroups for the two environmental matrixes (for example, Group B1 for pesticides in water and Group B2 for pesticides in sediment), depending on the methods used for prioritization. Constituent groups were assembled on the basis of physical or chemical properties, as was the case for the volatile organic compounds in water (Group A) and lipophilic organic compounds in sediment (Group F), or on the basis of uses or primary sources, as was the case for the pesticides in water or sediment (Group B) and disinfection by-products in water (Group G). Because some constituents can be important either because of their physical or chemical properties, or because of their uses or sources, some were included in two or more constituent groups. For example, a constituent that is an anti-fungal could be considered a pesticide (Group B) but also could be a pharmaceutical that is used on a prescription basis (Group C). Similarly, a constituent that is a volatile organic compound (Group A) also could be a disinfection by-product (Group G), a pesticide (Group B), or high-production-volume chemical (Group H). Methods for addressing overlaps between constituent groups are discussed in the "Methods of Prioritization" section.

Water and sediment were the environmental matrixes of interest for this prioritization, but not all constituents groups were prioritized for both matrixes. The NTAS constituent groups were evaluated only for the matrixes that were considered appropriate on the basis of the physical and chemical characteristics exhibited by the constituent group as a whole. For example, constituents in the volatile organic compounds in water constituent group (Group A) were evaluated for water 
but not sediment because VOCs generally partition preferentially into the atmosphere or water, rather than into sediment; however, some individual constituents that also are VOCs were evaluated as pesticides in sediment (Group B2) or as lipophilic organic compounds in sediment (Group F) if their uses or properties justified their inclusion in either of these other constituent groups.

\section{Purpose and Scope}

This report presents the methods used to prioritize constituents for national- and regional-scale ambient monitoring of water and sediment for Cycle 3 of the USGS's NAWQA Program and the results of that prioritization. Ambient monitoring includes studies of the quality of environmental resources (such as water or sediment) that are conducted under typical conditions without a predisposition that contamination is present. The results of this prioritization are suitable for national-scale, regional-scale, and statewide assessments of the quality of water or sediment in the United States. This effort does not preclude other prioritization efforts by other monitoring programs with different objectives, either within or external to the USGS. Results of this prioritization are being used by the NAWQA Program to update or develop new analytical methods with extensive constituent coverage prior to the start of Cycle 3 . This prioritization was completed in 2009-10, with the information resources available at that time. This report does not address prioritization of constituents for focused local-scale sampling; for example, for point-source releases, spills, hazardous waste sites, landfills, waste discharge sites, or infrequently used agricultural chemicals.

This report covers the prioritization of 2,541 constituents, organized into 10 constituent groups, considered for ambient monitoring of water (groundwater and surface water) and sediment (bed sediment and suspended sediment). The NTAS constituent groups included volatile organic compounds in water, pesticides in water or sediment, pharmaceuticals and hormones in water or sediment, trace elements and other inorganic constituents in water or sediment, cyanotoxins in surface water, lipophilic organic compounds in sediment, disinfection by-products in water, high-production-volume chemicals in water, wastewater-indicator and industrial compounds in water, and radionuclides in water. The prioritization of constituents for fish tissue was initiated but not completed and is not covered in this report. Microbial constituents (such as bacteria and viruses) and nutrients (such as nitrate, nitrite, phosphate, and sulfate) can potentially affect human health and aquatic life but were not considered for prioritization by the NTAS work group.

\section{Acknowledgments}

The authors would like to thank Gary Rowe and other members of the Cycle 3 Planning Team, who provided guidance and support to the NTAS work group on behalf of the
NAWQA Program, acted as the liaison with the NAWQA National Leadership Team, encouraged interactions with other organizational units within the USGS, provided excellent technical feedback on the prioritization approaches that were considered, and gave indispensable advice in the preparation of this report. The authors also thank Robert Gilliom (Chief of the NAWQA Pesticides National Synthesis Project and Cycle 3 Planning Team member), who participated in initial NTAS work-group conference calls that shaped the development of the prioritization process for pesticides in water and sediment. The authors are grateful to persons within and outside of the USGS who contributed to this work through past studies, contributions to databases, peer-reviewed publications, and consultations with ad hoc teams that were formed by the NTAS work group for the prioritization of constituents. The authors thank the Toxics Program staff, including Herb Buxton in particular, for providing guidance and references on contaminants of emerging concern. The authors thank the National Water Quality Laboratory (NWQL) staff for their generous contributions of time and access to laboratory method information, as well as shared file space to store materials used by the NTAS work group before and during preparation of this report. The authors also thank the NAWQA National Leadership Team for providing the charge to the NTAS work group to perform the prioritization presented in this report and for encouragement in completing the work.

The authors are grateful to Brooke F. Connor of the USGS Branch of Quality Systems; William T. Foreman and Steven D. Zaugg of the NWQL Methods Research and Development Program; Colleen E. Rostad of the National Research Program; Joseph D. Ayotte of the New Hampshire-Vermont Water Science Center; Sara L. Eldridge of the Oregon Water Science Center; and Christopher G. Ingersoll, David A. Alvarez, and Kathy R. Echols of the Columbia Environmental Research Center, who reviewed selected sections of this report and provided excellent comments toward its improvement. Finally, the authors thank Dana W. Kolpin of the Toxics Program and Joseph L. Domagalski of the NAWQA Program, who reviewed the report in its entirety for technical content and thus greatly contributed to the quality of the final publication.

\section{Methods of Prioritization}

The methods used to prioritize constituents for nationaland regional-scale ambient monitoring of water and sediment in the United States included defining categories (tiers) of increasing priority; identifying datasets that could be used to determine which constituents were of high, intermediate, or low priority for the matrixes of interest; and developing and applying a prioritization approach for each NTAS constituent group, taking into account the varying availability of information for each constituent group. Prioritization within all constituent groups generally relied on two factors: (1) the 
likelihood of a constituent to occur in the matrix of interest, and (2) the likelihood of that constituent to have adverse effects on human health or aquatic life, or both. Thus, a constituent that could occur widely in a matrix of interest, but which is unlikely to affect human health or aquatic life, would be considered of intermediate or low priority for ambient monitoring. Likewise, a constituent that could adversely affect human health or aquatic life, but which is unlikely to occur in a matrix of interest, also would be considered of intermediate or low priority for ambient monitoring. Consequently, a constituent that could occur widely in the environment and that is likely to affect human health or aquatic life would be considered a high priority for ambient monitoring. Information to support an evaluation of the likelihood of occurrence or the likelihood of effects was not consistently available for all constituents; therefore, methods of prioritization were customized for each of the different constituent groups.

In some cases, a constituent that could belong to two or more NTAS constituent groups was prioritized in only one of the constituent groups after discussion to determine which constituent group was most appropriate. In other cases, a constituent was retained in more than one constituent group. Comparable objectives were used for prioritizing constituents within the different NTAS constituent groups, but differences in the availability of information accessed by NTAS workgroup members for each constituent group led to the development of separate, but similar, prioritization approaches that were adapted to the characteristics of each constituent group. Constituents prioritized within more than one constituent group usually received the same prioritization "tier." In rare cases in which a constituent was prioritized differently for two or more constituent groups, the NTAS work-group members discussed the lines of evidence used in the prioritization for each constituent group and determined which constituent group had the stronger case. When conflicting evidence of equal reliability was considered in prioritizing a constituent, preference was given to the higher priority for that constituent; in other words, a conservative approach was taken that favored inclusion rather than exclusion from monitoring.

Some NTAS constituent groups were prioritized for water (groundwater and surface water) or for sediment (bed sediment and suspended sediment) only, if those constituents generally occur predominantly in one matrix or the other. Cyanotoxins were prioritized for surface water only. Human health was considered as a potential receptor for water (groundwater and surface water). Aquatic life was considered as a potential receptor for surface water and sediment (suspended sediment and bed sediment). Unfiltered water was not evaluated as a distinct matrix for future monitoring in this prioritization because unfiltered water can be represented as separate fractions by characterization of the constituent in filtered water and suspended sediment. [Note: Although VOCs in water are collected as an unfiltered sample to minimize loss from volatilization, analysis using purge-and-trap gas chromatography yields a result that is comparable to a filtered sample because the purge-and-trap process excludes suspended sediment from the gas chromatograph.] A summary of the environmental matrixes and potential receptors considered for each NTAS constituent group is provided in the side bar. More details on the methods of prioritization can be found in the subsequent sections and in the corresponding sections in the "Supplemental Information" sections provided with this report.
NTAS constituent groups

Volatile organic compounds in water (Group A)

Pesticides in water (Group B1) or sediment (Group B2)

Pharmaceuticals and hormones in water or sediment (Group C)

Trace elements and other inorganic constituents in water (Group D1) or sediment (Group D2)

Cyanotoxins in surface water (Group E)

Lipophilic organic compounds in sediment (Group F)

Disinfection by-products in water (Group G)

High-production-volume chemicals in water (Group H)

Wastewater-indicator and industrial compounds in water (Group I)
Environmental matrixes evaluated

Groundwater and surface water

Groundwater, surface water, and suspended or streambed sediment

Surface water and suspended or streambed sediment

Groundwater, surface water, and suspended or streambed sediment

Surface water

Suspended or streambed sediment

Groundwater and surface water

Groundwater and surface water

Groundwater and surface water

Groundwater and surface water
Potential receptors considered
Human health

Human health and aquatic life

Human health and aquatic life

Human health and aquatic life

Human health

Human health and aquatic life

Human health

Human health and aquatic life

Human health and aquatic life

Human health 


\section{Prioritization Categories (Tiers 1, 2, and 3)}

Constituents were assigned to one of three prioritization categories (NTAS "Tiers") shown in figure 1 and defined as follows:

- Tier 1. Constituents that are of the highest priority for ambient monitoring at the national or regional scale (such as NAWQA Cycle 3 monitoring) on the basis of information about actual or likely occurrence in water or sediment, actual or likely effects on human health or aquatic life, and other information, as appropriate for each NTAS constituent group. Specific criteria for occurrence and effects are provided in the "Supplemental Information" sections for the constituent groups.

- Tier 2. Constituents that are of intermediate priority because there was evidence of lower likelihood of occurrence in ambient water or sediment, or lower likelihood of effects on human health or aquatic life, than was observed for those in Tier 1, or because there was not enough evidence to support inclusion in Tier 1.

- Tier 3. Constituents that are of low or no priority because there was evidence of nonoccurrence or lack of effects on human health or aquatic life, or insufficient evidence of occurrence in water or sediment or of effects on human health or aquatic life to justify placement into Tier 2 .

Constituents were prioritized on the basis of information available at the time of this prioritization (generally 2010). Some constituents might warrant movement to a higher or lower tier if priorities change on the basis of new information that becomes available subsequent to this prioritization.

\section{Sources of Information Used to Identify and Prioritize Constituents}

The NTAS work group used information from many sources to identify candidate constituents and to support the prioritization of constituents for ambient monitoring in water or sediment. These sources included lists of constituents of human-health concern; lists of constituents of aquatic-life concern; large national and international databases of information on the toxicity and chemical properties of candidate constituents and regulatory and nonregulatory standards for water or sediment; and information from USGS programs and publications, including the NAWQA and Toxics Programs. Many of the constituents that were prioritized by the NTAS work group had information from multiple sources, and "overlap" is considerable among the lists and information sources.

\section{Lists of Constituents of Human-Health Concern}

Lists of constituents of human-health concern were used as a screening tool to identify candidate constituents for prioritization mainly for water; however, some constituents identified through these lists also were considered for sediment, depending on their properties. The lists of constituents of human-health concern compiled by the NTAS work group included compilations from other agencies and organizations for drinking-water programs and for general human-health concern. Some constituents identified through one or more lists were included on other lists, and overlap between lists
Likelihood of environmental occurrence

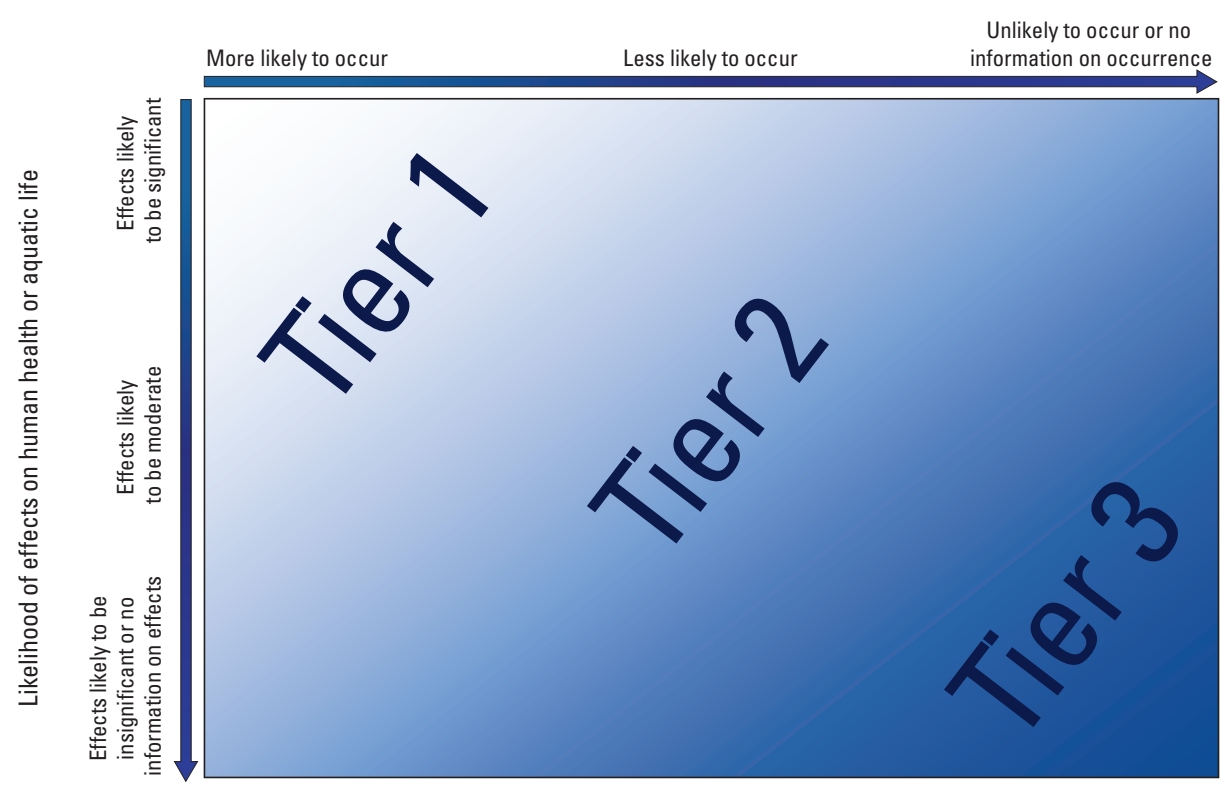

Figure 1. Categories (Tier 1, Tier 2, and Tier 3) used to prioritize constituents for national- and regional-scale ambient monitoring of water and sediment in the United States. 
was extensive. The lists that are specific to drinking-water programs included the following:

- USEPA Drinking-Water Standards and Advisories: The NTAS work group used information from the National Primary Drinking Water Regulations (U.S. Environmental Protection Agency, 2010b) and from the 2006 and 2009 editions of the Drinking Water Standards and Health Advisory tables (U.S. Environmental Protection Agency, 2006, 2009b) available at $h t t p: / /$ water.epa.gov/drink/standards/hascience.cfm\#dwstandards. These tables summarize drinking-water regulations, health-advisory levels, reference doses, and cancer-risk values for drinking-water contaminants (U.S. Environmental Protection Agency, 2010c). These standards and advisories include enforceable Maximum Contaminant Levels (MCLs), which are the highest concentrations of contaminants allowed in finished drinking water; nonenforceable Maximum Contaminant Level Goals (MCLGs); and Health-Advisory Levels (HALs) at which human-health effects are known or anticipated to occur over different durations of exposure. These tables also list drinking-water equivalent levels, which are lifetime exposure concentrations intended to be protective of noncancer health effects under a conservative assumption that all exposure to a contaminant is from drinking water. The NTAS work group prioritized constituents that met either of two criteria: (1) having an MCL, MCLG, or lifetime HAL, or (2) having a cancer rating of " $\mathrm{H}$ " (carcinogenic to humans), "L" (likely to be carcinogenic to humans), "L/N" (likely to be carcinogenic above a specified dose but unlikely to be carcinogenic below that dose), "A" (human carcinogen), "B1" (probable human carcinogen with limited human evidence), or "B2" (probable human carcinogen with sufficient evidence in animals and inadequate or no evidence in humans).

\section{- USEPA Contaminant Candidate List 3 (CCL3):} Contaminants on the CCL3 are not currently subject to proposed or promulgated national primary drinkingwater regulations, but are known or anticipated to occur in public water systems and may require future regulation under the Safe Drinking Water Act (U.S. Environmental Protection Agency, 2010d). The list includes pesticides, pharmaceuticals, disinfection by-products, chemicals used in commerce, waterborne pathogens, and biological toxins. The list was established using expert opinion and recommendations from the National Academy of Science's National Research Council and National Drinking Water Advisory Council, with consideration of occurrence and health effects (U.S. Environmental Protection Agency, 2010d). The NTAS work group evaluated 104 of the 116 constituents in the final CCL3; the remaining 12 are microbiological contaminants, which are beyond the scope of this prioritization effort.
- USEPA Unregulated Contaminant Monitoring Rule (UCMR) monitoring data: The NTAS work group accessed information for 25 unregulated constituents listed for the second cycle of UCMR sampling (UCMR 2), which was scheduled for 2008-10 (U.S. Environmental Protection Agency, 2010e). These constituents included a subset of those identified from the CCL3 and additional constituents identified on the basis of current research on occurrence and health-effects risk factors and evaluations by the USEPA Office of Water's Office of Science and Technology (U.S. Environmental Protection Agency, 2010e). Monitoring data collected for UCMR 2 were accessed to document the likelihood of occurrence for these constituents. Data from the Unregulated Contaminant Monitoring Program can be accessed through http://waterepa. gov/lawsregs/rulesregs/sdwa/ucmr/data.cfm. Although the final constituent list for the third cycle of UCMR sampling (UCMR 3) was not available at the time of this prioritization, the chemical constituents proposed for public comment on March 3, 2011 (U.S. Environmental Protection Agency, 2011f), were captured for NTAS prioritization through inclusion on other lists or other mechanisms.

- Guidelines for Canadian Drinking Water Quality: Guidelines for Canadian Drinking Water Quality are published by Health Canada on behalf of the Federal-Provincial-Territorial Committee on Drinking Water and are summarized at $h t t p: / / w w w . h c-s c . g c . c a l$ ewh-semt/pubs/water-eau/2012-sum_guide-res_recom/ index-eng.php. Maximum Acceptable Concentrations (MAC) are health-based guidelines established by the Federal-Provincial-Territorial Committee on Drinking Water for contaminants that meet all of the following criteria: (1) exposure to the contaminant could lead to adverse health effects, (2) the contaminant is frequently detected or could be expected to be found in a large number of drinking-water supplies throughout Canada, and (3) the contaminant is detected, or could be expected to be detected, at a level that is of possible health significance (Health Canada, 2008). Chemical constituents listed by Health Canada as having a MAC were prioritized by the NTAS work group.

- State of California maximum contaminant levels and public health goals: The State of California uses two types of health-based standards for drinking-water quality - maximum contaminant levels (California MCLs) and public-health goals (PHGs). Constituents with either of these standards were prioritized by the NTAS work group. The California MCL is an enforceable standard established by the California Department of Public Health to be met by public water systems to be protective of human health (California Department of Public Health, 2010a) and takes into account a chemical's health risks, as well as its detectability, 
treatability, and cost of treatment (California Department of Public Health, 2010b). The public-health goals are established by the California Environmental Protection Agency's Office of Environmental Health Hazard Assessment (OEHHA) and are concentrations below which a drinking-water contaminant has been determined to pose no significant health risk if consumed for a lifetime (California Department of Public Health, 2010b).

Additional lists that were not specific to drinking-water programs, but which represented human-health concerns potentially related to environmental exposure, included the following:

- USEPA Mid-Atlantic Risk Assessment: Screeninglevel information compiled by the USEPA for the MidAtlantic Risk Assessment User's Guide (U.S. Environmental Protection Agency, 2009c) for response actions at contaminated sites that fall under Federal authority under the Comprehensive Environmental Response, Compensation, and Liability Act (CERCLA), also known as "Superfund," for USEPA Regions 3, 6, and 9 was considered. Constituents with screening levels for tap water of less than or equal to 1 milligram per liter $(\mathrm{mg} / \mathrm{L})$ were included in the prioritization by the NTAS work group because these low constituent concentrations probably do not represent local-scale contamination such as point-source releases, spills, landfills, or hazardous waste sites.

- Centers for Disease Control and Prevention (CDC) National Health and Nutrition Examination Survey (NHANES): NHANES is a set of studies designed to assess the health and nutritional status of adults and children in the United States (Centers for Disease Control and Prevention, 2010). The fourth round of these studies, NHANES IV, will document chemicals detected in human blood or urine from a representative sample population of more than 30,000 individuals. Constituents analyzed for NHANES IV were selected based on known or hypothesized exposure in the U.S. population, data on health effects known or thought to result from levels of exposure, the need to assess the efficacy of public health actions to reduce exposure, availability of analytical methods, and the availability of adequate blood or urine samples (Falk, 2010). NHANES information can be accessed through http://www.cdc.gov/nchs/surveys.htm; however, results from NHANES IV have not been published or made available to the public by the CDC at the time of this publication. A list of 415 constituents of concern for NHANES IV (including some that overlap with other lists used in this process) was provided by John Osterloh (Centers for Disease Control and Prevention, National Center for Environmental Health, Division of Laboratory Sciences, written commun., July 1, 2009), and these constituents were considered for prioritization by the NTAS work group.

- Canada's Domestic Substances List Program: Environment Canada, in support of the Canadian Environmental Protection Act of 1999, screened constituents on their Domestic Substances List, which is a list of substances manufactured or imported into Canada in amounts of 100 kilograms $(\mathrm{kg})$ or more during any calendar year from 1984 through 1986, to determine whether they are toxic or capable of becoming toxic as defined in the Canadian Environmental Protection Act (Environment Canada, 2006, 2010). Under the Canadian Environmental Protection Act, a substance is "toxic" if it enters the environment in a quantity or concentration or under conditions that (1) may have an immediate or long-term harmful effect on the environment or its biological diversity, (2) may constitute a danger to the environment upon which life depends, or (3) may constitute a danger to human life or health in Canada. Constituents on the Domestic Substances List were categorized by Environment Canada into risk-based and exposure-based priorities (high, moderate, and low). Some constituents on the Domestic Substances List were removed from consideration by the NTAS work group if they were included primarily because of exposure through food (under the Canadian Food and Drugs Act) rather than through the environment. The remaining 229 high-priority constituents, including some that overlap with other lists, were prioritized by the NTAS work group under the rationale that manufacturing and importation practices in Canada are likely to be similar to those in the United States.

- USGS NAWQA Potential Endocrine Disruptors List: A list of potential endocrine disruptors was compiled in support of the NAWQA Program on the basis of literature reviews, relying mainly on three references: the Institute for Environment and Health (2005), Global Water Research Coalition (2003), and BKH Consulting Engineers (2000). Of 108 constituents identified as having evidence of endocrine disruption and high exposure concern (Kymm K. Barnes, U.S. Geological Survey, written commun., August 24, 2007), the following 22 constituents had the highest potential for exposure and endocrine disruption on the basis of a screening process described by the Institute for Environment and Health (2005): acetochlor, alachlor, atrazine, bisphenol A, bromomethane, 4-chloro2-methylphenol, cyfluthrin, diazinon, 3,4-dichloroaniline, 2,4-dichlorophenoxyacetic acid (2,4-D), dicofol, dieldrin, dimethoate, diuron, $\alpha$-endosulfan, $\beta$-endosulfan, linuron, malathion, 4-tert-octylphenols (branched), parathion-methyl, simazine, and tetrachloroethene. These constituents were prioritized by the NTAS work group. 
- Harvard School of Public Health, Industrial Chemicals with Neurotoxic Effects: Dr. Philippe Grandjean and Dr. Philip J. Landrigan of the Harvard School of Public Health identified industrial chemicals that are known to cause neurotoxic effects in humans through use of the hazardous substances data bank of the U.S. National Library of Medicine, fact sheets from the U.S. Agency for Toxic Substances and Disease Registry, the Integrated Risk Information System, or IRIS, database of the USEPA, and corresponding neurotoxicity data from the U.S. National Library of Medicine's PubMed, TOXNET, and TOXLINE databases, and other literature (Grandjean and Landrigan, 2006). Some industrial compounds were found to cause neurodevelopmental disorders, particularly during early fetal development. The 203 industrial constituents identified in the review article documenting this work (Grandjean and Landrigan, 2006) were prioritized by the NTAS work group.

- State of California Proposition 65 List: California Proposition 65, otherwise known as the Safe Drinking Water and Toxic Enforcement Act of 1986, requires the State of California to revise and republish, at least once a year, a list of compounds that are known to cause cancer or reproductive toxicity. The Proposition 65 list is available online through the California OEHHA at http://www.oehha.ca.gov/prop65.html. The list includes some toxicity information, including the no-significant-risk level and maximum allowable dose level for some constituents. As of June 2009, the list included 796 constituents, of which 285 had some information on toxicity (California Office of Environmental Health Hazard Assessment, 2009); this subset of 285 compounds was considered for prioritization by the NTAS work group.

\section{Lists of Constituents of Aquatic-Life Concern}

Lists of constituents of aquatic-life concern also were used as a screening tool to identify candidate constituents for prioritization on the basis of potential toxicity to organisms living in ambient surface water. Although the focus of these lists was effects on aquatic life, some of the lists included information applicable to human health or wildlife, including information relevant to fish consumption. Although the concerns addressed in these lists relate to unfiltered ambient surface water, rather than to filtered water (as is the case for drinking-water concerns), exposure to these constituents is likely of concern regardless of whether the constituent is in the aqueous phase (dissolved in water) or sorbed to sediment particles in the water. The NTAS work group focused on information that is appropriate for freshwater rather than marine water. The lists of constituents of aquatic-life concern included constituents with published literature studies of toxicity to aquatic life, as well as constituents of concern to other agencies and organizations, and many of the constituents were found on multiple lists. These lists included the following:

- USEPA National Recommended Water-Quality Criteria: The USEPA has compiled national recommended water-quality criteria for the protection of aquatic life and human health in surface water for approximately 150 pollutants (U.S. Environmental Protection Agency, 2010f). These criteria include the Critical Maximum Concentration, an estimate of the highest concentration of a material to which an aquatic community can be exposed briefly without resulting in an unacceptable effect (acute exposure), and the Criterion Continuous Concentration, which is an estimate of the highest concentration of a material to which an aquatic community can be exposed indefinitely without resulting in an unacceptable effect (chronic exposure). Critical Maximum Concentrations and Criterion Continuous Concentrations are to be considered within the context of the acute averaging period, chronic averaging period, frequency of allowed acute exceedances, and frequency of allowed chronic exceedances. Because the aquatic-life criteria from section 304(a) of the Clean Water Act are national guidance, they are intended to be protective of the vast majority of the aquatic communities in the United States. Constituents on this list that had freshwater Critical Maximum Concentration or Criterion Continuous Concentration values were considered for prioritization by the NTAS work group.

- Canadian Water-Quality Guidelines for the Protection of Aquatic Life: These Canadian water-quality guidelines are intended to provide protection of aquatic life at all life stages, including the most sensitive life stage of the most sensitive species over the long term, from anthropogenic stressors, such as chemical inputs or changes to physical components (for example, $\mathrm{pH}$, temperature, and debris), and are determined on the basis of scientifically defensible toxicological data (Canadian Council of Ministers of the Environment, 1999). The NTAS work group used the most recently updated guidelines available at the time of prioritization, found in summary tables published in 2007 (Canadian Council of Ministers of the Environment, 2007). Constituents having guideline concentrations for freshwater were considered for prioritization by the NTAS work group.

- The Great Lakes Water Quality Agreement of 1978: This agreement between the Governments of Canada and the United States had the goal of enhancing water quality in the Great Lakes System by adopting common objectives and developing and implementing cooperative programs and other measures. Objectives stemming from this agreement (U.S. Environmental Protection Agency, 2009d) are based on available 
information on cause-and-effect relations between pollutants and receptors and are designed to restore and maintain the chemical, physical, and biological integrity of the Great Lakes Basin Ecosystem. Each compound with a specific objective for aquatic lifethat is, having a reference concentration in micrograms per liter-was included in the list of constituents of aquatic-life concern as having a benchmark value.

- European Commission priority list of endocrine disrupters: The European Commission (2008) evaluated a candidate list of 553 suspected endocrine disrupters, of which 147 were considered likely to be persistent in the environment or produced in high volumes. Using expert advice, information on this subset of constituents was reviewed by the European Commission to determine the strength of evidence for endocrine disruption, and constituents were assigned to one of three categories: Category 1, evidence for endocrine disruption in living organisms; Category 2, evidence of potential to cause endocrine disruption; and Category 3 , no evident scientific basis. Of the 147 constituents evaluated, clear evidence of endocrine disrupting activity was noted for 66 constituents (Category 1), and some evidence indicating potential activity was noted for an additional 52 constituents (Category 2). These 118 constituents were included in the list of constituents of aquatic-life concern for subsequent evaluation in the NTAS prioritization process.

- Canadian Domestic Substances List-substances that are inherently toxic to the environment: An initiative in the Canadian Environmental Protection Act requires the Minister of the Environment and the Minister of Health to screen substances (the Domestic Substances List) used in Canadian commerce, used for manufacturing purposes, or manufactured in or imported into Canada in quantities of $100 \mathrm{~kg}$ or more in any calendar year. Chemical substances that are known or believed to adversely affect aquatic organisms, on the basis of laboratory studies, other studies, or models, as defined by Environment Canada (2010), were included in the list of constituents of aquaticlife concern for inclusion in the NTAS prioritization process.

\section{Constituents of International Concern}

Additional information sources were used to identify candidate constituents for prioritization that were of international concern, and that also may be present in water or sediment in the United States, as evidenced by treaties or collaborative programs. Many of these constituents overlapped with the aforementioned lists of human-health or aquatic-life concern. Constituent names and information, along with the organizations or programs for which the constituents were identified, were compiled from the following sources:

- Aboriginal Affairs and Northern Development Canada-Northern Contaminants Program (http://www. aadnc-aandc.gc.ca/eng/1100100035611) and Canadian Arctic Contaminants Assessment Report II (http:// bibvir1.uqac.ca/archivage/17718301.pdf),

- The Arctic Council-Arctic Monitoring and Assessment Programme (http://www.amap.no/),

- The Australian Department of Environment and Heritage and Department of Health and Ageing (http:// www.health.gov.au/),

- The Canadian Council of Ministers of the Environment-Canadian Sediment Quality Guidelines for the Protection of Aquatic Life (Canadian Council of Ministers of the Environment, 2002),

- The Commission for Environmental Cooperation of North America-North American Regional Action Plan and Sound Management of Chemicals (http:// www.cec.org/),

- Environment Canada-Ecological Screening Assessments, Existing Substances Evaluation, Global Atmosphere Passive Sampling [GAPS] Network, Great Lakes Binational Toxics Strategy and Integrated Atmospheric Deposition Network (in cooperation with the USEPA), and Toxic Substances Management Policy (http://www.ec.gc.ca),

- The European Commission-Joint Research Center Institute for Health and Consumer Protection (http:// ihcp.jrc.ec.europa.eu/) and Registration, Evaluation, Authorisation and Restriction of Chemicals [REACH] Program (http://ec.europa.eu/enterprise/sectors/ chemicals/reach/),

- The European Union-Monitoring Network in the Alpine Region for Persistent and other Organic Pollutants [MONARPOP; $h t t p: / / w w w . m o n a r p o p . a t /$, Water Framework Directive (http://ec.europa.eu/ environment/water/water-framework/index_en.html), and Water Information System for Europe (http:// water.europa.eu/)],

- The Norwegian Ministry of the Environment-Norwegian Pollution Control Authority (http://epanet.ew.eea. europa.eu/european_epas/countries/no/norwegianpollution-control-authority),

- The Oslo-Paris (OSPAR) Convention for the Protection of the Marine Environment of the North-East Atlantic-OSPAR List of Chemicals for Priority Action (OSPAR Commission, 2010), 
- The United Kingdom (UK) Department for Environment, Food and Rural Affairs [DEFRA] - UK Coordinated Chemical Risk Management Programme (http://archive.defra.gov.uk/environment/quality/ chemicals/ukrisk.htm) and UK Chemical Stakeholders Forum (http://www.defra.gov.uk/chemicals-forum/), and

- The United Nations (UN) - Convention on Long-range Transboundary Air Pollution (http://www.unece.org/ env/lrtap/), Regionally Based Assessment of Persistent Toxic Substances (in cooperation with the United Nations Environment Programme and the Global Environmental Facility; http://www.chem.unep.ch/ pts/), Rotterdam Convention on the Prior Informed Consent Procedure for Certain Hazardous Chemicals and Pesticides in International Trade (http://www.pic. int/), and Stockholm Convention on Persistent Organic Pollutants (http://chm.pops.int)).

\section{Human-Health Effects Information from the ACToR Database}

In prioritizing constituents, the NTAS work group focused on many characteristics of constituents of interest, including possible human-health effects. The USEPA Aggregated Computational Toxicology Resource (ACToR, http:// actor.epa.gov) database was queried for human-health information for compounds in several NTAS constituent groups. The ACToR database, maintained by the USEPA National Center for Computational Toxicology, is a warehouse of information organized by constituent that was compiled from a variety of publicly available government and research institution databases (summarized at http://actor.epa.gov/actor/faces/ DataCollectionSummary.jsp). The databases include peerreviewed studies, governmental data collections, and nongovernmental data collections. Most of the human-health data used for the NTAS prioritization effort came from the USEPA, U.S. Food and Drug Administration, California OEHHA, and other governmental agencies. The physical, chemical, assay, and toxicology data are sorted into categories of mechanism of action, including hazard, chronic and acute toxicity, carcinogenicity, food safety, and various other toxicological effects (such as genetic, developmental, or reproductive effects).

\section{ACToR Database Queries}

Information pulled from the ACToR database required distillation in order to be used effectively by the NTAS work group. Applicable data were identified and summarized, including toxicity, hazard, and carcinogenicity. If a constituent was found to be of concern by an institution tasked with the protection of human health, that concern was noted. Information about the availability of in vivo studies (animal testing) also was included, as needed, to improve information on chronic toxicity. This process did not seek to reproduce the
ACToR database for constituents of interest but to highlight the existence (or lack thereof) of human-health information. Queries of the ACToR database were performed for selected constituents in NTAS constituent groups A, C, D, E, F, G, $\mathrm{H}$, and I. (The ACToR data were not used for constituents in groups $\mathrm{B}$ and $\mathrm{J}$ because other sources of human-health information were used in the prioritization process for these groups.)

\section{Data Aggregation and Use of Human-Health “Bins”}

ACToR data for selected constituents were tabled, and each of these constituents was placed into one of three human-health (HH) "bins," depending on the type and extent of information available: HH bin 1 included constituents with quantitative human-health toxicity data (for example, oral reference dose) or cancer classification, HH bin 2 included constituents that were on a priority list related to human health but do not have quantitative toxicity information or a cancer classification, and HH bin NIA (no information available) included constituents with no human-health information available in the ACToR database (see sidebar on page 12).

\section{Aquatic-Life Effects Information from the ECOTOXicology Database}

In prioritizing constituents, the NTAS work group considered potential aquatic-life effects on the basis of acute toxicity information from the USEPA ECOTOXicology (ECOTOX) database of single-chemical toxicity data for aquatic life, terrestrial plants, and wildlife available at $h t t p: / / w w w . e p a . g o v /$ ecotox (U.S. Environmental Protection Agency, 2011a, 2007). The ECOTOX database is maintained by the USEPA Office of Research and Development and the National Health and Environmental Effects Research Laboratory's Mid-Continent Ecology Division and includes toxicity data derived predominantly from peer-reviewed literature (U.S. Environmental Protection Agency, 2011a). Advanced database queries were completed for selected compounds in NTAS constituent groups A, B, C, $\mathrm{D}, \mathrm{F}, \mathrm{H}$, and I.

\section{ECOTOXicology Database Queries}

Constituents were queried in the ECOTOX database using the "advanced database query" option for plants (algae, moss, and fungi) and animals (fish, crustaceans, insects and spiders, and mollusks and other invertebrates). The collected data included concentration-based endpoints, such as the $\mathrm{LC}_{50}$ (median lethal concentration-a concentration expected to cause death in 50 percent of test animals), $\mathrm{EC}_{50}$ (median effective concentration - a concentration expected to have an effect in 50 percent of test animals), LOEC (lowest-observed-effect concentration), NOEC (no-observed-effect concentration), and effects measurements (physiology, growth, mortality, and reproduction) for freshwater. Exposure types were limited to aquatic only-flow-through, renewal, and static. 


\begin{tabular}{|c|c|c|}
\hline $\begin{array}{l}\text { Human-health } \\
\text { bin } 1\end{array}$ & $\begin{array}{l}\text { Constituents of greatest concern: } \\
\text { Includes constituents with Federal- or State- } \\
\text { recognized reference dose, reference concen- } \\
\text { tration, slope factor, cancer classification, or } \\
\text { U.S. Food and Drug Administration intake- } \\
\text { limit information. Constituents with data of } \\
\text { this nature are of increased priority and interest } \\
\text { because of their recognized human-health } \\
\text { effects. }\end{array}$ & $\begin{array}{l}\text { Criteria used: } \\
\text { For constituents with more than one listed relevant } \\
\text { exposure limit, Federal listings were given preference } \\
\text { over State listings. Reference doses, slope factors, } \\
\text { reference concentrations, cancer classes, and U.S. Food } \\
\text { and Drug Administration intake limits were given prior- } \\
\text { ity in that order. Quantitative human-health effects data } \\
\text { come from the U.S. Environmental Protection Agency, } \\
\text { U.S. Food and Drug Administration, or California Of- } \\
\text { fice of Environmental Health Hazard Assessment. }\end{array}$ \\
\hline $\begin{array}{l}\text { Human-health } \\
\quad \text { bin } 2\end{array}$ & $\begin{array}{l}\text { Constituents of intermediate concern: } \\
\text { Includes constituents that have been listed as } \\
\text { priority substances by agencies tasked with } \\
\text { protection of human health and constituents } \\
\text { with data that indicate negative human-health } \\
\text { consequences following exposure but have } \\
\text { not been recognized by adoption of a formal } \\
\text { reference dose, reference concentration, slope } \\
\text { factor, or cancer classification. }\end{array}$ & $\begin{array}{l}\text { Criteria used: } \\
\text { Qualitative human-health effects data came from the } \\
\text { Clean Water Act List of Hazardous Substances; Com- } \\
\text { prehensive Environmental Response, Compensation, } \\
\text { and Liability Act (CERCLA) Priority List of Hazardous } \\
\text { Substances; U.S. Environmental Protection Agency's } \\
\text { High Production Volume Information System (HPVIS); } \\
\text { European Commission Detergent Ingredients Database; } \\
\text { and Health Canada. }\end{array}$ \\
\hline $\begin{array}{l}\text { Human-health } \\
\text { bin NIA }\end{array}$ & $\begin{array}{l}\text { Constituents with no information available: } \\
\text { No referenced priority substance list or human- } \\
\text { health information source has yielded any } \\
\text { substantial information for these constituents. }\end{array}$ & $\begin{array}{l}\text { Criteria used: } \\
\text { None. The ACToR database did not include quantita- } \\
\text { tive or qualitative human-health effects data for these } \\
\text { constituents. }\end{array}$ \\
\hline
\end{tabular}

\section{Data Aggregation and Use of Aquatic-Life "Bins"}

ECOTOX data for selected constituents, if available, were downloaded and imported into a spreadsheet. For fish, the acute median $\mathrm{LC}_{50}$ values for exposure durations of 48-96 hours or chronic median NOEC values were used. For cladocerans (water fleas), a type of crustacean, the acute median $\mathrm{EC}_{50}$ or $\mathrm{LC}_{50}$ values for exposure durations of $48-96$ hours or chronic NOEC values for exposure durations of 21 days or longer were used. For other crustaceans (for example, scud, amphipods, and crayfish), the acute median $\mathrm{EC}_{50}$ or $\mathrm{LC}_{50}$ values for exposure durations of 24-96 hours were used. For aquatic insects or spiders, the acute median $\mathrm{LC}_{50}$ values for exposure durations of 24-96 hours were used. For algae, moss, or fungi, the acute median $\mathrm{EC}_{50}$ values for exposure durations of 3-14 days were used. For mollusks, the acute median $\mathrm{LC}_{50}$ values for exposure durations of 24-96 hours were used. If no other studies were available, the median acute $\mathrm{LC}_{50}$ values for rotifers for exposure durations of 24-96 hours were used. Only studies with data reported in concentration units (usually micrograms per liter or moles per liter) were used. Some studies with nonstandard exposure durations were used if other studies were not available, and if the exposure durations were similar to the standard duration and could be used to infer the minimum or approximate toxicity at the standard duration.

Constituents were placed into one of four aquatic-life (AL) "bins," depending on the type and extent of toxicity information available (see sidebar on page 13). Criteria for these AL bins were consistent with thresholds used for the USEPA Office of Pesticide Programs' Environmental Fate and Effects Division's ecotoxicity categories (U.S. Environmental
Protection Agency, 2011b). If multiple studies were available for a constituent, or if a range of values was provided, the result with the highest toxicity (lowest concentration) or corresponding to the most sensitive taxonomic group usually was used to assign it to an AL bin, unless a clear preponderance of studies indicated that a different bin was more appropriate.

\section{Other Resources and Databases from the U.S. Environmental Protection Agency}

In addition to the human-health and aquatic-life information obtained from the USEPA ACToR and ECOTOX databases, constituent properties (for example, the base-10 logarithm of the octanol-water partition coefficient, $\log K_{\mathrm{OW}}$ ) and information about regulatory priorities and thresholds were obtained from other USEPA databases or resources, including, but not limited to, the following:

- The Estimation Program Interface Suite (EPI Suite ${ }^{\mathrm{TM}}$ ) set of physical/chemical property and environmental fate estimation models (U.S. Environmental Protection Agency, 2009e),

- The Ecological Structure Activity Relationships, or ECOSAR, Class Program, a predictive tool to estimate the aquatic toxicity of industrial chemicals based on chemical structure (U.S. Environmental Protection Agency, 2009f),

- The Priority Pollutants list in 40 CFR Part 423, Appendix A (U.S. Environmental Protection Agency, 2011c), 


\begin{tabular}{|c|c|c|}
\hline $\begin{array}{l}\text { Aquatic-life } \\
\text { bin } 1\end{array}$ & $\begin{array}{l}\text { Constituents of } \\
\text { greatest } \\
\text { concern }\end{array}$ & $\begin{array}{l}\text { Criteria used: } \\
\text { Median acute } \mathrm{LC}_{50} \text { (median lethal concentration; fish or aquatic insects or spiders), median } \\
\text { acute } \mathrm{EC}_{50}\left(\text { median effective concentration) or } \mathrm{LC}_{50} \text { (cladocerans or other crustaceans), or me- }\right. \\
\text { dian acute } \mathrm{EC}_{50} \text { (algae/moss/fungi) value less than } 100 \text { micrograms per liter }(\mu \mathrm{g} / \mathrm{L}) \text {; or median } \\
\text { chronic early life-stage (fish) or life-cycle (cladocerans) NOEC (no-observed-effect concentra- } \\
\text { tion) values less than } 10 \mu \mathrm{g} / \mathrm{L} \text {. }\end{array}$ \\
\hline $\begin{array}{l}\text { Aquatic-life } \\
\text { bin } 3\end{array}$ & $\begin{array}{l}\text { Constituents of } \\
\text { least concern }\end{array}$ & $\begin{array}{l}\text { Criteria used: } \\
\text { Median acute } \mathrm{LC}_{50}\left(\text { fish), median acute } \mathrm{EC}_{50} \text { or } \mathrm{LC}_{50} \text { (cladocerans or other crustaceans), median }\right. \\
\text { acute } \mathrm{LC}_{50}\left(\text { aquatic insects/spiders), or median acute } \mathrm{EC}_{50} \text { (algae/moss/fungi) values greater }\right. \\
\text { than } 100,000 \mu \mathrm{g} / \mathrm{L} \text {; or median chronic early life-stage (fish) or life-cycle (cladocerans) NOEC } \\
\text { values greater than } 10,000 \mu \mathrm{g} / \mathrm{L} \text {. }\end{array}$ \\
\hline $\begin{array}{l}\text { Aquatic-life } \\
\text { bin NIA }\end{array}$ & $\begin{array}{l}\text { Constituents with } \\
\text { no information } \\
\text { available }\end{array}$ & $\begin{array}{l}\text { Criteria used: } \\
\text { Studies were not available for this constituent or, if available, did not include aquatic-life ef- } \\
\text { fects information for the appropriate matrix (freshwater) or exposure duration. }\end{array}$ \\
\hline
\end{tabular}

- The Federal-State Toxicology Risk Analysis Committee (materials accessed through http://water.epa.gov/ scitech/research-riskassess/fstrac/index.cfm),

- The High Production Volume (HPV) Challenge program (U.S. Environmental Protection Agency, 2010g),

- The Persistent Bioaccumulative and Toxic (PBT) Chemical Program (no longer active, but materials are archived at http://www.epa.gov/pbt/),

- The Toxics Release Inventory PBT Chemical List (U.S. Environmental Protection Agency, 2010h),

- The Persistent, Bioaccumulative, and Toxic Profiles Estimated for Organic Chemicals (PBT Profiler) screening tool (U.S. Environmental Protection Agency, 2011d), and

- The Office of Pesticide Programs'Aquatic Life Benchmarks (U.S. Environmental Protection Agency, 2011e).

Details about the use of these USEPA resources are provided in the "Supplemental Information" sections for the constituent groups for which they were used.

\section{U.S. Geological Survey Programs and Publications}

Information from USGS programs and publications was used by the NTAS work group to support its prioritization of constituents for ambient monitoring in water and sediment. Many USGS publications are available online through the USGS Publications Warehouse at http://pubs.er.usgs.gov/. Most USGS monitoring data for water or sediment can be accessed through the USGS's National Water Information
System (NWIS) at http://waterdata.usgs.gov/nwis or through the USGS's Water Data Discovery Web page at http://water. usgs.gov/data/. Journal articles written by USGS authors, such as MacDonald and others (2000), who documented the development and evaluation of consensus-based quality guidelines for freshwater ecosystems, are cited in the "Supplemental Information" sections in which they are used. Publications from the USGS National Research Program also can be accessed through http://water.usgs.gov/nrp/publications.html. Additional USGS resources used in the prioritization came from the NAWQA and Toxics Programs, as described in the following sections and in the "Supplemental Information" sections for the constituent groups for which they were used.

\section{National Water-Quality Assessment Data Program and Publications}

The National Water-Quality Assessment (NAWQA) Program, established by the U.S. Congress in 1991, provides information on water-quality conditions, whether conditions are changing over time, and how natural features and human activities affect those conditions (U.S. Geological Survey, 2010b). Regional and national assessments of water-quality conditions are possible because of consistency in the methods of data collection and analysis. Information from the NAWQA Program, including its national synthesis assessments and topical studies, is available online at http://water. usgs.gov/nawqa/. The NAWQA monitoring data are available through the NAWQA Data Warehouse, at http://water.usgs. gov/nawqa/data.html, and most data also are stored in NWIS. The NAWQA publications, including many journal articles, are available through the NAWQA Publications Web page, at http://water.usgs.gov/nawqa/bib/. These publications cover a variety of topics, including VOCs, pesticides, trace elements, 
and other constituents of interest to the NTAS work group. Publications used for the NTAS prioritization of constituents are cited in the "Supplemental Information" sections for the constituent groups for which they were used.

The NAWQA Program also has supported the development of Health-Based Screening Levels (HBSLs) as a tool for evaluating water-quality data with respect to human-health effects for selected constituents that do not have USEPA MCLs. The HBSLs were developed by NAWQA in collaboration with the USEPA, the New Jersey Department of Environmental Protection, and Oregon Health and Science University. HBSLs are nonenforceable benchmarks developed using USEPA methodologies for establishing drinking-water guidelines, along with peer-reviewed, human-health toxicity information for drinking-water ingestion (Toccalino and others, 2008). For noncarcinogens, the HBSLs represent the contaminant concentrations in drinking water that are not expected to cause any adverse effects over a lifetime of exposure. For carcinogens, the HBSL ranges represent the contaminant concentrations in drinking water that correspond to an excess estimated lifetime cancer risk of 1 in 1 million to 1 in 10,000 (Toccalino and others, 2008). Methods for developing and applying HBSLs in water-quality assessments are described by Toccalino (2007). A searchable HBSL database can be accessed through http://water.usgs.gov/nawqa/HBSL/. Benchmarks, such as the USEPA MCL or USGS HBSL, can be used to calculate a benchmark quotient (BQ), which is the ratio of a constituent concentration (or an appropriate concentration statistic, such as the median or 95th or 99th percentile) to its respective MCL or HBSL (Toccalino and others, 2004). The BQs were used in the prioritization for some constituent groups to facilitate comparisons relative to concentrations at which human-health effects may be of concern.

\section{Toxic Substances Hydrology Program Data and Publications}

The USGS Toxic Substances Hydrology Program (Toxics Program) initiated in 1982 provides objective scientific information about selected examples of environmental contamination to improve characterization and management of contaminated sites, protect human and environmental health, and reduce potential future contamination problems (U.S. Geological Survey, 2011a). The Toxics Program investigates two major types of contamination problems: (1) subsurface pointsource contamination, and (2) watershed and regional contamination (Buxton, 2010). Highlights of research studies conducted by the Toxics Program are described by Buxton (2010) and at the Toxics Program Web page at http://toxics.usgs.gov/. Data collected by the Toxics Program can be obtained through journal articles and USGS publications, which can be accessed through the Toxics Program's Publications Web page at http:// toxics.usgs.gov/pubs/. As of January 2011, this bibliography included 5,222 references, of which 3,802 were online publications (U.S. Geological Survey, 2011b).
The Toxics Program's Emerging Contaminants Project (U.S. Geological Survey, 2011c) was an important source of information about new constituents to be prioritized for ambient monitoring in water or sediment by the NTAS work group for the NAWQA Program. The project bibliography for emerging contaminants in the environment (242 publications as of July 2011) is available at $h$ ttp://toxics.usgs.gov/bib/bibEmerging.html. Specific reports and journal articles that were produced by or for the Toxics Program and that were used for the NTAS prioritization of constituents are provided in the specific "Supplemental Information" sections for the constituent groups for which they were used.

\section{NTAS Prioritization Process}

Once an initial set of candidate constituents was identified, constituents were prioritized by the NTAS work group on the basis of available information on physical and chemical properties, observed or predicted environmental occurrence and fate, and observed or anticipated effects on human health and aquatic life. During the process of reviewing information for the initial set of constituents, additional constituents were identified that were potentially of comparable importance and were added to the set of candidate constituents for prioritization. Some compounds were not added to the candidate list if they were determined to be inappropriate for consideration; these included substances that widely occur naturally and are not considered contaminants (for example, cellulose), and substances that are not expected to be relevant to the matrixes of interest (water and sediment), such as gases, unstable molecules, and very short-lived radionuclides. Although comparable objectives were used in the prioritization of constituents within different groups, differences in the availability of information accessed by the NTAS work-group members led to the development of separate prioritization approaches adapted to each NTAS constituent group to make best use of available resources, including the expertise of the work-group members and associated staff and $a d$ hoc teams. At various milestones during the prioritization process, each constituent group's prioritization methods and results were reviewed by NTAS work-group members not directly involved in the prioritization for that constituent group and by informal USGS reviewers outside of the work group. A schematic of the generalized NTAS prioritization process is shown in figure 2.

In addition to placing constituents into prioritization tiers, NTAS work-group members communicated with chemists at the USGS NWQL and other USGS laboratories to obtain information about current and prospective future analytical methods for the constituents, which is provided in "Feasibility of Implementation" subsections within the "Supplemental Information" sections at the end of this report. Laboratory schedule (LS) numbers, which are used by the USGS to identify sets of constituents that can be analyzed by a particular analytical method, are used in this report. Method references 


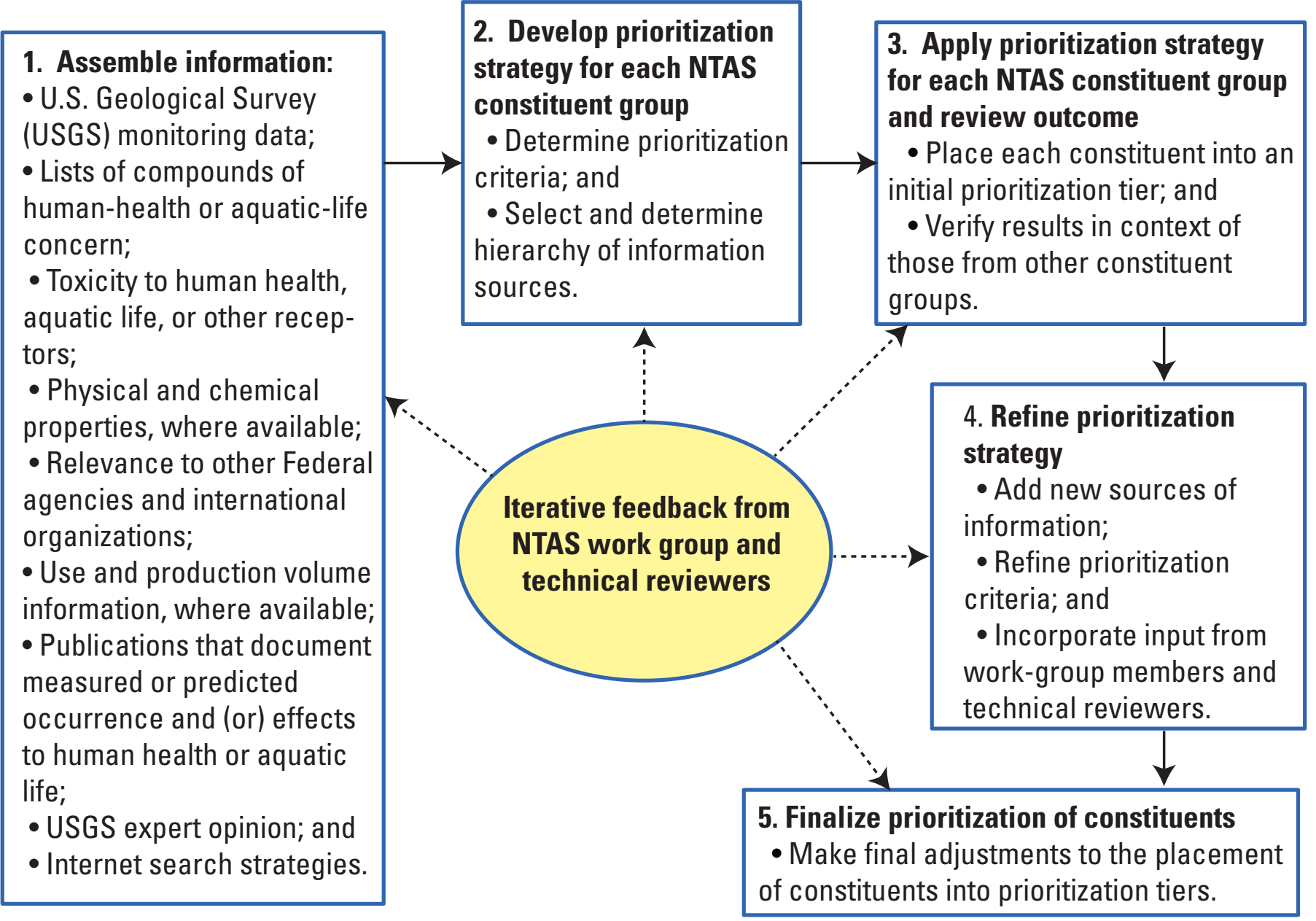

Figure 2. Generalized National Target Analyte Strategy (NTAS) process used to prioritize constituents for national- and regional-scale ambient monitoring of water and sediment in the United States.

for LSs mentioned in this report are provided in the appropriate "Supplemental Information" sections.

Documentation to support the prioritization, and ancillary information that could be useful in understanding constituent occurrence and fate in the environmental matrixes of interest, varied among NTAS constituent groups. Some constituent groups had extensive data tables documenting physical properties, occurrence, and effects; whereas, other constituent groups had little or no history of monitoring and, thus, had only estimated or predicted occurrence or effects information. Because of the disparities in supporting information collected for each NTAS constituent group, tables of complete and consistent supporting information could not be prepared for the entire set of candidate constituents. For these reasons, the detailed constituent prioritization methods and supporting documentation are provided in "Supplemental Information" sections included with this report. A brief synopsis of the prioritization methods used for each NTAS constituent group and citation information for the "Supplemental Information" sections for each constituent group are provided in the following sections.

\section{Prioritization Methods for Volatile Organic Compounds in Water (Group A)}

Compounds evaluated for the volatile organic compounds in water group (Group A) were limited to the 85 constituents on USGS NWQL LS 2020 (purge-and-trap gas chromatography with mass spectrometry) for which national-scale data are available, plus 4 constituents on LS 4024 (heated purge-andtrap gas chromatography with mass spectrometry) for which national-scale data are not available. Additional VOCs that also are HPVs were prioritized under Group H, and additional VOCs that are not HPVs were prioritized under Group I, and were not included in Group A. Constituents on LS 2020 met one or more of seven factors for inclusion on NTAS Tier 1 : (1) having a large detection frequency, defined in this report as greater than or equal to $(\geq) 10$ percent; (2) being a component of a mixture of known human-health concern; (3) having at least 20 percent of detections within two orders of magnitude of an MCL or HBSL; (4) having a large detection frequency in USEPA studies; (5) having a 99-percentile concentration greater than 0.01 of an MCL or HBSL (that is, having a BQ 
greater than 0.01); (6) having a benchmark, but not a detection limit that is low enough to provide an understanding of occurrence relative to that benchmark; or (7) usefulness as an indicator of constituent's source or degradation pathway. Constituents on LS 4024 were prioritized for Group A using the process described for the high-production-volume chemicals in water (Group H) in Supplemental Information $\mathrm{H}$.

Prioritization methods and results, an evaluation of feasibility with respect to laboratory methods, and additional information for the volatile organic compounds in water (Group A) are provided in the "Supplemental Information A" section, which can be cited as follows:

Zogorski, J.S., Wydoski, D.S., and Valder, J.F., 2013, Supplemental information A. Prioritization of volatile organic compounds in water (Group A), in Olsen, L.D., Valder, J.F., Carter, J.M., and Zogorski, J.S., Prioritization of constituents for national- and regional-scale ambient monitoring of water and sediment in the United States: U.S. Geological Survey Scientific Investigations Report 2012-5218, 203 p. (Also available at $h t t p: / / p u b s . u s g s . g o v / s i r / 2012 / 5218 /$ downloads/supplementalinformationA.)

\section{Prioritization Methods for Pesticides in Water or Sediment (Group B)}

The pesticides in water or sediment group (Group B) included constituents on existing USGS LSs and new constituents identified from a proprietary agricultural pesticide-use database. The prioritization for Group B was split into two processes: pesticides in water (Group B1) and pesticides in sediment (Group B2).

A total of 615 pesticides and pesticide degradates were prioritized for water (Group B1) on the basis of observed or predicted concentrations in surface water or groundwater, pesticide-use information, detection frequencies in surface water or groundwater, potential effects to human health or aquatic life, and importance to other agencies or organizations. One criterion that was used to assign constituents to NTAS Tier 1 for water was having a BQ greater than 0.01 , which is comparable to criteria used for other constituent groups. Another criterion was having a large detection frequency ( $\geq 10$ percent). Constituents that were degradates of other Tier 1 constituents also were placed into Tier 1 to allow for monitoring of degradation processes.

Similarly, 605 pesticides and pesticide degradates were prioritized for sediment (Group B2) on the basis of observed or predicted occurrence in sediment (as determined from persistence and other chemical and physical properties), comparisons to sediment-quality benchmarks or aquatic-life toxicity information (through the use of aquatic-life "bins"), consideration of pesticide-use information, and importance to other agencies or organizations. Constituents that were degradates of other Tier 1 constituents were placed into Tier 1 to allow for monitoring of degradation processes.
Prioritization methods and results, an evaluation of feasibility with respect to laboratory methods, and additional information for the pesticides in water (Group B1) and pesticides in sediment (Group B2) are described by Norman and others (2012) and are presented more briefly in the "Supplemental Information B1" and "Supplemental Information B2" sections, respectively, which can be cited as follows:

Norman, J.E., Nowell, L.H., Kuivila, K.M., Hladik, M.L., and Wydoski, D.S., 2013, Supplemental information B1. Prioritization of pesticides in water (Group B1), in Olsen, L.D., Valder, J.F., Carter, J.M., and Zogorski, J.S., Prioritization of constituents for national- and regional-scale ambient monitoring of water and sediment in the United States: U.S. Geological Survey Scientific Investigations Report 2012-5218, 203 p. (Also available at http://pubs.usgs.gov/ sir/2012/5218/downloads/supplementalinformationB1.)

Norman, J.E., Nowell, L.H., Kuivila, K.M., Van Metre, P.C., Pankow, J.F., and Wydoski, D.S., 2013, Supplemental information B2. Prioritization of pesticides in sediment (Group B2), in Olsen, L.D., Valder, J.F., Carter, J.M., and Zogorski, J.S., Prioritization of constituents for nationaland regional-scale ambient monitoring of water and sediment in the United States: U.S. Geological Survey Scientific Investigations Report 2012-5218, 203 p. (Also available at $h t t p: / / p u b s . u s g s . g o v /$ sir/2012/5218/downloads/ supplementalinformationB2.)

\section{Prioritization Methods for Pharmaceuticals and Hormones in Water or Sediment (Group C)}

The pharmaceuticals and hormones in water or sediment group (Group C) included constituents on several USGS LSs, including schedules 1433, 2434, 5433, 6434, 8058, and the proposed replacement for LS 2080 from the NWQL, and schedules LCAB and LCAS from the USGS Organic Geochemistry Laboratory at the Kansas Water Science Center. This constituent group also included constituents identified from lists of human-health and aquatic-life concern, and by the Toxics Program as being of potential interest for monitoring in water or sediment.

A total of 406 pharmaceutical constituents were prioritized using criteria for likelihood of occurrence (from occurrence data or predicted occurrence) and reason for concern (including potential effects to human health or aquatic life) using the prioritization process and information sources described in the "Supplemental Information C" section. Most pharmaceuticals have little or no USGS monitoring data, so external literature references documenting actual or predicted occurrence were used to supplement the USGS data. No benchmarks were available for pharmaceuticals at the time of the prioritization, so qualitative criteria were applied to most constituents. Constituents were evaluated for partitioning between water and sediment to determine whether each constituent was likely to occur predominantly in water (unfiltered 
samples) or sediment (suspended or streambed sediment) or have substantial proportions in both matrixes.

Prioritization methods and results, an evaluation of feasibility with respect to laboratory methods, and additional information for the pharmaceuticals and hormones in water or sediment (Group C) are provided in the "Supplemental Information C" section, which can be cited as follows:

Olsen, L.D., Wydoski, D.S., Furlong, E.T., and Focazio, M.J., 2013, Supplemental information C. Prioritization of pharmaceuticals and hormones in water or sediment (Group C), in Olsen, L.D., Valder, J.F., Carter, J.M., and Zogorski, J.S., Prioritization of constituents for national- and regional-scale ambient monitoring of water and sediment in the United States: U.S. Geological Survey Scientific Investigations Report 2012-5218, 203 p. (Also available at http://pubs.usgs.gov/sir/2012/5218/downloads/ supplementalinformationC.)

\section{Prioritization Methods for Trace Elements and Other Inorganic Constituents in Water or Sediment (Group D)}

For the trace elements and other inorganic constituents in water or sediment group (Group D), separate prioritization approaches were used for water (Group D1) and sediment (Group D2). A total of 38 trace elements and other inorganic constituents were prioritized for water, and a subset of 10 of these trace elements was prioritized for sediment (suspended and streambed sediment).

For water, constituents that were prioritized consisted of the 22 trace elements on USGS NWQL LS 2710, plus iron, for which NAWQA monitoring data were available, and 15 additional inorganic constituents that are regulated or are being considered for regulation in drinking water by the USEPA or that are of interest because of their potential usefulness as indicators of geochemical processes. Constituents with monitoring data were prioritized by comparing concentrations from NAWQA monitoring data for groundwater to human-health benchmarks from the USEPA regulations for drinking water or the USEPA ACToR database. Constituents without NAWQA monitoring data were prioritized by using toxicity information from the USEPA ACToR database and information from peerreviewed literature sources.

For sediment, 10 trace elements were selected for prioritization largely on the basis of availability of sediment-quality benchmarks for aquatic-life effects, including the consensusbased probable effect concentration and threshold effect concentration from MacDonald and others (2000). Concentrations from occurrence data collected through the NAWQA Program and through NAWQA's Contaminant Trends in Lake Sediments study were compared to these sediment-quality benchmarks to determine which trace elements were of highest concern with respect to aquatic life.
Prioritization methods and results, an evaluation of feasibility with respect to laboratory methods, and additional information for the trace elements and other inorganic constituents in water or sediment (Group D) are provided in the "Supplemental Information D" section, which can be cited as follows:

Focazio, M.J., Van Metre, P.C., Valder, J.F., Ayotte, J.D., Desimone, L.A., Dubrovsky, N.M., Norman, J.E., Rosen, M.R., and Zogorski, J.S., 2013, Supplemental information D. Prioritization of trace elements and other inorganic constituents in water or sediment (Group D), in Olsen, L.D., Valder, J.F., Carter, J.M., and Zogorski, J.S., Prioritization of constituents for national- and regional-scale ambient monitoring of water and sediment in the United States: U.S. Geological Survey Scientific Investigations Report 2012-5218, 203 p. (Also available at http://pubs.usgs.gov/ sir/2012/5218/downloads/supplementalinformationD.)

\section{Prioritization Methods for Cyanotoxins in Surface Water (Group E)}

For the cyanotoxins in surface water group (Group E), 15 cyanotoxins with analyses available from the USGS Organic Geochemistry Research Laboratory in Kansas on LS LCTX were considered for prioritization. Benchmarks and toxicity information are unavailable or sparse for these 15 constituents (except for microcystin LR). Constituents were prioritized on the basis of sparse occurrence data available from analyses done for the 2006 USGS Midwestern Cyanotoxin Reconnaissance (Graham and others, 2010) and nonspecific enzymelinked immunosorbent assay tests done for the USEPA National Lakes Assessment (U.S. Environmental Protection Agency, 2009d), and 12 of the 15 cyanotoxins were placed into NTAS Tier 1. Despite increasing interest in the effects of cyanotoxins on human health and aquatic life, no nationwide, systematic monitoring has been conducted to date (2011) for specific cyanotoxin variants in surface-water bodies used for drinking water or recreation.

Prioritization methods and results, an evaluation of feasibility with respect to laboratory methods, and additional information for the cyanotoxins in surface water (Group E) are provided in the "Supplemental Information E" section, which can be cited as follows:

Zogorski, J.S., Wydoski, D.S., and Valder, J.F., 2013, Supplemental information E. Prioritization of cyanotoxins in surface water (Group E), in Olsen, L.D., Valder, J.F., Carter, J.M., and Zogorski, J.S., Prioritization of constituents for national- and regional-scale ambient monitoring of water and sediment in the United States: U.S. Geological Survey Scientific Investigations Report 2012-5218, 203 p. (Also available at $h t t p: / / p u b s . u s g s . g o v /$ sir/2012/5218/downloads/ supplementalinformationE.) 


\section{Prioritization Methods for Lipophilic Organic Compounds in Sediment (Group F)}

The lipophilic organic compounds in sediment group had 699 constituents that were prioritized on the basis of likelihood of occurrence and potential effects to aquatic life. Criteria for likelihood of occurrence were met if a constituent had a large detection frequency ( $\geq 10$ percent) based on USGS NAWQA monitoring data or studies in the peer-reviewed literature or if the constituent satisfied thresholds for both (a) persistence (half-life in soil greater than 30 days, half-life in water or sediment greater than 60 days, or persistence score greater than 1$)$ and (b) predicted hydrophobicity $\left(\log K_{\text {OW }}\right.$ greater than 3 or water solubility less than $1 \mathrm{mg} / \mathrm{L}$ ). Criteria for potential effects to aquatic life were met if a constituent had concentrations greater than sediment-quality benchmarks in the NAWQA monitoring dataset, or if the constituent had observed or predicted aquatic-life toxicity (acute or chronic) that meets aquatic toxicity thresholds (through the use of aquatic-life "bins") for that constituent or for constituents that are structurally similar.

More details about the prioritization methods and results, an evaluation of feasibility with respect to laboratory methods, and additional information for the lipophilic organic compounds in sediment (Group F) are provided in the "Supplemental Information F" section, which can be cited as follows:

Nowell, L.H., Pankow, J.F., Van Metre, P.C., Wydoski, D.S., and Hladik, M.L., 2013, Supplemental information F. Prioritization of lipophilic organic compounds in sediment (Group F), in Olsen, L.D., Valder, J.F., Carter, J.M., and Zogorski, J.S., Prioritization of constituents for national- and regional-scale ambient monitoring of water and sediment in the United States: U.S. Geological Survey Scientific Investigations Report 2012-5218, 203 p. (Also available at $h t t p: / / p u b s . u s g s . g o v / s i r / 2012 / 5218 /$ downloads/ supplementalinformationF.)

\section{Prioritization Methods for Disinfection By-Products in Water (Group G)}

The disinfection by-products in water group (Group G) had 93 constituents that were prioritized for monitoring in water. Water was the matrix of interest for these constituents because disinfection by-products can form in treated (disinfected) drinking water or wastewater, including treated water that has leaked or been intentionally applied to the landscape. Precursors of disinfection by-products (for example, dissolved organic carbon and naturally occurring organic acids) were not considered in this prioritization because they are not considered contaminants, although these precursors are important for understanding and mitigating the formation of disinfection by-products.

Constituents predicted to occur in water and that were of human-health concern were placed into NTAS Tier 1. If a constituent had been part of a national monitoring program and had a large detection frequency ( $\geq 10$ percent), the constituent was placed into Tier 1. Constituents on NWQL LSs with human-health thresholds below the detection levels were placed into Tier 1 because additional data collection using analytical methods that provide lower detection levels is needed for these constituents. Constituents identified in the literature as having been detected in treated water were placed into Tier 2. Constituents with evidence of nonoccurrence (detected in less than 1 percent of samples) or insufficient information to justify placement into Tier 1 or Tier 2 were placed into Tier 3 .

Prioritization methods and results, an evaluation of feasibility with respect to laboratory methods, and additional information for the disinfection by-products in water (Group G) are provided in the "Supplemental Information G" section, which can be cited as follows:

Hladik, M.L., Focazio, M.J., Delzer, G.C., and Rostad, C.E., 2013, Supplemental information G. Prioritization of disinfection by-products in water (Group G), in Olsen, L.D., Valder, J.F., Carter, J.M., and Zogorski, J.S., 2013, Prioritization of constituents for national- and regional-scale ambient monitoring of water and sediment in the United States: U.S. Geological Survey Scientific Investigations Report 2012-5218, 203 p. (Also available at http://pubs.usgs.gov/ sir/2012/5218/downloads/supplementalinformationG.)

\section{Prioritization Methods for High-Production- Volume Chemicals in Water (Group H)}

A total of 318 constituents were prioritized as high-production-volume chemicals in water (Group H). These constituents were selected from the 2,782 entries on the USEPA's list of HPVs (U.S. Environmental Protection Agency, 2010g) at the time of this prioritization. Constituents were selected by first removing those HPVs that were poorly characterized or broadly defined as mixtures (for example, "petroleum distillates" fractions), organic polymers, and inorganic salts; this step removed many redundant entries for chemicals listed in multiple forms (for example, a complex acid and its salts), leaving 1,689 constituents. This list was further screened based on likelihood of occurrence by applying an algorithm that used information about constituents' production volumes, end uses (whether in original form, used as an intermediary, or chemically changed before use), persistence, and physical properties $\left(\log K_{\mathrm{OW}}\right)$. A distinct breakpoint in likelihood of occurrence was observed between the top 379 constituents and the remaining constituents, and of these, 61 constituents were removed from Group $\mathrm{H}$ because they were already identified for one or more other NTAS constituent groups.

The remaining 318 constituents were prioritized on the basis of a combination of (1) likelihood of effects to human health or aquatic life, and (2) likelihood of occurrence in water, as determined based on $\log K_{\mathrm{OW}}$. $\log K_{\mathrm{OW}}$ was used as an indicator of the tendency of a compound to partition into water (lower values) or sediment (higher values). A criterion of $\log K_{\text {OW }}$ less than 4 was used to identify the constituents 
most likely to occur in water. Constituents not found on any NTAS lists of human-health or aquatic-life concern, or with $\log K_{\text {OW }} \geq 4$, were placed into Tier 3. Constituents with no known human-health or aquatic-life concern (including those with insufficient information) and $\log K_{\text {ow }}$ less than 4 were placed into Tier 2. Constituents with human-health or aquaticlife concern and $\log K_{\mathrm{OW}}$ less than 4 were placed into Tier 1 . More details about the prioritization methods and results, an evaluation of feasibility with respect to laboratory methods, and additional information for the high-production-volume chemicals in water (Group H) are provided in the "Supplemental Information H" section, which can be cited as follows:

Pankow, J.F., Norman, J.E., Valder, J.F., Zogorski, J.S., and Olsen, L.D., 2013, Supplemental information H. Prioritization of high-production-volume chemicals in water (Group H), in Olsen, L.D., Valder, J.F., Carter, J.M., and Zogorski, J.S., Prioritization of constituents for national- and regional-scale ambient monitoring of water and sediment in the United States: U.S. Geological Survey Scientific Investigations Report 2012-5218, 203 p. (Also available at http://pubs.usgs.gov/sir/2012/5218/downloads/ supplementalinformationH.)

\section{Prioritization Methods for Wastewater-Indic ator and Industrial Compounds in Water (Group I)}

A total of 470 constituents were prioritized for monitoring as wastewater-indicator and industrial compounds in water (Group I). These constituents include semivolatile and nonvolatile organic compounds that can enter the environment through wastewater effluent, other intentional or unintentional discharge, air pollution, combustion, or through the routine use of consumer products. Group I also includes many organic compounds that were evaluated for sediment (Group F); these overlapping constituents have properties that support their occurrence in water as well as in suspended or bed sediment. A comparison of LSs from the NWQL_LS 1433 (wastewater compounds in filtered water), LS 4433 (wastewater compounds in unfiltered water), LS 1383 (semivolatile organic compounds in unfiltered water), and LS 2502 (semivolatile organic compounds in sediment) - showed that several constituents with $\log K_{\text {ow }}$ greater than 4 , including some constituents with $\log K_{\text {Ow }}$ greater than 6 , frequently have been detected (detection frequency $\geq 10$ percent) in filtered water, whereas other constituents with $\log K_{\text {ow }}$ values less than 4 have been found in the unfiltered water or sediment samples. Therefore, it is important to monitor the aqueous phase (filtered water) as well as the particulate phase (suspended sediment) for those constituents that overlap between Group I and Group F.

Constituents were prioritized on the basis of likelihood of occurrence and reason for concern. Likelihood of occurrence was determined on the basis of occurrence data from USGS sources (monitoring data) or external literature, or from literature sources describing simulated or predicted occurrence. Reasons for concern included human-health effects, aquatic-life effects (including chronic toxicity to fish), and usefulness as a tracer. Constituents that are unstable in water, that had evidence of likely nonoccurrence (for example, those banned or discontinued for use in the United States), or that were considered to be "safe" (those on the U.S. Food and Drug Administration's (2010) “Generally Recognized As Safe" list) were assigned to Tier 3.

More details about the prioritization methods and results, an evaluation of feasibility with respect to laboratory methods, and additional information for the wastewater-indicator and industrial compounds in water (Group I) are provided in the "Supplemental Information I" section, which can be cited as follows:

Olsen, L.D., Wydoski, D.S., and Valder, J.F., 2013, Supplemental information I. Prioritization of wastewater-indicator and industrial compounds in water (Group I), in Olsen, L.D., Valder, J.F., Carter, J.M., and Zogorski, J.S., Prioritization of constituents for national- and regional-scale ambient monitoring of water and sediment in the United States: U.S. Geological Survey Scientific Investigations Report 2012-5218, 203 p. (Also available at http://pubs.usgs.gov/ sir/2012/5218/downloads/supplementalinformationI.)

\section{Prioritization Methods for Radionuclides in Water (Group J)}

The radionuclides in water group (Group J) was composed of 14 constituents - 12 naturally occurring isotopic radionuclides, plus gross alpha-particle activity and gross betaparticle activity, which could be of human-health concern in water through inhalation and ingestion. All of the radionuclide constituents are carcinogenic and many have USEPA MCLs.

USGS monitoring data were available from NAWQA Cycles 1 and 2 for gross alpha- and beta-particle activities, radium $(-224,-226$, and -228$)$, radon, and elemental uranium for groundwater, and from the National Stream Quality Accounting Network (NASQAN) Program (U.S. Geological Survey, 2010c) for elemental uranium for surface water. Although elemental uranium was prioritized for Group D1 (trace elements and other inorganic constituents in water) rather than for Group J, information about the occurrence and distribution of elemental uranium in ambient water was useful toward understanding the likelihood of occurrence for uranium isotopes and other radionuclide constituents in Group J. Data from a targeted reconnaissance of groundwater used for drinking-water supply (Focazio and others, 2001) were used to improve the understanding of occurrence for radionuclides that were not monitored through the NAWQA or NASQAN Programs.

On the basis of occurrence data and human-health concerns for the radionuclides, 11 of the constituents were placed into Tier 1, and 3 were placed into Tier 2. More details about the prioritization methods and results, an evaluation of feasibility with respect to laboratory methods, and additional information for the radionuclides in water (Group J) are 
provided in the "Supplemental Information J" section, which can be cited as follows:

Rosen, M.R., Szabo, Zoltan, and Olsen, L.D., 2013, Supplemental information J. Prioritization of radionuclides in water (Group J), in Olsen, L.D., Valder, J.F., Carter, J.M., and Zogorski, J.S., Prioritization of constituents for national- and regional-scale ambient monitoring of water and sediment in the United States: U.S. Geological Survey Scientific Investigations Report 2012-5218, 203 p. (Also available at http://pubs.usgs.gov/sir/2012/5218/downloads/ supplementalinformationJ.)

\section{Results of Prioritization}

Of the 2,541 constituents evaluated by the NTAS work group for national- and regional-scale ambient monitoring of water and sediment in the United States, 89 were evaluated for Group A (volatile organic compounds in water), 646 were evaluated for Group B (pesticides in water or sediment), 406 constituents were evaluated for Group C (pharmaceuticals and hormones in water or sediment), 38 were evaluated for Group $\mathrm{D}$ (trace elements and other inorganic constituents in water or sediment), 15 were evaluated for Group E (cyanotoxins in surface water), 699 were evaluated for Group F (lipophilic organic compounds in sediment), 93 were evaluated for Group $\mathrm{G}$ (disinfection by-products in water), 318 were evaluated for Group H (high-production-volume chemicals in water), 470 were evaluated for Group I (wastewater-indicator and industrial compounds in water), and 14 were evaluated for Group J (radionuclides in water). Because several constituents were evaluated for more than one constituent group, the numbers of constituents in all groups do not total to 2,541.

Constituents identified as having the highest priority for ambient monitoring in water or sediment (NTAS Tier 1) are listed in table 1 and summarized briefly in the following section. Constituents that were of intermediate priority (Tier 2) or low or no priority (Tier 3) for ambient monitoring also are summarized, and these constituents are listed in the "Supplemental Information K" section. An Excel spreadsheet database with all of the constituents that were prioritized is available at http://pubs.usgs.gov/sir/2013/5218/downloads/NTASdatabase. $x l s x$. More detailed results of the prioritization process can be found in the "Supplemental Information" sections for each constituent group.

\section{Constituents Identified as Having Highest Priority (Tier 1) for Ambient Monitoring}

Of the 2,541 constituents evaluated by the NTAS work group for ambient monitoring in the United States, 1,081 constituents were identified as being of high priority (Tier 1) for water or sediment (table 1). Of these, 602 constituents were of high priority for water, and 686 constituents were of high priority for sediment. Table 1 provides the constituent name, Chemical Abstracts Service Registry Number ${ }^{\circledR}$ (CASRN), NTAS prioritization tiers for water and sediment, and the constituent group(s) for each constituent that was identified as having high priority for monitoring in water or sediment. Constituents in Tier 1 are being considered by the NAWQA Program for method development (if methods are not already available) and future monitoring as part of NAWQA Cycle 3 .

\section{Constituents Identified as Having Intermediate Priority (Tier 2) or Low or No Priority (Tier 3) for Ambient Monitoring}

Of the 2,541 constituents evaluated by the NTAS work group for ambient monitoring in the United States, 1,460 were identified as having intermediate priority (Tier 2) or low or no priority (Tier 3) for water or sediment, including 436 in Tier 2 for water, 246 in Tier 2 for sediment, 979 in Tier 3 for water, and 779 in Tier 3 for sediment. The "Supplemental Information K" section provides the names, CASRNs, NTAS prioritization tiers for water and sediment, and constituent groups for constituents that were identified as having intermediate, low, or no priority for ambient monitoring. These constituents range in importance from those that are of low or no priority because they are unlikely to occur in water or sediment or are unlikely to have effects on human health or aquatic life, to those that are not of intermediate priority for ambient monitoring but that could be important for studies of heavily contaminated settings or that could become more important in the future if use patterns change or if they become more widespread in the environment. Some constituents were placed into NTAS Tier 3 because of scarceness of information and could become important if additional information about occurrence or effects to human health or aquatic life were to become available.

Many constituents were placed into NTAS Tier 2 (436 for water and 246 for sediment) because they have information that indicates some degree of effects to human health or aquatic life or some likelihood of occurrence in the environmental matrixes of interest (water or sediment). Constituents in Tier 2 are not being considered for ambient monitoring by the NAWQA Program at this time because of resource limitations but could be of interest to other programs that focus on targeted sampling of contaminated sites, such as animal feeding operations, landfills, or wastewater effluent discharge points. If additional resources were to become available to increase the number of constituents that can be monitored in ambient water or sediment in the United States, some of the Tier 2 constituents in the "Supplemental Information K" section may warrant reconsideration for Tier 1. 
Table 1. Constituents identified as having high priority (Tier 1) for national- or regional-scale ambient monitoring of water or sediment in the United States.

[Tiers used to prioritize constituents are defined in the main body of the report; those identified as Tier 1 have a higher priority for monitoring than those identified as Tier 2 or Tier 3. An underlined constituent group is the preferred group in cases of differences in prioritization for the same matrix. Constituent groups: volatile organic compounds in water (A); pesticides in water (B1) or sediment (B2); pharmaceuticals and hormones in water or sediment (C); trace elements and other inorganic constituents in water (D1) or sediment (D2); cyanotoxins in surface water (E); lipophilic organic compounds in sediment (F); disinfection by-products in water $(\mathrm{G})$; high-production-volume chemicals in water $(\mathrm{H})$; wastewater-indicator and industrial compounds in water (I); and radionuclides in groundwater (J). CASRN, Chemical Abstracts Service Registry Number; --, constituent not evaluated for specified matrix; BDE, brominated diphenyl ether; C.I., Colour Index Constitution; FD\&C, U.S. Food and Drug Administration Food, Drug, and Cosmetic Act; PCB, polychlorinated biphenyl]

\begin{tabular}{|c|c|c|c|c|}
\hline Constituent name \{abbreviation or other name\} & CASRN $^{1}$ & $\begin{array}{l}\text { Tier for } \\
\text { water }\end{array}$ & $\begin{array}{l}\text { Tier for } \\
\text { sediment }\end{array}$ & $\begin{array}{l}\text { Constituent } \\
\text { group(s) }\end{array}$ \\
\hline Acenaphthene & $83-32-9$ & 1 & 1 & F, I \\
\hline Acephate & $30560-19-1$ & 1 & 3 & B1, B2 \\
\hline Acetaldehyde & $75-07-0$ & 1 & -- & $\underline{\mathrm{G}}, \mathrm{I}$ \\
\hline Acetamide & $60-35-5$ & 1 & -- & I \\
\hline $\begin{array}{l}\text { 2-[[5-Acetamide-4-[(2-chloro-4,6-dinitrophenyl)azo]-2-methoxyphenyl]benzylamino] } \\
\text { ethyl acetate }\end{array}$ & $16421-40-2$ & -- & 1 & $\mathrm{~F}$ \\
\hline Acetaminophen & $103-90-2$ & 1 & 3 & $\mathrm{C}$ \\
\hline Acetochlor oxanilic acid $\{$ Acetochlor OA $\}$ & $184992-44-4$ & 1 & 3 & B1, B2 \\
\hline Acetochlor sulfynilacetic acid & Not available & 1 & 3 & B1, B2 \\
\hline Acetonitrile & $75-05-8$ & 1 & -- & $\mathrm{H}$ \\
\hline Acetophenone & $98-86-2$ & 1 & 3 & $\mathrm{~F}, \mathrm{I}$ \\
\hline Acetyl hexamethyl tetrahydronaphthalene $\{$ AHTN $\}$ & $21145-77-7$ & 1 & 1 & $\mathrm{~F}, \mathrm{I}$ \\
\hline 5-Acetyl-3-isopropyl-1,1,2,6-tetramethylindane $\{$ Traseolide $\}$ & $68140-48-7$ & -- & 1 & $\mathrm{~F}$ \\
\hline Acridine & $260-94-6$ & 1 & 1 & $\mathrm{~F}, \mathrm{I}$ \\
\hline Acrolein & $107-02-8$ & 1 & -- & I \\
\hline Alachlor & $15972-60-8$ & 1 & 1 & $\mathrm{~B} 1, \mathrm{~B} 2$ \\
\hline Aldicarb sulfone & $1646-88-4$ & 1 & 3 & B1, B2 \\
\hline Aldicarb sulfoxide & $1646-87-3$ & 1 & 3 & $\mathrm{~B} 1, \mathrm{~B} 2$ \\
\hline Aldrin & $309-00-2$ & 3 & 1 & B1, B2 \\
\hline C18-22-tert-Alkyl (chloromethyl)phosphonate (2:1) amines & $79357-73-6$ & -- & 1 & $\mathrm{~F}$ \\
\hline C18-22-tert-Alkyl ethoxylated amines & $68443-10-7$ & -- & 1 & $\mathrm{~F}$ \\
\hline C12- and C18-30-Alkylphenol, calcium salts, sulfurized, overbased & $73758-62-0$ & -- & 1 & $\mathrm{~F}$ \\
\hline Allethrin & $584-79-2$ & -- & 1 & B2 \\
\hline Alprazolam & 28981-97-7 & 1 & 3 & $\mathrm{C}$ \\
\hline Aluminum & $7429-90-5$ & 1 & -- & D1 \\
\hline Ametryn & $834-12-8$ & 1 & 3 & $\mathrm{~B} 1, \mathrm{~B} 2$ \\
\hline
\end{tabular}


Table 1. Constituents identified as having high priority (Tier 1) for national- or regional-scale ambient monitoring of water or sediment in the United States.-Continued

[Tiers used to prioritize constituents are defined in the main body of the report; those identified as Tier 1 have a higher priority for monitoring than those identified as Tier 2 or Tier 3. An underlined constituent group is the preferred group in cases of differences in prioritization for the same matrix. Constituent groups: volatile organic compounds in water (A); pesticides in water (B1) or sediment (B2); pharmaceuticals and hormones in water or sediment (C); trace elements and other inorganic constituents in water (D1) or sediment (D2); cyanotoxins in surface water (E); lipophilic organic compounds in sediment (F); disinfection by-products in water $(\mathrm{G})$; high-production-volume chemicals in water $(\mathrm{H})$; wastewater-indicator and industrial compounds in water (I); and radionuclides in groundwater (J). CASRN, Chemical Abstracts Service Registry Number; --, constituent not evaluated for specified matrix; BDE, brominated diphenyl ether; C.I., Colour Index Constitution; FD\&C, U.S. Food and Drug Administration Food, Drug, and Cosmetic Act; PCB, polychlorinated biphenyl]

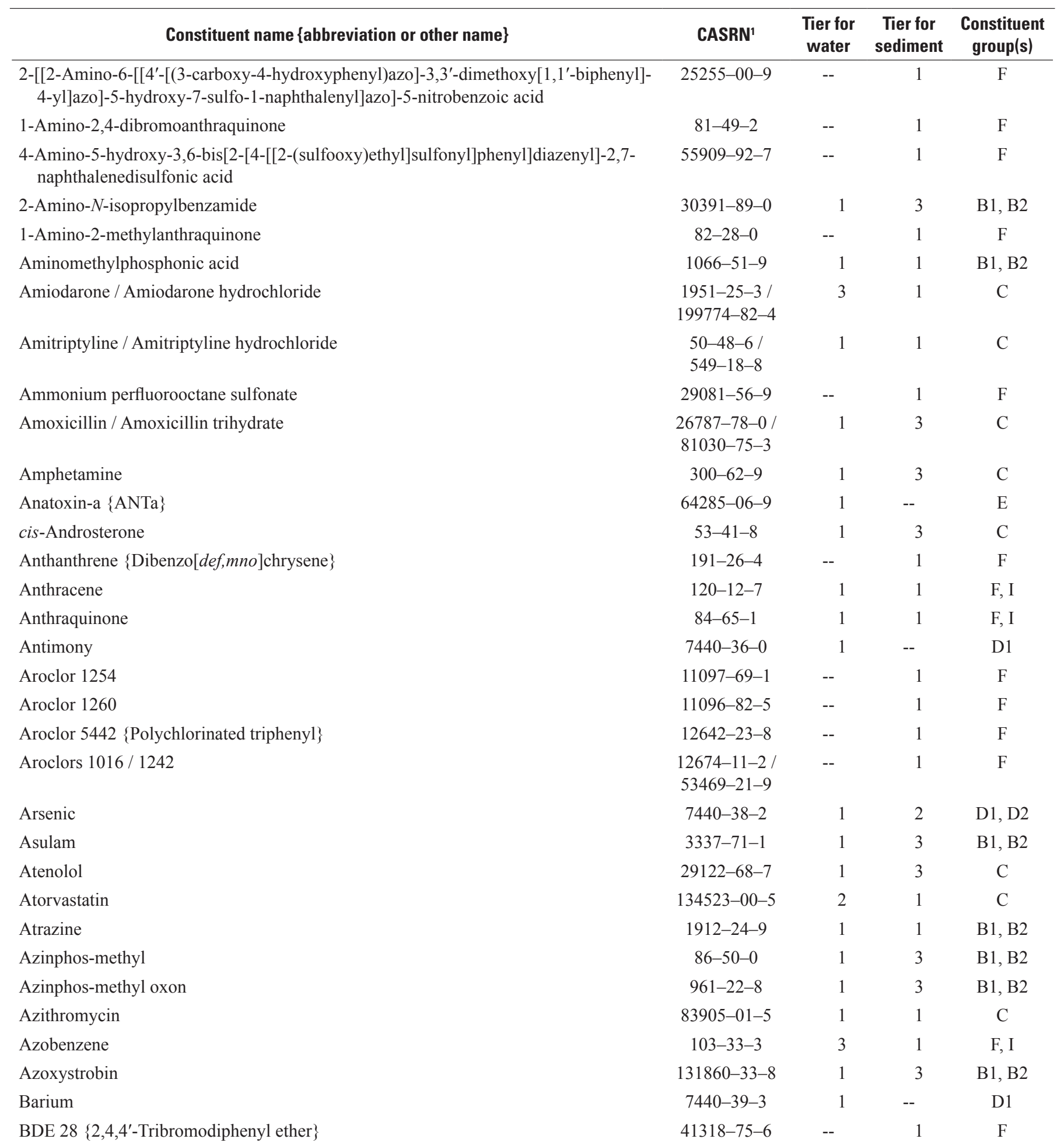


Table 1. Constituents identified as having high priority (Tier 1) for national- or regional-scale ambient monitoring of water or sediment in the United States.-Continued

[Tiers used to prioritize constituents are defined in the main body of the report; those identified as Tier 1 have a higher priority for monitoring than those identified as Tier 2 or Tier 3. An underlined constituent group is the preferred group in cases of differences in prioritization for the same matrix. Constituent groups: volatile organic compounds in water (A); pesticides in water (B1) or sediment (B2); pharmaceuticals and hormones in water or sediment (C); trace elements and other inorganic constituents in water (D1) or sediment (D2); cyanotoxins in surface water (E); lipophilic organic compounds in sediment (F); disinfection by-products in water $(\mathrm{G})$; high-production-volume chemicals in water $(\mathrm{H})$; wastewater-indicator and industrial compounds in water (I); and radionuclides in groundwater (J). CASRN, Chemical Abstracts Service Registry Number; --, constituent not evaluated for specified matrix; BDE, brominated diphenyl ether; C.I., Colour Index Constitution; FD\&C, U.S. Food and Drug Administration Food, Drug, and Cosmetic Act; PCB, polychlorinated biphenyl]

\begin{tabular}{|c|c|c|c|c|}
\hline Constituent name \{abbreviation or other name\} & CASRN ${ }^{1}$ & $\begin{array}{c}\text { Tier for } \\
\text { water }\end{array}$ & $\begin{array}{c}\text { Tier for } \\
\text { sediment }\end{array}$ & $\begin{array}{c}\text { Constituent } \\
\text { group(s) }\end{array}$ \\
\hline BDE $47\left\{2,2^{\prime}, 4,4^{\prime}-\right.$ Tetrabromodiphenyl ether $\}$ & $5436-43-1$ & -- & 1 & $\mathrm{~F}$ \\
\hline BDE $66\left\{2,3^{\prime}, 4,4^{\prime}-\right.$ Tetrabromodiphenyl ether $\}$ & $189084-61-5$ & -- & 1 & $\mathrm{~F}$ \\
\hline BDE $85\left\{2,2^{\prime}, 3,4,4^{\prime}\right.$-Pentabromodiphenyl ether $\}$ & $182346-21-0$ & -- & 1 & $\mathrm{~F}$ \\
\hline BDE $99\left\{2,2^{\prime}, 4,4^{\prime}, 5\right.$-Pentabromodiphenyl ether $\}$ & $60348-60-9$ & -- & 1 & $\mathrm{~F}$ \\
\hline BDE $100\left\{2,2^{\prime}, 4,4^{\prime}, 6\right.$-Pentabromodiphenyl ether $\}$ & $189084-64-8$ & -- & 1 & $\mathrm{~F}$ \\
\hline BDE $119\left\{2,3^{\prime}, 4,4^{\prime}, 6\right.$-Pentabromodiphenyl ether $\}$ & $189084-66-0$ & -- & 1 & $\mathrm{~F}$ \\
\hline BDE $153\left\{2,2^{\prime}, 4,4^{\prime}, 5,5^{\prime}\right.$-Hexabromodiphenyl ether $\}$ & $68631-49-2$ & -- & 1 & $\mathrm{~F}$ \\
\hline BDE $154\left\{2,2^{\prime}, 4,4^{\prime}, 5,6^{\prime}\right.$-Hexabromodiphenyl ether $\}$ & $207122-15-4$ & -- & 1 & $\mathrm{~F}$ \\
\hline BDE $183\left\{2,2^{\prime}, 3,4,4^{\prime}, 5^{\prime}, 6\right.$-Heptabromodiphenyl ether $\}$ & $207122-16-5$ & -- & 1 & $\mathrm{~F}$ \\
\hline BDE $209\left\{2,2^{\prime}, 3,3^{\prime}, 4,4^{\prime}, 5,5^{\prime}, 6,6^{\prime}\right.$-Decabromodiphenyl ether $\}$ & $1163-19-5$ & 3 & 1 & $\mathrm{~F}, \mathrm{H}$ \\
\hline Benfluralin & $1861-40-1$ & 1 & 1 & $\mathrm{~B} 1, \mathrm{~B} 2$ \\
\hline Benomyl & $17804-35-2$ & 1 & 1 & B1, B2 \\
\hline Bensulide & $741-58-2$ & 2 & 1 & $\mathrm{~B} 1, \mathrm{~B} 2$ \\
\hline Bentazon & 25057-89-0 & 1 & 3 & $\mathrm{~B} 1, \mathrm{~B} 2$ \\
\hline $11 H$-Benz $[b, c]$ aceanthrylene & $202-94-8$ & -- & 1 & $\mathrm{~F}$ \\
\hline Benz $[e]$ aceanthrylene & $199-54-2$ & -- & 1 & $\mathrm{~F}$ \\
\hline Benz $[j]$ aceanthrylene & $202-33-5$ & -- & 1 & $\mathrm{~F}$ \\
\hline Benz $[l]$ aceanthrylene & $211-91-6$ & -- & 1 & $\mathrm{~F}$ \\
\hline Benz $[a]$ anthracene & $56-55-3$ & 1 & 1 & $\mathrm{~F}, \mathrm{I}$ \\
\hline Benzenamine & $62-53-3$ & 1 & -- & $\mathrm{H}$ \\
\hline Benzene & $71-43-2$ & 1 & -- & A \\
\hline Benzo $[c]$ cinnoline & $230-17-1$ & 3 & 1 & $\mathrm{~F}, \mathrm{I}$ \\
\hline Benzo $[b]$ fluoranthene & $205-99-2$ & 1 & 1 & $\mathrm{~F}, \mathrm{I}$ \\
\hline Benzo $[g h i]$ fluoranthene & $203-12-3$ & -- & 1 & $\mathrm{~F}$ \\
\hline Benzo[j]fluoranthene & $205-82-3$ & 1 & 1 & $\mathrm{~F}, \mathrm{I}$ \\
\hline Benzo $[k]$ fluoranthene & $207-08-9$ & 1 & 1 & F, I \\
\hline Benzo $[c]$ fluorene & $205-12-9$ & -- & 1 & $\mathrm{~F}$ \\
\hline Benzo[ghi]perylene & $191-24-2$ & 1 & 1 & $\mathrm{~F}, \mathrm{I}$ \\
\hline Benzophenone & $119-61-9$ & 1 & 1 & $\mathrm{~F}, \mathrm{I}$ \\
\hline Benzo $[a]$ pyrene & $50-32-8$ & 1 & 1 & F, I \\
\hline Benzo[e]pyrene & $192-97-2$ & 1 & 1 & $\mathrm{~F}, \mathrm{I}$ \\
\hline Benzotriazole & $95-14-7$ & 1 & -- & I \\
\hline 2-(2H-Benzotriazol-2-yl)-4,6-bis(1,1-dimethylpropyl)phenol & $25973-55-1$ & -- & 1 & $\mathrm{~F}$ \\
\hline Benztropine $\{$ Benzatropine $\}$ & $86-13-5$ & 1 & 1 & $\mathrm{C}$ \\
\hline Benzyladenine & $1214-39-7$ & 3 & 1 & $\mathrm{~B} 1, \mathrm{~B} 2$ \\
\hline Benzyl alcohol & $100-51-6$ & 1 & -- & $\mathrm{H}$ \\
\hline Benzyltriphenylphosphonium $\{\mathrm{BTP}\}$ & $15853-35-7$ & -- & 1 & $\mathrm{~F}$ \\
\hline
\end{tabular}


Table 1. Constituents identified as having high priority (Tier 1) for national- or regional-scale ambient monitoring of water or sediment in the United States.-Continued

[Tiers used to prioritize constituents are defined in the main body of the report; those identified as Tier 1 have a higher priority for monitoring than those identified as Tier 2 or Tier 3. An underlined constituent group is the preferred group in cases of differences in prioritization for the same matrix. Constituent groups: volatile organic compounds in water (A); pesticides in water (B1) or sediment (B2); pharmaceuticals and hormones in water or sediment (C); trace elements and other inorganic constituents in water (D1) or sediment (D2); cyanotoxins in surface water (E); lipophilic organic compounds in sediment (F); disinfection by-products in water $(\mathrm{G})$; high-production-volume chemicals in water $(\mathrm{H})$; wastewater-indicator and industrial compounds in water (I); and radionuclides in groundwater (J). CASRN, Chemical Abstracts Service Registry Number; --, constituent not evaluated for specified matrix; BDE, brominated diphenyl ether; C.I., Colour Index Constitution; FD\&C, U.S. Food and Drug Administration Food, Drug, and Cosmetic Act; PCB, polychlorinated biphenyl]

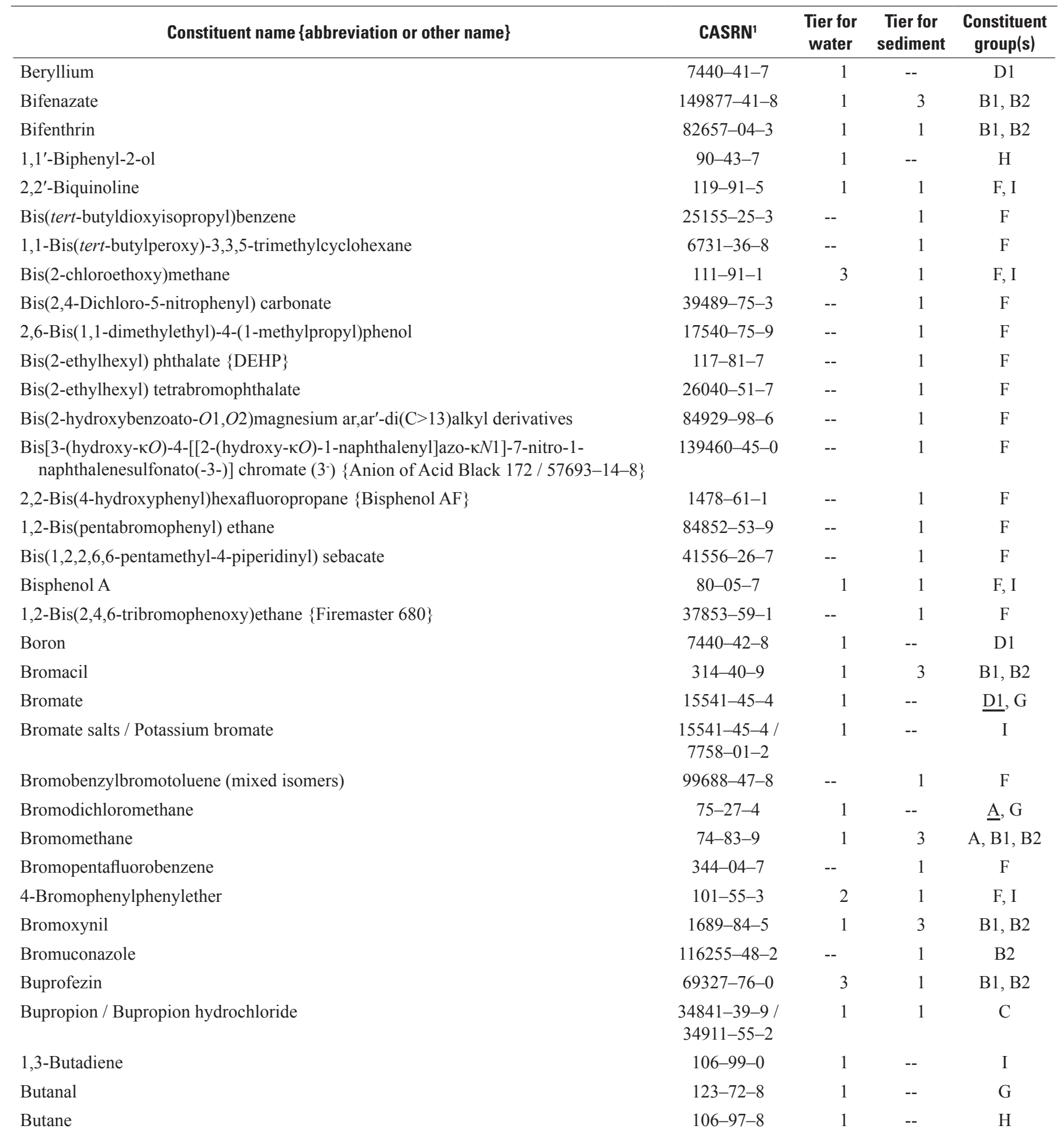


Table 1. Constituents identified as having high priority (Tier 1) for national- or regional-scale ambient monitoring of water or sediment in the United States.-Continued

[Tiers used to prioritize constituents are defined in the main body of the report; those identified as Tier 1 have a higher priority for monitoring than those identified as Tier 2 or Tier 3. An underlined constituent group is the preferred group in cases of differences in prioritization for the same matrix. Constituent groups: volatile organic compounds in water (A); pesticides in water (B1) or sediment (B2); pharmaceuticals and hormones in water or sediment (C); trace elements and other inorganic constituents in water (D1) or sediment (D2); cyanotoxins in surface water (E); lipophilic organic compounds in sediment (F); disinfection by-products in water $(\mathrm{G})$; high-production-volume chemicals in water $(\mathrm{H})$; wastewater-indicator and industrial compounds in water (I); and radionuclides in groundwater (J). CASRN, Chemical Abstracts Service Registry Number; --, constituent not evaluated for specified matrix; BDE, brominated diphenyl ether; C.I., Colour Index Constitution; FD\&C, U.S. Food and Drug Administration Food, Drug, and Cosmetic Act; PCB, polychlorinated biphenyl]

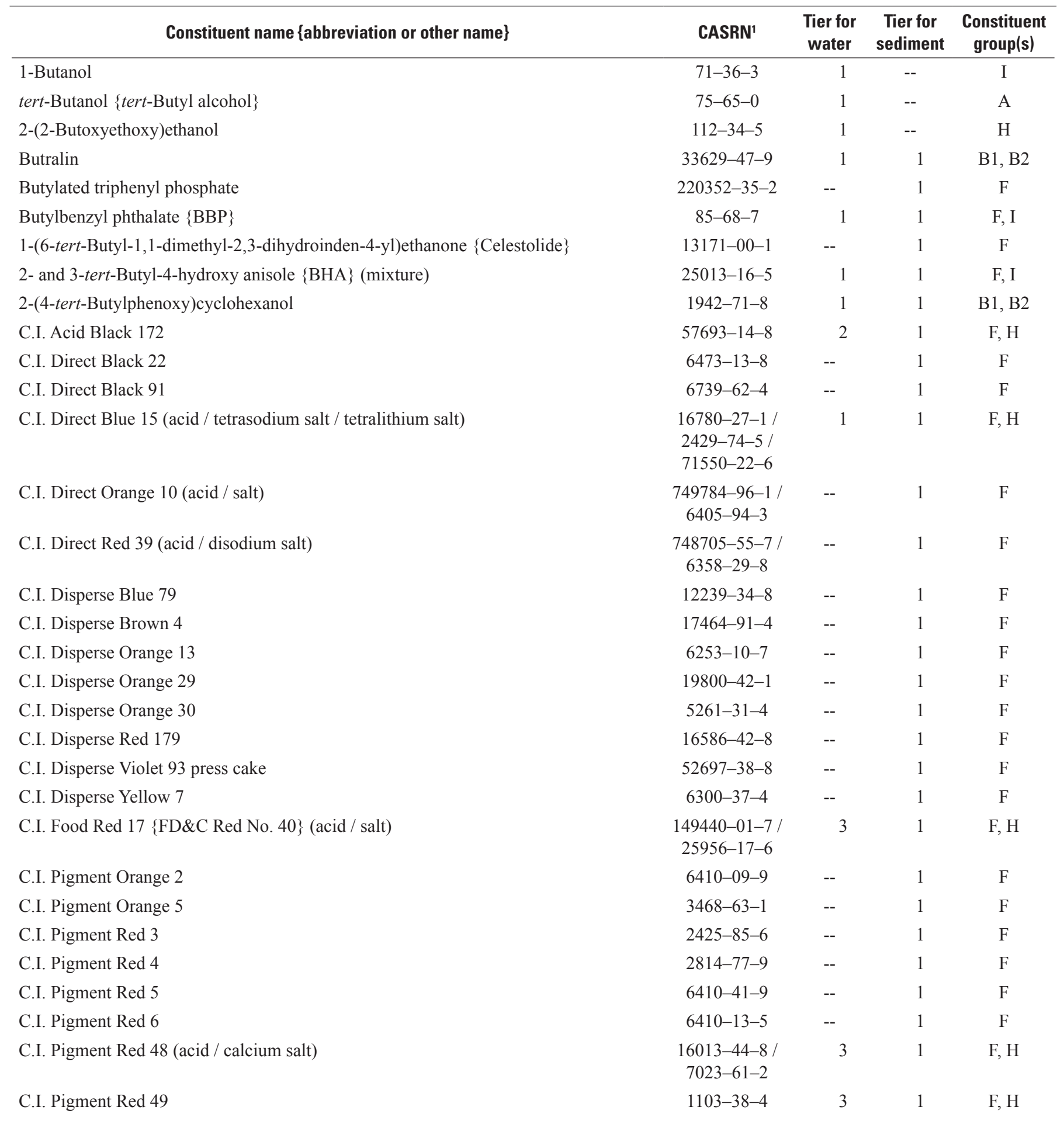


Table 1. Constituents identified as having high priority (Tier 1) for national- or regional-scale ambient monitoring of water or sediment in the United States.-Continued

[Tiers used to prioritize constituents are defined in the main body of the report; those identified as Tier 1 have a higher priority for monitoring than those identified as Tier 2 or Tier 3. An underlined constituent group is the preferred group in cases of differences in prioritization for the same matrix. Constituent groups: volatile organic compounds in water (A); pesticides in water (B1) or sediment (B2); pharmaceuticals and hormones in water or sediment (C); trace elements and other inorganic constituents in water (D1) or sediment (D2); cyanotoxins in surface water (E); lipophilic organic compounds in sediment (F); disinfection by-products in water $(\mathrm{G})$; high-production-volume chemicals in water $(\mathrm{H})$; wastewater-indicator and industrial compounds in water (I); and radionuclides in groundwater (J). CASRN, Chemical Abstracts Service Registry Number; --, constituent not evaluated for specified matrix; BDE, brominated diphenyl ether; C.I., Colour Index Constitution; FD\&C, U.S. Food and Drug Administration Food, Drug, and Cosmetic Act; PCB, polychlorinated biphenyl]

\begin{tabular}{|c|c|c|c|c|}
\hline Constituent name \{abbreviation or other name\} & CASRN $^{1}$ & $\begin{array}{l}\text { Tier for } \\
\text { water }\end{array}$ & $\begin{array}{c}\text { Tier for } \\
\text { sediment }\end{array}$ & $\begin{array}{c}\text { Constituent } \\
\text { group(s) }\end{array}$ \\
\hline C.I. Pigment Red 53 (strontium salt) & $15958-19-7$ & -- & 1 & $\mathrm{~F}$ \\
\hline C.I. Pigment Red 53 (barium salt / sodium salt) & $\begin{array}{c}5160-02-1 / \\
2092-56-0\end{array}$ & 3 & 1 & $\mathrm{~F}, \mathrm{H}, \mathrm{I}$ \\
\hline C.I. Pigment Red 57:1 \{D\&C Red No. 7$\}$ & $5281-04-9$ & 3 & 1 & $\mathrm{~F}, \mathrm{H}$ \\
\hline C.I. Pigment Red 88 & $14295-43-3$ & -- & 1 & $\mathrm{~F}$ \\
\hline C.I. Pigment Red 181 & $2379-74-0$ & -- & 1 & $\mathrm{~F}$ \\
\hline C.I. Pigment Red 187 & $59487-23-9$ & -- & 1 & $\mathrm{~F}$ \\
\hline C.I. Pigment Yellow 12 & $6358-85-6$ & 3 & 1 & $\mathrm{~F}, \mathrm{H}$ \\
\hline C.I. Pigment Yellow 13 & $5102-83-0$ & -- & 1 & $\mathrm{~F}$ \\
\hline C.I. Pigment Yellow 14 & $5468-75-7$ & 3 & 1 & $\mathrm{~F}, \mathrm{H}$ \\
\hline C.I. Pigment Yellow 60 & $6407-74-5$ & -- & 1 & $\mathrm{~F}$ \\
\hline C.I. Pigment Yellow 83 & $5567-15-7$ & -- & 1 & $\mathrm{~F}$ \\
\hline C.I. Reactive Black 5 & $17095-24-8$ & 2 & 1 & $\mathrm{~F}, \mathrm{H}$ \\
\hline C.I. Solvent Blue 4 & $6786-83-0$ & -- & 1 & $\mathrm{~F}$ \\
\hline C.I. Solvent Orange 7 & $3118-97-6$ & -- & 1 & $\mathrm{~F}$ \\
\hline C.I. Solvent Red 1 & $1229-55-6$ & 3 & 1 & $\mathrm{~F}, \mathrm{I}$ \\
\hline C.I. Solvent Red 23 & $85-86-9$ & -- & 1 & $\mathrm{~F}$ \\
\hline C.I. Solvent Red 80 & $6358-53-8$ & -- & 1 & $\mathrm{~F}$ \\
\hline C.I. Solvent Yellow 14 & $842-07-9$ & -- & 1 & $\mathrm{~F}$ \\
\hline C.I. Solvent Yellow 18 & $6407-78-9$ & -- & 1 & $\mathrm{~F}$ \\
\hline Cadmium & $7440-43-9$ & 1 & 2 & D1, D2 \\
\hline Caffeine & $58-08-2$ & 1 & 3 & $\mathrm{C}, \mathrm{I}$ \\
\hline Calcium long-chain alkyl salicylates & $83846-43-9$ & -- & 1 & $\mathrm{~F}$ \\
\hline Calcium thiobis[dodecylphenolate] \{Salt form of $28575-91-1\}$ & $26998-97-0$ & -- & 1 & $\mathrm{~F}$ \\
\hline Camphor & $76-22-2$ & 2 & 1 & $\mathrm{~F}, \mathrm{I}$ \\
\hline Caprolactam $\{$ Hexahydro- $2 H$-azepin-2-one $\}$ & $105-60-2$ & 1 & -- & $\mathrm{H}$ \\
\hline Carbamazapine & $298-46-4$ & 1 & 3 & $\mathrm{C}$ \\
\hline 1-Carbamoyl-3-cyano-4-hydroxy-2,5,6-trichlorobenzene & Not available & 1 & 1 & B1, B2 \\
\hline Carbaryl & $63-25-2$ & 1 & 2 & B1, B2 \\
\hline Carbazole & $86-74-8$ & 1 & 1 & $\mathrm{~F}, \mathrm{I}$ \\
\hline Carbendazim & $10605-21-7$ & 1 & 3 & B1, B2 \\
\hline Carbofuran & $1563-66-2$ & 1 & 2 & B1, B2 \\
\hline Carbofuran phenol & $1563-38-8$ & 1 & -- & $\mathrm{H}$ \\
\hline Carbon disulfide & $75-15-0$ & 1 & 3 & A, B2 \\
\hline Catechol $\{1,2$-Benzenediol $\}$ & $120-80-9$ & 1 & -- & I \\
\hline Cephalexin & $15686-71-2$ & 1 & 3 & $\mathrm{C}$ \\
\hline Cetrimonium chloride & $112-02-7$ & 1 & -- & $\mathrm{H}$ \\
\hline
\end{tabular}


Table 1. Constituents identified as having high priority (Tier 1) for national- or regional-scale ambient monitoring of water or sediment in the United States.-Continued

[Tiers used to prioritize constituents are defined in the main body of the report; those identified as Tier 1 have a higher priority for monitoring than those identified as Tier 2 or Tier 3. An underlined constituent group is the preferred group in cases of differences in prioritization for the same matrix. Constituent groups: volatile organic compounds in water (A); pesticides in water (B1) or sediment (B2); pharmaceuticals and hormones in water or sediment (C); trace elements and other inorganic constituents in water (D1) or sediment (D2); cyanotoxins in surface water (E); lipophilic organic compounds in sediment (F); disinfection by-products in water $(\mathrm{G})$; high-production-volume chemicals in water $(\mathrm{H})$; wastewater-indicator and industrial compounds in water (I); and radionuclides in groundwater (J). CASRN, Chemical Abstracts Service Registry Number; --, constituent not evaluated for specified matrix; BDE, brominated diphenyl ether; C.I., Colour Index Constitution; FD\&C, U.S. Food and Drug Administration Food, Drug, and Cosmetic Act; PCB, polychlorinated biphenyl]

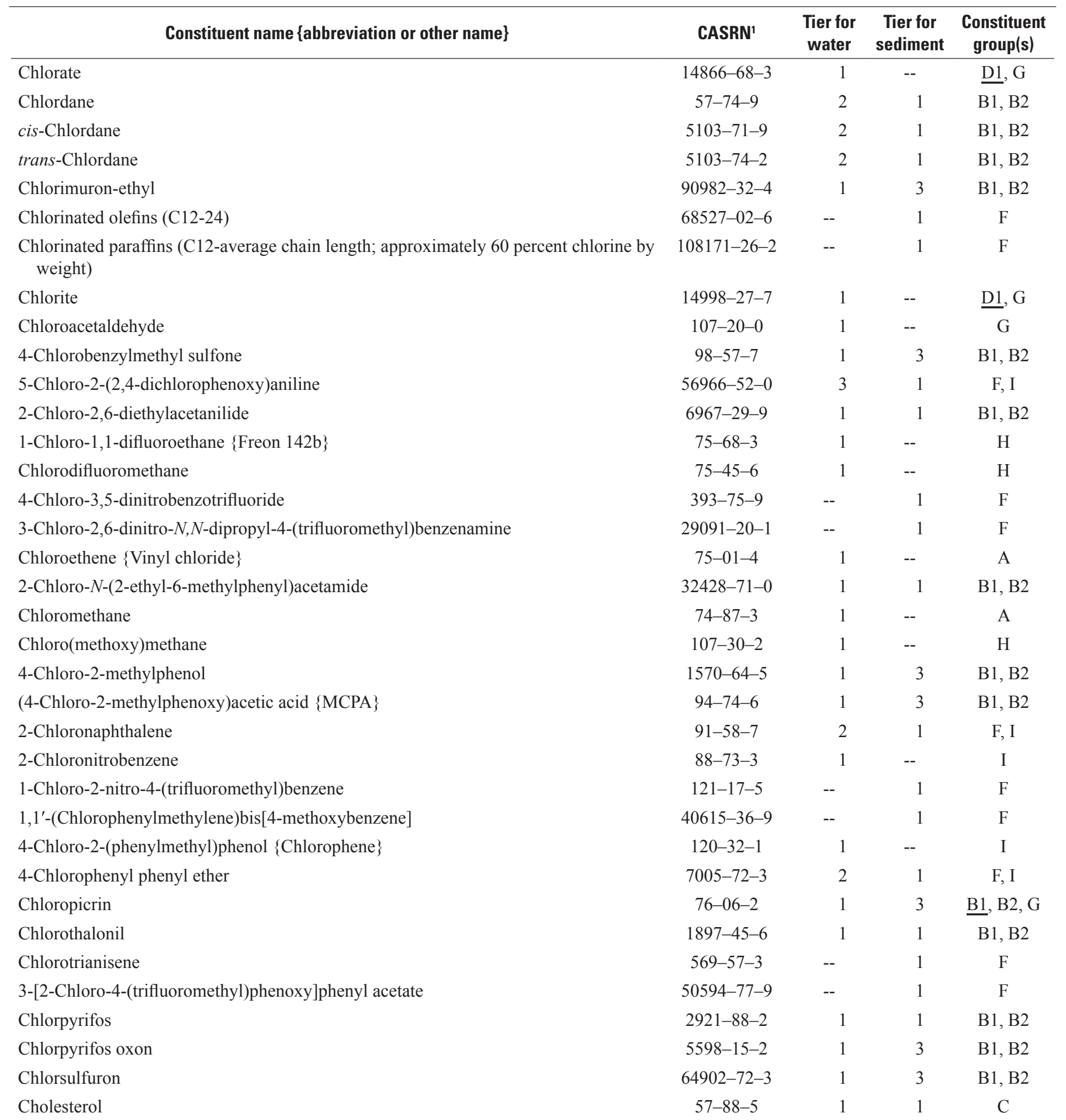


Table 1. Constituents identified as having high priority (Tier 1) for national- or regional-scale ambient monitoring of water or sediment in the United States.-Continued

[Tiers used to prioritize constituents are defined in the main body of the report; those identified as Tier 1 have a higher priority for monitoring than those identified as Tier 2 or Tier 3. An underlined constituent group is the preferred group in cases of differences in prioritization for the same matrix. Constituent groups: volatile organic compounds in water (A); pesticides in water (B1) or sediment (B2); pharmaceuticals and hormones in water or sediment (C); trace elements and other inorganic constituents in water (D1) or sediment (D2); cyanotoxins in surface water (E); lipophilic organic compounds in sediment (F); disinfection by-products in water $(\mathrm{G})$; high-production-volume chemicals in water $(\mathrm{H})$; wastewater-indicator and industrial compounds in water (I); and radionuclides in groundwater (J). CASRN, Chemical Abstracts Service Registry Number; --, constituent not evaluated for specified matrix; BDE, brominated diphenyl ether; C.I., Colour Index Constitution; FD\&C, U.S. Food and Drug Administration Food, Drug, and Cosmetic Act; PCB, polychlorinated biphenyl]

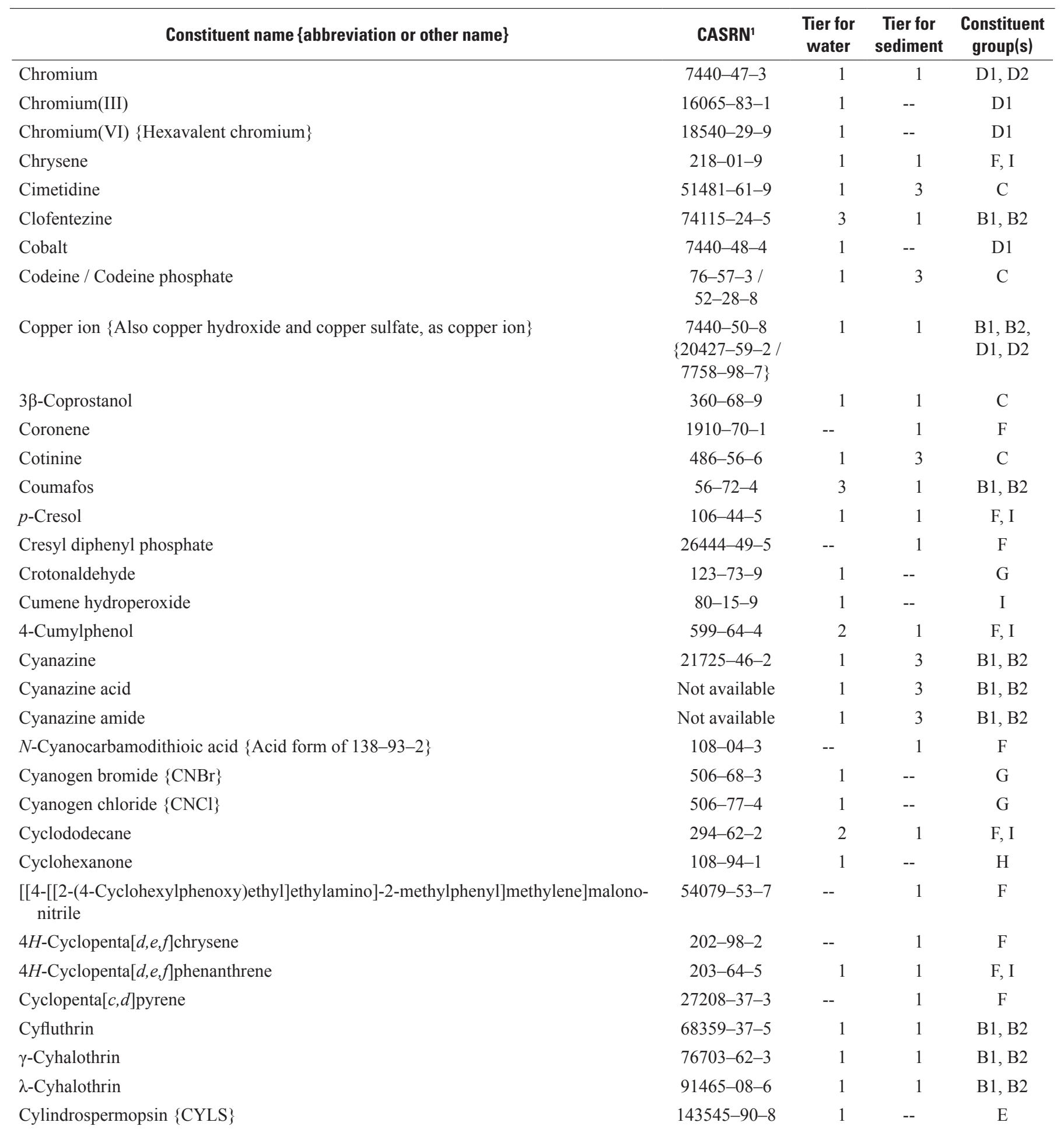


Table 1. Constituents identified as having high priority (Tier 1) for national- or regional-scale ambient monitoring of water or sediment in the United States.-Continued

[Tiers used to prioritize constituents are defined in the main body of the report; those identified as Tier 1 have a higher priority for monitoring than those identified as Tier 2 or Tier 3. An underlined constituent group is the preferred group in cases of differences in prioritization for the same matrix. Constituent groups: volatile organic compounds in water (A); pesticides in water (B1) or sediment (B2); pharmaceuticals and hormones in water or sediment (C); trace elements and other inorganic constituents in water (D1) or sediment (D2); cyanotoxins in surface water (E); lipophilic organic compounds in sediment (F); disinfection by-products in water $(\mathrm{G})$; high-production-volume chemicals in water $(\mathrm{H})$; wastewater-indicator and industrial compounds in water (I); and radionuclides in groundwater (J). CASRN, Chemical Abstracts Service Registry Number; --, constituent not evaluated for specified matrix; BDE, brominated diphenyl ether; C.I., Colour Index Constitution; FD\&C, U.S. Food and Drug Administration Food, Drug, and Cosmetic Act; PCB, polychlorinated biphenyl]

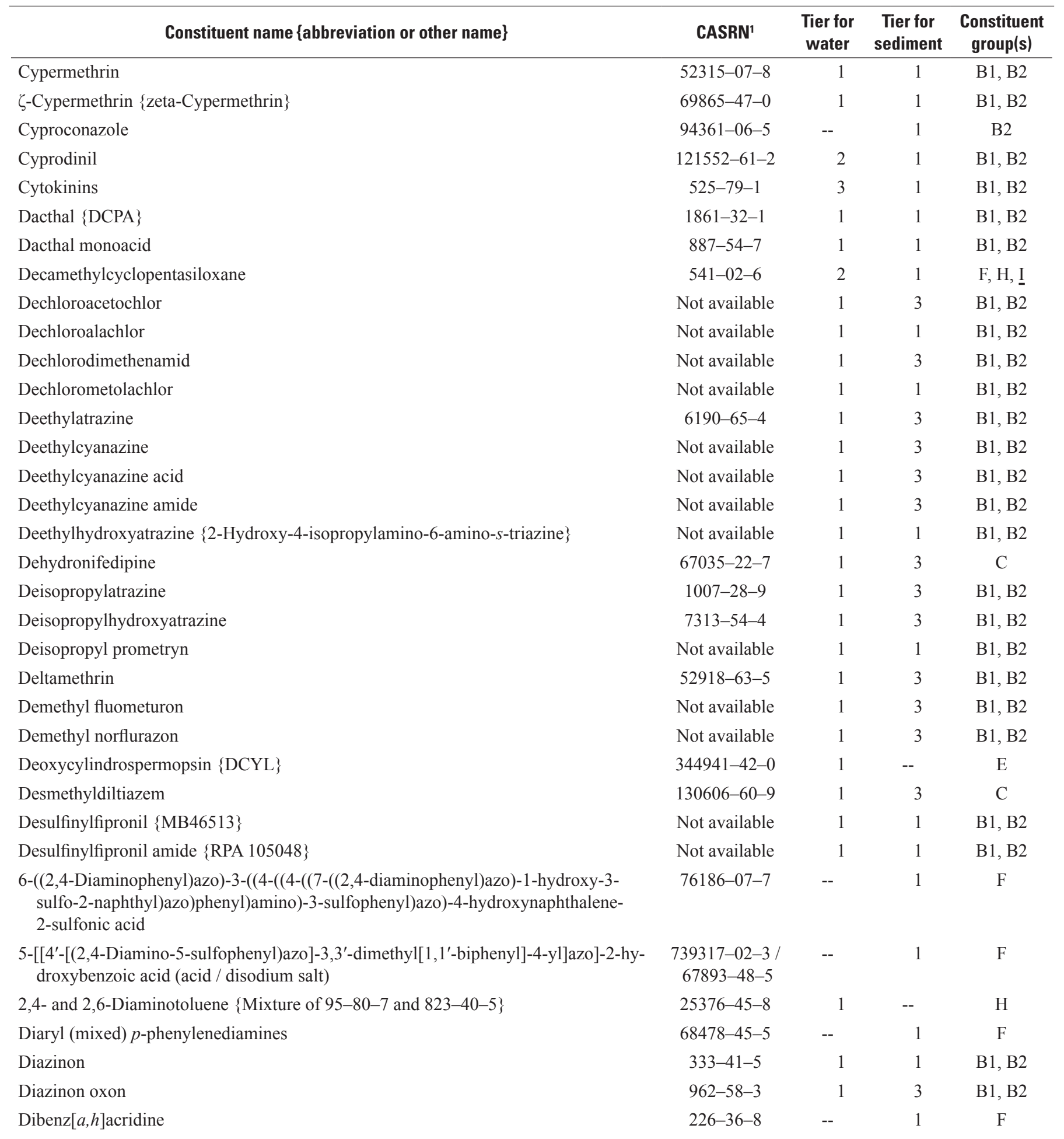


Table 1. Constituents identified as having high priority (Tier 1) for national- or regional-scale ambient monitoring of water or sediment in the United States.-Continued

[Tiers used to prioritize constituents are defined in the main body of the report; those identified as Tier 1 have a higher priority for monitoring than those identified as Tier 2 or Tier 3. An underlined constituent group is the preferred group in cases of differences in prioritization for the same matrix. Constituent groups: volatile organic compounds in water (A); pesticides in water (B1) or sediment (B2); pharmaceuticals and hormones in water or sediment (C); trace elements and other inorganic constituents in water (D1) or sediment (D2); cyanotoxins in surface water (E); lipophilic organic compounds in sediment (F); disinfection by-products in water $(\mathrm{G})$; high-production-volume chemicals in water $(\mathrm{H})$; wastewater-indicator and industrial compounds in water (I); and radionuclides in groundwater (J). CASRN, Chemical Abstracts Service Registry Number; --, constituent not evaluated for specified matrix; BDE, brominated diphenyl ether; C.I., Colour Index Constitution; FD\&C, U.S. Food and Drug Administration Food, Drug, and Cosmetic Act; PCB, polychlorinated biphenyl]

\begin{tabular}{|c|c|c|c|c|}
\hline Constituent name \{abbreviation or other name\} & CASRN $^{1}$ & $\begin{array}{c}\text { Tier for } \\
\text { water }\end{array}$ & $\begin{array}{c}\text { Tier for } \\
\text { sediment }\end{array}$ & $\begin{array}{c}\text { Constituent } \\
\text { group(s) }\end{array}$ \\
\hline $\operatorname{Dibenz}[a, j]$ acridine & $224-42-0$ & -- & 1 & $\mathrm{~F}$ \\
\hline Dibenz $[a, h]$ anthracene & $53-70-3$ & 1 & 1 & $\mathrm{~F}, \mathrm{I}$ \\
\hline $7 H$-Dibenzo $[c, g]$ carbazole & $194-59-2$ & -- & 1 & $\mathrm{~F}$ \\
\hline Dibenzo $[a, h]$ pyrene & $189-64-0$ & -- & 1 & $\mathrm{~F}$ \\
\hline Dibenzo $[a, i]$ pyrene & $189-55-9$ & -- & 1 & $\mathrm{~F}$ \\
\hline Dibenzo $[a, l]$ pyrene & $191-30-0$ & -- & 1 & $\mathrm{~F}$ \\
\hline 2,6-Di-tert-p-benzoquinone & $719-22-2$ & 1 & -- & I \\
\hline 1,2-Dibromo-3-chloropropane & $96-12-8$ & 1 & 3 & $\mathrm{~A}, \mathrm{~B} 2$ \\
\hline 1,2-Dibromo-4-(1,2-dibromoethyl)cyclohexane & $3322-93-8$ & -- & 1 & $\mathrm{~F}$ \\
\hline 1,2-Dibromoethane & $106-93-4$ & 1 & 3 & $\mathrm{~A}, \mathrm{~B} 2$ \\
\hline 4,6-Di-tert-butyl-m-cresol $\{\mathrm{DTBC}\}$ & $497-39-2$ & -- & 1 & $\mathrm{~F}$ \\
\hline Dibutyl 1,2,3,4,7,7-hexachlorobicyclo[2.2.1]hept-2-ene-5,6-dicarboxylate & $1770-80-5$ & -- & 1 & $\mathrm{~F}$ \\
\hline (3,5-Di-tert-butyl-4-hydroxyphenyl)methyl ethoxyphosphinic acid & $66165-37-5$ & -- & 1 & $\mathrm{~F}$ \\
\hline 2,6-Di-tert-butyl-4-methylphenol \{Butylated hydroxytoluene, BHT\} & $128-37-0$ & 2 & 1 & $\mathrm{~F}, \mathrm{I}$ \\
\hline 2,5-Di(tert-butylperoxy)-2,5-dimethyl-3-hexyne & $1068-27-5$ & -- & 1 & $\mathrm{~F}$ \\
\hline 2,4-Di-tert-butylphenol $\{2,4$-DTBP $\}$ & $96-76-4$ & -- & 1 & $\mathrm{~F}$ \\
\hline Dichloroacetamide & $683-72-7$ & 1 & -- & G \\
\hline Dichloroacetic acid & $79-43-6$ & 1 & -- & G \\
\hline 3,4-Dichloroaniline & $95-76-1$ & 1 & 1 & $\mathrm{~B} 1, \mathrm{~B} 2$ \\
\hline 3,5-Dichloroaniline & $626-43-7$ & 1 & 1 & $\mathrm{~B} 1, \mathrm{~B} 2$ \\
\hline 1,2-Dichlorobenzene & $95-50-1$ & 2 & 1 & $\mathrm{~A}, \mathrm{~F}$ \\
\hline 1,4-Dichlorobenzene & $106-46-7$ & 2 & 1 & $\mathrm{~A}, \mathrm{~F}$ \\
\hline 4,4'-Dichlorobenzophenone & $90-98-2$ & 1 & 1 & $\mathrm{~B} 1, \mathrm{~B} 2$ \\
\hline $3-[[4-[(5,6-$ Dichloro-2-benzothiazolyl)azo]phenyl] ethylamino]propanenitrile & $25176-89-0$ & -- & 1 & $\mathrm{~F}$ \\
\hline 3,4-Dichlorobenzotrifluoride & $328-84-7$ & 3 & 1 & $\mathrm{~F}, \mathrm{I}$ \\
\hline
\end{tabular}


Table 1. Constituents identified as having high priority (Tier 1) for national- or regional-scale ambient monitoring of water or sediment in the United States.-Continued

[Tiers used to prioritize constituents are defined in the main body of the report; those identified as Tier 1 have a higher priority for monitoring than those identified as Tier 2 or Tier 3. An underlined constituent group is the preferred group in cases of differences in prioritization for the same matrix. Constituent groups: volatile organic compounds in water (A); pesticides in water (B1) or sediment (B2); pharmaceuticals and hormones in water or sediment (C); trace elements and other inorganic constituents in water (D1) or sediment (D2); cyanotoxins in surface water (E); lipophilic organic compounds in sediment (F); disinfection by-products in water $(\mathrm{G})$; high-production-volume chemicals in water $(\mathrm{H})$; wastewater-indicator and industrial compounds in water (I); and radionuclides in groundwater (J). CASRN, Chemical Abstracts Service Registry Number; --, constituent not evaluated for specified matrix; BDE, brominated diphenyl ether; C.I., Colour Index Constitution; FD\&C, U.S. Food and Drug Administration Food, Drug, and Cosmetic Act; PCB, polychlorinated biphenyl]

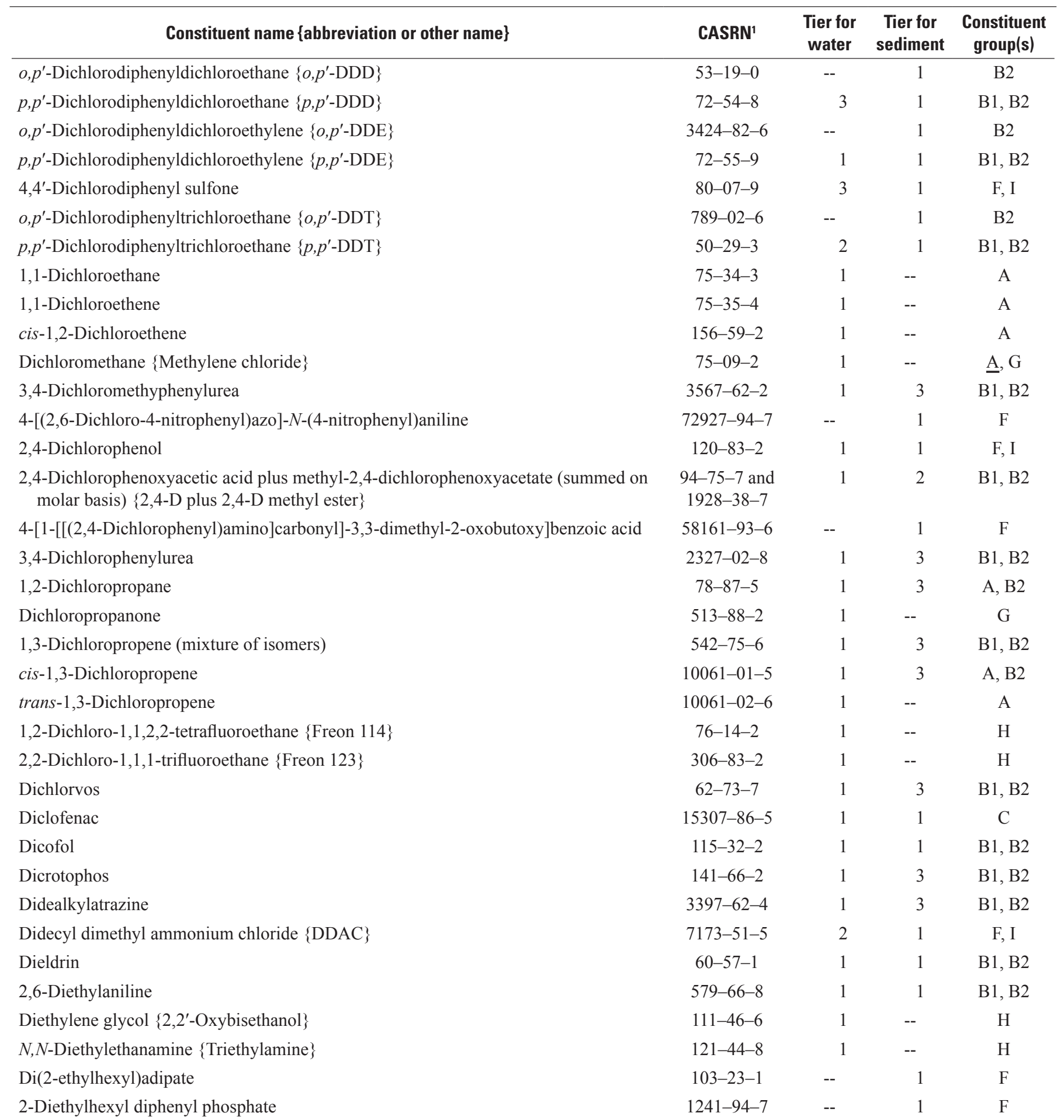


Table 1. Constituents identified as having high priority (Tier 1) for national- or regional-scale ambient monitoring of water or sediment in the United States.-Continued

[Tiers used to prioritize constituents are defined in the main body of the report; those identified as Tier 1 have a higher priority for monitoring than those identified as Tier 2 or Tier 3. An underlined constituent group is the preferred group in cases of differences in prioritization for the same matrix. Constituent groups: volatile organic compounds in water (A); pesticides in water (B1) or sediment (B2); pharmaceuticals and hormones in water or sediment (C); trace elements and other inorganic constituents in water (D1) or sediment (D2); cyanotoxins in surface water (E); lipophilic organic compounds in sediment (F); disinfection by-products in water $(\mathrm{G})$; high-production-volume chemicals in water $(\mathrm{H})$; wastewater-indicator and industrial compounds in water (I); and radionuclides in groundwater (J). CASRN, Chemical Abstracts Service Registry Number; --, constituent not evaluated for specified matrix; BDE, brominated diphenyl ether; C.I., Colour Index Constitution; FD\&C, U.S. Food and Drug Administration Food, Drug, and Cosmetic Act; PCB, polychlorinated biphenyl]

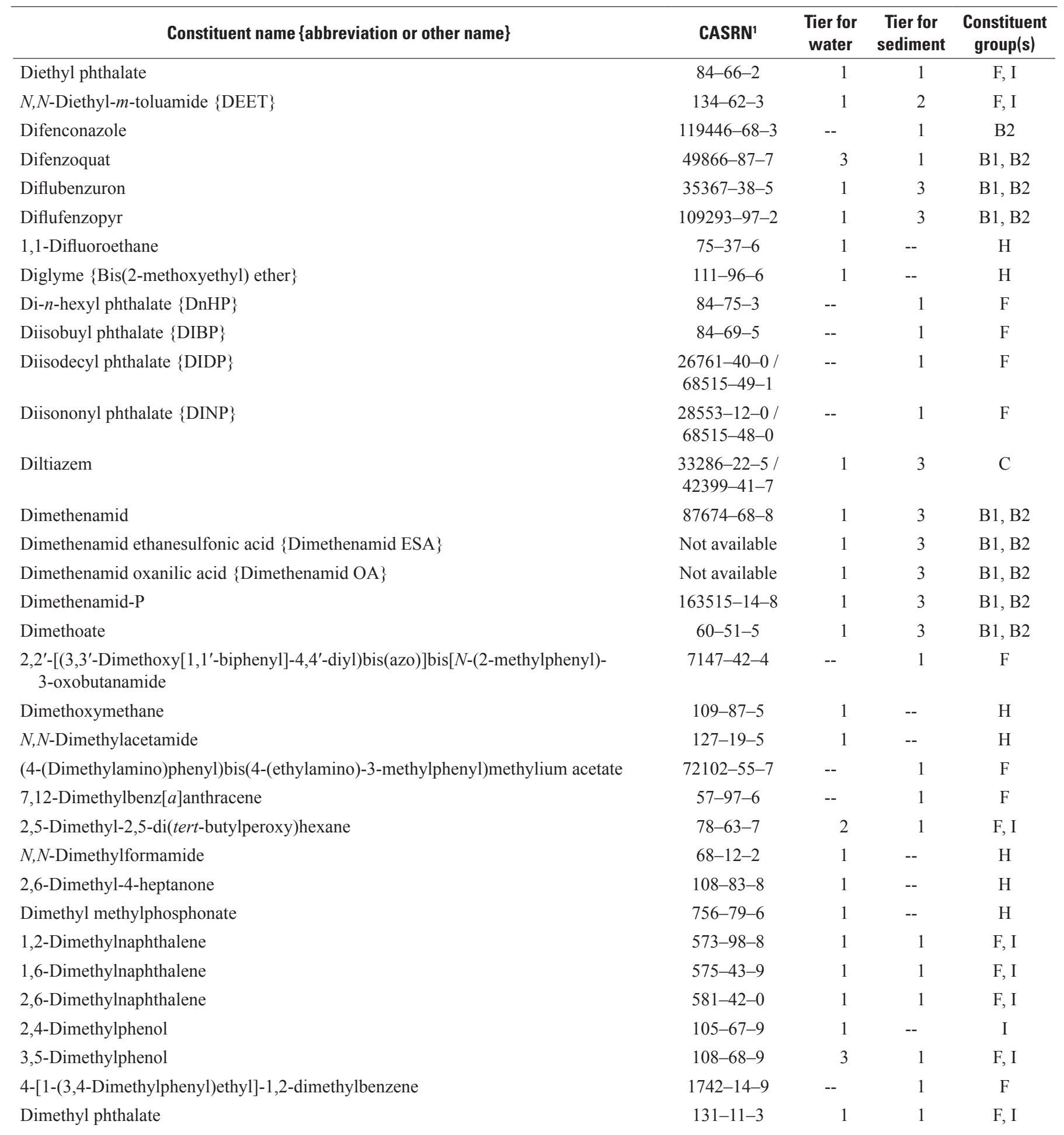


Table 1. Constituents identified as having high priority (Tier 1) for national- or regional-scale ambient monitoring of water or sediment in the United States.-Continued

[Tiers used to prioritize constituents are defined in the main body of the report; those identified as Tier 1 have a higher priority for monitoring than those identified as Tier 2 or Tier 3. An underlined constituent group is the preferred group in cases of differences in prioritization for the same matrix. Constituent groups: volatile organic compounds in water (A); pesticides in water (B1) or sediment (B2); pharmaceuticals and hormones in water or sediment (C); trace elements and other inorganic constituents in water (D1) or sediment (D2); cyanotoxins in surface water (E); lipophilic organic compounds in sediment (F); disinfection by-products in water $(\mathrm{G})$; high-production-volume chemicals in water $(\mathrm{H})$; wastewater-indicator and industrial compounds in water (I); and radionuclides in groundwater (J). CASRN, Chemical Abstracts Service Registry Number; --, constituent not evaluated for specified matrix; BDE, brominated diphenyl ether; C.I., Colour Index Constitution; FD\&C, U.S. Food and Drug Administration Food, Drug, and Cosmetic Act; PCB, polychlorinated biphenyl]

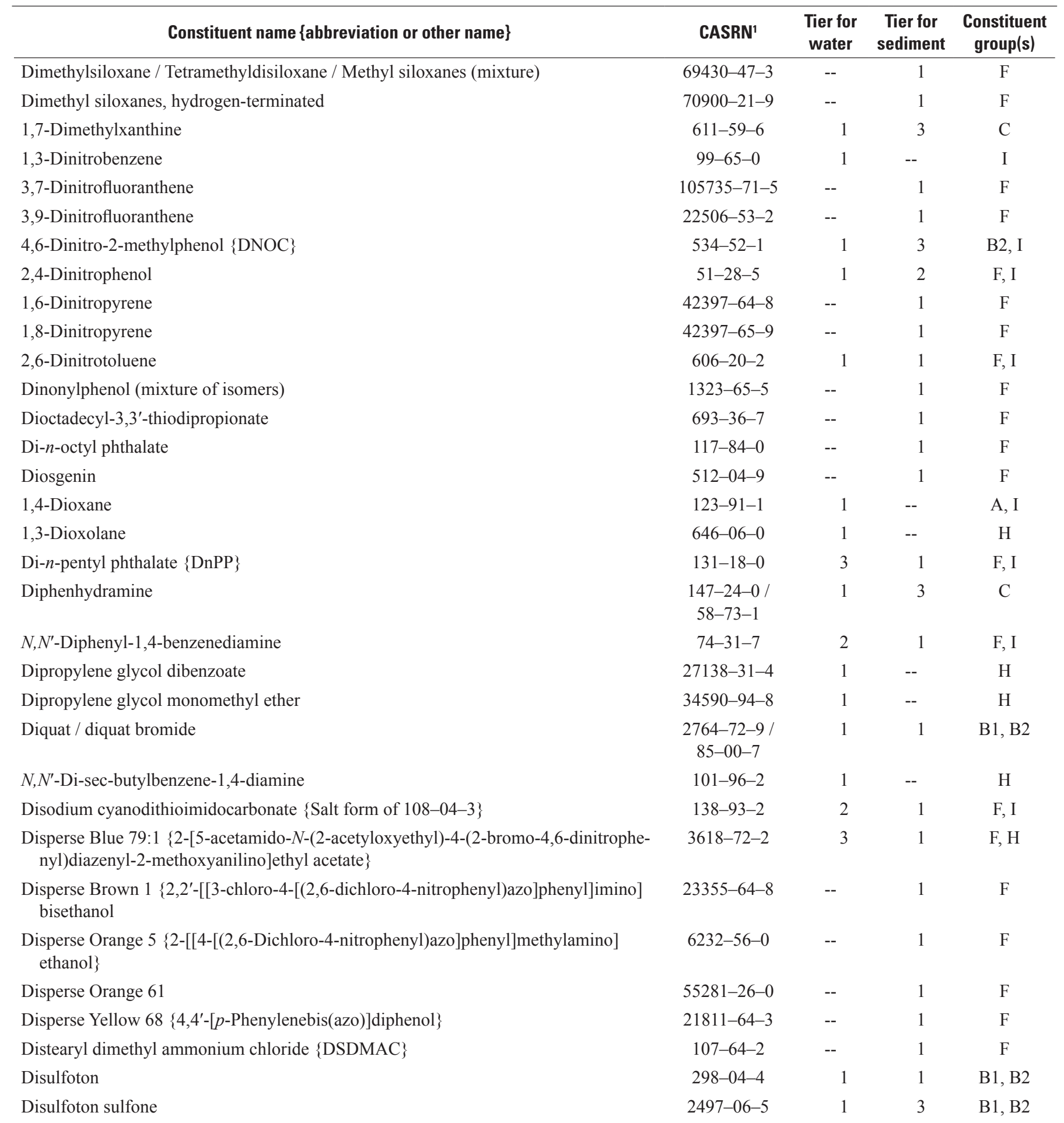


Table 1. Constituents identified as having high priority (Tier 1) for national- or regional-scale ambient monitoring of water or sediment in the United States.-Continued

[Tiers used to prioritize constituents are defined in the main body of the report; those identified as Tier 1 have a higher priority for monitoring than those identified as Tier 2 or Tier 3. An underlined constituent group is the preferred group in cases of differences in prioritization for the same matrix. Constituent groups: volatile organic compounds in water (A); pesticides in water (B1) or sediment (B2); pharmaceuticals and hormones in water or sediment (C); trace elements and other inorganic constituents in water (D1) or sediment (D2); cyanotoxins in surface water (E); lipophilic organic compounds in sediment (F); disinfection by-products in water $(\mathrm{G})$; high-production-volume chemicals in water $(\mathrm{H})$; wastewater-indicator and industrial compounds in water (I); and radionuclides in groundwater (J). CASRN, Chemical Abstracts Service Registry Number; --, constituent not evaluated for specified matrix; BDE, brominated diphenyl ether; C.I., Colour Index Constitution; FD\&C, U.S. Food and Drug Administration Food, Drug, and Cosmetic Act; PCB, polychlorinated biphenyl]

\begin{tabular}{|c|c|c|c|c|}
\hline Constituent name \{abbreviation or other name\} & CASRN ${ }^{1}$ & $\begin{array}{l}\text { Tier for } \\
\text { water }\end{array}$ & $\begin{array}{l}\text { Tier for } \\
\text { sediment }\end{array}$ & $\begin{array}{c}\text { Constituent } \\
\text { group(s) }\end{array}$ \\
\hline Disulfoton sulfoxide & $2497-07-6$ & 1 & 3 & $\mathrm{~B} 1, \mathrm{~B} 2$ \\
\hline Dithiopyr & $97886-45-8$ & 3 & 1 & B1, B2 \\
\hline Diuron & $330-54-1$ & 1 & 1 & $\mathrm{~B} 1, \mathrm{~B} 2$ \\
\hline Dodecachlorododecahydrodimethanodibenzocyclooctene $\{$ Dechlorane plus $\}$ & $13560-89-9$ & -- & 1 & $\mathrm{~F}$ \\
\hline Dodecamethylcylohexasiloxane & $540-97-6$ & -- & 1 & $\mathrm{~F}$ \\
\hline Dodecane & $93685-81-5$ & -- & 1 & $\mathrm{~F}$ \\
\hline Dodecylbenzene sodium sulfonate & $25155-30-0$ & 1 & -- & $\mathrm{H}$ \\
\hline $\begin{array}{l}\text { 3-Dodecyl-4-(2-dodecyl-4-hydroxyphenyl)sulfanylphenol \{Thiobis((tetrapropylene) } \\
\text { phenol)\} }\end{array}$ & $68815-67-8$ & -- & 1 & $\mathrm{~F}$ \\
\hline Dodecylphenol, calcium salt, sulfurized & $68855-45-8$ & -- & 1 & $\mathrm{~F}$ \\
\hline Dodecylphenol, calcium salt, sulfurized, overbased, carbonated & $68784-26-9$ & -- & 1 & $\mathrm{~F}$ \\
\hline Emamectin & $155569-91-8$ & 3 & 1 & $\mathrm{~B} 1, \mathrm{~B} 2$ \\
\hline Endosulfan & $115-29-7$ & 1 & 1 & $\mathrm{~B} 1, \mathrm{~B} 2$ \\
\hline$\alpha$-Endosulfan & $959-98-8$ & 1 & 1 & $\mathrm{~B} 1, \mathrm{~B} 2$ \\
\hline$\beta$-Endosulfan & $33213-65-9$ & 1 & 1 & $\mathrm{~B} 1, \mathrm{~B} 2$ \\
\hline Endosulfan ether & $3369-52-6$ & 1 & 1 & $\mathrm{~B} 1, \mathrm{~B} 2$ \\
\hline Endosulfan sulfate & $1031-07-8$ & 1 & 1 & $\mathrm{~B} 1, \mathrm{~B} 2$ \\
\hline Endothall & $145-73-3$ & 1 & 3 & B1, B2 \\
\hline Enrofloxacin & $93106-60-6$ & 1 & 3 & $\mathrm{C}$ \\
\hline Epichlorohydrin $\{2-($ Chloromethyl)oxirane $\}$ & $106-89-8$ & 1 & -- & $\mathrm{H}$ \\
\hline Equilenin & $517-09-9$ & 1 & 1 & $\mathrm{C}$ \\
\hline Equilin & $474-86-2$ & 1 & 3 & $\mathrm{C}$ \\
\hline Erythromycin / Erythromycin dihydrate & $\begin{array}{c}114-07-8 / \\
59319-72-1\end{array}$ & 1 & 3 & $\mathrm{C}$ \\
\hline Esfenvalerate & $66230-04-4$ & 1 & 1 & $\mathrm{~B} 1, \mathrm{~B} 2$ \\
\hline $17 \alpha$-Estradiol & $57-91-0$ & 1 & 1 & $\mathrm{C}$ \\
\hline $17 \beta$-Estradiol & $50-28-2$ & 1 & 1 & $\mathrm{C}$ \\
\hline Estriol & $50-27-1$ & 1 & 3 & $\mathrm{C}$ \\
\hline Estrone & $53-16-7$ & 1 & 3 & $\mathrm{C}$ \\
\hline Ethalfluralin & $55283-68-6$ & 1 & 1 & $\mathrm{~B} 1, \mathrm{~B} 2$ \\
\hline Ethoprop \{Ethoprophos\} & $13194-48-4$ & 1 & 3 & $\mathrm{~B} 1, \mathrm{~B} 2$ \\
\hline 2-Ethoxyethanol & $110-80-5$ & 1 & -- & $\mathrm{H}$ \\
\hline 2-(2-Ethoxyethoxy)ethanol & $111-90-0$ & 1 & -- & $\mathrm{H}$ \\
\hline 2-Ethoxyethyl acetate & $111-15-9$ & 1 & -- & $\mathrm{H}$ \\
\hline Ethyl acetate & $141-78-6$ & 1 & -- & $\mathrm{H}$ \\
\hline$S$-Ethyl dipropylthiocarbamate $\{$ EPTC $\}$ & $759-94-4$ & 1 & 1 & $\mathrm{~B} 1, \mathrm{~B} 2$ \\
\hline$N, N$-Ethylene-bis(tetrabromophthalimide) & $32588-76-4$ & -- & 1 & $\mathrm{~F}$ \\
\hline Ethylenediaminetetraacetic acid $\{$ EDTA $\}$ & $60-00-4$ & 1 & -- & $\mathrm{H}$ \\
\hline
\end{tabular}


Table 1. Constituents identified as having high priority (Tier 1) for national- or regional-scale ambient monitoring of water or sediment in the United States.-Continued

[Tiers used to prioritize constituents are defined in the main body of the report; those identified as Tier 1 have a higher priority for monitoring than those identified as Tier 2 or Tier 3. An underlined constituent group is the preferred group in cases of differences in prioritization for the same matrix. Constituent groups: volatile organic compounds in water (A); pesticides in water (B1) or sediment (B2); pharmaceuticals and hormones in water or sediment (C); trace elements and other inorganic constituents in water (D1) or sediment (D2); cyanotoxins in surface water (E); lipophilic organic compounds in sediment (F); disinfection by-products in water $(\mathrm{G})$; high-production-volume chemicals in water $(\mathrm{H})$; wastewater-indicator and industrial compounds in water (I); and radionuclides in groundwater (J). CASRN, Chemical Abstracts Service Registry Number; --, constituent not evaluated for specified matrix; BDE, brominated diphenyl ether; C.I., Colour Index Constitution; FD\&C, U.S. Food and Drug Administration Food, Drug, and Cosmetic Act; PCB, polychlorinated biphenyl]

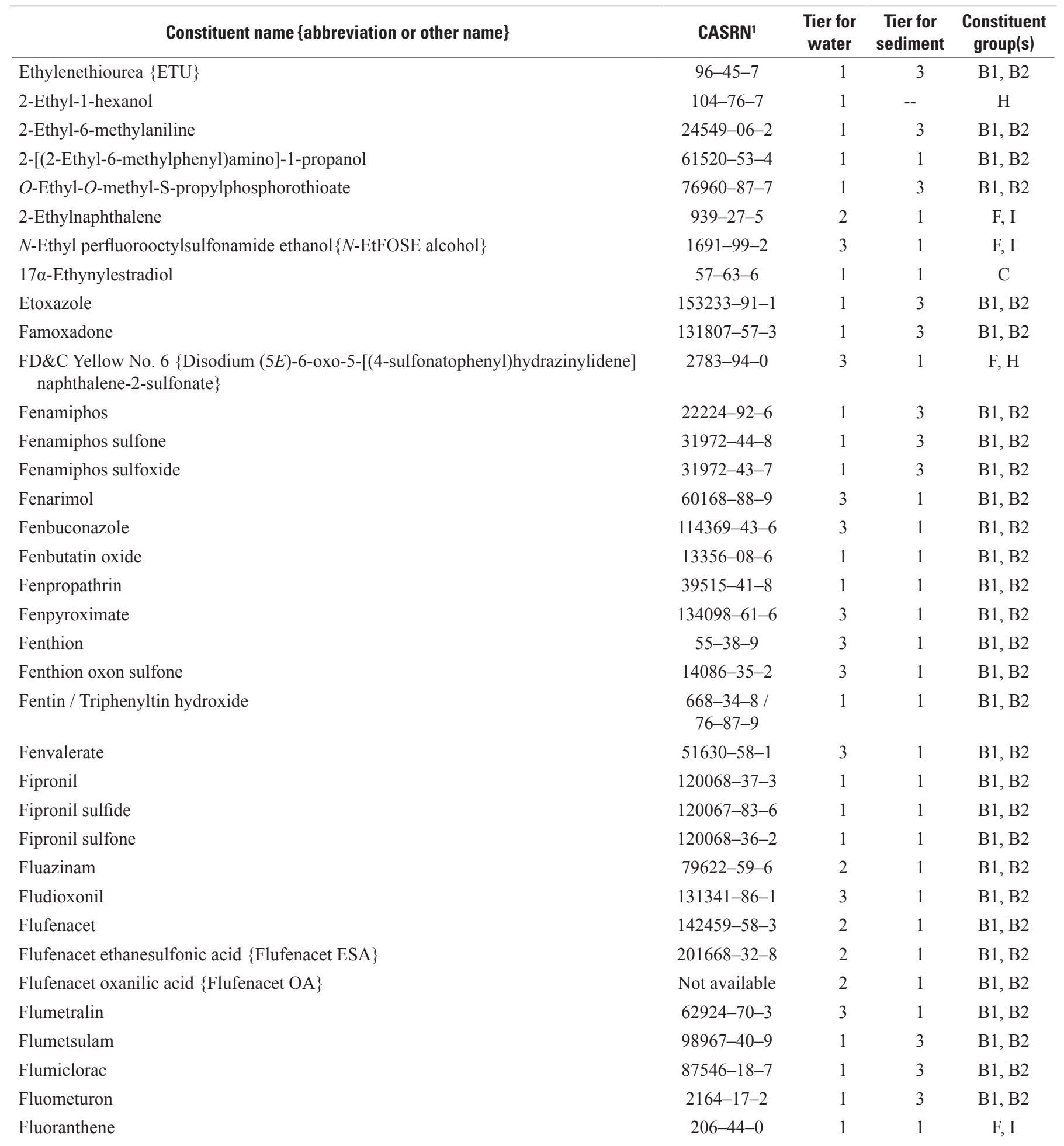


Table 1. Constituents identified as having high priority (Tier 1) for national- or regional-scale ambient monitoring of water or sediment in the United States.-Continued

[Tiers used to prioritize constituents are defined in the main body of the report; those identified as Tier 1 have a higher priority for monitoring than those identified as Tier 2 or Tier 3. An underlined constituent group is the preferred group in cases of differences in prioritization for the same matrix. Constituent groups: volatile organic compounds in water (A); pesticides in water (B1) or sediment (B2); pharmaceuticals and hormones in water or sediment (C); trace elements and other inorganic constituents in water (D1) or sediment (D2); cyanotoxins in surface water (E); lipophilic organic compounds in sediment (F); disinfection by-products in water $(\mathrm{G})$; high-production-volume chemicals in water $(\mathrm{H})$; wastewater-indicator and industrial compounds in water (I); and radionuclides in groundwater (J). CASRN, Chemical Abstracts Service Registry Number; --, constituent not evaluated for specified matrix; BDE, brominated diphenyl ether; C.I., Colour Index Constitution; FD\&C, U.S. Food and Drug Administration Food, Drug, and Cosmetic Act; PCB, polychlorinated biphenyl]

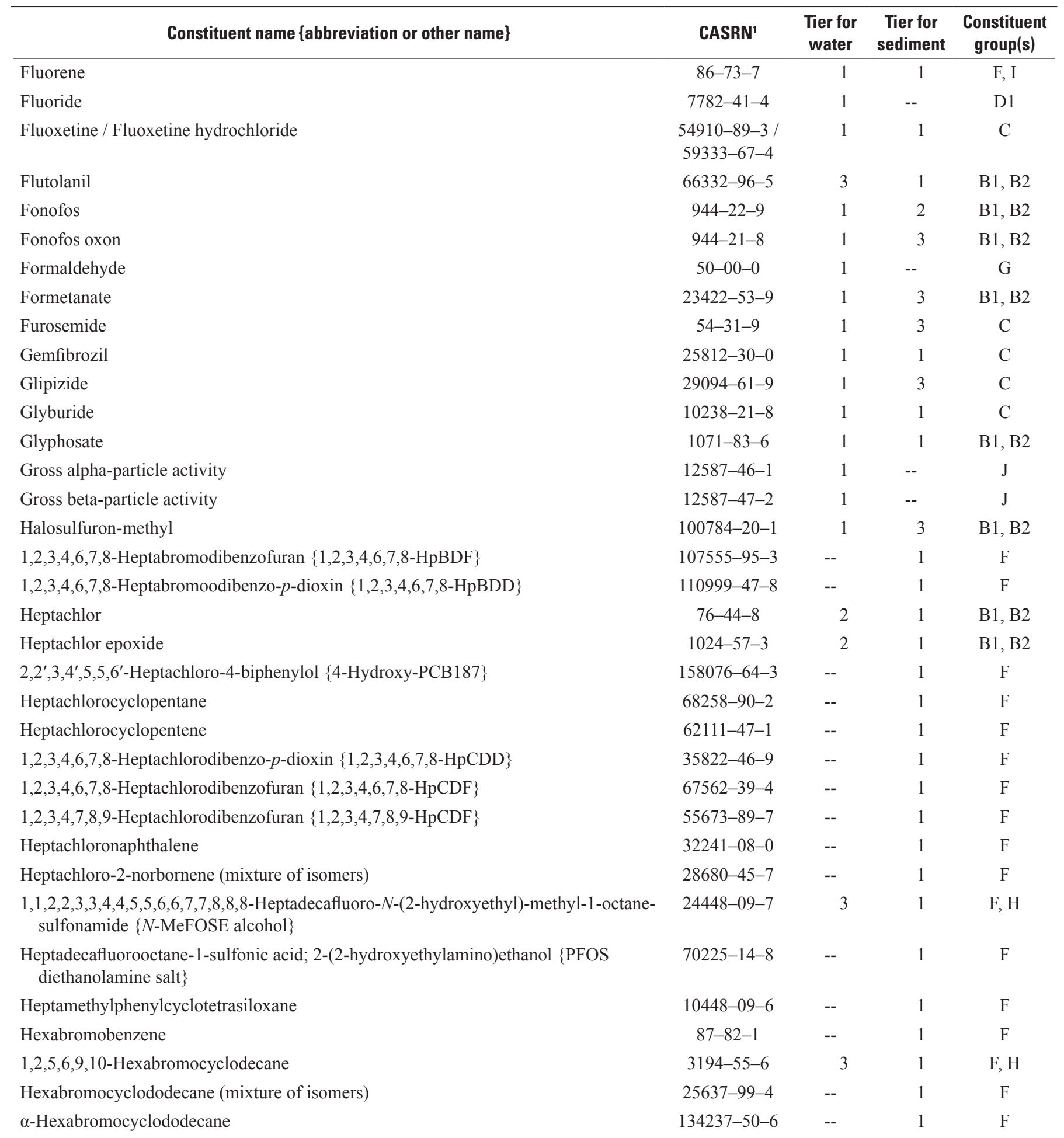


Table 1. Constituents identified as having high priority (Tier 1) for national- or regional-scale ambient monitoring of water or sediment in the United States.-Continued

[Tiers used to prioritize constituents are defined in the main body of the report; those identified as Tier 1 have a higher priority for monitoring than those identified as Tier 2 or Tier 3. An underlined constituent group is the preferred group in cases of differences in prioritization for the same matrix. Constituent groups: volatile organic compounds in water (A); pesticides in water (B1) or sediment (B2); pharmaceuticals and hormones in water or sediment (C); trace elements and other inorganic constituents in water (D1) or sediment (D2); cyanotoxins in surface water (E); lipophilic organic compounds in sediment (F); disinfection by-products in water $(\mathrm{G})$; high-production-volume chemicals in water $(\mathrm{H})$; wastewater-indicator and industrial compounds in water (I); and radionuclides in groundwater (J). CASRN, Chemical Abstracts Service Registry Number; --, constituent not evaluated for specified matrix; BDE, brominated diphenyl ether; C.I., Colour Index Constitution; FD\&C, U.S. Food and Drug Administration Food, Drug, and Cosmetic Act; PCB, polychlorinated biphenyl]

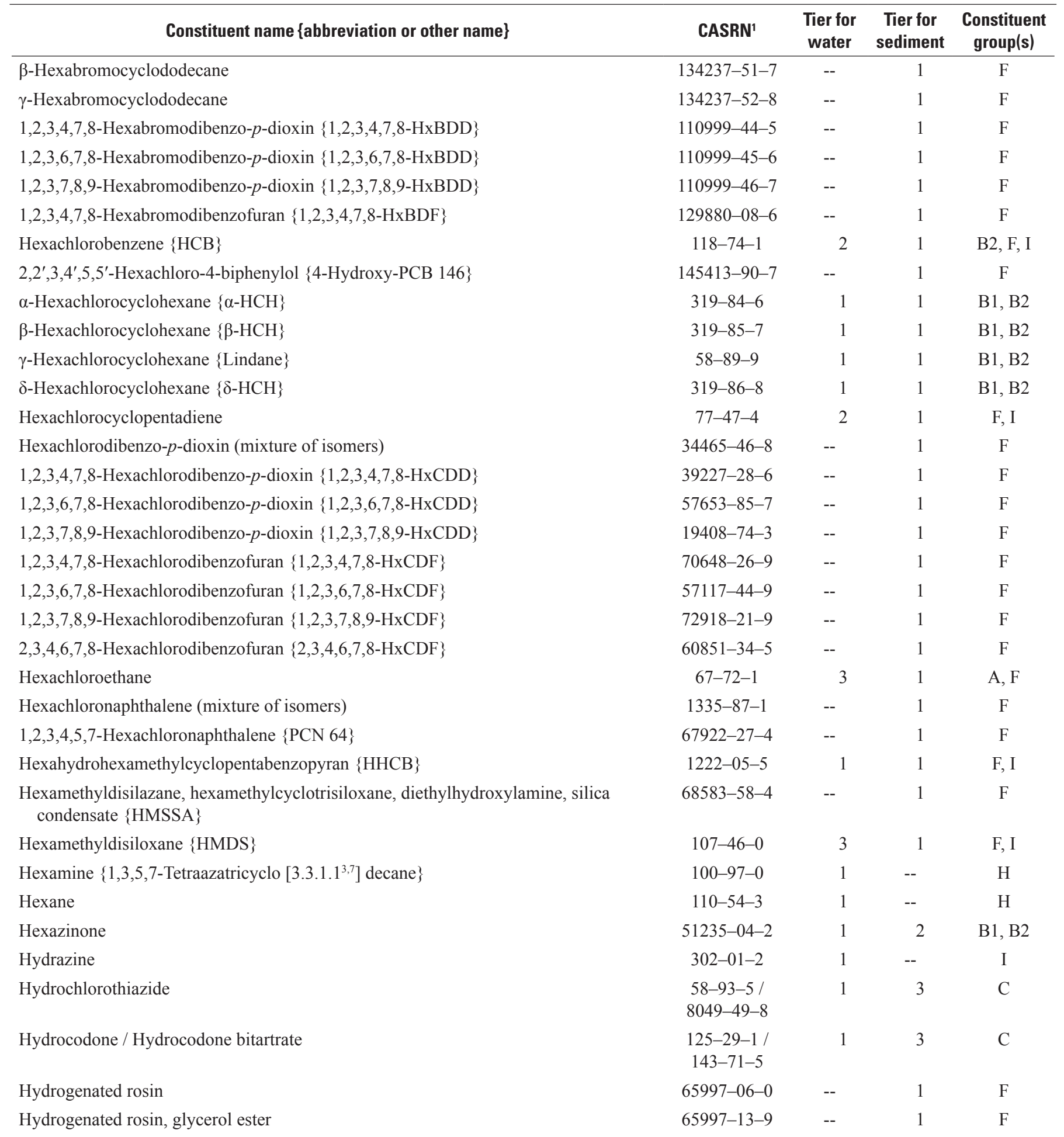


Table 1. Constituents identified as having high priority (Tier 1) for national- or regional-scale ambient monitoring of water or sediment in the United States.-Continued

[Tiers used to prioritize constituents are defined in the main body of the report; those identified as Tier 1 have a higher priority for monitoring than those identified as Tier 2 or Tier 3. An underlined constituent group is the preferred group in cases of differences in prioritization for the same matrix. Constituent groups: volatile organic compounds in water (A); pesticides in water (B1) or sediment (B2); pharmaceuticals and hormones in water or sediment (C); trace elements and other inorganic constituents in water (D1) or sediment (D2); cyanotoxins in surface water (E); lipophilic organic compounds in sediment (F); disinfection by-products in water $(\mathrm{G})$; high-production-volume chemicals in water $(\mathrm{H})$; wastewater-indicator and industrial compounds in water (I); and radionuclides in groundwater (J). CASRN, Chemical Abstracts Service Registry Number; --, constituent not evaluated for specified matrix; BDE, brominated diphenyl ether; C.I., Colour Index Constitution; FD\&C, U.S. Food and Drug Administration Food, Drug, and Cosmetic Act; PCB, polychlorinated biphenyl]

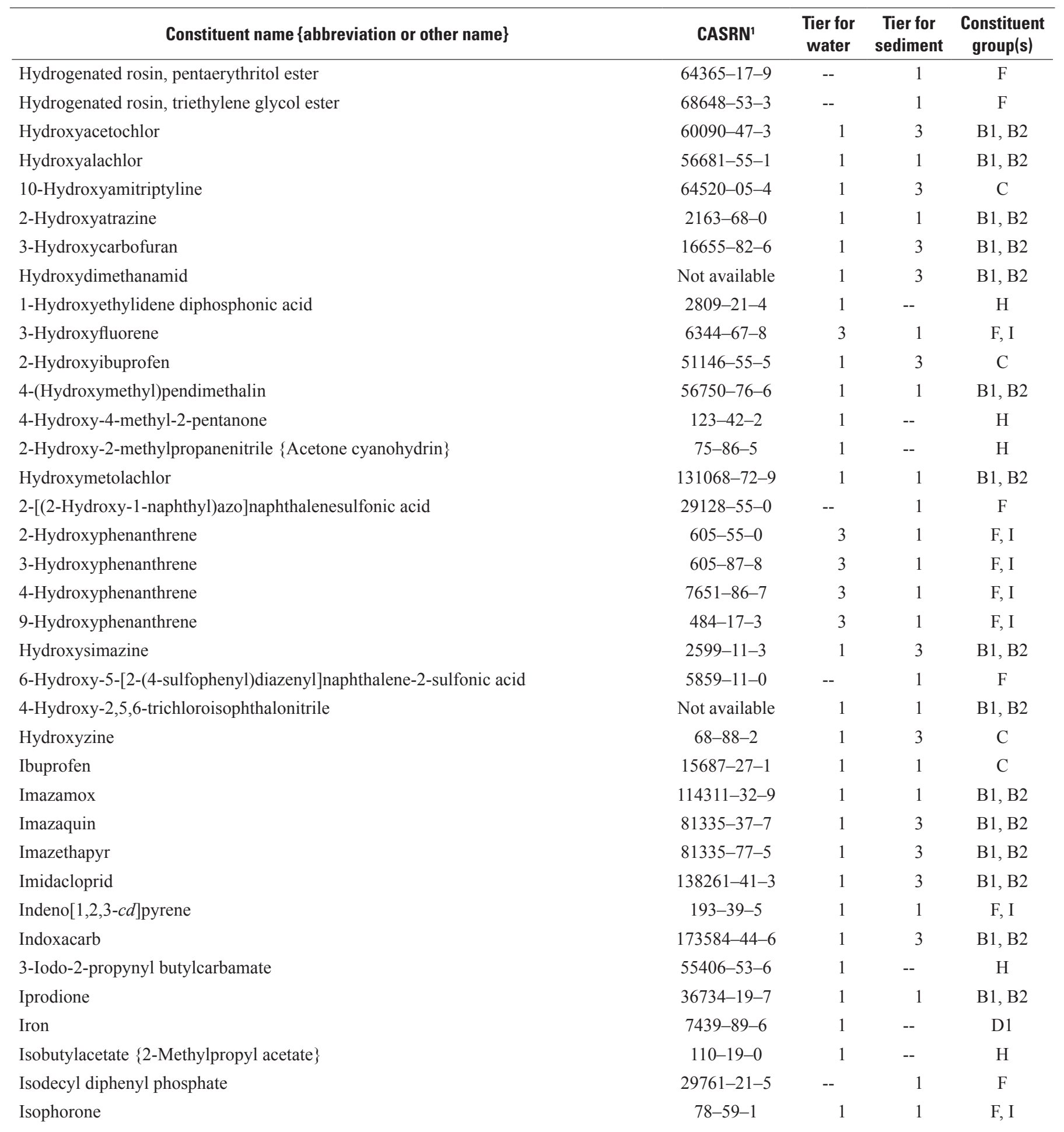


Table 1. Constituents identified as having high priority (Tier 1) for national- or regional-scale ambient monitoring of water or sediment in the United States.-Continued

[Tiers used to prioritize constituents are defined in the main body of the report; those identified as Tier 1 have a higher priority for monitoring than those identified as Tier 2 or Tier 3. An underlined constituent group is the preferred group in cases of differences in prioritization for the same matrix. Constituent groups: volatile organic compounds in water (A); pesticides in water (B1) or sediment (B2); pharmaceuticals and hormones in water or sediment (C); trace elements and other inorganic constituents in water (D1) or sediment (D2); cyanotoxins in surface water (E); lipophilic organic compounds in sediment (F); disinfection by-products in water $(\mathrm{G})$; high-production-volume chemicals in water $(\mathrm{H})$; wastewater-indicator and industrial compounds in water (I); and radionuclides in groundwater (J). CASRN, Chemical Abstracts Service Registry Number; --, constituent not evaluated for specified matrix; BDE, brominated diphenyl ether; C.I., Colour Index Constitution; FD\&C, U.S. Food and Drug Administration Food, Drug, and Cosmetic Act; PCB, polychlorinated biphenyl]

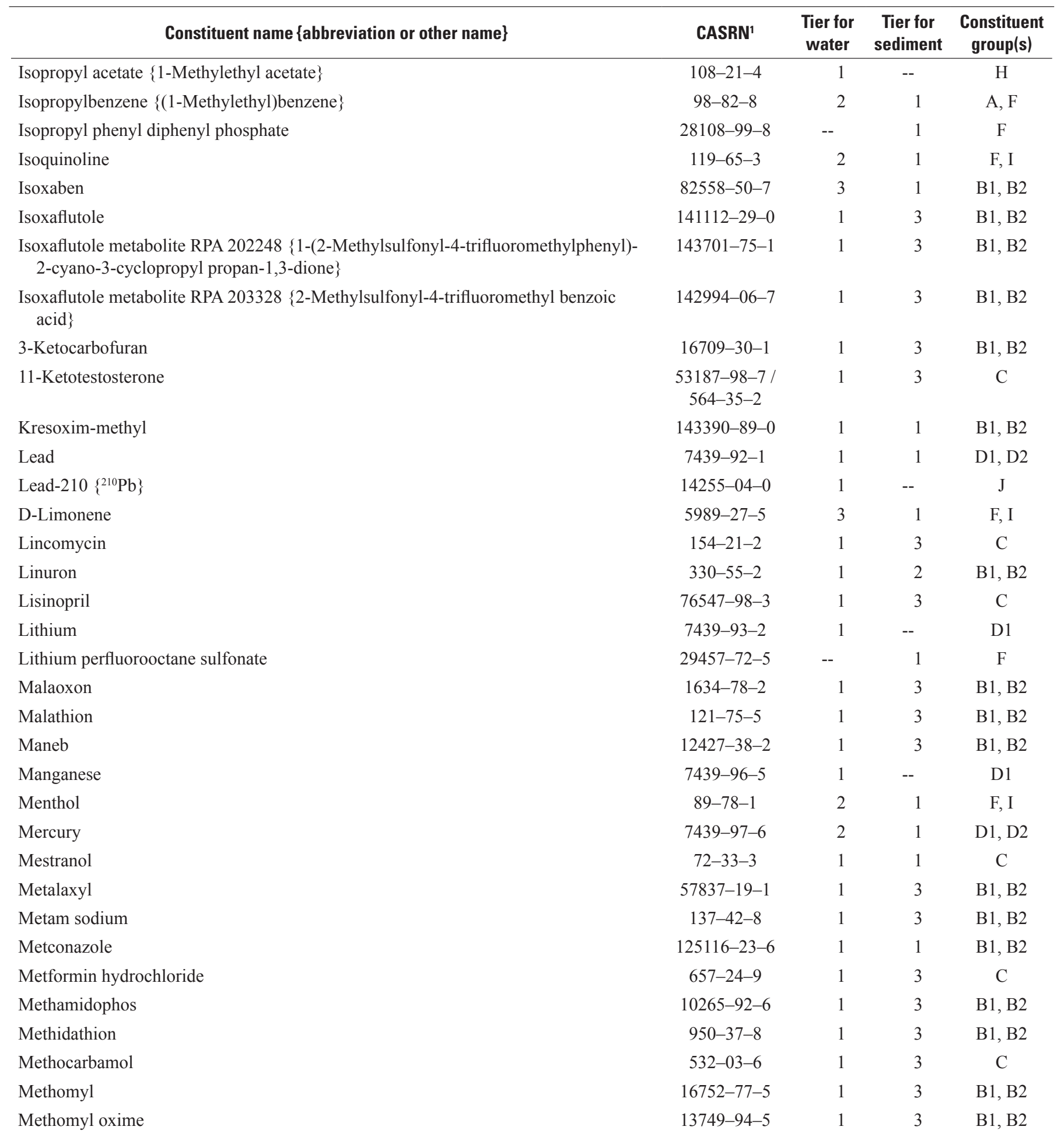


Table 1. Constituents identified as having high priority (Tier 1) for national- or regional-scale ambient monitoring of water or sediment in the United States.-Continued

[Tiers used to prioritize constituents are defined in the main body of the report; those identified as Tier 1 have a higher priority for monitoring than those identified as Tier 2 or Tier 3. An underlined constituent group is the preferred group in cases of differences in prioritization for the same matrix. Constituent groups: volatile organic compounds in water (A); pesticides in water (B1) or sediment (B2); pharmaceuticals and hormones in water or sediment (C); trace elements and other inorganic constituents in water (D1) or sediment (D2); cyanotoxins in surface water (E); lipophilic organic compounds in sediment (F); disinfection by-products in water $(\mathrm{G})$; high-production-volume chemicals in water $(\mathrm{H})$; wastewater-indicator and industrial compounds in water (I); and radionuclides in groundwater (J). CASRN, Chemical Abstracts Service Registry Number; --, constituent not evaluated for specified matrix; BDE, brominated diphenyl ether; C.I., Colour Index Constitution; FD\&C, U.S. Food and Drug Administration Food, Drug, and Cosmetic Act; PCB, polychlorinated biphenyl]

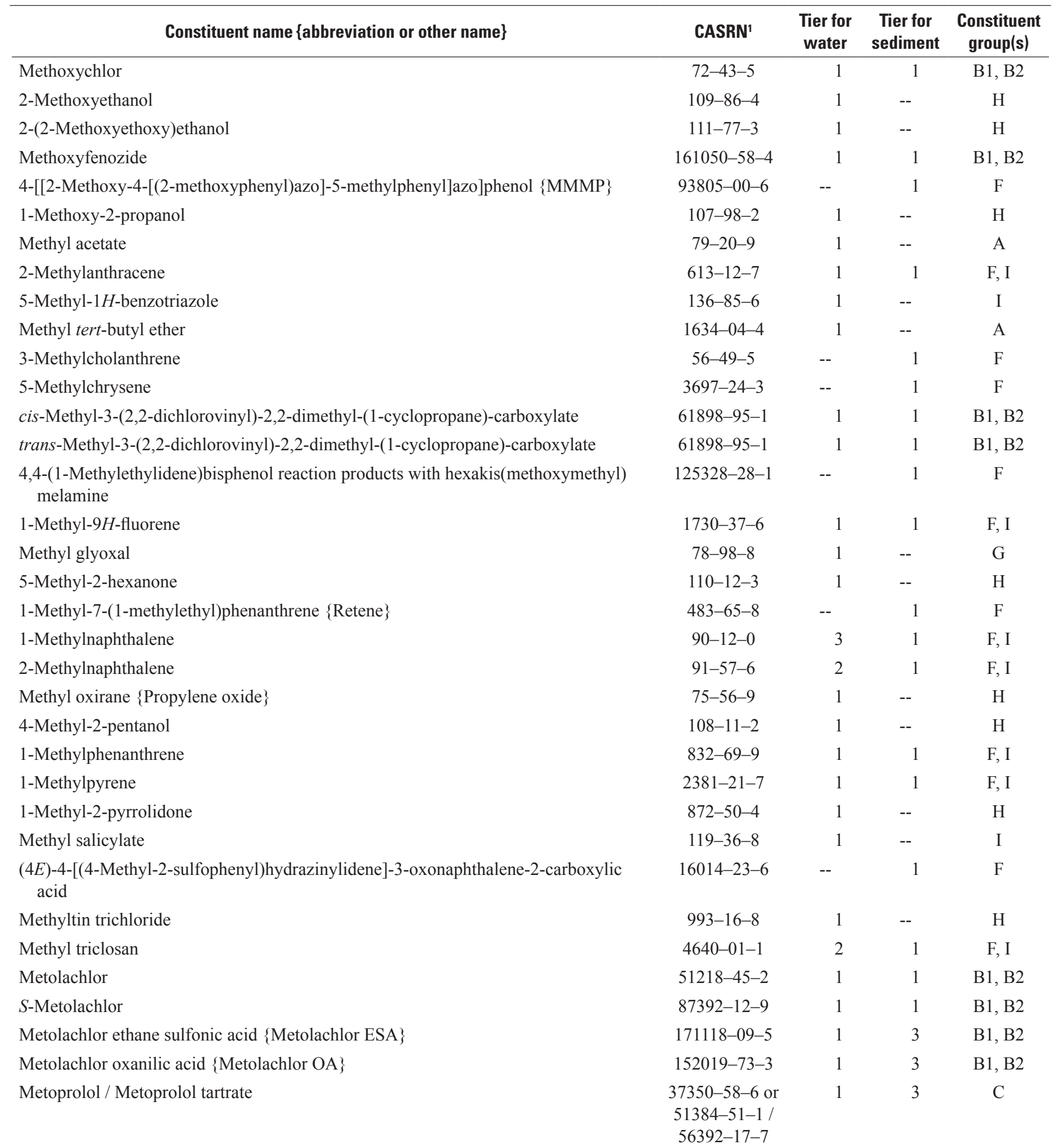


Table 1. Constituents identified as having high priority (Tier 1) for national- or regional-scale ambient monitoring of water or sediment in the United States.-Continued

[Tiers used to prioritize constituents are defined in the main body of the report; those identified as Tier 1 have a higher priority for monitoring than those identified as Tier 2 or Tier 3. An underlined constituent group is the preferred group in cases of differences in prioritization for the same matrix. Constituent groups: volatile organic compounds in water (A); pesticides in water (B1) or sediment (B2); pharmaceuticals and hormones in water or sediment (C); trace elements and other inorganic constituents in water (D1) or sediment (D2); cyanotoxins in surface water (E); lipophilic organic compounds in sediment (F); disinfection by-products in water $(\mathrm{G})$; high-production-volume chemicals in water $(\mathrm{H})$; wastewater-indicator and industrial compounds in water (I); and radionuclides in groundwater (J). CASRN, Chemical Abstracts Service Registry Number; --, constituent not evaluated for specified matrix; BDE, brominated diphenyl ether; C.I., Colour Index Constitution; FD\&C, U.S. Food and Drug Administration Food, Drug, and Cosmetic Act; PCB, polychlorinated biphenyl]

\begin{tabular}{|c|c|c|c|c|}
\hline Constituent name \{abbreviation or other name\} & CASRN ${ }^{1}$ & $\begin{array}{c}\text { Tier for } \\
\text { water }\end{array}$ & $\begin{array}{c}\text { Tier for } \\
\text { sediment }\end{array}$ & $\begin{array}{c}\text { Constituent } \\
\text { group(s) }\end{array}$ \\
\hline Metribuzin & $21087-64-9$ & 1 & 3 & $\mathrm{~B} 1, \mathrm{~B} 2$ \\
\hline Microcystin-LF $\{$ MCLF $\}$ & $154037-70-4$ & 1 & -- & $\mathrm{E}$ \\
\hline Microsystin-LR $\{$ MCLR $\}$ & $101043-37-2$ & 1 & -- & $\mathrm{E}$ \\
\hline Microsystin-RR $\{$ MCRR $\}$ & $111755-37-4$ & 1 & -- & $\mathrm{E}$ \\
\hline Microcystin-YR $\{\mathrm{MCYR}\}$ & $101064-48-6$ & 1 & -- & $\mathrm{E}$ \\
\hline Mirex & $2385-85-5$ & 2 & 1 & $\mathrm{~B} 1, \mathrm{~B} 2$ \\
\hline Molinate & $2212-67-1$ & 1 & 2 & $\mathrm{~B} 1, \mathrm{~B} 2$ \\
\hline Monochloroacetic acid & $79-11-8$ & 1 & -- & G \\
\hline Mono(2-ethyl-5-carboxypentyl) phthalate & $40809-41-4$ & 2 & 1 & F, I \\
\hline Mono-2-ethylhexyl phthalate & $4376-20-9$ & 2 & 1 & $\mathrm{~F}, \mathrm{I}$ \\
\hline Mono(2-ethyl-5-hydroxyhexyl) phthalate & $40321-99-1$ & 2 & 1 & $\mathrm{~F}, \mathrm{I}$ \\
\hline Mono(2-ethyl-5-oxohexyl) phthalate & $40321-98-0$ & 2 & 1 & $\mathrm{~F}, \mathrm{I}$ \\
\hline Mono-isononyl phthalate & $519056-28-1$ & -- & 1 & $\mathrm{~F}$ \\
\hline Mono- $n$-octyl phthalate & $5393-19-1$ & -- & 1 & $\mathrm{~F}$ \\
\hline Morpholine & $110-91-8$ & 1 & -- & $\mathrm{H}$ \\
\hline Musk xylene & $81-15-2$ & 1 & 1 & $\mathrm{~F}, \mathrm{I}$ \\
\hline 2-Naphthol \{2-Hydroxynaphthalene\} & $135-19-3$ & 2 & 1 & F, I \\
\hline Naphthylacetamide & $86-86-2$ & 3 & 1 & $\mathrm{~B} 1, \mathrm{~B} 2$ \\
\hline 2-Naphthylamine & $91-59-8$ & 3 & 1 & F, I \\
\hline Napropamide & 15299-99-7 & 2 & 1 & B1, B2 \\
\hline Naptho[2,3-e]pyrene & $196-42-9$ & -- & 1 & $\mathrm{~F}$ \\
\hline Nickel & $7440-02-0$ & 1 & 1 & D1, D2 \\
\hline Nicosulfuron & 111991-09-4 & 1 & 3 & $\mathrm{~B} 1, \mathrm{~B} 2$ \\
\hline Nitrapyrin & $1929-82-4$ & 1 & -- & $\mathrm{H}$ \\
\hline 5-Nitroacenaphthene & $602-87-9$ & 3 & 1 & F, I \\
\hline Nitrobenzene & $98-95-3$ & 1 & 1 & $\mathrm{~F}, \mathrm{I}$ \\
\hline
\end{tabular}


Table 1. Constituents identified as having high priority (Tier 1) for national- or regional-scale ambient monitoring of water or sediment in the United States.-Continued

[Tiers used to prioritize constituents are defined in the main body of the report; those identified as Tier 1 have a higher priority for monitoring than those identified as Tier 2 or Tier 3. An underlined constituent group is the preferred group in cases of differences in prioritization for the same matrix. Constituent groups: volatile organic compounds in water (A); pesticides in water (B1) or sediment (B2); pharmaceuticals and hormones in water or sediment (C); trace elements and other inorganic constituents in water (D1) or sediment (D2); cyanotoxins in surface water (E); lipophilic organic compounds in sediment (F); disinfection by-products in water $(\mathrm{G})$; high-production-volume chemicals in water $(\mathrm{H})$; wastewater-indicator and industrial compounds in water (I); and radionuclides in groundwater (J). CASRN, Chemical Abstracts Service Registry Number; --, constituent not evaluated for specified matrix; BDE, brominated diphenyl ether; C.I., Colour Index Constitution; FD\&C, U.S. Food and Drug Administration Food, Drug, and Cosmetic Act; PCB, polychlorinated biphenyl]

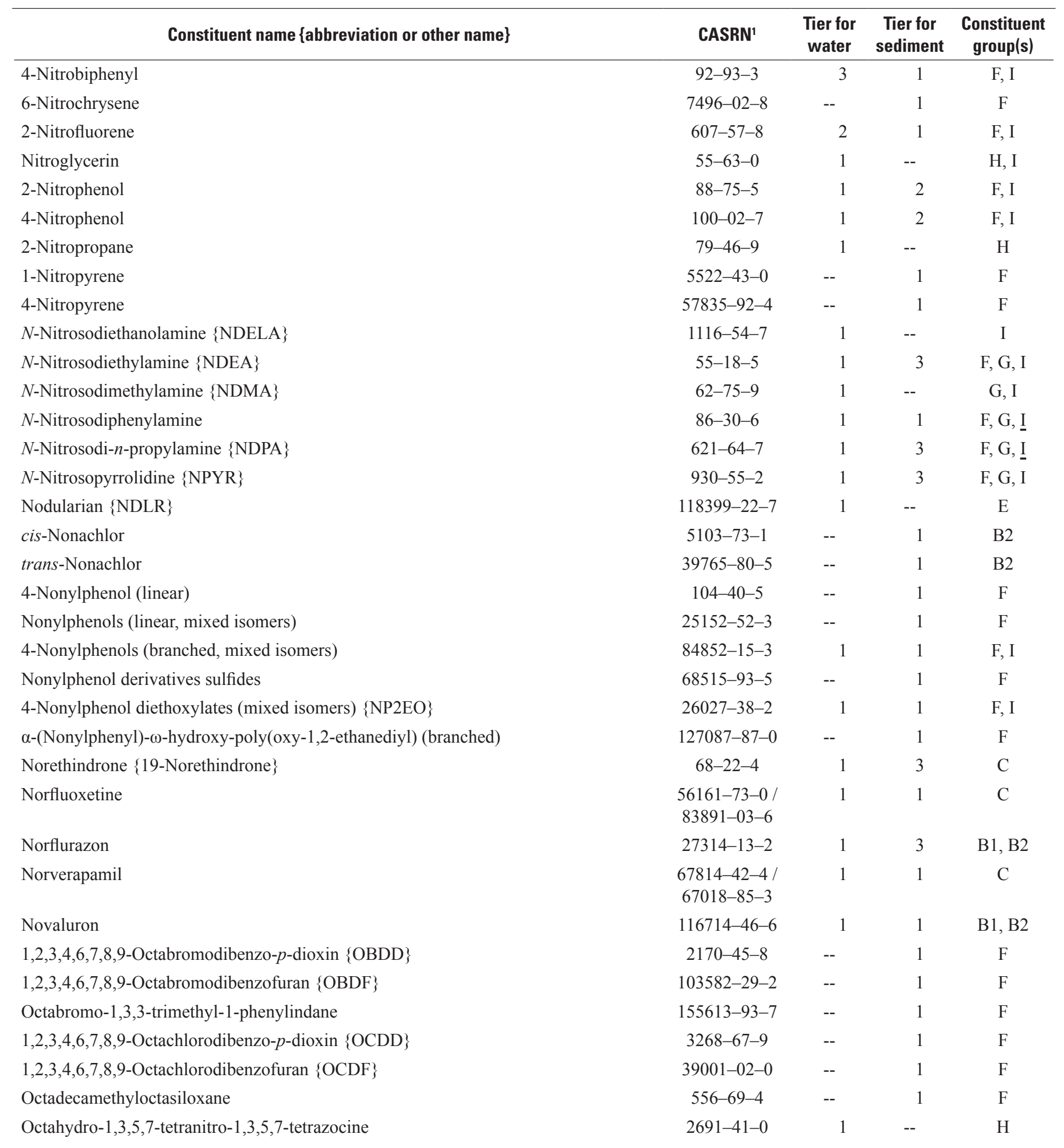


Table 1. Constituents identified as having high priority (Tier 1) for national- or regional-scale ambient monitoring of water or sediment in the United States.-Continued

[Tiers used to prioritize constituents are defined in the main body of the report; those identified as Tier 1 have a higher priority for monitoring than those identified as Tier 2 or Tier 3. An underlined constituent group is the preferred group in cases of differences in prioritization for the same matrix. Constituent groups: volatile organic compounds in water (A); pesticides in water (B1) or sediment (B2); pharmaceuticals and hormones in water or sediment (C); trace elements and other inorganic constituents in water (D1) or sediment (D2); cyanotoxins in surface water (E); lipophilic organic compounds in sediment (F); disinfection by-products in water $(\mathrm{G})$; high-production-volume chemicals in water $(\mathrm{H})$; wastewater-indicator and industrial compounds in water (I); and radionuclides in groundwater (J). CASRN, Chemical Abstracts Service Registry Number; --, constituent not evaluated for specified matrix; BDE, brominated diphenyl ether; C.I., Colour Index Constitution; FD\&C, U.S. Food and Drug Administration Food, Drug, and Cosmetic Act; PCB, polychlorinated biphenyl]

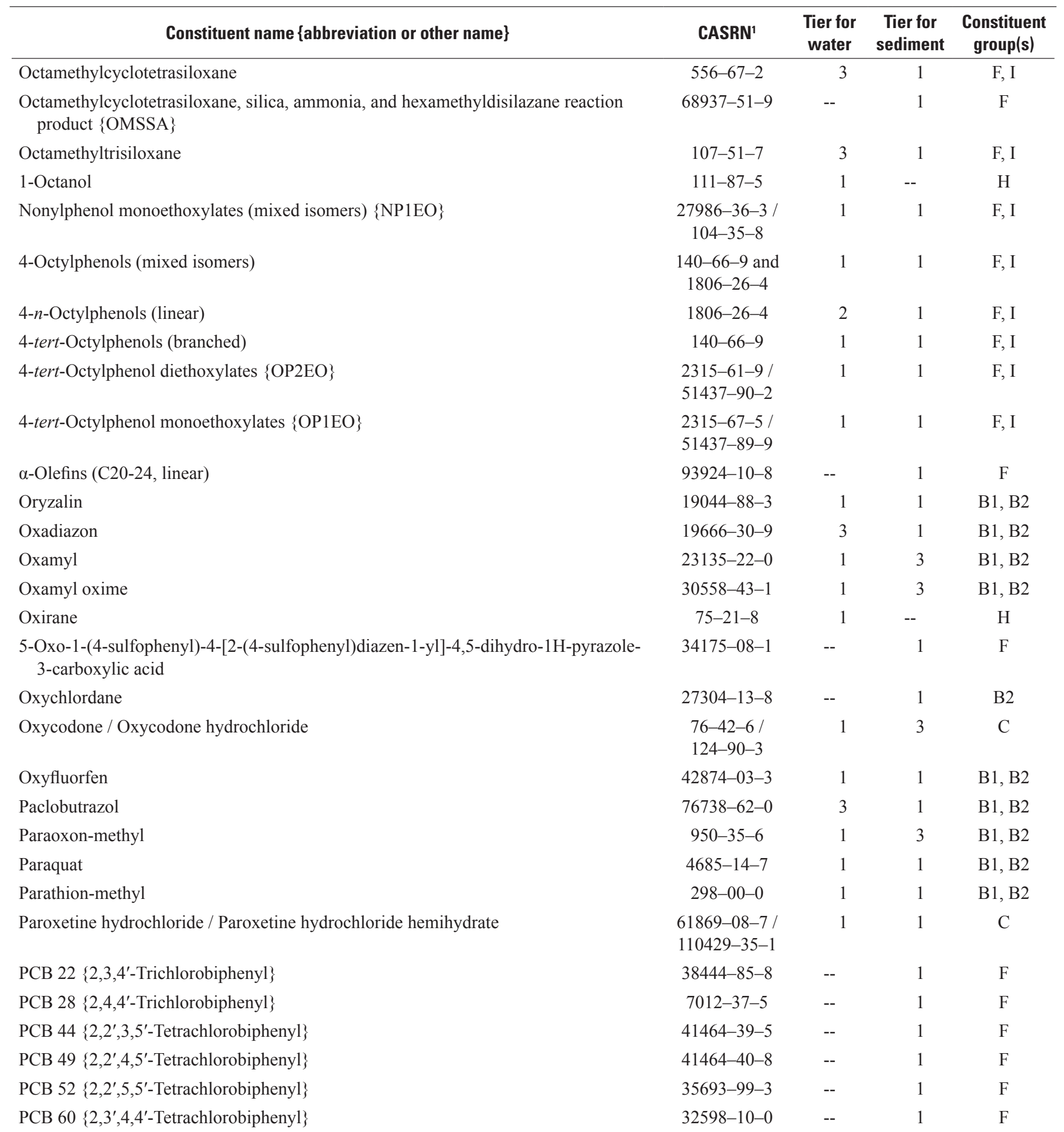


Table 1. Constituents identified as having high priority (Tier 1) for national- or regional-scale ambient monitoring of water or sediment in the United States.-Continued

[Tiers used to prioritize constituents are defined in the main body of the report; those identified as Tier 1 have a higher priority for monitoring than those identified as Tier 2 or Tier 3. An underlined constituent group is the preferred group in cases of differences in prioritization for the same matrix. Constituent groups: volatile organic compounds in water (A); pesticides in water (B1) or sediment (B2); pharmaceuticals and hormones in water or sediment (C); trace elements and other inorganic constituents in water (D1) or sediment (D2); cyanotoxins in surface water (E); lipophilic organic compounds in sediment (F); disinfection by-products in water $(\mathrm{G})$; high-production-volume chemicals in water $(\mathrm{H})$; wastewater-indicator and industrial compounds in water (I); and radionuclides in groundwater (J). CASRN, Chemical Abstracts Service Registry Number; --, constituent not evaluated for specified matrix; BDE, brominated diphenyl ether; C.I., Colour Index Constitution; FD\&C, U.S. Food and Drug Administration Food, Drug, and Cosmetic Act; PCB, polychlorinated biphenyl]

\begin{tabular}{|c|c|c|c|c|}
\hline Constituent name \{abbreviation or other name\} & CASRN ${ }^{1}$ & $\begin{array}{l}\text { Tier for } \\
\text { water }\end{array}$ & $\begin{array}{c}\text { Tier for } \\
\text { sediment }\end{array}$ & $\begin{array}{c}\text { Constituent } \\
\text { group(s) }\end{array}$ \\
\hline PCB $70\left\{2,3^{\prime}, 4^{\prime}, 5\right.$-Tetrachlorobiphenyl $\}$ & $32598-11-1$ & -- & 1 & $\mathrm{~F}$ \\
\hline PCB $74\left\{2,4,4^{\prime}, 5\right.$-Tetrachlorobiphenyl $\}$ & $32690-93-0$ & -- & 1 & $\mathrm{~F}$ \\
\hline PCB $77\left\{3,3^{\prime}, 4,4^{\prime}-\right.$ Tetrachlorobiphenyl $\}$ & $32598-13-3$ & -- & 1 & $\mathrm{~F}$ \\
\hline PCB $81\left\{3,4,4^{\prime}, 5\right.$-Tetrachlorobiphenyl $\}$ & $70362-50-4$ & -- & 1 & $\mathrm{~F}$ \\
\hline PCB $87\left\{2,2^{\prime}, 3,4,5^{\prime}\right.$-Pentachlorobiphenyl $\}$ & $38380-02-8$ & -- & 1 & $\mathrm{~F}$ \\
\hline PCB $95\left\{2,2^{\prime}, 3,5^{\prime}, 6\right.$-Pentachlorobiphenyl $\}$ & $38379-99-6$ & -- & 1 & $\mathrm{~F}$ \\
\hline PCB $99\left\{2,2^{\prime}, 4,4^{\prime}, 5\right.$-Pentachlorobiphenyl $\}$ & $38380-01-7$ & -- & 1 & $\mathrm{~F}$ \\
\hline PCB $101\left\{2,2^{\prime}, 4,5,5^{\prime}\right.$-Pentachlorobiphenyl $\}$ & $37680-73-2$ & -- & 1 & $\mathrm{~F}$ \\
\hline PCB $105\left\{2,3,3^{\prime}, 4,4^{\prime}\right.$-Pentachlorobiphenyl $\}$ & $32598-14-4$ & -- & 1 & $\mathrm{~F}$ \\
\hline PCB $110\left\{2,3,3^{\prime}, 4^{\prime}, 6\right.$-Pentachlorobiphenyl $\}$ & $38380-03-9$ & -- & 1 & $\mathrm{~F}$ \\
\hline PCB $114\left\{2,3,4,4^{\prime}, 5\right.$-Pentachlorobiphenyl $\}$ & $74472-37-0$ & -- & 1 & $\mathrm{~F}$ \\
\hline PCB $118\left\{2,3^{\prime}, 4,4^{\prime}, 5\right.$-Pentachlorobiphenyl $\}$ & $31508-00-6$ & -- & 1 & $\mathrm{~F}$ \\
\hline PCB $123\left\{2,3^{\prime}, 4,4^{\prime}, 5^{\prime}\right.$-Pentachlorobiphenyl $\}$ & $65510-44-3$ & -- & 1 & $\mathrm{~F}$ \\
\hline PCB $126\left\{3,3^{\prime}, 4,4^{\prime}, 5\right.$-Pentachlorobiphenyl $\}$ & $57465-28-8$ & -- & 1 & $\mathrm{~F}$ \\
\hline PCB $128\left\{2,2^{\prime}, 3,3^{\prime}, 4,4^{\prime}-\right.$ Hexachlorobiphenyl $\}$ & $38380-07-3$ & -- & 1 & $\mathrm{~F}$ \\
\hline PCB $138\left\{2,2^{\prime}, 3,4,4^{\prime}, 5^{\prime}\right.$ Hexachlorobiphenyl $\}$ & $35065-28-2$ & -- & 1 & $\mathrm{~F}$ \\
\hline PCB $146\left\{2,2^{\prime}, 3,4^{\prime}, 5,5^{\prime}\right.$-Hexachlorobiphenyl $\}$ & $51908-16-8$ & -- & 1 & $\mathrm{~F}$ \\
\hline PCB $149\left\{2,2^{\prime}, 3,4^{\prime}, 5^{\prime}, 6-\right.$ Hexachlorobiphenyl $\}$ & $38380-04-0$ & -- & 1 & $\mathrm{~F}$ \\
\hline PCB $151\left\{2,2^{\prime}, 3,5,5^{\prime}, 6-H e x a c h l o r o b i p h e n y l\right\}$ & $52663-63-5$ & -- & 1 & $\mathrm{~F}$ \\
\hline PCB $153\left\{2,2^{\prime}, 4,4^{\prime}, 5,5^{\prime}\right.$-Hexachlorobiphenyl $\}$ & $35065-27-1$ & -- & 1 & $\mathrm{~F}$ \\
\hline PCB $156\left\{2,3,3^{\prime}, 4,4^{\prime}, 5\right.$-Hexachlorobiphenyl $\}$ & $38380-08-4$ & -- & 1 & $\mathrm{~F}$ \\
\hline PCB $157\left\{2,3,3^{\prime}, 4,4^{\prime}, 5^{\prime}\right.$-Hexachlorobiphenyl $\}$ & $69782-90-7$ & -- & 1 & $\mathrm{~F}$ \\
\hline PCB $158\left\{2,3,3^{\prime}, 4,4^{\prime}, 6-\right.$-Hexachlorobiphenyl $\}$ & $74472-42-7$ & -- & 1 & $\mathrm{~F}$ \\
\hline PCB $167\left\{2,3^{\prime}, 4,4^{\prime}, 5,5^{\prime}\right.$-Hexachlorobiphenyl $\}$ & $52663-72-6$ & -- & 1 & $\mathrm{~F}$ \\
\hline PCB $169\left\{3,3^{\prime}, 4,4^{\prime}, 5,5^{\prime}\right.$-Hexachlorobiphenyl $\}$ & $32774-16-6$ & -- & 1 & $\mathrm{~F}$ \\
\hline PCB $170\left\{2,2^{\prime}, 3,3^{\prime}, 4,4^{\prime}, 5\right.$-Heptachlorobiphenyl $\}$ & $35065-30-6$ & -- & 1 & $\mathrm{~F}$ \\
\hline PCB $174\left\{2,2^{\prime}, 3,3^{\prime}, 4,5,6^{\prime}\right.$-Heptachlorobiphenyl $\}$ & $38411-25-5$ & -- & 1 & $\mathrm{~F}$ \\
\hline PCB $177\left\{2,2^{\prime}, 3,3^{\prime}, 4,5^{\prime}, 6^{\prime}\right.$-Heptachlorobiphenyl $\}$ & $52663-70-4$ & -- & 1 & $\mathrm{~F}$ \\
\hline PCB $178\left\{2,2^{\prime}, 3,3^{\prime}, 5,5^{\prime}, 6\right.$-Heptachlorobiphenyl $\}$ & $52663-67-9$ & -- & 1 & $\mathrm{~F}$ \\
\hline PCB $180\left\{2,2^{\prime}, 3,4,4^{\prime}, 5,5^{\prime}\right.$-Heptachlorobiphenyl $\}$ & $35065-29-3$ & -- & 1 & $\mathrm{~F}$ \\
\hline PCB $183\left\{2,2^{\prime}, 3,4,4^{\prime}, 5^{\prime}, 6\right.$-Heptachlorobiphenyl $\}$ & $52663-69-1$ & -- & 1 & $\mathrm{~F}$ \\
\hline PCB $187\left\{2,2^{\prime}, 3,4^{\prime}, 5,5^{\prime}, 6\right.$-Heptachlorobiphenyl $\}$ & $52663-68-0$ & -- & 1 & $\mathrm{~F}$ \\
\hline PCB $189\left\{2,3,3^{\prime}, 4,4^{\prime}, 5,5^{\prime}\right.$-Heptachlorobiphenyl $\}$ & $39635-31-9$ & -- & 1 & $\mathrm{~F}$ \\
\hline PCB $194\left\{2,2^{\prime}, 3,3^{\prime}, 4,4^{\prime}, 5,5^{\prime}\right.$-Octachlorobiphenyl $\}$ & $35694-08-7$ & -- & 1 & $\mathrm{~F}$ \\
\hline PCB $196\left\{2,2^{\prime}, 3,3^{\prime}, 4,4^{\prime}, 5,6^{\prime}\right.$-Octachlorobiphenyl $\}$ & $42740-50-1$ & -- & 1 & $\mathrm{~F}$ \\
\hline PCB $199\left\{2,2^{\prime}, 3,3^{\prime}, 4,5,5^{\prime}, 6^{\prime}\right.$-Octachlorobiphenyl $\}$ & $52663-75-9$ & -- & 1 & $\mathrm{~F}$ \\
\hline PCB $206\left\{2,2^{\prime}, 3,3^{\prime}, 4,4^{\prime}, 5,5^{\prime}, 6-\right.$ Nonachlorobiphenyl $\}$ & $40186-72-9$ & -- & 1 & $\mathrm{~F}$ \\
\hline
\end{tabular}


Table 1. Constituents identified as having high priority (Tier 1) for national- or regional-scale ambient monitoring of water or sediment in the United States.-Continued

[Tiers used to prioritize constituents are defined in the main body of the report; those identified as Tier 1 have a higher priority for monitoring than those identified as Tier 2 or Tier 3. An underlined constituent group is the preferred group in cases of differences in prioritization for the same matrix. Constituent groups: volatile organic compounds in water (A); pesticides in water (B1) or sediment (B2); pharmaceuticals and hormones in water or sediment (C); trace elements and other inorganic constituents in water (D1) or sediment (D2); cyanotoxins in surface water (E); lipophilic organic compounds in sediment (F); disinfection by-products in water $(\mathrm{G})$; high-production-volume chemicals in water $(\mathrm{H})$; wastewater-indicator and industrial compounds in water (I); and radionuclides in groundwater (J). CASRN, Chemical Abstracts Service Registry Number; --, constituent not evaluated for specified matrix; BDE, brominated diphenyl ether; C.I., Colour Index Constitution; FD\&C, U.S. Food and Drug Administration Food, Drug, and Cosmetic Act; PCB, polychlorinated biphenyl]

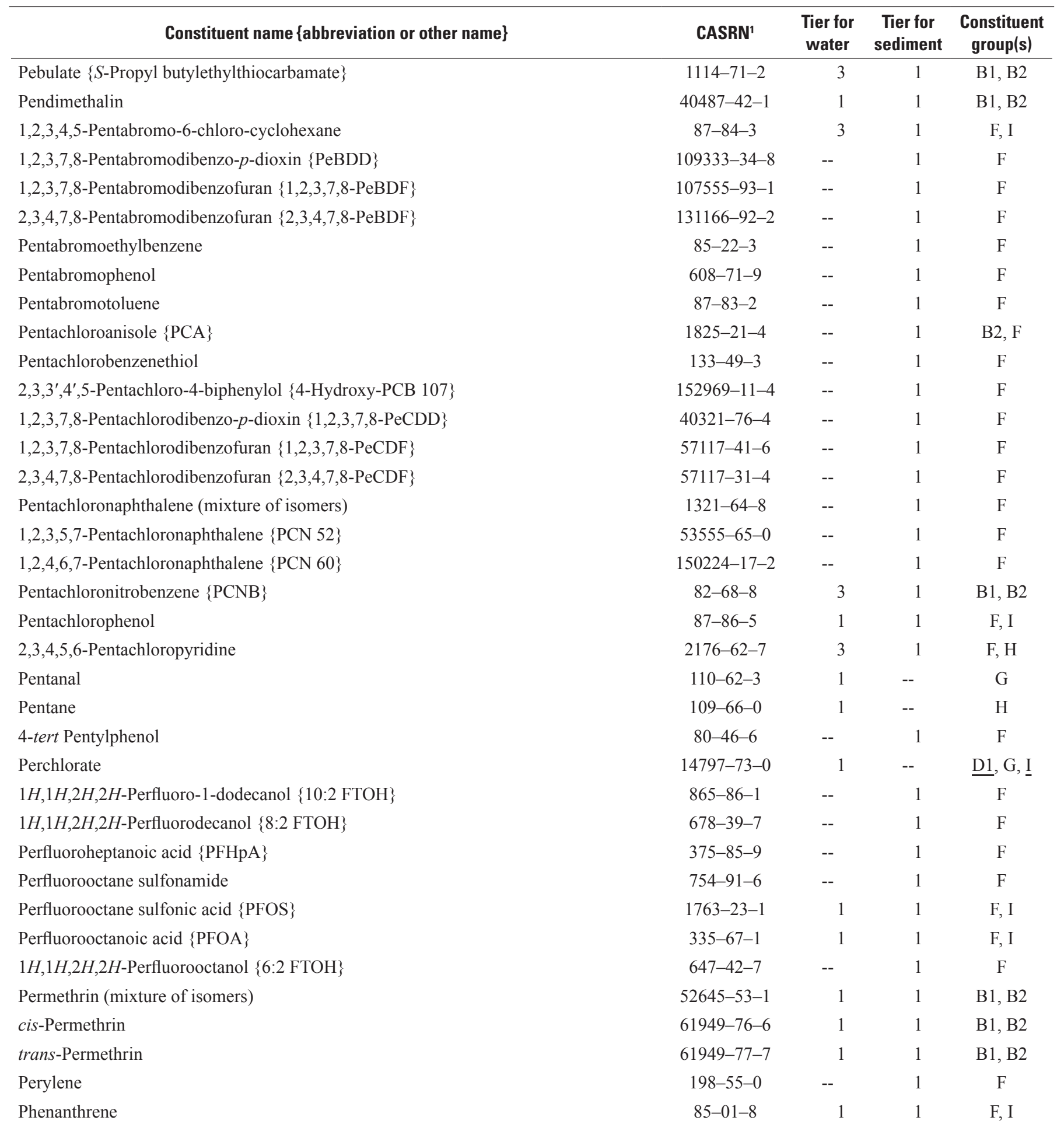


Table 1. Constituents identified as having high priority (Tier 1) for national- or regional-scale ambient monitoring of water or sediment in the United States.-Continued

[Tiers used to prioritize constituents are defined in the main body of the report; those identified as Tier 1 have a higher priority for monitoring than those identified as Tier 2 or Tier 3. An underlined constituent group is the preferred group in cases of differences in prioritization for the same matrix. Constituent groups: volatile organic compounds in water (A); pesticides in water (B1) or sediment (B2); pharmaceuticals and hormones in water or sediment (C); trace elements and other inorganic constituents in water (D1) or sediment (D2); cyanotoxins in surface water (E); lipophilic organic compounds in sediment (F); disinfection by-products in water $(\mathrm{G})$; high-production-volume chemicals in water $(\mathrm{H})$; wastewater-indicator and industrial compounds in water (I); and radionuclides in groundwater (J). CASRN, Chemical Abstracts Service Registry Number; --, constituent not evaluated for specified matrix; BDE, brominated diphenyl ether; C.I., Colour Index Constitution; FD\&C, U.S. Food and Drug Administration Food, Drug, and Cosmetic Act; PCB, polychlorinated biphenyl]

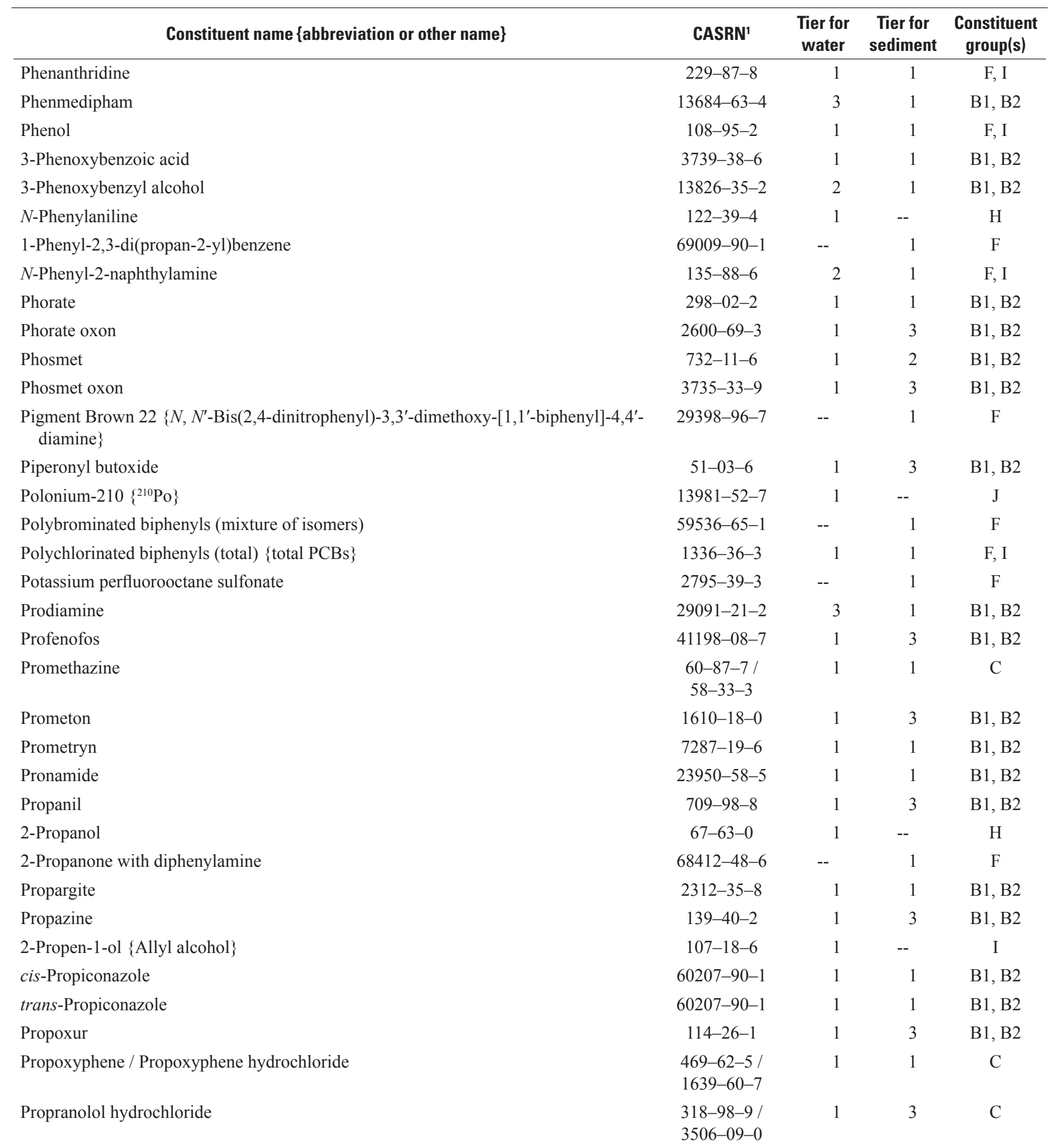


Table 1. Constituents identified as having high priority (Tier 1) for national- or regional-scale ambient monitoring of water or sediment in the United States.-Continued

[Tiers used to prioritize constituents are defined in the main body of the report; those identified as Tier 1 have a higher priority for monitoring than those identified as Tier 2 or Tier 3. An underlined constituent group is the preferred group in cases of differences in prioritization for the same matrix. Constituent groups: volatile organic compounds in water (A); pesticides in water (B1) or sediment (B2); pharmaceuticals and hormones in water or sediment (C); trace elements and other inorganic constituents in water (D1) or sediment (D2); cyanotoxins in surface water (E); lipophilic organic compounds in sediment (F); disinfection by-products in water $(\mathrm{G})$; high-production-volume chemicals in water $(\mathrm{H})$; wastewater-indicator and industrial compounds in water (I); and radionuclides in groundwater (J). CASRN, Chemical Abstracts Service Registry Number; --, constituent not evaluated for specified matrix; BDE, brominated diphenyl ether; C.I., Colour Index Constitution; FD\&C, U.S. Food and Drug Administration Food, Drug, and Cosmetic Act; PCB, polychlorinated biphenyl]

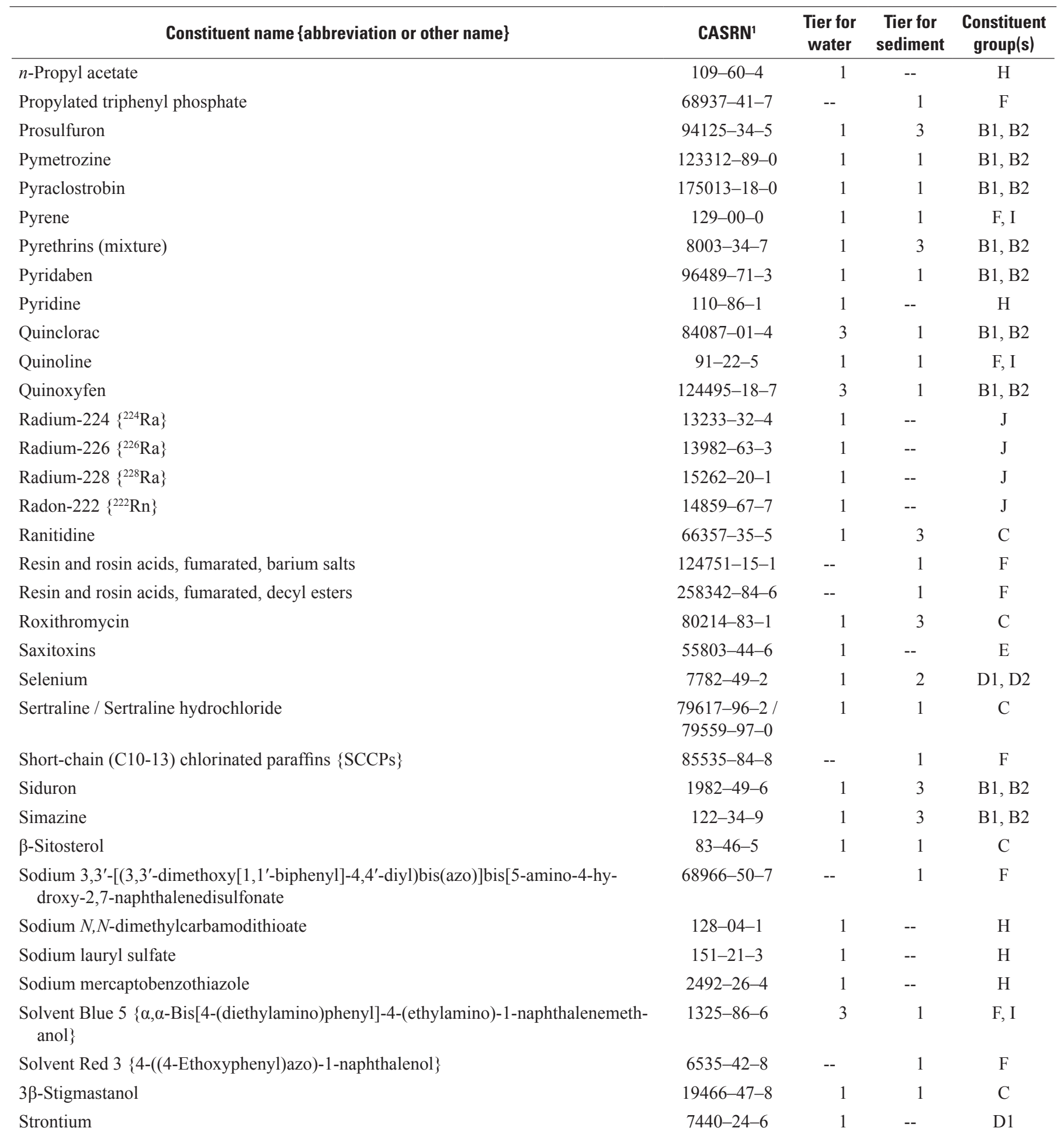


Table 1. Constituents identified as having high priority (Tier 1) for national- or regional-scale ambient monitoring of water or sediment in the United States.-Continued

[Tiers used to prioritize constituents are defined in the main body of the report; those identified as Tier 1 have a higher priority for monitoring than those identified as Tier 2 or Tier 3. An underlined constituent group is the preferred group in cases of differences in prioritization for the same matrix. Constituent groups: volatile organic compounds in water (A); pesticides in water (B1) or sediment (B2); pharmaceuticals and hormones in water or sediment (C); trace elements and other inorganic constituents in water (D1) or sediment (D2); cyanotoxins in surface water (E); lipophilic organic compounds in sediment (F); disinfection by-products in water $(\mathrm{G})$; high-production-volume chemicals in water $(\mathrm{H})$; wastewater-indicator and industrial compounds in water (I); and radionuclides in groundwater (J). CASRN, Chemical Abstracts Service Registry Number; --, constituent not evaluated for specified matrix; BDE, brominated diphenyl ether; C.I., Colour Index Constitution; FD\&C, U.S. Food and Drug Administration Food, Drug, and Cosmetic Act; PCB, polychlorinated biphenyl]

\begin{tabular}{|c|c|c|c|c|}
\hline Constituent name \{abbreviation or other name\} & CASRN ${ }^{1}$ & $\begin{array}{c}\text { Tier for } \\
\text { water }\end{array}$ & $\begin{array}{c}\text { Tier for } \\
\text { sediment }\end{array}$ & $\begin{array}{c}\text { Constituent } \\
\text { group(s) }\end{array}$ \\
\hline Styrenated phenols (mixture) & $61788-44-1$ & 3 & 1 & F, I \\
\hline Sulfamethoxazole & $723-46-6$ & 1 & 3 & $\mathrm{C}$ \\
\hline Sulfometuron-methyl & $74222-97-2$ & 1 & 3 & B1, B2 \\
\hline Tartrazine $\{$ FD\&C Yellow No. 5$\}$ & $1934-21-0$ & 3 & 1 & $\mathrm{~F}, \mathrm{H}$ \\
\hline Tebuconazole & $107534-96-3$ & 1 & 1 & $\mathrm{~B} 1, \mathrm{~B} 2$ \\
\hline Tebufenozide & $112410-23-8$ & 2 & 1 & B1, B2 \\
\hline Tebupirimfos & $96182-53-5$ & 1 & 1 & B1, B2 \\
\hline Tefluthrin metabolite [R 119364] & Not available & 1 & 1 & $\mathrm{~B} 1, \mathrm{~B} 2$ \\
\hline Tefluthrin metabolite [R 152912] & Not available & 1 & 1 & B1, B2 \\
\hline Tellurium & $13494-80-9$ & 1 & -- & D1 \\
\hline Terbacil & $5902-51-2$ & 1 & 3 & $\mathrm{~B} 1, \mathrm{~B} 2$ \\
\hline Terbufos & 13071-79-9 & 1 & 3 & $\mathrm{~B} 1, \mathrm{~B} 2$ \\
\hline Terbufos-oxon-sulfone & $56070-15-6$ & 1 & 3 & $\mathrm{~B} 1, \mathrm{~B} 2$ \\
\hline Terbufos sulfone & $56070-16-7$ & 1 & 3 & B1, B2 \\
\hline Terbuthylazine & $5915-41-3$ & 1 & 1 & B1, B2 \\
\hline Terbutylphenyl diphenyl phosphate & $56803-37-3$ & -- & 1 & $\mathrm{~F}$ \\
\hline Tetrabromodichlorocyclohexane & $30554-72-4$ & -- & 1 & $\mathrm{~F}$ \\
\hline Tetrabromophenolphthalein ethyl ester \{Malachite green oxalate\} & $1176-74-5$ & 3 & 1 & $\mathrm{~F}, \mathrm{I}$ \\
\hline 1,3,6,8-Tetrabromopyrene & $128-63-2$ & -- & 1 & $\mathrm{~F}$ \\
\hline 2,3,7,8-Tetrabromodibenzo- $p$-dioxin $\{$ TBDD $\}$ & $50585-41-6$ & -- & 1 & $\mathrm{~F}$ \\
\hline Tetrabutyltin & $1461-25-2$ & -- & 1 & $\mathrm{~F}$ \\
\hline $2,3,7,8$-Tetrachlorodibenzo- $p$-dioxin $\{\mathrm{TCDD}\}$ & $1746-01-6$ & 1 & 1 & $\mathrm{~F}, \mathrm{I}$ \\
\hline 2,3,7,8-Tetrachlorodibenzofuran $\{\mathrm{TCDF}\}$ & $51207-31-9$ & -- & 1 & $\mathrm{~F}$ \\
\hline Tetrachloroethene \{Perchloroethene\} & $127-18-4$ & 1 & -- & A \\
\hline Tetrachloromethane $\{$ Carbon tetrachloride $\}$ & $56-23-5$ & 1 & 3 & $\underline{\mathrm{A}}, \mathrm{B} 2, \mathrm{G}$ \\
\hline
\end{tabular}


Table 1. Constituents identified as having high priority (Tier 1) for national- or regional-scale ambient monitoring of water or sediment in the United States.-Continued

[Tiers used to prioritize constituents are defined in the main body of the report; those identified as Tier 1 have a higher priority for monitoring than those identified as Tier 2 or Tier 3. An underlined constituent group is the preferred group in cases of differences in prioritization for the same matrix. Constituent groups: volatile organic compounds in water (A); pesticides in water (B1) or sediment (B2); pharmaceuticals and hormones in water or sediment (C); trace elements and other inorganic constituents in water (D1) or sediment (D2); cyanotoxins in surface water (E); lipophilic organic compounds in sediment (F); disinfection by-products in water $(\mathrm{G})$; high-production-volume chemicals in water $(\mathrm{H})$; wastewater-indicator and industrial compounds in water (I); and radionuclides in groundwater (J). CASRN, Chemical Abstracts Service Registry Number; --, constituent not evaluated for specified matrix; BDE, brominated diphenyl ether; C.I., Colour Index Constitution; FD\&C, U.S. Food and Drug Administration Food, Drug, and Cosmetic Act; PCB, polychlorinated biphenyl]

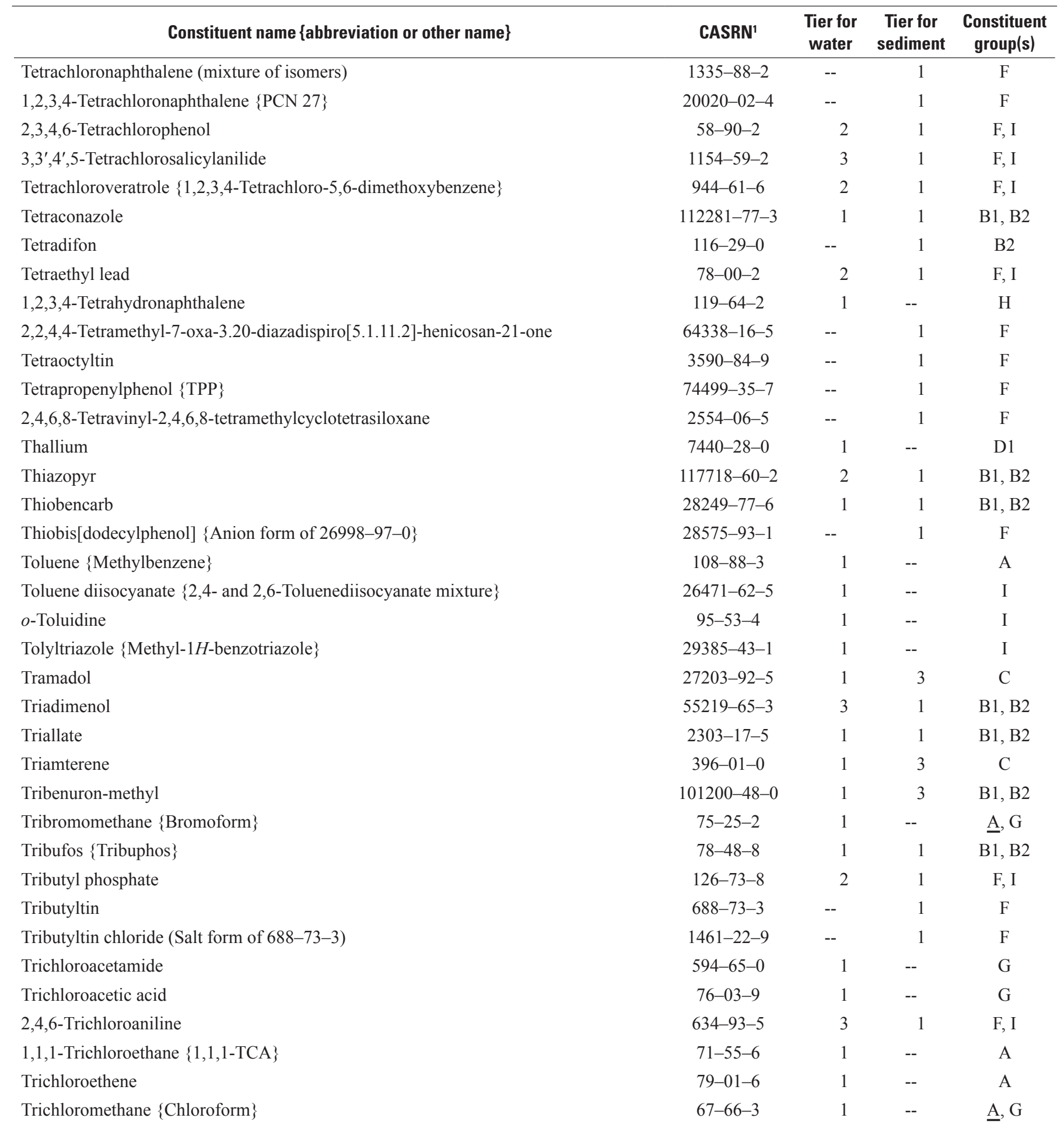


Table 1. Constituents identified as having high priority (Tier 1) for national- or regional-scale ambient monitoring of water or sediment in the United States.-Continued

[Tiers used to prioritize constituents are defined in the main body of the report; those identified as Tier 1 have a higher priority for monitoring than those identified as Tier 2 or Tier 3. An underlined constituent group is the preferred group in cases of differences in prioritization for the same matrix. Constituent groups: volatile organic compounds in water (A); pesticides in water (B1) or sediment (B2); pharmaceuticals and hormones in water or sediment (C); trace elements and other inorganic constituents in water (D1) or sediment (D2); cyanotoxins in surface water (E); lipophilic organic compounds in sediment (F); disinfection by-products in water $(\mathrm{G})$; high-production-volume chemicals in water $(\mathrm{H})$; wastewater-indicator and industrial compounds in water (I); and radionuclides in groundwater (J). CASRN, Chemical Abstracts Service Registry Number; --, constituent not evaluated for specified matrix; BDE, brominated diphenyl ether; C.I., Colour Index Constitution; FD\&C, U.S. Food and Drug Administration Food, Drug, and Cosmetic Act; PCB, polychlorinated biphenyl]

\begin{tabular}{|c|c|c|c|c|}
\hline Constituent name \{abbreviation or other name\} & CASRN ${ }^{1}$ & $\begin{array}{l}\text { Tier for } \\
\text { water }\end{array}$ & $\begin{array}{c}\text { Tier for } \\
\text { sediment }\end{array}$ & $\begin{array}{c}\text { Constituent } \\
\text { group(s) }\end{array}$ \\
\hline Trichloronaphthalene & $1321-65-9$ & -- & 1 & $\mathrm{~F}$ \\
\hline 1,2,3-Trichloropropane & $96-18-4$ & 1 & 3 & $\mathrm{~A}, \mathrm{~B} 2$ \\
\hline Trichloropropene sulfonic acid $\{$ TCPSA $\}$ & $65600-62-6$ & 1 & 1 & B1, B2 \\
\hline Triclopyr & $55335-06-3$ & 1 & 1 & $\mathrm{~B} 1, \mathrm{~B} 2$ \\
\hline Triclosan & $3380-34-5$ & 1 & 1 & F, I \\
\hline Tricresyl phosphate & $1330-78-5$ & -- & 1 & $\mathrm{~F}$ \\
\hline Tri(dichlorisopropyl) phosphate & $13674-87-8$ & 1 & -- & I \\
\hline Trifluralin & $1582-09-8$ & 1 & 1 & $\mathrm{~B} 1, \mathrm{~B} 2$ \\
\hline Trimethoprim & $738-70-5$ & 1 & 3 & $\mathrm{C}$ \\
\hline $\begin{array}{l}S \text {-(3-Trimethoxysilyl)propyl 19-isocyanato-11-(6-isocyanatohexyl)-10,12-dioxo- } \\
\text { 2,9,11,13-tetraazanonadecanethioate }\end{array}$ & $85702-90-5$ & -- & 1 & $\mathrm{~F}$ \\
\hline 1,2,4-Trimethylbenzene & $95-63-6$ & 1 & -- & A \\
\hline 2,3,6-Trimethylnaphthalene & $829-26-5$ & 1 & 1 & $\mathrm{~F}, \mathrm{I}$ \\
\hline 2,2,4-Trimethyl-1,3-pentanediolmono(2-methylpropanoate) & $25265-77-4$ & 1 & -- & $\mathrm{H}$ \\
\hline 2,4,6-Trimethyl-2,4,6-tris(3,3,3-trifluoropropyl)-cyclotrisiloxane & $2374-14-3$ & -- & 1 & $\mathrm{~F}$ \\
\hline 1,3,5-Trinitroperhydro-1,3,5-triazine & $121-82-4$ & 1 & -- & $\mathrm{H}$ \\
\hline Tris(2-chloroethyl) phosphate & $115-96-8$ & 1 & 3 & $\mathrm{~F}, \mathrm{I}$ \\
\hline Tris(2,4-di-tert-butylphenyl) phosphite & $31570-04-4$ & -- & 1 & $\mathrm{~F}$ \\
\hline 2,4,6-Tris(1,1-dimethylethyl)phenol & $732-26-3$ & -- & 1 & $\mathrm{~F}$ \\
\hline Tris(4-nonylphenyl) phosphite $\{\mathrm{TNPP}\}$ & $26523-78-4$ & -- & 1 & $\mathrm{~F}$ \\
\hline 2-[[4-[1,2,2-Tris[4-(oxiran-2-ylmethoxy)phenyl]ethyl]phenoxy]methyl]oxirane & $7328-97-4$ & -- & 1 & $\mathrm{~F}$ \\
\hline Tri-o-tolyl phosphate & $78-30-8$ & 2 & 1 & $\mathrm{~F}, \mathrm{I}$ \\
\hline Trixylenyl phosphate & $25155-23-1$ & -- & 1 & $\mathrm{~F}$ \\
\hline Tylosin & $1401-69-0$ & 1 & 3 & $\mathrm{C}$ \\
\hline Uniconazole / Uniconazole-P & $\begin{array}{c}83657-22-1 / \\
83657-17-4\end{array}$ & 3 & 1 & $\mathrm{~B} 1, \mathrm{~B} 2$ \\
\hline
\end{tabular}


Table 1. Constituents identified as having high priority (Tier 1) for national- or regional-scale ambient monitoring of water or sediment in the United States.-Continued

[Tiers used to prioritize constituents are defined in the main body of the report; those identified as Tier 1 have a higher priority for monitoring than those identified as Tier 2 or Tier 3. An underlined constituent group is the preferred group in cases of differences in prioritization for the same matrix. Constituent groups: volatile organic compounds in water (A); pesticides in water (B1) or sediment (B2); pharmaceuticals and hormones in water or sediment (C); trace elements and other inorganic constituents in water (D1) or sediment (D2); cyanotoxins in surface water (E); lipophilic organic compounds in sediment (F); disinfection by-products in water $(\mathrm{G})$; high-production-volume chemicals in water $(\mathrm{H})$; wastewater-indicator and industrial compounds in water (I); and radionuclides in groundwater (J). CASRN, Chemical Abstracts Service Registry Number; --, constituent not evaluated for specified matrix; BDE, brominated diphenyl ether; C.I., Colour Index Constitution; FD\&C, U.S. Food and Drug Administration Food, Drug, and Cosmetic Act; PCB, polychlorinated biphenyl]

\begin{tabular}{|c|c|c|c|c|}
\hline Constituent name \{abbreviation or other name\} & CASRN $^{1}$ & $\begin{array}{l}\text { Tier for } \\
\text { water }\end{array}$ & $\begin{array}{c}\text { Tier for } \\
\text { sediment }\end{array}$ & $\begin{array}{c}\text { Constituent } \\
\text { group(s) }\end{array}$ \\
\hline Uranium & $7440-61-1$ & 1 & -- & D1 \\
\hline Uranium-235 $\left\{{ }^{235} U\right\}$ & 15117-96-1 & 1 & -- & $\mathrm{J}$ \\
\hline Uranium-238 $\left\{{ }^{238} \mathrm{U}\right\}$ & $24678-82-8$ & 1 & -- & $\mathrm{J}$ \\
\hline Vanadium & $7440-62-2$ & 1 & -- & D1 \\
\hline Venlafaxine & $93413-69-5$ & 1 & 3 & $\mathrm{C}$ \\
\hline Verapamil / Verapamil hydrochloride & $\begin{array}{l}52-53-9 / \\
152-11-4\end{array}$ & 1 & 1 & $\mathrm{C}$ \\
\hline Warfarin & $81-81-2$ & 1 & 3 & $\mathrm{C}$ \\
\hline$o$-Xylene $\{1,2$-Dimethylbenzene $\}$ & $95-47-6$ & 1 & -- & A \\
\hline$m$ - and $p$-Xylenes $\{1,3$ - and 1,4-Dimethylbenzene $\}$ & $\begin{array}{c}108-38-3 \& \\
106-42-3 / \\
179601-23-1\end{array}$ & 1 & -- & $\mathrm{A}, \mathrm{H}$ \\
\hline Zinc & $7440-66-6$ & 1 & 1 & $\begin{array}{l}\mathrm{B} 1, \mathrm{~B} 2, \\
\mathrm{D} 1, \mathrm{D} 2\end{array}$ \\
\hline Zinc bis[bis(tetrapropylenephenyl)] bis(hydrogen dithiophosphate) & $11059-65-7$ & -- & 1 & $\mathrm{~F}$ \\
\hline Zinc bis(1,3-dimethylbutyl) dithiophosphate & $2215-35-2$ & -- & 1 & $\mathrm{~F}$ \\
\hline Zinc bis $[O-(6$-methylheptyl) $]$ bis $[O$-(sec-butyl) $]$ bis(dithiophosphate) & $93819-94-4$ & -- & 1 & $\mathrm{~F}$ \\
\hline
\end{tabular}

${ }^{1}$ This report contains Chemical Abstracts Service Registry Numbers (CASRN) ${ }^{\circledR}$, which is a registered trademark of the American Chemical Society. The CASRN online database provides the latest registry number information: http://www.cas.org/. Chemical Abstracts Service recommends the verification of the CASRNs through CAS Client Services ${ }^{\mathrm{SM}}$. 


\section{Summary}

A total of 2,541 constituents were evaluated and prioritized for national- and regional-scale ambient monitoring of water and sediment in the United States. This prioritization was done for the U.S. Geological Survey (USGS) in preparation for the upcoming third decade (Cycle 3; 2013-23) of the National Water-Quality Assessment (NAWQA) Program. The results from this prioritization could be useful to other agencies or organizations that seek to monitor ambient water or sediment for constituents that are of potential concern with respect to human health or aquatic life.

Constituents were prioritized by the NAWQA National Target Analyte Strategy (NTAS) work group within constituent groups that were identified on the basis of chemical class or use. Constituent groups included volatile organic compounds in water (Group A); pesticides in water or sediment (Group B); pharmaceuticals and hormones in water or sediment (Group C); trace elements and other inorganic constituents in water or sediment (Group D); cyanotoxins in surface water (Group E); lipophilic organic compounds in sediment (Group F); disinfection by-products in water (Group G); high-production-volume chemicals in water (Group H); wastewater-indicator and industrial compounds in water (Group I); and radionuclides in water (Group J). Methods of prioritization for all of the constituent groups generally relied on two factors: (1) the likelihood of a constituent to occur in the matrix of interest, and (2) the likelihood of that constituent to have effects on human health or aquatic life. Thus, a constituent that could occur widely in a matrix of interest, but which is unlikely to affect human health or aquatic life, was considered a low priority for ambient monitoring. Likewise, a constituent that could affect human health or aquatic life, but which is unlikely to occur in a matrix of interest (water or sediment), also was considered a low priority for ambient monitoring. Constituents that could occur widely in the environment and that are likely to affect human health or aquatic life were considered a high priority for ambient monitoring. Information to support an evaluation of the likelihood of occurrence or the likelihood of effects was not consistently available for all constituents; therefore, methods of prioritization were customized for the different NTAS constituent groups.

Sources of information used to support the prioritization of constituents included USGS monitoring data collected for the NAWQA Program, the Toxic Substances Hydrology Program, and other studies, as well as data documenting observed or predicted occurrence available in the scientific literature. Information about potential effects to aquatic life or human health was obtained from lists of constituents of concern to human health or aquatic life compiled from numerous references from the U.S. Environmental Protection Agency and other agencies, lists of constituents of international concern, large national and international databases of information on the toxicity and chemical properties of candidate constituents, and regulatory and nonregulatory standards for water and sediment. These numerous resources and references were documented in the report and in specific "Supplemental Information" sections that correspond to each of the NTAS constituent groups.

As a result of this prioritization, 1,081 constituents were identified as being of high priority (NTAS Tier 1) for ambient monitoring in water or sediment. An additional 1,460 constituents were identified as being of intermediate, low, or no priority (NTAS Tier 2 or Tier 3, respectively) for ambient monitoring in water or sediment. These included 436 constituents in Tier 2 for water, 246 in Tier 2 for sediment, 979 in Tier 3 for water, and 779 in Tier 3 for sediment. Constituents in Tier 2 are not being considered for ambient monitoring at this time because of resource limitations but could be of interest for targeted sampling of contaminated sites, such as animal feeding operations, landfills, or wastewater effluent discharge points. Constituents in Tier 1 are being considered by the USGS for method development (if methods are not already available) and for future monitoring as part of NAWQA Cycle 3 and for other programs.

\section{References Cited}

BKH Consulting Engineers, 2000, Towards the establishment of a priority list of substances for further evaluation of their role in endocrine disruption (final report): Delft, The Netherlands, BKH Consulting Engineers and the European Commission DG ENV, accessed December 21, 2010, at http:// ec.europa.eu/environment/archives/docum/pdf/bkh_main. pdf.

Buxton, H.T., 2010, USGS Toxic Substances Hydrology Program, 2010: U.S. Geological Survey Fact Sheet 2010-3011, 4 p., available online at http://pubs.usgs.gov/fs/2010/3011.

California Department Public Health, 2010a, Chemicals and contaminants in drinking water: California Department of Public Health, accessed December 20, 2010, at http://www.cdph.ca.gov/certlic/drinkingwater/Pages/ Chemicalcontaminants.aspx.

California Department of Public Health, 2010b, Comparison of MCLs and PHGs for regulated contaminants in drinking water: California Department of Public Health, accessed June 2, 2009, at http://www.cdph.ca.gov/certlic/ drinkingwater/Pages/MCLsandPHGs.aspx.

California Office of Environmental Health Hazard Assessment, 2009, State of California Environmental Protection Agency, Office of Environmental Health Hazard Assessment, Safe Drinking Water and Toxic Enforcement Act of 1986, chemicals known to the state to cause cancer or reproductive toxicity_-June 19, 2009: State of California Environmental Protection Agency, accessed on June 25, 2009, at http://oehha.ca.gov/prop65/prop65_list/files/ P65single061909.pdf. 
Canadian Council of Ministers of the Environment, 1999, Canadian water quality guidelines for the protection of aquatic life-Introduction, in Canadian Environmental Quality Guidelines: Winnipeg, Canada, Canadian Council of Ministers of the Environment, accessed on December 21, 2010, at http://ceqg-rcqe.ccme.ca/download/en/312/.

Canadian Council of Ministers of the Environment, 2002, Canadian sediment quality guidelines for the protection of aquatic life, summary tables, in Canadian Environmental Quality Guidelines: Winnipeg, Canada, Canadian Council of Ministers of the Environment, 7 p., accessed August 3, 2009, at http://ceqg-rcqe.ccme.ca/.

Canadian Council of Ministers of the Environment, 2007, Canadian water quality guidelines for the protection of aquatic life, summary table, update 7.1, in Canadian Environmental Quality Guidelines: Winnipeg, Canada, Canadian Council of Ministers of the Environment, accessed on December 21, 2010, at http://ceqg-rcqe.ccme.cal.

Centers for Disease Control and Prevention, 2010, National Health and Nutrition Examination Survey: Centers for Disease Control and Prevention, accessed December 21, 2010, at http://www.cdc.gov/nchs/nhanes.htm.

Environment Canada, 2006, Canadian Environmental Protection Act Domestic Substances List categorization overview and results [CD-ROM]: Gatineau, Canada, Environment Canada, Existing Substances Division, available on request.

Environment Canada, 2010, Domestic Substances List Categorization and Screening Program: Environment Canada, accessed December 21, 2010, at http://www.ec.gc.cal substances/ese/eng/dsl/dslprog.cfm.

European Commission, 2007, Detergent ingredients database (DID list), available at http://ec.europa.eu/environment/ ecolabel/documents/did_list/didlist_part_a_en.pdf.

European Commission, 2008, Endocrine disrupters website-Strategy: European Commission, accessed December 21, 2010, at http://ec.europa.eu/environment/endocrine/ strategy/substances_en.htm.

Falk, Henry, 2010, Testimony before the U.S. Senate Committee on Environment and Public Works, Subcommittee on Superfund, Toxics, and Environmental Health, on current science on public exposures to toxic chemicals, February 4, 2010: U.S. Department of Health and Human Services, accessed December 21, 2010, at http://www.hhs.gov/asl/ testify/2010/02/t20100204j.html.

Focazio, M.J., Szabo, Zoltan., Kraemer, T.F., Mullin, A.H., Barringer, T.H., and dePaul, V.T., 2001, Occurrence of selected radionuclides in ground water used for drinking water in the United States: U.S. Geological Survey WaterResources Investigations Report 00-4273, 40 p. (Also available at $h t t p: / / p u b s . u s g s . g o v / w r i / w r i 004273 /$.
Global Water Research Coalition, 2003, Endocrine disrupting compounds, priority list of EDCs, September 2003: London, Global Water Research Coalition, $29 \mathrm{p}$.

Graham, J.L., Loftin, K.A., Meyer, M.T., and Ziegler, A.C., 2010, Cyanotoxin mixtures and taste-and-odor compounds in cyanobacterial blooms from the Midwestern United States: Environmental Science and Technology, v. 44, no. 19, p. 7,361-7,368.

Grandjean, Phillippe, and Landrigan, P.J., 2006, Developmental neurotoxicity of industrial chemicals: The Lancet, v. 368, no. 9553 , p. 2,167-2,178.

Health Canada, 2008, Guidelines for Canadian drinking water quality - Summary table: Ottawa, Ontario, FederalProvincial-Territorial Committee on Drinking Water of the Federal-Provincial Territorial Committee on Health and the Environment, accessed September 20, 2011, at http://www. ocpro.ca/docs/Library/summary-sommaire-eng.pdf.

Institute for Environment and Health, 2005, Chemicals purported to be endocrine disruptors-A compilation of published lists (web report W20): Leicester, U.K., MRC Institute for Environment and Health, accessed December 21, 2010, at http://www.cranfield.ac.uk/health/researchareas/ environmenthealth/ieh/ieh\%20publications/w20.pdf.

Judson R.S., Richard, A.M., Dix, D.J., Houck, K.A., Martin, M.T., Kavlock, R.J., Dellarco, V.L., Henry, T., Holderman, T.S., Sayre, P., Tan, S.W., Carpenter, T., and Smith, E.R., 2009, The toxicity data landscape for environmental chemicals: Environmental Health Perspectives, v. 117, no. 5, p. 685-695.

MacDonald, D.D., Ingersoll, C.G., and Berger, T.A., 2000, Development and evaluation of consensus-based quality guidelines for freshwater ecosystems: Archives of Environmental Contamination and Toxicology, v. 39, p. 20-31.

Norman, J.E., Kuivila, K.M., and Nowell, L.H., 2012, Prioritizing pesticide compounds for analytical methods development: U.S. Geological Survey Scientific Investigations Report 2012-5045, 206 p. (Also available at http://pubs. usgs.gov/sir/2012/5045/pdf/sir20125045.pdf.)

OSPAR Commission, 2010, OSPAR list of chemicals for priority action (revised 2010): Reference number 2004-12, $6 \mathrm{p}$.

Toccalino, P.L., 2007, Development and application of HealthBased Screening Levels for use in water-quality assessments: U.S. Geological Survey Scientific Investigations Report 2007-5106, 12 p., accessed December 8, 2010, at http://pubs.usgs.gov/sir/2007/5106/. 
Toccalino, P.L., Norman, J.E., Booth, N.L, and Zogorski, J.S., 2008, Health-based screening levels_-Benchmarks for evaluating water-quality data: U.S. Geological Survey, National Water-Quality Assessment Program, accessed December 21, 2010, at http://water.usgs.gov/nawqa/HBSL/.

Toccalino, P.L., Norman, J.E., Phillips, R.H., Kauffman, L.J., Stackelberg, P.E., Nowell, L.H., Krietzman, S.J., and Post, G.B., 2004, Application of health-based screening levels to ground-water quality data in a State-scale pilot effort: U.S. Geological Survey Scientific Investigations Report 20045174, 64 p., accessed January 10, 2010, at http://pubs.usgs. gov/sir/2004/5174/sir20045174.pdf.

U.S. Environmental Protection Agency, 2006, 2006 Edition of the drinking water standards and health advisories, updated August 2006: U.S. Environmental Protection Agency, Office of Water EPA 822-R-06-013, accessed December 20, 2010, at http://water.epa.gov/action/advisories/drinking/ upload/2009_04_27_criteria_drinking_dwstandards.pdf.

U.S. Environmental Protection Agency, 2007, ECOTOX user guide: ECOTOX database, version 4.0, accessed December 20, 2010, through http://www.epa.gov/ecotox/.

U.S. Environmental Protection Agency, 2009a, National Water Quality Inventory Report to Congress, 2004 reporting cycle: U.S. Environmental Protection Agency, Office of Water, EPA 841-R-08-001, 37p., accessed June 17, 2010, at http:// water.epa.gov/lawsregs/guidance/cwa/305b/upload/2009_0 1_22_305b_2004report_2004_305Breport.pdf.

U.S. Environmental Protection Agency, 2009b, 2009 Edition of the drinking water standards and health advisories, updated October 2009: U.S. Environmental Protection Agency, Office of Water EPA 822-R-09-011, accessed December 20, 2010, at http:/water.epa.gov/action/ advisories/drinking/upload/dwstandards2009.pdf.

U.S. Environmental Protection Agency, 2009c, Mid-Atlantic risk assessment user's guide: U.S. Environmental Protection Agency, accessed June 26, 2009, at http://www.epa.gov/ reg3hwmd/risk/human/rb-concentration_table/usersguide. htm.

U.S. Environmental Protection Agency, 2009d, National Lakes Assessment-A collaborative survey of the Nation's lakes: Washington, D.C., Office of Water and Office of Research and Development, EPA 841-R-09-001, accessed January 20, 2011, at http://www.epa.gov/owow/LAKES/lakessurvey/ pdf/nla_report_low_res.pdf.
U.S. Environmental Protection Agency, 2009e, EPI Suite ${ }^{\mathrm{TM}}$ version 4.0: U.S. Environmental Protection Agency, Office of Pollution Prevention and Toxics and Syracuse Research Corporation.

U.S. Environmental Protection Agency, 2009f, Ecological structure activity relationships (ECOSAR): U.S. Environmental Protection Agency, v. 1.00a, February, 2009, accessed January 10, 2011, through http://www.epa.gov/ oppt/newchems/tools/21ecosar.htm.

U.S. Environmental Protection Agency, 2010a, TSCA Chemical Substance Inventory: U.S. Environmental Protection Agency, accessed December 1, 2010, at http://www.epa.gov/ opptintr/existingchemicals/pubs/tscainventory/index.html.

U.S. Environmental Protection Agency, 2010b, Drinking water contaminants: U.S. Environmental Protection Agency, accessed December 20, 2010, at http://www.epa.gov/ safewater/contaminants/index.html.

U.S. Environmental Protection Agency, 2010c, Drinking water science and regulatory support: U.S. Environmental Protection Agency, accessed December 20, 2011, through http:// water.epa.gov/drink/standards/hascience.cfm.

U.S. Environmental Protection Agency, 2010d, Contaminant Candidate List 3-CCL3: U.S. Environmental Protection Agency, accessed December 20, 2010, at http://water.epa. gov/scitech/drinkingwater/dws/ccl/ccl3.cfm.

U.S. Environmental Protection Agency, 2010e, Unregulated Contaminant Monitoring Rule 2 (UCMR 2): U.S. Environmental Protection Agency, accessed December 20, 2010, at http://water.epa.gov/lawsregs/rulesregs/sdwa/ucmr/ucmr2/ index.cfm.

U.S. Environmental Protection Agency, 2010f, National recommended water quality criteria: U.S. Environmental Protection Agency, accessed December 27, 2010, at http:// water.epa.gov/scitech/swguidance/standards/current/.

U.S. Environmental Protection Agency, 2010g, High Production Volume (HPV) Challenge: U.S. Environmental Protection Agency, accessed December 28, 2010, at http://www. epa.gov/HPV/.

U.S. Environmental Protection Agency, 2010h, Toxics Release Inventory TRI PBT chemical list: U.S. Environmental Protection Agency Toxics Release Inventory (TRI) Program, accessed December 28, 2010, at http://www.epa.gov/tri/ trichemicals/pbt chemicals/pbt_chem_list.htm. 
U.S. Environmental Protection Agency, 2011a, ECOTOXicology Database System, version 4.0: U.S. Environmental Protection Agency, Office of Research and Development and the National Health and Environmental Effects Research Laboratory's Mid-Continent Ecology Division, accessed January 5, 2011, at http://www.epa.gov/ecotox/.

U.S. Environmental Protection Agency, 2011b, PesticidesEnvironmental effects, technical overview of ecological risk assessment analysis phase-Ecological effects characterization: U.S. Environmental Protection Agency, accessed January 10,2011, at http://www.epa.gov/oppefedl/ecorisk_ders/ toera_analysis_eco.htm.

U.S. Environmental Protection Agency, 2011c, Priority pollutants: U.S. Environmental Protection Agency, accessed January 10, 2011, at http://water.epa.gov/scitech/methods/ cwa/pollutants.cfm.

U.S. Environmental Protection Agency, 2011d, Persistent, bioaccumulative, and toxic profiles estimated for organic chemicals (PBT profiler): U.S. Environmental Protection Agency, Environmental Health Analysis Center, accessed January 10, 2011, at http://www.pbtprofiler.net/.

U.S. Environmental Protection Agency, 2011e, Office of Pesticide Programs, Aquatic life benchmarks (freshwater): U.S. Environmental Protection Agency, Office of Pesticide Programs, updated April 9, 2009, last accessed March 4, 2011, at http://www.epa.gov/oppefed1/ecorisk_ders/ aquatic_life_benchmark.htm.

U.S. Environmental Protection Agency, 2011f, Unregulated Contaminant Monitoring Rule 3 (UCMR 3): U.S. Environmental Protection Agency, accessed September 20, 2011, at http://water.epa.gov/lawsregs/rulesregs/sdwa/ucmr/ucmr3/ index.cfm.
U.S. Food and Drug Administration, 2010, Generally Recognized as Safe (GRAS): U.S. Food and Drug Administration, accessed February 18, 2011, at http://www.fda.gov/Food/ IngredientsPackagingLabeling/GRAS/ucm2006850.htm.

U.S. Geological Survey, 2010a, Planning the third decade (Cycle 3) of the National Water-Quality Assessment (NAWQA) Program-An update presented to the NAWQA National Liaison Committee, March 26, 2010, 14 p.: U.S. Geological Survey, accessed December 3, 2010, at http:// water.usgs.gov/nawqa/design_plans.pdf.

U.S. Geological Survey, 2010b, National Water-Quality Assessment (NAWQA) Program: U.S. Geological Survey, accessed December 7, 2010, at http://water.usgs.gov/ nawqa/.

U.S. Geological Survey, 2010c, NASQAN National Stream Quality Accounting Network: U.S. Geological Survey, accessed April 4, 2011, at http://water.usgs.gov/nasqan/.

U.S. Geological Survey, 2011a, Toxic Substances Hydrology Program, accessed January 10, 2010, at http://toxics.usgs. gov/.

U.S. Geological Survey, 2011b, Toxic Substances Hydrology Program-Publications: U.S. Geological Survey, accessed January 10, 2010, at http://toxics.usgs.gov/pubs/.

U.S. Geological Survey, 2011c, Toxic Substances Hydrology Program research projects-Emerging contaminants: U.S. Geological Survey, accessed January 10, 2010, at http:// toxics.usgs.gov/regional/emc/index.html. 



\section{Supplemental Information}

The Excel file for the NTAS database can be accessed at http://pubs.usgs.gov/sir/2012/5218/ downloads/NTASdatabase.xlsx. 


\section{Supplemental Information A.}

\section{Prioritization of Volatile Organic Compounds in Water (Group A)}

By John S. Zogorski, Duane S. Wydoski, and Joshua F. Valder

\section{Abbreviations and Acronyms Used in Supplemental Information A}

$\begin{array}{ll}\text { 1,2,3-TCP } & \text { 1,2,3-trichloropropane } \\ \text { BO } & \text { benchmark quotient (USGS) } \\ \text { CCL3 } & \text { Contaminant Candidate List 3 (USEPA) } \\ \text { DBCP } & \text { 1,2-dibromo-3-chloropropane } \\ \text { EDB } & \text { 1,2-dibromoethane } \\ \text { GC/ECD } & \text { gas chromatography with electron-capture detection } \\ \text { GC/MS } & \text { gas chromatography with mass spectrometry } \\ \text { HBSL } & \text { Health-Based Screening Level (water-quality benchmark, USGS) } \\ \text { HH } & \text { human health } \\ \text { HPV } & \text { high-production volume or high-production-volume chemical } \\ \text { HPV-VOC } & \text { high-production-volume volatile organic compound } \\ \text { log } K_{\text {ow }} & \text { base-10 logarithm of the octanol-water partition coefficient } \\ \text { LS } & \text { laboratory schedule } \\ \text { LT-MDL } & \text { long-term method detection level (USGS NWOL) } \\ \text { MCL } & \text { Maximum Contaminant Level (drinking-water-quality benchmark, USEPA) } \\ \text { NAWOA } & \text { National Water-Quality Assessment (USGS) } \\ \text { NIA } & \text { no information available } \\ \text { NTAS } & \text { National Target Analyte Strategy } \\ \text { NWOL } & \text { National Water Quality Laboratory (USGS) } \\ \text { SIM } & \text { selected-ion monitoring } \\ \text { SWQA } & \text { Source Water-Quality Assessment (USGS NAWQA) } \\ \text { USEPA } & \text { U. S. Environmental Protection Agency } \\ \text { USGS } & \text { U.S. Geological Survey } \\ \text { VOC } & \text { volatile organic compound } \\ \end{array}$


This supplemental information section of the report describes the prioritization of 89 volatile organic compounds in water (Group A) by the U.S. Geological Survey (USGS) National Target Analyte Strategy (NTAS) work group, for national- and regional-scale ambient monitoring in the United States, in support of planning for the third decade (Cycle 3) of the National Water-Quality Assessment (NAWQA) Program. The feasibility of implementing analytical methods for high-priority volatile organic compounds (VOCs) and knowledge and concerns of VOCs as a constituent group also are described in this section.

Constituents in Group A were limited to 85 compounds currently (2011) analyzed by the USGS National Water Quality Laboratory (NWQL) on laboratory schedule (LS) 2020 (purge-and-trap gas chromatography with mass spectrometry; Connor and others, 1997) for which national-scale data are available, and 4 constituents on LS 4024 (heated purge-andtrap gas chromatography with mass spectrometry; Rose and Sandstrom, 2003) for which national-scale data are not available. Additional VOCs that also are high-production-volume chemicals (HPVs) were prioritized under Group $\mathrm{H}$ and were not included in Group A, and additional VOCs that are not HPVs were prioritized under Group I and were not included in Group A.

Of the 13 constituents in Group A that overlap with other NTAS constituent groups for water, 2 were pesticides in Group B1 (bromomethane and iodomethane); 7 were disinfection by-products in Group $\mathrm{G}$ (the four trihalomethanes, bromodichloromethane, dibromochloromethane, tribromomethane, and trichloromethane, plus dibromomethane, dichloromethane, and tetrachloromethane); 1 was an HPV in Group H ( $m$ - and $p$ xylenes, treated as a single constituent because they coelute); and 3 were wastewater-indicator and industrial compounds in Group I (1,4-dioxane, hexachlorobutadiene, and naphthalene). In addition, cis- and trans-1,3-dichloropropene, which were evaluated separately for Group A, were evaluated together as "1,3-dichloropropene (mixture of isomers)" for Group B. All of the constituents in Group A that overlapped with Groups $\mathrm{B}, \mathrm{H}$, or I were prioritized using methods from both constituent groups and were found to have equivalent results; prioritization methods for these other groups are provided in the "Supplemental Information" sections B, H, and I. All of the VOCs that overlapped between Group A and Group G were prioritized using only the prioritization methods for Group A, described in the following section.

An additional 12 constituents in Group A overlap with other NTAS constituent groups for sediment, namely with Group B2 (pesticides in sediment) and Group F (lipophilic organic compounds in sediment); however, these overlaps do not represent potential conflicts because the prioritization methods and results for Group A apply to water only and not to sediment.

\section{Prioritization of Volatile Organic Compounds in Water}

The prioritization of VOCs in Group A applies to surface water and groundwater. The VOCs (as a constituent group) were not prioritized for sediment because the large solubility and low octanol-water partition coefficients of many of the VOCs indicate that VOCs favor partitioning into the aqueous phase (dissolved in water) rather than to sediment (Rathbun, 1998); however, selected VOCs that are relevant to sediment were prioritized in Group B2 or Group F, as mentioned previously.

Detection frequency and concentration information from six NAWQA datasets that used LS 2020 - three for surface water and three for groundwater-were considered in this process. Data for surface water came from (1) surface-water sources to public water systems (Kingsbury and others, 2008); (2) NAWQA integrator sites located at the outlets of major streams with relatively large drainage areas (David Bender, U.S. Geological Survey, written commun., 2010; data available from the USGS National Water Information System at http://waterdata.usgs.gov/nwis); and (3) NAWQA urban intensive fixed sites with increased sampling frequency during selected periods (Bender and others, 2009). Data for groundwater came from (1) groundwater sources to public water systems (Hopple and others, 2009); (2) NAWQA urban land-use studies (Squillace and others, 2004); and (3) ambient groundwater from domestic and public wells (Zogorski and others, 2006; data available at http://water.usgs.gov/nawqa/ vocs/national_assessment/data/index.html).

Three fuel-related constituents on LS 4024 were considered for prioritization on the basis of occurrence data collected in NAWQA Source Water-Quality Assessments (SWQAs) methyl acetate, 2-methyl-2-butanol (tert-amyl alcohol), and tert-butanol (tert-butyl alcohol). These three constituents were analyzed to obtain information about the occurrence of selected degradates of ether gasoline oxygenates. An additional constituent on LS 4024 (available as a custom addition) -1,4-dioxane, a solvent and by-product of the manufacturing of some detergents and cosmetics-also was considered for prioritization. Because the SWQAs focused on a small number of rivers and a small number of communities supplied from public wells, the occurrence data for these VOCs are not available at a national scale. As such, these four VOCs were prioritized in a similar manner to the approach used for HPVs that currently are not routinely analyzed by the USGS NQWL (see the "Supplemental Information H" section for details).

The initial screening of VOCs was done during the summer of 2009. The prioritization was subsequently refined in October 2009 to incorporate new information from (1) the NTAS lists of human-health concern, including the release of the final U.S. Environmental Protection Agency (USEPA) Contaminant Candidate List 3 (CCL3; U.S. Environmental Protection Agency, 2010a); (2) newly available or revised human-health information for three constituents 
(bromobenzene, 2-hexanone, and 1,2,3-trichloropropane); and (3) an analysis of benchmark quotients (BQs), defined as the ratio of a constituent concentration to a human-health benchmark concentration for water. For example, new information about concentrations of human-health concern for 1,2,3-trichloropropane (U.S. Environmental Protection Agency, 2010a) resulted in its placement into Tier 1 because this constituent warrants a lower long-term method detection level (LT-MDL) than was used for previous NAWQA studies documenting its occurrence in environmental waters.

\section{Prioritization Methods for Volatile Organic Compounds in Water}

A consistent prioritization procedure was developed and used for the VOCs, as shown in the flow chart in figure A.1. The VOCs on LS 2020 met one or more of seven criteria for inclusion in NTAS Tier 1: (1) having a large detection frequency, defined as greater than or equal to 10 percent; (2) being a component of a mixture of known human-health concern; (3) having at least 20 percent of detections within two orders of magnitude of a USEPA Maximum Contaminant Level (MCL) or USGS Health-Based Screening Level (HBSL; Toccalino and others, 2008); (4) having a large detection frequency in USEPA studies; (5) having a 99-percentile concentration greater than 0.01 of an MCL or HBSL (that is, having a BQ greater than 0.01); (6) having a benchmark, but not a detection limit that is low enough to provide an understanding of occurrence relative to that benchmark; or (7) usefulness as an indicator of constituent's source or degradation pathway. As previously mentioned, the four constituents on LS 4024-methyl acetate, 2-methyl-2-butanol, tert-butanol, and 1,4-dioxane-were prioritized in a manner similar to the approach used for HPVs that are not currently analyzed by the USGS NWQL (see the "Supplemental Information H" section for details).

\section{Results of Prioritization of Volatile Organic Compounds in Water}

A total of 32 VOCs are included in NTAS Tier 1 and 24 in Tier 2 (table A.1 at http://pubs.usgs.gov/sir/2012/5218/ downloads/tableA.xls). Of the 85 VOCs on LS 2020, 52 were placed into NTAS Tier 1 or Tier 2. Of these, 29 are included in Tier 1 and are considered to be of highest priority for ambient monitoring and warrant inclusion in NAWQA Cycle 3. The 23 compounds in Tier 2 would warrant inclusion in Cycle 3 if NAWQA seeks to enhance monitoring of constituents with some human-health concern or of priority to other agencies; however, based on past monitoring, most of these constituents are not expected to occur frequently in ambient waters or at concentrations near a benchmark. Of the four VOCs on LS 4024, three were placed in Tier 1 and one was placed in Tier 2.

The fumigants bromomethane, cis-1,3-dichloropropene, and trans-1,3-dichloropropene were included in Tier 1 based on the results of predicted occurrence in surface water with agricultural land use obtained as part of the prioritization of pesticides in water (Group B1) described in the "Supplemental Information B" section. The review of their NAWQA occurrence data as part of the VOC screening approach initially placed these three compounds in a lower prioritization tier; however, NAWQA monitoring for VOCs has not targeted land-use settings where these fumigants are anticipated to occur frequently. As such, the prioritization process used for pesticides in water was considered more appropriate for these fumigants.

Similarly, naphthalene, a VOC with relatively low vapor pressure, was included in Tier 1 based on the prioritization process used for wastewater-indicator and industrial compounds in water (Group I) described in the "Supplemental Information I" section. This decision was based, in part, on the enhanced analytical method performance for naphthalene by using solid-phase extraction gas chromatography with mass spectrometry, in comparison to purge-and-trap gas chromatography with mass spectrometry, which is used for LS 2020.

For the four VOCs analyzed on LS 4024, a prioritization process equivalent to the process described for high-production-volume chemicals in water (Group H) in the "Supplemental Information H" section was adopted for Group A. Two constituents, methyl acetate and tert-butanol, were placed into Tier 1 on the basis of having a base- 10 logarithm of the octanol-water partition coefficient $\left(\log K_{\text {ow }}\right)$ less than 4 , indicating that it is soluble in water (occurrence concern) and being in NTAS human-health (HH) bin of 1 (human-health concern). A third constituent, 2-methyl-2-butanol, was placed into Tier 2 on the basis of having a $\log K_{\mathrm{OW}}$ less than 4 (occurrence concern) and HH bin of NIA (no information available for human toxicity). A fourth constituent, 1,4-dioxane, a high-productionvolume volatile organic compound (HPV-VOC), was placed into Tier 1 based on its high predicted occurrence in water and an $\mathrm{HH}$ bin of 1; this constituent also was placed into Tier 1 based on the prioritization process used for wastewater-indicator and industrial compounds in water (Group I) described in the "Supplemental Information I" section.

In addition to the VOCs that were prioritized for Group A, 20 high-priority HPV-VOCs that were identified as highproduction-volume chemicals in water (Group $\mathrm{H}$ ) that are not currently analyzed could be considered as potential additions to LS 2020 or LS4024 for the future. These constituents were prioritized using the process described for the high-production-volume chemicals in water (Group H) in the "Supplemental Information H" section.

From the results of the VOC prioritization procedure, it appears that as many as 33 constituents could be dropped from routine analysis. These constituents have not been detected or were rarely detected (less than 0.5 percent) in NAWQA water samples and do not have concentrations near benchmarks (if such exist). Constituents identified as being of low or no priority (Tier 3 ) for national- and regional-scale ambient monitoring are listed in table A.2 at http://pubs.usgs.gov/ sir/2012/5218/downloads/tableA.xls). 


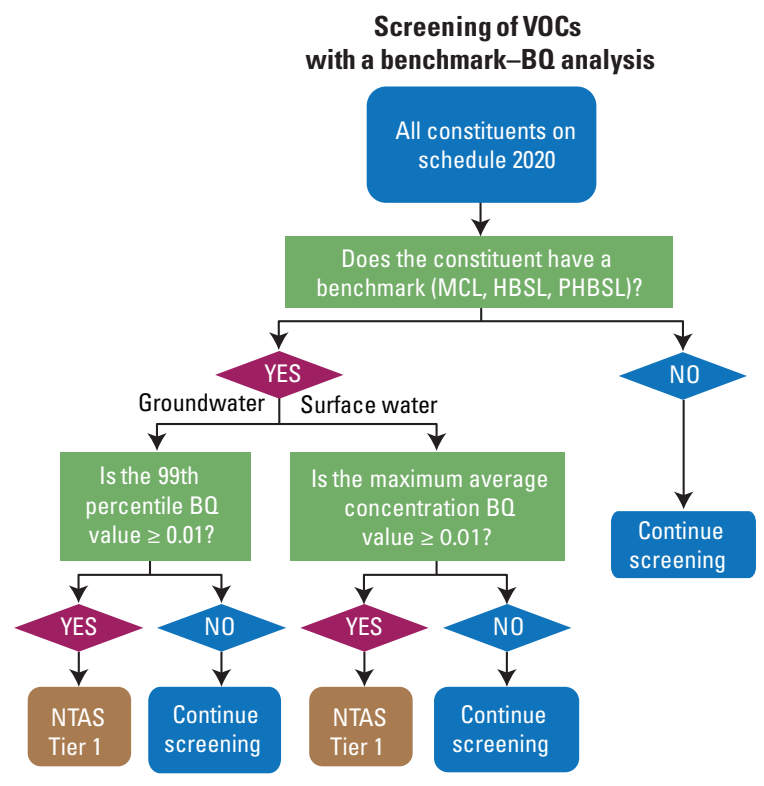

Screening of LTMDL compared
to benchmark concentrations
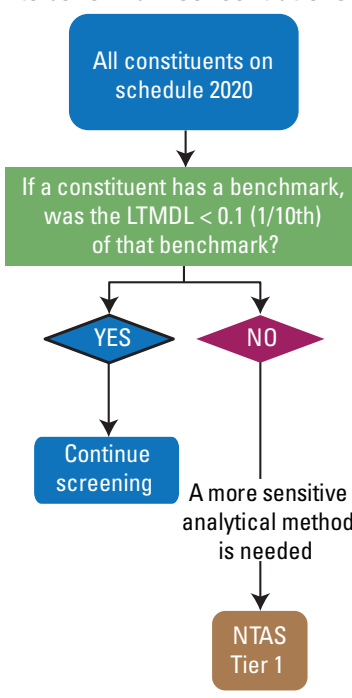

Screening for priority to other agencies

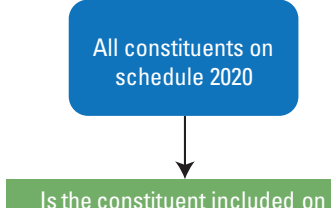

Is the constituent included on

a regulatory list by other agencies?

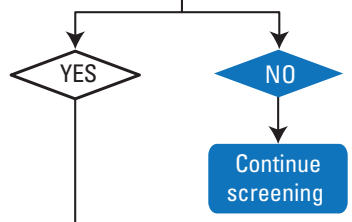

NTAS

Screening of VOCs for detection frequency and other considerations

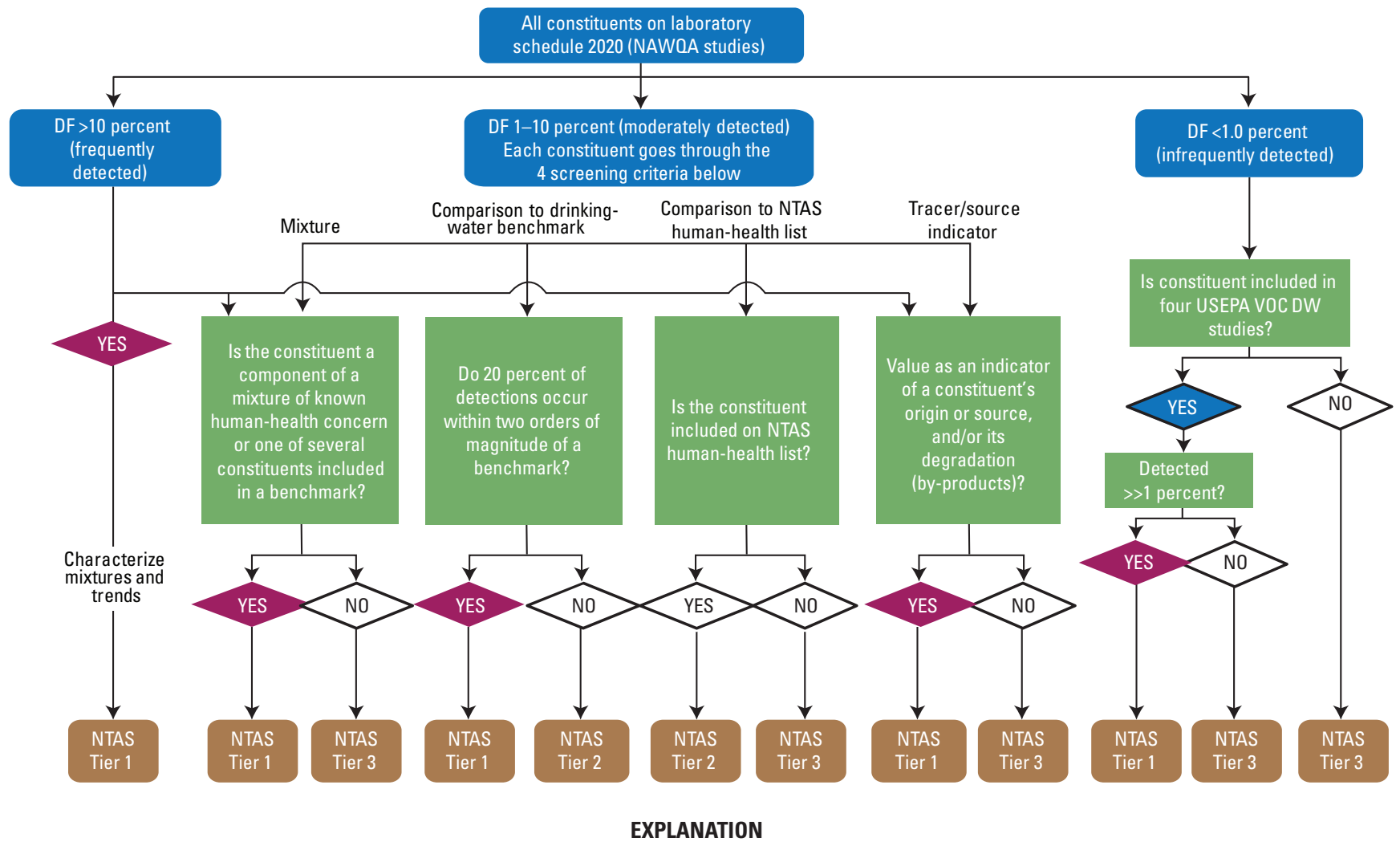

[All processes are considered in parallel and not in sequence to identify if multiple reasons would result in a Tier 1 designation. If parallel processes resulted in different prioritization results, the higher priority tier was retained. BQ, benchmark quotient; DF, detection frequency; DW, drinking water; HBSL, Health-Based Screening Level; LTMDL, long-term method detection level; MCL, Maximum Contaminant Level; NAWQA, National Water-Quality Assessment Program; NTAS, National Target Analyte Strategy; PHBSL, Provisional Health-Based Screening Level; USEPA, U.S. Environmental Protection Agency; $>$, greater than; $>>$, much greater than; $\geq ;$ greater than or equal to; $<$, less than]
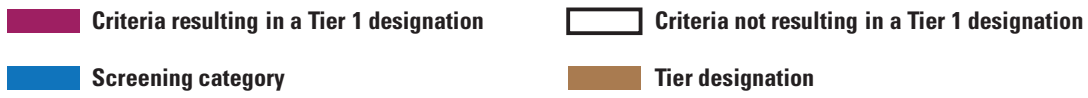

Screening criteria

Figure A.1. Flow chart for prioritizing volatile organic compounds (VOCs) for national- and regional-scale monitoring in water in the United States (used for constituents on National Water Quality Laboratory schedule 2020). 


\section{Basis for Prioritization of Volatile Organic Compounds in Water}

One or more of seven criteria were the basis for inclusion of VOCs on LS 2020 in NTAS Tier 1: (1) having a large detection frequency (greater than or equal to 10 percent) in NAWQA studies; (2) being a component of a mixture of known human-health concern; (3) having at least 20 percent of detections within two orders of magnitude of a MCL or HBSL; (4) having a large detection frequency in one or more USEPA studies; (5) having a BQ greater than 0.01 for the 99th-percentile concentration in source waters sampled for NAWQA studies; (6) having a benchmark, but the LT-MDL is not low enough relative to that benchmark, such that a complete understanding of the human-health significance cannot be determined; or (7) usefulness as an indicator of constituent's source or degradation pathway. The bases for inclusion in Tier 1 for constituents on LS 2020 are listed in table A.3 at http://pubs.usgs.gov/sir/2012/5218/downloads/tableA.xls), and those in Tier 2 are listed in table A.4 at http://pubs.usgs.gov/ sir/2012/5218/downloads/tableA.xls).

Many of the Tier 1 constituents are included in national programs, including monitoring programs, pollutant lists, and agency reviews. Several VOCs in Tier 1 are included on the USEPA's Priority Pollutants list (U.S. Environmental Protection Agency, 2011), the USEPA's drinking-water standards and health advisories (U.S. Environmental Protection Agency, 2009), Centers for Disease Control and Prevention's National Health and Nutrition Examination Survey monitoring of human blood, serum, or urine (Centers for Disease Control and Prevention, 2010), and the USEPA's review of HPVs (U.S. Environmental Protection Agency, 2010b). National programs in which high-priority (Tier 1) and intermediate-priority (Tier 2) VOCs are included are listed in tables A.3 and A.4, respectively.

\section{Feasibility of Implementation for High-Priority Volatile Organic Compounds}

Traditionally, VOC analysis for the USGS NAWQA Program has been accomplished by purge-and-trap gas chromatography with full-scan mass spectrometry (GC/MS) using LS 2020 or LS 4024. This technology has proven reliable, with good performance for most compounds, and a change in technology is not warranted. The NWQL capacity is about 3,000 samples per year for LS 2020 and for LS 4024. Three constituents were identified that do not have low enough LT-MDLs relative to benchmarks using these methods: 1,2-dibromo-3-chloropropane (DBCP), 1,2-dibromoethane (EDB), and 1,2,3-trichloropropane (1,2,3-TCP). These constituents might be amenable to using a micro-extraction method and gas chromatography with electron-capture detection (GC/ECD) that achieves lower detection levels. Similarly, state-of-the art electronics to allow for simultaneous collection of full-scan and selected-ion monitoring (SIM) for the compounds that need lower detection limits and expanded use of the heated purge-and-trap method might negate the need for a separate analysis by $\mathrm{GC} / \mathrm{ECD}$ to meet the need for lower detection limits for DBCP, EDB, and 1,2,3-TCP.

The NTAS work group has identified approximately 20 new HPV-VOC constituents (see the "Supplemental Information H" section) that are being tested by NWQL staff as possible additions to LS 2020 or LS 4024. If constituents are added to the existing schedules, some additional method approval will be needed. Through the VOC screening procedure, the NTAS work group also identified 33 constituents that have proven to be infrequently detected in routine monitoring studies, and these constituents (table A.2) could be omitted from NAWQA Cycle 3 monitoring.

Based on NAWQA monitoring data, field blanks have been susceptible to low-level contamination for some VOCs (for example, toluene and 1,2,4-trimethylbenzene) through processes that do not necessarily or equally affect the environmental samples, causing the results of such field blanks to be nonrepresentative of the environmental samples (Bender and others, 2011). Strict adherence to the USGS protocols for equipment cleaning and sample collection in the National Field Manual (U.S. Geological Survey, 2011) is necessary to prevent or minimize contamination in the field blanks and thus obtain adequate quality-control data for these constituents (Thiros and others, 2011).

\section{Knowledge and Concerns of Volatile Organic Compounds as a Constituent Group}

A well-developed understanding of the occurrence of the VOCs on LS 2020 exists for ambient groundwater (Zogorski and others, 2006), urban streams (Bender and others, 2009), surface-water and groundwater sources of public water systems (Kingsbury and others, 2008; Hopple and others, 2009), and domestic wells (Rowe and others, 2007). Four constituents on LS 4024-1,4-dioxane, methyl acetate, 2-methyl-2-butanol (tert-amyl alcohol), and tert-butanol (tert-butyl alcohol) have not been widely monitored and warrant additional monitoring to establish a national-scale understanding of their occurrence.

Many of the VOCs are widely used in industry and in commercial and household products. A total of 60 of the constituents currently on LS 2020 and 2 constituents on LS 4024 are classified by the USEPA (U.S. Environmental Protection Agency, 2010b) as HPVs, and other HPV-VOCs that are not on these schedules are described in the "Supplemental Information H" section. Because these constituents come from manmade sources, they can be used as indicators of water that has been affected by human activities.

For ambient waters, one main concern for VOCs is their presence in sources of drinking water. The presence of VOCs is an important consideration in source-water protection strategies and plans. The USEPA MCLs for drinking water supplied from public water systems are available for 29 VOCs 
(U.S. Environmental Protection Agency, 2006, 2009), and HBSLs (Toccalino and others, 2008) have been developed for an additional 28 VOCs that are routinely analyzed on LS 2020. Some aquatic-life criteria are available for VOCs; however, the concentrations for these aquatic-life benchmarks are very large compared to those found in ambient waters. For this reason, aquatic-life criteria were not included in the prioritization approach for VOCs. Concentrations of VOCs at spill sites and in industrial discharges, for example, can be very large and represent a potential concern to aquatic life and wildlife; however, such highly contaminated sites generally are not a focus in ambient monitoring programs, including the NAWQA Program.

Monitoring objectives concerning VOCs, within the scope of a national- or regional-scale ambient monitoring program such the NAWQA Program, could include (1) documenting occurrence and human exposure by way of domestic wells and public water systems; (2) assessing occurrence in major aquifers as an indicator of aquifer vulnerability, including the use of trihalomethanes as indicators of potential presence of other disinfection by-products; (3) evaluating factors that affect the transport of VOCs to supply wells, and (4) evaluating the degree of persistence in ambient groundwater under various oxidation-reduction (redox) conditions. Long-term trends in VOC occurrence, including trends for the gasoline additives and oxygenates and their degradates, also could be monitored.

\section{References for Volatile Organic Compounds in Water (Group A)}

Bender, D.A., Delzer, G.C., Price, C.V., and Zogorski, J.S., 2009, Occurrence of volatile organic compounds in selected urban streams in the United States, 1995-2003: U.S. Geological Survey Scientific Investigations Report 2009-5203, 87 p. (Also available at http://pubs.usgs.gov/ sir/2009/5203/.)

Bender, D.A., Zogorski, J.S., Mueller, D.K., Rose, D.L., Martin, J.D., and Brenner, C.K., 2011, Quality of volatile organic compound data from groundwater and surface water for the National Water-Quality Assessment Program, October 1996-December 2008: U.S. Geological Survey Scientific Investigations Report 2011-5204, 128 p., accessed March 14, 2012, at http://pubs.usgs.gov/sir/2011/5204/.

California Department Public Health, 2010, Chemicals and contaminants in drinking water, accessed December 20, 2010, at http://www.cdph.ca.gov/certlic/drinkingwater/ Pages/Chemicalcontaminants.aspx.

Centers for Disease Control and Prevention, 2010, National Health and Nutrition Examination Survey, accessed December 21, 2010, at http://www.cdc.gov/nchs/nhanes.htm.
Connor, B.F., Rose, D.L., Noriega, M.C., Murtagh, L.K., and Abney, S.R., 1997, Methods of analysis by the U.S. Geological Survey National Water Quality Laboratory-Determination of 86 volatile organic compounds in water by gas chromatography/mass spectrometry, including detections less than reporting limits: U.S. Geological Survey OpenFile Report 97-829, 78 p.

Hopple, J.A., Delzer, G.C., and Kingsbury, J.A., 2009, Anthropogenic organic compounds in source water of selected community water systems that use groundwater, 2002-05: U.S. Geological Survey Scientific Investigations Report 2009-5200, 74 p. (Also available at http://pubs.usgs.gov/ sir/2009/5200/.)

Kingsbury, J.A., Delzer, G.C., and Hopple, J.A., 2008, Anthropogenic organic compounds in source water of nine community water systems that withdraw from streams, 2002-05: U.S. Geological Survey Scientific Investigations Report 2008-5208, 66 p. (Also available at http://pubs.usgs. gov/sir/2008/5208/.)

Rathbun, R.E., 1998, Transport, behavior, and fate of volatile organic compounds in streams: U.S. Geological Survey Professional Paper 1589, 151 p.

Rose, D.L., and Sandstrom, M.W., 2003, Methods of analysis by the U.S. Geological Survey National Water Quality Laboratory-Determination of gasoline oxygenates, selected degradates, and BTEX in water by heated purge and trap/ gas chromatography/mass spectrometry: U.S. Geological Survey Water-Resources Investigations Report 03-4079, $31 \mathrm{p}$.

Rowe, B.L., Toccalino, P.L., Moran, M.J., Zogorski, J.S., and Price, C.V., 2007, Occurrence and potential human-health relevance of volatile organic compounds from domestic wells in the United States: Environmental Health Perspectives, v. 115 , no. 11 , p. 1,539-1,546.

Squillace, P.J., Moran, M.J., and Price, C.V., 2004, VOCs in shallow groundwater in new residential/commercial areas of the United States: Environmental Science and Technology, v. 38 , p. 5,327-5,338.

Thiros, S.A., Bender, D.A., Mueller, D.K., Rose, D.L., Olsen, L.D., Martin, J.D., Bernard, Bruce, and Zogorski J.S., 2011, Design and evaluation of a field study on the contamination of selected volatile organic compounds and wastewaterindicator compounds in blanks and groundwater samples: U.S. Geological Survey Scientific Investigations Report 2011-5027, 85 p., accessed March 14, 2012, at http://pubs. usgs.gov/sir/2011/5027/. 
Toccalino, P.L., Norman, J.E., Booth, N.L, and Zogorski, J.S., 2008, Health-Based Screening Levels_-Benchmarks for evaluating what water-quality data may mean to human health: U.S. Geological Survey, National Water-Quality Assessment Program, accessed December 21, 2010, at http://water.usgs.gov/nawqa/HBSL/.

U.S. Environmental Protection Agency, 2006, 2006 Edition of the drinking water standards and health advisories (updated August 2006): U.S. Environmental Protection Agency, Office of Water EPA 822-R-06-013, accessed December 20, 2010, at http://water.epa.gov/action/advisories/drinking/ upload/2009_04_27_criteria_drinking_dwstandards.pdf.

U.S. Environmental Protection Agency, 2009, 2009 Edition of the Drinking Water Standards and Health Advisories (updated October 2009): U.S. Environmental Protection Agency, Office of Water EPA 822-R-09-011, accessed December 20, 2010, at http://water.epa.gov/action/ advisories/drinking/upload/dwstandards2009.pdf.

U.S. Environmental Protection Agency, 2010a, Contaminant Candidate List 3-CCL3, accessed December 20, 2010, at http://water.epa.gov/scitech/drinkingwater/dws/ccl/ccl3.cfm.
U.S. Environmental Protection Agency, 2010b, High Production Volume (HPV) Challenge, accessed December 28, 2010, at http://www.epa.gov/HPV/.

U.S. Environmental Protection Agency, 2010c, Unregulated Contaminant Monitoring Rule 2 (UCMR 2), accessed December 20, 2010, at http://water.epa.gov/lawsregs/ rulesregs/sdwa/ucmr/ucmr2/index.cfm.

U.S. Environmental Protection Agency, 2011, Priority pollutants, accessed January 10, 2011, at http://water.epa.gov/ scitech/methods/cwa/pollutants.cfm.

U.S. Geological Survey, 2011, National field manual for the collection of water-quality data: U.S. Geological Survey Techniques of Water-Resources Investigations, book 9, chaps. A1-A9, accessed January 10, 2011, at http://pubs. water.usgs.gov/twri9A.

Zogorski, J.S., Carter, J.M., Ivahnenko, Tamara, Lapham, W.W., Moran, M.J., Rowe, B.L., Squillace, P.J., and Toccalino, P.L., 2006, The quality of our Nation's watersVolatile organic compounds in the Nation's ground water and drinking-water supply wells: U.S. Geological Survey Circular 1292, 101 p. (Also available at http://pubs.usgs. gov/circ/circ1292/.) 


\title{
Supplemental Information B1. \\ Prioritization of Pesticides in Water (Group B1)
}

By Julia E. Norman, Lisa H. Nowell, Kathryn M. Kuivila, Michelle L. Hladik, and Duane S. Wydoski

\author{
Abbreviations and Acronyms Used in Supplemental Information B1 \\ BO benchmark quotient \\ CCL3 Contaminant Candidate List 3 (USEPA) \\ ECOSAR Ecological Structure Activity Relationships (toxicity estimation software, USEPA) \\ ECOTOX ECOTOXicology (database, USEPA) \\ EPI Suite ${ }^{\mathrm{TM}} \quad$ Estimation Program Interface Suite (screening software, USEPA) \\ FIFRA Federal Insecticide, Fungicide, and Rodenticide Act \\ GC/MS gas chromatography with mass spectrometry \\ HBSL Health-Based Screening Level (water-quality benchmark, USGS) \\ LC/MS liquid chromatography with mass spectrometry \\ LC/MS/MS liquid chromatography with tandem mass spectrometry \\ LS laboratory schedule \\ MCL Maximum Contaminant Level (drinking-water-quality benchmark, USEPA) \\ NAWQA National Water-Quality Assessment (USGS) \\ NTAS National Target Analyte Strategy (USGS NAWQA) \\ NWOL National Water Quality Laboratory (USGS) \\ OPP Office of Pesticide Programs (USEPA) \\ SFIREG State FIFRA Issues Research and Evaluation Group \\ UCMR Unregulated Contaminant Monitoring Rule; UCMR 2, second round of UCMR sampling (USEPA) \\ USEPA U.S. Environmental Protection Agency \\ USGS U.S. Geological Survey \\ WARP Watershed Regressions for Pesticides (USGS NAWQA)
}


This supplemental information section of the report describes the prioritization of pesticides in water (Group B1) by the U.S. Geological Survey (USGS) National Target Analyte Strategy (NTAS) work group for national- and regional-scale ambient monitoring in the United States. This prioritization of pesticides in water was done in support of planning for the third decade (Cycle 3) of the National WaterQuality Assessment (NAWQA) Program. The prioritization of pesticides in sediment (Group B2) is presented in Supplemental Information B2. The feasibility of implementing analytical methods for high-priority pesticides in water and knowledge and concerns of pesticides in water as a constituent group also are described in this section. This supplemental information section was prepared concurrently with a USGS Scientific Investigations Report (Norman and others, 2012) that documents in more detail the prioritization of pesticide constituents for analytical methods development.

A total of 615 constituents (pesticides and pesticide degradates) were considered for prioritization for water. Of these, 11 constituents overlap with other NTAS constituent groups for water, including 3 volatile organic compounds in Group A (bromomethane, 1,3-dichloropropene (mixture of cisand trans-isomers), and iodomethane); 3 pharmaceuticals or hormones in Group C (oxytetracycline, penicillin G, and thiabendazole); 2 trace elements in Group D, (copper and zinc); 1 disinfection by-product in Group G (chloropicrin); 2 highproduction-volume chemicals in Group $\mathrm{H}$, (sulfcarbamide and thiram); and 2 wastewater-indicator and industrial compounds in Group I (cinnamaldehyde and 2,4,6-trichlorophenol).

Several additional pesticides in Group B1 have properties or other uses that are consistent with other constituents groups; however, only the 11 constituents listed in this section as overlapping were prioritized for multiple constituent groups.

The overlapping constituents in Groups A and G were prioritized using the procedures (described in the following section "Prioritization of Pesticides in Water") for Group B1 and were placed into NTAS Tier 1, except for iodomethane, which was placed into Tier 2 on the basis of the prioritization procedures used for Group A (described in the "Supplemental Information A" section). Two trace elements in Group D, copper and zinc, can be used (in various forms) as pesticides and were initially evaluated as such; however, preference was given to their placement into Tier 1 as trace elements using the procedures described in the "Supplemental Information D" section. Copper hydroxide and copper sulfate were not evaluated as distinct constituents because their predominant form in water would be as dissolved copper; however, other copper salts (copper octanoate, copper oxychloride, copper oxychloride sulfate, copper sulfate tribasic, and cuprous oxide) were prioritized using the procedures for Group B1. The two pesticides that overlap with Group H, sulfcarbamide and thiram, were prioritized using the procedures for Group B1 and were placed into Tier 2 on the basis of having "other agency priority" because they are high-production-volume chemicals. Although these two constituents have nonpesticide uses, the understanding of their environmental fate as pesticides did not support placement into Tier 1. All other overlapping constituents (three pharmaceuticals and two wastewater-indicator or industrial compounds) were prioritized using procedures developed for their other respective constituent groups ( $\mathrm{C}$ and I) and were assigned to Tier 2, except for cinnamaldehyde, which was assigned to Tier 3 .

\section{Prioritization of Pesticides in Water}

This section describes the methods used to prioritize pesticide constituents in water and the results of that prioritization. The prioritization of pesticide constituents was performed in parallel for surface water and groundwater, and the results apply to "water" as a single matrix. Constituents that were prioritized include those currently (2011) available on laboratory schedules from the USGS National Water Quality Laboratory (NWQL) and other selected USGS laboratories, as well as new constituents that do not yet have USGS laboratory methods.

\section{Prioritization Methods for Pesticides in Water}

A screening procedure was developed to prioritize pesticide constituents using (1) observed concentrations in streams and groundwater from previous NAWQA monitoring during 1993-2000, (2) detection frequencies for constituents analyzed in streams and groundwater for the NAWQA Program during 1993-2006, and (3) predicted concentrations in streams and groundwater based on agricultural-use estimates (when available) and on chemical and physical properties for those constituents without NAWQA monitoring data. Constituents were further evaluated for their regulatory and nonregulatory importance to other agencies or organizations.

Benchmark quotients (BQs), defined as the ratio of a constituent concentration to an appropriate aquatic-life or humanhealth benchmark, were used in the prioritization procedure. Aquatic-life benchmarks used, in order of priority, were the U.S. Environmental Protection Agency (USEPA) Office of Pesticide Programs' (OPP) aquatic-life benchmarks for freshwater (U.S. Environmental Protection Agency, 2009a), aquatic-life benchmarks developed for constituents without OPP benchmarks using OPP methodology and aquatic-life toxicity data (U.S. Environmental Protection Agency, 2010a), and USEPA National Recommended Water-Quality Criteria for the protection of aquatic life (U.S. Environmental Protection Agency, 2010b). The most conservative benchmark value (lowest concentration) for the most sensitive taxonomic group was selected for each constituent. For constituents that lacked benchmarks, aquatic-life toxicity data were obtained from USEPA OPP ecological-risk-assessment or Reregistration Eligibility Decision documents (U.S. Environmental Protection Agency, 2010a), the USEPA ECOTOXicology (ECOTOX) database (U.S. Environmental Protection Agency, 2007), or the USEPA OPP Pesticide Ecotoxicity Database (U.S. Environmental Protection Agency, 2009b), or, in the absence of other data, predicted toxicity values were obtained from the 
USEPA's Ecological Structure Activity Relationships (ECOSAR) program, a part of the EPI Suite ${ }^{\mathrm{TM}}$ software (Estimation Program Interface Suite; U.S. Environmental Protection Agency, 2009c). A level-of-concern factor of 0.5 was used to convert acute fish and invertebrate toxicity values to values comparable to acute aquatic-life benchmarks, consistent with OPP methodology (U.S. Environmental Protection Agency, 2009a). Human-health benchmarks included USEPA Maximum Contaminant Levels (MCLs) for drinking water (U.S. Environmental Protection Agency, 2006, 2009d) and USGS Health-Based Screening Levels (HBSLs) or provisional HBSLs developed for the NTAS prioritization effort using methods described by Toccalino and others (2008). Maximum Acceptable Concentrations developed by Health Canada (2010) were used for a few constituents without MCLs or HBSLs.

A flow chart of the prioritization procedure is given in figure B1.1, with details described in the following subsections. This procedure was developed on the basis of input from a working group that included Bob Gilliom, Lisa Nowell, Patty Toccalino, Gail Thelin, Naomi Nakagaki, Jack Barbash, Jeff Martin, Mark Sandstrom, Kathy Kuivila, Jim Orlando, and others (from the NAWQA Program's Pesticide National Synthesis group, the NWQL, and the Toxic Substances Hydrology Program) and from the NTAS work group. Predicted pesticide concentrations in streams and groundwater were determined and provided by Wes Stone and Paul Stackelberg, of the NAWQA Program, using methods described within this section.

Observed pesticide concentrations in surface water (streams) and groundwater from NAWQA monitoring during 1993-2000 (Gilliom and others, 2006; Norman and others, 2012) were compared to benchmarks, through the use of $B Q$ values, as one component of the procedure used to prioritize pesticide constituents (fig. B1.1). Data for 83 constituents in surface water and groundwater were used to calculate concentration statistics. Pesticide concentrations from surface water (agricultural and urban land-use streams) were compared to aquatic-life and human-health benchmarks, when available; concentrations for groundwater (agricultural, urban, and mixed land-use well networks) were compared only to human-health benchmarks. The maximum of the 95th-percentile concentrations among streams sites for each constituent was compared to an aquatic-life benchmark, and the maximum annual mean concentration was compared to the human-health benchmark, producing $\mathrm{BQ}$ values for evaluating pesticides in surface water. Similarly, the 99th-percentile concentration in groundwater for each constituent was compared to the human-health benchmark, producing BQ values for evaluating pesticides in groundwater.

Evaluation of pesticide detection frequency data collected for the NAWQA Program was a second component of the prioritization process for pesticides for surface water and groundwater, using procedures shown in figure B1.1. This additional screening was applied to 218 pesticide constituents analyzed in agricultural and urban streams and groundwater during 1993-2006 (Jeffrey D. Martin, U.S. Geological Survey, written commun., 2009; Norman and others, 2012). This procedure captured additional constituents that did not have aquatic-life or human-health benchmarks for the calculation of $\mathrm{BQ}$ values, or that had $\mathrm{BQ}$ values that were low (less than 0.01 ) but that might be detected frequently in water.

For current-use pesticides that had agricultural-use estimates (proprietary data from DMRkynetec (2007), currently (2012) GfK Kynetec), including constituents with or without NAWQA monitoring data, a third component of the prioritization process was the comparison of predicted concentrations for streams to aquatic-life and human-health benchmarks (figs. B1.1 and B1.2) and predicted concentrations for groundwater to human-health benchmarks through the use of BQ values (fig. B1.1).

For surface water, the Watershed Regressions for Pesticides (WARP) model designed to predict atrazine concentrations in streams (Stone and others, 2008; Stone and Gilliom, 2009) was adapted to predict concentrations for other pesticides by substituting their agricultural-use estimates and physical-chemical properties as described in Norman and others (2012). Data for parent compounds were used to predict concentrations for their corresponding degradates. If physical-chemical properties were not available for a constituent, atrazine properties were used to provide an estimate of the predicted concentration; this estimate was considered to be conservative (presumed higher) for most pesticides because atrazine is relatively persistent and mobile in water (Gilliom and others, 2006). For each constituent, the maximums of the predicted 95th-percentiles were divided by aquatic-life benchmarks (fig. B1.2), and predicted annual mean concentrations were divided by human-health benchmarks to determine BQs that were used to identify constituents with the potential to occur in surface water at concentrations of aquatic-life or human-health concern.

For groundwater, a regression model for predicting atrazine and deethylatrazine concentrations in shallow groundwater (Stackelberg and others, 2006) was used to predict pesticide concentrations on the basis of agricultural-use estimates from DMRkynetec (2007) as described in Norman and others (2012). This model was used without adjusting for differences in physical-chemical properties among pesticides (compared to atrazine and deethylatrazine), and thus, provides predicted concentrations that are conservative for most pesticides. This method was chosen because a multiconstituent model has not yet been developed for groundwater. Predicted concentrations (99th-percentiles) were generated for more than 300 pesticide constituents and were divided by each constituent's humanhealth benchmark, if available, to calculate BQs used to identify constituents with the potential to occur in groundwater at concentrations of human-health concern (Norman and others, 2012).

The pesticide prioritization procedure also considered other agency or organizational priorities as a fourth component (fig. B.1.1). These priorities could be used to elevate a constituent to a higher-priority tier than was assigned using 


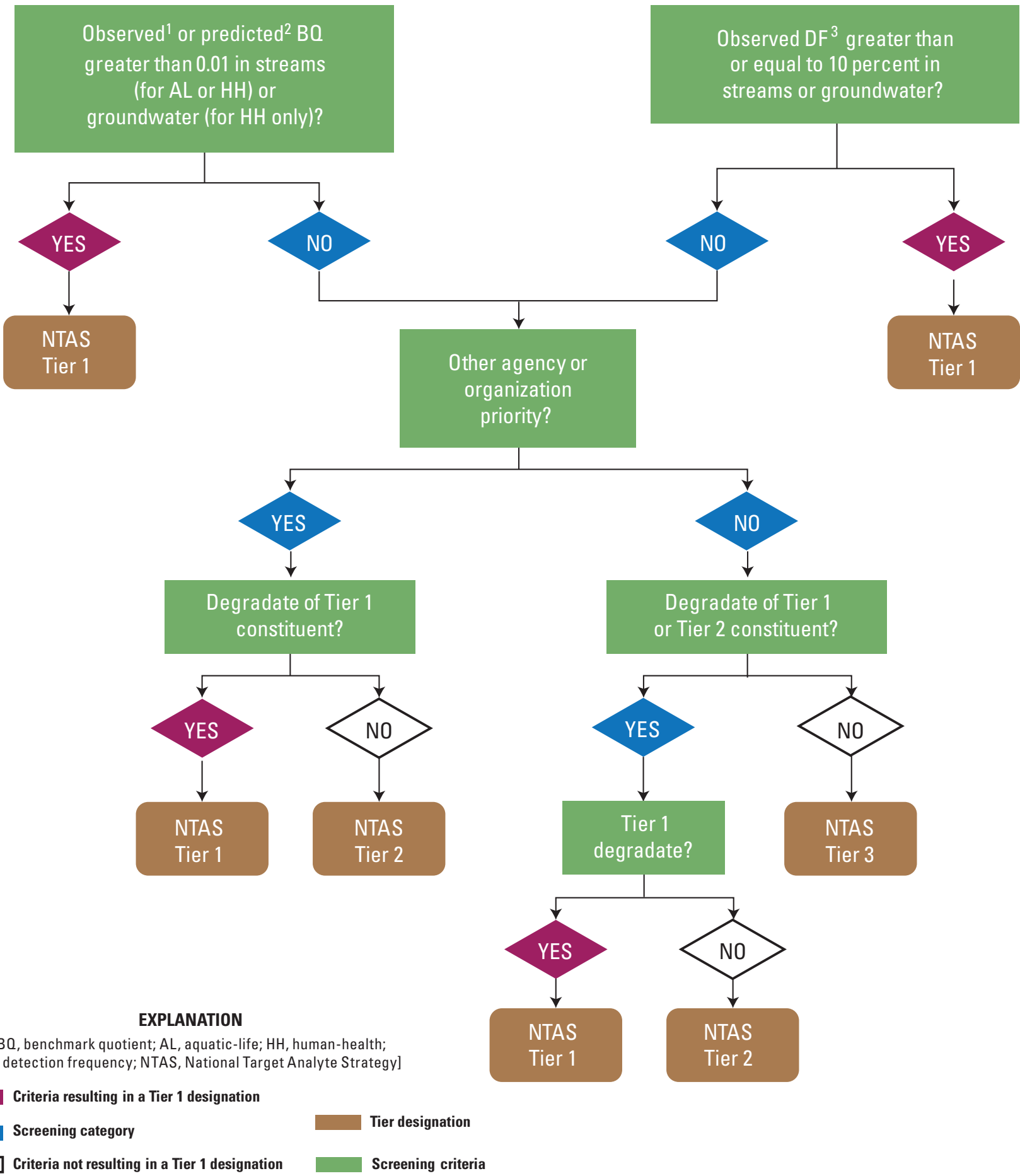

${ }^{1} \mathrm{~B} 0$ s for observed concentrations in streams are the maximum of the 95th-percentile concentrations (among stream sites) divided by the AL benchmark, and the maximum of the annual mean concentrations divided by the $\mathrm{HH}$ benchmark. BOs for observed concentrations in groundwater are the 99 th-percentile concentration (of wells) divided by the $\mathrm{HH}$ benchmark. Observed concentration statistics are for agricultural and urban land-use streams and agricultural, urban, and mixed landuse wells.

${ }^{2} \mathrm{BQs}$ for predicted concentrations in streams are the maximum of the 95th-percentile concentrations (among stream reaches) divided by the AL benchmark, and the maximum of the annual mean concentrations divided by the $\mathrm{HH}$ benchmark. BOs for predicted concentrations in groundwater are the 99 th-percentile concentration divided by the $\mathrm{HH}$ benchmark. Predicted concentration statistics in streams and groundwater are for current (2007) agricultural-use pesticides.

${ }^{3}$ Observed DFs are for pesticide constituents measured in streams and groundwater in agricultural and urban land-use areas.

Figure B1.1. Flow chart for prioritizing pesticide constituents for national- and regional-scale monitoring of surface water (streams) and groundwater in the United States. 


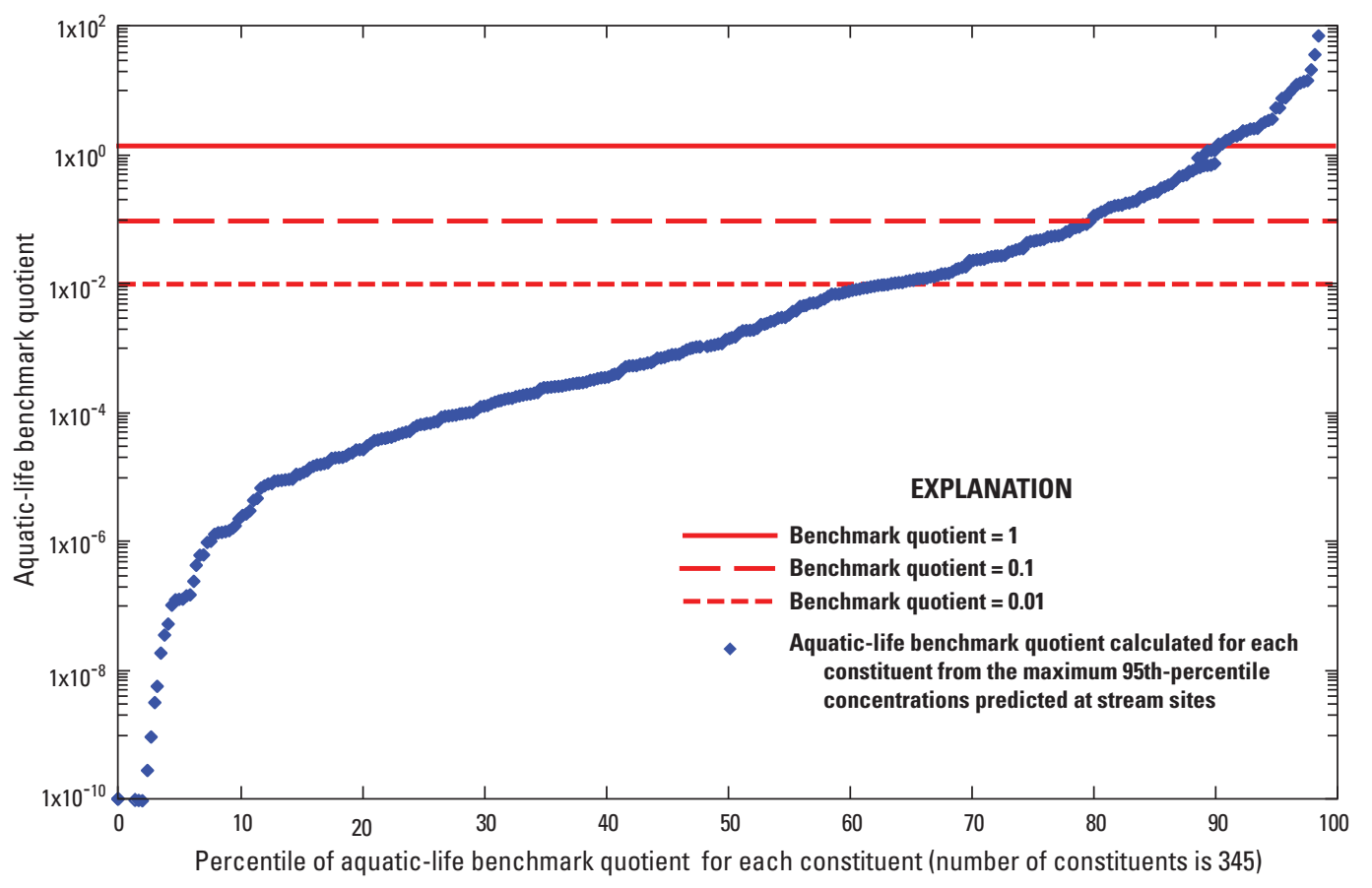

Figure B1.2. Distribution of aquatic-life benchmark quotient values for predicted pesticide concentrations in surface water using the maximum of the 95th-percentile concentrations among stream sites for each constituent. the criteria outlined in the first three components described previously. Constituents were considered to be of priority to other agencies if they have USEPA National Recommended Water-Quality Criteria for aquatic life (U.S. Environmental Protection Agency, 2010b); have Canadian water-quality guidelines for aquatic life (Health Canada, 2010); have specific objectives for aquatic life from the Great Lakes Water Quality Agreement of 1978 (U.S. Environmental Protection Agency, 2009e); are on the Association of American Pesticide Control Officials' State Federal Insecticide, Fungicide, and Rodenticide Act (FIFRA) Issues Research and Evaluation Group's (SFIREG) list of pesticides of water-quality concern (Association of American Pesticide Control Officials, 2005); have recent active ingredient registrations with the USEPA (1997-2008; U.S. Environmental Protection Agency, 2010a); are on the USEPA Contaminant Candidate List 3 (CCL3; U.S. Environmental Protection Agency, 2010c); are included in USEPA's second cycle of the Unregulated Contaminant Monitoring Rule sampling (UCMR 2; U.S. Environmental Protection Agency, 2010d); or have USEPA MCLs for drinking water (U.S. Environmental Protection Agency, 2006, 2009d).

Pesticide degradates that fell into a lower priority tier than their parent compound (commonly because of a lack of toxicity information or monitoring data) were placed into the same tier as their parent compound to allow monitoring of degradation processes. Monitoring degradates also can be useful in quantifying toxicity from multiple forms of a pesticide for those degradates that are themselves toxic.

\section{Results of Prioritization for Pesticides in Water}

A total of 251 pesticide constituents (not counting copper) were placed into NTAS Tier 1 for water and warrant consideration for national- or regional-scale monitoring (table B1.1 at http://pubs.usgs.gov/sir/2012/5218/downloads/ tableB1.xls). Of these, 211 constituents are currently available on USGS laboratory schedules (as of 2011), and an additional 40 constituents warrant consideration for methods development for NAWQA Cycle 3 monitoring. An additional 95 pesticide constituents (not counting zinc) were placed into Tier 2, of which 36 are on existing USGS laboratory schedules (table B1.2 at http://pubs.usgs.gov/sir/2012/5218/downloads/ tableB1.xls).

On the basis of the pesticide screening procedure, monitoring for some of the 52 Tier 3 pesticide constituents on current (2011) USGS laboratory schedules could be discontinued (table B1.3 at http://pubs.usgs.gov/sir/2012/5218/downloads/ tableB1.xls) unless rationale to retain these constituents emerges. More than 200 additional pesticide constituents that are not on current USGS laboratory schedules were placed into Tier 3 on the basis of the prioritization procedure, including several pesticide constituents that are mixtures or microorganisms.

\section{Basis for Prioritization of Pesticides in Water}

A flow chart summarizing the prioritization process and placement of pesticide constituents into tiers is shown in figure B1.1. For the constituents that were placed into Tier 1, the reasons for prioritization are provided in table B1.1; some constituents had multiple reasons to justify placement into Tier 1. 
For the evaluation for surface water, pesticide constituents with observed or predicted concentrations and aquatic-life or human-health benchmarks resulting in BQ values greater than 0.01 were placed into Tier 1 ; this criterion was met by 152 of the 251 Tier 1 constituents (excluding copper). For groundwater, pesticide constituents with observed or predicted concentrations and human-health benchmarks resulting in BQ values greater than 0.01 also were placed into Tier 1 ; this criterion was met by 17 of the 251 Tier 1 constituents (table B1.1). A BQ greater than 0.01 indicates a constituent concentration that is greater than one-hundredth $(1 / 100)$ of the benchmark value. This threshold was chosen to be more conservative than those commonly used in evaluating water quality; for example, concentrations greater than one-tenth $(1 / 10)$ of a respective human-health benchmark commonly are used to identify constituents that warrant additional monitoring to identify trends in occurrence or to provide an early indication of concentrations that are approaching their respective benchmarks (Toccalino, 2007; Toccalino and others, 2008).

Detection frequency of greater than or equal to 10 percent in surface water or groundwater datasets was used as an additional criterion for placing pesticides into Tier 1; this criterion was met by 71 of the 251 Tier 1 constituents (table B1.1). Figure B1.3 shows the distribution of pesticide detection frequencies in the four datasets (agricultural land use for surface water and groundwater, and urban land use for surface water and groundwater) used for the prioritization. The 10-percent detection frequency criterion captured approximately 25 percent of the most frequently occurring constituents in surface water; the same criterion was used for groundwater.

Many of the Tier 1 constituents are included in several national regulatory programs related to drinking water12 Tier 1 constituents are regulated in drinking water and have USEPA MCLs (U.S. Environmental Protection Agency, 2009d), 29 constituents are included on the USEPA CCL3 (U.S. Environmental Protection Agency, 2010c), and 23 constituents have been monitored under the USEPA UCMR (U.S. Environmental Protection Agency, 2011). Of those constituents in Tier 1, 144 (including copper) were identified as high priority because of potential aquatic-life concerns; some of these constituents also were identified as high priority for human-health reasons (table B1.1). Of these 144 constituents, 79 were placed into Tier 1 on the basis of BQ values calculated from aquatic-life benchmarks from the USEPA OPP (U.S. Environmental Protection Agency, 2009a). Two constituents in Tier 1 have USEPA national recommended waterquality criteria for aquatic life (U.S. Environmental Protection Agency, 2010b). An additional 95 pesticide constituents (not counting zinc) that did not qualify for Tier 1 were placed into Tier 2 on the basis of other priorities relevant to aquatic life or human health (table B1.2).

In contrast to most other constituent groups, most pesticides are anthropogenic compounds that, by definition, are biologically active compounds designed to be toxic to target organisms. Information on toxicity (aquatic and human) generally is more abundant for this constituent group than for
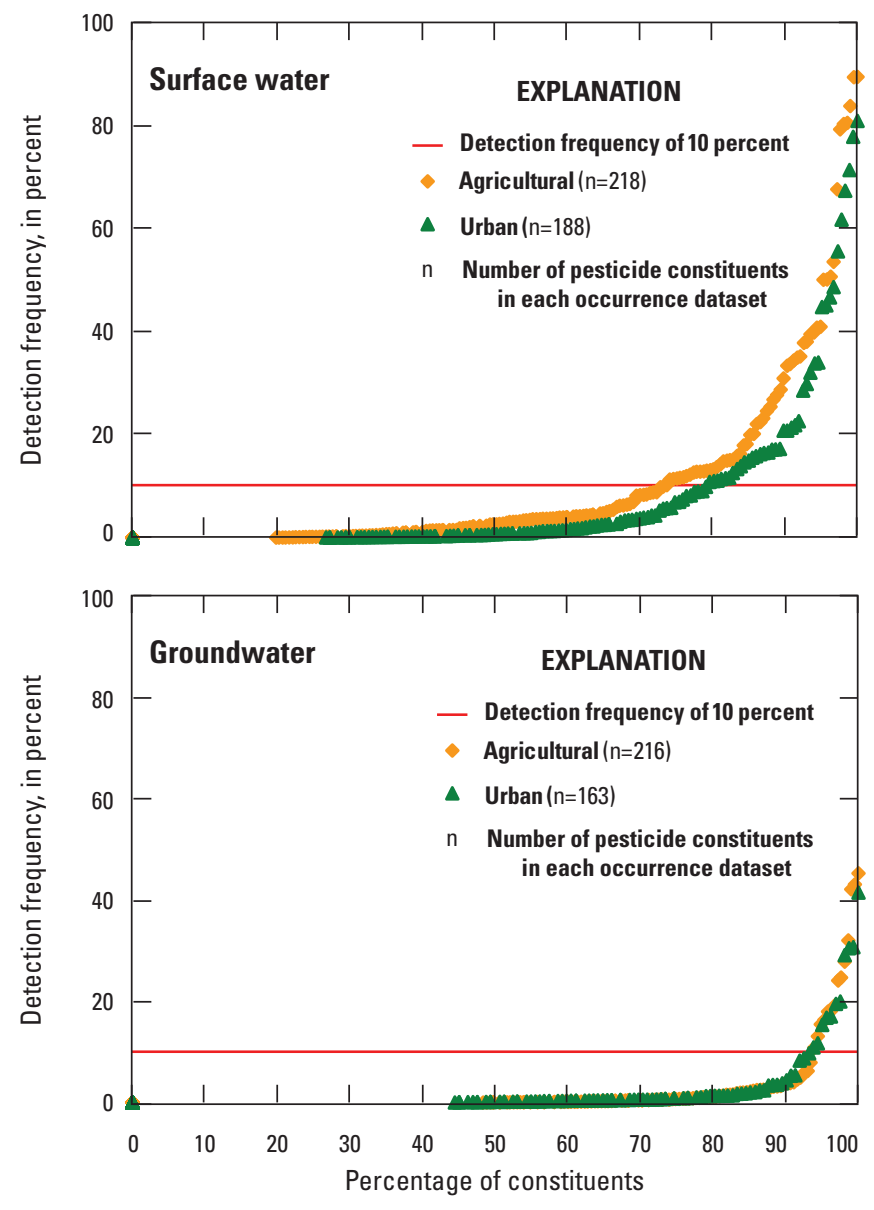

Figure B1.3. Distribution of detection frequencies for surfacewater and groundwater pesticide datasets collected for the National Water-Quality Assessment Program during 1993-2006.

other groups; however, data are lacking for some constituents, particularly for pesticide degradates. Pesticide concentrations relevant to aquatic life and human health were used as the primary tool for prioritizing constituents for this evaluation; thus, specific concerns to aquatic life and human health are not further summarized here.

\section{Feasibility of Implementation for High-Priority Pesticides in Water}

Information on current (2011) analytical methods for pesticide constituents is listed in table B1.4 at http://pubs.usgs.gov/ sir/2012/5218/downloads/tableB1.xls. An improved method using high-performance liquid chromatography with tandem mass spectrometry (LC/MS/MS) and direct aqueous injection to replace laboratory schedule (LS) 2060 is under development by the NWQL. The method for LS 2060 uses solid-phaseextraction sample preparation and liquid chromatography with mass spectrometry (LC/MS) analysis for the determination of polar pesticides in filtered water. The replacement LC/MS/MS 
method should improve analytical performance because it allows for direct aqueous injection of the filtered-water sample and, thus, bypasses the solid-phase-extraction steps where procedural losses in analyte recovery might occur. This method change will allow for reduced sample volumes required for analysis compared to LS 2060. The use of tandem mass spectrometry should improve the specificity in identifying constituents. The LC/MS/MS method will be used to accommodate as many Tier 1 pesticide constituents as possible.

Laboratory detection levels for the analytical methods under consideration for pesticides were compared to humanhealth benchmarks to ensure that the methods are capable of detecting constituents at concentrations relevant to human health; benchmarks for human health were used because they tend to be lower than benchmarks used for aquatic life. A dataquality objective for the NTAS prioritization process was for detection levels to be less than $1 / 10(0.10)$ of the respective benchmarks for each constituent. Ratios of detection levels to human-health benchmarks for constituents on current (2011) laboratory schedules used for the determination of pesticides in water are listed in table B1.5 at http://pubs.usgs.gov/ sir/2012/5218/downloads/tableB1.xls. Nearly all constituents had ratios less than 0.10 , and many were less than 0.010 . Only two pesticides were identified as having current detection levels that are too high relative to a human-health benchmark. These were dicrotophos (ratio of 0.80 ) and dieldrin (ratio of 2.25) for analyses by method LS 2033, which uses gas chromatography with mass spectrometry (GC/MS) operated in the electron-impact ionization and selected-ion monitoring modes. This method warrants additional evaluation to determine if detection levels for these compounds can be improved or if an alternative method (for example, electron-capture negative-ion mass spectrometry) could be used, especially for dieldrin.

The 39 new pesticide constituents placed into Tier 1 (table B1.1) will warrant evaluation for feasibility of integration into existing laboratory schedules or into the development of new methods, such as the LC/MS/MS method described previously. The 59 new constituents placed into Tier 2 (table B1.2) also may warrant evaluation for analytical feasibility, depending on availability of resources and whether a decision is made to monitor for constituents from Tier 2 .

Additional method validation will be necessary if improvements in the GC/MS method used for LS 2033 are required in order to accommodate additional constituents. These improvements might include the use of simultaneous data acquisition using selected-ion monitoring and full-scan modes, which would allow for the reporting of tentatively identified compounds, similar to data provided for volatile organic compounds using LS 2020. Alternatively, tandem mass spectrometry might be used to provide lower reporting levels. Another improvement that could be explored is the use of large-volume injection, which could lower detection levels or reduce the required sample volume. Table B1.4 summarizes the status of current analytical methods for pesticides in water.

For the two pesticide methods from the Sacramento Pesticide Fate Research Laboratory in California, the CAPYRWAT method for pyrethroids in water (Hladik and others, 2009a) has been approved, but the CAPEST method for pesticides in filtered water has not been approved. When monitoring for pyrethroid insecticides in water, the field sampling procedures outlined in Hladik and others (2009b) also would warrant consideration, because these constituents tend to associate with the surfaces of sampling equipment and require modified field methods to achieve good recoveries in field samples.

\section{Knowledge and Concerns of Pesticides in Water as a Constituent Group}

Occurrence and concentration data for pesticide constituents in surface water and groundwater are of high interest for water-resource management from aquatic-life and humanhealth perspectives. Occurrence and concentrations in streams and groundwater have been characterized in national- and regional-scale assessments of major hydrologic systems (Gilliom and others, 2006). The USEPA's regulatory programs document the occurrence of regulated pesticides in public water systems; however, relatively few pesticides are regulated in drinking water.

The presence of pesticides in drinking-water supplies is a concern for surface water and groundwater resources. The USEPA has established MCLs for drinking water supplied from public water systems for 20 pesticide constituents evaluated by the NTAS work group. USGS HBSL values, although not regulatory, have been developed for 129 pesticide constituents that are on current (2011) USGS laboratory schedules.

For ambient surface waters, one major concern is to aquatic organisms in streams affected by agricultural and nonagricultural pesticide application. The USEPA OPP recently began publishing aquatic-life benchmarks for freshwater species (U.S. Environmental Protection Agency, 2009a), available at http://www.epa.gov/oppefed1/ecorisk_ders/aquatic_life_ benchmark.htm. These benchmarks, although not regulatory, are based on USEPA-reviewed toxicity values used in their most recent risk assessments that are developed as part of the pesticide registration process. Each USEPA aquatic-life benchmark is based on the most sensitive, scientifically acceptable toxicity endpoint available to USEPA for a given taxon (for example, freshwater fish and invertebrates).

NAWQA's roles in pesticide studies have included determining the (1) occurrence in (and potential human exposure from) water from domestic wells, (2) occurrence in ambient source waters of public water systems, (3) occurrence in streams and potential exposure to aquatic organisms, (4) factors that affect the fate and transport of pesticides to streams and groundwater, and (5) long-term trends in occurrence related to land use. Additional areas of current interest for pesticides include monitoring the occurrence, persistence, toxicity, and fate of pesticide degradation products in streams and groundwater, relative to their respective parent compounds. 


\section{References Cited for Pesticides in Water (Group B1)}

Association of American Pesticide Control Officials, 2005, State FIFRA (Federal Insecticide, Fungicide, and Rodenticide Act) Issues Research and Evaluation Group's (SFIREG) State List of Pesticides of Water Quality Concern: accessed April 7, 2011, at http://www.epa.gov/ compliance/resources/policies/state/grants/fifra/08-10appendix11.pdf.

DMRkynetec, 2007, Proprietary agricultural pesticide-use data from DMRkynetec (known as GfK Kynetec after January 19, 2010).

Furlong, E.T., Anderson, B.D., Werner, S.L., Soliven, P.P., Coffey, L.J., and Burkhardt, M.R., 2001, Methods of analysis by the U.S. Geological Survey National Water Quality Laboratory-Determination of pesticides in water by graphitized carbon-based solid-phase extraction and high-performance liquid chromatography/mass spectrometry: U.S. Geological Survey Water-Resources Investigations Report 01-4134, 73 p. (Also available at http://nwql.usgs. gov/Public/pubs/WRIR01-4134.html.)

Gilliom, R.J., Barbash, J.E., Crawford, C.G., Hamilton, P.A., Martin, J.D., Nakagaki, Naomi, Nowell, L.H., Scott, J.C., Stackelberg, P.E., Thelin, G.P., and Wolock, D.M., 2006, The Quality of our Nation's waters - Pesticides in the Nation's streams and ground water, 1992-2001: U.S. Geological Survey Circular 1291, 172 p. (Also available at http://pubs.usgs.gov/circ/2005/1291/.)

Health Canada, 2010, Guidelines for Canadian drinking water quality - Summary table: Ottawa, Canada, FederalProvincial-Territorial Committee on Drinking Water of the Federal-Provincial Territorial Committee on Health and the Environment, accessed March 16, 2012, at http://www. hc-sc.gc.ca/ewh-semt/pubs/water-eau/2010-sum_guideres_recom/index-eng.php. [Guidelines updated August 2012 at http://www.hc-sc.gc.ca/ewh-semt/pubs/water-eau/2012sum_guide-res_recom/index-eng.php.]

Hladik, M.L., Smalling, K.L., and Kuivila, K.M., 2008, A multi-residue method for the analysis of pesticides and pesticide degradates in water using HLB solid-phase extraction and gas chromatography-ion-trap mass spectrometry: Bulletin of Environmental Contamination and Toxicology, v. 80 , p. $139-144$.
Hladik, M.L., Smalling, K.L., and Kuivila, K.M., 2009a, Methods of analysis-Determination of pyrethroid insecticides in water and sediment using gas chromatography/ mass spectrometry: U.S. Geological Survey Techniques and Methods Report 5-C2, 18 p., accessed April 7, 2011, at http://pubs.usgs.gov/tm/tm5c2/.

Hladik, M.L., Orlando J.L., and Kuivila, K.M., 2009b, Collection of pyrethroids in water and sediment matrices-Development and validation of a standard operating procedure: U.S. Geological Survey Scientific Investigations Report 2009-5012, 22 p., accessed April 7, 2011, at http://pubs. usgs.gov/sir/2009/5012/.

Kish, J.L., Thurman, E.M., Scribner, E.A., and Zimmerman, L.R., 2000, Methods of analysis by the U.S. Geological Survey Organic Geochemistry Research Group-Determination of selected herbicides and their degradation products in water using solid-phase extraction and gas chromatography/mass spectrometry: U.S. Geological Survey Open-File Report 00-385, 13 p.

Lee, E.A., and Strahan, A.P., 2003, Methods of analysis by the U.S. Geological Survey Organic Geochemistry Research Group_-Determination of acetamide herbicides and their degradation products in water using online solid-phase extraction and liquid chromatography/mass spectrometry: U.S. Geological Survey Open-File Report 03-173, 17 p.

Lee, E.A., Strahan, A.P., and Thurman, E.M., 2002a, Methods of analysis by the U.S. Geological Survey Organic Geochemistry Research Group-Determination of glyphosate, aminomethylphosphonic acid, and glufosinate in water using online solid-phase extraction and high-performance liquid chromatography/mass spectrometry: U.S. Geological Survey Open-File Report 01-454, 13p.

Lee, E.A., Strahan, A.P., and Thurman, E.M., 2002b, Methods of analysis by the U.S. Geological Survey Organic Geochemistry Research Group-Determination of triazine and phenylurea herbicides and their degradation products in water using solid-phase extraction and liquid chromatography/mass spectrometry: U.S. Geological Survey Open-File Report 02-436, 19 p.

Meyer, M.T., Lee, E.A., and Scribner, E.A., 2007, Methods of analysis by the U.S. Geological Survey Organic Geochemistry Research Group-Determination of dissolved isoxaflutole and its sequential degradation products, diketonitrile and benzoic acid [sic], in water using solid-phase extraction and liquid chromatography/tandem mass spectrometry: U.S. Geological Survey Techniques and Methods, book 5, chap. A9, 13 p., accessed March 16, 2012, at http://pubs.usgs.gov/ $\mathrm{tm} / 2007 / \mathrm{tm} 5 \mathrm{a9} /$. 
Norman, J.E., Kuivila, K.M., and Nowell, L.H., 2012, Prioritizing pesticide compounds for analytical methods development: U.S. Geological Survey Scientific Investigations Report 2012-5045, 206 p. (Also available at $h t t p: / / p u b s$. usgs.gov/sir/2012/5045/pdf/sir20125045.pdf.)

Stackelberg, P.E., Gilliom, R.J., Wolock, D.M., and Hitt, K.J., 2006, Development and application of a regression equation for estimating the occurrence of atrazine in shallow ground water beneath agricultural areas of the United States: U.S. Geological Survey Scientific Investigations Report 20055287, 22 p., accessed March 16, 2012, at http://pubs.usgs. gov/sir/2005/5287/.

Stone, W.W., and Gilliom, R.J., 2009, Update of Watershed Regressions for Pesticides (WARP) for predicting atrazine concentration in streams: U.S. Geological Survey OpenFile Report 2009-1122, 22 p., accessed March 16, 2012, at http://pubs.usgs.gov/of/2009/1122/.

Stone, W.W., Gilliom, R.J., and Crawford, C.G., 2008, Watershed Regressions for Pesticides (WARP) for predicting annual maximum and maximum moving-average concentrations of atrazine in streams: U.S. Geological Survey OpenFile Report 2008-1186, 19 p., accessed March 16, 2012, at http://pubs.usgs.gov/of/2008/1186/.

Toccalino, P.L., 2007, Development and application of HealthBased Screening Levels for use in water-quality assessments: U.S. Geological Survey Scientific Investigations Report 2007-5106, 12 p., accessed April 7, 2011, at http:// pubs.usgs.gov/sir/2007/5106/.

Toccalino, P.L., Norman, J.E., Booth, N.L, and Zogorski, J.S., 2008, Health-Based Screening Levels-Benchmarks for evaluating what water-quality data may mean to human health: U.S. Geological Survey, National Water-Quality Assessment Program, accessed December 21, 2010, at http://water.usgs.gov/nawqa/HBSL/.

U.S. Environmental Protection Agency, 2006, 2006 Edition of the drinking water standards and health advisories (updated August 2006): U.S. Environmental Protection Agency, Office of Water EPA 822-R-06-013, accessed December 20,2010, at http://water.epa.gov/action/advisories/drinking/ upload/2009_04_27_criteria_drinking_dwstandards.pdf.

U.S. Environmental Protection Agency, 2007, ECOTOXicology Database System, version 4.0: U.S. Environmental Protection Agency, Office of Research and Development and the National Health and Environmental Effects Research Laboratory's Mid-Continent Ecology Division, accessed May 12, 2010, at http://www.epa.gov/ecotox/.
U.S. Environmental Protection Agency, 2009a, Office of Pesticide Programs' aquatic life benchmarks (freshwater) (updated April 9, 2009): U.S. Environmental Protection Agency, Office of Pesticide Programs, accessed May 12, 2010, at http://www.epa.gov/oppefedl/ecorisk_ders/ aquatic_life_benchmark.htm.

U.S. Environmental Protection Agency, 2009b, OPP Pesticide Ecotoxicity Database (database version April 10, 2009): U.S. Environmental Protection Agency, Office of Pesticide Programs, accessed January 22, 2010, at http://www. ipmcenters.org/Ecotox/index.cfm.

U.S. Environmental Protection Agency, 2009c, EPI Suite ${ }^{\mathrm{TM}}$ version 4.0: U.S. Environmental Protection Agency, Office of Pollution Prevention and Toxics and Syracuse Research Corporation.

U.S. Environmental Protection Agency, 2009d, 2009 Edition of the drinking water standards and health advisories (updated October 2009): U.S. Environmental Protection Agency, Office of Water EPA 822-R-09-011, accessed December 20, 2010, at http://water.epa.gov/action/ advisories/drinking/upload/dwstandards2009.pdf.

U.S. Environmental Protection Agency, 2009e, The Great Lakes Water Quality Agreement: accessed April 6, 2011, at http://www.epa.gov/glnpo/glwqa/1978/index.html.

U.S. Environmental Protection Agency, 2010a, Pesticide reregistration status: U.S. Environmental Protection Agency, Office of Pesticide Programs, accessed May 12, 2010, at http://www.epa.gov/oppsrrd1/reregistration/status.htm.

U.S. Environmental Protection Agency, 2010b, National recommended water quality criteria: accessed December 27, 2010, at http://water.epa.gov/scitech/swguidance/standards/ current/.

U.S. Environmental Protection Agency, 2010c, Contaminant Candidate List 3-CCL3: accessed December 20, 2010, at http://water.epa.gov/scitech/drinkingwater/dws/ccl/ccl3.cfm.

U.S. Environmental Protection Agency, 2010d, Unregulated Contaminant Monitoring Rule 2 (UCMR 2): accessed December 20, 2010, at http://water.epa.gov/lawsregs/ rulesregs/sdwa/ucmr/ucmr2/index.cfm.

U.S. Environmental Protection Agency, 2011, Unregulated Contaminant Monitoring Program: accessed April 6, 2011, at http://water.epa.gov/lawsregs/rulesregs/sdwa/ucmr/. 
Zaugg, S.D., Sandstrom, M.W., Smith, S.G., and Fehlberg, K.M., 1995, Methods of analysis by the U.S. Geological Survey National Water Quality Laboratory-Determination of pesticides in water by $\mathrm{C}-18$ solid-phase extraction and capillary-column gas chromatography/mass spectrometry with selected-ion monitoring: U.S. Geological Survey Open-File Report 95-181, 49 p.

Zimmerman, L.R., and Thurman, E.M., 1999, Method of analysis by the U.S. Geological Survey Organic Geochemistry Research Group-Determination of triazine and chloroacetanilide herbicides in water by solid-phase extraction and capillary-column gas chromatography/mass spectrometry with selected-ion monitoring: U.S. Geological Survey Open-File Report 98-634, 21 p. 


\section{Supplemental Information B2. \\ Prioritization of Pesticides in Sediment (Group B2)}

By Julia E. Norman, Lisa H. Nowell, Kathryn M. Kuivila, Peter C. Van Metre, James F. Pankow, and Duane S. Wydoski

\section{Abbreviations and Acronyms Used in Supplemental Information B2}

$\begin{array}{ll}\text { AL bins } & \text { aquatic-life "bins" } \\ \text { DEG } & \text { degradation pathway } \\ \text { DF } & \text { detection frequency } \\ \text { ECOSAR } & \text { Ecological Structure Activity Relationships (toxicity estimation software, USEPA) } \\ \text { ECOTOX } & \text { ECOTOXicology (database, USEPA) } \\ \text { EPI Suite } & \text { Estimation Program Interface Suite (screening software, USEPA) } \\ \text { FIFRA } & \text { Federal Insecticide, Fungicide, and Rodenticide Act } \\ \text { GC/MS } & \text { gas chromatography with mass spectrometry } \\ K_{\text {OC }} & \text { organic carbon-water partition coefficient } \\ \text { LC/MS } & \text { liquid-chromatography with mass spectrometry } \\ \text { NAWQA } & \text { National Water-Quality Assessment (USGS) } \\ \text { NIA } & \text { no information available } \\ \text { NTAS } & \text { National Target Analyte Strategy (USGS NAWOA) } \\ \text { OPP } & \text { Office of Pesticide Programs (USEPA) } \\ \text { PPDB } & \text { Pesticide Properties Database (European Commission) } \\ \text { SFIREG } & \text { State FIFRA (Federal Insecticide, Fungicide, and Rodenticide Act) Issues Research and Evaluation Group } \\ \text { USEPA } & \text { U.S. Environmental Protection Agency } \\ \text { USGS } & \text { U.S. Geological Survey }\end{array}$


This supplemental section of the report describes the prioritization of pesticides in sediment (Group B2) by the U.S. Geological Survey (USGS) National Target Analyte Strategy (NTAS) work group for national- and regional-scale ambient monitoring in the United States. This prioritization of pesticides in sediment was done in support of planning for the third decade (Cycle 3) of the National Water-Quality Assessment (NAWQA) Program. The prioritization of pesticides in water (Group B1) is presented in the "Supplemental Information B1" section. The feasibility of implementing laboratory methods for high-priority pesticides in sediment, and knowledge and concerns about pesticides in sediment as a constituent group, also are described in this section. This supplemental information section was prepared concurrently with a USGS Scientific Investigations Report (Norman and others, 2012) that documents in more detail the prioritization of pesticide constituents for analytical methods development.

A total of 605 pesticide constituents (pesticides and pesticide degradates) were considered for prioritization for sediment. Of these, eight constituents overlap with other NTAS constituent groups for sediment, including three pharmaceuticals or hormones in Group C (oxytetracycline, penicillin G, and thiabendazole); two trace elements in Group D (copper and zinc); and four lipophilic organic compounds in Group $\mathrm{F}$ (hexachlorobenzene, naphthalene, pentachloroanisole, and triphenyl phosphate).

The three pesticide constituents that also are pharmaceuticals were prioritized using the procedures used for Group B2 (described later in this section) and Group C (described in the "Supplemental Information C" section); oxytetracycline and thiabendazole were determined to be of intermediate priority and placed into NTAS Tier 2, and penicillin G was placed into Tier 3. For the two trace elements that also are used (in various forms) as pesticides, copper and zinc, preference was given to their prioritizations as trace elements (Group D) using the procedure described in the "Supplemental Information D" section, which resulted in placement into Tier 1 for both constituents. Copper and zinc are considered as "trace elements" for analytical purposes. For the four pesticide constituents that also are considered lipophilic organic compounds, all were placed into Tier 1: hexachlorobenzene and pentachloroanisole on the basis of the prioritization procedures used for both Group B2 and Group F, and naphthalene and triphenyl phosphate on the basis of the prioritization procedure used for Group $\mathrm{F}$ described in the "Supplemental Information F" section, which was preferred for these two constituents because of their likely entry into the environment through nonagricultural uses.

\section{Prioritization of Pesticides in Sediment}

This section describes the generalized methods used for prioritization of pesticide constituents in sediment (streambed sediment and suspended sediment) and the results of that prioritization. Constituents prioritized include those currently (2011) available on laboratory schedules from the USGS
National Water Quality Laboratory and other selected USGS laboratories, as well as new constituents that do not yet have USGS laboratory methods.

\section{Prioritization Methods for Pesticides in Sediment}

A screening procedure was developed to prioritize pesticide constituents using (1) detection frequencies for pesticide constituents analyzed for selected USGS programs, (2) observed concentrations compared to sediment benchmarks for aquatic life (when available) or aquatic-life toxicity, and (3) predicted occurrence in sediment on the basis of pesticide properties and agricultural-use information. Pesticide constituents were further evaluated for their regulatory and nonregulatory importance to other agencies or organizations.

Benchmark quotients, defined as the ratio of a constituent concentration to an appropriate aquatic-life or humanhealth benchmark, were used in the prioritization procedure. Benchmarks used, in order of priority, were draft equilibriumpartitioning sediment guidelines from the U.S. Environmental Protection Agency (U.S. Environmental Protection Agency, 2004), Canadian sediment-quality guidelines for the protection of aquatic life (Canadian Council of Ministers of the Environment, 2002), and consensus-based sediment-quality guidelines for freshwater ecosystems from MacDonald and others (2000). For each of these sources, the most conservative value (lowest concentration) for the most sensitive taxonomic group was selected for each constituent. Each of these benchmark sources has a high and low value, corresponding to acute and chronic toxicity. If sediment-quality benchmarks were not available, aquatic-life toxicity data were used from, in order of priority, USEPA Office of Pesticide Programs (OPP) ecological risk assessment or Reregistration Eligibility Decision documents (U.S. Environmental Protection Agency, 2010a), the USEPA Ecotoxicology (ECOTOX) database (U.S. Environmental Protection Agency, 2007), the USEPA OPP Pesticide Ecotoxicity Database (U.S. Environmental Protection Agency, 2009a), or predicted toxicity values from the USEPA's Ecological Structure Activity Relationships (ECOSAR) program, a part of the EPI Suite ${ }^{\mathrm{TM}}$ software (Estimation Program Interface Suite; U.S. Environmental Protection Agency, 2009c). The most conservative toxicity value (lowest concentration using standard test species and durations) from the chosen source was selected for each constituent. A level-of-concern of 0.5 was used to convert acute fish and invertebrate toxicity values to values comparable to acute aquatic-life benchmarks, consistent with OPP methodology (U.S. Environmental Protection Agency, 2009b). This toxicity information was used in defining three NTAS aquatic-life "bins" (AL bins), as described in Norman and others (2012) and shown in table B2.1 at http://pubs.usgs.gov/sir/2012/5218/downloads/tableB2_1-3. $p d f)$. These AL bins are consistent with those described in the "Human-Health Effects Information from the ACToR Database" section in the main body of the report, although the concentration criteria for acute toxicity appear to differ because of the application of the level-of-concern of 0.5 ; for example, 
the threshold of less than 50 micrograms per liter for AL bin 1 in table B2.1 is equivalent to the criterion of less than 100 micrograms per liter for AL bin 1 used in the main body of the report.

A flow chart of the prioritization procedure is given in figure B2.1 with screening pathways (for example, P1, OF2, DEG3) described in table B2.2 at http://pubs.usgs.gov/ sir/2012/5218/downloads/tableB2_1-3.pdf). This procedure was developed using the procedure for lipophilic organic compounds in sediment (Group F) as a starting point and revising as appropriate for pesticides in sediment. Input on this process was provided by members of the NTAS work group and Robert Gilliom of the USGS NAWQA Program's Pesticide National Synthesis group.

Evaluation of detection frequency data from selected USGS programs was one component of the procedure used to prioritize pesticide constituents for sediment, as shown in figure B2.1. Data were obtained from the following sources:

- NAWQA streambed-sediment data for 34 organochlorine pesticides and degradates collected during 1992-2001 from streams draining multiple land uses (176-242 samples from agricultural, 71-125 samples from urban, and 235-361 samples from mixed land use) (Gilliom and others, 2006);

- NAWQA sediment-core data (155 samples) for 14 organochlorine pesticides and degradates collected during 1994-2001 from 38 urban and reference lakes in the United States (Van Metre and Mahler, 2005); and

- USGS Toxic Substances Hydrology Program streambed and suspended-sediment data for 67 constituents (including legacy and current-use pesticide constituents) collected during 2001-08 from streams draining agricultural (California) and urban (national) land uses (Norman and others, 2012).

Constituents with detection frequency (DF) greater than 10 percent were placed into the highest-priority tier, NTAS Tier 1, by pathway P1 in the flow chart (fig. B2.1); this assignment based on DF is coupled with the understanding that pesticides generally are designed to have some degree of toxicity. Infrequently detected constituents (DF less than 1 percent) were placed into the lowest-priority tier, NTAS Tier 3, by pathway P9 (fig. B2.1), unless other factors (that is, pathways OF1 or OF2) subsequently elevated them to a higher tier. Constituents of intermediate occurrence (DF of 1 to 10 percent) were further evaluated through the use of AL bins.

Evaluation of pesticide concentrations from the aforementioned data sources, by comparison to benchmarks and the use of AL bins, was a second component of the procedure used to prioritize constituents (fig. B2.1; table B2.2). If the detection frequency for a constituent was greater than 1 percent and constituent concentrations were greater than the sediment benchmark for that constituent, that constituent was determined to have "high" toxicity and was placed into Tier 1 (fig. B.2.1; table B.2.1); this criterion was consistent with the criteria used for evaluating lipophilic organic compounds in sediment (Group F). Similarly, constituents in AL bins 1 and 2 were determined to have "high" toxicity and were placed into Tier 1 or Tier 2, depending on subsequent evaluation of pesticide use and persistence (fig. B2.1; table B2.2). Constituents with "high" aquatic-life toxicity (AL bins 1 or 2) and a DF of less than 5 percent that are no longer used and that are not overly persistent (soil half-life less than 1 year) were placed into Tier 2. Constituents in AL bin 3 or with no information available (NIA) were determined to have "low" toxicity and were placed into Tier 1 or Tier 2 , depending on a subsequent evaluation of pesticide use. Constituents with "low" aquaticlife toxicity (AL bin 3) were placed into Tier 2, unless they had high (within top 10th percentile of use by volume) or increasing pesticide use, in which case they would have been placed into Tier 1; however, no constituents actually met this combination of criteria.

Evaluation of predicted pesticide occurrence, on the basis of physical-chemical properties or agricultural and nonagricultural use data, was a third component of the prioritization procedure. Sources of measured or estimated physical-chemical properties - persistence, hydrophobicity, and soil organic carbon-water partition coefficient $\left(K_{\mathrm{OC}}\right)$-were the Pesticide Properties Database (PPDB) from the European Commission FOOTPRINT project (European Commission, 2011), literature sources compiled by the NAWQA Pesticide National Synthesis Project (Norman and others, 2012), and experimental and estimated data from EPI Suite (U.S. Environmental Protection Agency, 2009c). The properties and thresholds used to predict likelihood of occurrence in sediment are summarized in table B2.3 at http://pubs.usgs.gov/sir/2012/5218/downloads/ tableB2_1-3.pdf). Constituents that were found to be persistent and hydrophobic, or stable with a high tendency to sorb to organic matter, were evaluated for aquatic-life toxicity, as described previously. Constituents that did not meet thresholds for persistence and hydrophobicity or sorption to organic matter were placed into NTAS Tier 3 (fig. B2.1). Estimates of agricultural pesticide use for 2007 were obtained from a proprietary database developed by DMRkynetec (2007), currently (2012) GfK Kynetec, and estimates of nonagricultural use collected during 2000-07 were obtained from the USEPA (Gail P. Thelin, U.S. Geological Survey, written commun., December $15,2009)$. Trends in agricultural and nonagricultural pesticide use - increasing or decreasing - from the most recent 5 years of data (2003-07) were used qualitatively in the screening procedure for pesticide constituents in sediment. Conceptually, the flow chart allows for constituents with low aquatic toxicity but high or increasing pesticide use to be placed in Tier 1 (fig. B2.1); however, in practice, no constituents met both of these criteria.

The pesticide prioritization procedure also considered other agency or organizational priorities as a fourth component (fig. B2.1), and these priorities could be used to elevate a constituent to a higher-priority tier. Constituents were considered to be of priority to other agencies if they were on the State FIFRA (Federal Insecticide, Fungicide, and Rodenticide 


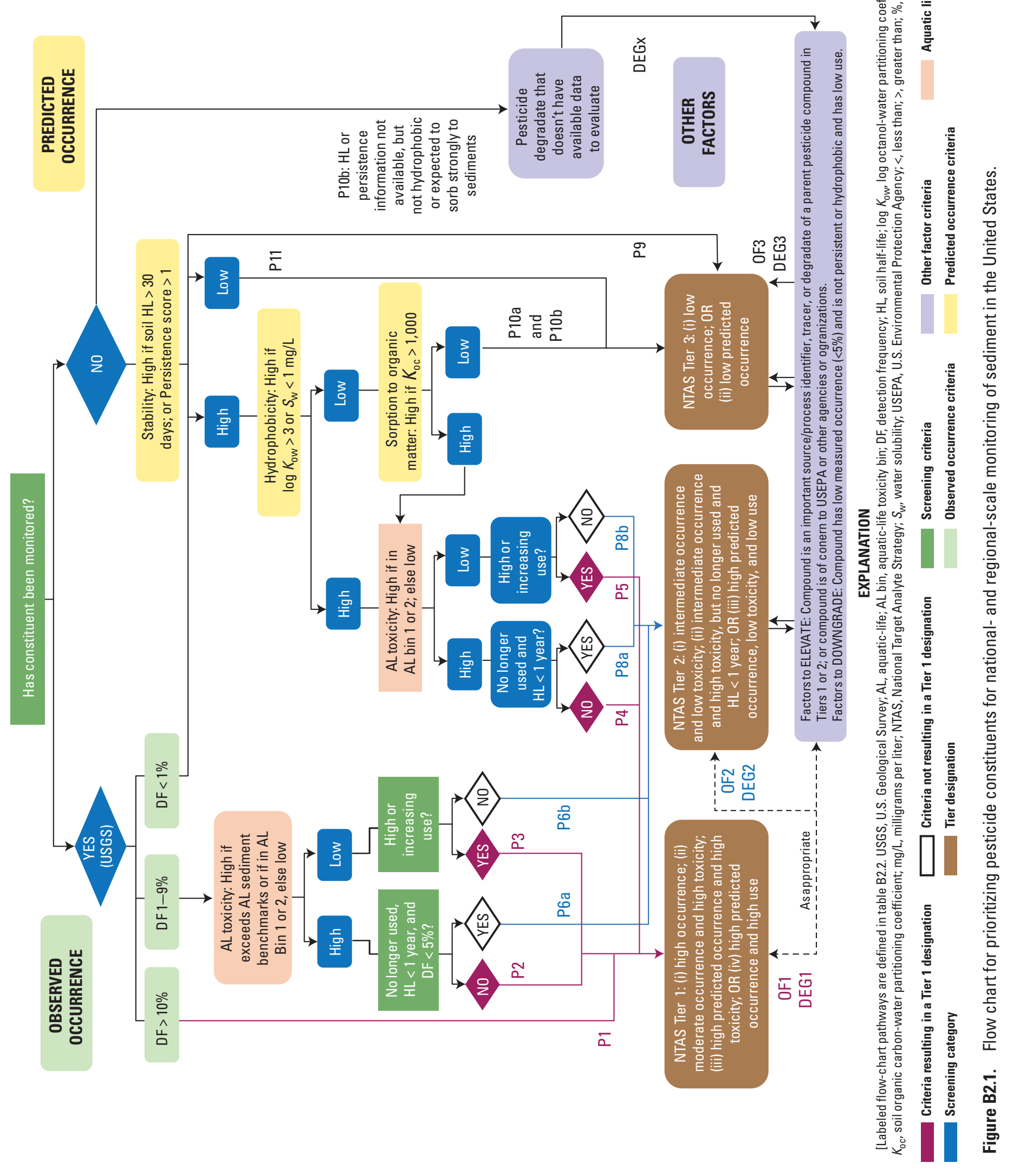


Act) Issues Research and Evaluation Group's (SFIREG) list of pesticides of water-quality concern (Association of American Pesticide Control Officials, 2005), were on the USEPA list of High Production Volume chemicals (U.S. Environmental Protection Agency, 2010b), were on the USEPA Toxics Release Inventory Persistent Bioaccumulative and Toxic list (U.S. Environmental Protection Agency, 2010c), or were on the USEPA Great Lakes Initiative list of bioaccumulative chemicals of concern (U.S. Environmental Protection Agency, 2000).

Pesticide degradates that could not be evaluated by the screening procedure because of a lack of data were placed in the same NTAS Tier as their parent compound. Degradates that were evaluated on the basis of their own data and placed into a lower NTAS Tier than their parent compound (for example, were not predicted to be persistent or hydrophobic) were reevaluated to determine if other factors indicated that they should be elevated to the same NTAS Tier as their parent compound. Degradates placed into an NTAS Tier to match their parent compound(s) were indicated by the various degradate (DEG) pathways (that is, DEG1, DEG2, or DEG3) (fig. B2.1; table B2.2).

\section{Results of Prioritization of Pesticides in Sediment}

A total of 173 pesticide constituents (not counting naphthalene, triphenyl phosphate, and zinc, which were prioritized using procedures for other constituent groups) were placed into NTAS Tier 1 for sediment and warrant consideration for national- or regional-scale monitoring (table B2.4 at http:// pubs.usgs.gov/sir/2012/5218/downloads/tableB2_4-7.xls). Of these, 106 constituents are on USGS laboratory schedules currently available (2011) for sediment, and an additional 67 constituents warrant consideration for methods development for NAWQA Cycle 3 monitoring. Constituents that were placed into either Tier 2 (65 constituents of intermediate priority) or Tier 3 (364 constituents of low or no priority) do not warrant consideration for ambient monitoring in sediment (table B2.5 at http://pubs.usgs.gov/sir/2012/5218/downloads/tableB2_4-7. $x l s)$.

Modifications to the prioritization criteria could be considered to reduce the number of Tier 1 constituents, if necessary to conserve resources, or to allow greater focus on certain objectives, such as monitoring trends in legacy constituents, characterizing sediment toxicity, or documenting fate and occurrence of high-use pesticides. Three modifications that could be considered (and numbers of constituents that would be affected) are as follows:

1. Modify stability threshold for predicted occurrence from soil half-life greater than 30 days to soil half-life greater than 60 days (affects 19 constituents).

2. Modify hydrophobicity threshold for predicted occurrence from $\log K_{\text {Ow }}$ greater than 3 to $\log K_{\text {Ow }}$ greater than 4 (affects 27 constituents).
3. Modify aquatic toxicity threshold to include only the most toxic compounds (AL bin =1) (affects 51 constituents).

Collectively, if all three changes were made, the number of Tier 1 constituents could be reduced to the 107 constituents that are the most persistent, hydrophobic, and toxic.

\section{Basis for Prioritization for Pesticides in Sediment}

A simplified flow chart illustrating the placement of pesticide constituents into NTAS Tier 1 for sediment is shown in figure B2.2 (see fig. B2.1 for the complete flow chart and table B2.2 for pathway descriptions). Including naphthalene, triphenyl phosphate, and zinc, which were prioritized using procedures for other constituent groups, a total of 176 ( 29 percent of the 605 constituents evaluated) pesticide constituents were placed into Tier 1 . Of the 173 constituents evaluated using the procedures for pesticides in sediment, 30 are organochlorine pesticides or degradates, most of which are legacy compounds without current use. Broken down by their main pathways, 36 percent (62) of the Tier 1 constituents were identified on the basis of frequent detection in USGS monitoring studies (observed) or a combination of intermediate occurrence (observed), potential toxicity to aquatic life, and pesticide use; 42 percent (72) were placed into Tier 1 on the basis of predicted likelihood of occurrence, aquatic-life toxicity, and pesticide use; and 22 percent (39) constituents were placed into Tier 1 on the basis of other factors or because they are degradates of parent compounds in Tier 1 (fig. B2.2). A more detailed illustration of results for Tier 1 , broken down by prioritization pathway, is shown in figure B2.3.

Some of the Tier 1 pesticide constituents for sediment are included in national regulatory programs or other programs not necessarily specific to sediment (table B2.4). These include 6 constituents that are listed as persistent, bioaccumulative, and toxic by the USEPA Toxics Release Inventory (U.S. Environmental Protection Agency, 2010c), and 15 constituents that are listed as bioaccumulative chemicals of concern for the Great Lakes Initiative (U.S. Environmental Protection Agency, 2000). Additionally, 23 constituents are listed on the SFIREG list of pesticides of water-quality concern (Association of American Pesticide Control Officials, 2005), and 7 constituents are considered to be highproduction-volume chemicals (U.S. Environmental Protection Agency, 2010b).

In contrast to most other constituent groups, most pesticides are anthropogenic compounds that, by definition, are biologically active and designed to be toxic to target organisms. Information on toxicity to aquatic organisms generally is more abundant for this NTAS constituent group than the other groups; however, data are lacking for some pesticide constituents, particularly for pesticide degradates. Of the 173 constituents in Tier 1 for sediment, 45 percent are very highly toxic to aquatic organisms, as defined by the USEPA (U.S. Environmental Protection Agency, 2011); these correspond to 
OBSERVED

OCCURRENCE
PREDICTED OCCURRENCE
Detection frequency greater than 10 percent (36 compounds)

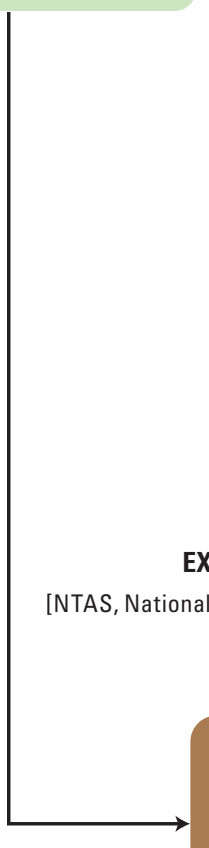

Detection frequency 1-9 percent AND

- Exceeds sediment benchmarks or moderate to high aquatic-life toxicity, and current pesticide use, or

- Low or unknown aquatic-life toxicity, but high or increasing use

(26 constituents)

EXPLANATION

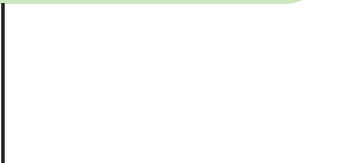

Persistent and hydrophobic AND

- Moderate to high aquatic-life toxicity and current pesticide use, or

- Low or unknown aquatic-life toxicity, but high or increasing use

(72 constituents)

\section{NTAS Tier 1: high-priority constituents \\ (173 constituents, not including 3 constituents prioritized in other constituent groups)}

Figure B2.2. Simplified flow chart for prioritzing pesticide constituents of high priority for national- and regional-scale monitoring of sediment in the United States.

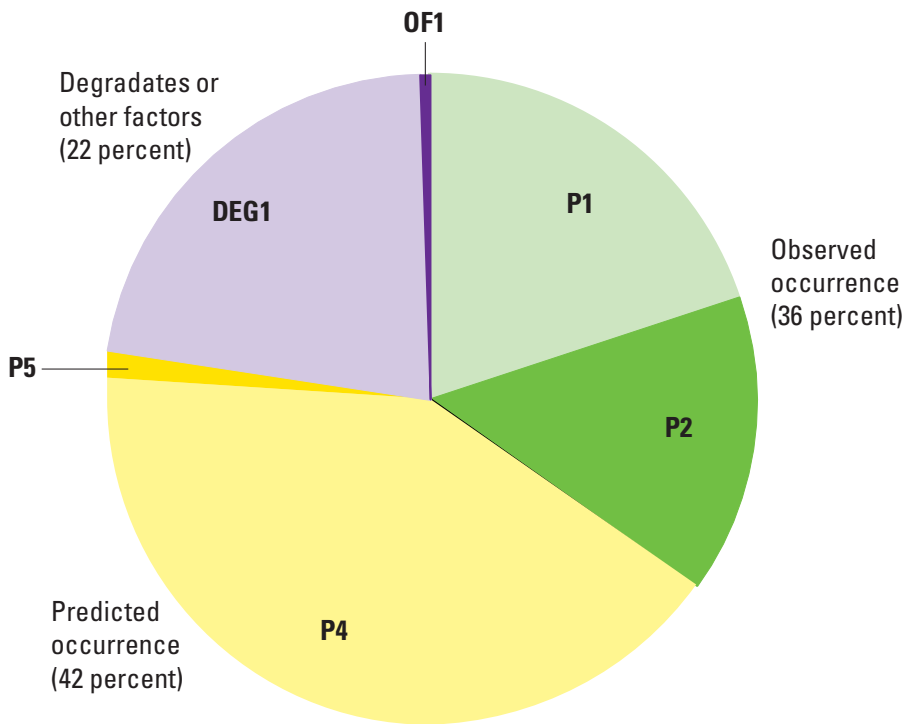

\section{EXPLANATION}

Pathways to NTAS Tier 1 (173 constituents)Pathways defined in table B2.2

P1 Detection frequency greater than 10 percent

P2 Intermediate detection frequency, moderate or high aquatic toxicity, current use or long half-life

P4 Moderate or high aquatic toxicity, current use or long half-life

P5 Low aquatic toxicity, high or increasing use

DEG1 Degradate of NTAS Tier 1 parent compound

OF1 Otherfactors

Figure B2.3. Detailed breakdown of pesticide constituents in sediment prioritized for National Target Analyte Strategy (NTAS) Tier 1 by prioritization pathway. 
constituents in AL bin 1. An additional 32 percent are in $\mathrm{AL}$ bin 2. Together, more than three-quarters of the Tier 1 pesticide constituents were classified as "high" toxicity, as defined for this prioritization (fig. B2.1).

\section{Feasibility of Implementation for High-Priority Pesticides for Sediment}

A summary of information on analytical methods available in 2011 for pesticides in sediment is provided on table B2.6 at http://pubs.usgs.gov/sir/2012/5218/downloads/ tableB2_4-7.xls), and reporting levels are provided on table B2.7 at http://pubs.usgs.gov/sir/2012/5218/downloads/ tableB2_4-7.xls). These tables summarize pesticides that are included on 11 USGS laboratory schedules for sediment, representing methods from the National Water Quality Laboratory, the California Water Science Center Pesticide Fate Research Laboratory, and the Kansas Water Science Center Organic Geochemistry Research Laboratory. The 106 pesticide constituents in Tier 1 that are currently available on one or more of these schedules (table B2.4) will need to be evaluated to determine which constituents could be combined into fewer methods. The 69 new pesticide constituents in Tier 1 that are not available on existing USGS laboratory schedules will need to be evaluated for feasibility of integrating into existing analytical methods or development of new methods, as needed.

One implementation approach for the analysis of pesticides in sediment is to split the list of constituents into two groups with different analytical methods. Several USGS methods using gas chromatography with mass spectrometry (GC/MS) are available, and new constituents could be added to an existing laboratory schedule. The most comprehensive USGS laboratory schedule that could be used for Tier 1 pesticides in sediment is for a GC/MS method with microwaveassisted extraction and sample clean-up using gel-permeation chromatography and either stacked carbon and alumina solidphase extraction cartridges or a deactivated Florisil column (Smalling and Kuivila, 2008); this method has been refined to achieve good recovery of pyrethroids (Hladik and others, 2009) and could be used as a base technology for revision to include additional constituents.

Many of the pesticide degradates are more amenable to high-performance liquid-chromatography with mass spectrometry (LC/MS) compared to GC/MS because of their chemical and physical properties or thermal instability. Although several USGS LC/MS methods have been developed for sediment, none can accommodate the number of constituents or chemical classes that would be required. New methods may be needed to capture the additional Tier 1 pesticides, including the more chemically polar constituents (molecules with an electric dipole or separation of charge), many of which are not on current USGS laboratory schedules.

\section{Knowledge and Concerns of Pesticides in Sediment as a Constituent Group}

Occurrence and concentration data for pesticides in sediment are of interest to resource managers from an aquatic-life perspective. Pesticides have the potential to cause unintended adverse effects to nontarget organisms that come into contact with contaminated suspended or streambed sediment. Extensive pesticide use and the nonpoint-source nature of releases from pest-management applications can result in widespread occurrence of these constituents in the environment. For streambed sediment, one pressing concern is to benthic organisms in streams affected by agricultural or nonagricultural pesticide application or that have an accumulation of legacy pesticides. An understanding of pesticide occurrence can be useful toward improving the management of pesticides in the future.

Several benchmarks are available for pesticides in sediment (including those considered in this prioritization); however, these benchmarks are guidelines and are not used in the same regulatory context as are benchmarks for water. This lower level of regulatory emphasis, compared to regulations concerning water, can result in less attention to monitoring of sediment, even though the effects of pesticides in sediment on aquatic life can have underappreciated and poorly understood long-term consequences, including potential effects on endangered species. Sediments can interact with the water column and act as a continual source of sorbed legacy and current-use contaminants. Pesticide occurrence and concentrations in streambed sediment and lake cores have been characterized to some degree in large-scale assessments of major hydrologic systems (Gilliom and others, 2006; Van Metre and Mahler, 2005; Lopes and Furlong, 2001). Despite uses being discontinued 20-30 years ago, some legacy organochlorine pesticides and degradates have been found to occur widely in streambed sediment across various land-use settings, sometimes at concentrations greater than aquatic-life benchmarks for sediment, which demonstrates their persistence in the environment.

Areas of scientific interest for pesticides in sediment include (1) characterizing how occurrence relates to various land uses, as well as to agricultural and nonagricultural pesticide use; (2) determining factors that affect transport to streams; (3) characterizing the partitioning of constituents between streambed sediment and the water column (including suspended sediment); (4) characterizing the occurrence, toxicity, and fate of legacy pesticides and degradates in streambed sediment; (5) characterizing the toxicity of degradates relative to their parent compounds, and (6) determining potential exposure and effects of pesticides on benthic organisms through comparison to sediment-quality benchmarks. NAWQA's role in pesticide studies in sediment could include monitoring for legacy pesticides and degradates and for current-use pesticides and degradates that have not yet been studied, but which are likely to occur and contribute to adverse effects on nontarget aquatic organisms. Long-term trends in pesticide occurrence in streambed sediment are of interest, and the potential for 
combined toxic effects from mixtures of legacy compounds with frequent occurrence and current-use compounds that enter into aquatic ecosystems is an area of study to which NAWQA could contribute. In addition, the USGS Toxic Substances Hydrology Program (http://toxics.usgs.gov/) conducts targeted studies of current-use and understudied pesticide constituents, including pyrethroids, fungicides, and pesticide degradates in suspended and streambed sediment in agricultural and urban environments on regional and national scales.

\section{References for Pesticides in Sediment (Group B2)}

Association of American Pesticide Control Officials, 2005, State FIFRA (Federal Insecticide, Fungicide, and Rodenticide Act) Issues Research and Evaluation Group's (SFIREG) State List of Pesticides of Water Quality Concern: accessed May 12, 2012, at http://www.epa.gov/ compliance/resources/policies/state/grants/fifra/08-10appendix11.pdf.

Burkhardt, M.R., Zaugg, S.D., Smith, S.G., and ReVello, R.C., 2006, Determination of wastewater compounds in sediment and soil by pressurized solvent extraction, solid-phase extraction, and capillary-column gas chromatography/ mass spectrometry: U.S. Geological Survey Techniques and Methods, book 5, chap. B2, 33 p.

Canadian Council of Ministers of the Environment, 2002, Canadian sediment quality guidelines for the protection of aquatic life, summary tables, in Canadian Environmental Quality Guidelines: Winnipeg, Canada, Canadian Council of Ministers of the Environment, 7 p., accessed August 3, 2009, at http://ceqg-rcqe.ccme.ca/.

DMRkynetec, 2007, Proprietary agricultural pesticide-use data from DMRkynetec (known as GfK Kynetec after January 19, 2010).

European Commission, 2011, The FOOTPRINT Pesticide Properties Database (Functional TOOls for Pesticide RIsk assessmenNt and managemenT) (funded by the European Commission as part of its 6th Framework Programme for Research and Technological Development): accessed on January 10, 2011, at http://www.eu-footprint.org/ppdb.html.

Furlong, E.T., Vaught, D.G., Merten, L.M., Foreman, W.T., and Gates, P.M., 1996, Methods of analysis by the U.S. Geological Survey National Water Quality LaboratoryDetermination of semivolatile organic compounds in bottom sediment by solvent extraction, gel permeation chromatographic fractionation, and capillary-column gas chromatography/mass spectrometry: U.S. Geological Survey OpenFile Report 95-719, 67 p.
Gilliom, R.J., Barbash, J.E., Crawford, C.G., Hamilton, P.A., Martin, J.D., Nakagaki, Naomi, Nowell, L.H., Scott, J.C., Stackelberg, P.E., Thelin, G.P., and Wolock, D.M., 2006, The quality of our Nation's waters-Pesticides in the Nation's streams and ground water, 1992-2001, Supporting information, appendix 7C: U.S. Geological Survey Circular 1291, accessed March 19, 2012, at http://water.usgs.gov/ nawqa/pnsp/pubs/circ1291/appendix7/7c.html.

Hladik, M.L., and Kuivila, K.M., 2008, Analysis of chlorothalonil and three degradates in sediment and soil: Journal of Agricultural and Food Chemistry, v. 56, no. 7, p. 2,3102,314 .

Hladik, M.L., Smalling, K.L., and Kuivila, K.M., 2009, Methods of analysis - Determination of pyrethroid insecticides in water and sediment using gas chromatography/ mass spectrometry: U.S. Geological Survey Techniques and Methods 5-C2, 18 p., accessed April 7, 2011, at http://pubs. usgs.gov/tm/tm $5 \mathrm{c} 2 /$.

Jha, V.K., and Wydoski, D.S., 2003, Methods of analysis by the U.S. Geological Survey National Water Quality Laboratory-Determination of organophosphate pesticides in bottom sediment by gas chromatography with flame photometric detection: U.S. Geological Survey Water-Resources Investigations Report 02-4222, $30 \mathrm{p}$.

Lopes, T.J., and Furlong, E.T., 2001, Occurrence and potential adverse effects of semivolatile organic compounds in streambed sediment, United States, 1992-1995: Environmental Toxicology and Chemistry, v. 20, no. 4, p. 727-737.

MacDonald, D.D., Ingersoll, C.G., and Berger, T.A., 2000, Development and evaluation of consensus-based sediment quality guidelines for freshwater ecosystems: Archives of Environmental Contamination and Toxicology, v. 39, p. 20-31.

Noriega, M.C., Wydoski, D.S., and Foreman, W.T., 2004, Methods of analysis by the U.S. Geological Survey National Water Quality Laboratory-Determination of organochlorine pesticides and polychlorinated biphenyls in bottom and suspended sediment by gas chromatography with electroncapture detection: U.S. Geological Survey Water-Resources Investigations Report 03-4293, 46 p.

Norman, J.E., Kuivila, K.M., and Nowell, L.H., 2012, Prioritizing pesticide compounds for analytical methods development: U.S. Geological Survey Scientific Investigations Report 2012-5045, 206 p. (Also available at http://pubs. usgs.gov/sir/2012/5045/pdf/sir20125045.pdf.)

Smalling, K.L., and Kuivila, K.M., 2008, Multi-residue method for the analysis of 85 current-use and legacy pesticides in bed and suspended sediments: Journal of Chromatography A, v. 1210, no. 1, p. 8-18. 
U.S. Environmental Protection Agency, 2000, Great Lakes Initiative-Bioaccumulative chemicals of concern affected by the ban on mixing zones in the Great Lakes (updated October 9, 2009): U.S. Environmental Protection Agency, accessed January 10, 2010, at http://water.epa.gov/lawsregs/ lawsguidance/cwa/criteria/gli/chemicals.cfm.

U.S. Environmental Protection Agency, 2004, The incidence and severity of sediment contamination in surface waters of the United States, National Sediment Quality Survey (2d ed.), Appendix C-Values used for chemicals evaluated: U.S. Environmental Protection Agency, Office of Science and Technology, EPA-823-R-04-007, 280 p.

U.S. Environmental Protection Agency, 2007, ECOTOXicology Database System, version 4.0: U.S. Environmental Protection Agency, Office of Research and Development and the National Health and Environmental Effects Research Laboratory's Mid-Continent Ecology Division, accessed May 12, 2010, at http://www.epa.gov/ecotox/.

U.S. Environmental Protection Agency, 2009a, OPP Pesticide Ecotoxicity Database (database version April 10, 2009): U.S. Environmental Protection Agency, Office of Pesticide Programs, accessed January 22, 2010, at http://www. ipmcenters.org/Ecotox/index.cfm.

U.S. Environmental Protection Agency, 2009b, Office of Pesticide Programs' aquatic life benchmarks (freshwater) (updated April 9, 2009): U.S. Environmental Protection Agency, Office of Pesticide Programs, accessed May 12, 2010, at http://www.epa.gov/oppefedl/ecorisk_ders/ aquatic_life_benchmark.htm.

U.S. Environmental Protection Agency, 2009c, EPI Suite ${ }^{\mathrm{TM}}$ version 4.0: U.S. Environmental Protection Agency, Office of Pollution Prevention and Toxics and Syracuse Research Corporation.
U.S. Environmental Protection Agency, 2010a, Pesticide reregistration status (main page and decision documents and fact sheets for individual chemicals): accessed December 27, 2010, at http://www.epa.gov/pesticides/reregistration/ status.htm.

U.S. Environmental Protection Agency, 2010b, High Production Volume (HPV) Challenge: accessed December 28, 2010, at http://www.epa.gov/HPV/.

U.S. Environmental Protection Agency, 2010c, Toxics Release Inventory TRI PBT Chemical List: accessed December 28, 2010, at http://www.epa.gov/tri/trichemicals/pbt chemicals/ pbt_chem_list.htm.

U.S. Environmental Protection Agency, 2011, PesticidesEnvironmental effects, technical overview of ecological risk assessment analysis phase-Ecological effects characterization: accessed January 10, 2011, at http://www.epa.gov/ oppefed1/ecorisk_ders/toera_analysis_eco.htm.

Van Metre, P.C., and Mahler, B.J., 2005, Trends in hydrophobic organic contaminants in urban and reference lake sediments across the United States, 1970-2001: Environmental Science and Technology, v. 39, no. 5, p. 5,567-5,574.

Zaugg, S.D., Burkhardt, M.R., Burbank, T.L., Olsen, M.C., Iverson, J.L., and Schroeder, M.P., 2006, Determination of semivolatile organic compounds and polycyclic aromatic hydrocarbons in solids by gas chromatography/mass spectrometry: U.S. Geological Survey Techniques and Methods, book 5, chap. B3, 44 p. 


\title{
Supplemental Information C.
}

\section{Prioritization of Pharmaceuticals and Hormones in Water or Sediment (Group C)}

\author{
By Lisa D. Olsen, Duane S. Wydoski, Ed T. Furlong, and Michael J. Focazio
}

\section{Abbreviations and Acronyms Used in Supplemental Information C}

$\begin{array}{ll}\text { AL bins } & \text { aquatic-life toxicity "bins" (USGS NAWQA) } \\ \text { CCL3 } & \text { Contaminant Candidate List 3 (USEPA) } \\ \text { ECOTOX } & \text { ECOTOXicology (database, USEPA) } \\ \text { EPI Suite }{ }^{\text {TM }} & \text { Estimation Program Interface Suite (screening software, USEPA) } \\ \text { GC/MS } & \text { gas chromatography with mass spectrometry } \\ \text { GC/MS/MS } & \text { gas chromatography with tandem mass spectrometry } \\ \text { LC/MS } & \text { liquid chromatography with mass spectrometry } \\ \text { LC/MS/MS } & \text { liquid chromatography with tandem mass spectrometry } \\ \text { LS } & \text { laboratory schedule } \\ \text { log K } & \text { base-10 logarithm of the octanol-water partition coefficient } \\ \text { NAWOA } & \text { National Water-Quality Assessment (USGS) } \\ \text { NTAS } & \text { National Target Analyte Strategy (USGS NAWQA) } \\ \text { NWOL } & \text { National Water Quality Laboratory (USGS) } \\ \text { PBT Profiler } & \text { Persistent, Bioaccumulative, and Toxic Profiles Estimated for Organic Chemicals (USEPA) } \\ \text { SPE } & \text { solid-phase extraction } \\ \text { Toxics Program } & \text { Toxic Substances Hydrology Program (USGS) } \\ \text { USEPA } & \text { U.S. Environmental Protection Agency } \\ \text { USGS } & \text { U.S. Geological Survey }\end{array}$


This supplemental information section of the report describes the prioritization of pharmaceuticals and hormones in water or sediment (Group C) by the U.S. Geological Survey (USGS) National Target Analyte Strategy (NTAS) work group for national- and regional-scale ambient monitoring in the United States. This prioritization was done in support of planning for the third decade (Cycle 3) of the National WaterQuality Assessment (NAWQA) Program. The feasibility of implementing analytical methods for high-priority pharmaceutical constituents, and knowledge and concerns about pharmaceutical constituents also are described in this section.

A total of 406 pharmaceuticals and hormones were considered for prioritization for water and sediment. These pharmaceutical constituents included selected analytes from several USGS National Water Quality Laboratory (NWQL) laboratory schedules (LS) - 1433, 2434, 4433, 5433, 6434, 8058 , and the proposed replacement for 2080 - as well as analytes on laboratory schedules LCAB and LCAS from the Kansas Organic Geochemistry Research Laboratory. Additional constituents were prioritized that are not on current (2011) USGS laboratory schedules. These constituents were identified as being of potential concern with respect to human health or aquatic life, are of interest to other Federal agencies, are of international concern, or otherwise were found or predicted to have a high likelihood of occurrence in the environmental matrixes of interest (water or sediment). The set of constituents prioritized in this report might omit human or veterinary pharmaceutical constituents that are very new or that have not yet been identified as being important with respect to potential occurrence in the environment; therefore, additional pharmaceutical constituents might warrant consideration as new information becomes available.

Of the 406 pharmaceuticals or hormones that were evaluated as pharmaceutical constituents in water or sediment, 4 constituents overlap with other NTAS constituent groups. These were three pesticides in water or sediment for Group B (oxytetracycline, penicillin $\mathrm{G}$, and thiabendazole) and one wastewater-indicator compound in water for Group I (caffeine). The three pharmaceutical constituents that also are used as pesticides were prioritized using the procedures for both groups (Group B described in the "Supplemental Information B" section, and Group C described later in this section); results for Group $\mathrm{C}$ were given preference because this process resulted in equal- or higher-priority tier placements as those obtained for Group B. The pharmaceutical that also is a wastewater-indicator compound (caffeine) was retained in both groups (Groups $\mathrm{C}$ and I), and this constituent was placed into NTAS Tier 1 through both prioritization processes.

\section{Prioritization of Pharmaceutical Constituents in Water or Sediment}

This section describes the methods used for prioritization of pharmaceutical constituents in water or sediment, the results of the prioritization, and the basis for the prioritization, using specific examples from the results. The predominant mechanism of entry into the environment for the pharmaceutical constituents is understood to be through wastewater, as indicated from a review of scientific literature (described in subsequent sections). Subsequent partitioning between water and sediment, however, can cause specific constituents to be found (1) predominantly in the aqueous phase (monitored as filtered-water samples), (2) predominantly adsorbed to sediment particles (monitored as suspended-sediment or bedsediment samples), or (3) distributed between both of these matrixes. For these reasons, pharmaceutical constituents were prioritized by evaluating their likelihood of occurrence in environmental waters or sediment, coupled with their likelihood of effects to human health or aquatic life, and then their physical-chemical characteristics were reviewed to determine whether partitioning to additional phases was likely.

\section{Prioritization Methods for Pharmaceutical Constituents in Water or Sediment}

Pharmaceutical constituents were prioritized into NTAS Tiers 1, 2, or 3 using criteria described in this section of the report and illustrated in the flow chart in figure C.1. The prioritization relied heavily on literature sources, which are identified for each constituent in the results tables and referenced at the end of this supplemental information section. Some of these literature sources (Kostich and Lazorchak, 2008; Besse and Garric, 2008) reported the results of robust prioritization methods that incorporated factors such as sales or use volumes and the effects of water treatment for many constituents. For the NTAS prioritization process, the results of these studies were used for the constituents that they addressed rather than attempt to repeat their work, which spared resources. For other constituents, a compound-by-compound literature search was necessary to obtain the information needed for prioritization.

The prioritization approach for the pharmaceutical constituents in water or sediment took into consideration the relative lack of benchmarks for these constituents, and the possibility that long-term exposure to low concentrations (for example, nanograms per liter in water) could have effects on human health and aquatic life that are not yet fully understood (Purdom and others, 1994; Goodbred and others, 1997; Baronti and others, 2000). For this reason, concentrations relative to benchmarks could not be used consistently as a basis for prioritization, and a more qualitative approach was used to assign constituents to one of the three NTAS prioritization tiers:

- Tier 1. This tier includes pharmaceutical constituents that have the highest priority for ambient monitoring at the national or regional scale. Tier 1 constituents are those with the highest likelihood of occurrence in ambient water or sediment, and that have reason for concern based on human-health or aquatic-life effects, as indicated in the literature or other information sources described later. 


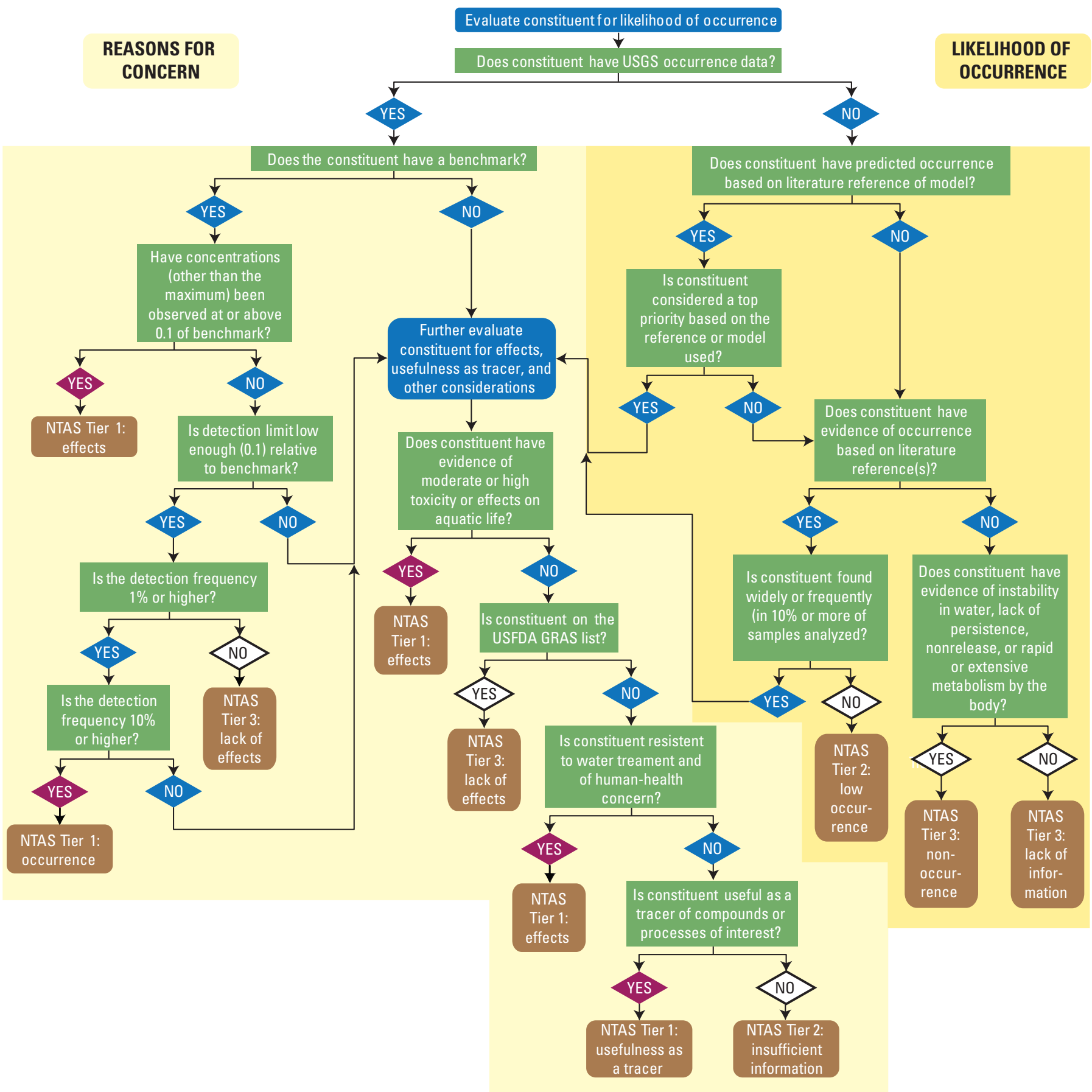

EXPLANATION

[USGS, U.S. Geological Survey; GRAS, Generally Recognized As Safe;

NTAS, National Target Analyte Strategy; USFDA, U.S. Food and Drug Administration; \%, percent]

Criteria resulting in a Tier 1 designation

Screening category
Criteria not resulting in a Tier 1 designation

Screening criteria

Figure C.1. Flow chart for prioritizing pharmaceuticals and hormones for national- and regional-scale monitoring of water or sediment in the United States. 
- Tier 2. This tier includes pharmaceutical constituents that are of intermediate priority for ambient monitoring at the national or regional scale. For the pharmaceuticals, Tier 2 constituents have some evidence of possible occurrence, but not of widespread occurrence, and have reason for concern based on human-health or aquatic-life effects, as indicated in the literature or other information sources described later.

- Tier 3. This tier includes pharmaceutical constituents that have no evidence of occurrence in ambient water or sediment or that have evidence of nonoccurrence. This tier also includes constituents that lack evidence of effects on human health or aquatic life. Tier 3 constituents with evidence of likely nonoccurrence include those that are unstable in water, extensively metabolized by the body, or discontinued for use in the United States. Although it is not impossible for some Tier 3 constituents to occur in localized areas of concentrated wastewater effluent or animal wastes, it is anticipated that they would not be found (or would be rarely found) in the ambient environment through a routine national or regional-scale monitoring program.

Criteria for prioritization were divided into two categories: (1) likelihood of occurrence, and (2) reasons for concern (including potential effects to human health or aquatic life) (fig. C.1). A constituent was required to meet criteria in both categories in order to be assigned to Tiers 1 or 2; however, a constituent that failed to meet the criteria for likelihood of occurrence could be placed into Tier 3 without being evaluated for reasons for concern because an understanding of potential human-health or aquatic-life effects was not needed for compounds that are unlikely to occur and thus are unlikely to be detected through ambient monitoring. The references used to support the prioritization are listed in tables C. $1 A, B ;$ C. $2 A, B$, and C.3 at http://pubs.usgs.gov/sir/2012/5218/downloads/ tableC.xls.

Likelihood of occurrence (right section of flow chart, fig. C.1) was documented either on the basis of occurrence data from USGS sources or external sources, or on the basis of predicted or modeled occurrence from internal or external sources. A constituent could be assigned to Tier 3 if no evidence was found to support its potential occurrence in the environment or if the constituent had evidence of likely nonoccurrence because of instability in water, lack of persistence, rapid or extensive metabolism by the body, or nonrelease (for example, if a constituent is used only for laboratory research in a controlled setting); these Tier 3 constituents were not evaluated further. Constituents with detection frequencies of 10 percent or higher in water or sediment were placed into Tier 1 without requiring further evaluation for reasons for concern on the basis that pharmaceuticals are explicitly designed to have biological effects; only a few pharmaceuticals met this criterion. Constituents with detection frequencies less that 1 percent based on USGS occurrence data, or for which occurrence in the literature was limited to point discharges of wastewater, sewage lagoons, landfill leachate, or other such heavily contaminated sites, were placed into Tier 2 . Constituents with an intermediate likelihood of occurrence- those with detection frequencies of 1-10 percent or with a literature designation of "top" or "high" priority on the basis of predicted or modeled occurrence - were evaluated further for reasons for concern before assigning them to a tier.

Reasons for concern (left section of flow chart, fig. C.1) included human-health effects, aquatic-life effects, and usefulness as a tracer. Constituents with observed concentrations equal to or greater than a factor of 0.01 of a human-health benchmark (for drinking water) or aquatic-life benchmark (for sediment) would have been placed into Tier 1; however, none of the pharmaceutical constituents had benchmarks at the time of this prioritization. Constituents were considered to have sufficient reason for concern for placement into Tier 1 if the chronic toxicity value for fish obtained from the USEPA's Persistent, Bioaccumulative, and Toxic Profiles Estimated for Organic Chemicals (PBT Profiler) screening tool (http://www. pbtprofiler.net/) was less than 10,000 micrograms per liter or if information from the U.S. Environmental Protection Agency's (USEPA) ECOTOXicology (ECOTOX) database (U.S. Environmental Protection Agency, 2007) placed them into a moderate or high NTAS aquatic-life "bin" (AL bin 1 or 2) (information on file with the NTAS work group). Constituents also could be placed into Tier 1 on the basis of literature sources documenting predicted or modeled occurrence if that source included toxicity or aquatic effects in its prioritization process, or if a constituent was considered particularly useful as a tracer of wastewater or leachate within the ambient environment. In addition, because pharmaceuticals generally are known to be biologically and potentially estrogenically active, constituents could be placed into Tier 1 if there was a clear mechanism of entry into the environment (based on the literature) and if persistence in water was 30 days or longer, or in sediment was 120 days or longer, based on information obtained from the PBT Profiler (U.S. Environmental Protection Agency, 2011). Interest in a constituent by other agencies or the international community (for example, presence on the USEPA Contaminant Candidate List 3 (CCL3); U.S. Environmental Protection Agency, 2010) was not by itself considered a reason for concern but was used as a starting point for identifying constituents with reason for concern based on toxicity, aquatic-life effects, persistence, or usefulness as a tracer.

After all constituents were initially evaluated, partitioning between water and sediment was considered. Constituents that were initially assigned to Tiers 1 and 2 for a particular matrix (water or sediment) were evaluated to determine whether occurrence was as likely for the other matrix, in which case, the constituent would be assigned to the same tier for both matrixes. If occurrence in the other matrix was less likely or unlikely, the constituent was assigned to a lower-priority tier for that other matrix. If occurrence in the other matrix was more likely, the constituent would be assigned to a higherpriority tier; however, in practice, this circumstance did not happen. Constituents that had been initially placed into Tier 3 
were retained in Tier 3 for both water and sediment. Sources of information used to evaluate constituents for partitioning included the following:

- The base-10 logarithm of the octanol-water partition coefficient $\left(\log K_{\text {OW }}\right)$ obtained from literature sources used in the prioritization process or as estimated values from the PBT Profiler, which come from the USEPA's EPI Suite ${ }^{\mathrm{TM}}$ software (Estimation Program Interface Suite; U.S. Environmental Protection Agency, 2009a) calculated using the estimation method described by Meylan and Howard (1996);

- Estimated percentage in each matrix relative to the total amount in the environment obtained from the PBT Profiler, calculated using the default settings of the Level III fugacity model from Mackay and others (1992); and

- Documented occurrence in reconnaissance studies, particularly if occurrence was documented in a matrix that was not predicted on the basis of $\log K_{\text {ow }}$ or fugacity model information; for example, cholesterol and some other natural sterols with $\log K_{\text {Ow }}$ values greater than 6 have been observed in unfiltered water samples (Kolpin and others, 2002; Barnes and others, 2008; Focazio and others, 2008) and were included in Tier 1 for water because occurrence in the aqueous phase cannot be ruled out.

Generally, a constituent was determined to be of concern predominantly for water if the $\log K_{\text {ow }}$ was less than 3.6, for both water and sediment if the $\log K_{\text {ow }}$ was between 3.6 and 6.0 , and predominantly for sediment if the $\log K_{\text {ow }}$ was greater than 6.0, except in cases in which the matrix information from the PBT Profiler or literature sources indicated a likelihood of occurrence in the nonpreferred matrix.

\section{Results of Prioritization of Pharmaceutical Constituents in Water or Sediment}

Reasons for each pharmaceutical constituent's placement into a particular NTAS tier and literature sources used in the prioritization process are provided or cited on tables C. $1 A, B$; C. $2 A, B$, and C.3. Of the 406 pharmaceutical constituents evaluated, 78 were assigned to Tier 1 (76 for water and 27 for sediment), 136 were assigned to Tier 2 (133 for water and 33 for sediment), and 349 were assigned to Tier 3 (197 for water and 346 for sediment); these numbers do not sum to 406 because of overlapping constituents between water and sediment. Of the 349 constituents assigned to Tier 3 for water or sediment, 193 constituents were identified as Tier 3 in both water and sediment (table C3).

\section{Basis for Prioritization of Pharmaceutical Constituents in Water or Sediment}

This section describes the resources that were used as the basis for the prioritization of pharmaceutical constituents by the NTAS work group. Constituents addressed in a national reconnaissance of pharmaceuticals and other organic wastewater contaminants in the United States (Barnes and others, 2008; Focazio and others, 2008) and those addressed in earlier large-scale USGS studies (Kolpin and others, 2002; Barnes and others, 2002) were reviewed for occurrence and detection frequency to assist in prioritization using the criteria described previously (fig. C.1). Constituents assigned to Tiers 2 or 3 on the basis of information from these large-scale studies were further evaluated for factors that could support an assignment to a higher-priority tier, as described later in this section. All but two constituents addressed in the national reconnaissance studies were assigned to Tier 1 or 2 after all steps of the evaluation.

Constituents presented in Batt and others (2008) also were evaluated. Constituents in this study were selected on the basis of a risk-based prioritization of 371 active pharmaceutical ingredients, as described in Kostich and Lazorchak (2008), which considered human drug sales, potency, metabolic inactivation, and ability to persist through wastewater treatment. Kostich and Lazorchak (2008) and Batt and others (2008) include some major metabolites of drugs that are mostly metabolized before elimination but might enter the environment through wastewater. Because these literature sources considered factors that directly relate to likelihood of occurrence and reason for concern, constituents detected in wastewater (from seven wastewater effluent sites) or surface-water samples (one stream) collected for Batt and others (2008) were assigned to Tier 1. Constituents listed, but not detected, in the study were assigned to Tier 2, unless additional information sources were identified to support an assignment to Tier 1. All constituents identified by Batt and others (2008) warrant method development (as Tier 1 constituents) or already have existing USGS methods or methods in development.

Constituents of interest to the USGS Toxic Substances Hydrology Program (hereafter abbreviated as Toxics Program) included 58 constituents in Tier 1 for water and 20 constituents in Tier 1 for sediment, and 89 constituents in Tier 2 for water and 19 constituents in Tier 2 for sediment. Since 1998, the Toxics Program's Emerging Contaminants Research project has prioritized analytes for method development using criteria that include usage or prescription data (where available), documented or suspected occurrence in the environment (for example, in water, wastewater, or sediment), anticipated persistence based on chemical and physical properties, compatibility with existing methods, potential for ecological effects, stakeholder input, and other criteria such as potential use as environmental tracers. Information to support this prioritization comes from contacts in other Federal agencies (for example, USEPA, U.S. Food and Drug Administration, and U.S. Department of Agriculture), external scientists, published literature, publically 
accessible databases, and from previous experience gained through ongoing research. Objectives of the NAWQA Program and the Toxics Program lead to some overlap in the prioritization of constituents for environmental matrixes that are of interest to NAWQA (water and sediment); however, the Toxics Program has interests in additional matrixes (for example, raw wastewater and source-affected environmental compartments) and in additional constituents that may be less likely to be detected through a routine ambient monitoring program, but that are important in pursuing their research goals. Occurrence information and literature sources provided by the Toxics Program were considered in the NTAS prioritization process. Method development activities for the Toxics Program likely will include constituents that were not placed into Tiers 1 or 2 because, as stated previously, the Toxics Program's objectives differ from those of the NAWQA Program. Methods for these additional constituents for the Toxics Program might be available at production-scale by the start of Cycle 3, and future research involving these constituents might provide new information at a later date that could warrant their inclusion in NAWQA monitoring.

Constituents on the USEPA Contaminant Candidate List 3 (CCL3) were prioritized on the basis of likelihood of occurrence and reason for concern as described previously in the section "Prioritization Methods for Pharmaceutical Constituents in Water or Sediment." Of the 10 pharmaceutical constituents on the CCL3, 9 are hormones and 1 is an antibiotic, and all have USGS analytical methods. USGS occurrence data were used in the prioritization process, along with toxicity information from the literature and the PBT Profiler. All 10 of the CCL 3 constituents were assigned to Tier 1 on the basis of these sources and are identified as "CCL3" in the reference columns on tables C. $1 A, B$.

Constituent-by-constituent Internet searches were performed, in addition to using the aforementioned sources, using a search strategy shown in table C.4 at http://pubs.usgs.gov/ sir/2012/5218/downloads/tableC.xls. Searching stopped when one or more references were found to support the likelihood of occurrence for a constituent or when all of the searchstrategy options were exhausted for a constituent; therefore, not all search terms were used for all constituents and not all possible references were provided for a given constituent. References supporting nonoccurrence were used only after all other search-strategy options were exhausted, and references supporting occurrence were considered to disprove those supporting nonoccurrence. In addition to using standard search engines, unpublished materials (for example, Wikipedia and manufacturer's Material Safety Data Sheets) sometimes were used as a source of references to more quickly target searches onto published sources or databases. Many of the constituents considered for prioritization had little information about environmental occurrence or effects on aquatic life. Compounds for which no evidence of occurrence could be found were assigned to Tier 3 . Constituents with evidence supporting occurrence (Tier 1 or 2) were evaluated further, as described previously. A low threshold of evidence was set for likelihood of occurrence for assigning constituents into Tier 2; any documented detection of a compound within an environmental compartment that could allow transfer to matrixes of interest for the NAWQA Program was considered sufficient, including detections as tentatively identified compounds and detections in samples of wastewater effluent or leachate from landfills or animal feeding operations. References from largerscale studies were preferred over those from smaller-scale studies, and Government-agency Web sites and databases and peer-reviewed publications were favored over nonpublished sources. For some constituents, the only information found was in nonpublished sources (excluding product marketing literature, which was not considered). References used to support the prioritization into Tiers 1, 2, or 3 are provided in tables C.1-C.3.

\section{Feasibility of Implementation for High-Priority Pharmaceutical Constituents}

Of the 78 constituents in Tier 1 (tables C.1A, B), 56 are on USGS laboratory schedules or have methods in the late stages of development and are high-priority constituents for continuation in NAWQA Cycle 3. A total of 88 of the 134 constituents in Tier 2 (tables C. $2 A, B$ ) are on existing USGS laboratory schedules or have methods in the late stages of development. The 22 Tier 1 constituents without USGS analytical methods would require method development and validation to the extent that this is feasible. Analytical methods for pharmaceuticals and hormones are still in development at the NWQL (Duane S. Wydoski, U.S. Geological Survey, written commun., 2010) and the Organic Geochemistry Research Laboratory at the Kansas Water Science Center (Michael T. Meyer, U.S. Geological Survey, written commun., 2009).

The older methods in use for pharmaceutical constituents warrant improvement or replacement. Previously, NAWQA and other USGS programs used LS 2080, which uses solidphase extraction (SPE) and liquid chromatography with mass spectrometry (LC/MS), for determining 14 pharmaceuticals in water (Furlong and others, 2008). This technique is prone to sample-preparation problems and lacks specificity needed for evaluation of additional pharmaceutical constituents. The NWQL is evaluating a combination of two techniques - gas chromatography with mass spectrometry (GC/MS) and highpressure liquid chromatography with tandem mass spectrometry (LC/MS/MS) - for the determination of pharmaceuticals in water (Duane S. Wydoski, U.S. Geological Survey, written commun., 2010). The use of negative-ion LC/MS/MS can be evaluated as a means of extending the instrument capability to add more high-priority constituents. The LC/MS/MS technique has greatly improved specificity in identification of compounds and uses direct aqueous injection, which circumvents problematic extraction steps and reduces the potential for cross-contamination. This new technique uses more expensive instrumentation, but requires less total labor and lower sample volumes (which can lower shipping costs) and 
has improved analytical performance. The planned suite of analytical techniques can be modified to accommodate most of the new Tier 1 constituents.

Antibiotic constituents can be analyzed using methods in development at the NWQL and Kansas Organic Geochemistry Research Laboratory. The method in development at the Kansas laboratory for the determination of antibiotics in water (LS "LCAB") uses LC/MS/MS and SPE, and a comparable method is in development for sediment (LS "LCAS"). These methods have been used successfully on a limited basis (Michael T. Meyer, U.S. Geological Survey, written commun., 2009), but additional method validation would be needed if these methods are adopted for the analysis of constituents for NAWQA Cycle 3 monitoring of water and sediment. The NWQL has developed a method for the determination of hormones in water and sediment using gas chromatography with tandem mass spectrometry (GC/MS/MS), using isotopic dilution and isolation by SPE; this method currently (2011) is undergoing review and approval. This technique shows adequate specificity; however, additional evaluation of the sample-preparation procedure is needed. This technique covers all of the hormones on the USEPA CCL3, some of which are new constituents in Tier 1 that have not previously been monitored by NAWQA. Both the NWQL and Kansas Organic Geochemistry Research Laboratory also are planning hormone analysis using LC/MS/MS. The LC/MS/MS method is preferred over the current (2011) GC/MS/MS method because the current method requires complicated derivatization for the analytical standards and environmental samples, and because the compounds are not compatible with gas chromatography unless they are first derivatized (Duane S. Wydoski, U.S. Geological Survey, written commun., 2010).

From the prioritization procedure used for the pharmaceutical constituents, it appears that as many as 20 constituents on existing laboratory schedules, including 11 constituents on the proposed replacement for LS 2080, could be dropped from the laboratory schedules used for national- or regional-scale ambient monitoring. These Tier 3 compounds (table C.3) have a low likelihood of occurring in the environmental matrixes of interest to NAWQA, and some might not be found even in wastewater effluent because of disuse, low mass loading, chemical instability, or extent of metabolism by persons or animals that use them. Some of these constituents are of interest for future research by the Toxics Program; therefore, any changes to existing or planned laboratory schedules will be made after incorporating input from the Toxics Program to ensure that ongoing and future research needs can be met. Similarly, 88 Tier 2 constituents on existing USGS laboratory schedules or with methods in development might be of lesser importance with respect to NAWQA objectives. Most of these constituents are likely to occur only in wastewater or in streams or sediment in areas that are highly contaminated by wastewater, animal feeding operations (including aquaculture), or disposal activities and probably are not appropriate candidates for routine, ambient water-quality monitoring. If future studies show wider occurrence of any of the Tier 2 constituents than was anticipated at the time of this prioritization, those constituents would warrant reevaluation for inclusion in NAWQA Cycle 3 monitoring.

Future method development for pharmaceutical constituents is focused on filtered water and sediment rather than on whole water. It is preferable to analyze whole water as the combination of a filtered water sample and a suspendedsediment sample (sediment fraction), rather than perform labor-intensive liquid-liquid extractions on variable mixtures of water and sediment; this preferred approach would provide a more accurate understanding of contaminant fate in water and sediment than the analysis of unfiltered (whole) water and would reduce the potential for cross-contamination through the liquid-liquid extraction equipment.

Also, given the disparate requirements for routine ambient monitoring on a national or regional scale compared to targeted monitoring of contaminated resources at specific locations, use of a single laboratory schedule is unlikely to meet the needs of all study types for pharmaceutical constituents. The NWQL could modularize the pharmaceuticals into two complementary schedules: (1) a "core" schedule for routine ambient monitoring (Tier 1 constituents) and (2) an "add-on" schedule for highly contaminated environments (selected Tier 2 constituents). The modularized approach would result in reduced costs and easier data management for those doing routine ambient monitoring than offering a fixed set of Tier 1 and 2 constituents to all customers. For filtered water samples, capacity for the NWQL for a "core" schedule of approximately 75 constituents would be about 3,000 samples per year; an "add-on" schedule of approximately 150 constituents would be about 1,500 samples per year (Duane S. Wydoski, U.S. Geological Survey, written commun., 2010). For sediment samples, capacity for the NWQL for comparable schedules likely would be one-third to one-half of the capacity for filtered water samples because of the additional labor required for sample preparation and extraction. Capacity for the Kansas Organic Geochemistry Research Laboratory would be about 1,500 samples per year for water samples and about 750 samples per year for sediment samples (Michael T. Meyer, U.S. Geological Survey, written commun., 2009).

\section{Knowledge and Concerns of Pharmaceutical Constituents in Water or Sediment as a Constituent Group}

Information on the occurrence and concentrations of pharmaceutical constituents in water and sediment generally is lacking, and additional information would be beneficial to the NAWQA Program and its stakeholders. The inclusion of high-priority (Tier 1) pharmaceutical constituents in NAWQA Cycle 3 monitoring would improve the understanding of the occurrence and fate of these constituents in ambient water and sediment.

With the implementation of analytical methods that have cleaner preparation steps and higher sensitivity, it is likely 
that future field quality-control samples will reveal a need for improved field-sampling methods. Field contamination that might not have been detected using less-sensitive methods, or that was masked by concurrent laboratory contamination, could become more apparent. It will be important during method validation to closely monitor the quality of field blanks collected using the full assortment of NAWQA protocols, equipment, and staff, so that potential problems can be addressed before the new methods are fully and officially implemented. Precautions that have been adopted for nonUSGS sampling programs, including wearing a full-face shield or particle mask or avoiding breathing directly over the equipment while collecting samples to avoid the risk of cross-contamination from field staff (Richard Zimmer, MWH Laboratories, written commun., 2010; Carrithers and others, 2008), could be warranted when updating NAWQA field-sampling protocols for pharmaceutical constituents. In addition, with the smaller sample volumes that are expected for the new analytical methods, it would be feasible to include routine collection of a "spare" sample bottle to cover all organic analyses in case of breakage or need for an analytical rerun or for use in quality-assurance monitoring or method development.

One final issue of importance for pharmaceuticals as a constituent group is the shift away from collecting wholewater samples towards a more robust representation of whole water by the collection and analysis of filtered water and a corresponding sample of the sediment fraction (suspended sediment). Current analytical method development is focused on filtered water and sediment. If whole-water analyses are of interest, a separate suite of sample-preparation methods and laboratory schedules for unfiltered water would need to be developed and put through the method development and validation process. A shift away from whole-water analyses to the paired sampling of filtered water and suspended-sediment samples likely will warrant some review and modification of NAWQA field-sampling protocols and training.

\section{References for Pharmaceuticals and Hormones in Water or Sediment (Group C)}

Al-Ahmad, Ali, and Kümmerer, Klaus, 2001, Biodegradation of the antineoplastics vindesine, vincristine, and vinblastine and their toxicity against bacteria in the aquatic environment: Cancer Detection and Prevention, v. 25, p. 102-107.

Alonso, S.G.; Catalá, Myriam; Maroto, R.R.; Gil, J.L.R.; de Miguela, A.G.; and Valcárcel, Yolanda; 2010, Pollution by psychoactive pharmaceuticals in the Rivers of Madrid metropolitan area (Spain): Environment International, v. 36, no. 2, p. 195-201.

Andreozzi, Roberto; Raffaele, Marotta; and Nicklas, Paxéus, 2003, Pharmaceuticals in STP effluents and their solar photodegradation in aquatic environment: Chemosphere, v. 50, p. $1,319-1,330$.
Associated Press, 2008, An AP Investigation-Pharmaceuticals found in drinking water: accessed April 8, 2011, at http://hosted.ap.org/specials/interactives/pharmawater_ site/.

Bacaloni, Alessandro; Cavaliere, Chiara; Faberi, Angelo; Foglia, Patrizia; Samperi, Roberto; and Laganà, Aldo, 2005, Determination of isoflavones and coumestrol in river water and domestic wastewater sewage treatment plants: Analytica Chimica Acta, v. 531, p. 229-237.

Barnes, K.K., Kolpin, D.W., Furlong, E.T., Zaugg, S.D., Meyer, M.T., and Barber, L.B., 2008, A national reconnaissance of pharmaceuticals and other organic wastewater contaminants in the United States-I. Groundwater: Science of the Total Environment, v. 402, p. 192-200.

Barnes, K.K., Kolpin, D.W., Meyer, M.T., Thurman, E.M., Furlong, E.T., Zaugg, S.D., and Barber, L.B., 2002, Waterquality data for pharmaceuticals, hormones, and other organic wastewater contaminants in U.S. streams, 19992000: U.S. Geological Survey Open-File Report 02-94. (Also available at $h t t p: / / t o x i c s . u s g s . g o v / p u b s / O F R-02-94 /$.

Baronti, Chiara; Curini, Roberta; D’Ascenzo, Giuseppe; Di Corcia, Antonio; Gentili, Alessandra; and Samperi, Roberto, 2000, Monitoring natural and synthetic estrogens at activated sludge sewage treatment plants and in receiving river water: Environmental Science and Technology, v. 34, no. 24 , p. 5,059-5,066.

Barroso, Mário; Gallardo, Eugenia; Margalho, C.I.R.; Monstanto, Paul; and Vieira, D.N., 2006, Analytical approach to determine ticlopidine in post-mortem blood: Forensic Science International, v. 162, no. 1-3, p. 121-125.

Batt, A.L., Kostich, M.S., and Lazorchak, J.M., 2008, Analysis of ecologically relevant pharmaceuticals in wastewater and surface water using selective solid-phase extraction and UPLC-MS/MS: Analytical Chemistry, v. 80, p. 5,021-5,030, accessed November 2, 2009, at http://environmentalhealthc ollaborative.org/images/batt-ecopharms.pdf.

Benotti, M.J., and Brownawell, B.J., 2009, Microbial degradation of pharmaceuticals in estuarine and coastal seawater: Environmental Pollution, v. 157, no. 3, p. 994-1,002.

Benotti, M.J., Trenholm, R.A., Vanderford, B.J., Holady, J.C., Stanford, B.D., and Snyder, S.A., 2009, Pharmaceuticals and endocrine disrupting compounds in U.S. drinking water: Environmental Science and Technology, v. 43, no. 3, p. 597-603.

Bergheim, Marlies; Helland, Tone; Kallenborn, Roland; and Kümmerer, Klaus, 2010, Benzyl-penicillin (Penicillin G) transformation in aqueous solution at low temperature under controlled laboratory conditions: Chemosphere, v. 81, no. 11, p. $1,477-1,485$. 
Besse, Jean-Philippe, and Garric, Jeanne, 2008, Human pharmaceuticals in surface waters-Implementation of a prioritization methodology and application to the French situation: Toxicology Letters, v. 176, p. 104-123.

Black, Marsha, and Armbrust, Kevin, 2007, Final report-The environmental occurrence, fate, and ecotoxicity of selective serotonin reuptake inhibitors (SSRIs) in aquatic environments: EPA STAR Grant Number R829006, accessed April 8, 2011, at http://cfpub.epa.gov/ncer abstracts/index.cfm/ fuseaction/display.abstractDetail/abstract/1755/report/0.

Boxenbaum, H.G., Geitner, K.A., Jack, M.L., Dixon, W.R., Spiegel, H.E., Symington, J., Christian, R., Moore, J.D., Weissman, L., and Kaplan, S.A., 1977, Pharmacokinetic and biopharmaceutic profile of chlordiazepoxide $\mathrm{HCl}$ in healthy subjects - Single-dose studies by the intravenous, intramuscular, and oral routes: Journal of Pharmacokinetics and Pharmacodynamics, v. 5, no. 1, p. 3-23.

Bradley, P.M., Barber, L.B., Chapelle, F.H., Gray, J.L., Kolpin, D.W., and McMahon, P.B., 2009, Biodegradation of $17 \beta$-estradiol, estrone and testosterone in stream sediments: Environmental Science and Technology, v. 43, no. 6, p. $1,902-1,910$.

Brown, K.D.; Kulis, Jerzy; Thomson, Bruce; Chapman, T.H.; and Mawhinney, D.B., 2006, Occurrence of antibiotics in hospital, residential, and dairy effluent, municipal wastewater, and the Rio Grande in New Mexico: The Science of the Total Environment, v. 366, no. 2-3, p. 772-783.

Buerge, I.J., Buser, H.-R., Poiger, Thomas, and Müller, M.D., 2006, Occurrence and fate of the cytostatic drugs cyclophosphamide and ifosfamide in wastewater and surface waters: Environmental Science and Technology, v. 40, no. 23 , p. $7,242-7,250$.

Campagnolo, E.R., Johnson, K.R., Karpati, Adam, Rubing, C.S., Kolpin, D.W., Meyer, M.T., Esteban, J.E., Currier, R.W., Smith, Kathleen, Thu, K.M., and McGeehin, Michael, 2002, Antimicrobial residues in animal waste and water resources proximal to large-scale swine and poultry feeding operations: The Science of the Total Environment, v. 299, no. 1, p. 89-95.

Carrithers, Suzanna; Sessoms, Holly; and Crone, Tammy, 2008, Pharmaceutical screening of surface water, ground water, and streambed sediment in Gallatin Valley, Montana-Final report for NRCS-CIG agreement \#65-0325-06023, Natural Resources Conservation Service, 31 p.

Chang, Hong; Hu, Jianying; and Shao, Bing, 2007, Occurrence of natural and synthetic glucocorticoids in sewage treatment plants and receiving river waters: Environmental Science and Technology, v. 41, no. 10, p. 3,462-3,468.
Christensen, H.D., Freudenthal, R.I., Gidley, J.T., Rosenfeld, R., Boegli, G., Testino, L., Brine, D.R., Pitt, C.G., and Wall, M.E., 1971, Activity of delta8- and delta9-tetrahydrocannabinol and related compounds in the mouse: Science, v. 172, no. 3979, p. 165-167.

Clarke, T.A., and Waskell, L.A., 2002, Metabolism of clopidogrel is catalyzed by human cytochrome P450 and is inhibited by atorvastatin: Drug Metabolism and Disposition, v. 31 , no. 1 , p. 53-59.

Contreras-Sánchez, W.M., Fitzpatrick, M.S., and Schreck, C.B., 2001, Fate of methyltestosterone in the pond environment-Detection of MT in pond soil from a CRSP site, in Gupta, Anu; McElwee, Kris; Burke, Deborah; Burright, Jeff; Cummings, Xena; and Egna, Hillary, eds., Eighteenth Annual Technical Report: Corvallis, Oregon, Pond Dynamics/Aquaculture CRSP, Oregon State University.

Cornu-Chagnon, M.-C., Dupont, H., and Edgar, A., 1995, Fenofibrate-Metabolism and species differences for peroxisome proliferation in cultured hepatocytes: Fundamental and Applied Toxicology, v. 26, p. 63-74.

Cottrell, P.R.; Streete, J.M.; Berry, D.J.; Schäfer, H.; Pisani, Francesco; Perucca, Emilio; and Richens, A., 1982, Pharmacokinetics of phenylethylmalonamide (PEMA) in normal subjects and in patients treated with antiepileptic drugs: Epilepsia, v. 23, no. 3, p. 307-313.

Crane, H.M., Pickford, D.B., Hutchinson, T.H., and Brown, J.A., 2006, The effects of methimazole on development of the fathead minnow, Pimephales promelas, from embryo to adult: Toxicological Sciences, v. 93v. 93, no. 2, p. 278-285.

Davis, H.R., 2004, Ezetimibe-First in a new class of cholesterol absorption inhibitors: International Congress Series, v. 1262, p. 243-246.

Dietze, J.E., Scribner, E.A., Meyer, M.T., and Kolpin, D.W., 2005, Occurrence of antibiotics in water from 13 fish hatcheries, 2001-2003: International Journal of Environmental Analytical Chemistry, v. 85, no. 15, p. 1,141-1,152.

DrugLib.com, 2012, Active ingredient-EsomeprazoleBrands, medical use, clinical data: accessed March 21, 2012, at http://www.druglib.com/activeingredient/ esomeprazole/.

Drugs.com, 2012a, Halazepam: accessed April 11, 2011, at http://www.drugs.com/mtm/halazepam.html.

Drugs.com, 2012b, Nifedipine: accessed April 11, 2011, at http://www.drugs.com/ppa/nifedipine.html.

Drugs.com, 2012c, Valacyclovir: accessed April 11, 2011, at http://www.drugs.com/pro/valacyclovir.html. 
Durhan, E.J., Lambright, C.S., Makynen, E.A., Lazorchak, James, Hartig, P.C., Wilson, V.S., Gray, L.E., and Ankley, G.T., 2006, Identification of metabolites of trenbolone acetate in androgenic runoff from a beef feedlot: Environmental Health Perspectives, v. 114 (Suppl. 1), p. 65-68.

Eckel, W.P., Ross, Benjamin, and Isensee, R.K., 1993, Pentobarbital found in ground water: Ground Water, v. 31, no. 5, p. 801-914, accessed April 11, 2011, at https://info.ngwa. org/GWOL/pdf/932558950.PDF.

Eitel, Andreas; Scherrer, Martin; and Kümmerer, Klaus, 2000, Handling cytostatic drugs-A practical guide ( $2 \mathrm{~d}$ ed.): Kenzingen und Freiburg, Germany, Kehrer Digital and Print, 43 p., accessed February 11, 2011, at http://www.bms. com/Documents/sustainability/downloads/zyto_e.pdf.

Environment Canada, 2009, Screening assessment for the challenge-5H-Dibenz[b,f]azepine-5-propanamine, 3-chloro-10,11-dihydro-N,N-dimethyl-, monohydrochloride (clomipramine hydrochloride) - Chemical Abstracts Service Registry Number 17321-77-6: accessed April 11, 2011, at http://www.ec.gc.ca/substances/ese/eng/challenge/batch4/ batch4_17321-77-6_en.pdf.

Factor, S.A., and Weiner, W.J., eds., 2002, The biochemistry and metabolism of levodopa, in Parkinson's Disease-Diagnosis and clinical management: New York, Domos Medical Publishing, accessed April 11, 2011, at http://www.ncbi.nlm. nih.gov/books/NBK27570/.

Favetta, P., Degoute, C.-S., Perdrix, J.-P., Dufresne, C., Boulieu, R., and Guitton, J., 2002, Propofol metabolites in man following propofol induction and maintenance: British Journal of Anaesthesia, v. 88, p. 653-658.

Focazio, M.J., Kolpin, D.W., Barnes, K.K., Furlong, E.T., Meyer, M.T., Zaugg, S.D., Barber, L.B., and Thurman, E.M., 2008, A national reconnaissance of pharmaceuticals and other organic wastewater contaminants in the United States-II. Untreated drinking water sources: Science of the Total Environment, v. 402, no. 2-3, p. 201-216.

Furlong, E.T., Ferrer, Imma, Gates, P.M., Cahill, J.D., and Thurman, E.M., 2003, Identification of labile polar organic contaminants by atmospheric-pressure ionization tandem mass spectrometry, in Ferrer, Imma, and Thurman, E.M., eds., LC/MS/MS and TOF/MS - Analysis of emerging contaminants: American Chemical Society Symposium Series Number 850, p. 175-187.

Furlong, E.T., Werner, S.L., Anderson, B.D., and Cahill, J.D., 2008, Determination of human-health pharmaceuticals in filtered water by chemically modified styrene-divinylbenzene resin-based solid-phase extraction and high-performance liquid chromatography/mass spectrometry: U.S. Geological Survey Techniques and Methods, book 5, sec. B, chap. B5, 56 p.
Garcia-Ac, Araceli, Segura, P.A., Gagnon, Christian, and Sauvé, Sébastien, 2009, Determination of bezafibrate, methotrexate, cyclophosphamide, orlistat and enalapril in waste and surface waters using on-line solid-phase extraction liquid chromatography coupled to polarity-switching electrospray tandem mass spectrometry: Journal of Environmental Monitoring, v. 11, no. 4, p. 830-838.

Gaworecki, K.M., and Klaine, S.J., 2008, Behavioral and biochemical responses of hybrid striped bass during and after fluoxetine exposure: Aquatic Toxicology, v. 88, no. 4, p. 207-213.

Ghosh, G.C.; Nakada, Norihide; Yamashita, Naoyuki; and Tanaka, Hiroaki; 2010, Oseltamivir carboxylate, the active metabolite of oseltamivir phosphate (Tamiflu), detected in sewage discharge and river water in Japan: Environmental Health Perspectives, v. 118, no. 1, p. 103-107.

Glassmeyer, S.T., Furlong, E.T., Kolpin, D.W., Cahill, J.D., Zaugg, S.D., Werner, S.L., Meyer, M.T., and Kryak, D.D., 2005, Transport of chemical and microbial compounds from known wastewater discharges - Potential for use as indicators of human fecal contamination: Environmental Science and Technology, v. 39 , no. 14 , p. 5,157-5,169.

Godfrey, Emily, Woessner, W.W., and Benotti, M.J., 2007, Pharmaceuticals in on-site sewage effluent and ground water, western Montana: Ground Water, v. 45, no. 3, p. 263-271.

Goodbred, S.L., Gilliom, R.J., Gross, T.S., Denslow, N.P., Bryant, W.L., and Schoeb, T.R., 1997, Reconnaissance of 17b-estradiol, 11-ketotestosterone, vitellogenin, and gonad histopathology in common carp of United States streamsPotential for contaminant-induced endocrine disruption: U.S. Geological Survey Open-File Report 96-627, 47 p.

Guo, C.Y., and Krasner, S.W., 2009, Occurrence of primidone, carbamazepine, caffeine, and precursors for N-nitrosodimethylamine in drinking water sources impacted by wastewater: Journal of the American Water Resources Association, v. 45, no. 1, p. 58-67.

Guo, Weilin; Wang, Hongzhi; Shi, Yahui; and Zhang, Guangyou; 2010, Sonochemical degradation of the antibiotic cephalexin in aqueous solution: Water SA, v. 36, no. 5, p. $651-654$.

Harden, S.L., 2009, Reconnaissance of organic wastewater compounds at a concentrated swine feeding operation in the North Carolina Coastal Plain, 2008: U.S. Geological Survey Open-File Report 2009-1128, 14 p., accessed April 11, 2011, at http://pubs.usgs.gov/of/2009/1128/. 
Huang, Qiuxin; Yu, Yiyi; Tang, Caiming; and Peng, Xianzhi; 2010, Determination of commonly used azole antifungals in various waters and sewage sludge using ultra-high performance liquid chromatography-tandem mass spectrometry: Journal of Chromatography A, v. 1217, no. 21, p. 3,4813,488 .

Hummel, Daniela; Löffler, Dirk; Fink, Guido; and Ternes, T.A.; 2006, Simultaneous determination of psychoactive drugs and their metabolites in aqueous matrices by liquid chromatography mass spectrometry: Environmental Science and Technology, v. 40, no. 23, p. 7,321-7,328.

International Programme on Chemical Safety, 1986, 5-Methoxypsoralen (last updated on April 22, 1998): International Agency for Research on Cancer, v. 40, accessed March 21, 2012, at http://www.inchem.org/documents/iarc/ vol40/5-methoxypsoralen.html.

International Programme on Chemical Safety, 2012, Diazepam: accessed April 11, 2011, at http://www.inchem.org/ documents/pims/pharm/pim181.htm.

Jarman, Michael; Foster, A.B.; Goss, P.E.; Griggs, L.J.; Howe, Ian; and Coombes, R.C., 1983, Metabolism of aminoglutethimide in humans - Identification of hydroxylaminoglutethimide as an induced metabolite: Biomedical Mass Spectrometry, v. 10, no. 11, p. 620-625.

Jensen, K.M., Makynen, E.A., Kahl, M.D., and Ankley, G.T., 2006, Effects of the feedlot contaminant 17alpha-trenbolone on reproductive endocrinology of the fathead minnow: Environmental Science and Technology, v. 40, no. 9, p. $3,112-3,117$.

Jones-Lepp, T.L., Alvarez, D.A., Petty, J.D., and Huckins, J.N., 2004, Polar organic chemical integrative sampling and liquid chromatography-electrospray/ion-trap mass spectrometry for assessing selected prescription and illicit drugs in treated sewage effluents: Archives of Environmental Contamination and Toxicology, v. 47, no. 4, p. 427-439.

Kapur, K., and Toor, H.S., 1979, The effect of clomiphene citrate on ovulation and spawning in indomethacin treated carp, Cyprinus carpio: Journal of Fish Biology, v. 14, p. 59-66.

Karthikeyan, K.G., and Meyer, M.T., 2006, Occurrence of antibiotics in wastewater treatment facilities in Wisconsin, USA: The Science of the Total Environment, v. 361, no. 1-3, p. 196-207.

Kasprzyk-Hordern, Barbara; Dinsdale, R.M.; and Guwy, A.J.; 2008, The occurrence of pharmaceuticals, personal care products, endocrine disruptors and illicit drugs in surface water in South Wales, UK: Water Research, v. 42, p. $3,498-3,518$.
Kelch, W.J., and Lee, J.S., 1978, Antibiotic resistance patterns of gram-negative bacteria isolated from environmental sources: Applied and Environmental Microbiology, v. 36, no. 3 , p. $450-456$.

Kiparissis, Yiannis; Balch, G.C.; Metcalfe, T.L.; and Metcalfe, C.D.; 2003, Effects of the isoflavones genistein and equol on the gonadal development of Japanese medaka Oryzias latipes: Environmental Health Perspectives, v. 111, no. 9, p. 1,158-1,163, accessed April 11, 2011, at http://www. ncbi.nlm.nih.gov/pmc/articles/PMC1241568/pdf/ehp0111001158.pdf.

Kolpin, D.W., Furlong, E.T., Meyer, M.T., Thurman, E.M., Zaugg, S.D., Barber, L.B., and Buxton, H.T., 2002, Pharmaceuticals, hormones, and other organic wastewater contaminants in U.S. streams, 1999-2000-A national reconnaissance: Environmental Science and Technology, v. 36, no. 6, p. 1,202-1,211, doi:10.1021/es011055j.

Kosonen, Jussi, and Kronberg, Leif, 2009, The occurrence of antihistamines in sewage waters and in recipient rivers: Environmental Science and Pollution Research, v. 16, no. 5, p. 555-564.

Kostich, M.S., and Lazorchak, J.M., 2008, Risks to aquatic organisms posed by human pharmaceutical use: The Science of the Total Environment, v. 389, no. p. 329-339.

Kümmerer, Klaus, and Al-Ahmad, Ali, 1997, Biodegradability of the anti-tumour agents 5-fluorouracil, cytarabine, and gemcitabine-Impact of the chemical structure and dynergistic toxicity with hospital effluents: Acta Hydrochimica et Hydrobiologica, v. 25, p. 166-172.

Kümmerer, Klaus; Al-Ahmad, Ali; and Mersch-Sundermann, V.; 2000, Biodegradability of some antibiotics, elimination of the genotoxicity and affection of wastewater bacteria in a simple test: Chemosphere, v. 40, no. 7, p. 701-710.

Lai, C.M., Stoll, R.G., Look, Z.M., and Yacobi, A., 2006, Urinary excretion of chlorpheniramine and pseudoephedrine in humans: Journal of Pharmaceutical Sciences, v. 68, no. 10, p. 1,243-1,246.

Lajeunesse, André; Gagnon, Christian; and Sauvé, Sébastien; 2008, Determination of basic antidepressants and their $\mathrm{N}$-desmethyl metabolites in raw sewage and wastewater using solid-phase extraction and liquid chromatographytandem mass spectrometry: Analytical Chemistry, v. 80, no. 14 , p. $5,325-5,333$.

Leclercq, Marie; Mathieu, Olivier; Gomez, Elena; Casellas, Claude; Fenet, Hélène; and Hillaire-Buys, Dominique; 2009, Presence and fate of carbamazepine, oxcarbazepine, and seven of their metabolites at wastewater treatment plants: Archives of Environmental Contamination and Toxicology, v. 56, no. 3, p. 408-415. 
Lee, K.E., Barber, L.B., Furlong, E.T., Cahill, J.D., Kolpin, D.W., Meyer, M.T., and Zaugg, S.D., 2004, Presence and distribution of organic wastewater compounds in wastewater, surface, ground, and drinking waters, Minnesota, 2000-02: U.S. Geological Survey Scientific Investigations Report 2004-5138, $47 \mathrm{p}$.

Lefkowitz, E.R., Creasey, W.A., Calabresi, Paul, and Sartorelli, A.C., 1965, Clinical and pharmacologic effects of combinations of 6-thioguanine and duazomycin A in patients with neoplastic disease: Cancer Research, v. 25, p. 1,207-1,212, accessed April 11, 2011, at http://cancerres. aacrjournals.org/content/25/8/1207.full.pdf.

Levy, R.H., Mattson, R.H., and Meldrum, B.S., eds., 1995, Antiepileptic drugs (4th ed.): New York, Raven Press, 1,150 p.

Li, Dong; Yang, Min; Hu, Jianying; Zhang, Yu; Chang, Hong; and Jin, Fen; 2008, Determination of penicillin G and its degradation products in a penicillin production wastewater treatment plant and the receiving river: Water Research, v. 42 , no. $1-2$, p. $307-317$.

Lietz, A.C., and Meyer, M.T., 2006, Evaluation of emerging contaminants of concern at the South District Wastewater Treatment Plant based on seasonal events, Miami-Dade County, Florida, 2004: U.S. Geological Survey Scientific Investigations Report 2006-5240, 38 p.

Lissemore, L., Hao, C.Y., Yang, P., Sibley, P.J., Mabury, S., and Solomon, K.R., 2006, An exposure assessment for selected pharmaceuticals within a watershed in southern Ontario: Chemosphere, v. 64, no. 5, p. 717-729.

Lorphensri, Oranuj; Intravijit, Jittipong; Sabatini, D.A.; Kibbey, T.C.G.; Osathaphan, Khemarath; and Saiwan, Chintana, 2006, Sorption of acetaminophen, 17a-ethynyl estradiol, nalidixic acid, and norfloxacin with silica, alumina, and a hydrophobic medium: Water Resources, v. 40, p. $1,481-1,491$.

Mackay, Donald; Paterson, S.; and Shiu, W.Y.; 1992, Generic models for evaluating the regional fate of chemicals: Chemosphere, v. 24, no. 6, p. 695-718.

Martin-Diaz, Laura; Franzellitti, Silvia; Buratti, Sara; Valbonesi, Paola; Capuzzo, Antonio; and Fabbri, Elena; 2009, Effects of environmental concentrations of the antiepileptic drug carbamazepine on biomarkers and cAMP-mediated cell signaling in the mussel Mytilus galloprovincialis: Aquatic Toxicology, v. 94, no. 3, p. 177-185.

Matsuo, H.; Sakamoto, H.; Arizono, Koji; and Ryota, Shinohara; 2011, Behavior of pharmaceuticals in waste water treatment plant in Japan: Bulletin of Environmental Contamination and Toxicology, v. 87, no 1, p. 31-35.
McArdell, Christa; Molnar, Eva; Suter, M.J.; and Giger, Walter; 2003, Occurrence and fate of macrolide antibiotics in wastewater treatment plants and in the Glatt Valley watershed, Switzerland: Environmental Science and Technology, v. 37 , no. 24 , p. $5,479-5,486$.

Metcalfe, C.D.; Chu, Shaogang; Judt, Colin; Li, Hongxia; Oakes, K.D.; Servos, M.R.; and Andrews, D.M.; 2010, Antidepressants and their metabolites in municipal wastewater, and downstream exposure in an urban watershed: Environmental Toxicology and Chemistry, v. 29, no. 1, p. 79-89.

Metcalfe, C.D., Miao, X.-S., Hua, W., Letcher, R., and Servos, M.R., 2004, Pharmaceuticals in the Canadian environment, in Kümmerer, Klaus, ed., Pharmaceuticals in the environment-Sources, fate, effects and risks: Heidelberg, Germany, Springer, p. 67-90.

Meyer, M.T.; Ferrell, Gloria; Bumgarner, Joe; Cole, Dana; and Hutchins, Steve; 2004, Occurrence of antibiotics in hog-waste lagoons from confined-animal feeding operations from 1998 to 2002 [abs.], in 21st Annual Water and Future of Kansas Conference, March 11, 2004, Lawrence, Kansas: Manhattan, Kansas Water Resources Research Institute, p. 13.

Meylan, W.M., and Howard, P.W., 1996, Atom/fragment contribution method for estimating octanol-water partition coefficients: Journal of Pharmaceutical Science, v. 84, p. 83-92.

Miao, X.-S.; Bishay, Farida; Chen, Mei; and Metcalfe, C.D.; 2004, Occurrence of antimicrobials in the final effluents of wastewater treatment plants in Canada: Environmental Science and Technology, v. 38 , no. 13, p. 3,533-3,541.

Miao, X.-S., Yang, J.-J., and Metcalfe, C.D., 2005, Carbamazepine and its metabolites in wastewater and in biosolids in a municipal wastewater treatment plant: Environmental Science and Technology, v. 39, no. 19, p. 7,469-7,475.

Möhle, Edda, and Metzger, Jörg, 2001, Drugs in municipal sewage effluents-Screening and biodegradation studies, in Daughton, C.G., and Jones-Lepp, Tammy, eds., Pharmaceuticals and personal care products in the environment-Scientific and regulatory issues: Washington, D.C., American Chemical Society, Symposium Series 791.

Mutlib, A.E., Chen, H., Nermeth, G.A., Markwalder, J.A., Seitz, S.P., Gan, L.S., and Christ, D.D., 1999, Identification and characterization of efavirenz metabolites by liquid chromatography/mass spectrometry and high field NMR Species differences in the metabolism of efavirenz: Drug Metabolism and Disposition, v. 27, no. 11, p. 1,319-1,333, accessed April 11, 2011, at http://dmd.aspetjournals.org/ content/27/11/1319.abstract. 
National Highway Traffic Safety Administration, 2012, Cannabis/marijuana (delta 9-tetrahydrocannabinol, THC): accessed April 11, 2011, at http://www.nhtsa.gov/people/ injury/research/job185drugs/cannabis.htm.

National Institute for Occupational Safety and Health, 2010a, The Emergency Response Safety and Health Database - Emergency response card for colchicine: accessed April 1, 2010, at http://www.cdc.gov/niosh/ershdb/ EmergencyResponseCard_29750016.html.

National Institute for Occupational Safety and Health, 2010b, The Emergency Response Safety and Health Database-Emergency response card for nicotine: accessed April 1, 2010, at http://www.cdc.gov/niosh/ershdb/ EmergencyResponseCard_29750028.html.

Nilsen, E.B., Rosenbauer, R.R., Furlong, E.T., Burkhardt, M.R., Werner, S.L., Greaser, Lisa, and Noriega, M.C., 2007, Pharmaceuticals, personal care products and anthropogenic waste indicators detected in streambed sediments of the Lower Columbia River and selected tributaries, in 6th International Conference on Pharmaceuticals and Endocrine Disrupting Chemicals in Water, National Ground Water Association, Costa Mesa, California, Paper 4483, 15 p.

Njoku, Dolores, Laster, M.J., Gong, D.H., Eger, E.I., II, Reed, G.F., and Martin, J.L., 1997, Biotransformation of halothane, enflurane, isoflurane, and desflurane to trifluoroacetylated liver proteins - Association between protein acylation and hepatic injury: Anesthesia and Analgesia, v. 84, p. 173-178, accessed April 11, 2011, at http://www.anesthesiaanalgesia.org/content/84/1/173.full.pdf.

Oberemm, A., and Kirschbaum, F., 1992, Valproic acid induced abnormal development of the central nervous system of three species of amphibians - Implications for neural tube defects and alternative experimental systems: Teratogenesis, Carcinogenesis, and Mutagenesis, v. 12, no. 6, p. 251-262.

OSPAR Commission, 2005, Hazardous Substances SeriesOSPAR background document on clotrimazole: OSPAR Publication 2005/199, ISBN 1-904426-38-7.

Packer, J.L., Werner, J.J., Latch, D.E., McNeill, Kristopher, and Arnold, W.A., 2003, Photochemical fate of pharmaceuticals in the environment-Naproxen, diclofenac, clofibric acid, and ibuprofen: Aquatic Sciences, v. 65, p. 342-351.

Painter, M.M., Buerkley, M.A., Julius, M.L., Vajda, A.M., Norris, D.O., Barber, L.B., Furlong, E.T., Schultz, M.M., and Schoenfuss, H.L., 2009, Antidepressants at environmentally relevant concentrations affect predator avoidance behavior of larval fathead minnows (Pimephales promelas): Environmental Toxicology and Chemistry, v. 28, no. 12, p. 2,677-2,684, doi:10.1897/08-556.1.
Patel, Jigna, Sheehan, Valerie, and Gurk-Turner, Cheryle, 2003, Ezetimibe (Zetia) - A new type of lipid-lowering agent: Baylor University Medical Center Proceedings, v. 16, no. 3, p. 354-358, accessed April 11, 2011, at http://www. ncbi.nlm.nih.gov/pmc/articles/PMC1200795/.

Paulson, S.K.; Hribar, J.D.; Liu, N.W.K.; Hajdu, Elizabeth; Bible, Roy, Jr.; Piergies, Antoni; and Karim, Aziz; 2000, Metabolism and excretion of $\left[{ }^{14} \mathrm{C}\right]$ celecoxib in healthy male volunteers: Drug Metabolism and Disposition, v. 28, no. 3, p. 308-314.

Pedersen, J.A., Soliman, Mary, and Suffet, I.H., 2005, Human pharmaceuticals, hormones, and personal care product ingredients in runoff from agricultural fields irrigated with treated wastewater: Journal of Agricultural and Food Chemistry, v. 53, no. 5, p. 1,625-1,632.

Peschka, Manuela; Eubeler, J.P.; and Knepper, T.P.; 2006, Occurrence and fate of barbiturates in the aquatic environment: Environmental Science and Technology, v. 40, no. 23, p. 7,200-7,206.

Phelps, R.P., Cole, W., and Katz, T., 1992, Effect of fluoxymesterone on sex ratio and growth of Nile tilapia Oreochromis niloticus (L.): Aquaculture and Fisheries Management, v. 23, p. 405-410.

Phillips, P.J., Smith, S.G., Kolpin, D.W., Zaugg, S.D., Buxton, H.T., Furlong, E.T., and others, 2010, Pharmaceutical formulation facilities as sources of opiods and other pharmaceuticals to wastewater treatment plants effluents: Environmental Science and Technology, v. 44, no. 13, p. 4,910-4,916.

Phillips, P.J., Smith, S.G., Steven, Z.D. [sic, Zaugg, S.D.], Furlong, E.T., Kolpin, D.W., Esposito, A.K., Stinson, B., and Laurel, Eddy, 2007, Pharmaceuticals and chloroxylenol in treated wastewater effluent samples from across the United States, 2003-2006: SETAC North America 28th Annual Meeting, Abstract Book, p. 114, ISSN 1087-8939.

Prasse, Carsten; Schlüsener, M.P.; Schulz, Ralf; and Ternes, T.A.; 2010, Antiviral drugs in wastewater and surface waters-A new pharmaceutical class of environmental relevance?: Environmental Science and Technology, v. 44, no. 5 , p. $1,728-1,735$.

Purdom, C.E., Hardiman, P.A., Bye, V.J., Eno, N.C., Tyler, C.R., and Sumpter, J.P., 1994, Estrogenic effects of effluents from sewage treatment works: Chemistry and Ecology, v. 8, no. 4, p. 275-285.

Rappold, R.S., 2008, Drugs in water is food for thought: The Colorado Springs Gazette, Sept. 28, 2008, accessed December 30, 2010, at http://www.gazette.com/articles/water41054-drugs-colorado.html. 
Rodriquez-Mozaz, Sara; López de Alda, Maria; and Barceló, Damià; 2004, Monitoring of estrogens, pesticides and bisphenol A in natural water and drinking water treatment plants by solid-phase extraction-liquid chromatographymass spectrometry: Journal of Chromatography A, v. 1045, no. 1-2, p. 85-92.

Rosal, Roberto; Rodríguez, Antonio; Perdigón-Melón; J.A., Petre; Alice, García-Calvo; Eloy, Gómez; M.J., Agüera, Ana; and Fernández-Alba, A.R.; 2009, Occurrence of emerging pollutants in urban wastewater and their removal through biological treatment followed by ozonation: Water Research, v. 44, no. 2, p. 578-588, doi:10.1016/j. watres.2009.07.004.

RxList.com, 2012a, Doral: accessed March 21, 2012, at http:// www.rxlist.com/doral-drug.htm.

RxList.com, 2012b, Zyflo: accessed March 21, 2012, at http:// www.rxlist.com/zyflo-drug.htm.

Schrap, S.M., Rijs, G.B.J., Beek, M.A., Maaskant, J.F.N., Staeb, Joan, Stroomberg, Gerard, and Tiesnitsch, Jordan, 2003, Humane en veterinaire geneesmiddelen in Nederlands oppervlaktewater en afvalwater [Human and veterinary pharmaceuticals in Dutch surface and waste water]: Een screening in 2002, RIZA-rapport 2003.023, ISBN 36956234.

Schultz, I.R., Skillman, Ann, Nicolas, J.M., Cyr, D.G., and Nagler, J.J., 2003, Short-term exposure to 17 alpha-ethynylestradiol decreases the fertility of sexually maturing male rainbow trout (Oncorhynchus mykiss): Environmental Toxicology and Chemistry, v. 22, no. 6, p. 1,272-1,280.

Schultz, M.M., and Furlong, E.T., 2008, Trace analysis of antidepressant pharmaceuticals and their select degradates in aquatic matrixes by LC/ESI/MS/MS: Analytical Chemistry, v. 80 , no. 5 , p. $1,756-1,762$.

Scribner, E.A., Dietze, J.E., Meyer, M.T., and Kolpin, D.W., 2004, Occurrence of antibiotics in water from fish hatcheries [abs.], in 21st Annual Water and Future of Kansas Conference, March 11, 2004, Lawrence, Kansas: Manhattan, Kansas Water Resources Research Institute, p. 68.

Seiler, R.L., Zaugg, S.D., Thomas, J.M., and Howcroft, D.L., 1999, Caffeine and pharmaceuticals as indicators of waste water contamination in wells: Ground Water, v. 37, no. 3, p. 405-410, accessed April 11, 2011, at https://info.ngwa.org/ GWOL/pdf/991565002.PDF.

Shah, V.P., Epstein, W.L., and Riegelman, Sidney, 1974, Role of sweat in accumulation of orally administered griseofulvin in skin: The Journal of Clinical Investigation, v. 53, p. $1,673-1,678$.
Shine, J.P., 2008, Pharmaceutical compounds in the environment: Harvard School of Public Health, Department of Environmental Health, accessed November 2, 2010, at http://www.mwra.com/04water/html/pharma/shine_hsph. $p d f$.

Spectrum Laboratories, Inc., 2010, Chemical fact sheet for nicotine: accessed April 1, 2010, at http://www.speclab.com/ compound/c54115.htm.

Straub, J.O., 2009, An environmental risk assessment for oseltamivir (Tamiflu) for sewage works and surface waters under seasonal-influenza- and pandemic-use conditions: Ecotoxicology and Environmental Safety, v. 72, no. 6, p. $1,625-1,634$.

Suzuki, Yutaka; Komori, Koya; Nakada, Norihide; and Harada, Arata; 2009, Status of pharmaceuticals and personal care products (PPCPs) in river water and wastewater and evaluation of their effects on aquatic organisms [abs.]: Japan, National Institute of Public Health Public Works Research Institute, accessed on April 1, 2010, at http://www. niph.go.jp/soshiki/suido/pdf/h21JPUS/abstract/r3-3.pdf.

Swan, G.E.; Cuthbert, Richard; Quevedo, Miguel; Green, R.E.; Pain, D.J.; Bartels, Paul; Cunningham, A.A.; Duncan, Neil; Meharg, A.A.; Oaks, J.L.; Parry-Jones, Jemima; Shultz, Susanne; Taggart, M.A.; Verdoorn, Gerhard; and Wolter, Kerri; 2006, Toxicity of diclofenac to Gyps vultures: Biology Letters, June 22, v. 2, no. 2, p. 279-282, accessed November 9, 2009, at http://www.ncbi.nlm.nih.gov/pmc/ articles/PMC1618889/.

Tertuliani, J.S., Alvarez, D.A., Furlong, E.T., Meyer, M.T., Zaugg, S.D., and Koltun, G.F., 2008, Occurrence of organic wastewater compounds in the Tinkers Creek watershed and two other tributaries to the Cuyahoga River, Northeast Ohio: U.S. Geological Survey Scientific Investigations Report 2008-5173, 60 p. (Also available at http://pubs.usgs. gov/sir/2008/5173/.)

Thurman, E.M., Dietz, J.E., and Scribner, E.A., 2003, Occurrence of antibiotics in water from fish hatcheries: U.S. Geological Survey Fact Sheet 120-02, 4 p.

Tong, Lei; Li, Ping; Wang, Yanxin; and Zhu, Kuanzheng; 2009, Analysis of veterinary antibiotic residues in swine wastewater and environmental water samples using optimized SPE-LC/MS/MS: Chemosphere, v. 74, no. 8, p. 1,090-1,097.

Trubnikova, O.B., 2003, Effects of cycloheximide, aminoglutethimide, cytochalasin B, and colchicine on ovulation and the ultrastructure of the ovarian follicle wall in the stellate sturgeon Acipenser stellatus: Russian Journal of Developmental Biology, v. 34, no. 2, p. 110-120. 
Umweltbundesamt, 1995, Endocrinically active chemicals in the environment: Berlin, Germany, UBA Texte Series 3, v. 36, Expert Round, 9-10 March 1995, accessed on April 1, 2010, at http://www.epa.gov/edrlupvx/Pubs/uba3_96.pdf.

U.S. Department of Health and Human Services, 2005, Report on carcinogens (11th ed.): U.S. Department of Health and Human Services, Public Health Service, National Toxicology Program, accessed April 11, 2011, at http://ntp.niehs. nih.gov/ntp/roc/toc11.htm.

U.S. Environmental Protection Agency, 1994, R.E.D. FACTS - Chloroxylenol: Washington, D.C., U.S. Environmental Protection Agency, EPA-738-F-94-028, 4 p.

U.S. Environmental Protection Agency, 1996, R.E.D. FACTS - Chlorhexidine diacetate: Washington, D.C., U.S. Environmental Protection Agency, EPA-738-F-96-025, 5 p.

U.S. Environmental Protection Agency, 2007, ECOTOXicology Database System, version 4.0: U.S. Environmental Protection Agency, Office of Research and Development and the National Health and Environmental Effects Research Laboratory's Mid-Continent Ecology Division, accessed May 12, 2010, at http://www.epa.gov/ecotox/.

U.S. Environmental Protection Agency, 2009a, EPI Suite ${ }^{\mathrm{TM}}$ version 4.0: U.S. Environmental Protection Agency, Office of Pollution Prevention and Toxics and Syracuse Research Corporation.

U.S. Environmental Protection Agency, 2009b, Occurrence of contaminants of emerging concern in wastewater from nine publicly owned treatment works: Washington, D.C., U.S. Environmental Protection Agency, EPA-821-R-09-009, $85 \mathrm{p}$.

U.S. Environmental Protection Agency, 2010, Contaminant Candidate List 3-CCL3: accessed December 20, 2010, at http://water.epa.gov/scitech/drinkingwater/dws/ccl/ccl3.cfm.

U.S. Environmental Protection Agency, 2011, Persistent, Bioaccumulative, and Toxic Profiles Estimated for Organic Chemicals (PBT Profiler): accessed January 10, 2011, at http://www.pbtprofiler.net/.

U.S. Environmental Protection Agency Water Security Initiative, 2010, Performance verification testing-Rapid toxicity monitoring and detection systems overview and analysis: accessed April 1, 2010, at http://www.epa.gov/safewater/ watersecurity/pubs/fs_security_rapid-tox.pdf.

U.S. Food and Drug Administration, 2010, Drugs@FDAParadione (Paramethadione): accessed April 1, 2010, at http://www.accessdata.fda.gov/scripts/cder/drugsatfda/ index.cfm?fuseaction=Search.Search_Drug_Name.
U.S. National Library of Medicine, 2012, TOXNET_-Toxicology Data Network: accessed March 12, 2012, at http:// toxnet.nlm.nih.gov/.

van Nuijs, Alexander; Pecceu, Bert; Laetitia, Theunis; Dubois, Nathalie; Charlier, Corinne; Jorens, P.G.; Bervoets, Lieven; Blust, Ronny; Neels, Hugo; and Covaci, Adrian; 2008, Cocaine and metabolites in waste and surface water across Belgium: Environmental Pollution, v. 157, p. 123-129.

Wang, Jian, MacNeil, J.D., and Kay, J.F., 2011, Chemical analysis of antibiotic residues in food: Hoboken, N.J., Wiley and Sons, $384 \mathrm{p}$.

Wang, Li; Ying, G.G.; Zhao, J.L.; Yang, X.B.; Chen, Feng; Tao, Ran; Liu, Shan; and Zhou, L.J.; 2010, Occurrence and risk assessment of acidic pharmaceuticals in the Yellow River, Hai River and Liao River of north China: Science of the Total Environment, v. 408, no. 16, p. 3,139-3,147.

Watkinson, A.J., Murby, E.J., Kolpin, D.W., and Costanzo, S.D., 2009, The occurrence of antibiotics in an urban watershed-From wastewater to drinking water: Science of the Total Environment, v. 407, no. 8, p. 2,711-2,723.

Wisconsin Department of Natural Resources, 2008, N,N-Bis (2-chloroethyl)-2-naphthylamine (chlornaphazine): accessed April 11, 2011, at http://dnr.wi.gov/air/emission/NR438/ pollutants/489.htm.

Wood, Nolan; Tan, Keith; Purkins, Lynn; Layton, Gary; Hamlin, Julia; Kleinermans, Diane; and Nichols, Don; 2003, Effect of omeprazole on the steady-state pharmacokinetics of voriconazole: British Journal of Clinical Pharmacology, v. 56, p. 56-61, accessed April 11, 2011, at http://www.ncbi. nlm.nih.gov/pmc/articles/PMC1884317/.

World Health Organization, 1999, Laxatives containing dantron and phenolphthalein-Unacceptable ingredients in OTC drug products, USA: WHO Pharmaceuticals Newsletter, no. 03-04, 16 p., accessed April 11, 2011, at http://apps. who.int/medicinedocs/en/d/Js2271e/1.7.html.

Xiao, Yang; Chang, Hong; Jia, Ai; and Hu, Jianying; 2008, Trace analysis of quinolone and fluoroquinolone antibiotics from wastewaters by liquid chromatography-electrospray tandem mass spectrometry: Journal of Chromatography A, v. 1214 , no. 1-2, p. 100-108.

Yang, Lihua; Lin, Li; Weng, Shaoping; Feng, Zhiqin; and Luan, Tiangang; 2008, Sexually disrupting effects of nonylphenol and diethylstilbestrol on male silver carp (Carassius auratus) in aquatic microcosms: Ecotoxicology and Environmental Safety, v. 71, p. 400-411. 
Yasojima, Makoto; Nakada, Norihide; Komori, Koya; Suzuki, Yutaka; and Tanaka, Hiroaki; 2006, Occurrence of levofloxacin, clarithromycin and azithromycin in wastewater treatment plant in Japan: Water Science and Technology, v. 53, no. 11, p. 227-233.

Yin, Jie; Shao, Bing; Zhang, Jing; and Li, Keji; 2010, A preliminary study on the occurrence of cytostatic drugs in hospital effluents in Beijing, China: Bulletin of Environmental Contamination and Toxicology, v. 84, p. 39-45.

Yoshimura, Haruo, and Endoh, Y.S., 2005, Acute toxicity to freshwater organisms of antiparasitic drugs for veterinary use: Environmental Toxicology, v. 20, p. 60-66.
Young, R.B., and Borch, Thomas, 2009, Sources, presence, analysis, and fate of steroid sex hormones in freshwater ecosystems - A review, in Nairne, G.H., ed., Aquatic ecosystem research trends: Hauppauge, New York, Nova Science Publishers, Inc., p. 103-164.

Zhou, J.L.; Zhang, Z.L.; Banks, Elina; Grover, D.P.; and Jiang, J.Q.; 2009, Pharmaceutical residues in wastewater treatment works effluents and their impact on receiving river water: Journal of Hazardous Materials, v. 166, no. 2-3, p. 655-661.

Zuccato, Ettore; Chiabrando, Chiara; Castiglioni, Sara; Bagnati, Renzo; and Fanelli, Roberto; 2008, Estimating community drug abuse by wastewater analysis: Environmental Health Perspectives, v. 116, no. 8, p. 1,027-1,032. 


\section{Supplemental Information D.}

\section{Prioritization of Trace Elements and Other Inorganic Constituents (Group D) in Water (Group D1) or Sediment (Group D2)}

By Michael J. Focazio, Peter C. Van Metre, Joshua F. Valder, Joseph D. Ayotte, Leslie A. Desimone, Neil M. Dubrovsky, Julia E. Norman, Michael R. Rosen, and John S. Zogorski

\section{Abbreviations and Acronyms Used in Supplemental Information D}

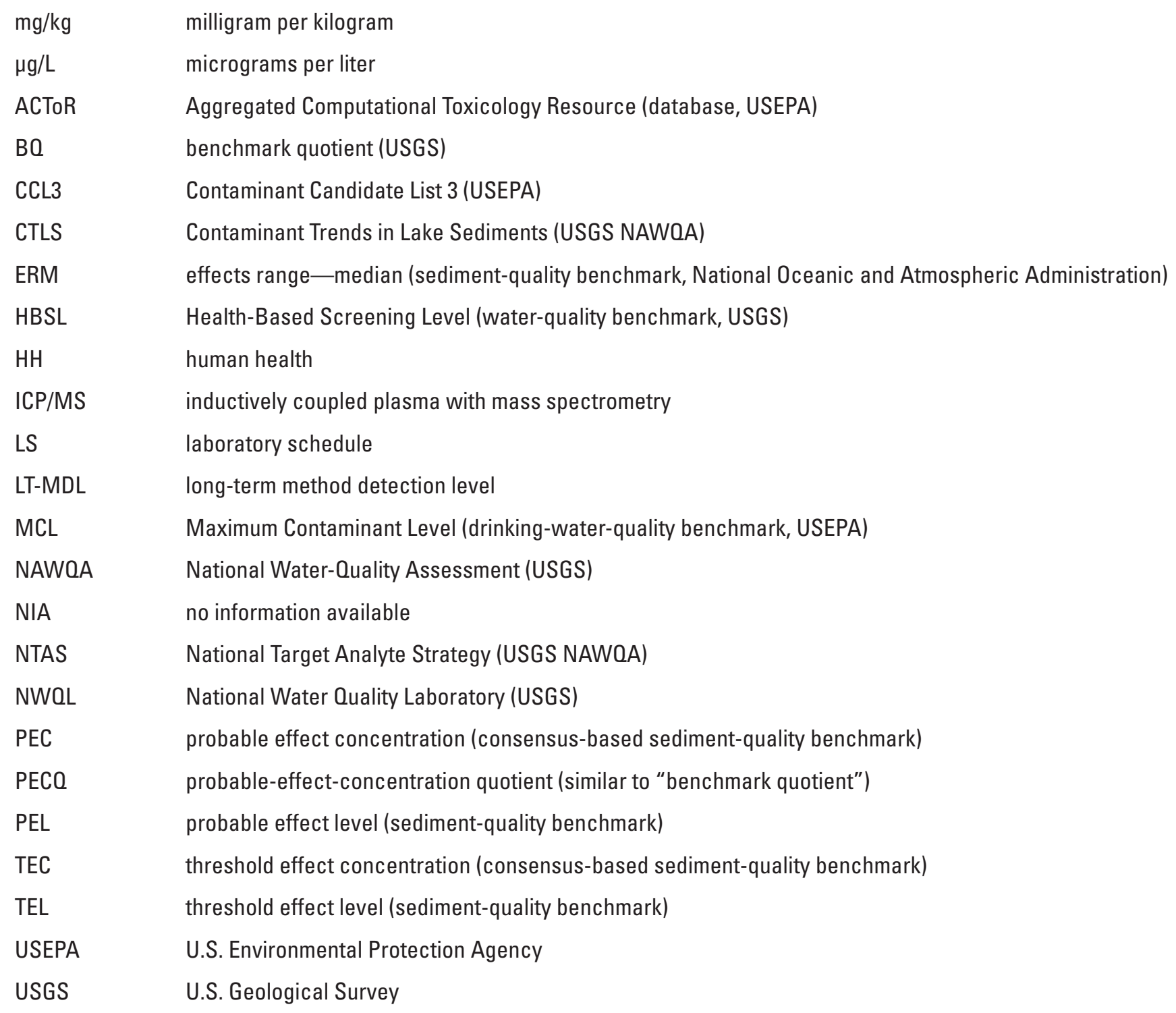


This supplemental information section of the report describes the prioritization of trace elements and other inorganic constituents (Group D) in water (Group D1) and sediment (Group D2) by the U.S. Geological Survey (USGS) National Target Analyte Strategy (NTAS) work group for national- and regional-scale ambient monitoring in the United States, in support of planning for the third decade (Cycle 3) of the National Water-Quality Assessment (NAWQA) Program. Water, for the purpose of the NTAS prioritization, is understood to mean filtered water samples (operationally, the dissolved phase). The emphasis for the prioritization for water (Group D1) was on groundwater resources; however, the results also are applicable to filtered surface water within the context of drinking-water sources. Constituents in streambed or suspended sediment are addressed separately in the sections on sediment. The emphasis for the prioritization for sediment (Group D2) was on potential effects to aquatic life, including effects from exposure to suspended sediment in unfiltered water. The feasibility of implementing analytical methods for high-priority trace elements, and knowledge and concerns of trace elements as a constituent group, also are described in this section.

A total of 38 trace elements and other inorganic constituents were prioritized, including 38 constituents for water, and 10 constituents for sediment. Most of the prioritization effort for trace elements focused on 23 constituents from the USGS National Water Quality Laboratory (NWQL) laboratory schedule (LS) used for filtered water samples in previous NAWQA cycles (except where noted), which was LS 2710 with iron added. Additional constituents were considered, such as mercury, selected species (valences) of arsenic, chromium, and iron, and selected inorganic disinfection by-products (water only), in response to concerns about effects to human health, chiefly through exposure by way of drinking water or because of their potential use as indicators of geochemical processes. Nutrients, such as nitrate, nitrite, phosphate, and sulfate, are known to be important with respect to human health and aquatic life (Dubrovsky and others, 2010) and will continue to be monitored for NAWQA Cycle 3; therefore, nutrients were omitted from this prioritization. Although many other additional trace elements are listed on the periodic table of elements, only those that were identified as NTAS candidate constituents through the lists of human-health or aquatic-life concern or other documentation (described in the "Sources of Information Used to Identify and Prioritize Constituents" section in the main body of this report) were prioritized; this practice is consistent with those of other NTAS constituent groups, as it was impractical to prioritize the entire universe of possible candidate constituents.

Six constituents that were evaluated as trace elements or other inorganic constituents (Group D) overlap with other NTAS constituent groups. These include three inorganic constituents in water (Group D1) that also were disinfection by-products in Group G (bromate, chlorate, and chlorite); one inorganic constituent in water (Group D1) that also was evaluated as a disinfection by-product in Group $\mathrm{G}$ and as a wastewater-indicator and industrial compound in Group I (perchlorate); and two trace elements in water (Group D1) and sediment (Group D2) that also were evaluated as pesticides in Groups B1 and B2 (copper and zinc). For all of these overlapping constituents, the prioritization performed for Group D matched the prioritization performed for the other constituent groups (as was the case for bromate, chlorate, chlorite, and perchlorate) or superseded the prioritization performed for the other constituent group (as was the case for copper and zinc).

\section{Prioritization of Trace Elements and Other Inorganic Constituents in Water (Group D1)}

This section describes the methods used for prioritization of trace elements and other inorganic constituents in water and the results of that prioritization. Benchmark quotients (BQs) for constituents in water were calculated as the ratio of a constituent concentration to an appropriate human-health benchmark, such as the U.S. Environmental Protection Agency's (USEPA) Maximum Contaminant Level (MCL) or other type of national recommended water-quality criteria (U.S. Environmental Protection Agency, 2010a), or the USGS Health-Based Screening Level (HBSL; Toccalino, 2007). For constituents that did not have sufficient occurrence data or benchmarks to allow calculation of BQs, the prioritization relied on the NTAS human-health $(\mathrm{HH})$ "bins" defined in the "Human-Health Effects Information from the ACToR Database" section in the main body of this report (the ACToR database is the USEPA Aggregated Computational Toxicology Resource database) or on other information, as described in this supplemental section.

\section{Prioritization Methods for Trace Elements and Other Inorganic Constituents in Water}

The prioritization of trace elements and other inorganic constituents in water considered occurrence, toxicity, adequacy of current analytical methods, and other potentially valuable factors, such as the use of the constituent as an environmental tracer. Traditional toxicological endpoints and data (for example, cancer endpoints) for human-health screening were used in the prioritization of constituents; this approach does not completely reflect the role of nontraditional biological endpoints, such as endocrine disruption, or the effects of mixtures.

Of the 38 trace elements and other inorganic constituents considered for prioritization, 23 constituents comprised the 22 trace elements on LS 2710 (table D1.1 at http://pubs.usgs. gov/sir/2012/5218/downloads/tableD1.xls) plus iron; NAWQA data for these constituents were available from previous cycles of monitoring (fig. D1.1). NAWQA data used for prioritization (DeSimone, 2009; Toccalino and others, 2010) were limited to groundwater data because trace elements were not consistently monitored in surface water during previous cycles of NAWQA, and because surface-water data can be 
more difficult to interpret than groundwater data because of the varying degrees of sorption of trace elements to suspended sediment in the water. The dataset for public-supply wells had distributions of concentrations similar to those in the dataset for domestic wells (fig. D1.1); therefore, data from both well types were combined for the prioritization of constituents. An additional 15 constituents (table D1.1) were considered for prioritization because they are regulated in drinking water by the U.S. Environmental Protection Agency (2009a, 2010a) or are being considered for regulation by the USEPA as part of the Contaminant Candidate List 3 (CCL3; U.S. Environmental Protection Agency, 2010b), or for enhanced monitoring in drinking water (U.S. Environmental Protection Agency, 2011), or because of their potential usefulness as environmental tracers or indicators of geochemical processes.

Consistent with approaches used by the NTAS work group for other constituent groups, percentile concentrations (50th and 99th percentiles) for constituents with occurrence data for drinking water (domestic and public-supply wells) were compared with human-health benchmarks, if available (table D1.2 at http://pubs.usgs.gov/sir/2012/5218/downloads/ tableD1.xls; figs. D1.2 and D1.3). Constituents with 99th percentiles greater than $1 / 10$ of their respective benchmark concentrations, corresponding to a BQ of 0.1 , were considered to be of high priority for monitoring and were placed into NTAS Tier 1.

For constituents that did not warrant placement into Tier 1 (cobalt, lithium, silver, and vanadium on LS 2710 and the additional 15 constituents that have not been monitored as widely) on the basis of their BQ values or because they lacked available human-health benchmarks, additional factors, such as human-health concern and usefulness as a tracer, were considered. Constituents with $\mathrm{HH}$ bins of 1 or 2 were placed into Tier 1, and all other constituents had evidence of usefulness as a tracer and were placed into Tier 2 .

\section{Results of Prioritization of Trace Elements and Other Inorganic Constituents in Water}

All constituents on the widely used laboratory schedule for trace elements, LS 2710, plus iron (table D1.1), were placed into NTAS Tier 1, except for silver, which was placed into Tier 2. Silver did not meet criteria for Tier 1 because of its low detection frequency in water (table D1.2) and low BQ values (figs. D1.2 and D1.3). Additional constituents were

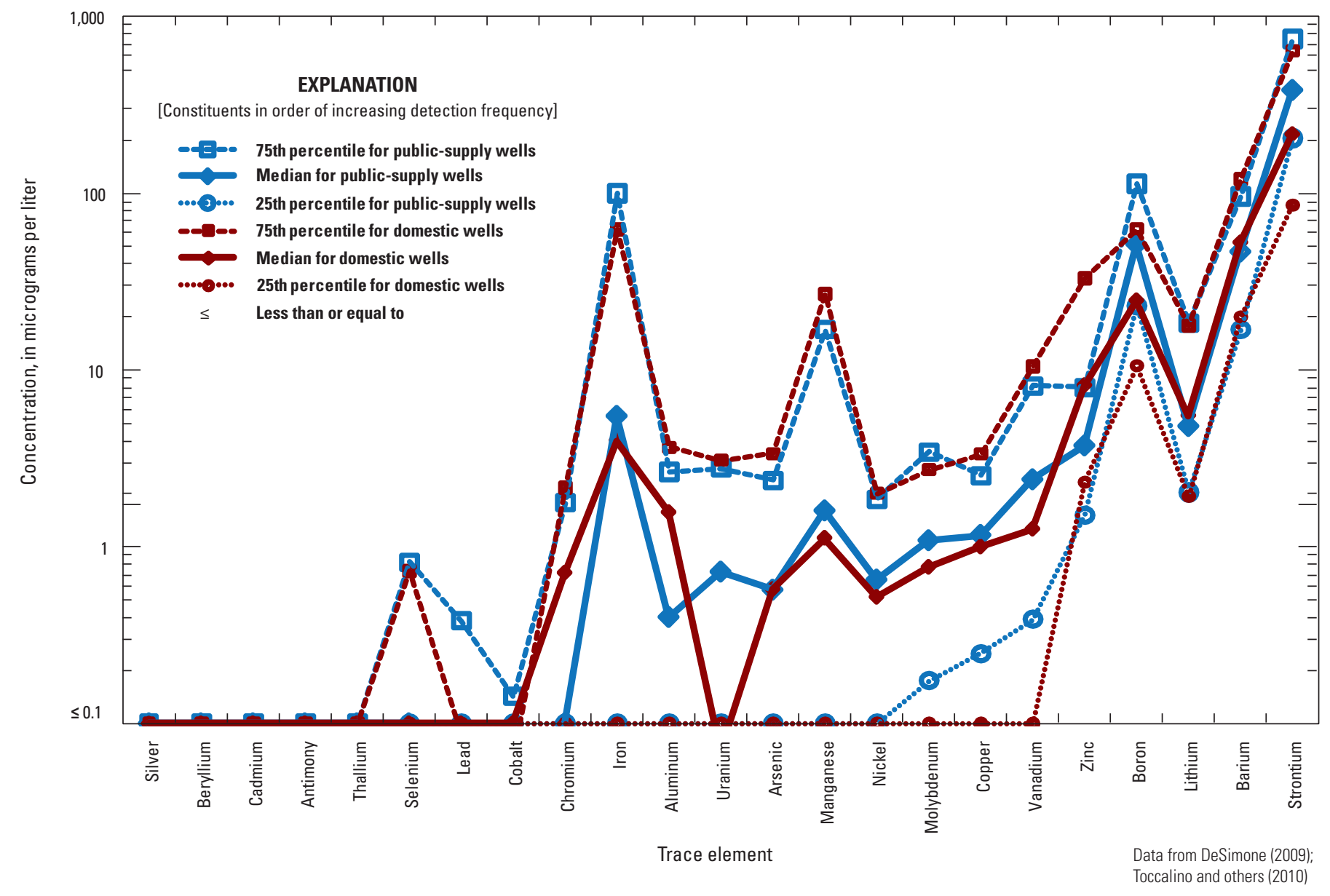

Figure D1.1. Percentile concentrations of trace elements for public-supply wells sampled from 1991-94 and domestic wells sampled from 1993-2007 by the National Water-Quality Assessment Program. 


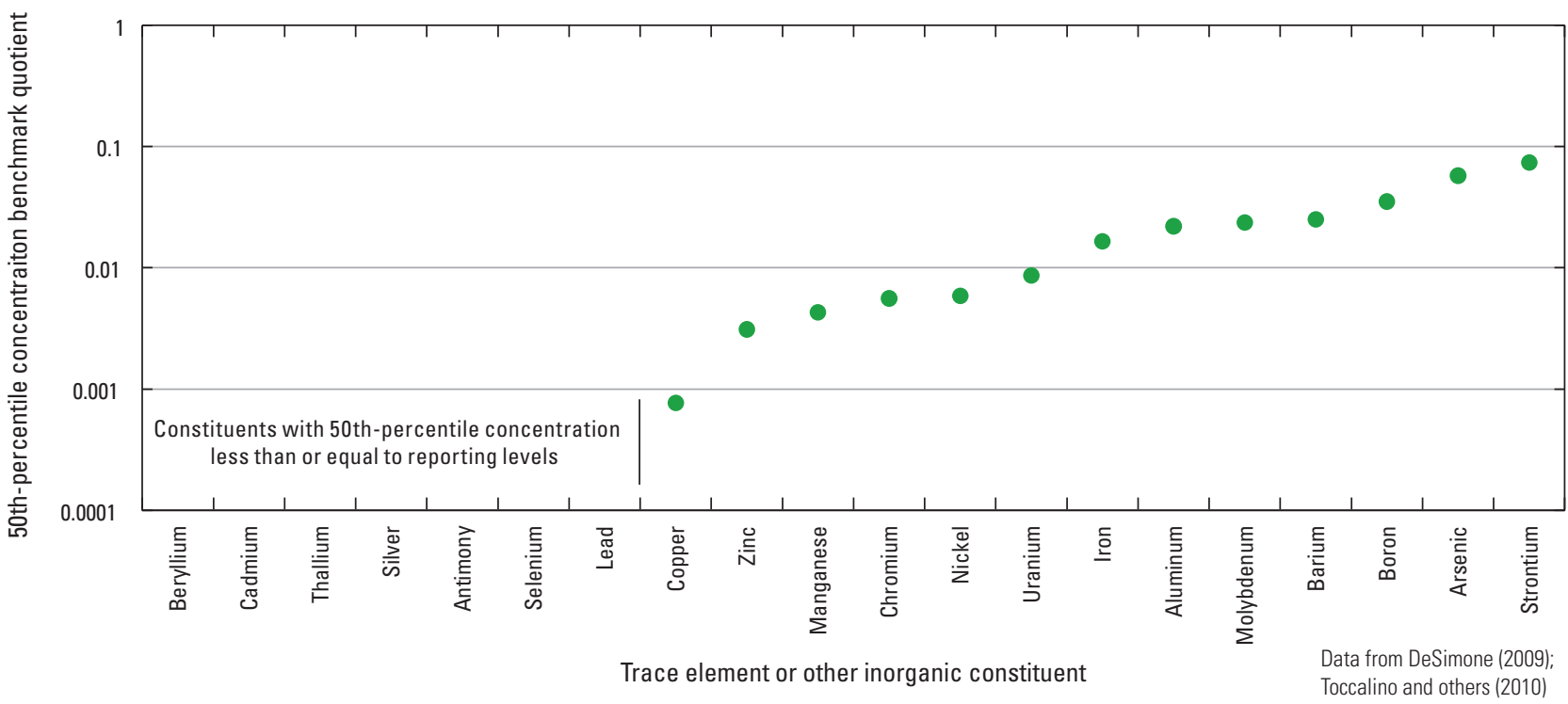

Figure D1.2. 50th-percentile concentration benchmark quotients for trace elements and other inorganic constituents in water.

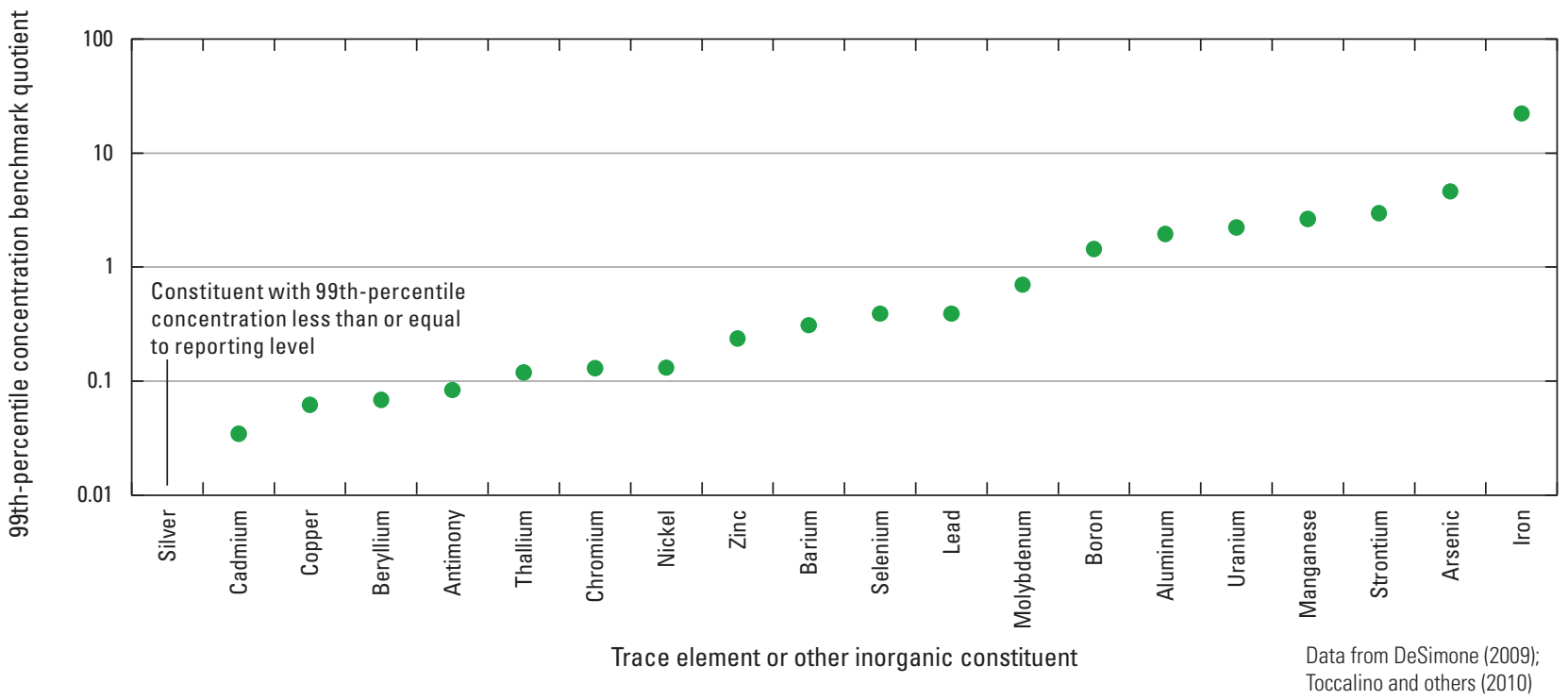

Figure D1.3. 99th-percentile concentration benchmark quotients for trace elements and other inorganic constituents in water.

prioritized, including some that were evaluated for other NTAS constituent groups:

- Bromate, chlorite, fluoride, and mercury were considered for prioritization on the basis of their inclusion in USEPA national primary drinking-water regulations (U.S. Environmental Protection Agency, 2009a). Bromate, chlorite, and fluoride were placed into Tier 1 because each had been assigned to HH bin 1. Fluoride has been detected at concentrations greater than a 0.1 of a benchmark (Toccalino and others, 2010). Mercury was placed into Tier 2 (intermediate priority for ambient monitoring) because it generally has not been detected in ambient groundwater at concentra- tions greater than human-health benchmarks-BQs for mercury in water generally are less than 0.1 -however, mercury could be an important constituent for studies of heavily contaminated settings.

- Chlorate, germanium, perchlorate, and tellurium were considered for prioritization on the basis of their inclusion on the USEPA CCL3 (U.S. Environmental Protection Agency, 2010b). Chlorate, perchlorate, and tellurium were placed into Tier 1 because each had been assigned to HH bin 1 or 2. Germanium had been assigned to HH bin NIA (no information available) and was placed into Tier 2 because of its potential usefulness as a tracer (Kurtz and others, 2011). 
- Chromium (III) and chromium (VI) were placed into Tier 1 because each had been assigned to HH bin 2 based on toxicological reviews (U.S. Environmental Protection Agency, 1998, 2010c) and because of recent concerns about potential presence in drinking water (U.S. Environmental Protection Agency, 2011).

- Species of selected trace elements, including arsenic (III), arsenic (V), iron (II), and iron (III), and the trace element gadolinium were considered for prioritization on the basis of their potential usefulness as tracers or indicators of geochemical or environmental processes and were placed into Tier 2 .

None of the constituents considered for prioritization were placed into Tier 3. For example, although the 99th-percentile concentrations of silver did not approach the benchmark concentration (table D1.2), silver was placed into Tier 2. Although silver was in HH bin 1 and placement into Tier 3 could not be justified, silver's concentrations and detection frequency were too low to justify placement into Tier 1.

\section{Basis for Prioritization of Trace Elements and Other Inorganic Constituents in Water}

With the exception of silver, all of the trace elements on LS 2710, plus iron, were placed into NTAS Tier 1 for reasons described previously, including their BQ values obtained from occurrence data (DeSimone, 2009; Toccalino and others, 2010) and USEPA benchmarks. Several additional constituents - bromate, chlorate, chlorite, chromium (III), chromium (VI), fluoride, perchlorate, and tellurium - were placed into Tier 1 on the basis of their assigned NTAS HH bins or BQ values; these constituents also are of interest to the USEPA as being of concern with respect to drinking water. These eight new constituents that were included in Tier 1 for monitoring are anticipated to occur in ambient water and are of humanhealth concern with respect to drinking water.

Arsenic (III), arsenic (V), gadolinium, germanium, iron (II), and iron (III) were placed into Tier 2 because of their potential use as environmental tracers or in fate and transport studies related to key human-health questions. Mercury was placed into Tier 2 because concentrations in ambient water generally are at least an order of magnitude less than the USEPA MCL of 2 micrograms per liter $(\mu \mathrm{g} / \mathrm{L})$ (Krabbenhoft and others, 1999), resulting in low BQ values. Silver was placed into Tier 2 because concentrations in ambient water generally are several orders of magnitude less than the HBSL of $100 \mu \mathrm{g} / \mathrm{L}$ (table D1.2).

\section{Feasibility of Implementation for High- Priority Trace Elements and Other Inorganic Constituents in Water}

The NWQL laboratory schedule currently (2011) used for trace elements, LS 2710, uses inductively-coupled plasma with mass spectrometry (ICP/MS; Fishman and Friedman, 1989; Garbarino, 1999; Garbarino and others, 2006) and is suitable for analysis of trace elements in filtered water samples because current detection levels are adequately below humanhealth benchmarks (table D1.2). Constituents measured using LS 2710 in previous cycles of the NAWQA Program do not require any modification of laboratory methods. Dropping silver from LS 2710 is not warranted despite its placement into Tier 2, because the potential cost saving is very small, and because likelihood of occurrence or importance of silver in groundwater could change in the future. The current NWQL capacity for LS 2710 is approximately 3,000 samples per year (Duane S. Wydoski, U.S. Geological Survey, written commun., 2010).

Constituents that have not been part of previous USGS monitoring will require method validation, determination of detection and reporting levels, and evaluation of performance data for environmental matrixes. Laboratory schedule 2710 could be modified to include gadolinium, germanium, and tellurium; performance for these constituents would need to be validated. Bromate, chlorate, and chlorite could be added to existing ion-chromatography methods or may require minor method development with existing equipment; the resulting methods would have to be validated, and costs would be similar to those of other ion-chromatography methods (Duane S. Wydoski, U.S. Geological Survey, written commun., 2010). Species of arsenic, chromium, and iron could require new methods or expansion and validation of existing research or custom methods (table D1.1) if these constituents are of interest for monitoring. An approved method exists for the separation and determination of arsenic species by collision/ reaction cell ICP-MS (Garbarino and others, 2006). Methods would have to be validated and approved for chromium and iron species.

Several options are available for perchlorate, including USEPA Methods 314.0 (Hautman and others, 1999), 331.0 (Wendelken and others, 2005), 332.0 (Hedrick and others, 2005), and 6850 (U.S. Environmental Protection Agency, 2007). Determination of perchlorate in water by commercial laboratories relies on ion chromatography with mass spectrometry or high-performance liquid chromatography with mass spectrometry. One of the USEPA methods could be implemented at the NWQL but would require validation by the NWQL. Analysis of perchlorate using liquid chromatography with tandem mass spectrometry, similar to methods being developed for pesticides and pharmaceuticals, also may be feasible.

When monitoring for disinfection by-products (for example, bromate, chlorate, and chlorite), residual chlorine might 
need to be quenched with additives at the time of sample collection (see details in the "Supplemental Information G" section). This practice could interfere with the analysis of other inorganic constituents by producing a source of contamination during sample collection and warrants further investigation of sampling protocols and quality assurance and quality control. Separate sample bottles may be needed for certain analyses. In addition, the disposable nitrile gloves used as part of USGS field sampling protocols can act as a source of certain constituents, such as phosphorus and nitrosamines (Alfred J. Driscoll, U.S. Geological Survey, written commun., December 2008; Lisa D. Olsen, U.S. Geological Survey, written commun., December 2010). It would be important to evaluate possible contamination by nitrile gloves and other potential sources of low-level contamination in the field (for example, sampling lines and fittings) for any new trace elements or other inorganic constituents that are added to laboratory schedules.

\section{Knowledge and Concerns of Trace Elements and Other Inorganic Constituents in Water as a Constituent Group}

Because trace elements are naturally occurring, they are known to occur in ambient water resources. However, many also have anthropogenic sources from industry, manufacturing, and use in consumer goods. In addition, some land-use activities can enhance the mobilization and transport of some inorganic constituents and increase their presence and magnitude in the aquifers as well as at the wellhead (Jurgens and others, 2010). Indeed, the very act of water withdrawal for public or domestic supply can mobilize some inorganic constituents (Ayotte and others, 2011). The USGS has a role in leading large-scale investigations of the occurrence of these constituents and their relation to natural sources, anthropogenic sources, or anthropogenically enhanced transport. The USGS has a unique role in assessing the spatial and temporal trends of these constituents in drinking-water sources over time, including the effects of land use and climate change. Organizations that manage natural resources, such as water supplies, would benefit from an improved understanding of the natural factors compared to anthropogenic factors in the transport of these contaminants. The USGS also has a role in understanding environmental water chemistry (including ambient, source, and finished water) in terms of background concentrations likely to occur bcause of the natural processes, such as weathering, erosion, or dissolution of aquifer materials. The role of inorganic constituents as environmental tracers is of scientific interest; for example, gadolinium has been used as a tracer for hospital waste (Verplanck and others, 2005), and germanium can be used in conjunction with silicon as a tracer of groundwater-flow paths (Kurtz and others, 2011).

Inorganic constituents, such as arsenic and uranium, are important contaminants because of their tendency to occur at concentrations equal to or greater than levels of human-health concern, such as MCLs or HBSLs. As a group, trace elements and other inorganic constituents tend to have widespread occurrence in environmental sources of drinking water and are frequently detected at concentrations greater than benchmarks (Toccalino and others, 2010). Current research is documenting previously understudied health effects of inorganic constituents (for example, arsenic, cadmium, and manganese) at low concentrations in vertebrate animals, including humans. For example, using age-specific exposure assessments and hazard quotients, researchers from the National Institutes of Health and USEPA have elevated concern of manganese in drinking waters used by infants and children (Wasserman and others, 2006; Bouchard and others, 2007). Cadmium has been found to act as an endocrine disruptor (Takiguchi and Yoshihara, 2006). Regulators may focus on nontraditional toxicological endpoints in the future and, in concert, seek analytical methods with lower detection levels, which would likely change the understanding of the occurrence and distribution of these constituents in water.

\section{Prioritization of Trace Elements in Sediment (Group D2)}

This section describes the methods used for prioritization of trace elements in suspended sediment and streambed sediment and describes the results and basis of that prioritization. For sediment, the concern is potential effects on aquatic life. Ten trace elements were considered for prioritization for sediment: arsenic, cadmium, chromium, copper, lead, mercury, nickel, selenium, silver, and zinc. These elements were considered because they are widely recognized as being potentially toxic to aquatic life, as indicated by their inclusion in several sets of sediment-quality guidelines (MacDonald and others, 2000) or because they have been identified as toxic contaminants of concern in selected settings, as is the case for silver (Flegal and others, 2007) and selenium (He and others, 2005). The prioritization of these trace elements for sediment was based on the following information:

1. More than 1,200 streambed-sediment samples collected for NAWQA Cycle 1 monitoring (Horowitz and Stephens, 2008) and

2. Age-dated sediment cores from 35 lakes from across the United States collected during NAWQA Cycle 1 and Cycle 2 for the Contaminant Trends in Lake Sediments (CTLS) study (Mahler and others, 2006; Van Metre and others, 2006).

Copper and zinc were the only trace elements in Group D2 that overlapped with other NTAS constituent groups for sediment, specifically with pesticides in sediment (Group B2). For both of these constituents, the prioritization approach for Group D2 (described in the following section) was given preference over the approach used for Group B2 (described in the "Supplemental Information B2" section). 


\section{Prioritization Methods for Trace Elements in Sediment}

Eight of the 10 trace elements in sediment (arsenic, cadmium, chromium, copper, lead, mercury, nickel, and zinc) were evaluated by comparing USGS monitoring data from the aforementioned sources to sediment-quality benchmarks designed for the protection of aquatic life. Trace elements were prioritized on the basis of the ratio of each elemental concentration to its respective aquatic-life benchmark, which is a type of benchmark quotient. A BQ of 1.0 or higher indicates a concentration that is equal to, or greater than, the benchmark concentration. Aquatic-life benchmarks used for these comparisons were the probable effect level (PEL), developed by Environment Canada and others (Smith and others, 1996), and the consensus-based guideline probable effect concentration (PEC) (MacDonald and others, 2000). The consensus-based guidelines are statistical summaries of six sets of sediment-quality guidelines (including PELs) developed by various Federal, State, and provincial agencies in North America (MacDonald and others, 2000). The PELs and PECs are the higher-level benchmarks for each set of guidelines and represent the concentration above which adverse effects on aquatic biota are likely to occur. The lower-level benchmarks are the threshold effect level (TEL) (Smith and others, 1996) and threshold effect concentration (TEC) (MacDonald and others, 2000), the concentrations below which no adverse effects are likely to occur. The TELs and TECs were not used as prioritization benchmarks because they are frequently exceeded, even at reference sites in areas of undeveloped land use. For seven trace elements reported by Mahler and others (2006), for example, the median concentration in 9 reference lakes exceeded the TEL or the TEC in 9 of 14 cases.

The NAWQA Cycle 1 streambed-sediment data used by Horowitz and Stephens (2008) included data from 100 reference sites in undeveloped areas. Among these sites, 0 percent (cadmium and copper) to 13 percent (chromium) of the samples had concentrations greater than their respective PECs. Baseline concentrations determined from these reference sites compared well with other published estimates of baseline concentrations (Horowitz and Stephens, 2008). For ambient monitoring, it is useful to focus on trace elements that tend to occur at concentrations greater than their baseline concentrations as a result of human activity. With the exception of mining areas for some metals, the highest concentrations of trace elements typically are found in urban settings; therefore, NAWQA Cycle 1 sediment samples from urban settings were compared to those from the undeveloped reference sites to determine which trace elements were frequently elevated as a result of human (urban) activities. Trace elements that had at least 10 percent more samples with concentrations greater than their PEC or PEL for the urban sites than the percentage of samples greater than the PEC or PEL for the reference sites were placed into NTAS Tier 1. This approach was used to identify trace elements that were most likely to be affected by anthropogenic activity as a result of their proximity to urban locations. A limitation of this approach, however, is that the NAWQA streambed sediments were sieved at 63 microns and analyzed as total digestions; both of these steps could result in higher concentrations than were observed in many of the sediment samples used to develop the sediment-quality guidelines, indicating that $\mathrm{BQs}$ developed from these data might overestimate potential toxicity.

A different prioritization approach was used with the CTLS data. BQs based on the PEC (the probable-effectconcentration quotient or PECQ) were evaluated for sediments deposited in the lakes after 1990. If the median PECQ for a trace element in the 13 urban lakes studied by Mahler and others (2006) for sediments deposited after 1990 was greater than 0.5 , that trace element was placed into Tier 1 . This is equivalent to 50 percent or more of the samples exceeding one-half of the PEC. As shown by MacDonald and others (2000) and Ingersoll and others (2001), a mean PECQ (mean of the individual PECQ values) greater than 0.5 has been shown to be a reliable predictor of increased toxicity and adverse biological effects.

If the criteria used for the NAWQA Cycle 1 streambedsediment data or the criteria used for the CTLS data did not cause a trace element to be placed into Tier 1 , it was placed into Tier 2, with the exception of mercury. None of the 10 trace elements that were prioritized for ambient monitoring in sediment and NAQWA Cycle 3 were assigned to Tier 3 because all 10 have toxicity concerns and have been detected in streams or lakes.

Mercury was prioritized differently than the other seven trace elements with sediment-quality guidelines. The sediment-quality guidelines used here are primarily based on toxicity to benthic organisms and do not consider the potential for bioaccumulation and adverse biological effects on higher trophic levels (MacDonald and others, 2000), which is the primary concern for mercury. Mercury, particularly in its methylated form (methylmercury), poses well-documented risks to wildlife and humans (U.S. Environmental Protection Agency, 1997; Holmes and others, 2009). Therefore, mercury was evaluated qualitatively on the basis of studies of relations between sediment concentrations and fish-tissue concentrations (Scudder and others, 2009), in addition to comparison to sediment-quality guidelines.

Selenium and silver, which do not have sediment-quality guidelines and which have sparse USGS monitoring data, were prioritized differently than the other eight trace elements. Selenium was monitored in NAWQA Cycle 1 at streambed sediment sites but not in analyses for the CTLS cores. Selenium is of concern for wildlife, especially in the western United States (Seiler and others, 2003). The U.S. Department of the Interior Bureau of Reclamation's National Irrigation Water Quality Program (U.S. Department of Interior, 1998) has a screening level of 4 milligrams per kilogram $(\mathrm{mg} / \mathrm{kg})$ for selenium. Selenium was prioritized by comparing the NAWQA Cycle 1 streambed-sediment data to this screening level. Silver was included in CTLS core analyses beginning in 2001, with a method reporting level ranging from 1 to $3 \mathrm{mg} / \mathrm{kg}$. 
The National Oceanic and Atmospheric Administration has an "effects range - median" (ERM) sediment-quality guideline for silver of $3.7 \mathrm{mg} / \mathrm{kg}$ (Long and others, 1995), which is analogous to the PEL and PEC. Silver was prioritized by comparing the CTLS data to this guideline.

\section{Results of Prioritization of Trace Elements in Sediment}

Chromium, copper, lead, nickel, and zinc were placed into NTAS Tier 1 on the basis of their potential adverse effects to aquatic biota, as indicated by comparison to sedimentquality guidelines. Mercury was placed into Tier 1 because of widespread concerns for aquatic life and human health associated with mercury contamination and its strong association with sediment. Arsenic, cadmium, selenium, and silver were placed into Tier 2 because these constituents are less likely to occur at concentrations greater than their respective benchmarks but still have toxicity concerns and typically occur in sediment.

\section{Basis for Prioritization of Trace Elements in Sediment}

The prioritization of trace elements was based on streambed-sediment data from NAWQA Cycle 1 monitoring (Horowitz and Stephens, 2008) and NAWQA lake-sediment data collected for the CTLS study during Cycle 1 and Cycle 2 (Van Metre and others, 2006). Although trends in trace element concentrations are of interest to the USGS and could be relevant to study design, trends were not considered in the prioritization approach. Trace element concentrations were compared to benchmarks, as described previously. Seven of the eight constituents with consensus-based sediment-quality guidelines (MacDonald and others, 2000) were prioritized using these guidelines. One of these eight trace elements (mercury) and two other elements (selenium and silver) were prioritized using alternative evaluations or screening levels, as described previously. More details about these datasets and comparisons follow.

\section{Comparison of NAWQA Data to Sediment-Quality Benchmarks for Eight Trace Elements}

NAWQA streambed-sediment data from Cycle 1 monitoring, compiled and analyzed by Horowitz and Stephens (2008), were used to evaluate trace-element occurrence relative to sediment-quality benchmarks. Horowitz and Stephens (2008) evaluated trace-element data by land-use type. Undeveloped reference sites were used to describe baseline concentrations, and agricultural sites showed "little or no impact" relative to these baseline concentrations. However, in their words, "urban land use appears to exert a substantial influence on downstream sediment chemistry." The percentages of samples from urban and reference streams that had concentrations greater than the PEL or PEC are listed in table D2.1 for eight trace elements. Four of these eight elements were placed into NTAS Tier 1 because the percentage of samples with concentrations greater than the PEC or PEL for the urban sites was at least 10 percent greater than the percentage of samples with concentrations above the PEC or PEL for the reference sites.

Trace-element concentrations and trends also were interpreted in sediment cores from 35 lakes for the NAWQA CTLS study (Mahler and others, 2006). Thirteen of the 35 lakes were in densely urban watersheds, those with 50 percent or more urban land use, with predominantly commercial and residential land uses. Core samples of sediment deposited after 1990 in these 13 urban lakes were used in the prioritization presented in this report. The median PECQs for these lakes, based

Table D2.1. Percentages of streambed-sediment samples collected for Cycle 1 of the National Water-Quality Assessment Program from urban streams with trace-element concentrations greater than the probable effect level (PEL) or probable effect concentration (PEC).

[The PEL and PEC differences are differences between the urban sites and reference sites in percentages of samples with concentrations greater than the respective sediment-quality benchmark. A PEL or PEC difference greater than 10 percent (bold-faced type) resulted in placement into Tier 1; NTAS, National Target Analyte Strategy]

\begin{tabular}{lcccccrrr}
\hline \multirow{2}{*}{\multicolumn{1}{c}{ Benchmark }} & \multicolumn{7}{c}{ Percentage of samples with concentrations greater than benchmark } \\
\cline { 2 - 9 } & Arsenic & Cadmium & Chromium & Copper & Mercury & Nickel & Lead & Zinc \\
\hline PEL for reference sites & 23.0 & 2.0 & 21.0 & 0.0 & 5.0 & -- & 6.0 & 3.0 \\
PEL for urban sites & 14.5 & 6.4 & 41.8 & 10.0 & 12.7 & -- & 47.3 & 40.9 \\
PEC for reference sites & 10.0 & 0.0 & 13.0 & 0.0 & 0.0 & 21.0 & 5.0 & 2.0 \\
PEC for urban sites & 5.5 & 3.6 & 26.4 & 15.5 & 2.7 & 30.0 & 25.5 & 19.1 \\
PEL difference & -8.5 & 4.4 & $\mathbf{2 0 . 8}$ & $\mathbf{1 0 . 0}$ & 7.7 & -- & $\mathbf{4 1 . 3}$ & $\mathbf{3 7 . 9}$ \\
PEC difference & -4.5 & 3.6 & $\mathbf{1 3 . 4}$ & $\mathbf{1 5 . 5}$ & 2.7 & 9.0 & $\mathbf{2 0 . 5}$ & $\mathbf{1 7 . 1}$ \\
NTAS tier assigned & 2 & 2 & 1 & 1 & 12 & 22 & 1 & 1 \\
\hline
\end{tabular}

${ }^{1}$ Mercury was subsequently assigned to NTAS Tier 1 through consideration of additional information.

${ }^{2}$ Nickel was subsequently assigned to NTAS Tier 1 on the basis of core data from the Contaminant Trends in Lake sediments (CTLS) study. 
on the mean PECQ for post-1990 samples from each lake, are shown in table D2.2. Five trace elements had a median PECQ greater than the 0.5 threshold: the four elements classified as Tier 1 using the NAWQA streambed-sediment data (table D2.1), plus nickel.

\section{Additional Evaluation for Mercury, Selenium, and Silver}

Because the widely used sediment-quality guidelines do not adequately represent the range of concerns about mercury, mercury received additional evaluation. Similarly, because widely used sediment-quality guidelines were not available for selenium and silver, these trace elements received additional evaluation.

Mercury is not only of concern to aquatic life, but also to human health from exposure through fish tissue; 80 percent of all fish consumption advisories in the United States as of 2008 were based at least in part on mercury (U.S. Environmental Protection Agency, 2009b). Sediment is a primary reservoir of mercury in aquatic systems. Mercury transformation into methylmercury and its subsequent accumulation in biota involve complex processes that can result in a lack of a strong correlation between total mercury in streambed sediment and fish; however, Scudder and others (2009) found a significant relation between methylmercury concentrations in sediment and mercury concentrations in fish. Mercury generally enters aquatic systems through atmospheric deposition (Fitzgerald and others, 1998), but the understanding of atmospheric deposition patterns, trends, and links to emission sources remains incomplete (Lindberg and others, 2007). To improve the understanding of emissions-to-deposition processes for mercury, sediment cores collected from reference lakes for the NAWQA CTLS study were used to reconstruct mercury deposition histories (Van Metre and Fuller, 2009). For these reasons, mercury and, for some studies, methylmercury, will continue to be priority constituents for ambient monitoring in sediment, and mercury has been placed into Tier 1 .

Selenium was monitored in streambed sediments during NAWQA Cycle 1 but not in CTLS cores. Selenium concentrations were low in streambed sediment, with no land-use category having more than 5 percent of samples greater than the screening level of $4 \mathrm{mg} / \mathrm{kg}$ for the National Irrigation Water Quality Program (U.S. Department of Interior, 1998). Because selenium rarely exceeded this screening level and because it is of local interest and generally not of national concern, selenium was placed into Tier 2 .

Silver has been detected in only a few samples collected for the NAWQA CTLS study since 2000. These samples were analyzed using reporting levels ranging from 1 to $3 \mathrm{mg} / \mathrm{kg}$, which are only slightly less than the ERM guideline of $3.7 \mathrm{mg} / \mathrm{kg}$ (Long and others, 1995). None of the CTLS samples had concentrations greater than the ERM. Even in the most densely urban watersheds in the CTLS study in which other metals were detected at relatively high concentrations, for example, Lake Whitney in New Haven, Connecticut (number of samples $(n)=17$ ), and Echo Lake in Fort Worth, Texas $(n=18)$, silver was not detected at a concentration greater than a reporting level of $3 \mathrm{mg} / \mathrm{kg}$ (data on file in the USGS Texas Water Science Center). Although ideally the laboratory reporting level would be one-tenth of the benchmark or lower, the lack of detections at concentrations less than $3.7 \mathrm{mg} / \mathrm{kg}$ in some of the more heavily urbanized lakes sampled for the CTLS study indicates that silver contamination is not a concern for aquatic life in most streams and lakes. Silver, therefore, was placed into Tier 2 .

\section{Feasibility of Implementation for High-Priority Trace Elements in Sediment}

The USGS Minerals Program Denver Laboratory operated by Geologic Discipline scientists in Colorado analyzes 40 major and trace elements in sediment by inductively coupled plasma with mass spectrometry (ICP/MS) (schedule 1631). This laboratory schedule includes 8 of the 10 trace elements prioritized for this report. Mercury and selenium would need to be analyzed separately. Currently (2011), the NWQL and Minerals Program Denver Laboratory do not offer methylmercury analyses, but the USGS Mercury Laboratory at the Wisconsin Water Science Center does. Methylmercury and total mercury analyses could be performed there.

Methods for individual trace elements are available; however, they generally are not cost-effective relative to the ICP/ MS method, if more than a few trace elements are determined. Considering the wealth of information that can be obtained by determining a large number of major and trace elements together, the 40-element ICP/MS method (or its equivalent) is a feasible analytical method for NAWQA Cycle 3 monitoring.

Table D2.2. Median probable-effect-concentration quotient (PECQ) for selected trace elements in sediment deposited after 1990 in 13 urban lakes.

[Data from Mahler and others, 2006]

\begin{tabular}{ccccccccc}
\hline \multicolumn{7}{c}{ Median probable effect concentration quotient } \\
\hline Arsenic & Cadmium & Chromium & Copper & Lead & Mercury & Nickel & Zinc \\
\hline 0.44 & 0.33 & 0.67 & 0.55 & 1.67 & 0.28 & 0.68 & 0.75 \\
\hline
\end{tabular}




\section{Knowledge and Concerns of Trace Elements in Sediment as a Constituent Group}

The long-term downward trends in sediment concentrations of most of the trace elements in Tier 1 or 2 warrant consideration in future monitoring; however, low-frequency sampling might be sufficient to monitor and verify trends. Concentration trends of the eight trace elements (except for arsenic and zinc) monitored in streambed sediment for NAWQA Cycle 1 were predominantly downward in urban and reference lakes from 1970-2001 (Mahler and others, 2006).

An ongoing collaborative study between the CTLS study and the University of Texas at El Paso is using zinc isotopes to identify zinc sources to urban lakes. The isotopic results indicate that over the last approximately 40 years, the dominant zinc source has shifted away from atmospheric deposition of industrial emissions to runoff that contains tire dust (Thapalia and others, 2010). In addition to the direct concerns posed by trace elements to aquatic biota, the relative proportions of major and trace element analyses in sediments also have explanatory value and can be used to improve the understanding of sediment provenance and transport processes.

\section{References for Trace Elements and other Inorganic Constituents in Water or Sediment (Group D)}

Ayotte, J.D., Szabo, Zoltan, Focazio, M.J., and Eberts, S.M., 2011, Effects of human-induced alteration of groundwater flow on concentrations of naturally-occurring trace elements at water-supply wells: Applied Geochemistry, v. 26, no. 5, p. 747-762.

Bouchard, Maryse; Laforest, François; Vandelac, Louise; Bellinger, David; and Mergler, Donna; 2007, Hair manganese and hyperactive behaviors-Pilot study of school-age children exposed through tap water: Environmental Health Perspectives, v. 115, no. 1, p. 122-127.

DeSimone, L.A., 2009, Quality of water from domestic wells in principal aquifers of the United States, 1991-2004: U.S. Geological Survey Scientific Investigations Report 2008-5227, 139 p. (Also available at http://pubs.usgs.gov/ sir/2008/5227/.)

Dubrovsky, N.M., Burow, K.R., Clark, G.M., Gronberg, J.M., Hamilton P.A., Hitt, K.J., Mueller, D.K., Munn, M.D., Nolan, B.T., Puckett, L.J., Rupert, M.G., Short, T.M., Spahr, N.E., Sprague, L.A., and Wilber, W.G., 2010, The quality of our Nation's waters-Nutrients in the Nation's streams and groundwater, 1992-2004: U.S. Geological Survey Circular 1350, 174 p. (Also available at http://pubs.usgs.gov/ circ/1350/.)
Fishman, M.J., and Friedman, L.C., eds., 1989, Methods for determination of inorganic substances in water and fluvial sediments: Techniques of Water-Resources Investigations of the United States Geological Survey, book 5, chap. A1, $545 \mathrm{p}$.

Fitzgerald, D.J., Engstrom, D.R., Mason, R.P., and Nater, E.A., 1998, The case for atmospheric mercury contamination in remote areas: Environmental Science and Technology, v. 32 , no. 1 , p. $1-7$.

Flegal, A.R., Brown, C.L., Squire, S., Ross, J.R.M., Scelfo, G.M., and Hibdon, S.A., 2007, Spatial and temporal variations in silver contamination and toxicity in San Francisco Bay: Environmental Research, v. 105, no. 1, p. 34-52.

Garbarino, J.R., 1999, Methods of analysis by the U.S. Geological Survey National Water Quality LaboratoryDetermination of dissolved arsenic, boron, lithium, selenium, strontium, thallium, and vanadium using inductively coupled plasma-mass spectrometry: U.S. Geological Survey Open-File Report 99-093, 31 p.

Garbarino, J.R., Kanagy, L.K., and Cree, M.E., 2006, Determination of elements in natural-water, biota, sediment and soil samples using collision/reaction cell inductively coupled plasma-mass spectrometry: U.S. Geological Survey Techniques and Methods, book 5, sec. B, chap.1, 88 p.

Hautman, D.P., Munch, D.J., Eaton, A.D., and Haghani, A.W., 1999, Method 314.0 - Determination of perchlorate in drinking water using ion chromatography: Cincinnati, Ohio, Office of Research and Development, 49 p., accessed March 23, 2012, at http://www.epa.gov/ogwdw/methods/pdfs/ methods/met314.pdf.

He, Z.L., Yang, X.E., and Stoffella. P.J., 2005, Trace elements in agroecosystems and impacts on the environment: Journal of Trace Elements in Medicine and Biology, v. 19, no. 2-3, p. 125-140.

Hedrick, Elizabeth; Behymer, Thomas; Slingsby, Rosanne; and Munch, David; 2005, Method 332.0-Determination of perchlorate in drinking water by ion chromatography with suppressed conductivity and electrospray ionization mass spectrometry: Cincinnati, Ohio, U.S. Environmental Protection Agency EPA/600/R-05/049, accessed March 23, 2012, at $h t t p: / / w w w . e p a . g o v / n e r l c w w w / d o c u m e n t s / m \_332 \_0 . p d f$.

Holmes, P., James, K.A.F., and Levy, L.S., 2009, Is low-level environmental mercury exposure of concern to human health?: Science of the Total Environment, v. 408, no. 8, p. 171-182. 
Horowitz, A.J., and Stephens, V.C., 2008, The effects of land use on fluvial sediment chemistry for the conterminous U.S.- Results from the first cycle of the NAWQA Program-Trace and major elements, phosphorus, carbon, and sulfur: Science of the Total Environment, v. 400, no. 1-3, p. $290-314$

Ingersoll, C.G.; MacDonald, D.D.; Wang, Ning; Crane, J.L.; Field, L.J.; Haverland, P.S.; Kemble, N.E.; Lindskoog, R.A.; Severn, Corinne; and Smorog, D.E.; 2001, Predictions of sediment toxicity using consensus-based freshwater sediment quality guidelines: Archives of Environmental Contamination and Toxicology, v. 41, no. 1, p. 8-21.

Jurgens, B.C.; Fram, M.S.; Belitz, Kenneth; Burow, K.R.; and Landon, M.K.; 2010, Effects of groundwater development on uranium-Central Valley, California, USA: Ground Water, v. 48, no. 6, p. 913-928.

Krabbenhoft, D.P., Wiener, J.G., Brumbaugh, W.G., Olson, M.L., DeWild, J.F., and Sabin, T.J., 1999, A national pilot study of mercury contamination of aquatic ecosystems along multiple gradients in U.S. Geological Survey Toxic Substances Hydrology Program-Proceedings of the Technical Meeting, Charleston, South Carolina, March 8-12, 1999, volume 2 of Contamination of hydrologic systems and related ecosystems: U.S. Geological Survey WaterResources Investigations Report 99-4018B, p. 147-160.

Kurtz, A.C., Lugolobi, Festo, and Salvucci, Guido, 2011, Germanium-silicon as a flow path tracer: Application to the Rio Icacos watershed: Water Resources Research, v. 47, W06516, 16 p.

Lindberg, Steve; Bullock, Russell; Ebinghaus, Ralf; Engstrom, D.R.; Feng, Xinbin; Fitzgerald, W.F.; Pirrone, Nicola; Prestbo, Eric; and Seigneur, Christian; 2007, A synthesis of progress and uncertainties in attributing the sources of mercury in deposition: AMBIO-A Journal of the Human Environment, v. 36, no. 1, p. 19-32.

Long, E.R., MacDonald, R.W., Smith, S.L., and Calder, F.D., 1995, Incidence of adverse biological effects within ranges of chemical concentrations in marine and estuarine sediments: Environmental Management, v. 19, no. 1, p. 81-97.

MacDonald, D.D., Ingersoll, C.G., and Berger, T.A., 2000, Development and evaluation of consensus-based quality guidelines for freshwater ecosystems: Archives of Environmental Contamination and Toxicology, v. 39, p. 20-31.

Mahler, B.J., Van Metre, P.C., and Callender, Edward, 2006, Trends in metals in urban and reference lake sediments across the United States, 1970-2001: Environmental Toxicology and Chemistry, v. 25, no. 7, p. 1,698-1,709.
Scudder, B.C., Chasar, L.C., Wentz, D.A., Bauch, N.J., Brigham, M.E., Moran, P.W., and Krabbenhoft, D.P., 2009, Mercury in fish, bed sediment, and water from streams across the United States, 1998-2005: U.S. Geological Survey Scientific Investigations Report 2009-5109, 74 p.

Seiler, R.L., Skorupa, J.P., Naftz, D.L., and Nolan, B.T., 2003, Irrigation-induced contamination of water, sediment, and biota in the Western United States - Synthesis of data from the National Irrigation Water Quality Program: U.S. Geological Survey Professional Paper 1655, 123 p.

Smith, S.L., MacDonald, D.D., Keenleyside, K.A., Ingersoll, C.G., and Field, Jay, 1996, A preliminary evaluation of sediment quality assessment values for freshwater ecosystems: Journal of Great Lakes Research, v. 22, p. 624-638.

Takiguchi, Masufumi, and Yoshihara, Shin'ichi, 2006, New aspects of cadmium as endocrine disruptor: Environmental Sciences, v. 13, no. 2, p. 107-116.

Thapalia, Anita; Borrok, D.M.; Van Metre, P.C.; Musgrove, MaryLynn; and Landa, E.R., 2010, $\mathrm{Zn}$ and $\mathrm{Cu}$ isotopes as tracers of anthropogenic contamination in a sediment core from an urban lake: Environmental Science and Technology, v. 44 , no. 5 , p. $1,544-1,550$.

Toccalino, P.L., 2007, Development and application of HealthBased Screening Levels for use in water-quality assessments: U.S. Geological Survey Scientific Investigations Report 2007-5106, 12 p., accessed December 8, 2010, at http://pubs.usgs.gov/sir/2007/5106/.

Toccalino, P.L., Norman, J.E., and Hitt, K.J., 2010, Quality of source water from public-supply wells in the United States, 1993-2007: U.S. Geological Survey Scientific Investigations Report 2010-5024, 206 p. (Also available at http:// pubs.usgs.gov/sir/2010/5024/.)

U.S. Department of Interior, 1998, Guidelines for the interpretation of the biological effects of selected constituents in water, biota, and sediment - Selenium: National Irrigation Water Quality Program Information Report No. 3, accessed April 13, 2011, at http://www.usbr.gov/niwqp/guidelines/ pdf/Selenium.pdf.

U.S. Environmental Protection Agency, 1997, Mercury study report to Congress-Volume VII, Characterization of human health and wildlife risks from mercury exposure in the United States: U.S. Environmental Protection Agency, EPA-452/R-97-009, 152 p, accessed April 22, 2011, at http://www.epa.gov/ttn/oarpg/t3/reports/volume7.pdf.

U.S. Environmental Protection Agency, 1998, Toxicological review of hexavalent chromium: Washington, D.C., U.S. Environmental Protection Agency, accessed March 23, 2012, at http://www.epa.gov/iris/toxreviews/0144tr.pdf. 
U.S. Environmental Protection Agency, 2007, Perchlorate in water, soils and solid wastes using ion chromatography/ electrospray ionization/mass spectrometry: U.S. Environmental Protection Agency, 27 p., accessed March 23, 2012, at $h t t p: / / w w w . e p a . g o v / o s w / h a z a r d / t e s t m e t h o d s / p d f s / 6850$. $p d f$.

U.S. Environmental Protection Agency, 2009a, 2009 Edition of the drinking water standards and health advisories (updated October 2009): U.S. Environmental Protection Agency, Office of Water EPA 822-R-09-011, accessed December 20, 2010, at http://water.epa.gov/action/ advisories/drinking/upload/dwstandards2009.pdf.

U.S. Environmental Protection Agency, 2009b, 2008 Biennial national listing of fish consumption advisories: U.S. Environmental Protection Agency Fact Sheet EPA-

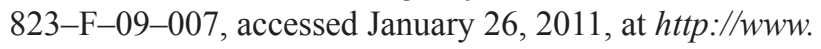
epa.gov/waterscience/fish/advisories/tech2008.html.

U.S. Environmental Protection Agency, 2010a, National recommended water quality criteria: accessed December 27, 2010, at http://water.epa.gov/scitech/swguidance/standards/ current/.

U.S. Environmental Protection Agency, 2010b, Contaminant Candidate List 3-CCL3: accessed December 20, 2010, at http://water.epa.gov/scitech/drinkingwater/dws/ccl/ccl3.cfm.

U.S. Environmental Protection Agency, 2010c, Draft toxicological review of hexavalent chromium: Washington, D.C., U.S. Environmental Protection Agency, EPA/635/R10/004A.

U.S. Environmental Protection Agency, 2011, EPA issues guidance for enhanced monitoring of hexavalent chromium in drinking water (press release, January 11, 2011): accessed March 23, 2012, at http://yosemite.epa.gov/opa/admpress. $n s f / d 0 c f 6618525 a 9 e f b 85257359003 f b 69 d / 93 a 75 b 03149 d 30$ b08525781500600f62\%21OpenDocument.
Van Metre, P.C., and Fuller, C.C., 2009, Dual-core mass-balance approach for evaluating mercury and ${ }^{210} \mathrm{~Pb}$ atmospheric fallout and focusing to lakes: Environmental Science and Technology, v. 43, no. 1, p. 26-32.

Van Metre, P.C., Mahler, B.J., Wilson, J.T., and Callender, Edward, 2006, Major and trace elements in 35 lake and reservoir sediment cores from across the United States, 1994-2001: U.S. Geological Survey Data Series Report 166, accessed April 22, 2011, at http://pubs.usgs.gov/ds/ ds $166 /$.

Verplanck, P.L., Taylor, H.E., Nordstrom, D.K., and Barbar, L.B., 2005, Aqueous stability of gadolinium in surface waters receiving sewage treatment plant effluent, Boulder Creek, Colorado: Environmental Science and Technology, v. 39 , no. 18 , p. 6,923-6,929.

Wasserman, G.A.; Liu, Xinhua; Parvez, Faruque; Ahsan, Habibul; Levy, Diane; Factor-Litvak, Pam; Kline, Jennie; van Green, Alexander; Slavkovich, Vesna; Lolacono, N.J.; Cheng, Zhongqi; Zheng, Yan; and Graziano, J.H.; 2006, Water manganese exposure and children's intellectual function in Araihazar, Bangladesh: Environmental Health Perspectives, v. 114, no. 1, p. 124-129.

Wendelken, S.C., Munch, D.J., Pepich, B.V., Later, D.W., and Pohl, C.A., 2005, Method 331.0-Determination of perchlorate in drinking water by liquid chromatography electrospray ionization mass spectrometry: Cincinnati, Ohio, U.S. Environmental Protection Agency 815-R-05-007. 


\title{
Supplemental Information E.
}

\section{Prioritization of Cyanotoxins in Surface Water (Group E)}

By John S. Zogorski, Duane S. Wydoski, and Joshua F. Valder

\section{Abbreviations and Acronyms Used in Supplemental Information E}

\author{
$\mu \mathrm{g} / \mathrm{L} \quad$ micrograms per liter \\ ACToR Aggregated Computational Toxicology Resource (database. USEPA) \\ CASRN Chemical Abstracts Service Registry Number ${ }^{\circledR}$ (American Chemical Society) \\ CCL3 Contaminant Candidate List 3 (USEPA) \\ ECOTOX ECOTOXicology (database, USEPA) \\ ELISA enzyme-linked immunosorbent assay \\ EPI Suite ${ }^{\mathrm{TM}} \quad$ Estimation Program Interface Suite (screening software, USEPA) \\ HAB harmful algal bloom \\ LC/MS liquid chromatography with mass spectrometry \\ LC/MS/MS liquid chromatography with tandem mass spectrometry \\ $\log K_{\text {ow }} \quad$ base-10logarithm of the octanol-water partition coefficient \\ MAC Maximum Acceptable Concentration (drinking-water-quality benchmark, Health Canada) \\ NAWQA National Water-Quality Assessment (USGS) \\ NTAS National Target Analyte Strategy (USGS NAWQA) \\ OGRL Organic Geochemistry Research Laboratory (USGS Kansas Water Science Center) \\ TOXNET Toxicology Data Network (database, U.S. National Library of Medicine) \\ USEPA U.S. Environmental Protection Agency \\ USGS U.S. Geological Survey
}


This supplemental information section of the report describes the prioritization of cyanotoxins in surface water (Group E) by the U.S. Geological Survey (USGS) National Target Analyte Strategy (NTAS) work group for national- and regional-scale ambient monitoring in the United States. This prioritization was done in support of planning for the third decade (Cycle 3) of the National Water-Quality Assessment (NAWQA) Program. The feasibility of implementing analytical methods for high-priority cyanotoxins, as well as knowledge and concerns of cyanotoxins as a constituent group, also are described in this section. The prioritization focused on 15 cyanotoxins (also known as "cyanobacterial toxins") available on laboratory methods that were developed and used by the USGS Organic Geochemistry Research Laboratory (OGRL) in the Kansas Water Science Center. The term "algal toxins" sometimes is used to refer to cyanotoxins; however, this term is a misnomer because the toxins of interest are produced by cyanobacteria rather than by algae, though both may be present in an algal bloom.

Cyanotoxins are produced by cyanobacteria or Cyanophyta (a taxonomic group of phototrophic bacteria that produce oxygen), which are the primary cause of freshwater harmful algal blooms (HABs). Cyanobacteria are a natural component of aquatic ecosystems and are found in various environments throughout the world. Between 2005 and 2009, at least 19 U.S. States have issued health advisories or closed recreational areas because of cyanobacterial blooms (Graham and others, 2009). Concentrations of cyanotoxins greater than levels of human-health concern can occur in water, especially during periods of high bacterial biomass. Cyanotoxins are known to cause lethal, sub-lethal, and chronic effects in humans, domestic animals, wildlife, and aquatic organisms (Hudnell, 2009). Short-term effects from exposure can include gastrointestinal problems, liver inflammation and hemorrhage, dermatitis, tingling, numbness, drowsiness, incoherent speech, and respiratory paralysis leading to death (Lopez and others, 2008). Long-term health effects can include liver failure, cardiac arrhythmia, anorexia, and skin tumors (Lopez and others, 2008). Cyanobacteria also can cause taste and odor problems in drinking-water sources (Graham and others, 2010; Izaguirre and others, 1982). Because cyanotoxins are associated with cyanobacterial blooms in lakes and reservoirs, the prioritization of these constituents was limited to surface water.

All 15 of the cyanotoxins prioritized for the NTAS effort are of human-health concern; however, toxicity studies are incomplete for all but possibly microcystin-LR. MicrocystinLR is one of more than 80 microcystin variants that have been identified (Welker and Von Döhren, 2006) and is one of the variants that is most commonly found in water supplies around the world (Health Canada, 2011). The U.S. Environmental Protection Agency (2010) Contaminant Candidate List 3 (CCL3) for drinking water includes anatoxin-a, cylindrospermopsin, and microcystin-LR. The World Health Organization (2003) has established a health-based provisional guideline of 1 microgram per liter $(\mu \mathrm{g} / \mathrm{L})$ for microcystin-LR in drinking water. Health Canada (2011) has established a Maximum
Allowable Concentration (MAC) of $1.5 \mu \mathrm{g} / \mathrm{L}$ for total microcystins for Canadian drinking-water supplies based on the toxicity of microcystin-LR. For recreational exposure, the World Health Organization (Chorus and Bartram, 1999) has established guidance values for acute health effects for microcystinLR of less than $10 \mu \mathrm{g} / \mathrm{L}$ for low risk, $10-20 \mu \mathrm{g} / \mathrm{L}$ for moderate risk, and $20-2,000 \mu \mathrm{g} / \mathrm{L}$ for high risk.

\section{Prioritization of Cyanotoxins in Surface Water (Group E)}

This section describes the methods used for prioritization of 15 cyanotoxins and the results of that prioritization. Emphasis was placed on cyanotoxins that could be produced in lakes and reservoirs that could be used for public drinkingwater supply. Information sources used for this prioritization included (1) USGS occurrence data for cyanotoxin constituents in water samples collected from lakes during the 2006 USGS Midwestern Cyanotoxin Reconnaissance (Graham and others, 2010); (2) study summaries provided by Jennifer Graham, Keith Loftin, and Mike Meyer of the Kansas Water Science Center (U.S. Geological Survey, 2011); and (3) literature for several of the cyanotoxins, including the U.S. Environmental Protection Agency (USEPA) National Lakes Assessment (U.S. Environmental Protection Agency, 2009a; 2011), a review by Hudnell (2009) covering occurrence, risk assessment, and U.S. legislation to address cyanotoxin issues, and a review of the state of the science by Carmichael (2008). Likelihood of occurrence in water was confirmed through consideration of the base-10 logarithms of the octanol-water partition coefficients $\left(\log K_{\mathrm{OW}}\right)$ estimated by using the "SPARC" calculator (http://ibmlc2.chem.uga.edu/sparc/) developed by the USEPA and University of Georgia with methods described in Hilal and others (2004) or from the EPI Suite ${ }^{\mathrm{TM}}$ (Estimation Program Interface Suite) set of estimation models (U.S. Environmental Protection Agency, 2009b).

In addition, information on human-health effects was used from the USEPA Aggregated Computational Toxicology Resource (ACToR) database (http://actorepa.gov), the U.S. National Library of Medicine's TOXNET (Toxicology Data Network) database (http://toxnet.nlm.nih.gov/), and USEPA toxicological profiles (U.S. Environmental Protection Agency, 2006a, 2006b, 2006c). With the exception of studies for microcystin LR, few studies were listed and typically were limited to short-term median lethal-dose studies of rodents. Information on aquatic-life effects was not available in the USEPA's ECOTOXicoloogy (ECOTOX) database (U.S. Environmental Protection Agency, 2007) for the 15 constituents but was found for some of the microcystin variants in California's Office of Environmental Health Hazard Assessment (Butler and others, 2009). The sparse information on effects limited comparisons of concentrations to benchmarks or thresholds. 


\section{Prioritization Methods for Cyanotoxins in Surface Water}

Cyanotoxins were not included in previous NAWQA studies (Cycle 1 and Cycle 2); however, laboratory methods developed by the OGRL in Kansas for cyanotoxins have been used for several studies (U.S. Geological Survey, 2011) in the past 10 years, including the 2006 USGS Midwestern Cyanotoxin Reconnaissance (Graham and others, 2010) and to confirm findings from enzyme-linked immunosorbent assay (ELISA) tests for the USEPA National Lakes Assessment (U.S. Environmental Protection Agency, 2009a, 2011). Constituents analyzed in filtered water by the OGRL are listed in table E.1 at http://pubs.usgs.gov/sir/2012/5218/downloads/ tableE.xlsx with their Chemical Abstracts Service Registry Numbers ${ }^{\circledR}$ (CASRN), methods available, reporting levels, and $\log K_{\text {OW }}$ values.

Because all 15 constituents are considered to be of human-health concern through potential drinking water or recreational exposure, the prioritization of these constituents focused on the likelihood of occurrence in surface water (fresh, not marine), on the basis of the aforementioned information sources. Generally, constituents with occurrence frequency of greater than 1 percent of surface-water samples in one or more studies were placed into NTAS Tier 1 and are of highest priority for ambient monitoring. Constituents with the potential to occur in freshwaters (but no documented occurrence) were placed into NTAS Tier 2 (intermediate priority for ambient monitoring), and constituents that are unlikely to occur in freshwaters were placed into NTAS Tier 3 (low or no priority for ambient monitoring).

\section{Results of Prioritization of Cyanotoxins in Surface Water}

Twelve of the cyanotoxin constituents were placed into NTAS Tier 1-anatoxin-a, cylindrospermopsin, deoxycylindrospermopsin, nodularian, saxitoxins, and seven microcystin variants (LA, LF, LR, LW, LY, RR, and YR). One constituent was placed into Tier 2 (lyngbyatoxin-a), and two constituents were placed into Tier 3 (domoic acid and okadaic acid). Among the 12 constituents in Tier 1, anatoxin-a, cylindrospermopsin, and microcystin-LR could warrant special priority for national- or regional-scale ambient monitoring of surface water because of their presence on the CCL3 (U.S. Environmental Protection Agency, 2010). Results of the prioritization and reasons used to assign cyanotoxin constituents to Tiers 1, 2, or 3 are given in table E.2 at http://pubs.usgs.gov/ sir/2012/5218/downloads/tableE.xlsx

\section{Basis for Prioritization of Cyanotoxins in Surface Water}

Occurrence data from the 2006 USGS Midwestern Cyanotoxin Reconnaissance, a study of 23 eutrophic lakes and reservoirs in Iowa, Kansas, Minnesota, and Missouri (Graham and others, 2010), were used to determine detection frequencies for the constituents. Occurrence data documented from other literature (Carmichael, 2008; Hudnell, 2009; U.S. Environmental Protection Agency, 2009a, 2011; U.S. Geological Survey, 2011) also were considered. In addition, concentrations were compared to U.S. Environmental Protection Agency provisional Health Reference Levels for three constituents - anatoxin-a, cylindrospermopsin, and microcystin-LR (U.S. Environmental Protection Agency, 2006a, 2006b, 2006c). The prioritization approach emphasized determining whether a toxin has evidence of occurrence in freshwaters; this was the case for 11 of the 12 Tier 1 constituents. The exception was deoxycylindrospermopsin, which was placed into Tier 1 on the basis of its occurrence in freshwater lake samples (Everson and others, 2009) and the fact that it is an analog of cylindrospermopsin, which has been detected in USGS monitoring studies, including the 2006 USGS Midwestern Cyanotoxin Reconnaissance (Graham and others, 2010). Tier 1 constituent microcystin-LR could warrant special attention on the basis of its frequent occurrence (detected in 21 of the 23 lakes in 2006 [Graham and others, 2010]) and increasing State and Federal regulatory interest.

At the time of this prioritization (2011), no comprehensive, national-scale set of monitoring data was available for the specific cyanotoxin variants in freshwater lakes, reservoirs, and streams. (The USEPA National Lakes Assessment was limited to ELISA tests.) As such, it seems prudent to include all 15 of the cyanotoxins currently (2011) analyzed by the USGS OGRL in future NAWQA studies of surface-water bodies (particularly those used for drinking water or recreation) until comprehensive occurrence data have been collected.

\section{Feasibility of Implementation for High-Priority Cyanotoxins in Surface Water}

Analytical methods used by the USGS OGRL in Kansas for the cyanotoxins have included liquid chromatography with mass spectrometry (LC/MS); however, direct-aqueousinjection liquid chromatography with tandem mass spectrometry (LC/MS/MS) and ELISA are techniques that are proving to work well in studies (Graham and others, 2010). The LC/MS/MS method can be used for water samples that have undergone cell lysis and filtration (Loftin and others, 2008). This method has higher specificity and will likely result in increased analytical sensitivity compared to LC/MS. The laboratory capacity for the LC/MS/MS method has been estimated as several hundred samples per year, and method approval is tentatively planned for 2012 (Mike Meyer, U.S. Geological Survey, written commun., 2011). The ELISA method, on the other hand, is nonspecific and provides results that can include multiple variants of a toxin (for example, total microcystins). ELISA tests are relatively inexpensive and could be used as a screening tool in advance of (or in conjunction with) collection of surface-water samples in locations where algal 
blooms could be present. ELISA tests also could be used for the saxitoxins, which currently (2011) are not available on the LC/MS/MS method.

Field methods for the cyanotoxins require consideration of optimal sampling locations, depths, and timing. The antecedent conditions of algal blooms, including which ancillary data should be collected (for example, water temperature and nutrient concentrations) warrant consideration in order to more fully understand what is controlling the blooms. The sampling of lakes and reservoirs for cyanotoxins would likely best be approached by targeting individual regions during times of year when blooms are most likely to occur. Cyanotoxins are expected to have both a large spatial and temporal variability because of environmental conditions than can promote algal growth (for example, sunlight, temperature, nutrients, and turbulence), which warrants consideration in the sampling design. In addition, it is important that field staff receive the proper training and guidance in sample collection and processing, including potential safety issues. USGS sampling guidance for cyanotoxins and cyanobacteria in lakes and reservoirs is provided by Graham and others (2008a, 2008b). The lake sampling equipment needed for organics is available in most USGS Water Science Centers. Field protocols for the sampling of cyanotoxins in streams and rivers have not yet been developed.

Finally, it has not yet been determined whether analysis of a whole (unfiltered) water sample, a dissolved-phase (filtered) water sample, or analysis of both phases for cyanotoxins is most appropriate. Jennifer Graham of the Kansas Water Science Center has advised the NTAS work group that both analyses are potentially important and that a sound approach would be to routinely collect samples for both analyses, but request the dissolved-phase analysis only after the wholewater analysis indicates that cyanotoxins are present in a sample.

\section{Knowledge and Concerns of Cyanotoxins in Surface Water as a Constituent Group}

Cyanotoxins are an area of emerging international scientific interest and regulatory concern because of their potential effects to human health and aquatic life. Future research is needed for the development and refinement of robust and quantitative analytical methods for a variety of cyanotoxins, improvement of the understanding of the spatial and temporal distribution of these toxins in ambient waters, identification of the antecedent environmental conditions that can lead to algal blooms or the presence of cyanotoxins, and the development of predictive models to help determine when unhealthful algal blooms are imminent or occurring.

The USEPA notes that primary public exposure to cyanotoxins can come from drinking water or recreational water (through ingestion and inhalation of water, cells, or aerosols). Secondary human exposure can come from algal biotoxin residue on fruit and vegetables from contaminated irrigation water and by consumption of animal tissue (U.S. Environmental Protection Agency, 2001). Cyanotoxins include neurotoxins, dermatoxins, cytotoxins (can cause cell abnormalities), and hepatotoxins (can affect the liver) and are considered a known threat to public health because of their potency and association with human disease (Lopez and others, 2008). No Federal programs have been identified (to date) that focus on effects to aquatic life.

Growth in the number of published articles concerning cyanobacterial HABs has been large during the past three decades, in part attributed to the widely held belief that the incidence of HABs and associated cyanotoxins has increased during this period as a result of cultural eutrophication (Carmichael, 2008). The frequency of HABs in the United States is not well documented; however, cyanobacterial HABs are considered by some experts to be an "infrequent but repeated occurrence in all areas of the United States" (Carmichael, 2008). The only national-scale study completed to date, the 2007 USEPA National Lakes Assessment (U.S. Environmental Protection Agency, 2009a), used ELISA tests for total microcystins, rather than the more sensitive and reliable LC/MS/MS method that can measure specific variants. An awareness exists that a national-scale study of cyanotoxins should be undertaken, as expressed by Fristachi and Sinclair (2008):

"There is an immediate need for a nation-wide survey(s) on the occurrence and distribution of toxigenic cyanobacteria and their toxins throughout the US. Some surveys of cyanobacterial toxins have been conducted; however, information on cyanotoxin occurrence is still fragmented and limited. Any information of cyanotoxin occurrence is useful, but in particular, national surveys, consistently conducted, are needed to assess cyanotoxin occurrence on a large scale."

The 2006 USGS Midwestern Cyanotoxin Reconnaissance (Graham and others, 2010) targeted 23 lakes and reservoirs with a history of late summer cyanobacterial blooms and found that microcystins were detected in all blooms. The most commonly occurring microcystin variant was microcystin-LR, which was detected at 21 sites, with a median concentration of $1.6 \mu \mathrm{g} / \mathrm{L}$. Anatoxin-a was detected at 30 percent of the sites. Multiple toxin classes co-occurred in 48 percent of blooms, and toxins and taste-and-odor compounds co-occurred in 91 percent of blooms. All blooms with detectable taste-andodor compounds also had detectable toxins, but toxins also occurred without taste-and-odor compounds.

As of 2010, no USEPA drinking-water standards were available for cyanotoxins and no Federal freshwater aquaticlife criteria were available. Only microcystin-LR has a World Health Organization guideline for drinking water and established risk categories for recreational exposure (Chorus and Bartram, 1999; World Health Organization, 2003). Graham and others (2009) noted that at least 36 States have had issues with cyanotoxins, and that at least 11 States have established values for beach advisories or closures based on cell counts or 
concentrations of microcystin. State guidance or action levels for recreational exposure for microcystin range from $6 \mu \mathrm{g} / \mathrm{L}$ (Vermont and Washington) to $20 \mu \mathrm{g} / \mathrm{L}$ (Iowa, Nebraska, and Indiana). In 1998, the Harmful Algal Blooms and Hypoxia Research and Control Act was passed in the United States (16 U.S.C. 1451 note), with the National Oceanic and Atmospheric Administration as the lead Federal agency. Programs stemming from this Act have focused on coastal waters, estuaries, and the Great Lakes.

Future monitoring for NAWQA Cycle 3 could focus on lakes and reservoirs that supply drinking water. Monitoring also could target slow-moving rivers (near water supply intakes), where cyanotoxins also might be expected to occur, or focus on development of national-scale occurrence datasets for raw waters in comparison to finished waters, because knowledge about treatment and removal for these constituents is very limited.

\section{References for Cyanotoxins in Surface Water (Group E)}

Butler, Ned, Carlisle, J.C., Linville, Regina, and Washburn, Barbara, 2009, Microcystins-A brief overview of their toxicity and effects, with special reference to fish, wildlife, and livestock: Office of Environmental Health Hazard Assessment, California Environmental Protection Agency, 17 p., accessed February 12, 2011, at http://oehha.ca.gov/ecotox/ documents/Microcystin031209.pdf.

Carmichael, Wayne, 2008, A world overview-One hundredtwenty-seven years of research on toxic cyanobacteriaWhere do we go from here?, in Hudnell, K.H., ed., Cyanobacterial harmful algal blooms - State of the science and research needs: New York, Springer Science and Business Media, LLC, p. 105-125.

Chorus, Ingrid, and Bartram, Jamie, eds., 1999, Toxic cyanobacteria in water-A guide to their public health consequences, monitoring and management: New York, E and FN Spon Press, World Health Organization, 432 p., accessed May 24, 2011, at http://www.who.int/water_sanitation_ health/resources/toxicyanbact/en/.

Everson, Sally; Fabbro, Larelle; Kinnear, Susan; Eaglesham, Geoff; and Wright, Paul; 2009, Distribution of the cyanobacterial toxins cylindrospermopsin and deoxycylindrospermopsin in a stratified lake in north-eastern New South Wales, Australia: Marine and Freshwater Research, v. 60, no. 1, p. 25-33.

Fristachi, Anthony, and Sinclair, J.L., 2008, Occurrence of cyanobacterial harmful algal blooms workgroup report, in Hudnell, K.H., ed., Cyanobacterial harmful algal bloomsState of the science and research needs: New York, Springer Science and Business Media, LLC, p. 45-103.
Graham, J.L., Loftin, K.A., and Kamman, Neil, 2009, Monitoring recreational freshwater (for algal toxins): Lakeline, summer 2009 issue, p. 18-24.

Graham, J.L., Loftin, K.A., Ziegler, A.C., and Meyer, M.T., 2008a, Guidelines for design and sampling for cyanobacterial toxin and taste-and-odor studies in lakes and reservoirs: U.S. Geological Survey Scientific Investigations Report 2008-5038, 39 p. (Also available at http://pubs.usgs.gov/ sir/2008/5038/.)

Graham, J.L., Loftin, K.A., Ziegler, A.C., and Meyer, M.T., 2008b, Cyanobacteria in lakes and reservoirs-Toxin and taste-and-odor sampling guidelines (ver. 1.0): U.S. Geological Survey Techniques of Water-Resources Investigations, book 9, chap. A7, section 7.5, accessed January 10, 2011, at http://pubs.water.usgs.gov/twri9A/.

Graham, J.L., Loftin, K.A., Meyer, M.T., and Ziegler, A.C., 2010, Cyanotoxin mixtures and taste-and-odor compounds in cyanobacterial blooms from the Midwestern United States: Environmental Science and Technology, v. 44, no. 19, p. 7,361-7,368.

Hilal, S.H., Carreira, L.A., and Karickhoff, S.W., 2004, Prediction of the solubility, activity coefficient, gas/liquid and liquid/liquid distribution coefficients of organic compounds: QSAR and Combinatorial Science, v. 23, no. 9, p. 709-720.

Health Canada, 2011, Environmental and workplace healthBlue-green algae (cyanobacteria) and their toxins: accessed January 20, 2011, at http://www.hc-sc.gc.ca/ewh-semt/pubs/ water-eau/cyanobacter-eng.php\#water.

Hudnell, H.K., 2009, The state of U.S. freshwater harmful algal bloom assessments, policy and legislation: Toxicon, $\mathrm{v}$. 55, p. $1,024-1,034$.

Izaguirre, George; Hwang, C.J.; Krasner, S.W.; and McGuire, M.J.; 1982, Geosmin and 2-methylisoborneol from cyanobacteria in three water supply systems: Applied and Environmental Microbiology, v. 43, no. 3, p. 708-714.

Loftin, K.A.; Meyer, M.T.; Rubio, Fernando; Kamp, Lisa; Humphries, Edythe; and Whereat, Ed; 2008, Comparison of two cell lysis procedures for recovery of microcystins in water samples from Silver Lake in Dover, Delaware with microcystin producing cyanobacterial accumulations: U.S. Geological Survey Open-File Report 2008-1341, 9 p.

Lopez, C.B.; Jewett, E.B.; Dortch, Quay; Walton, B.T.; and Hundnell, H.K.; 2008, Scientific assessment of freshwater harmful algal blooms: Washington, D.C., Interagency Working Group on Harmful Algal Blooms, Hypoxia, and Human Health of the Joint Subcommittee on Ocean Science and Technology, 65 p., accessed May 24, 2011, at http:// www.whitehouse.gov/sites/default/files/microsites/ostp/ frshh2o0708.pdf. 
U.S. Environmental Protection Agency, 2001, Creating a cyanotoxin list for the Unregulated Contaminant Monitoring Rule, meeting summary: Cincinnati, Ohio, accessed February 10, 2010, at http://www.epa.gov/safewater/ucmr/ pdfs/meeting_ucmr1_may2001.pdf.

U.S. Environmental Protection Agency, 2006a, Integrated Risk Information System-IRIS toxicological review of cyanobacterial toxins-Anatoxin-a (external review draft): Washington, D.C., U.S. Environmental Protection Agency, EPA/600/R-06/137.

U.S. Environmental Protection Agency, 2006b, Integrated Risk Information System-IRIS toxicological review of cyanobacterial toxins-Cylindrospermopsin (external review draft): Washington, D.C., U.S. Environmental Protection Agency, EPA/600/R-06/138.

U.S. Environmental Protection Agency, 2006c, Integrated Risk Information System-IRIS toxicological review of cyanobacterial toxins-Microcystins LR, RR, YR and LA (external review draft): Washington, D.C., U.S. Environmental Protection Agency, EPA/600/R-06/139.

U.S. Environmental Protection Agency, 2007, ECOTOXicology Database System, version 4.0: U.S. Environmental Protection Agency, Office of Research and Development and the National Health and Environmental Effects Research Laboratory's Mid-Continent Ecology Division, accessed May 12, 2010, at http://www.epa.gov/ecotox/.

U.S. Environmental Protection Agency, 2009a, National Lakes Assessment-A collaborative survey of the Nation's lakes: Washington, D.C., Office of Water and Office of Research and Development, EPA 841-R-09-001, accessed January 20, 2011, at http://www.epa.gov/owow/LAKES/lakessurvey/ pdf/nla_report_low_res.pdf.
U.S. Environmental Protection Agency, 2009b, EPI Suite ${ }^{\mathrm{TM}}$ version 4.0: U.S. Environmental Protection Agency, Office of Pollution Prevention and Toxics and Syracuse Research Corporation.

U.S. Environmental Protection Agency, 2010, Contaminant Candidate List 3-CCL3: accessed December 20, 2010, at http://water.epa.gov/scitech/drinkingwater/dws/ccl/ccl3.cfm.

U.S. Environmental Protection Agency, 2011, National Lakes Assessment: accessed January 10, 2010, at http://waterepa. gov/type/lakes/lakessurvey_index.cfm.

U.S. Geological Survey, 2011, USGS Kansas Algal Toxin Research Team: Kansas Water Science Center, accessed January 10, 2011, at http://ks.water.usgs.gov/studies/qw/ cyanobacteria/.

Welker, Martin, and Von Döhren, Hans, 2006, Cyanobacteria peptides-Nature's own combinatorial biosynthesis: FEMS Microbiology Reviews, v. 30, no. 4, p. 530-563.

World Health Organization, 2003, Cyanobacterial toxinsMicrocystin-LR in drinking-water-Background document for development of WHO guidelines for drinking-water quality: Geneva, Switzerland, World Health Organization, WHO/SDE/WSH/03.04/57, 18 p., accessed January 20, 2011, at http://www.who.int/water_sanitation_health/dwq/ chemicals/cyanobactoxins.pdf. 


\section{Supplemental Information F.}

\section{Prioritization of Lipophilic Organic Compounds in Sediment (Group F)}

By Lisa H. Nowell, James F. Pankow, Peter C. Van Metre, Duane S. Wydoski, and Michelle L. Hladik

\section{Abbreviations and Acronyms Used in Supplemental Information F}

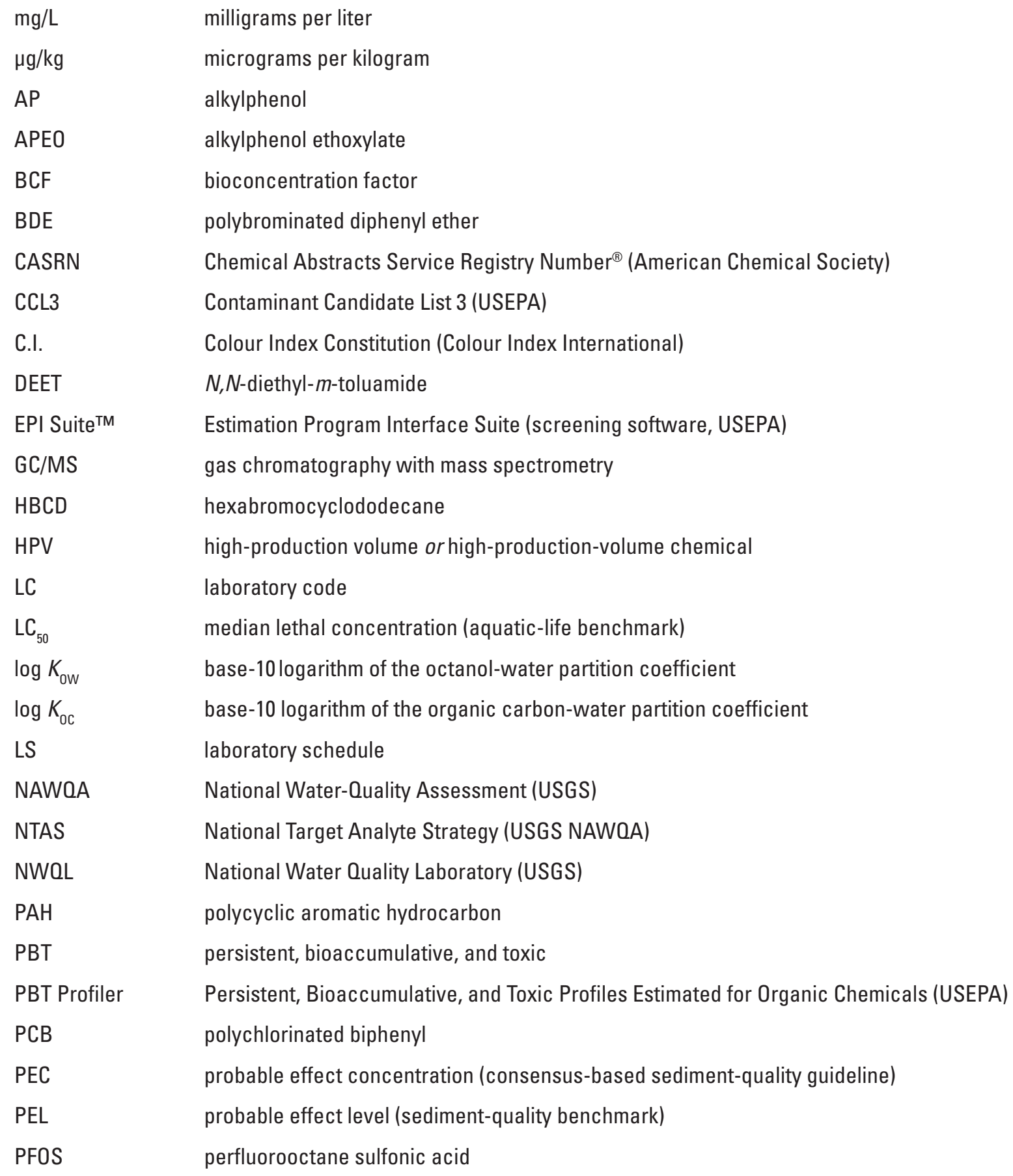


PVC polyvinyl chloride

RPF relative potency factor

2,3,7,8-TCDD

TEC

TEF

TEL

TEO

TSCA

UKCSF

USEPA

USGS 2,3,7,8-tetrachlorodibenzo- $p$-dioxin

threshold effect concentration (consensus-based sediment-quality benchmark)

toxic equivalency factor

threshold effect level (sediment-quality benchmark)

toxic-equivalent index

Toxic Substances Control Act

UK Chemicals Stakeholder Forum

U.S. Environmental Protection Agency

U.S. Geological Survey 
This supplemental information section of the report describes the prioritization of lipophilic organic compounds in sediment (Group F) by the U.S. Geological Survey (USGS) National Target Analyte Strategy (NTAS) work group, for national- and regional-scale ambient monitoring in the United States, in support of planning for the third decade (Cycle 3) of the National Water-Quality Assessment (NAWQA) Program. The feasibility of implementing analytical methods for highpriority lipophilic organic compounds, and the knowledge and concerns of these constituents in sediment, also are described in this section.

Lipophilic organic compounds tend to accumulate in aquatic sediment, where they might adversely affect aquatic organisms (for example, benthic invertebrates) (Nowell and others, 1999). If not readily metabolized, these constituents could bioaccumulate in the tissues of those organisms, where they could subsequently adversely affect other aquatic organisms, wildlife, or humans that consume them. Lipophilic organic compounds have water solubility values (for pure compounds) that typically are less than 0.1 milligram per liter $(\mathrm{mg} / \mathrm{L})$. Most of the constituents prioritized for this effort are characterized by values of the base- 10 logarithm of the octanol-water partition coefficient $\left(\log K_{\text {OW }}\right)$ that are greater than 3.

A total of 699 lipophilic organic compounds that could be relevant to sediment were prioritized. Constituents evaluated for Group F included those that had been identified on the NTAS lists of human-health and aquatic-life concern, on lists of constituents of regulatory interest, and through the scientific literature. Some of the constituents are mixtures of compounds, isomers, or congeners; for example, pentachloronaphthalene, with Chemical Abstracts Service Registry Number ${ }^{\circledR}$ (CASRN) 1321-64-8, is a mixture of multiple isomers. Consequently, when a statement appears in this section regarding, for example, "four constituents," one or more of those four might be a mixture. Several constituents that were prioritized for this effort are on laboratory schedules (LS) available from the USGS National Water Quality Laboratory (NWQL), including LS 2502, LS 5433, LS 5504, LS 5506, and a custom (unpublished) method identified as laboratory code (LC) 8093 for sediment, and LS 2101 and LS 8079 for tissue. Additional constituents were prioritized that are not on current (2011) USGS laboratory schedules; these constituents were identified as being of potential concern to human health, aquatic life, or wildlife, are of interest to other Federal agencies or to the international community, or otherwise were anticipated to have a high likelihood of occurrence in sediment.

Many of the constituents in Group F also can be found in water, resulting in numerous overlaps with Groups A (volatile organic compounds in water), B1 (pesticides in water), $\mathrm{G}$ (disinfection by-products in water), $\mathrm{H}$ (high-productionvolume chemicals in water), and I (wastewater-indicator and industrial compounds in water); however, these overlaps were inconsequential to the prioritization process because they apply to a different matrix. On the other hand, four constituents overlap with Group B2 (pesticides in sediment). Of these, naphthalene and triphenyl phosphate were placed into NTAS Tier 1 (of highest priority for monitoring) on the basis of the prioritization procedure used for Group F, which was preferred for these constituents because of their likely entry into the environment through nonagricultural uses. Hexachlorobenzene and pentachloroanisole were placed into Tier 1 on the basis of the prioritization procedures used for Group B2 and Group F.

The Group F constituents were divided into 16 subgroups based on chemical structure and use (table F.1 at http://pubs. usgs.gov/sir/2012/5218/downloads/tableF1.pdf) to facilitate the prioritization process. Chemical characteristics, uses, physical-chemical properties, environmental occurrence, and potential environmental effects of each subgroup are briefly described in the section "Knowledge and Concerns of Lipophilic Organic Compounds by Subgroup." Constituents in each subgroup were evaluated together because constituents within each subgroup had similar or related characteristics, and because information in the scientific literature also tends to be organized in this fashion. Example chemical structures are provided in table F.1 for each of the 16 subgroups.

\section{Prioritization of Lipophilic Organic Compounds in Sediment}

This section describes the methods used for prioritization of lipophilic organic compounds in sediment and the results of the prioritization for each of the 16 subgroups of constituents. Constituents were prioritized on the basis of likelihood of occurrence in ambient sediment, using information indicating evidence of occurrence, and potential effects to aquatic life using comparisons to sediment-quality benchmarks designed for the protection of sediment-dwelling aquatic life. Two types of sediment-quality benchmarks were used: lower screening values (indicating concentrations below which effects are rare or not expected) and upper screening values (designating concentrations above which adverse effects are probable or frequently observed). The threshold effect level (TEL) and probable effect level (PEL) described by the Canadian Council of Ministers of the Environment (2002) and the threshold effect concentration (TEC) and probable effect concentration (PEC) described by MacDonald and others (2000) were used, if available; if not available, other benchmarks were used from Lopes and Furlong (2001).

USGS monitoring data from Cycle 1 of the NAWQA Program were available for many lipophilic organic compounds, including (1) polycyclic aromatic hydrocarbons (PAHs) in streambed sediment and lake-sediment cores; (2) polychlorinated biphenyls (PCBs) in streambed sediment, lake-sediment cores, and (for a few sites) suspended sediment, (3) phthalates in streambed sediment; and (4) some semivolatile organic compounds from subgroups F-4, F-9, F-12, F-13, and F-16 in streambed sediment (described in the "Basis for Prioritization of Lipophilic Organic Compounds in Sediment" section). The prioritization process also used observed or predicted values compiled for production volumes (where available), 
physical-chemical properties representing hydrophobicity (log $K_{\mathrm{Ow}}$ and water solubility), persistence, and toxicity to aquatic organisms. For constituents with little or no USGS monitoring data, these additional data were valuable in estimating the likelihood of occurrence and potential effects to aquatic life. Information on use and production of lipophilic organic compounds was obtained from the U.S. Environmental Protection Agency (USEPA) High Production Volume Information System (http://www.epa.gov/hpv/hpvis/index.html) and the USEPA 2006 Inventory Update Reporting data compilation (http:// cfpub.epa.gov/iursearch/). These information sources were supplemented, as needed, with additional scientific literature documenting contaminant occurrence in sediment.

The lipophilic organic compounds in sediment (Group F) were prioritized using the procedure shown in figure F.1. This procedure was consistent with those used for other NTAS constituent groups; for example, thresholds used to evaluate constituents for detection frequency and toxicity to aquatic life were similar to those used for other groups. Constituents were evaluated relative to criteria in five categories: (1) observed or reported occurrence (if available), (2) predicted likelihood of occurrence based on physical or chemical properties, (3) production volume/use/trends/regulation, (4) potential effects (toxicity) to aquatic life, and (5) other factors.

\section{Prioritization Methods for Lipophilic Organic Compounds in Sediment}

Details of the prioritization method for sediment are shown in figure F.1. Criteria for likelihood of occurrence in sediment were met if a constituent had a sufficiently high detection frequency based on USGS monitoring data or studies in the literature (fig. F.1) or else satisfied thresholds for both (1) persistence (half-life in soil greater than 30 days, half-life in water or sediment greater than 60 days, or persistence score greater than 1 , and (2) hydrophobicity $\left(\log K_{\text {ow }}\right.$ greater than 3 or water solubility less than $1 \mathrm{mg} / \mathrm{L}$ ). These thresholds were consistent with those used by the USEPA's "Persistent, Bioaccumulative, and Toxic Profiles Estimated for Organic Chemi-

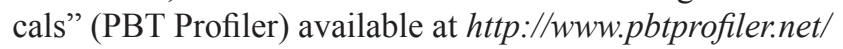
(U.S. Environmental Protection Agency, 2011a), and Nowell and others (1999). Criteria for potential effects to aquatic life were met if a constituent (1) had concentrations in NAWQA monitoring data greater than sediment-quality benchmarks at a sufficient percentage of streams of any land-use type (greater than 50 percent of sites for lower screening values or greater than 5 percent for upper screening values); (2) has a measured or estimated toxicity (acute or chronic) that meets aquatic toxicity thresholds that are consistent with USEPA ecotoxicity categories for aquatic organisms (U.S. Environmental Protection Agency, 2011b) or thresholds from the Pesticides Properties Database (University of Hertfordshire, 2010); or (3) is structurally similar to other constituents that meet these aquatic toxicity thresholds. These aquatic toxicity thresholds are used to define aquatic-life (AL) "bins" 1 and 2 (fig. F.1), which indicate high and moderate toxicity, respectively, as described in the "Human-Health Effects Information from the ACToR Database" section in the main body of the report. Constituents were assigned to NTAS Tier 1 (highest priority) if they had:

1. High observed occurrence in streambed or lake-core sediment samples (detection frequency greater than 10 percent) collected for any land-use type for the NAWQA Program (pathway P1 in fig. F.1);

2. Intermediate observed occurrence (detection frequency of 1-9 percent) in samples collected for the NAWQA Program and either moderate toxicity (AL bin 2) or high toxicity (AL bin 1) (pathway P2);

3. Intermediate observed occurrence (detection frequency of 1-9 percent) in samples collected for the NAWQA

Program and high or increasing use/production volume (pathway P3);

4. Been reported in the literature to be widely detected and of moderate to high toxicity (AL bins 1 or 2) (pathway P4);

5. High predicted likelihood of occurrence (based on physical-chemical properties) and moderate to high toxicity (AL bins 1 or 2) (pathway P4); or

6. High predicted likelihood of occurrence and high or increasing use/production volume and high end use (pathway P5).

Constituents were assigned to NTAS Tier 2 (intermediate priority) if they had:

1. Intermediate occurrence in samples collected for the NAWQA Program and low or unknown toxicity and no evidence of increasing use/production (pathway P6); or

2. High predicted likelihood of occurrence (based on physical-chemical properties), but low use (pathway P8) or low "end use" (that is, largely used as a chemical intermediate that is destroyed during the production process) (pathway P7) and low or unknown (that is, data not available) toxicity.

Constituents were assigned to NTAS Tier 3 (low or no priority) if they had:

1. Low observed occurrence in samples collected for the NAWQA Program (detection frequency of less than 1 percent) (pathway P9); or

2. Low predicted likelihood of occurrence in sediment by failing to meet either (or both) the hydrophobicity (pathway P10) or persistence (pathway P11) thresholds for high predicted likelihood of occurrence; or

3. Been widely monitored but reported in the literature to occur infrequently (pathway P12). 


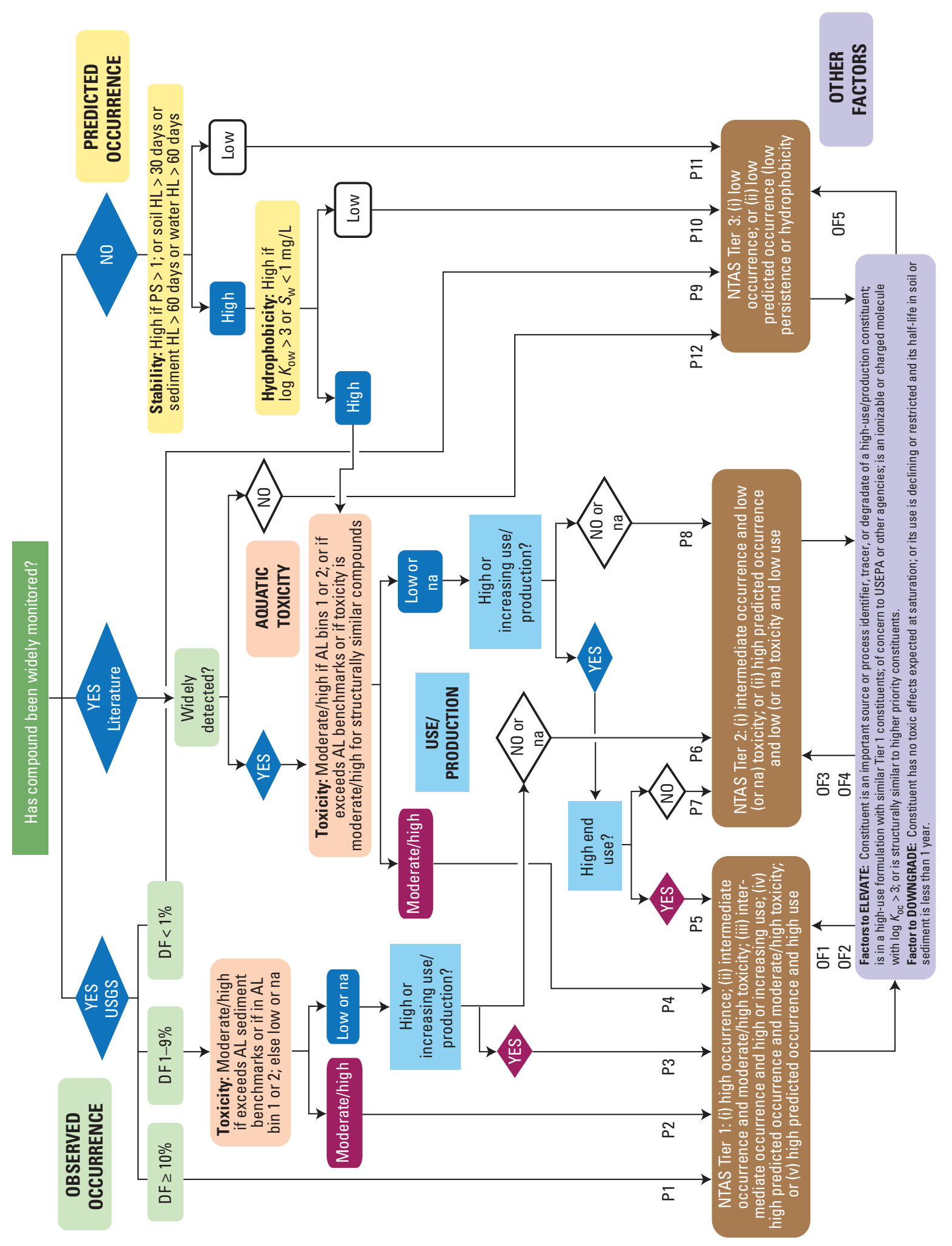

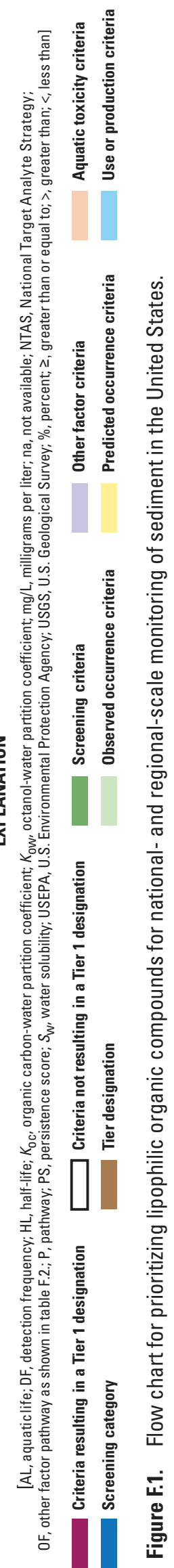


In some cases, adjustments to these assignments were made on the basis of other factors (OF1-5 in fig. F.1). For example, a constituent could be moved to a higher-priority tier (from Tier 3 to Tier 2 or from Tier 2 to Tier 1) if one or more of the following other factors was met:

- The constituent is a degradate of one or more high-use compounds;

- The constituent is found in a high-use formulation with other Tier 1 constituents;

- The constituent is important in the identification of contaminant sources;

- The constituent is a charged or ionizable molecule with a base-10 logarithm of the organic carbon-water partition coefficient $\left(\log K_{\mathrm{OC}}\right)$ greater than 3 ; or

- The constituent has been designated by the USEPA as a priority pollutant (U.S. Environmental Protection Agency, 2011b) or as a persistent, bioaccumulative, and toxic (PBT) chemical (U.S. Environmental Protection Agency, 2011a) or is on the Contaminant Candidate List 3 (CCL3; U.S. Environmental Protection Agency, 2010a) (these considerations alone would be sufficient to move a constituent from Tier 3 to Tier 2, but not to Tier 1).

Similarly, a constituent could be moved to a lower-priority tier if one or more of the following other factors was met:

- The constituent is not expected to have toxic effects when present in water at its saturation concentration;

- The constituent has a half-life less than 1 year;

- The constituent has been discontinued or is declining in use in the United States; or

- The constituent is no longer a preferred analytical target for monitoring, for example, congener-specific analyses of PCBs now are preferred over Aroclor mixtures.

\section{Results of Prioritization of Lipophilic Organic Compounds in Sediment}

A total of 699 lipophilic organic compounds in sediment were prioritized for Group F (table F.2 at http://pubs.usgs. gov/sir/2012/5218/downloads/tableF2.xlsx). The tier assignments for a few of the Group F constituents that are mixtures could warrant reconsideration if additional compositional information is obtained about these mixtures. If one or more individual constituents within a mixture are determined to be adequately representative of the whole mixture, or are determined to be of greater importance than the rest of the mixture, it is likely that the laboratory analyses would be performed for those individual constituents rather than for the whole mixture.
More details about current and prospective laboratory methods for Group F are provided in the "Feasibility of Implementation for High-Priority Lipophilic Organic Compounds" section.

A summary of the prioritization results by subgroup is provided in table F.3 at http://pubs.usgs.gov/sir/2012/5218/ downloads/tableF3.pdf. Of the total of 699 Group F constituents, 96 had been monitored in sediment during NAWQA Cycle 1, and of these, 85 were placed into NTAS Tier 1 (table F.3). One constituent was placed into Tier 2 (4-chloro3 -methylphenol), and 10 were placed into Tier 3 . The 10 constituents in Tier 3 consist of five semivolatile organic compounds (2-chlorophenol, 1,3-dichlorobenzene, 2,4-dinitrotoluene, $N$-nitrosodi- $n$-propylamine, and 1,2,4-trichlorobenzene) and five PCB congeners. These constituents had been detected in less than 1 percent of samples of streambed or lake sediment collected during Cycle 1. Although "total PCBs" (CASRN 1336-36-3) was monitored in sediment during NAWQA Cycle 1 and was placed into Tier 1, the NTAS work group recommends that future monitoring focus on the specific PCB congeners that also are in Tier 1. A total of 483 lipophilic organic constituents were assigned to NTAS Tier 1, including 398 constituents that were not monitored during NAWQA Cycle 1.

\section{Basis for Prioritization of Lipophilic Organic Compounds in Sediment}

This section presents the basis of prioritization for the 16 subgroups of lipophilic organic compounds that are listed in table F.1. Information sources used in the prioritization process, including NAWQA Cycle 1 monitoring data (tables F.4.A-D at http://pubs.usgs.gov/sir/2012/5218/downloads/ tableF4.xlsx) from NWQL schedule LS 2502, also are described in this section. Table F.2 shows the screening pathways, which correspond to those in figure F.1, that led to the final tier placements for each of the 699 Group F constituents.

\section{Polychlorinated Biphenyls (Subgroup F-1)}

Of the 64 PCBs in subgroup F-1, 50 constituents were placed into NTAS Tier 1 and 14 constituents were placed in NTAS Tier 3 (table F.2). The Tier 1 assignments were made as follows: 26 PCBs were placed into Tier 1 based on NAWQA Cycle 1 monitoring data (including "total PCBs") and 24 were placed into Tier 1 based on predicted occurrence. The Tier 3 assignments were made as follows: 5 were prioritized based on low detection frequencies in NAWQA data for urban lakes (Peter C. Van Metre, U.S. Geological Survey, written commun., March 2010), and 4 were prioritized based on literature information that indicated infrequent environmental occurrence. In addition, 5 Aroclor mixtures of PCB compounds (described in the "Knowledge and Concerns of Lipophilic Organic Constituents by Subgroup" section) were moved from their initial placement into Tier 1 to Tier 3 using the "other factors" pathway because quantification of the individual congeners is preferred to quantification of the mixtures. 


\section{Polycyclic Aromatic Hydrocarbons (Subgroup F-2)}

Of the 70 PAHs in subgroup F-2 (table F.2), 32 are on laboratory schedules used by the NWQL, including all but one of the PAHs with benchmarks or on the USEPA Priority Pollutant list (U.S. Environmental Protection Agency, 2011c). Of these 70 PAHs, 69 were placed into Tier 1, including 29 constituents on the basis of NAWQA monitoring data for streambed or lake sediment (tables F.4A-D; Van Metre and Mahler, 2005). The remaining 40 were placed into Tier 1 on the basis of high predicted occurrence with moderate to high toxicity (AL bins 1 or 2) or high use/production volume. Predictions for most of these 40 PAHs were based on estimated properties from the USEPA's EPI Suite ${ }^{\mathrm{TM}}$ (Estimation Program Interface Suite) screening software (U.S. Environmental Protection Agency, 2009a) or the USEPA's PBT Profiler. Nine of the 40 are identified by the PBT Profiler as persistent, bioaccumulative, and toxic (PBT) organic chemicals (U.S. Environmental Protection Agency, 2011a). The PBT Profiler was not used for the 29 PAHs that have NAWQA monitoring data, 9 of which also are PBTs. The 1 PAH constituent (a PAH degradate) that was placed into Tier 3 was placed in that tier because of its low $\log K_{\text {ow }}$.

\section{Phthalates (Subgroup F-3)}

A total of 27 phthalates were prioritized for subgroup F-3, and of these, 18 were placed into Tier 1 (table F.2). These included six phthalates that were monitored in streambed-sediment samples collected during NAWQA Cycle 1 (1992-2001). All six phthalates were detected in samples from 25 to 90 percent of urban sites and 17 to 72 percent of mixed land-use sites, even after four constituents with chronic laboratory blank contamination were censored at the 95th-percentile concentration of laboratory blanks (tables F.4A, $B$ ). The remaining 12 phthalates in Tier 1 consist of 5 phthalates (di-esters) with high predicted occurrence and moderate to high toxicity (AL bins 1 or 2), and 7 persistent, hydrophobic mono-esters that are degradates of Tier 1 phthalates. Six other phthalates were assigned to Tier 2-dicyclohexylphthalate, a persistent, hydrophobic, and toxic di-ester phthalate that has low use in the United States (Silva and others, 2004); its mono-ester metabolite; and four mono-ester metabolites of other di-ester phthalates that are in Tier 1. Although the latter four metabolites are characterized by $\log K_{\mathrm{OW}}$ less than 3 (which normally would result in assignment to Tier 3 because of low hydrophobicity), these metabolites were placed into Tier 2 because the parent di-esters are high-production-volume chemicals (HPVs). Three phthalates were placed into Tier 3; all three are characterized by $\log K_{\mathrm{OW}}$ less than 2 and are unlikely to accumulate in sediment.

\section{Azo Dyes (Subgroup F-4)}

A total of 142 azo dyes, which include a number of salts and their conjugate acids, were prioritized for subgroup F-4 (table F.2). Salts and conjugate acids were prioritized together because (1) a salt and its conjugate acid are two forms of the same constituent, related by acid dissociation; and (2) some information (such as production volume) is available for salts whereas other information (such as toxicity or $\log K_{\text {OW }}$ values) tends to be available for the conjugate acids. Of the 142 azo dyes prioritized, 64 were placed into Tier 1, 77 into Tier 2, and 1 into Tier 3. One azo dye (azobenzene) that was observed in NAWQA streambed-sediment samples (tables F.4A-D) was placed into Tier 1 because of its intermediate occurrence and high predicted toxicity (AL bin 1). The 63 remaining azo dyes in Tier 1 have high predicted occurrence and moderate to high toxicity (AL bins 1 or 2) or high-production volume. The azo dyes in Tier 2 also have high predicted occurrence but are not HPVs and are not expected to be toxic at saturation, or they have low toxicity or no toxicity data.

\section{Brominated Flame Retardants (Subgroup F-5)}

The 53 brominated flame retardants in subgroup F-5 (table F.2) include polybrominated biphenyls, polybrominated diphenyl ethers (BDEs), and the HPVs hexabromocyclododecane, tetrabromobisphenol-A, and 1,2-bis(2,4,6-tribromophenoxy)ethane (Firemaster 680). Of these 53 brominated flame retardants, 29 were placed into Tier 1 . All but one of these 29 Tier 1 constituents were assigned on the basis of either reported occurrence in the scientific literature or predicted occurrence and moderate to high toxicity (AL bins 1 or 2) or high-production volume. The last of these 29 constituents (4-bromophenylphenylether) was assigned to Tier 1 despite a low detection frequency (less than 1 percent) in streambed-sediment samples because (1) it was detected in 1 to 10 percent of NAWQA water samples during Cycle 1 even though the USEPA PBT Profiler predicts that 22 percent of this constituent is likely to be found in sediment compared to 11 percent in water, (2) its laboratory reporting level in sediment was fairly high (50 micrograms per kilogram $[\mu \mathrm{g} / \mathrm{kg}]$ ), and (3) it has high predicted occurrence and moderate toxicity to aquatic life (AL bin 2). Ten constituents were placed into Tier 2 for sediment, including four constituents with no effects at saturation or no toxicity data, plus six BDE congeners that are reported to be components of commercial products, but that have not been reported to occur in the environment and have no reported or predicted toxicity. In addition, 14 brominated flame retardants were placed into Tier 3 for sediment; these constituents either are not predicted to be PBTs or are BDE congeners that are not reported to occur in the environment or in commercial products, and they have no reported or predicted toxicity.

\section{Chlorinated Naphthalenes (Subgroup F-6)}

Of the 17 chlorinated naphthalenes in subgroup F-6 (table F.2), 10 were placed into NTAS Tier 1: one constituent (2-chloronaphthalene) was assigned on the basis of intermediate occurrence in sediment and moderate toxicity (AL bin 2), and the rest were assigned on the basis of high predicted occurrence and moderate to high predicted toxicity (AL bins 
1 or 2). Six chlorinated naphthalene constituents were placed into Tier 2 on the basis of low toxicity or an absence of toxicity information. One constituent, polychlorinated naphthalenes (mixture of isomers), was placed into Tier 3 because it consists of a mixture not amenable to direct analysis and is redundant to other chlorinated naphthalene constituents.

\section{Chlorinated Paraffins (Subgroup F-7)}

Four chlorinated paraffin constituents were prioritized for subgroup F-7 (table F.2), and two of these are mixtures of short-chain chlorinated paraffins that differ by degree of chlorination. The two short-chain chlorinated paraffin mixtures were placed into Tier 1 on the basis of their persistence, toxicity, and potential for accumulation in sediment. Some evidence indicates that medium-chain or long-chain chlorinated paraffins also might be important but not enough is known at present (2010) to justify placement in Tier 1, and these constituents were placed into Tier 2 .

\section{Perfluorinated Compounds (Subgroup F-8)}

The 24 perfluorinated compounds in subgroup F-8 (table F.2) have not been systematically monitored in ambient sediment on a national or regional scale; therefore, the prioritization of constituents in this subgroup was based on predicted occurrence. Like other halogenated compounds, the perfluorinated constituents tend to be persistent in the environment. Of the 24 perfluorinated compounds, 13 were assigned to Tier 1 based on predicted occurrence and moderate to high toxicity (AL bins 1 or 2) or high-production volume. Seven constituents were assigned to Tier 2 because they have high predicted occurrence but are not expected to be toxic at their saturation concentrations or have no toxicity information. Four constituents were assigned to Tier 3, of which three are unstable precursors of perfluorooctane sulfonic acid (PFOS), and one is declining in use.

\section{Alkylphenols, Alkylphenol Ethoxylates, and other Phenols (Subgroup F-9)}

Subgroup F-9 consists of 51 constituents (table F.2). These 27 alkylphenols (APs), 6 alkylphenol ethoxylates (APEOs), and 18 other phenols. The APs and APEOs include nonylphenols and octylphenols, along with some of their degradates. The other phenols include three nitrophenols, six chlorophenols, three cresols (methylphenols), and six other phenol constituents.

Of the 33 APs and APEOs in this subgroup, 29 constituents were placed into Tier 1 on the basis of either observed intermediate occurrence in streambed sediment from urban streams sampled by the NAWQA Program (1 constituent, C8-alkylphenols, which consists of mixed isomers of octylphenols; table F.4A), reported occurrence in the scientific literature (nonylphenol and 2 of its ethoxylates, which have been found in rivers, lakes, and sediment cores; Ahel and others, 1994b; Kolpin and others, 2002; Li and others, 2004;
Mibu and others, 2004), or high predicted occurrence (25 constituents) and either moderate to high toxicity (AL bins 1 or 2) or high-production volumes. Three of the 33 APs and APEOs were placed into Tier 2-one because of its low hydrophobicity and two for low aquatic toxicity. The last one of the 33 AP and APEO constituents was placed into Tier 3 because it did not meet the persistence threshold. Although some of the AP and APEO constituents have been analyzed by the USGS in sediment on a limited basis, USGS monitoring data for all but one of these constituents (mixed isomers of 4-octylphenols in Tier 1, CASRNs 140-66-9 and 1806-26-4) were too sparse or sporadic to be used in the prioritization process.

Of the 18 other phenols in this subgroup, 11 were placed into Tier 1, either for a combination of moderate to high observed occurrence and moderate toxicity (AL bin 2; 3 constituents) or a combination of high predicted occurrence and moderate to high toxicity (AL bins 1 or 2) or high use (8 constituents). Six of the other phenols were placed into Tier 2 because of low observed occurrence in NAWQA stream samples (one constituent), no toxicity expected at saturation (one constituent), or other factors (four constituents), and one was placed into Tier 3 on the basis of low hydrophobicity. Five of the 18 other phenols were previously analyzed in sediment by the NAWQA Program and had sufficient monitoring for use in the prioritization process (tables F. $4 A-D$ ).

\section{Organophosphorous Compounds (Subgroup F-10)}

Subgroup F-10 consists of 22 organophosphorus compounds (table F.2). Four of these constituents can be analyzed in sediment by the NWQL (on LS 5433; tributyl phosphate, triphenyl phosphate, tris(2-butoxyethyl)phosphate, and tris(2chloroethyl)phosphate); however, USGS monitoring data were too sparse to be used in the prioritization process. Because most of these constituents have not been widely monitored in the environment, all 22 were prioritized on the basis of predicted occurrence in sediment, inferred from physical-chemical properties. Sixteen organophosphorus compounds were assigned to Tier 1 on the basis of high persistence and hydrophobicity, combined with moderate to high toxicity (AL bins 1 or 2) or high-production volume, except for one constituent (propylated triphenyl phosphate) that is a persistent degradate of an HPV. Four organophosphorus compounds were placed into Tier 2 because no aquatic toxicity was expected at saturation or because toxicity data were lacking, and two compounds with low hydrophobicity were placed into Tier 3 .

\section{Halogenated Dioxins and Furans (Subgroup F-11)}

Subgroup F-11 consists of 31 halogenated dioxins and furans (15 halogenated dioxins and 16 halogenated furans; table F.2). On the basis of the prioritization procedures shown in figure F.1 and pathways listed in table F.2 and as supported by widespread observed occurrence (U.S. Environmental Protection Agency, 2007), all 31 halogenated dioxins and furans were placed into NTAS Tier 1 for sediment. However, chlorinated dioxins and furans have been the subject of 
numerous Federal and State regulations and clean-up actions, and environmental dioxin residues have been declining since the 1970s (U.S. Environmental Protection Agency, 2010b). Previous and ongoing studies of dioxins warrant consideration for any monitoring effort planned for these constituents.

\section{Other Organohalogens (Subgroup F-12)}

Of the 47 other organohalogens that make up subgroup F-12 (table F.2), 37 constituents were assigned to NTAS Tier 1. Of these Tier 1 constituents, 31 were assigned to Tier 1 because of high predicted occurrence and moderate to high toxicity (AL bins 1 or 2) or high-production volume, and 6 were assigned to Tier 1 because of intermediate observed occurrence in sediment samples collected during NAWQA Cycle 1 and moderate to high toxicity or high-production volume. Five constituents in subgroup F-12 were assigned to Tier 2 for sediment because of missing data or other factors, such as declining or restricted use or reported occurrence limited to areas near certain types of point sources. Five constituents in subgroup F-12 were assigned to Tier 3 for sediment: two constituents because of their low observed occurrence in streambed sediment during NAWQA Cycle 1 (less than 1 percent of samples), and three constituents because they are not predicted to occur in sediment.

\section{Azaarenes (Subgroup F-13)}

All 10 azaarenes in subgroup F-13 (table F.2) were placed into NTAS Tier 1 on the basis of frequent observed occurrence in sediment samples collected during NAWQA Cycle 1 (6 constituents), intermediate occurrence in sediment samples collected during NAWQA Cycle 1 and moderate toxicity (AL bin 2; 1 constituent), or predicted occurrence and moderate toxicity ( 3 constituents).

\section{Siloxanes (Subgroup F-14)}

Of the 18 siloxanes in subgroup F-14 (table F.2), 13 constituents were assigned to NTAS Tier 1 on the basis of high predicted stability in sediment or $\log K_{\mathrm{OW}}$ and moderate to high toxicity (AL bins 1 or 2) or high-production volume. The five remaining siloxanes were assigned to Tier 2 because the predicted toxicity levels were more than five times greater than the predicted water solubility levels, indicating no effects are likely at saturation. The factor of five for the relation between predicted toxicity and water solubility was selected on the basis of recommendations from Christopher G. Ingersoll of the USGS Columbia Environmental Research Center and David R. Mount of the USEPA Environmental Effects Research Laboratory, and provides a reasonable margin for uncertainties in the predicted toxicity and predicted solubility levels.

\section{Resin and Rosin Acids (Subgroup F-15)}

Subgroup F-15 consists of eight resin and rosin acids (table F.2), all of which are complex mixtures. Of these, six constituents were assigned to NTAS Tier 1 on the basis of high predicted occurrence in sediment and moderate to high predicted toxicity (AL bins 1 or 2) or high-production volume. For two of these Tier 1 constituents-hydrogenated rosin, glycerol ester (CASRN 65997-13-9) and hydrogenated rosin, pentaerythritol ester (CASRN 64365-17-9)-measured toxicity tests submitted to the U.S. Environmental Protection Agency (2011f) indicated no acute toxicity to aquatic organisms at the water solubility concentrations (that is, at saturation concentration) for these substances. However, the measured solubilities for these substances were very low (less than 0.22 and $0.15 \mathrm{mg} / \mathrm{L}$, respectively) and have a high degree of uncertainty, potentially underestimating exposure and confounding the test results; therefore, the acute toxicity values were assumed to be equal to the water solubilities for these two substances, which put them into the AL bin 2 and therefore into Tier 1. The two remaining constituents in subgroup F-15 were assigned to Tier 2 because although they are HPVs in Europe (Organisation for Economic Co-operation and Development, 2009) and their physical and chemical properties were assumed to be similar to structurally similar compounds within subgroup F-15, they were downgraded in priority because they are not HPVs in the United States (U.S. Environmental Protection Agency, 2011f) and their use is likely to be limited.

\section{Miscellaneous Compounds (Subgroup F-16)}

Subgroup F-16 consists of 111 lipophilic organic constituents that could not be categorized with any of the other subgroups, 75 of which were assigned to NTAS Tier 1 (table F.2). One of these miscellaneous compounds (anthraquinone) was assigned to Tier 1 because of its high observed occurrence (detection frequency greater than 10 percent) in NAWQA streambed-sediment samples; four constituents because of their intermediate observed occurrence in NAWQA samples (detection frequency of 1 to 9 percent) and moderate aquatic toxicity (AL bin 2) or high-production volume; and 70 constituents because they have high predicted occurrence and moderate to high aquatic toxicity or high-production volumes. Thirteen constituents were assigned to Tier 2 for sediment —of these, 10 compounds had low expected aquatic toxicity or no toxicity data. Three compounds - indole, a component of fragrances and precursor to pharmaceuticals; skatole, a component of feces; and the insect repellant $N, N$-diethyl- $m$-toluamide (DEET) - were assigned to Tier 2 despite having fairly low $\log K_{\text {Ow }}$ values (between 2 and 3) because they are wastewater indicators that have been found in sediment near point-source inputs. One of these, DEET, also is an HPV. Twenty-three constituents were assigned to Tier 3 for sediment; of these, 2 constituents have $\log K_{\text {OW }}$ values less than 3 and were monitored but not detected in NAWQA streambed-sediment samples, 17 constituents have low predicted occurrence because they do not meet thresholds for persistence (3 compounds) or hydrophobicity (14 compounds), and 4 constituents are hemoglobin 
adducts (formed in blood) and so are not relevant to determination in ambient suspended or streambed sediment.

\section{Feasibility of Implementation for High-Priority Lipophilic Organic Compounds}

The feasibility of implementation for laboratory analysis of the high-priority lipophilic organic compounds is presented in this section. Determination of Group F constituents in sediment (483 constituents in NTAS Tier 1) will require a combination of currently approved methods and new methods that would need to be developed, tested, and approved before the start of NAWQA Cycle 3 sampling. For example, the NWQL does not currently (2011) have a method for determination of perfluorinated compounds (subgroup F-8), although numerous methods are described in the scientific literature.

Table F.5 at http://pubs.usgs.gov/sir/2012/5218/ downloads/tableF5.pdf summarizes the methods that are available or currently (2011) in development at the NWQL for Group F constituents (Duane S. Wydoski, U.S. Geological Survey, written commun., 2010). These methods cover many (but not all) of the constituents from 10 of the 16 Group F subgroups: polychlorinated biphenyls (F-1); polycyclic aromatic hydrocarbons (F-2); phthalates (F-3); brominated flame retardants (F-5); chlorinated naphthalenes (F-6); alkylphenols, alkylphenol ethoxylates, and other phenols (F-9); organophosphorous compounds (F-10); other organohalogens (F-12); azaarenes (F-13); and miscellaneous compounds (F-16). Some of these methods can cover constituents from multiple subgroups. For example, laboratory code (LC) 8093 (organohalogenated compounds) includes several PCB congeners, brominated flame retardants, organochlorine pesticides, and other organohalogenated compounds. Because most of these methods use accelerated solvent extraction, sample preparation steps might be combined for multiple methods, which would reduce analytical costs and thus might allow better coverage of the Group F constituents.

Some of the NTAS Tier 1 constituents from the above subgroups potentially could be added to schedules that are not yet approved for those constituents. For example, although a newly developed specialized method for phenols might provide superior analytical performance, analysis of some phenols of interest might have adequate performance with some of the existing methods listed in table F.5. Similarly, it might be possible to add more PCB congeners to LC 8093; this is being evaluated by the NWQL. A potential complementary method to chemical analysis for PCB congeners and similar constituents is the H4IIE rat hepatoma cell line bioassay (Tillitt and others, 1991), which measures enzyme induction originating from planar halogenated hydrocarbons (which include PCBs, chlorinated dioxins and furans, and some PAHs). Chlorinated naphthalenes and organophosphorous compounds are expected to have good analytical performance in sediment analyses using GC/MS with negative chemical ionization or electronimpact ionization.
For constituents for which the NWQL does not have adequate resources for new method development, other USGS laboratories, such as the Columbia Environmental Research Center in Columbia, Missouri, or commercial laboratories, could be considered provided that project-specific data-quality objectives can be met. Additional method development would be needed for new Tier 1 constituents from the following subgroups:

- Polychlorinated biphenyls (subgroup F-1): Of the 209 possible PCB congeners, those of high priority were used mainly in well-characterized mixtures under the trade name "Aroclors." As a result, a smaller suite of representative PCB congeners can be used to screen sediment samples for the presence of Aroclor mixtures. If substantial contamination is found at sites that have not been previously characterized, those sites could be targeted for future studies of the full suite of 209 PCB congeners. Analysis of the full suite of PCB congeners could be provided by the Columbia Environmental Research Center laboratory, or a commercial laboratory that uses gas chromatography with high-resolution mass spectrometry could be used on a contract basis.

- Azo dyes (subgroup F-4): Liquid chromatography with mass spectrometry and gas chromatography with mass spectrometry (GC/MS) are the preferred approaches for determining these constituents. Some of the azo dyes might be determinable with existing or proposed methods. Alternatively, it might be more effective to develop a class-specific method for the 64 azo dye constituents in NTAS Tier 1. Complex azo dyes might require special attention to method development to control for their reactivity, large $\log K_{\mathrm{OW}}$ values, and tendency to adhere to surfaces.

- Chlorinated paraffins (subgroup F-7): This subclass is composed of $n$-alkanes with chains of 10 to 22 carbon atoms and different degrees of chlorination (typically 40-70 percent). The two constituents in NTAS Tier 1 (both of which are mixtures of short-chain chlorinated paraffins with 10 to 13 carbon atoms) could potentially be integrated into existing methods; however, a main problem with this subgroup is that the chlorinated paraffins are complex mixtures and consequently represent a large (unknown) number of discrete compounds. Unfortunately, the compound distributions in these mixtures are poorly understood, and some 4,000 individual compounds are considered possible.

- Perfluorinated compounds (subgroup F-8): The NWQL has plans to develop a method for the determination of "surfactants," which would include some of the perfluorinated compounds. As an alternative, if the planned method does not become available in time for NAWQA Cycle 3 monitoring, several commercial laboratories are available that provide analyses of 
perfluorinated compounds, including several of the constituents that were prioritized as NTAS Tier 1.

- Halogenated dioxins and furans (subgroup F-11): Substantial laboratory costs would be associated with any method for dioxins and furans, including the high cost of analytical standards, emissions control, and waste disposal. Methods to distinguish between specific dioxins typically rely upon high-resolution mass spectrometry, which would have to be added at the NWQL. As an alternative, the USGS Columbia Environmental Research Center and several commercial laboratories can perform these analyses using gas chromatography with high-resolution mass spectrometry and could be used on a contract basis.

- Siloxanes (subgroup F-14): Most individual siloxanes are amenable to determination by GC/MS. Some constituents in this subgroup are mixtures (for example, "dimethyl siloxanes, hydrogen-terminated" with CASRN of 70900-21-9). Important components in a given mixture potentially could be determined, their concentrations summed, and the results reported as the equivalent concentration of the mixture. Two constituents in NTAS Tier 1 (CASRNs 68937-51-9 and 68583-58-4) are synthetic amorphous silica surfacetreated with organosilicones to form reaction products, dimethylsilyl- and trimethylsilyl-end-capped silica. These reaction products are examples of constituents whose compositions may not be well characterized. In such cases, obtaining relevant analytical standards will be problematic. Lastly, some chromatography columns contain siloxanes, which can "bleed" and generate siloxane breakdown products, which could interfere with the determination of target siloxanes.

- Resin and rosin acids (subgroup F-15): The NWQL currently (2011) does nto have methods for the complex mixtures of resin acids and rosin acids in subgroup F-15. Some individual resin acids are amenable to analysis by $\mathrm{GC} / \mathrm{MS}$. The more polar compounds must be determined by high-performance liquid chromatography with tandem mass spectrometry. In some published studies, individual resin acids have been quantified in sediment or tissue samples using Soxhlet extraction and fractionation, followed by GC/MS (Rediske and others, 2001). Free and conjugated forms of resin acids have been determined in fish tissue by Niimi and Lee (1992). For constituents that are poorly characterized and variable mixtures of resin and rosin acid reaction products, the major components will need to be identified before method development can proceed. Sample stability and chemical properties present additional challenges for these constituents. Resin acids and rosin acids are subject to binding to surfaces, especially to clay substrates, and also to degradation. Protocols for field sampling, sample preservation, and sample preparation would need to be developed to address these issues.

The large number of lipophilic organic compounds in NTAS Tier 1 for sediment represents a potential obstacle to implementation. The cost per sample could be very high. If laboratory or fiscal resources are limited, it could be necessary to select a subset of Tier 1 constituents that are of higher priority than the others or representative of the other Tier 1 constituents. Several approaches can be envisioned for selecting such a subset of Tier 1 constituents, including (1) adjusting the criteria for likelihood of occurrence, persistence, and (or) toxicity used in the prioritization process to identify a smaller number of highest-priority constituents; (2) adding information for use volumes and patterns, to identify and eliminate from consideration those constituents that are least likely to have widespread occurrence in ambient sediment; (3) eliminating from consideration certain subgroups on the basis of NAWQA Cycle 3 study objectives; (4) identifying one or more constituents within a subgroup that can be used as "indicators" of contamination from that subgroup; or (5) a combination of two or more of these approaches.

Finally, it is important to note that the physical and chemical properties of the lipophilic organic compounds (for example, relatively high $\log K_{\text {OW }}$ values) can cause these constituents to adhere to surfaces and thus be prone to crosscontamination in the field and in the laboratory. Protocols for sample handling and preparation, including extraction steps, will have to be evaluated to ensure that they minimize the potential for cross-contamination of high-priority constituents. If cross-contamination cannot be eliminated, it will be important to collect a sufficient number of field and laboratory quality-control samples (blanks) to permit a robust characterization of the background contaminant concentrations that can be used to adjust reporting levels to minimize the reporting of false positives from the laboratory and (if necessary) the field.

\section{Knowledge and Concerns of Lipophilic Organic Compounds by Subgroup}

This section describes the knowledge and concerns of lipophilic organic compounds in sediment, which were categorized into 16 different subgroups.

\section{Knowledge and Concerns of Polychlorinated Biphenyls (Subgroup F-1)}

PCBs once were used in hundreds of industrial and commercial applications but were placed under voluntary control in 1971 (Hickey and others, 2006) and banned from manufacturing in the United States in 1979 (U.S. Environmental Protection Agency, 2011d). PCBs include 209 variations in geometry and positions of chlorine substitution, which are called "congeners." Congeners vary widely in toxicity and persistence. The trade name "Aroclor" refers to a series 
of technical mixtures of PCBs made by Monsanto during the 1930s through 1977. Although phased out over much of the developed world, PCBs continue to enter the environment through incineration of municipal and industrial waste, leaks or releases from electrical transformers, emissions from landfills that received PCB-containing consumer products, and poorly maintained hazardous waste sites (U.S. Environmental Protection Agency, 2011d). Continuing sources of PCBs to water bodies include the disturbance of historically contaminated sediment and soils and cycling of PCBs between deposited sediment, the water column, and atmosphere. Volatilization of PCBs to the atmosphere results in continued dispersal throughout the environment, including transport and deposition to cold climates in northern latitudes and high elevations (Bard, 1999).

PCBs are internationally recognized as persistent, bioaccumulative, and toxic (PBT) compounds. Some PCB congeners are known animal carcinogens and probable human carcinogens. Some congeners can cause serious noncancer effects on the immune, reproductive, nervous, and endocrine systems in animals (U.S. Environmental Protection Agency, 2011e). Toxicity of PCBs to humans can be expressed using the toxicequivalent (TEQ) index, which represents toxicity relative to 2,3,7,8-tetrachlorodibenzo- $p$-dioxin (2,3,7,8-TCDD), a highly toxic planar halogenated hydrocarbon. The 2,3,7,8-TCDD equivalents for a PCB mixture can be calculated by summing weighted concentrations of 12 congeners (PCBs 77, 81, 105, $114,118,123,126,156,157,167,169$, and 189) using the toxic-equivalency factors (TEFs) for humans (Van den Berg and others, 1998).

In NAWQA streambed-sediment sampling (1992-2001), 37 percent of samples from urban sites and 18 percent of samples from mixed land-use sites had detectable concentrations of total PCBs (tables F.4A-D). In comparison to aquaticlife benchmarks, 3 percent of urban streams had concentrations greater than the probable-effect concentration (PEC), and 9 percent of urban streams had concentrations greater than the probable-effect level (PEL). Both of these benchmarks are upper screening values, so they indicate concentrations above which adverse effects are likely; however, they are primarily based on toxicity to benthic invertebrates and do not consider bioaccumulation, which is a concern for PCBs. Because of potential human-health effects from consuming contaminated fish, 1,025 active fish consumption advisories were issued as of 2008 for PCBs that affected more than 6 million lake acres and 130,000 river miles (U.S. Environmental Protection Agency, 2009b).

PCB concentrations in the environment have decreased substantially since their manufacture was banned in the United States in 1979. In 38 age-dated lake and reservoir sediment cores collected by NAWQA, trends in total PCB concentrations since 1970 were significantly downward in about one-third of urban lakes, and no lakes had upward concentration trends (Van Metre and Mahler, 2005). Median concentrations in these cores decreased 47 percent from 1965-75 to
1990-2001; the decrease was 59 percent for lakes in densely urban areas. First-order rate models fitted to PCB profiles in these cores indicate a median half-life of 9.6 years (Van Metre and Mahler, 2005). However, in some lakes (including Lake Michigan) the rate of decline has decreased, and models with first-order kinetics must include an asymptote (constant) in the rate equation. As concentrations in fish decline exponentially, they appear to approach an "irreducible concentration," postulated to be an effect of stable contaminant sources (Hickey and others, 2006). Moreover, although total PCBs in fish appear to be decreasing in most of the Great Lakes, the TEQ index is not decreasing - driven in part by recent (although not significant) increases within four lakes of a highly toxic congener (PCB126) that is especially persistent and resistant to degradation (Hickey and others, 2006).

PCBs typically occur at higher concentrations in suspended sediment than in deposited bottom sediment, as was observed by Van Metre and Mahler (2004) for suspendedsediment samples from 11 tributary locations relative to 3 urban lakes where fish consumption advisories or bans are in effect for PCBs. In another study, moderate concentrations of PCBs $(30-120 \mu \mathrm{g} / \mathrm{kg}$ ) were found in suspended sediment in the Donna Canal and Donna Reservoir, a Superfund site in southern Texas with very high concentrations in fish (Mahler and Van Metre, 2003). PCBs were rarely detected, however, in bottom sediment in the canal and reservoir, indicating that suspended sediment can be an effective pathway for fish exposure to PCBs.

Since PCB monitoring began in the 1960s, substantial changes and improvements have been made in the analytical methods used to determine PCBs. Early monitoring reported PCBs as "Aroclors" or "total PCBs." More recently, congenerspecific determination of PCBs has become preferred. As demonstrated by the Great Lakes fish trends study (Hickey and others, 2006), congener-specific determination can provide important information about potential toxicity. Congenerspecific determination also can provide chemical profiles ("fingerprints") for source analyses (Johnson and others, 2000). The recently developed halogenated compound method of the NWQL (Mark Burkhardt, U.S. Geological Survey, written commun., 2008; currently custom method LC 8093) quantifies 18 PCB congeners; however, it only includes 1 of the 12 congeners used to calculate the TEQ.

\section{Knowledge and Concerns of Polycyclic Aromatic Hydrocarbons (Subgroup F-2)}

PAHs are a large group of chemically related compounds, each of which is composed of two or more fused benzene rings. Many PAHs are toxic, mutagenic, and teratogenic (Baumann and Harshbarger, 1995; Lewtas, 2007). Six of the PAH constituents evaluated by the NTAS work group are listed as probable human carcinogens (U.S. Environmental Protection Agency, 2009c), and 15 have been identified by the USEPA as "Priority Pollutants" (U.S. Environmental Protection Agency, 2011c). 
PAHs in the environment largely are a consequence of the incomplete combustion of petroleum, coal, and wood (Edwards, 1983). Such "pyrogenic" PAHs are dominated by higher molecular weight and unsubstituted parent compounds, such as benzo $[a]$ pyrene. Pyrogenic sources include industrial emissions (Marvin and others, 2000); home heating with fuel oil, wood, and coal; power plants (Sims and Overcash, 1983); and vehicles (Rogge and others, 1993; Takada and others, 1990). One important source of pyrogenic PAHs is coal tar, which is the base of most pavement sealants ("sealcoats") used east of the Continental Divide (Mahler and others, 2005). In addition to pyrogenic sources, there are "petrogenic" sources of PAHs that are related to the acquisition or use of petroleum (for example, production or transportation of fossil fuels), characterized by a higher proportion of lower molecular weight and alkylated PAHs (Baumard and others, 1998; Silliman and others, 1998).

PAHs have been detected widely in stream sediment (Lopes and others, 1997; tables F.4A-D), and relatively high concentrations have been found in sediment from most of the urban lakes sampled by the Contaminant Trends in Lake Sediments study of the NAWQA Program (Van Metre and Mahler, 2005). Detection frequencies of PAHs in the Contaminant Trends in Lake Sediments study approached 100 percent; the lowest detection frequency for the 12 PAHs used in receptor modeling of PAH sources was 96 percent (Van Metre and Mahler, 2010). Mean total PAH concentrations in dated sediment cores collected in the 1990s from 31 urban lakes exceeded the PEC in 13 percent of lakes and the TEC in 65 percent of lakes. For streambed sediment, one or more PAHs was detected at 89 percent of the (more than 1,000) sites sampled by the NAWQA Program (1992-2010), and concentrations were greater than their respective PECs for one or more PAHs at 8 percent of those sites. Of those sites with urban land use, PAHs were detected in 98 percent of samples, and at concentrations greater than the PECs in 30 percent of samples (Lisa H. Nowell, U.S. Geological Survey, written commun., March 2010).

PAHs, like PCBs, typically occur at higher concentrations in suspended sediment than in deposited bottom sediment (Van Metre and Mahler, 2004). PAH concentrations in 47 samples of suspended sediment collected during runoff events from 11 streams in Fort Worth, Texas (about four events per stream), indicate higher PAH concentrations on average than were observed in bottom (streambed) sediment in the streams or in downstream reservoirs.

PAHs are of increasing regulatory interest following recent USGS studies that identified coal-tar-based sealcoat as a major, previously unrecognized urban source of PAHs (Mahler and others, 2005). These studies found high PAH concentrations in dust from coal-tar sealed pavement dust and showed a link to lake-sediment PAH contamination in U.S. cities (Van Metre and others, 2009), and reported elevated PAH concentrations in house dust in apartments near sealcoated parking lots (Mahler and others, 2010). Coal-tar-based sealcoat has been shown to be toxic to benthic organisms (Bryer and others, 2006) and to cause impairments to stream communities (Scoggins and others, 2007). Since 2006, eight jurisdictions have banned use of coal-tar-based sealcoat and four, including the State of Minnesota, have restricted its use.

PAH concentrations have increased significantly since 1970 in most of the urban lakes sampled by the NAWQA Program (Van Metre and Mahler, 2005). A recent evaluation of PAH sources to 40 urban lakes (distributed nationally) using a mass-balance receptor model indicated that coal-tar-based sealcoat is, on average, the largest PAH source, accounting for about one-half of all PAH loading to the lakes (Van Metre and Mahler, 2010). Lakes in the central and eastern United States had higher PAH concentrations and a larger proportional contribution of PAHs from coal-tar-based sealcoat than lakes in the western United States, consistent with sealcoat use patterns. The Spearman's rank-correlation coefficient between total PAH concentration and estimated PAH mass loading from sealcoat for the 40 lakes is 0.98 (Van Metre and Mahler, 2010). Trends in PAH sources to eight lakes (spanning 40-100 years) also were evaluated using the model. Seven of the eight lakes had upward trends in PAH concentrations since about 1960, and in six of those seven lakes, model results indicated that increases in PAH loading from coal-tar-based sealcoat are the primary cause of the upward trends.

PAHs occur as mixtures, and the USEPA benchmarks for evaluating sediment toxicity from PAHs assume that their toxicities are additive, indicating that the determination of a large number of PAHs is optimal (U.S. Environmental Protection Agency, 2009d). Nine individual PAHs have PEC values, and the PEC for "total" PAHs is based on the sum of 13 individual PAHs (MacDonald and others, 2000). Information on humanhealth effects can be found for many individual PAHs and for various sums of PAHs. Six parent PAHs are identified as "B2" (probable human carcinogens) by the USEPA (U.S. Environmental Protection Agency, 2009c). In February 2010, the USEPA released a draft report for comment that presents a relative potency factor (RPF) approach for evaluating cancer risk from exposure to PAH mixtures. The RPF is computed using concentrations of 25 PAHs, most of which currently (2011) are not on USGS laboratory schedules. Initial work is underway at NWQL (2010) to evaluate the potential for expanding PAH coverage to include more of the compounds used in the RPF.

\section{Knowledge and Concerns of Phthalates (Subgroup F-3)}

Phthalates are a group of chemicals used to soften and increase the flexibility of plastic and vinyl. National and international concerns regarding phthalates focus on human exposure by way of food, consumer products, and indoor air, rather than on aquatic organisms exposed to sediment. The ubiquitous detection of phthalates in stream sediment is indicative of their widespread environmental occurrence. Phthalates can enter the environment by way of municipal or industrial wastewater, burning of plastic products, transport 
from landfills into soil or water including groundwater, or directly from consumer products. Phthalates can accumulate in the sediment of urban or developed streams and can affect benthic organisms. If the USEPA takes future action to ban or restrict phthalate use, monitoring will be important to establish trends.

Several phthalates, including bis(2-ethylhexyl) phthalate, butylbenzyl phthalate, di- $n$-butyl phthalate, and diisodecyl phthalate, are produced and used in large volumes. High molecular-weight phthalates, such as bis(2-ethylhexyl) phthalate, are used as plasticizers in flexible vinyl plastic, such as polyvinyl chloride (PVC), and are found in consumer products such as construction materials, wall and floor coverings, shower curtains, rainwear, upholstery, toys, packaging and film, and medical devices (Meeker and others, 2009). Low molecular-weight phthalates, such as diethylphthalate and di- $n$-butyl phthalate, can be found in insect sprays, coatings on pharmaceuticals, solvents, and in some personal-care products, such as perfumes, lotions, and cosmetics (Agency for Toxic Substances and Disease Registry, 1995, 2001). Some phthalates, such as diisononyl phthalate, have different isomeric forms with distinct CASRNs, with compositions depending on the production method (European Commission, 2003).

Because phthalates are not covalently bound to the plastic matrixes in which they are used, they can leach out of plastics over time. Toxics Release Inventory data available for two constituents, di- $n$-butyl phthalate and bis(2-ethylhexyl) phthalate, indicate that releases to all primary environmental media can be expected but will be highest to terrestrial media, followed by air, then water (U.S. Environmental Protection Agency, 2009e). The primary pathway by which phthalates can reach stream sediment is probably by off-gassing from PVC products into the atmosphere, sorption to particulates in air (including dust), deposition to soils and surfaces, and then transport by runoff into storm drains and streams (Sediment Phthalates Work Group, 2007). PVC and other phthalate-containing materials constitute a long-term, dispersive, nonpoint source of phthalates (U.S. Environmental Protection Agency, 2009e).

The widespread use of phthalates, including use in plastic laboratory equipment, contributes to their presence in laboratory settings, which can increase the likelihood of their detection in laboratory blanks that are analyzed for quality-control purposes. Four of the six phthalates analyzed in streambed sediment by the NAWQA Program were found to be chronic laboratory blank contaminants (detected in more than 10 percent of laboratory blanks; Teresa L. Burbank, U.S. Geological Survey National Water Quality Laboratory, written commun., September 2006). Thus, concentrations observed in field samples for these constituents could be attributable, in part or in whole, to laboratory sources of contamination. To account for the potential bias indicated by the laboratory blanks, the environmental data were censored at the 95th-percentile concentration of the laboratory blanks, as described in Lopes and Furlong (2001), before using the data to calculate detection frequencies. After this adjustment, detection frequencies ranged from 25 to 90 percent for the six phthalates in urban sediment samples, and one phthalate (bis(2-ethylhexyl)phthalate) had concentrations greater than its upper screening value in about 10 percent of samples (table F.4A).

Several phthalates are of human-health concern (Agency for Toxic Substances and Disease Registry, 1995, 2001, 2002), especially for possible effects on children's health (http:// edocket.access.gpo.gov/2010/2010-13389.htm). Phthalate metabolites (the monoesters) are prevalent in urine, and elevated concentrations of metabolites from constituents such as bis(2-ethylhexyl) phthalate in pregnant women have been associated with preterm birth (Meeker and others, 2009). Frequent detection of seven phthalate metabolites (the monoesters) in urine samples from the general U.S. population (1999-2000) indicates widespread exposure to diethyl phthalate, diisobutyl phthalate, benzylbutyl phthalate, and bis(2-ethylhexyl) phthalate (Silva and others, 2004). Phthalates are weakly estrogenic (Agency for Toxic Substances and Disease Registry, 2001). Recent studies in animals found that all phthalate mixtures showed cumulative effects on testosterone production, fetal mortality, and male and female reproductive development later in life (U.S. Environmental Protection Agency, 2009e).

In December 2009, the USEPA designated eight phthalates as "chemicals of concern," and issued a phthalates action plan to investigate concerns related to human exposure from contact with plastic products and potential adverse effects, especially on reproduction and development (U.S. Environmental Protection Agency, 2009e). According to the action plan, the USEPA will consider initiating rulemaking under the Toxic Substances Control Act (TSCA) to ban or restrict phthalates. In coordination with this action plan, and in support of the Consumer Product Safety Improvement Act of 2008, the Consumer Product Safety Commission is investigating the effects of phthalates used in toys and child-care articles on children's health.

Water solubility values for phthalates generally are low but vary inversely over 12 orders of magnitude as the alkyl chain length increases from 1 to 13 carbons. Similarly, as alkyl chain length increases over this range, the $K_{\text {ow }}$ values increase by eight orders of magnitude, and vapor pressure values decrease by four orders of magnitude (Staples and others, 1997). Many values reported in the literature for water solubility and $\log K_{\mathrm{OW}}$ for higher-molecular-weight phthalates may be erroneous (too high and too low, respectively) because of experimental difficulties at very low solubility and very high $\log K_{\mathrm{OW}}$ (Staples and others, 1997).

Because phthalates are metabolized and excreted by organisms within the higher trophic levels, they have not been thought to pose much risk to such organisms (Sediment Phthalates Work Group, 2007). Some studies show that metabolism by aquatic organisms increases with trophic level (Staples and others, 1997). This causes bioconcentration factors (BCFs) to decrease with increasing trophic level, all other factors being equal. For example, mean BCFs in algae, crustaceans, and fish were observed to be $3,399,662$, and 167 , 
respectively, for di-n-butyl phthalate, and 3,173, 1,164, and 280 for bis(2-ethylhexyl) phthalate (Staples and others, 1997). BCFs for "total phthalates" (including metabolites) in fish in radiotracer studies were observed to be between 50 and 2,000, but BCFs for the parent compounds were lower by a factor of about 2 to 50 (Staples and others, 1997). Although bioaccumulation in aquatic organisms is limited by metabolism, phthalates have been reported in fish and shellfish tissues at concentrations in the part-per-billion to part-per-million range (Agency for Toxic Substances and Disease Registry, 1995, 2001, 2002), although much of this information is more than 20 years old (Agency for Toxic Substances and Disease Registry, 2001). Fish and other aquatic biota living in contaminated waters are expected to contain phthalates and their degradation products in their tissues (Agency for Toxic Substances and Disease Registry, 1995), although relatively rapid depuration is expected for organisms subsequently placed in uncontaminated water.

\section{Knowledge and Concerns of Azo Dyes (Subgroup F-4)}

Azo compounds contain the linkage sequence, $\mathrm{R}-\mathrm{N}=\mathrm{N}-$ $\mathrm{R}^{\prime}$, where $\mathrm{R}$ and $\mathrm{R}^{\prime}$ may be alkyl or aryl groups. The prefix "azo" refers to the $\mathrm{N}=\mathrm{N}$ linkage. Aryl azo compounds tend to have vivid colors and commonly are used as dyes. Azobenzene, in which $\mathrm{R}$ and $\mathrm{R}^{\prime}$ are phenyl groups, is the simplest aromatic azo compound. Thousands of azo dyes are used in the textile, paper, and food industries, and many are ultimately released into the environment (Chung and Stevens, 1993). Some azobenzenes are not expected to be toxic, based on available toxicity tests for Colour Index Constitution (C.I.) Pigments Yellow 12 and 83 (European Chemicals Bureau, 2008a,b). However, dyes that are metabolized to benzidine $\left(\mathrm{H}_{2} \mathrm{~N}-\phi-\phi-\mathrm{NH}_{2}\right.$, where $\phi$ is a benzene ring $)$ are carcinogenic to animals (U.S. Department of Health and Human Services, 2005). Some azo dyes have been restricted in the European Union from uses in which they can come in contact with skin (Püntener and Page, 2004). Recently, the U.S. Environmental Protection Agency (2010c) issued an action plan for azo dyes that are derived from benzidine and its congeners. This action plan focuses on human exposure and carcinogenicity issues and is restricted to azo dyes that may be metabolized in the human body to benzidine or its congeners.

Azo dyes have high estimated $\log K_{\mathrm{OW}}$ values (between 4.0 and 9.6) and are predicted to be persistent (European Chemicals Bureau, 2008a-e). Indeed, azo dyes have been observed to be resistant to aerobic degradation but may be degraded in activated sludge in wastewater-treatment plants (Chung and Stevens, 1993). Azo dyes have some potential to accumulate in sediment because of their high $\log K_{\mathrm{OW}}$ values and resistance to degradation, although no monitoring studies targeting azo dyes in sediment were available. Azobenzene, analyzed in streambed-sediment samples at NAWQA sites during Cycle 1 (using NWQL schedule 2502), was detected at 4 percent of urban sites and at 2 percent of mixed landuse sites (tables F.4A, $B$ ). In anaerobic soils, some azo dyes (depending on their structure) may undergo azo reduction to benzidine or its congeners (U.S. Environmental Protection Agency, 2010c). Benzidine itself (CASRN 92-87-5) is not hydrophobic $\left(\log K_{\mathrm{OW}}=1.9\right)$, and was evaluated as part of Group I (wastewater-indicator and industrial compounds in water) rather than for Group F (lipophilic organic compounds in sediment).

\section{Knowledge and Concerns of Brominated Flame Retardants (Subgroup F-5)}

Brominated flame retardants are of international concern, as recognized by the Stockholm Convention on Persistent Organic Pollutants (2009a) and the Rotterdam Convention on the Prior Informed Consent Procedure for Certain Hazardous Chemicals and Pesticides in International Trade (2011). Several brominated flame retardants are included in long-range atmospheric sampling networks such as the United Nations' Regionally Based Assessment of Persistent Toxic Substances (2003), the Arctic Council's Arctic Monitoring and Assessment Programme (2012), and the Monitoring Network in the European Union's Monitoring Network in the Alpine Region for Persistent and other Organic Pollutants (MONARPOP, 2011).

Brominated flame retardants are used in fabrics, plastics, and fire-fighting foams and include polybrominated biphenyls, polybrominated diphenyl ethers (or "brominated diphenyl ethers" BDEs), and other compounds. Polybrominated biphenyls are the brominated analogs of polychlorinated biphenyls (PCBs). The BDEs are structurally similar to the polybrominated biphenyls, except that an ether linkage connects the two aromatic rings rather than a direct carbon-carbon bond. Similar to the PCBs and polybrominated biphenyls, 209 $\mathrm{BDE}$ congeners are possible, although relatively few are found in commercial products or the environment. Hexabromocyclododecane (HBCD) is another category of brominated flame retardants, consisting of 16 possible stereo-isomers. HBCD is an HPV and is widely used in polystyrene foam for building and construction, textiles used for upholstery, and electric and electronic appliances. Four HBCD constituents were evaluated for Group F, consisting of HBCD (undefined mixture of isomers) and its three main stereo-isomers ( $\alpha-, \beta-$, and $\gamma$-HBCD).

Polybrominated biphenyls bind strongly to soil and sediment, which reduces their mobilities in terrestrial systems and affects their mobilities in air (by sorption to airborne particles). Polybrominated biphenyls have been detected in air, sediments, surface water, fish, and higher marine animals (U.S. Environmental Protection Agency, 2008). Polybrominated biphenyls have not been produced in the United States since 1976, when they were banned following their accidental introduction into animal feed in 1973 (U.S. Environmental Protection Agency, 2008). 
BDEs also bind to sediment and tend to persist. Two of the three commercial formulations of BDEs (penta-BDE and octa-BDE) have not been produced in North America and Europe since 2004 because of PBT concerns; the third type (deca-BDE) remains in worldwide commercial use. Although penta-BDE and octa-BDE are no longer produced, they can continue to be released to the environment from recycling facilities, incineration plants, and from landfill disposal of older BDE-containing equipment. Deca-BDE is highly persistent, has a low water solubility and volatility, sorbs to particulates, and tends to accumulate in soils, sediments, and sewage sludge (Hale and others, 2001; Hale and others, 2006). Relatively low bioaccumulation has been observed in rats, likely because of its low sorption from the gut and rapid elimination in feces. Despite its relatively low bioaccumulation potential, deca-BDE frequently has been measured in fish, birds, polar bears, cats, and humans (blood and breast milk) (Oregon Department of Health Services, 2008). Because occurrence of deca-BDEs in biota is driven by recent exposures (Oregon Department of Health Services, 2008), when it is observed in biota, the data indicate generally continuous exposure (Thuresson and others, 2006). From 1981 to 2000, concentrations of penta-BDE and hexa-BDE increased exponentially in Canadian Arctic seals (doubling time of approximately 5 years), whereas trends for deca-BDE have not yet been identified (an important data gap). On a contaminant mass basis, BDEs are projected to surpass PCBs as the most prevalent organohalogen compounds in Canadian arctic ringed seals by 2050 (Ikonomou and others, 2002).

HBCD has been detected in air, sediment, marine mammals, freshwater and marine fish, aquatic invertebrates, birds and bird eggs, as well as in human adipose tissue, milk, and blood (U.S. Environmental Protection Agency, 2010d). The U.S. Environmental Protection Agency (2010d) recently issued an action plan for HBCD on the basis of human-health and environmental concerns because of long-range transport, potential bioaccumulation, reproductive and neurologic effects, and aquatic toxicity. Sparse data from laboratory studies show that HBCD can be degraded, with a half-life of 2 months or less. Nonetheless, HBCD has been detected widely in biota, including in remote locations where no demonstrable local sources have been shown to account for the exposure.

A single constituent in subgroup F-5 (4-bromophenylphenylether) was analyzed in NAWQA streambed sediment during Cycle 1. This constituent was rarely detected (in less than 1 percent of samples), and concentrations were less than the applicable benchmark (a lower screening value), indicating that adverse effects are not expected (tables F.4A-D).

\section{Knowledge and Concerns of Chlorinated Naphthalenes (Subgroup F-6)}

Chlorinated naphthalenes, including polychlorinated naphthalenes, are used as industrial feedstock chemicals in the production of cable insulation, wood preservatives, engine oil additives, electroplating masking compounds, and capacitor fluids. Large-scale production of polychlorinated naphthalenes in the United States ceased in 1980 (World Health Organization, 2001). Past sources of release to the environment included the use of polychlorinated naphthalene pesticides and emissions from manufacturing sites. Currently (2011), the primary means of release is likely to be from waste incineration and disposal of items containing chlorinated naphthalenes. Formation of polychlorinated naphthalenes also has been shown to occur during chlorination of drinking water and might occur during the chlor-alkali process, as inferred from the reported presence of these compounds in sediment and biota near a chlor-alkali plant (World Health Organization, 2001).

Including the monochloronaphthalene congeners, 75 chlorinated naphthalene congeners are possible, each with varying numbers of chlorine atoms. Polychlorinated naphthalenes can sorb strongly to soils and sediments, with $\log K_{\text {Ow }}$ and $\log K_{\mathrm{OC}}$ values increasing with degree of chlorination. The World Health Organization (2001) reported that monochloronaphthalenes appear to be readily biodegradable under aerobic conditions but did not find information on biodegradation of polychlorinated naphthalenes. Some polychlorinated naphthalenes (pentachloro and hexachloro congeners) have large BCFs and are persistent in humans (half-lives of several years). Polychlorinated naphthalenes can bioaccumulate in fish (less so in invertebrates), and bioaccumulation increases as the degree of chlorination increases, except that very highly chlorinated molecules (for example, octachloronaphthalene) do not bioaccumulate substantially, because very large molecules cannot pass through cell membranes (World Health Organization, 2001). Residues of polychlorinated naphthalenes have been detected widely in fish, fish-eating birds, and mammals. When polychlorinated naphthalenes are found in fish, the congener distribution generally is dominated by tetrachloro and pentachloro congeners (World Health Organization, 2001). When found in humans, the congener distribution almost always is dominated by two pentachloro and two hexachloro congeners (World Health Organization, 2001). In humans, dioxin-like congeners have been detected in adipose tissue, liver, blood, and breast milk, at lipid concentrations in the nanogram per kilogram range.

The few polychlorinated naphthalenes that have been tested for mutagenicity have not been found to be mutagenic. Polychlorinated naphthalenes can induce the cytochrome P-450 enzymes to a degree dependent on the relative number and positions of chlorine substituents. The congeners 1,2,3,4,6,7- and 1,2,3,5,6,7-hexachloronaphthalene, and 1,2,3,4,5,6,7-heptachloronaphthalene have been found to be potent inducers of ethoxyresorufin-O-deethylase and aryl hydrocarbon hydroxylase activity in several test systems (World Health Organization, 2001). Some of the effects of polychlorinated naphthalenes (for example, enzyme induction, hormonal changes, weight loss, hepatotoxicity, and reproductive toxicity) are thought to be mediated through the cytosolic 
Ah receptor, which is similar to the mechanism operating with chlorinated dioxins and other halogenated hydrocarbons. Congeners with four lateral chlorines at the 2,3,6,7 positions may have comparable toxicity to the more toxic PCBs (World Health Organization, 2001). However, because of insufficient experimental data, polychlorinated naphthalenes have not been included in the toxic-equivalency factor (TEF) system that provides toxicity factors relative to $2,3,7,8$-TCDD (Van den Berg and others, 1998).

In acute aquatic toxicity tests, chlorinated naphthalenes range from practically nontoxic (for example, octachloronaphthalene) to moderately to highly toxic (for example, the monochloro congeners). The 48-hour median lethal concentration $\left(\mathrm{LC}_{50}-\mathrm{a}\right.$ concentration expected to cause death in 50 percent of test animals) values for daphnids are 1 to $2 \mathrm{mg} / \mathrm{L}$ for the monochloro congeners, compared to greater than $530 \mathrm{mg} / \mathrm{L}$ for the octachloro congener. Results for fish were similar (96-hour $\mathrm{LC}_{50}$ values of $2 \mathrm{mg} / \mathrm{L}$ and greater than $560 \mathrm{mg} / \mathrm{L}$, respectively). Some Halowax products (technical mixtures) have been found to be highly toxic to marine shrimp, with 96-hour $\mathrm{LC}_{50}$ concentrations ranging from 0.0075 to $0.4 \mathrm{mg} / \mathrm{L}$ (World Health Organization, 2001).

One constituent in subgroup F-6 (2-chloronaphthalene) has been determined in NAWQA streambed-sediment samples as part of NWQL schedule 2502 (tables F.4A-D), but rarely was detected (found in 3 percent of urban streams and less than 1 percent of streams in other land-use settings). No sediment-quality benchmarks are available for this compound. Currently (2011), analyses for other chlorinated naphthalenes are not available on NWQL schedules. Analysis of total polychlorinated naphthalenes by gas chromatography with electron-capture detection was offered until approximately 1990 by the NWQL but was discontinued primarily because of cost, infrequency of detections, and lack of requests for analyses (Duane S. Wydoski, U.S. Geological Survey, written commun., 2010). It would be possible to add selected chlorinated naphthalene congeners to the halogenated sediment methods that are in development.

\section{Knowledge and Concerns of Chlorinated Paraffins (Subgroup F-7)}

The chlorinated paraffins are complex mixtures of chlorinated $n$-alkanes (30-70 percent chlorine, by weight) that are used as flame retardants, plasticizers, and as additives in sealants, paints, and coatings (European Chemical Agency, 2008). Chlorinated paraffins of various chain lengths currently (2011) are produced in the United States, European Union, India, China, Japan, Brazil, and Slovakia. These are short-chain chlorinated paraffins (approximately 10-13 carbon atoms), medium-chain chlorinated paraffins (approximately 14-17 carbon atoms), and long-chain chlorinated paraffins (approximately 18-28 carbon atoms). Generally, little specificity in the chlorine content is available, and the chlorinated paraffins, as described in the previous sentence, probably include 4,000-6,000 possible individual compounds. The U.S. Environmental Protection Agency (2009f) has developed an action plan to address the manufacturing, processing, distribution in commerce, and use of short-chain chlorinated paraffins in the United States. Additionally, USEPA is considering a possible ban on short-chain chlorinated paraffins under TSCA section 6(a). Data on production volumes of chlorinated paraffins are sparse, and USEPA plans to collect such data under TSCA section 5.

Short-chain chlorinated paraffins can be released during production (including manufacturing of PVC plastics), storage, transportation, and use in metalworking (Stockholm Convention on Persistent Organic Pollutants, 2009b). Shortchain chlorinated paraffins are subject to long-range atmospheric transport, as evidenced by their detection in Arctic sediments, fish, and marine mammals (European Chemical Agency, 2008). They also have been detected in surface waters (including the Great Lakes), lake sediment cores, river bottom sediment, fish, invertebrates, marine mammals, and terrestrial wildlife (Stockholm Convention on Persistent Organic Pollutants, 2009b).

Short-chain chlorinated paraffins are very persistent (predicted half-lives of 1,630 days in freshwater sediment), with considerable potential for bioaccumulation. Depending on the chlorine content and chain length, $\log K_{\mathrm{OW}}$ values for these constituents range from 4.4 to 8.0 (European Chemical Agency, 2008). Water solubilities of chlorinated paraffins with 10-12 carbons range from 0.40 to $0.96 \mathrm{mg} / \mathrm{L}$ (Stockholm Convention on Persistent Organic Pollutants, 2009b). In laboratory bioaccumulation studies with rainbow trout, the depuration half-lives of two 12-carbon highly chlorinated paraffins with the chemical formulas $\mathrm{C}_{12} \mathrm{H}_{16} \mathrm{Cl}_{10}$ and $\mathrm{C}_{12} \mathrm{H}_{20} \mathrm{Cl}_{16}$ were greater than 1,000 days; less-chlorinated compounds can be metabolized by such fish (Stockholm Convention on Persistent Organic Pollutants, 2009b). The report of the Stockholm Convention on Persistent Organic Pollutants (2009b) provides the following toxicity information: (1) the lowest no-observedeffect concentrations that have been reported are for daphnids in freshwater (5 micrograms per liter); (2) the lowest reported no-observed-effect concentration for fish is 9.6 micrograms per liter for the Japanese medaka; and (3) the lowest-observedeffect concentration in sediment for benthic organisms is 35.5 milligrams per kilogram dry weight (obtained using an equilibrium-partitioning method).

Unfortunately, the best available analytical standards for chlorinated paraffins are technical mixtures of chlorinated alkanes (U.S. Environmental Protection Agency, 2009f). This greatly complicates congener-specific quantitation. At the same time, attempts to quantitate chlorinated paraffins in environmental samples as mixtures would be complicated by the fact that the various congeners vary in the degree to which they degrade, are metabolized, or partition between solid and aqueous phases. Thus, the congener patterns in environmental samples are altered relative to the patterns in the technical mixtures used as standards. This makes quantitation of the mass concentration of a mixture in an environmental sample 
an imperfect pattern-recognition exercise. One alternative to quantitation as a mixture would be to select and obtain specific congeners for use as standard compounds that are representative of the types of compounds in the commercial chlorinated paraffin products and then base quantitation on those specific compounds. High-resolution mass spectrometry could provide an attractive means to verify the specific chemical formulas for chlorinated paraffin molecules in samples. Unfortunately, obtaining standards for the large number of individual compounds is likely to be difficult and costly.

\section{Knowledge and Concerns of Perfluorinated Compounds (Subgroup F-8)}

The perfluorinated compounds tend to be highly fluorinated. One of the most widely recognized constituents in this subgroup is perfluorooctane sulfonic acid (PFOS), which commonly has been incorporated into high-molecular-weight polymers used for surface treatments, paper protection, and performance-enhancing chemicals such as surfactants, shampoos, chemical intermediates, and fire-fighting foams (Organisation for Economic Co-operation and Development, 2002). PFOS is a PBT chemical and has been linked to endocrine disruption. In 2009, PFOS was added to the Stockholm Convention Annex B list of Persistent Organic Pollutants slated for restriction (Stockholm Convention press release, May 9, 2009, http://chm.pops.int/Convention/Media/PressReleases/ COP4Geneva9May2009/tabid/542/Default.aspx). PFOS is highly resistant to hydrolysis, photolysis, and biodegradation under environmental conditions. It has potential for long-range atmospheric transport. The $\log K_{\mathrm{OW}}$ value for PFOS is not easily measured because of its surface-active properties. PFOS has been detected in drinking water, landfill leachate, sewage sludge, sediment downstream from a production site, various foods (including fish, milk, and meat), fish and bivalves, fish-eating birds and mammals, and marine mammals (Organisation for Economic Co-operation and Development, 2002; Woldegiorgis and others, 2006).

In humans, PFOS has been measured in serum of workers with occupational exposure. Relative to those levels, PFOS is found at much lower concentrations in the general population (Organisation for Economic Co-operation and Development, 2002). Repeated exposure results in hepatotoxicity and mortality, and the dose-response curve for mortality is steep. Epidemiologic studies have shown an association between PFOS exposure and bladder cancer. PFOS appears to cause reproductive and developmental effects. The lowest no-observed-adverse-effect level for aquatic organisms is $0.25 \mathrm{mg} / \mathrm{L}$ for mysid shrimp (Swedish Chemicals Inspectorate (KemI), 2005). The Organisation for Economic Co-operation and Development (2002) hazard assessment indicated a need for a national or regional exposure assessment. In 2000, 3M, then the primary producer of PFOS and related compounds in the United States, began a phaseout of the manufacture of PFOS, perfluorooctanoic acid (PFOA), and related compounds because of concerns for widespread environmental distribution and toxicity (Organisation for Economic Co-operation and Development, 2002). In 2006, USEPA established a voluntary 2010/2015 PFOA Stewardship Program in cooperation with eight chemical manufacturing companies; the goals were to reduce facility emissions and product content of long-chain perfluorinated chemicals, including PFOA, by 95 percent by 2010 , and to work towards complete elimination of these chemicals by 2015 (U.S. Environmental Protection Agency, 2012a). Four companies have met the intermediate goal of reducing global emissions and product content by 95 percent (DuPont, Daikin America, Inc., 3M/Dyneon, and Solvay Solexis), although the USEPA remains concerned about longchain perfluorinated chemicals still being produced by other companies not participating in the stewardship program (U.S. Environmental Protection Agency, 2012a). A ban on PFOS in Canada was proposed in 2004, and its use is restricted in Europe (Swedish Chemicals Inspectorate, 2005).

\section{Knowledge and Concerns of Alkylphenols, Alkylphenol Ethoxylates, and Other Phenols (Subgroup F-9)}

The alkylphenol ethoxylates (APEOs) are nonionic surfactants used in textiles, paper and pulp production, plastic manufacturing, detergents, cleaners, household and personalcare products, and other commercial applications (Staples and others, 1998). Alkylphenols are used in some industries and are degradates of APEOs. The alkylphenol structures in APEOs most commonly are variations of octylphenol and nonylphenol.

Nonylphenol ethoxylates and nonylphenols are produced in large volumes, with uses that can lead to widespread environmental release (U.S. Environmental Protection Agency, 2010e). They are complex mixtures because the nonyl group may be linear or branched and may be positioned at various locations on the aromatic ring (usually para-substituted, with small amounts of ortho- and di-substituted nonylphenols). Constituent names and CASRNs are not reliably used by manufacturers, so it is difficult to quantify the use of these constituents. However, the U.S. demand for nonylphenols (production plus imports minus exports) in 2010 was estimated to be about 380 million pounds, and U.S. consumption of nonylphenol ethoxylates is about 270 to 370 million pounds per year (U.S. Environmental Protection Agency, 2010e). Nonylphenols are released during production of nonylphenol ethoxylates, epoxy resins, and plastics, and during use of cleaning products. Nonylphenol ethoxylates can be released from paper and textile processes and other industrial processes such as use of deicer formulations and cleaning products.

In aquatic environments and during aerobic treatment of wastewater, APEOs can degrade by cleaving or oxidation of ethoxy groups, leaving relatively persistent products including alkylphenol mono- and di-ethoxylates, alkylphenoxy acetic acid, alkylphenoxypolyethoxy acetic acid, and ultimately 
the alkylphenols. These metabolites are poorly degraded in wastewater- treatment plants and in rivers (Ahel and others, 1994a,b; Kolpin and others, 2002); anaerobic conditions generally lead to accumulation of the alkylphenols. Nonylphenol mono- and di-ethoxylates are characterized by small to moderate BCFs, ranging from 87 to 344 in fish and from 14 to 3,400 in mussels (Ahel and others, 1993; U.S. Environmental Protection Agency, 2010e). Nonylphenols are highly toxic to fish, aquatic invertebrates, and aquatic plants (U.S. Environmental Protection Agency, 2010e). The toxicity of nonylphenol ethoxylates to aquatic organisms tends to decrease with increasing degree of ethoxylation. For example, Environment Canada (2002) estimates that nonylphenols are twice as toxic as nonylphenol monoethoxylate and nonylphenol diethoxylate. Alkylphenols and other metabolites are weakly estrogenic in fish (Jobling and Sumpter, 1993). ). Only one alkylphenol was determined in stream sediments as part of NAWQA Cycle 1, namely "C8-alkyl phenol," which is shown in this report as "4-octylphenol (mixed isomers)." This mixture is thought to consist predominantly of the branched isomer (4-tertoctylphenol) relative to the linear isomer (4-n-octylphenol). This constituent (4-octylphenol (mixed isomers)) was detected in stream sediment at approximately 2 percent of sites (tables F. $4 A-D)$.

The USEPA announced new water-quality criteria for nonylphenols in 2006. A study in 2006-07 by USEPA and the USGS National Research Program laboratories in Boulder, Colo., found relatively large, seasonally variable concentrations of APEOs in effluent and effluent-dominated stream waters and some indications of estrogenic effects in fish (Todd Nettesheim, U.S. Environmental Protection Agency, written commun., November 14, 2007). The U.S. Environmental Protection Agency (2010e) recently issued an action plan for nonylphenols and nonylphenol ethoxylates, announcing its intention to initiate actions to reduce exposure to these chemicals. Possible actions include voluntary phaseout of some uses, TSCA rulemaking, and other regulatory actions.

The other phenols in subgroup F-9 are three nitrophenols, six chlorophenols, three cresols (methylphenols), and six other phenols. Nitrophenols are used as intermediates in industrial manufacturing and processing. Environmental sources of nitrophenols include industrial releases to air, landfills, disposal by underground injection, vehicle exhausts, photodegradation in air of other anthropogenic aromatics (Agency for Toxic Substances and Disease Registry, 1992). Chlorophenols have been used as biocides (for example, as disinfectants and wood preservatives), and mono- and dichlorinated phenols have been used as industrial intermediates. Environmental sources of chlorinated phenols include industrial waste discharges, landfills, application of pesticides made from chlorinated phenols, and chlorination of water containing phenols. Increasing the degree of chlorine-substitution tends to decrease water solubility, increase the tendency to sorb to sediments and to bioaccumulate, and increase toxicity (Agency for Toxic Substances and Disease Registry, 1999).
Simple cresols (methylphenols without additional alkyl substituents), although technically alkylphenols, are considered separately from the alkylphenols with longer alkyl substituents described previously because they have different uses and are less lipophilic and tend to behave differently in the environment. Cresols include natural products and manufactured chemicals. They are used as solvents in the manufacturing of other chemicals and as disinfectants in soaps. Sources of cresols to the environment include disposal of manufacturing wastes and burning of wood, coal, and fossil fuels (Agency for Toxic Substances and Disease Registry, 2008). Four of the six other phenols evaluated by the NTAS work group are HPVs, including two constituents - bisphenol A and phenolwith production volumes in excess of 1 billion pounds in 2006 (U.S. Environmental Protection Agency, 2011f). Bisphenol A is a plasticizer and has been shown to have estrogenic effects; the USEPA is considering regulating bisphenol A under the TSCA (Hogue, 2009). Phenol is toxic to humans and is used primarily in production of phenolic resins, which are used in construction, automotive and appliance industries; in production of other reaction intermediates (including bisphenol A); and as a disinfectant and in medicinal products (U.S. Environmental Protection Agency, 2002).

Five simple mono- or di-substituted phenols were determined in streambed sediment as part of NAWQA Cycle 1. The most widely detected phenols were $p$-cresol (detected in samples from more than 70 percent of urban and mixed landuse streams) and phenol (detected in samples from 61 percent of urban streams and 40 percent of mixed land-use streams) (tables F.4A, B). Both $p$-cresol and phenol have aquatic-life benchmarks, and concentrations greater than these benchmarks were observed at some sites. After accounting for background concentrations observed in laboratory blanks, phenol concentrations greater than its benchmark were observed in less than 1 percent of the sampled streams. Concentrations of $p$-cresol greater than the lower screening value were observed in samples from 18 percent of urban streams and 7 percent of mixed land-use streams. Detection frequencies for the three other simple phenols ranged from 0 to 4 percent of streams of all land-use types (tables F.4A, $B$ ).

\section{Knowledge and Concerns of Organophosphorous Compounds (Subgroup F-10)}

Organophosphorous compounds are used as flame retardants, plasticizers, antifoaming agents, and as components in lubricants and hydraulic fluids. Organophosphorous flame retardants have been replacing BDEs in the United States since the phaseout of the penta-BDEs and octa-BDEs began in 2002. Twelve of the 22 constituents in subgroup F-10 are HPVs in the United States, and some are HPVs in Europe (Marklund and others, 2005). Many organophosphorous compounds are chlorinated, for example, tris(2-chloroisopropyl)phosphate and tris(2-chloroethyl) phosphate. Examples of nonchlorinated organophosphorous compounds are triphenyl phosphate and 
tris(2-butoxyethyl) phosphate. One of the 22 constituents in the subgroup F-10 is a mixture, namely butylated triphenyl phosphate.

Direct entry of organophosphorous compounds to the environment can occur during use (such as with flame retardants applied to forest and grass fires) or indirectly because of volatilization and leaching from products that contain organophosphorous compounds (Marklund and others, 2005). Organophosphorous compounds have been detected in dry and wet deposition and in surface waters from streams across the United States (Kolpin and others, 2002), and are prevalent in sewage-treatment-plant effluents. Several studies show that organophosphorous compounds, especially chlorinated ones, tend to pass through sewage-treatment plants without being removed (Meyer and Bester, 2004; Marklund and others, 2005). Some organophosphorous compounds are reported to be neurotoxic, and others are carcinogenic to animals.

Some organophosphorous compounds, especially chlorinated organophosphorous compounds, are being reevaluated by the European regulatory bodies on environmental issues (Meyer and Bester, 2004).

Individual organophosphorous compounds appear to vary in their biodegradability - for example, aerobic degradation occurs rapidly for triphenyl phosphate but is slow for tris(1,3dichloro-2-propyl) phosphate (U.S. Environmental Protection Agency, 2005). The generally high $\log K_{\mathrm{OW}}$ values for these constituents indicate potential for bioaccumulation. However, some organophosphorous compounds are metabolized by fish (for example, triphenyl phosphate), which limits their bioaccumulation. Some constituents, such as triphenyl phosphate have been found (or predicted) to be moderately to highly toxic to aquatic organisms. Triphenylphosphine was selected as one of the 50 top priority chemicals recommended by Muir and others (2009) for consideration in Great Lakes sampling on the basis of potential persistence and bioaccumulation. However, opinions on this compound vary; for example, the European Chemicals Bureau (2008f) has concluded that it is not a PBT chemical.

\section{Knowledge and Concerns of Halogenated Dioxins and Furans (Subgroup F-11)}

Most of the halogenated dioxins and furans evaluated by the NTAS work group are polychlorinated, and a few are polybrominated. When substitution with just one type of halogen is considered, 75 polyhalogenated dibenzo- $p$-dioxins and 135 polyhalogenated dibenzo- $p$-furans, including the monohalogenated congeners, are possible. Of the chlorinated compounds, the most toxic to mammals is 2,3,7,8-TCDD (Agency for Toxic Substances and Disease Registry, 1998).

Halogenated dioxins and furans can form as by-products of incineration and combustion processes, synthesis of various chlorinated organic chemicals, and chlorine bleaching in pulp and paper mills. Their semivolatility and resistance to degradation have led to wide distribution in the environment.
Halogenated dioxins have never been intentionally produced, except as pure compounds in small quantities for research (Agency for Toxic Substances and Disease Registry, 1998).

Halogenated dioxins and furans can bioaccumulate in aquatic organisms living in surface water and sediment and can be biomagnified through terrestrial and aquatic food chains. For the general human population, 90 percent of exposure to these constituents occurs through consumption of meat, dairy products, and fish (Agency for Toxic Substances and Disease Registry, 1998). Occurrence in sediment can result from the same atmospheric deposition processes that lead to contamination of meat and dairy products. Chlorinated dioxins have been characterized as likely human carcinogens and are anticipated to increase the risk of cancer even at background levels of exposure (U.S. Environmental Protection Agency, 1984). Because of their toxicities at very low concentrations and their tendencies to persist, chlorinated dioxin and furan compounds are among the "dirty dozen" Persistent Organic Pollutants identified by the Stockholm Convention. Regulatory agencies in North America and Europe have made long-term efforts to reduce incidental releases and human exposure that have resulted in downward trends in human dietary exposure of 9-12 percent per year in Europe (Buckley-Golder, 1999).

\section{Knowledge and Concerns of Other Organohalogens (Subgroup F-12)}

An organohalogen compound is defined as containing one or more covalent carbon-halogen bonds. In addition to the constituents in subgroup F-12, organohalogen compounds are in subgroups F-1 (PCBs), F-5 (brominated flame retardants), F-6 (chlorinated naphthalenes), F-7 (chlorinated paraffins), F-8 (perfluorinated compounds), F-9 (alkylphenols, alkylphenol ethoxylates, and other phenols), F-10 (organophosphorus compounds), and F-11 (halogenated dioxins and furans). Subgroup F-12 contains a variety of chlorinated aromatics, chlorinated anisoles, chlorinated alkenes, brominated aromatics, and halogenated ethers that do not fit into the other (more specific) Group F subgroups.

As a general rule, increasing the degree of halogenation on an organohalogen causes decreasing water solubility and increasing lipophilicity, $\log K_{\mathrm{OW}}$, resistance to microbial degradation, and toxicity. For chlorinated benzenes, for example, the acute and chronic toxicity to fathead minnows increases as the number of chlorines increases from two to four; BCFs increase as the number of chlorines increases from two to six (Carlson and Kosian, 1987).

Eight of the 47 constituents in subgroup F-12 were determined in streambed-sediment samples during NAWQA Cycle 1 (tables F.4A-D). Of these eight constituents, detection frequencies were highest for 1,4-dichlorobenzene ( 8 percent in samples from mixed land-use streams and 6 percent in samples from urban streams) and hexachlorobenzene ( 3 percent in mixed land-use streams and 8 percent in urban streams), although these constituents have different reporting levels 
(50 $\mu \mathrm{g} / \mathrm{kg}$ for 1,4-dichlorobenzene and $1 \mu \mathrm{g} / \mathrm{kg}$ for hexachlorobenzene). Five of the eight subgroup F-12 constituents that were analyzed by the NAWQA Program have aquatic-life benchmarks for sediment, but concentrations rarely exceeded benchmark values ( 1 percent of sites or less); the benchmarks exceeded were lower screening values, except for 1,4-dichlorobenzene at one urban site (table F.4A).

\section{Knowledge and Concerns of Azaarenes (Subgroup F-13)}

Azaarenes are PAHs in which one carbon atom in one of the aromatic rings is substituted with a nitrogen atom. Some azaarenes are produced naturally by organisms, and some are released into the environment from coal tar and oil shale processing, wood preservation, and some types of chemical manufacturing. Azaarenes are widely observed in water and sediment samples but at lower concentrations than PAHs (de Voogt and Lane, 2009). Azaarenes are more water soluble than their PAH analogues and may be more bioavailable. Two- and three-ringed azaarenes can be relatively easily transformed by bacteria, fungi, invertebrates, and vertebrates (Bleeker and others, 2002). As with their PAH analogues, the toxicity of azaarenes generally increases as the number of rings increases (Black and others, 1983). Baseline toxicity models, based on the PAH analogues, apply to azaarenes (Bleeker and others, 2002). Mutagenicity of azaarenes generally proceeds through pathways similar to the PAH analogue pathways. For a given ring system, the position of the nitrogen atom affects the toxicity. The mechanisms by which the PAHs and azaarenes lead to cancer are similar, except that naphthalene (two-ringed PAH) does not induce liver cancer but quinoline (analogous tworinged azaarene) does (Bleeker and others, 2002). Like PAHs, the azaarenes tend to photodegrade and have photoenhanced toxicity to algae (Wiegman and others, 2001).

Seven of the 10 azaarenes in subgroup F-13 were determined in streambed-sediment samples collected during Cycle 1, of which six were detected in samples collected from 10 percent or more of the sites in urban or mixed land-use settings (tables F.4A, $B$ ). Of these, carbazole and acridine were widely detected (observed in more than 60 percent of samples from urban stream sites and in more than 30 percent of samples from mixed land-use sites).

\section{Knowledge and Concerns of Siloxanes (Subgroup F-14)}

Siloxanes are compounds composed of repeating units of $-\mathrm{Si}\left(\mathrm{R}^{\prime} \mathrm{R}^{\prime \prime}\right)-\mathrm{O}-$, wherein $\mathrm{R}^{\prime}$ and $\mathrm{R}^{\prime \prime}$ can be a hydrogen atom or a hydrocarbon group (see example structure in table F.1). If $\mathrm{R}^{\prime}$ and $\mathrm{R}^{\prime \prime}$ are methyl groups, the result is a dimethyl siloxane. The repeating units can extend to form a linear chain or can form a ring. The term "silicones" refers to products or materials containing one or more types of siloxanes. The physical and chemical properties of siloxanes are affected by
(1) molecular weight, (2) the nature of the $\mathrm{R}^{\prime}$ and $\mathrm{R}^{\prime}$ groups, (3) whether cross-linking exists (that is, connection to another -Si-O- chain rather than to the $\mathrm{R}^{\prime}$ or R" groups), and (4) for linear siloxanes, the nature of the terminal (chain-ending) groups. Oxidative stability is achieved when $\mathrm{R}^{\prime}$ and $\mathrm{R}^{\prime \prime}$ are phenyl groups, water repellency is achieved when $\mathrm{R}^{\prime}$ and $\mathrm{R}^{\prime \prime}$ are alkyl groups, and water solubility is enhanced when $R^{\prime}$ and $\mathrm{R}^{\prime \prime}$ are aminopropyl or polyether groups (Danish Environmental Protection Agency, 2005).

Siloxanes are used in building and construction; as additives in fuels, car polish, and cleaners; in biomedical products; and in personal-care products (Nordic Council of Ministers, 2005). Cyclotetrasiloxane, cyclopentasiloxane, and cyclohexasiloxane are HPV chemicals in the United States. In 2002, the annual import/production volume was between 100 and 500 million pounds for cyclotetrasiloxane and cyclopentasiloxane, respectively, and between 10 and 50 million pounds for cyclohexasiloxane (California Office of Environmental Health Hazard Assessment, 2008). Cyclopentasiloxane is used as a drycleaning agent and has been marketed as a safer alternative to tetrachloroethene ("perchloroethylene"). Siloxanes can enter the environment upon volatilization of cyclosiloxanes from cosmetics; incineration or landfill disposal of construction materials, paints, plastic additives, and paper coatings; discharge of wastewaters containing cleaning agents, waxes, polishes, textile sizings, cosmetics, and toiletries; and disposal of industrial wastes (for example, heat-transfer fluids) and medical wastes (Danish Environmental Protection Agency, 2005). Some siloxanes are resistant to oxidation, reduction, and photodegradation; reports vary regarding resistance to hydrolysis (Nordic Council of Ministers, 2005). In general, it is reasonable to conclude that siloxanes have considerable stability in the environment.

Cyclic siloxanes have been found in sediment of Lake Ontario near Toronto (at concentrations greater than 700 $\mu \mathrm{g} / \mathrm{kg}$ ) but not elsewhere in the lake (D. Powell, Dow Corning, unpublished data, cited by Muir and others, 2007). Studies covering six Nordic countries (2004-05) identified siloxanes in sediment, sludge, soil, water, air, fish, and mussels (Nordic Council of Ministers, 2005; Schlabach and others, 2007). Concentrations of siloxanes typically were in the range of less than 5 to $100 \mu \mathrm{g} / \mathrm{kg}$ in sediment, freshwater fish livers, and marine fish livers sampled at urban/diffuse (nonpointsource) sites, although concentrations greater than $2,000 \mu \mathrm{g} / \mathrm{kg}$ were detected at one site each for sediment (in Denmark) and marine fish livers (in the Inner Oslofjord, Norway). Cyclic siloxanes were present at higher concentrations than linear siloxanes in all sampling media (Nordic Council of Ministers, 2005; Schlabach and others, 2007). In the Nagara River, Japan, siloxanes have been found in water, sediment $(300-6,000 \mu \mathrm{g} / \mathrm{kg})$, and muscle tissue of fish $(360-890 \mu \mathrm{g} / \mathrm{kg})$ (Watanabe and others, 1988).

Siloxanes are recognized as international analytes of concern. Ten siloxanes were identified by Howard and Muir (2010) as high priority, emerging PBT chemicals of concern on the basis of their high predicted BCF values, persistence, 
and high-production volumes. Bioaccumulation studies with goldfish and guppies (Opperhuizen and others, 1987) indicated rapid uptake of cyclic and linear siloxanes with 14 or fewer silicon units after dietary exposure and aqueous exposure. However, although uptake efficiencies were similar to those of some PCBs, the maximum amounts of the siloxanes observed in fish tissue never exceeded three times the daily exposure dose, probably because of rapid elimination. Elimination halflives were estimated to range from less than 1 day to less than 5 days. Linear siloxanes with more than 14 silicon units were not detected in fish, probably because of reduced membrane permeability (Opperhuizen and others, 1987). Cyclohexasiloxane is expected to be less bioavailable to aquatic organisms than cyclotetrasiloxane and cyclopentasiloxane because of its high $\log K_{\mathrm{OW}}$ value (Environment Canada and Health Canada, $2008 \mathrm{a}-\mathrm{c})$.

Siloxanes are predicted to have moderate to high toxicity to aquatic organisms, although in some cases (including cyclopentasiloxane and cyclohexasiloxane) water solubility values are lower than chronic toxicity values predicted by the USEPA's PBT Profiler. Environment Canada and Health Canada $(2008 \mathrm{a}-\mathrm{c})$ conducted screening assessments for cyclotetrasiloxane, cyclopentasiloxane, and cyclohexasiloxane as part of their Challenge Program. Cyclotetrasiloxane was identified as being toxic to sensitive pelagic aquatic organisms at concentrations that are less than the measured water solubility of this constituent $(0.056 \mathrm{mg} / \mathrm{L})$. Cyclopentasiloxane caused no adverse effects on pelagic organisms in experimental studies at concentrations as much as its measured water solubility, although the possibility is acknowledged that "toxicity may manifest at the solubility limit if sufficient exposure and sensitive species were present" (Environment Canada and Health Canada, 2008a). Toxicity to benthic organisms living in sediment contaminated with cyclotetrasiloxane and cyclopentasiloxane has been observed experimentally (Environment Canada and Health Canada, 2008a,c). For cyclohexasiloxane, no adverse effects were observed on pelagic organisms at concentrations as much as the measured water solubility. Because cyclohexasiloxane is less bioavailable than cyclotetrasiloxane and cyclopentasiloxane, Environment Canada and Health Canada (2008b) concluded that cyclohexasiloxane is not expected to have adverse effects at its water solubility limit; however, cyclotetrasiloxane and cyclopentasiloxane might adversely affect fish and aquatic organisms because of their wide use and environmental persistence.

\section{Knowledge and Concerns of Resin and Rosin Acids (Subgroup F-15)}

As used here, the term "resins" refers to hydrocarbon secretions of plants (especially coniferous trees) or synthetic versions of such secretions. ("Amber" is fossilized tree resin.) Typically, resins are viscous liquids composed mostly of terpenes plus dissolved nonvolatile solids and resin acids. "Rosins" are solid forms of resins, from which the volatile terpenes have been lost or removed. "Resin acids" typically have a three-ring fused skeleton with double bonds and one carboxyl group. They commonly have the molecular formula $\mathrm{C}_{19} \mathrm{H}_{29} \mathrm{COOH}$ and occur in several isomeric forms. The most prevalent types of resin acids are abietic-type acids and pimaric-type acids (Baldwin and others, 1958).

Resin and rosin acids (particularly abietic-type acids) are released from coniferous wood during manufacture of wood pulp by the kraft pulping processes. Individual resin acids have been measured in sediment near kraft pulp mills (Wilkins, Singh-Thandi, and Langdon, 1996; Wilkins, Davidson, Langdon, and Hendy, 1996; Travendale and others, 1995). Resin acids and their biodegradation products have been detected in sediments from shallow streams in remote forested areas (Judd and others, 1998). Resin acids also have been observed to bioaccumulate in caged fish (Niimi and Lee, 1992) and freshwater mussels exposed to kraft mill effluent (Burggraaf and others, 1996). In Manistee Lake (near a Superfund site) in Michigan, resin acids were detected in lake sediment cores, although not in the fish that were sampled; thermal stratification of the lake was a possible means of isolation of the fish from the contaminated sediments (Rediske and others, 2001).

The eight constituents in subgroup F-15 are complex mixtures of specific resin and rosin acids that have been hydrogenated, fumarated, or reacted with alcohols or polyalcohols. Under TSCA, the general classification "unknown or variable composition, complex reaction products, or biological materials" has been used to refer to the resin and rosin acids (U.S. Environmental Protection Agency, 2012b). Resin acids and rosin acids are used in a variety of products including pigments, dyes, adhesives, binders, sealants, colorants, solvents, and strippers/de-inkers (Environment Canada and Health Canada, 2009a-e). Some of these substances are HPVs (U.S. Environmental Protection Agency, 2011f; Organisation for Economic Co-operation and Development, 2009).

In chemical profiles for five of the eight constituents in subgroup F-15, Environment Canada and Health Canada (2009a-e) estimated physical and chemical properties, degradation rates, and toxicity characteristics using representative compounds for each mixture. These constituents were estimated to have low water solubilities, low vapor pressures, low Henry's Law constants, high BCFs, and high $\log K_{\mathrm{OC}}$ values (Environment Canada and Health Canada, 2009a-e). The resin acids were predicted to undergo substantial partitioning into soil and sediment, where they are likely to persist (sediment half-life greater than 700 days). These five constituents also were predicted by Environment Canada and Health Canada (2009a-e) to have acute toxicity to aquatic organisms at concentrations less than $1 \mathrm{mg} / \mathrm{L}$. For two of these substances (CASRNs 64365-17-9 and 65997-13-9), information submitted under the HPV Challenge Program reported that no acute toxicity was observed for either substance at nominal (that is, calculated, not measured) concentrations ranging from 1 to 1,000 $\mathrm{mg} / \mathrm{L}$ in toxicity tests with fathead minnow and daphnids (U.S. Environmental Protection Agency, 2011f). However, exposure 
levels in these tests exceeded the water solubilities of the test substances, which were measured in the same study (less than 0.22 and $0.15 \mathrm{mg} / \mathrm{L}$, respectively); the nominal exposure levels therefore have a high degree of uncertainty and might overestimate actual exposure, confounding the test results.

Resin acid compounds in wastewaters from wood processing have been found to be toxic to fish at concentrations of 200-800 $\mu \mathrm{g} / \mathrm{L}$ (McFarlane and Clark, 1988). The most commonly monitored resin acids in discharges from aqueous pulping processes include abietic acid, dehydroabietic acid, neoabietic acid, pimaric acid, isopimaric acid, sandaracopimaric acid, levopimaric acid, and palustric acid. Isopimaric acid is considered to be the most toxic of all the resin acids (Wilson and others, 1996; as reviewed by Ali and Sreekrishnan, 2001). In sediment, the bioavailability of these substances (similar to most Group F constituents with low water solubilities) will depend on the organism and on factors such as ambient levels of dissolved and particulate organic carbon; benthic organisms may be exposed to both dissolved and particulate-associated contaminants (for example, by ingestion) (Nowell and others, 1999).

\section{Knowledge and Concerns of Miscellaneous Compounds (Subgroup F-16)}

Miscellaneous compounds not included in the previously described 15 subgroups in Group F span a variety of constituents, including nitroaromatic compounds, nitrosoamines, aromatic amines, hemoglobin adducts, organometallics, and xanthene dyes. Seven of the constituents in subgroup F-16 were determined in NAWQA streambed-sediment samples during Cycle 1: three nitroaromatic compounds (detected at 2 percent or less of urban sites), two nitrosoamine compounds (detected at 0 and 10 percent of urban sites), one cyclic ketone (detected at 1 percent of urban sites), and one quinone (anthraquinone, detected at 79 percent of urban sites) (table F.4A). Only one of these seven constituents ( $N$-nitrosodiphenylamine) has an aquatic-life benchmark (a lower screening value), which was exceeded at 5.8 percent of urban stream sites (table F.4A).

\section{References for Lipophilic Organic Compounds in Sediment (Group F)}

Agency for Toxic Substances and Disease Registry, 1992, Toxicological profile for nitrophenols: accessed February 18, 2010, at http://www.atsdr.cdc.gov/toxprofiles/tp50.pdf.

Agency for Toxic Substances and Disease Registry, 1995, Toxicological profile for diethyl phthalate: accessed February 18,2010 , at $h t t p: / / w w w . a t s d r . c d c . g o v / t o x p r o f i l e s / t p 73$. $p d f$.
Agency for Toxic Substances and Disease Registry, 1998, Toxicological profile for chlorinated dibenzo-p-dioxins: accessed February 18, 2010, at http://www.atsdr.cdc.gov/ toxprofiles/tp104.pdf.

Agency for Toxic Substances and Disease Registry, 1999, Toxicological profile for chlorophenols: accessed February 18, 2010, at http://www.atsdr.cdc.gov/toxprofiles/tp107.pdf.

Agency for Toxic Substances and Disease Registry, 2001, Toxicological profile for di-n-butyl phthalate: accessed February 18, 2010, at http://www.atsdr.cdc.gov/toxprofiles/ tp135.pdf.

Agency for Toxic Substances and Disease Registry, 2002, Toxicological profile for di(2-ethylhexyl)phthalate: accessed February 18, 2010, at http://www.atsdr.cdc.gov/toxprofiles/ tp9.pdf.

Agency for Toxic Substances and Disease Registry, 2008, Toxicological profile for cresols: accessed February 18, 2010, at $h t t p: / / w w w . a t s d r . c d c . g o v / t o x p r o f i l e s / t p 34 . p d f$.

Ahel, Marijan; McEvoy, J.; and Giger, Walter; 1993, Bioaccumulation of the lipophilic metabolites of nonionic surfactants in freshwater organisms: Environmental Pollution, v. 79 , p. 243-248.

Ahel, Marijan; Giger, Walter; and Koch, Markus; 1994a, Behaviour of alkylphenol polyethoxylate surfactants in the aquatic environment- - I. Occurrence and transformation in sewage treatment: Water Research, v. 28, no. 5, p. $1,131-1,142$.

Ahel, Marijan; Giger, Walter; and Schaffner, Christian; 1994b, Behaviour of alkylphenol polyethoxylate surfactants in the aquatic environment-II. Occurrence and transformation in rivers: Water Research, v. 28, no. 5, p. 1,143-1,152.

Ali, Muna, and Sreekrishnan, T.R., 2001, Aquatic toxicity from pulp and paper mill effluents-A review: Advances in Environmental Research, v. 5, no. 2, p. 175-196.

Arctic Monitoring and Assessment Programme, 2012, Home page: accessed January 10, 2011, at http://www.amap.no/.

Baldwin, D.E., Loeblich, V.M., Lawrence, R.V., 1958, Acidic Composition of Oleoresins and Rosins: Industrial and Engineering Chemistry, v. 3, no. 2, p. 342-346.

Bard, S.M., 1999, Global transport of anthropogenic contaminants and the consequences for the Arctic marine ecosystem: Marine Pollution Bulletin, v. 38, p. 356-379.

Baumann, P.C., and Harshbarger, J.C., 1995, Decline in liver neoplasms in wild brown bullhead catfish after coking plant closes and environmental PAHs plummet: Environmental Health Perspectives, v. 103, no. 2, p. 168-170. 
Baumard, Pascale; Budzinski, Hélène; and Garrigues, Philippe; 1998, Polycyclic aromatic hydrocarbons in sediments and mussels of the western Mediterranean Sea: Environmental Toxicology and Chemistry, v. 17, no. 5, p. 765-776.

Black, J.A., Birge, W.J., Westerman, A.G., and Francis, P.C., 1983, Comparative aquatic toxicology of aromatic hydrocarbons: Fundamental and Applied Toxicology, v. 3, no. 5, p. 353-358.

Bleeker, E.A., Wiegman, S., de Voogt, P., Kraak, M., Leslie, H.A., de Haas, E., and Admiraal, W., 2002, Toxicity of azaarenes: Reviews of Environmental Contamination and Toxicology, v. 173, p. 39-83.

Bryer, Pamela, Elliot, J.N., and Willingham, E.J., 2006, The effects of coal tar based pavement sealer on amphibian development and metamorphosis: Ecotoxicology, v. 15, no. 3, p. 241-247.

Buckley-Golder, Deborah, 1999, Compilation of EU dioxin exposure and health data-Summary report: Abingdon, Oxfordshire, United Kingdom, AEA Technology, accessed January 10, 2011, at http://ec.europa.eu/environment/dioxin/ pdf/summary.pdf.

Burggraaf, Shane, Langdon, A.G., Wilkins, A.L., and Roper, D.S., 1996, Accumulation and depuration of resin acids and fichtelite by the freshwater mussel Hyridella menziesi: Environmental Toxicology and Chemistry, v. 15, no. 3, p. 369-375.

Burkhardt, M.R., Zaugg, S.D., Smith, S.G., and ReVello, R.C., 2006, Determination of wastewater compounds in sediment and soil by pressurized solvent extraction, solid-phase extraction, and capillary-column gas chromatography/ mass spectrometry: U.S. Geological Survey Techniques and Methods, book 5, chap B2, 33 p.

California Office of Environmental Health Hazard Assessment, 2008, Cyclosiloxanes-Materials for the December 4-5, 2008, meeting of the California Environmental Contaminant Biomonitoring Program (CECBP) Scientific Guidance Panel: accessed January 27, 2011, at http://oehha. ca.gov/multimedia/biomon/pdf/1208cyclosiloxanes.pdf.

Canadian Council of Ministers of the Environment, 2002, Canadian sediment quality guidelines for the protection of aquatic life-Summary tables (updated), in Canadian environmental quality guidelines, 1999: Winnipeg, Canadian Council of Ministers of the Environment, accessed February 18, 2010, at http://ceqg-rcqe.ccme.cal.

Carlson, A.R., and Kosian, P.A., 1987, Toxicity of chlorinated benzenes to fathead minnows (Pimephales promelas): Washington, D.C., U.S. Environmental Protection Agency, EPA/600/J-87/015.
Chung, K-T., and Stevens, S.E., Jr., 1993, Degradation of azo dyes by environmental microorganisms and helmonths: Environmental Toxicology and Chemistry, v. 12, p. 2,1212,132 .

Danish Environmental Protection Agency, 2005. Siloxanes - Consumption, toxicity and alternatives (version 1.0, September 2005): Miljøstyrelsen, Danish Environmental Protection Agency, accessed January 10, 2011, at http:// www2.mst.dk/common/Udgivramme/Frame.asp?http:// www2.mst.dk/Udgiv/publications/2005/87-7614-756-8/html/ indhold_eng.htm.

de Voogt, P., and Lane, R.W.P.M., 2009, Assessment of azaarenes and azaarones (oxidized azaarene derivatives) in the Dutch coastal zone of the North Sea: Chemosphere, v. 76, no. 8, p. 1,076-1,074.

Edwards, N.T., 1983, Polycyclic aromatic hydrocarbons (PAHs) in the terrestrial environment-A review: Journal of Environmental Quality, v. 12, p. 427-441.

Environment Canada, 2002, Canadian environmental quality guidelines for nonylphenol and its ethoxylates (water, sediment, and soil), scientific supporting document, ecosystem health: Ottawa, Canada, National Guidelines and Standards Office, Environmental Quality Branch, Environment Canada, Science-based Solutions Report No. 1-3.

Environment Canada and Health Canada, 2008a, Screening assessment for the challenge decamethylcyclopentasiloxane (D5), Chemical Abstracts Service Registry Number 541-02-6: accessed April 11, 2012, at http://www.ec.gc.cal substances/ese/eng/challenge/batch2/batch2_541-02-6.cfm.

Environment Canada and Health Canada, 2008b, Screening assessment for the challenge dodecamethylcyclohexasiloxane (D6), Chemical Abstracts Service Registry Number 540-97-6: accessed April 11, 2012, at http://www.ec.gc.ca/ ese-ees/FC0D11E7-DB34-41AA-B1B3-E66EFD8813F1/ batch2_540-97-6_en.pdf.

Environment Canada and Health Canada, 2008c, Screening assessment for the challenge, octamethylcyclotetrasiloxane (D4), Chemical Abstracts Service Registry Number 556-67-2: accessed April 11, 2012, at http://www.ec.gc.cal substances/ese/eng/challenge/batch2/batch2_556-67-2.cfm.

Environment Canada and Health Canada, 2009a, Substance profile for the challenge- - Resin acids and rosin acids, hydrogenated, esters with glycerol, Chemical Abstracts Service Registry Number 65997-13-9: accessed January 10, 2011, at http://www.ec.gc.ca/substances/ese/eng/challenge/ batch10/batch10_65997-13-9.cfm. 
Environment Canada and Health Canada, 2009b, Substance profile for the challenge-Resin acids and rosin acids, hydrogenated, esters with pentaerythritol, Chemical Abstracts Service Registry Number 64365-17-9: accessed January 11, 2011, at http://www.ec.gc.ca/substances/ese/ eng/challenge/batch10/batch10_64365-17-9_en.pdf.

Environment Canada and Health Canada, 2009c, Substance profile for the challenge- - Resin acids and rosin acids, hydrogenated, esters with triethylene glycol, Chemical Abstracts Service Registry Number 68648-53-3: accessed September 23, 2010, at http://www.ec.gc.ca/substances/ese/ eng/challenge/batch10/batch10_68648-53-3.cfm.

Environment Canada and Health Canada, 2009d, Substance profile for the challenge- - Resin acids and rosin acids, fumarated, barium salts, Chemical Abstracts Service Registry Number 124751-15-1: accessed April 11, 2012, at http://www.ec.gc.ca/substances/ese/eng/challenge/batch10/ batch10_124751-15-1.cfm.

Environment Canada and Health Canada, 2009e, Substance profile for the challenge-Rosin, hydrogenated, Chemical Abstracts Service Registry Number 65997-06-0: accessed April 11, 2012, at http://www.ec.gc.ca/substances/ese/eng/ challenge/batch10/batch10_65997-06-0.cfm.

European Chemical Agency, 2008, Annex XV, Proposal for identification of a substance as a CMR Cat 1 or 2, PBT, $\mathrm{vPvB}$ or a substance of an equivalent level of concernAlkanes, $\mathrm{C}_{10-13}$, chloro: accessed February 18, 2010, at http://echa.europa.eu/documents/10162/13640/svhc axvrep_uk_pbt_sccp_20083006_en.pdf.

European Chemicals Bureau, 2008a, TC NES Subgroup on identification of PBT and VPVB substances-Results of the evaluation of the PBT/VPVB properties of butanamide, 2,2'[(3,3'-dichloro[(1,1'-biphenyl)]-4,4'diyl)bis(azo) bis[N-(4-chloro-2,5-dimethoxyphenyl)-3-oxo-(C.I. Pigment Yellow 83: accessed February 18, 2010, at http://esis.jrc. ec.europa.eu/doc/PBT-evaluation/PBT_sum008_CAS_556715-7.pdf.

European Chemicals Bureau, 2008b, TC NES Subgroup on identification of PBT and VPVB substances - Results of the evaluation of the PBT/VPVB properties of butanamide, 2,2' [(3,3'-dichloro[(1,1'-biphenyl)]-4,4'diyl)bis(azo)bis[N(2,4-dimethylphenyl)-3-oxo- (C.I. Pigment Yellow 13): accessed February 18, 2010, at http://esis.jrc.ec.europa.eu/ doc/PBT-evaluation/PBT_sum006_CAS_5102-83-0.pdf.

European Chemicals Bureau, 2008c, TC NES Subgroup on identification of PBT and VPVB substances-Results of the evaluation of the PBT/VPVB properties of barium bis[2-[(2-hydroxynaphthyl)azo]naphthalenesulphonate]: accessed February 18, 2010, at http://esis.jrc.ec.europa.eu/ doc/PBT-evaluation/PBT_sum033_CAS_1103-38-4.pdf.
European Chemicals Bureau, 2008d, TC NES Subgroup on identification of PBT and VPVB substances-Results of the evaluation of the PBT/VPVB properties of butanamide, 2,2'[(3,3'-dichloro[(1,1'-biphenyl)]-4,4'diyl)bis(azo) bis[N-(2-methylphenyl)-3-oxo- (C.I. Pigment Yellow 14): accessed February 18, 2010, at http://esis.jrc.ec.europa.eu/ doc/PBT-evaluation/PBT_sum007_CAS_5468-75-7.pdf.

European Chemicals Bureau, 2008e, TC NES Subgroup on identification of PBT and VPVB substances-Results of the evaluation of the PBT/VPVB properties of 3H_Pyrazol3-one, 4,4'[(3.3'-dichloro[(1,1'-biphentyl)]-4,4'-diyl $)]$ bis(azo)]bis[2,4-dihydro-5-methyl-2-phenyl- (C.I. Pigment Orange 13): accessed February 18, 2010, at http://esis.jrc. ec.europa.eu/doc/PBT-evaluation/PBT_sum009_CAS_352072-7.pdf.

European Chemicals Bureau, 2008f, TC NES Subgroup on identification of PBT and VPVB substances-Results of the evaluation of the PBT/VPVB properties of triphenylphosphine: accessed February 18, 2010, at http://esis.jrc. ec.europa.eu/doc/PBT-evaluation/PBT_sum094_CAS_60335-0.pdf.

European Commission, 2003, 1,2-benzenedicarboxylic acid, di-C8-10-branched alkyl esters, C9-rich and di-"isononyl" phthalate (DINP) - Summary risk assessment report: Special Publication I.03.101, accessed February 18, 2010, at http://www.dinp-facts.com/upload/documents/webpage/ document2.pdf.

Furlong, E.T., Vaught, D.G., Merten, L.M., Foreman, W.T., and Gates, P.M., 1996, Methods of analysis by the U.S. Geological Survey National Water Quality LaboratoryDetermination of semivolatile organic compounds in bottom sediment by solvent extraction, gel permeation chromatographic fractionation, and capillary-column gas chromatography/mass spectrometry: U.S. Geological Survey OpenFile Report 95-719, 67 p.

Hale, R.C., La Guardia, M.J., Harvey, E.P., Gaylor, M.O., and Mainor, T.M., 2006, Brominated flame retardant concentrations and trends in abiotic media: Chemosphere, v. 64, p. 181-186.

Hale, R.C., La Guardia, M.J., Harvey, E.P., Gaylor, M.O., Mainor, T.M., and Duff, W.H., 2001, Persistent pollutants in land-applied sludges: Nature, v. 412, p. 140-141.

Hickey, J.P., Batterman, S.A., and Chernyak, S.M., 2006, Trends of chlorinated organic contaminants in Great Lakes trout and walleye from 1970 to 1998: Archives of Environmental Contamination and Toxicology, v. 50, p. 97-110.

Hogue, Cheryl, 2009, Chemical rules face change: Chemical and Engineering News, v. 87, no. 42, p. 828-29. 
Howard, P.H., and Muir, D.C.G., 2010, Identifying new persistent and bioaccumulative organics among chemicals in commerce: Environmental Science and Technology, v. 44, no. 7, p. 2,277-2,295.

Ikonomou, M.G., Rayne, Sierra, and Addison, R.F., 2002, Exponential increases of the brominated flame retardants, polybrominated diphenyl ethers, in the Canadian Arctic from 1981 to 2000: Environmental Science and Technology, v. 36 , no. 9 , p. $1,886-1,892$.

Jobling, S., and Sumpter, J.P., 1993, Detergent components in sewage effluent are weakly oestrogenic to fish-An in vitro study using rainbow trout (Oncorhynchus mykiss) hepatocytes: Aquatic Toxicology, v. 27, p. 361-372.

Johnson, G.W., Jarman, W.M., Bacon, C.E., Davis, J.A., Ehrlich, Robert, and Risebrough, R.W., 2000, Resolving polychlorinated biphenyl source fingerprints in suspended particulate matter of San Francisco Bay: Environmental Science and Technology, v. 34, no. 4, p. 552-559.

Judd, M.C., Stuthridge, T.R., and Price, R.W., 1998, Pulp mill sourced organic compounds from New Zealand sediments, Part 3-Mechanical pulp mills and remote sites: Chemosphere, v. 36, no. 10, p. 2,311-2,320.

Kolpin, D.W., Furlong, E.T., Meyer, M.T., Thurman, E.M., Zaugg, S.D., Barber, L.B., and Buxton, H.T., 2002, Pharmaceuticals, hormones, and other organic wastewater contaminants in U.S. streams, 1999-2000-A national reconnaissance: Environmental Science and Technology, v. 36, p. $1,202-1,211$.

Lewtas, Joellen, 2007, Air pollution combustion emissionsCharacterization of causative agents and mechanisms associated with cancer, reproductive, and cardiovascular effects: Mutation Research, v. 636, p. 95-133.

Li, Zhengyan; Li, Donghao; Oh, J.R.; and Je, J.G.; 2004, Seasonal and spatial distribution of nonylphenol in Shihwa Lake, Korea: Chemosphere, v. 56, no. 6, p. 611-618.

Lopes, T.J., and Furlong, E.T., 2001, Occurrence and potential adverse effects of semivolatile organic compounds in streambed sediment, United States, 1992-1995: Environmental Toxicology and Chemistry, v. 20, no. 4, p. 727-737.

Lopes, T.J., Furlong, E.T., and Pritt, J.W., 1997, Occurrence and distribution of semivolatile organic compounds in stream bed sediments, United States, 1992-1995: Environmental Toxicology and Risk Assessment, v. 7, p. 105-119.

MacDonald, D.D., Ingersoll, C.G., and Berger, T.A., 2000, Development and evaluation of consensus-based sediment quality guidelines for freshwater ecosystems: Archives of Environmental Contamination and Toxicology, v. 39, p. 20-31.
Mahler, B.J., and Van Metre, P.C., 2003, A simplified approach for monitoring of hydrophobic organic contaminants associated with suspended sediment-Methodology and applications: Archives of Environmental Contamination and Toxicology, v. 44, no. 3, p. 288-297.

Mahler, B.J., Van Metre, P.C., Bashara, T.J., Wilson, J.T., and Johns, D.A., 2005, Parking lot sealcoat-An unrecognized source of urban PAHs: Environmental Science and Technology, v. 39 , no. 15 , p. $5,560-5,566$.

Mahler, B.J., Van Metre, P.C., Wilson, J.T., and Musgrove, MaryLynn, 2010, Coal-tar-based parking lot sealcoat-An unrecognized source of PAH to settled house dust: Environmental Science and Technology, v. 44, no. 3, p. 894-900.

Marklund, Anneli; Andersson, Barbro; and Haglund, Peter; 2005, Organophosphorus flame retardants and plasticizers in Swedish sewage treatment plants: Environmental Science and Technology, v. 39, no. 19, p. 7,423-7,429.

Marvin, C.H.; McCarry, B.E.; Villella, John; Allan, L.M.; and Bryant, D.W.; 2000, Chemical and biological profiles of sediments as indicators of sources of genotoxic contamination in Hamilton Harbour, Part I-Analysis of polycyclic aromatic hydrocarbons and thia-arene compounds: Chemosphere, v. 41, p. 979-988.

McFarlane, P.N., and Clark, T.A., 1988, Metabolism of resin acids in anaerobic systems: Water Science and Technology, v. 20 , p. $273-276$.

Meeker, J.D.; Hu, Howard; Cantonwine, D.E.; LamadridFigueroa, Hector; Calafat, A.M.; Ettinger, A.S.; HernandezAvila, Mauricio; Loch-Caruso, Rita; and Téllez-Rojo, M.M.; 2009, Urinary phthalate metabolites in relation to preterm birth in Mexico City: Environmental Health Perspectives, v. 117, p. 1,587-1,592.

Meyer, J., and Bester, K., 2004, Organophosphate flame retardants and plasticizers in wastewater treatment plants: Journal of Environmental Monitoring, v. 6, p. 599-605.

Mibu, Katsuhiro; Wada, Junnosuke; Okayasu, Yuji; Tsumori, Jun; Komori, Koya; Tanaka, Hiroaki; Li, Jian-hua; Sasaki, Minoru; and Sato, Chikashi; 2004, Distribution of estrogen, nonylphenol and its derivatives in the sediments of a shallow lake: Water Science and Technology, v. 50, no. 5, p. 173-179.

MONARPOP, 2011, Monitoring Network in the Alpine Region for Persistent and other Organic Pollutants: accessed January 18, 2011, at $h t t p: / / w w w . m o n a r p o p . a t /$. 
Muir, Derek; Alaee, Mehran; Lee, Bill; and Scott, Brian; 2007, New contaminants in Lake Ontario-Siloxanes, perfluoros, organophosphates, and halogenated phenolics: Burlington, Ontario, Aquatic Ecosystem Research Protection Division, Water Science and Technology Directorate, Environment Canada, accessed March 14, 2010, at http://canamglass.org/ low/files/MuirNewContam GrandIsland28Mar07.pdf.

Muir, Derek, Howard, P.H., and Meylan, William, 2009, Identification of new, possible PB\&T substances important in the Great Lakes region by screening of chemicals in commerce: Report to the U.S. Environmental Protection Agency, accessed on February 19, 2010, at http://www.epa. gov/grtlakes/p2/PBTReport.pdf.

Niimi, A.J., and Lee, H.B., 1992, Free and conjugated concentration of nine resin acids in rainbow trout (Oncorhynchus mykiss) following waterborne exposure: Environmental Toxicology and Chemistry, v. 11, p. 1,403-1,407.

Nordic Council of Ministers, 2005, Siloxanes in the Nordic environment: Copenhagen (TemaNord 2005:593), accessed March 14, 2010, at http://www.norden.org/en/publications/ publications/2005-593? set_language $=e n$.

Nowell, L.H., Capel, P.D., and Dileanis, P.D., 1999, Pesticides in stream sediment and aquatic biota-Distribution, trends, and governing factors: Boca Raton, Fla., CRC Press, Pesticides in the Hydrologic System series, v. 4, 1,040 p.

Opperhuizen, Antoon; Damen, H.W.J.; Asyee, G.M.; Van Der Steen, J.M.D.; and Hutzinger, Otto; 1987, Uptake and elimination by fish of polydimethylsiloxanes (silicones) after dietary and aqueous exposure: Toxicology and Environmental Chemistry, v. 13, p. 265-285.

Organisation for Economic Co-operation and Development, 2002, Hazard assessment of perfluorooctane sulfonate (PFOS) and its salts: ENV/JM/RD(2002)17/FINAL, accessed February 18, 2010, at http://www.fluoridealert.org/ pesticides/pfos.final.report.nov.2002.pdf.

Organisation for Economic Co-operation and Development, 2009, The 2007 OECD List of High Production Volume Chemicals: ENV/JM/MONO(2009)40, 104 p.

Oregon Department of Health Services, 2008, Polybrominated diphenyl ether (PBDE) flame retardants: Report to the Oregon Legislature, February 2008, accessed April 12, 2012, at http://library.state.or.us/repository/2009/200908311122431/ index.pdf.

Püntener, A., and Page, C., 2004, European ban on certain azo dyes: TFL Leather Technology Ltd, Quality and Environment, accessed February 18, 2010, at http://www.tfl.com/ web/files/eubanazodyes.pdf.
Rediske, Richard; Gabrosek, John; Thompson, Cynthia; Bertin, Carissa; Blunt, Jessica; and Meier, P.G.; 2001, Preliminary investigation of the extent of sediment contamination in Manistee Lake: U.S. Environmental Protection Agency, Great Lakes National Program Office, and National Oceanic and Atmospheric Administration, AWRI Publication no. TM-2001-7.

Rogge, W.F., Hildemann, L.M., Mazurek, M.A., and Cass, G.R., 1993, Sources of fine organic aerosol-3. Road dust, tire debris, and organometallic brake lining dust—Roads as sources and sinks: Environmental Science and Technology, v. 27 , no. 9 , p. $1,892-1,904$.

Rotterdam Convention on the Prior Informed Consent Procedure for Certain Hazardous Chemicals and Pesticides in International Trade, 2011, Text and Annexes (revised 2011): accessed April 12, 2012, at http://www.pic.int/ TheConvention/Overview/TextoftheConvention/tabid/1048/ language/en-US/Default.aspx.

Schlabach, Martin; Andersen, M.S.; Green, Norman; Schøyen, Merete; and Kaj, Lennart; 2007, Siloxanes in the environment of the Inner Oslofjord, TA-2269/2007: Norwegian Pollution Control Authority, accessed September 23, 2010, at http://www.klif.no/publikasjoner/2269/ta2269.pdf.

Scoggins, Mateo; McClintock, N.M.; Gosselink, Leila; and Bryer, P.J.; 2007, Occurrence of polycyclic aromatic hydrocarbons below coal-tar-sealed parking lots and effects on benthic macroinvertebrate communities: Journal of the North American Benthological Society, v. 26, p. 693-706.

Sediment Phthalates Work Group, 2007, Summary of findings and recommendations: Prepared by City of Tacoma, City of Seattle, King County, Washington Department of Ecology, U.S. Environmental Protection Agency, September 2007, $135 \mathrm{p}$.

Silliman, J.E., Meyers, P.A., and Eadie, B.J., 1998, PeryleneAn indicator of alteration processes or precursor materials?: Organic Geochemistry, v. 9, no. 5-7, p. 1,737-1,744.

Silva, M.J., Barr, D.B., Reidy, J.A., Malek, N.A., Hodge, C.C., Caudill, S.P., Brock, J.W., Needham, L.L., and Calafat, A.M., 2004, Urinary levels of seven phthalate metabolites in the U.S. population from the National Health and Nutrition Examination Survey (NHANES) 1999-2000: Environmental Health Perspectives, v. 112, p. 331-338.

Sims, R.C., and Overcash, M.R., 1983, Fate of polynuclear aromatic compounds (PNAs) in soil-plant systems: New York, Springer-Verlag, Inc., v. 88, p. 67.

Staples, C.A., Peterson, D.R., Parkerton, T.F., and Adams, W.J., 1997, The environmental fate of phthalate esters-A literature review: Chemosphere, v. 35, no. 4, p. 667-749. 
Staples, C.A.; Weeks, John; Hall, J.F.; and Naylor, C.G.; 1998, Evaluation of aquatic toxicity and bioaccumulation of C8and C9-alkylphenol ethoxylates: Environmental Toxicology and Chemistry, v. 17 , no. 12 , p. $2,470-2,480$.

Stockholm Convention on Persistent Organic Pollutants, 2009a, Convention text and Amendments to Annexes A, B and C in 2009: accessed April 12, 2012, at http://chm.pops. int/Convention/ConventionText/tabid/2232/Default.aspx.

Stockholm Convention on Persistent Organic Pollutants, 2009b, Revised draft risk profile-Short-chained chlorinated paraffins: UNEP/POPS/POPRC.5/2/Rev. 1, November 2009, accessed April 12, 2012, at http://chm.pops.int/ Portals/O/download.aspx?d=UNEP-POPS-POPRC.5-2Rev.1.English.pdf.

Swedish Chemicals Inspectorate (KemI), 2005, Proposal for listing perfluorooctane sulfonate (PFOS) in Annex A of the Stockholm Convention on Persistent Organic Pollutants: Prepared by the Swedish Chemicals Inspectorate (KemI), Sweden, June 2005, accessed April 12, 2012, at http:// www.pops.int/documents/meetings/poprc/meeting_docs/en/ POPRC1-INF9-b.pdf.

Takada, Hideshige; Onda, Tomoko; and Ogura, Norio; 1990, Determination of polycyclic aromatic hydrocarbons in urban street dusts and their source materials by capillary gas chromatography: Environmental Science and Technology, v. 24 , no. 8 , p. $1,179-1,186$.

Travendale, M.H., Wilkins, A.L., Langdon, A.G., Mackie, K.L., Stuthridge, T.R., and McFarlane, P.N., 1995, Analytical methodology for the determination of freely available bleached kraft mill effluent-derived organic constituents in recipient sediments: Environmental Science and Technology, v. 29 , no. 5 , p. 1,407-1,414.

Thuresson, Kaj; Höglund, Peter; Hagmar, Lars; Sjödin, Andreas; Bergman, Åke; and Jakobsson, Kristina; 2006, Apparent half-lives of hepta- to decabrominated diphenyl ethers in human serum as determined in occupationally exposed workers: Environmental Health Perspectives, v. 114, p. 176-181.

Tillitt, D.E., Giesy, J.P., and Ankley, G.T., 1991, Characterization of the H4IIE rat hepatoma cell bioassay as a tool for assessing toxic potency of planar halogenated hydrocarbons in environmental samples: Environmental Science and Technology, v. 25 , no. 1 , p. 87-92.

United Nations Environmental Program, 2003, 2003 Global report-Regionally based assessment of persistent toxic substances: Chátelaine, Switzerland, United Nations Environment Programme, UNEP Chemicals, 211 p.
University of Hertfordshire, 2010, Pesticide Properties Database (April 2009 version): University of Hertfordshire, United Kingdom, Agriculture and Environment Research Unit (AERU), Science and Technology Research Institute, accessed September 23, 2010, at http://sitem.herts.ac.uk/ aeru/footprint/en/index.htm.

U.S. Department of Health and Human Services, 2005, Report on carcinogens (11th ed.): U.S. Department of Health and Human Services, Public Health Service, National Toxicology Program, accessed January 11, 2011, at http://ntp.niehs. nih.gov/ntp/roc/tocll.htm.

U.S. Environmental Protection Agency, 1984, Health effects assessment for 2,3,7,8-tetrachlorodibenzo- $p$-dioxin: Washington, D.C., U.S. Environmental Protection Agency, EPA/540/1-86/044 (NTIS Pb86134558).

U.S. Environmental Protection Agency, 2002, Toxicological review of phenol (CAS No. 108-95-2) in support of summary information on the integrated risk information system (IRIS): Washington, D.C., U.S. Environmental Protection Agency, EPA/635/R-02/006.

U.S. Environmental Protection Agency, 2005, Furniture Flame Retardancy Partnership: Environmental profiles of chemical flame-retardant alternatives for low-density polyurethane foam, Volume 1: Washington, D.C., U.S. Environmental Protection Agency, EPA 742-R-05-002A, 153 p.

U.S. Environmental Protection Agency, 2007, Pilot survey of levels of polychlorinated dibenzo- $p$-dioxins, polychlorinated dibenzofurans, polychlorinated biphenyls, and mercury in rural soils of the United States: Washington, D.C., National Center for Environmental Assessment, EPA/600/R-05/048F.

U.S. Environmental Protection Agency, 2008, Emerging contaminants - Polybrominated diphenyl ethers (PBDE) and polybrominated biphenyls (PBB): U.S. Environmental Protection Agency Fact Sheet EPA 505-F-07-007.

U.S. Environmental Protection Agency, 2009a, EPI Suite ${ }^{\mathrm{TM}}$ version 4.0: U.S. Environmental Protection Agency, Office of Pollution Prevention and Toxics and Syracuse Research Corporation.

U.S. Environmental Protection Agency, 2009b, 2008 Biennial national listing of fish advisories: Technical Fact Sheet EPA-823-F-09-007, accessed February 18, 2010, at http://water.epa.gov/scitech/swguidance/fishshellfish/ fishadvisories/upload/2009_09_16_fish_advisories_ tech2008.pdf.

U.S. Environmental Protection Agency, 2009c, 2009 Edition of the Drinking Water Standards and Health Advisories: accessed July 21, 2010, at http://water.epa.gov/action/ advisories/drinking/upload/dwstandards2009.pdf. 
U.S. Environmental Protection Agency, 2009d, Evaluating ecological risk to invertebrate receptors from PAHs in sediments at hazardous waste sites: Cincinnati, Ohio, Ecological Risk Assessment Support Center, Office of Research and Development, EPA/600/R-06/162F, 23 p.

U.S. Environmental Protection Agency, 2009e, Phthalates action plan (December 30, 2009): accessed February 18, 2010 at http://www.epa.gov/oppt/existingchemicals/pubs/ actionplans/phthalates_ap_2009_1230_final.pdf.

U.S. Environmental Protection Agency, 2009f, Short-chain chlorinated paraffins (SCCPs) and other chlorinated paraffins action plan (December 30, 2009): accessed September 23, 2010 at http://www.epa.gov/opptintr/existingchemicals/ pubs/actionplans/sccps_ap_2009_1230_final.pdf.

U.S. Environmental Protection Agency, 2010a, Contaminant Candidate List 3-CCL3: accessed December 20, 2010, at http://water.epa.gov/scitech/drinkingwater/dws/ccl/ccl3.cfm.

U.S. Environmental Protection Agency, 2010b, Environmental assessment—Dioxin: accessed August 11, 2011, at http:// cfpub.epa.gov/ncea/CFM/nceaQFind.cfm?keyword=Dioxin .

U.S. Environmental Protection Agency, 2010c, Benzidine dyes action plan summary (August 18, 2010): accessed September 3,2010, at http://www.epa.gov/oppt/existingchemicals/ pubs/actionplans/benzidine.html.

U.S. Environmental Protection Agency, 2010d, Hexabromocyclododecane (HBCD) action plan (August 18, 2010): accessed September 3, 2010, at http://www.epa.gov/oppt/ existingchemicals/pubs/actionplans/hbcd.html.

U.S. Environmental Protection Agency, 2010e, Nonylphenol (NP) and nonylphenol ethoxylates (NPEs) action plan (August 18, 2010): accessed September 3, 2010, at http:// www.epa.gov/oppt/existingchemicals/pubs/actionplans/ np-npe.html.

U.S. Environmental Protection Agency, 2011a, Persistent, Bioaccumulative, and Toxic Profiles Estimated for Organic Chemicals (PBT Profiler): accessed January 10, 2011, at http://www.pbtprofiler.net/.

U.S. Environmental Protection Agency, 2011b, PesticidesEnvironmental effects-Technical overview of ecological risk assessment analysis phase-Ecological effects characterization: accessed January 10, 2011, at $h t t p: / / w w w . e p a$. gov/oppefed1/ecorisk_ders/toera_analysis_eco.htm.

U.S. Environmental Protection Agency, 2011c, Priority pollutants: accessed January 10, 2011, at http://water.epa.gov/ scitech/methods/cwa/pollutants.cfm.

U.S. Environmental Protection Agency, 2011d, Polychlorinated biphenyls (PCBs) — Basic information: accessed January 10, 2011, at http://www.epa.gov/epawaste/hazard/ tsd/pcbs/pubs/about.htm.
U.S. Environmental Protection Agency, 2011e, Polychlorinated biphenyls (PCBs) - Health effects of PCBs: accessed January 10, 2011, at http://www.epa.gov/epawaste/hazard/ tsd/pcbs/pubs/effects.htm.

U.S. Environmental Protection Agency, 2011f, High Production Volume (HPV) Challenge: accessed March 14, 2010, at http://www.epa.gov/chemrtk/index.htm.

U.S. Environmental Protection Agency, 2012a, Industry progressing in voluntary effort to reduce toxic chemicals / Companies have successfully developed over 150 alternatives to long-chain perfluorinated chemicals: Washington, D.C., U.S. Environmental Protection Agency Office of Chemical Safety and Pollution Prevention press release, February 10, 2012.

U.S. Environmental Protection Agency, 2012b, Toxic Substances Control Act Inventory representation for chemical substances of unknown or variable composition, complex reaction products and biological materials: UVCB substances, accessed June 6, 2012, at http://www.epa.gov/oppt/ existingchemicals/pubs/tscainventory/uvcb.pdf.

United Nations Environmental Program, 2003, 2003 Global report-Regionally based assessment of persistent toxic substances: Chátelaine, Switzerland, United Nations Environment Programme, UNEP Chemicals, 211 p.

Van den Berg, Martin; Birnbaum, Linda; Bosveld, A.T.; Brunström, Björn; Cook, Philip; Feeley, Mark; Giesy, J.P.; Hanberg, Annika; Hasegawa, Ryuichi; Kennedy, S.W.; Kubiak, Timothy; Larsen, J.C.; Rolaf van Leeuwen, F.X.; Djien Liem, A.K.; Nolt, Cynthia; Peterson, R.E.; Poellinger, Lorenz; Safe, Stephen; Schrenk, Dieter; Tillitt, Donald; Tysklind, Mats; Younes, Maged; Waern, Fredrik; and Zacharewski, Tim; 1998, Toxic equivalency factors (TEFs) for PCBs, PCDDs, PCDFs for humans and wildlife: Environmental Health Perspectives, v. 106, no. 12, p. 775-792.

Van Metre, P.C., Jones, S.A., Moring, J.B., Wilson, J.T., and Mahler, B.J., 2003, Chemical quality of water, sediment, and fish in Mountain Creek Lake, Dallas, Texas, 1994-97: U.S. Geological Survey Water-Resources Investigations Report 03-4082, $70 \mathrm{p}$.

Van Metre, P.C., and Mahler, B.J., 2004, Contaminant trends in reservoir sediment cores as records of influent stream quality: Environmental Science and Technology, v. 38, no. 11, p. 2,978-2,986.

Van Metre, P.C., and Mahler, B.J., 2005, Trends in hydrophobic organic contaminants in urban and reference lake sediments across the United States, 1970-2001: Environmental Science and Technology, v. 39, no. 15, p. 5,567-5,574. 
Van Metre, P.C., and Mahler, B.J., 2010, Contribution of PAHs from coal-tar pavement sealcoat and other sources to 40 U.S. lakes: Science of the Total Environment, v. 409, no. 2, p. 334-344.

Van Metre, P.C., Mahler, B.J., and Wilson, J.T., 2009, PAHs underfoot - Contaminated dust from coal-tar sealcoated pavement is widespread in the United States: Environmental Science and Technology, v. 43, no. 1, p. 20-25.

Watanabe, Norito; Nagase, Hisamitsu; and Ose, Youki; 1988, Distribution of silicones in water, sediment, and fish in Japanese rivers: Science of the Total Environment, v. 73, p. $1-9$.

Wiegman, Saskia, van Vlaardingen, P.L.A., Bleeker, E.A.J., de Voogt, Pim, and Kraak, M.H.S., 2001, Phototoxicity of azaarene isomers to the marine flagellate Dunaliella tertiolecta: Environmental Toxicology and Chemistry, v. 20, no. 7, p. 1,544-1,550.

Wilkins, A.L., Singh-Thandi, M., and Langdon, A.G., 1996, Pulp mill sourced organic compounds and sodium levels in water and sediments from the Tarawera River, New Zealand: Bulletin of Environmental Contamination and Toxicology, v. 57, p. 434-441.

Wilkins, A.L., Davidson, J.A.C., Langdon, A.G., and Hendy, C.H., 1996, Sodium, calcium, and resin acid levels in ground water and sediments from two sites adjacent to the Tarawera River, New Zealand: Bulletin of Environmental Contamination and Toxicology, v. 58, p. 575-581.
Wilson, A.E.J., Moore, E.R.B., and Mohn, W.W., 1996. Isolation and characterization of isopimaric acid-degrading bacteria from sequencing batch reactor: Applied and Environmental Microbiology, v. 62, no. 9, p. 3,146-3,151.

Woldegiorgis, Andreas; Andersson, Jeanette; Remberger, Mikael; Kaj, Lennart; Ekheden, Ylva; Blom, Lena; Brorström-Lundén, Eva; Borgen, Anders; Dye, Christian; and Schlabach, Martin; 2006, Results from the Swedish National Programme 2005, Subreport 3-Perfluorinated alkylated substances (PFAS), IVL report B1698: Stockholm, Sweden, Swedish Environmental Research Institute.

World Health Organization, 2001, Chlorinated naphthalenesConcise International Chemical Assessment Document 34: Geneva, Published under the joint sponsorship of the United Nations Environment Programme, the International Labour Organization, and the World Health Organization and produced within the framework of the Inter-Organization Programme for the Sound Management of Chemicals, accessed February 18, 2010, at http://www.inchem.org/documents/ cicads/cicads/cicad34.htm.

Zaugg, S.D., Burkhardt, M.R., Burbank, T.L., Olsen, M.C., Iverson, J.L., and Schroeder, M.P., 2006, Determination of semivolatile organic compounds and polycyclic aromatic hydrocarbons in solids by gas chromatography/mass spectrometry: U.S. Geological Survey Techniques and Methods, book 5, chap. B3, 44 p. 


\title{
Supplemental Information G.
}

\section{Prioritization of Disinfection By-Products in Water (Group G)}

\author{
By Michelle L. Hladik, Michael J. Focazio, Gregory C. Delzer, and Colleen E. Rostad
}

\author{
Abbreviations and Acronyms Used in Supplemental Information G \\ CCL3 Contaminant Candidate List 3 (USEPA) \\ DBP disinfection by-product \\ GC/MS gas chromatography with mass spectrometry \\ GC/MS/MS gas chromatography with tandem mass spectrometry \\ $\mathrm{HH} \quad$ human health \\ HPV high production volume \\ LC/MS/MS high-performance liquid chromatography with tandem mass spectrometry \\ LS laboratory schedule \\ LT-MDL Iong-term method detection level (USGS NWQL) \\ MCL Maximum Contaminant Level (drinking-water-quality benchmark, USEPA) \\ NAWQA National Water-Quality Assessment (USGS) \\ NDMA N-nitrosodimethylamine \\ NDPA $\quad N$-nitrosodi- $n$-propylamine \\ NTAS National Target Analyte Strategy (USGS NAWQA) \\ NWQL National Water Quality Laboratory (USGS) \\ THM trihalomethane \\ Toxics Program Toxic Substances Hydrology Program (USGS) \\ UCMR Unregulated Contaminant Monitoring Rule; UCMR 2, second cycle of UCMR sampling (USEPA) \\ USEPA U.S. Environmental Protection Agency \\ USGS U.S. Geological Survey \\ VOC volatile organic compound
}


This supplemental information section of the report describes the prioritization of disinfection by-products in water (Group G) by the U.S. Geological Survey (USGS) National Target Analyte Strategy (NTAS) work group for national- and regional-scale ambient monitoring in the United States. This prioritization was done in support of planning for the third decade (Cycle 3) of the National Water-Quality Assessment (NAWQA) Program. The feasibility of implementing analytical methods for high-priority disinfection by-products, and knowledge and concerns about these constituents as a group, also are described in this section.

A total of 93 disinfection by-products (DBPs) were considered for prioritization for ambient monitoring in water. These constituents were identified through current monitoring programs and literature, as well as through the NTAS lists of human-health concern and other documentation described in the "Sources of Information Used to Identify and Prioritize Constituents" section of this report. Water was the matrix of interest for these constituents because DBPs can form as by-products of disinfection and treatment of drinking water or wastewater, and because these constituents generally are volatile or small molecules (aldehydes, acids, amides, and ketones) that do not tend to partition to sediment. DBPs also can form in ambient environmental waters if disinfectants such as chlorine, chlorine dioxide, or chloramine in treated water that has leaked or been intentionally applied (or injected) react with naturally occurring substances, such as organic carbon (U.S. Environmental Protection Agency, 2012).

Of the 21 constituents in Group G that overlap with other NTAS constituent groups for water, most were prioritized by using the procedures described for the other constituent groups. Of these, seven were volatile organic compounds (VOCs) in Group A-bromodichloromethane, dibromochloromethane, dibromomethane, dichloromethane (methylene chloride), tetrachloromethane (carbon tetrachloride), tribromomethane (bromoform), and trichloromethane (chloroform); all seven were prioritized using procedures described in the "Supplemental Information A" section. Two of the DBPs also are used as pesticides (Group B) - chloropicrin, which was prioritized using the process described for Group B1 ("Supplemental Information B1" section), and tetrachloromethane, which was prioritized as a pesticide only for sediment (Group B2; "Supplemental Information B2" section); the water prioritization for tetrachloromethane was done in Group A, as mentioned previously. Four DBP constituents overlap with Group D1 (trace elements and other inorganic constituents in water) - bromate, chlorate, chlorite, and perchlorate - all were prioritized using the procedures described in the "Supplemental Information D" section; of these, perchlorate also was prioritized using the procedures for Group I (wastewater-indicators and industrial compounds in water) described in the "Supplemental Information I" section. In addition to perchlorate, nine other constituents overlap with Group I-acetaldehyde, 2-chlorophenol, and seven nitrosamines (nitroso-di- $n$ butylamine, $N$-nitrosodiethylamine, $N$-nitrosodimethylamine, $N$-nitrosodiphenylamine, $N$-nitrosodi- $n$-propylamine,
$\mathrm{N}$-nitrosomorpholine, and $\mathrm{N}$-nitrosopyrrolidine). Of these, all were prioritized using the procedures for Group $\mathrm{G}$ and Group I (with equivalent outcomes) except for acetaldehyde, which was prioritized using the procedures for Group G (described in this section of the report), and 2-chlorophenol, $N$-nitrosodiphenylamine, $N$-nitrosodi- $n$-propylamine, and $\mathrm{N}$-nitrosomorpholine, which are thought to originate predominantly from wastewater or industrial sources and were prioritized using the procedures for Group I ("Supplemental Information I" section). Several constituents also overlap with Group F (lipophilic organic compounds in sediment), but these overlaps do not present conflicts in prioritization because they apply to different matrixes (sediment matrix rather than the water matrix).

\section{Prioritization of Disinfection By-Products in Water}

This section describes the methods used for prioritization of DBP constituents in water and the results of the prioritization. The constituents prioritized included compounds that currently (2011) have drinking-water standards such as Maximum Contaminant Levels (MCLs) or Health-Advisory Levels as those promulgated by the U.S. Environmental Protection Agency (2009a), as well as those that could be of future regulatory concern as indicated by their inclusion in the U.S. Environmental Protection Agency (USEPA) Contaminant Candidate List 3 (CCL3; U.S. Environmental Protection Agency, 2010a), Unregulated Contaminant Monitoring Rule 2 (UCMR 2; U.S. Environmental Protection Agency, 2010b), or High Production Volume (HPV) Challenge (U.S. Environmental Protection Agency, 2010c).

Because the USGS Toxic Substances Hydrology Program (hereafter termed Toxics Program) was in the early stages of developing a plan for DBP research, the methods of prioritization for DBPs were based in part on identifying collaborative roles for three different USGS programs - the NAWQA Program, the National Research Program, and the Toxics Program. The NAWQA Program aims to assess water quality on a national scale through routine monitoring of water (groundwater and surface water) and sediment (suspended sediment and streambed sediment) under ambient conditions, the National Research Program aims to explore emerging water-resources problems and provide insights into complex hydrologic processes that are not well understood, and the Toxics Program aims to provide information on environmental contamination in order to protect human and environmental health. The methods of prioritization documented in this report were designed chiefly to support the objectives of the NAWQA Program and do not necessarily cover all of the DBP constituents that could be important at sites that are known or suspected to be heavily contaminated, such as wastewater-treatment ponds, landfills, or spill sites. The priorities identified in this report largely are focused on drinking water, where potential human-health effects, rather than aquatic-life effects, are of paramount 
importance. The constituents that were prioritized were limited to the DBPs themselves and not their precursors (for example, dissolved organic carbon and organic acids), although these latter compounds are crucial to understanding and mitigating DBP formation.

\section{Prioritization Methods for Disinfection By-Products in Water}

After starting with 93 constituents and eliminating those that were prioritized using the procedures for other constituent groups, the remaining 72 constituents were identified as being of high priority (NTAS Tier 1), intermediate priority (NTAS Tier 2), or low or no priority (NTAS Tier 3) by the procedure shown in the flow chart (fig. G.1). Constituents that are of priority to other agencies or of regulatory interest - for example, those listed on the USEPA's National Primary Drinking Water Regulations, Unregulated Contaminant Monitoring Rule (UCMR), or Contaminant Candidate List 3 (CCL3) - were not automatically placed into Tier 1 (part A, fig. G.1); constituents also had to have a high human-health $(\mathrm{HH})$ ranking (NTAS $\mathrm{HH}$ "bin" of 1 or 2) to be considered of high priority. Constituents on National Water Quality Laboratory (NWQL) schedules for which monitoring data are available, but that had long-term method detection levels (LT-MDLs) higher than the concentrations used for human-health benchmarks, were placed into Tier 1 (part B, figure G.1); additional data collection at relevant concentrations (as low as 0.1 of their respective benchmarks) is needed for these constituents. Constituents predicted to occur in water and also to be of human-health concern were placed into Tier 1 (part C, fig. G.1). If a constituent had been part of a national monitoring program, such as the second cycle of Unregulated Contaminant Monitoring Rule sampling (UCMR 2), and was frequently detected (in greater than 10 percent of samples) and was of human-health concern, it was placed into Tier 1 (part D, fig. G.1). In contrast, constituents that had evidence of nonoccurrence (detected in less than 1 percent of samples) were placed into Tier 3 , even if they met the criteria for a higher tier in parts $\mathrm{A}, \mathrm{B}$, or $\mathrm{C}$.

Additional evidence from scientific literature was used to aid in prioritizing constituents that could not be placed into NTAS Tier 1 or Tier 2 on the basis of information considered for parts A-D, described in the previous paragraph. For example, if a DBP constituent has been detected in treated water (Krasner and others, 2009), that constituent was placed no lower than Tier 2, on the basis of likelihood of occurrence. Many of the constituents that were placed into Tier 2 or Tier 3 and that have no occurrence information will undergo additional review and research through the Toxics Program.

\section{Results of Prioritization of Disinfection By-Products in Water}

Of the 93 constituents that were prioritized by the NTAS work group, 34 DBPs were placed into Tier 1, 14 were placed into Tier 2, and 45 were placed into Tier 3 (table G.1 at http:// pubs.usgs.gov/sir/2012/5218/downloads/tableG.xlsx). Constituents that were prioritized using procedures from other NTAS constituent groups are identified in the first column of table G.1.

\section{Basis for Prioritization of Disinfection By-Products in Water}

One or more of the following three factors were used as the basis for placing DBP constituents into NTAS Tier 1: (1) the constituent has a human-health benchmark, but the constituent's current LT-MDL is higher than this benchmark; (2) the constituent is expected to occur in water and is toxic to humans (HH bin 1 or 2); or (3) the constituent is frequently detected (in greater than 10 percent of samples) based on large monitoring datasets. A diagram illustrating the criteria for inclusion for each constituent in Tier 1 is shown in figure G.1. Information supporting the prioritization of each DBP, including supplemental information for DBPs prioritized for other NTAS constituent groups, is provided in table G.2 at $h t t p: / /$ pubs.usgs.gov/sir/2012/5218/downloads/tableG.xlsx.

In addition to constituents that have MCLs set by the USEPA, the constituents that are included in the USEPA's UCMR 2 and CCL3 programs are of potential concern to human health and are being considered for future regulation. These and other national regulatory programs that include DBP constituents are listed in table G.2. The USEPA currently (2011) regulates drinking water for four trihalomethanes (THMs; bromodichloromethane, dibromochloromethane, tribromomethane, and trichloromethane) and two other Tier 1 volatile organic compounds (VOCs) that are DBPs (dichloromethane and tetrachloromethane), as well as five haloacetic acids (dibromoacetic acid, dichloroacetic acid, monobromoacetic acid, monochloroacetic acid, and trichloroacetic acid), and two inorganic anions (bromate and chlorite). Additionally, the six nitrosamines that are in Tier 1 are on the UCMR 2 list, and five of the Tier 1 nitrosamines, two of the Tier 1 aldehydes, and chlorate are on the CCL3. Most of these constituents have shown mammalian carcinogenicity, genotoxicity, or both (Bull and others, 2007; Muellner and others, 2007; Richardson and others, 2007).

\section{Feasibility of Implementation for High-Priority Disinfection By-Products}

DBPs have not been considered (as a class) by previous NAWQA (Cycle 1 and Cycle 2) studies; however, several DBPs are available on current NWQL laboratory schedules (table G.1). For example, laboratory schedule (LS) 2020 VOCs by purge-and-trap gas chromatography with mass spectrometry (GC/MS) - includes dichloromethane, tetrachloromethane, and the four THMs, with adequate performance and reporting levels. Several other DBPs are available on LS 1383 (GC/MS) and LS 8384 (gas chromatography with 
Part A.

Screening for priority to other agencies

Constituents for potential monitoring
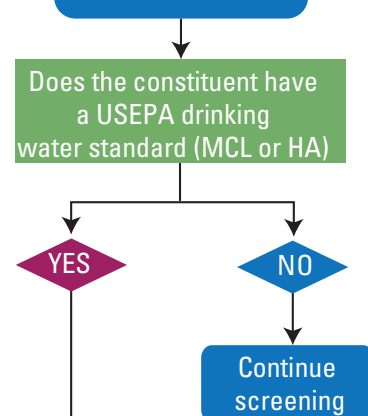

screening
Part B.

Screening of LTMDL compared to benchmark concentrations

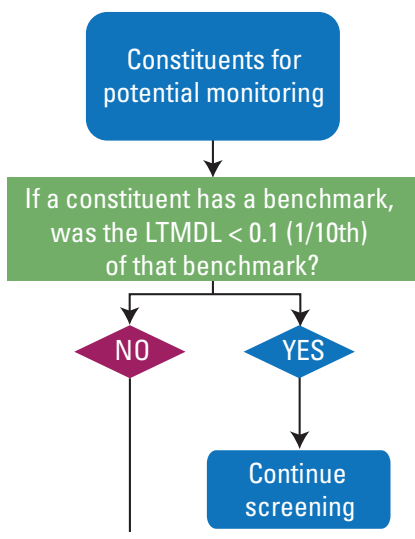

A more sensitive analytical method is needed

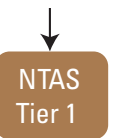

Part C.

Screening for predicted occurrence and human-health concerns (Note: Persistence is not considered because some NAWOA studies focus on treated drinking water; that is, finished water)

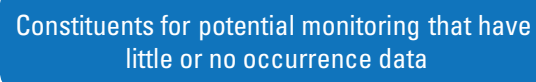

Constituents for potential monitoring that have little or no occurrence data

\section{Log $K_{\text {ow }}<4$ or solubility in water $>01 \mathrm{~mol} / \mathrm{L}$ ?}

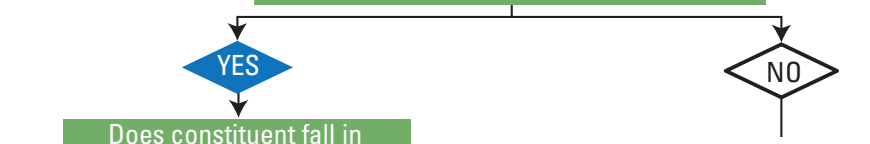

Not a concern for presence in water; could become of interest for sediment or tissue
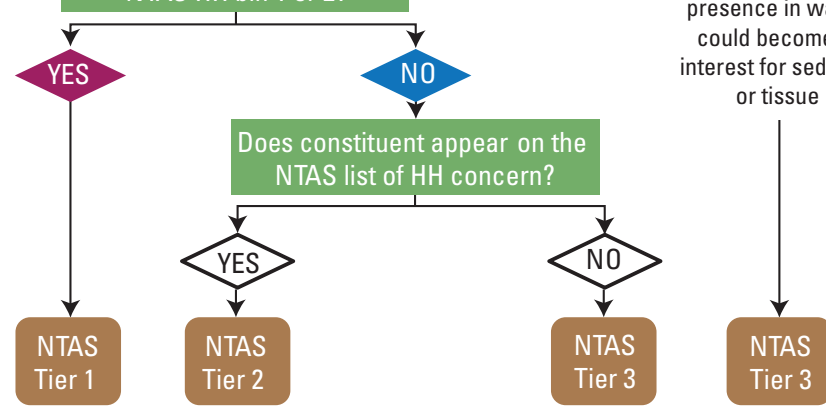

Part D.

Screening for detection frequency and human-health concern

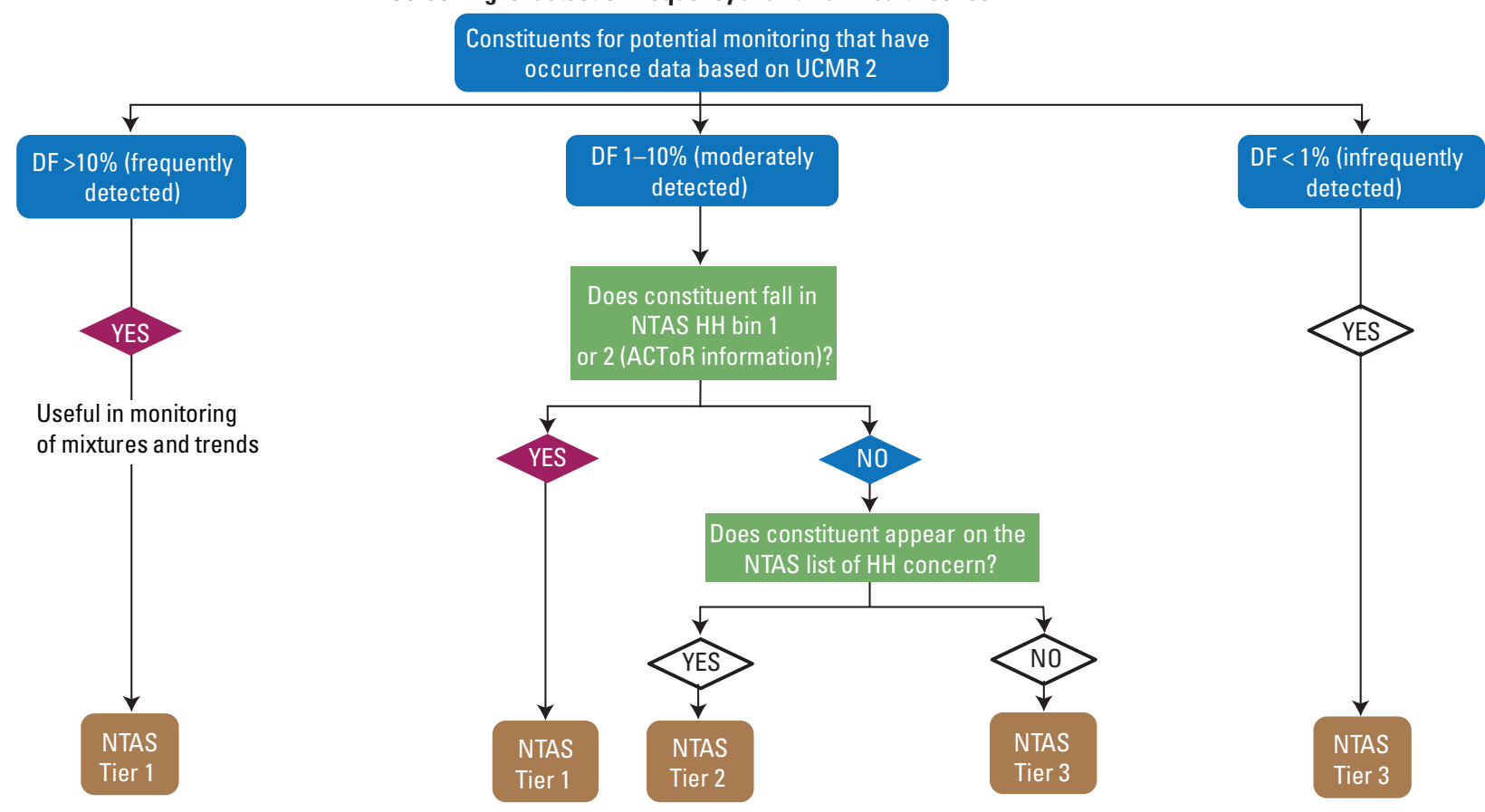

EXPLANATION

[All processes were considered in parallel to identify if multiple reasons would result in a Tier 1 designation. If parallel processes resulted in different prioritization results, the higher priority tier was retained, except where evidence of nonoccurrence (DF<1) warranted a Tier 3 designation. ACToR, Aggregated Computational Toxicology Resource database;

DF, detection frequency; HH, human-health; NAWQA, National Water-Quality Assessment Program; NTAS, National Target Analyte Strategy; P, pathway;

UCMR, Unregulated Contaminant Monitoring Rule; >, greater than; <, less than; \%, percent; log $K_{\text {ow }}$, base-10 logarithm of the octanol-water partition coefficient;

LTMDL, long-term method detection level; mol/L, mole per liter; MCL, Maximum Contaminant Level; HA, health advisory; USEPA, U.S. Environmental Protection Agency]

Criteria resulting in a Tier 1 designation

Criteria not resulting in a Tier 1 designation

Screening criteria

Screening category

Tier designation

Figure G.1. Flow chart for prioritizing disinfection by-products (DBPs) for national- and regional-scale ambient monitoring of water in the United States. 
electron-capture detection, with derivatization of the aldehydes); however, three of the Tier 1 DBPs that are on LS $1383-N$-nitrosodimethylamine (NDMA), $N$-nitrosodi- $n$ propylamine (NDPA), and $N$-nitrosodiphenylamine - have benchmarks that are less than current (2011) reporting levels, so analyses of these constituents would require a change or modification of methods. Additional Tier 1 DBPs that are not available on USGS laboratory schedules would require method development if they are to be monitored in Cycle 3 . The USGS Toxics Program's research plan for DBPs also has identified these constituents for method development.

Some DBPs that are not on current NWQL laboratory schedules might be amenable to inclusion in laboratory schedules used by the NAWQA Program (for example, LS 2020) or could be grouped into one or more schedules that target constituents with similar structures (for example, haloacetic acids or nitrosamines). A standard method for determination of nitrosamines using solid-phase extraction and large-volumeinjection gas chromatography with tandem mass spectrometry (GC/MS/MS) has been developed (USEPA Method 521; U.S. Environmental Protection Agency, 2004) and could be used as a starting point for USGS method development and validation. The DBP $N$-nitrosodiphenylamine, however, is not stable under analysis by GC/MS/MS, which is used for USEPA Method 521, so this constituent would need to be analyzed by using high-performance liquid chromatography with tandem mass spectrometry (LC/MS/MS). For the remaining high-priority constituents, new methods would need to be developed as resources permit. Although it might be possible to combine several constituents into a single analytical method (for example, haloacetic acids or nitrosamines), it is unlikely that all of the constituents that cannot be added to existing LSs could be combined in a single method (not counting the inorganic ions, bromate, and chlorite, which would need their own method) because of differences in chemical properties.

Samples for DBP analyses will be focused on treated drinking water with little or no anticipated matrix interferences. Sample preservation is a concern because the current VOC method (LS 2020) uses hydrochloric acid as a preservative. Although the addition of hydrochloric acid to samples might not affect the current schedule of constituents, other DBPs that may be of interest can be formed by the addition of hydrochloric acid. Any potential interference between additional constituents and added preservatives would warrant evaluation as part of method validation for any DBP additions to LS 2020. DBPs that might be amenable to addition to LS 2020 or LS 4024 (heated purge-and-trap with GC/MS) include acetaldehyde, formaldehyde, cyanogen chloride, cyanogen bromide, dichloroacetonitrile, and dibromoacetonitrile.

Sample-collection methods warrant consideration when evaluating the feasibility of monitoring for DBPs. Although the NAWQA Program traditionally has focused on ambient environmental matrixes, the occurrence of DBPs, at the tap or in the environment, is intrinsically related to the treatment (usually chlorination) of drinking water or wastewater. A suitable dechlorination reagent must be added to any samples of finished (treated) water collected in the field in order to quench any residual chlorine. The USEPA recommends ascorbic acid and maleic acid, as part of Method 524.3 for the determination of purgeable organic compounds in finished drinking waters (U.S. Environmental Protection Agency, 2009b). USGS data show that constituents currently (2011) included in LS 2020 are not degraded by the addition of ascorbic acid (Valder and others, 2008), but additional testing would be needed to determine that dechlorination reagent(s) do not interfere with other constituents added to LS 2020.

\section{Knowledge and Concerns of Disinfection By-Products as a Constituent Group}

DBPs can form in treated drinking water or wastewater and can enter ambient surface-water or groundwater resources by way of irrigation with reclaimed wastewater or treated drinking water. DBPs also can form in the ambient environment when treated water leaks or is intentionally applied to the landscape for infiltration into aquifers, if organic carbon is present (U.S. Environmental Protection Agency, 2012). DBP precursors (for example, dissolved organic carbon and naturally occurring organic acids) were not considered in this prioritization because they are not considered contaminants, although these precursors are important for understanding and mitigating the formation of DBPs. Ambient monitoring of common DBP precursors in raw source waters would be of great interest to water-resource managers.

Some DBPs have regulatory benchmarks for drinking water (U.S. Environmental Protection Agency, 2009a), and inclusion of these constituents in U.S. regulatory and monitoring programs is shown in table G.2. Compliance monitoring data are available for some of these constituents for drinking water; however, monitoring data are sparse or unavailable for most DBPs in ambient water resources. The increasing use of treated reclaimed water and wastewater from municipal and agricultural sources, including the increasing practice of artificial storage and recovery (particularly in the western United States), and leakage of treated drinking water from aging distribution systems, represent sources of these constituents to ambient groundwater and surface waters. Programmatically, it would be efficient for NAWQA Cycle 3 monitoring to focus on those DBPs that are available on current (2011) NWQL laboratory schedules (for example, the THMs) or that are known to occur in ambient water (for example, NDMA; California Department of Public Health, 2009), whereas the Toxics Program could focus on additional DBPs that are of potential concern, but for which occurrence in ambient water has not yet been widely documented.

Although drinking-water standards have been established for a few DBPs, recent research (Richardson and others, 2007) indicates that other known or suspected DBPs might be more toxic to humans than those currently regulated. DBPs with MCLs for drinking water supplied from public systems include the four THMs, five haloacetic acids, and two 
inorganic anions (bromate and chlorite) (U.S. Environmental Protection Agency, 2009a). Some DBPs are included in the Centers for Disease Control and Prevention National Health and Nutrition Examination Survey (2010). Additional constituents are included on USEPA's UCMR 2 list and CCL3 (U.S. Environmental Protection Agency, 2010a,b); these constituents may undergo future regulations. Concentrations of concern for NDMA and other nitrosamines are particularly low; Health-Based Screening Levels developed by the USGS for NDMA and NDPA are 0.0007-0.0700 microgram per liter and 0.005-0.500 microgram per liter, respectively (table G.1). Only the potential effects to human health, and not potential effects to aquatic life, were considered in prioritizing these constituents as part of the NTAS effort; however, where DBPs are found in the aquatic environment, their effects on aquatic life might be of interest to the NAWQA Program.

Largely because of the increases in the understanding of DBP toxicity and occurrence as a result of disinfection by free chlorine, some drinking-water treatment plants have experimented with or implemented alternative disinfection procedures (for example, ozonation) (Richardson and others, 2007), which might produce DBPs other than those considered for this report. Because disinfection of drinking water is important to public health, drinking-water managers have an interest in the relations between DBP precursors, disinfection methods, and DBP formation. Examples of current interest for DBPs include: (1) identifying DBP precursors and mitigating DBP formation (2) DBPs entering the environment from wastewater, (3) DBPs entering the environment through the irrigation of lawns, golf courses, and parks with finished drinking water or reclaimed wastewater, and (4) occurrence and concentrations in finished drinking water.

\section{References for Disinfection By-Products in Water (Group G)}

Bull, R.J., Reckhow, D.A., Rotello, Vincent, Bull, O.M., and Kim, Jimsung, 2007, Use of toxicological and chemical models to prioritize DBP research: American Water Works Association Research Foundation Report 91135F, 380 p.

California Department of Public Health, 2009, NDMA and other nitrosamines - Drinking water issues: accessed on January 10, 2011, at http://www.cdph.ca.gov/certlic/ drinkingwater/Pages/NDMA.aspx.

Centers for Disease Control and Prevention, 2010, National Health and Nutrition Examination Survey: accessed December 21, 2010, at http://www.cdc.gov/nchs/nhanes.htm.

Krasner, S.W.; Westerhoff, Paul; Chen, Baiyang; Rittmann, B.E.; and Amy, Gary; 2009, Occurrence of disinfection byproducts in the United States wastewater treatment plant effluents: Environmental Science and Technology, v. 43, no. 21, p. $8,320-8,325$.
Muellner, M.G; Wagner, E.D.; McCalla, Kristin; Richardson, S.D.; Woo, Y.-T.; and Plewa, M.J.; 2007, Haloacetonitriles vs. regulated haloacetic acids-Are nitrogen-containing DBPs more toxic?: Environmental Science and Technology, v. 41 , no. 2, p. 645-651.

Richardson, S.D., Plewa, M.J., Wagner, E.D., Schoeny, Rita, and DeMarini, D.M., 2007, Occurrence, genotoxicity, and carcinogenicity of regulated and emerging disinfection by-products in drinking water-A review and roadmap for research: Mutation Research, v. 636, p. 178-242.

U.S. Environmental Protection Agency, 2004, Method 521Determination of nitrosamines in drinking water by solid phase extraction and capillary column gas chromatography with large volume injection and chemical ionization mass spectrometry (MS/MS), version 1.0: Cincinnati, Ohio, U.S. Environmental Protection Agency, Office of Research and Development, EPA 600/R-05/054, accessed on February 18, 2011, at http://www.epa.gov/nerlcwww/documents/m_521. $p d f$.

U.S. Environmental Protection Agency, 2009a, 2009 Edition of the drinking water standards and health advisories (updated October 2009): U.S. Environmental Protection Agency, Office of Water, EPA 822-R-09-011, accessed December 20, 2010, at http://water.epa.gov/action/ advisories/drinking/upload/dwstandards2009.pdf.

U.S. Environmental Protection Agency, 2009b, Method 524.3 - Measurement of purgeable organic compounds in water by capillary column gas chromatography/mass spectrometry, version 1.0: Cincinnati, Ohio, U.S. Environmental Protection Agency, Office of Ground water and Drinking Water, EPA 815-B-09-009, accessed on January 10, 2011, at http://www.epa.gov/ogwdw000/methods/pdfs/methods/ met524-3.pdf.

U.S. Environmental Protection Agency, 2010a, Contaminant Candidate List 3-CCL3: accessed December 20, 2010, at http://water.epa.gov/scitech/drinkingwater/dws/ccl/ccl3.cfm.

U.S. Environmental Protection Agency, 2010b, Unregulated Contaminant Monitoring Rule 2 (UCMR 2): accessed December 20, 2010, at http://water.epa.gov/lawsregs/ rulesregs/sdwa/ucmr/ucmr2/index.cfm.

U.S. Environmental Protection Agency, 2010c, High Production Volume (HPV) Challenge: accessed December 28, 2010, at $h t t p: / / w w w . e p a . g o v / H P V /$.

U.S. Environmental Protection Agency, 2012, Aquifer Recharge (AR) and Aquifer Storage \& Recovery (ASR): accessed April 13, 2012, at http://water.epa.gov/type/ groundwater/uic/aquiferrecharge.cfm. 
Valder, J.F., Delzer, G.C., Price, C.V., and Sandstrom, M.W., 2008, Study design and percent recoveries of anthropogenic organic compounds with and without the addition of ascorbic acid to preserve water samples containing free chlorine, 2004-06: U.S. Geological Survey, Open-File Report 2008-1226, 85 p., accessed April 13, 2012, at http://pubs. usgs.gov/of/2008/1226/. 


\section{Supplemental Information H. \\ Prioritization of High-Production-Volume Chemicals in Water (Group H)}

By James F. Pankow, Julia E. Norman, Joshua F. Valder, John S. Zogorski, and Lisa D. Olsen

\section{Abbreviations and Acronyms Used in Supplemental Information H}

$\begin{array}{ll}\sim & \text { approximately } \\ { }^{\circ} \mathrm{C} & \text { degrees Celsius } \\ \text { AL } & \text { aquatic life } \\ \text { atm } & \text { atmospheres } \\ \text { atm-m³/mol } & \text { atmosphere-cubic meters per mole } \\ \text { CASRN } & \text { Chemical Abstracts Service Registry Number }{ }^{\circledR} \text { (American Chemical Society) } \\ \text { DTPA } & \text { diethylenetriaminepentaacetic acid } \\ \text { EDTA } & \text { ethylenediaminetetraacetic acid } \\ \text { GC/MS } & \text { gas chromatography with mass spectrometry } \\ \text { GRAS } & \text { "Generally Recognized as Safe" list (U.S. Food and Drug Administration) } \\ \text { HH } & \text { human health } \\ \text { HPV } & \text { high-production volume or high-production-volume chemical } \\ \text { log H } & \text { base-10 logarithm of Henry's Gas Law constant } \\ \text { log } K_{\text {ow }} & \text { base-10 logarithm of the octanol-water partition coefficient } \\ \text { log } p_{\mathrm{L}}^{\circ} & \text { base-10 logarithm of vapor pressure } \\ \text { LS } & \text { laboratory schedule } \\ \text { Hg/L } & \text { microgram per liter } \\ \text { MDL } & \text { method detection limit } \\ \text { MTBE } & \text { methyl tert-butyl ether } \\ \text { NAWOA } & \text { National Water-Quality Assessment (USGS) } \\ \text { NIA } & \text { no information available } \\ \text { NTAS } & \text { National Target Analyte Strategy (USGS NAWOA) } \\ \text { NWOL } & \text { U.S. Geological Survey } \\ \text { USEPA } & \text { USGS } \\ \text { VOC } & \end{array}$


This supplemental information section of the report describes the prioritization of high-production-volume chemicals in water (Group H) by the U.S. Geological Survey (USGS) National Target Analyte Strategy (NTAS) work group for national- and regional-scale ambient monitoring in the United States in support of planning for the third decade (Cycle 3) of the National Water-Quality Assessment (NAWQA) Program. The feasibility of implementing analytical methods for high-priority high-production-volume chemicals (HPVs), and knowledge and concerns of HPV chemicals as a constituent group, also are described in this section.

HPVs are those chemicals that are produced in or imported into the United States in quantities of 1 million pounds or more per year. HPVs span a wide range of constituent classes and uses. As of the time of this prioritization (2011), the U.S. Environmental Protection Agency's (USEPA) list of HPVs had a total of 2,782 entries, a subset of which were evaluated by the NTAS work group. In addition to discrete compounds of known identity, some of the entries on the USEPA's HPV list are (1) mixtures that include only a few compounds (for example, xylenes, which can include ortho-, meta-, and para-xylenes); (2) mixtures of organic compounds that are poorly characterized or only very broadly defined (for example, various "petroleum distillate" fractions); (3) organic polymers; or (4) inorganic salts.

Some chemicals appear as HPVs in multiple forms as separate entries. For example, ethylenediaminetetraacetic acid (EDTA) appears six times on the USEPA HPV list, first and foremost as the tetrasodium salt (Chemical Abstracts Services Registry Number (CASRN) 64-02-8), as the neutral acid (CASRN 60-00-4), and in four other forms. Entries in categories $2-4$ in the previous paragraph were consolidated to reduce the number of closely related entries. This process left 1,689 entries, which the NTAS work group called the "HPV1689 list." Additional criteria were applied to the HPV1689 list using the screening algorithm described in the next section to identify those constituents with the highest likelihood of occurrence in ambient water, and the resulting list of 379 HPVs, representing 384 constituents, was prioritized by the NTAS work group (table H.1 at http://pubs.usgs. gov/sir/2012/5218/downloads/tableH.xlsx). Of these 384 constituents, 66 were already addressed by other NTAS constituent groups for water and did not require prioritization under Group H; these are listed on table H.1 with their constituent groups so that readers can refer to the prioritization procedures for those groups.

Of the 318 constituents that were prioritized using the methods described for Group H, six were identified that overlap between Group H and other NTAS constituent groups: (1) one volatile organic compound (VOC) for Group A ( $m$ - and $p$-xylenes), (2) two pesticides in water for Group B1 (sulfcarbamide and thiram), and (3) three wastewater-indicator or industrial compounds in water for Group I (C.I. Pigment Red 53 [barium salt or sodium salt], decamethylcyclopentasiloxane, and nitroglycerin). The " $m$ - and $p$-xylenes" were prioritized as a single constituent for Group A, as described in the
"Supplemental Information A" section, but were prioritized separately as 1,3-dimethylbenzene and 1,4-dimethylbenzene for Group $\mathrm{H}$ with equivalent results. Because these two isomers coelute and are not easily resolved, " $m$ - and $p$-xylenes" are listed as a single constituent in the body of this report. The two pesticide HPVs were prioritized using the approach for Group B, described in the "Supplemental Information B" section because entry into the environment for these substances is thought to be mainly as pesticides; however, the procedure for Group B also took into account their status as HPVs. The constituents C.I. Pigment Red 53 and nitroglycerin were prioritized using approaches for Group I (described in the "Supplemental Information I" section) and Group H (described in the following section) with equivalent results; the initial duplication of these constituents had resulted from naming differences in the literature. Decamethylcyclopentasiloxane was prioritized using the approach for Group I, which resulted in a higher tier placement (Tier 2 instead of Tier 3 ) on the basis of additional lines of evidence used for Group I. Several additional constituents were prioritized as lipophilic organic constituents in sediment (Group F) but do not represent true "overlaps," because Groups H and F pertain to different matrixes (water matrix for Group $\mathrm{H}$ in contrast to the sediment matrix for Group F).

Additional constituents in other constituent groups also could be HPVs, beyond the 379 HPVs (representing 384 constituents in table H.1) that were identified through the process used for Group H. The process used to identify constituents for Group $\mathrm{H}$ focused on production volumes, uses, and physical properties; whereas additional HPVs could have been captured by other constituent groups on the basis of additional information sources that were particular to a specific constituent class or use.

\section{Prioritization of High-Production-Volume Chemicals in Water}

This section describes the methods used for prioritization of HPVs in water and the results of the prioritization. The prioritization of HPVs followed the process shown in figure H.1. This process included reducing the HPV1689 list to the set of 318 constituents that were prioritized for Group H, followed by applying criteria relating to likelihood of occurrence and likelihood of human-health or aquatic-life concern. Constituents were placed into one of three NTAS prioritization tiersTier 1 (highest priority), Tier 2 (intermediate priority), or Tier 3 (low or no priority) - for ambient monitoring in water.

\section{Prioritization Methods for High-Production- Volume Chemicals in Water}

The prioritization of HPVs focused on a set of 318 constituents from the HPV1689 list that were identified as having the highest likelihood of occurrence in ambient water. 


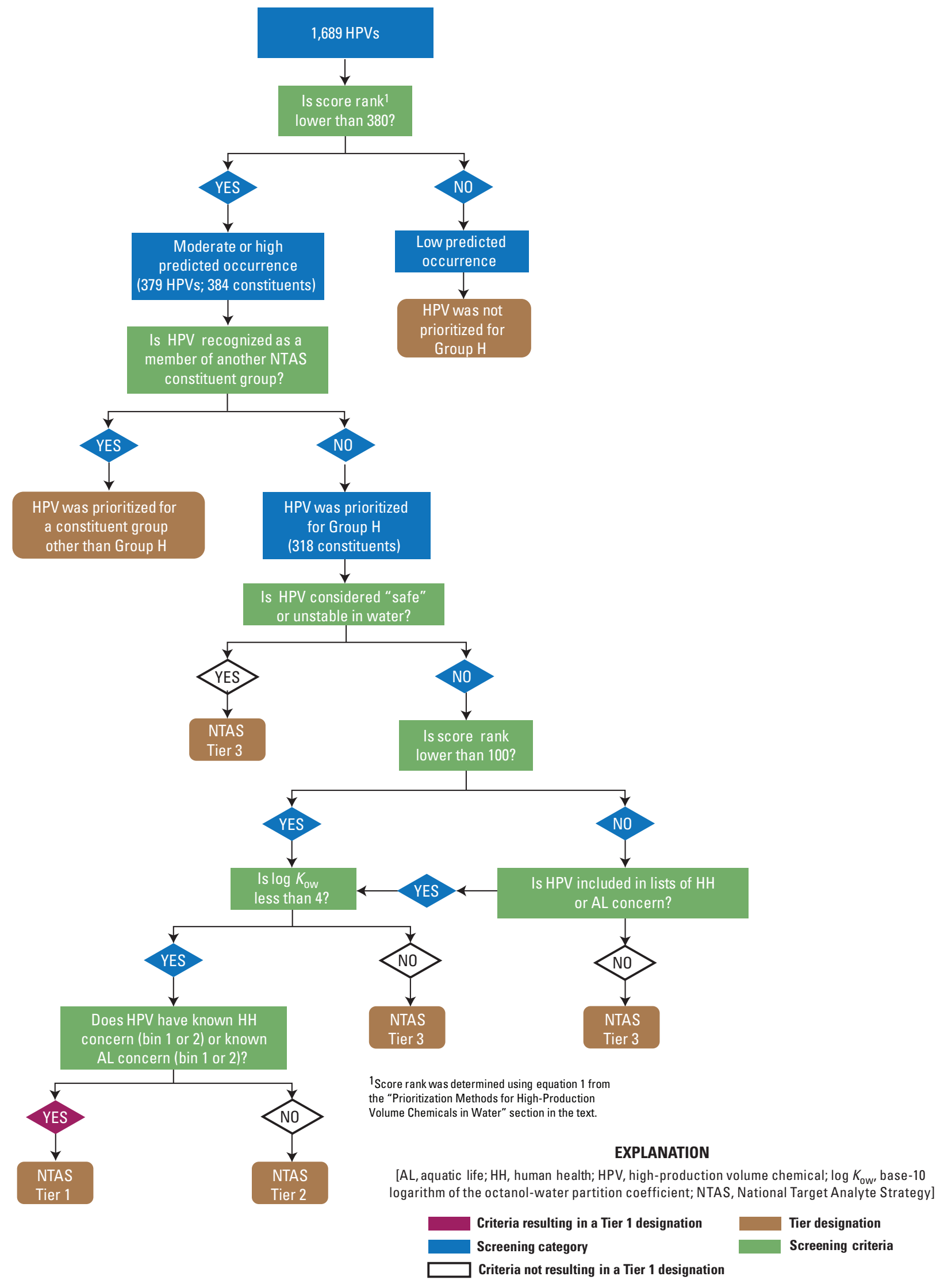

Figure H.1. Flow chart for prioritizing high-production-volume chemicals (HPVs) for national- and regional-scale monitoring of water in the United States. 
Information considered in ranking the constituents on the HPV1689 list included the following:

1. Upper and lower bounds for production (pounds per year);

2. End-use score (from 1 to 3, with values of 1 assigned to constituents used as feedstock chemicals that are not intentionally released directly into the environment and values of 3 assigned to constituents with final uses as their listed form, such as surfactant chemicals and methyl tertbutyl ether);

3. Persistence score ( 1 to 3 , with values of 1 assigned to the least persistent chemicals and values of 3 assigned to the most persistent chemicals);

4. Physical property information, including the base-10 logarithm of the octanol-water partition coefficient, $\log K_{\mathrm{OW}}$.

Large "scores" or values for production, end-use, persistence, or negative (-) $\log K_{\mathrm{OW}}$ for a constituent can individually contribute to that constituent's tendency to occur in ambient waters. Constituents on the HPV1689 list were ranked for expected occurrence in water by use of an algorithm formulated by an ad hoc group at Portland State University (Oregon) (James F. Pankow, Portland State Univeristy, written commun., 2009):

Score $=1 / 2 \log [$ Production $($ low end $)]+1.0 \times$ End-Use Score + $1.0 \times$ Persistence Score $-1 / 2 \log K_{\text {OW }}$ (binned 1-6).

Constituents with high scores from equation 1 tend to be those that are heavily produced, found unchanged in industrial and consumer products, persistent, or soluble in water. For the HPV1689 list, the maximum score was 9.5, the minimum score was 2.5, and several HPVs were tied at various scores. For example, methyl tert-butyl ether (MTBE) shared third place with six other constituents with a score of 9.0. The top 379 constituents had scores ranging from 9.50 to 6.85 . The 380th-ranked constituent had a score of 6.52; this natural break in the scores was selected as cutoff for defining the set of Group H constituents. The top 379-ranked HPVs (table H.1) comprised the top 22.4 percent of the HPV1689 list.

The 384 constituents in the "top 379" list were screened to identify those that were already covered by other NTAS constituent groups; for example, some of the HPVs are VOCs that were prioritized for Group A. The prioritization process for Group $\mathrm{H}$ was designed to focus on those constituents that were not already under consideration by other groups; however, a few overlapping constituents not initially recognized as such were prioritized for Group $\mathrm{H}$ as well as for other NTAS constituent groups (table H.1). The 318 constituents prioritized for Group $\mathrm{H}$ were divided into two sets - constituents with a score rank of 100 or less and constituents with a score rank of 101 to 379 (fig. H.1). Constituents were further evaluated on the basis of additional criteria, including $\log K_{\mathrm{OW}}$ and concern to human health or aquatic life on the basis of the NTAS lists of human-health or aquatic-life concern, or the human-health $(\mathrm{HH})$ or aquatic-life (AL) "bins" determined by the NTAS work group, as described in the "Human-Health Effects Information from the ACToR Database" section in the main body of the report.

Constituents that were determined to be unstable in water or that were considered "safe" because they were included on the U.S. Food and Drug Administration's (2010) "Generally Recognized as Safe" (GRAS) list were placed into NTAS Tier 3. Constituents ranked 101 to 379 that were not found on the NTAS lists of human-health concern or aquatic-life concern also were placed into Tier 3 . Those that were not placed into Tier 3 were evaluated further as shown in figure H.1 and tables H.2, H.3, and H4 at http://pubs.usgs.gov/sir/2012/5218/ downloads/tableH.xlsx, on the basis of the following criteria:

- NTAS Tier 1: $\log K_{\mathrm{OW}}$ less than 4 and of known human-health concern (HH bin 1 or 2) or known aquatic-life concern (AL bin 1 or 2);

- NTAS Tier 2: $\log K_{\mathrm{OW}}$ less than 4 but with no known human-health concern (HH bin NIA [no information available]) or no known aquatic-life concern (AL bin 3 or NIA);

- NTAS Tier 3: $\log K_{\mathrm{OW}}$ greater than 4, regardless of the level of human-health concern or aquatic-life concern. (This criterion applies only to HPVs in water and is not an appropriate criterion for sediment.)

The criteria of $\log K_{\mathrm{OW}}$ greater than 4 was used to identify constituents that would not be of high priority for water because of their tendency to partition into sediment rather than into the aqueous phase. (A similar ranking algorithm and prioritization process could be used for HPVs that might be found in sediment; however, the $\log K_{\mathrm{OW}}$ term of the equation would have to be changed so that higher partitioning to sediment would lead to higher rankings, with higher priority going to constituents with higher $\log K_{\mathrm{OW}}$ values.)

\section{Results of Prioritization of High-Production- Volume Chemicals in Water}

Of the $318 \mathrm{HPV}$ constituents that were identified for Group $\mathrm{H}$ as described in the previous section, 74 constituents were placed into NTAS Tier 1 (table H.2). These Tier 1 constituents represent those HPVs that have a high likelihood of occurrence in water and that are of concern with respect to human health or aquatic life. An additional 54 constituents were placed into Tier 2 (table H.3), including three overlapping constituents (two pesticides and one wastewater-indicator or industrial compound) that were prioritized using approaches described for other constituent groups (Group B and Group I). A total of 190 constituents were placed into Tier 3 (table H.4). 


\section{Feasibility of Implementation for High-Priority High-Production-Volume Chemicals in Water}

Physical and chemical properties for those HPVs that were identified as being of high priority (Tier 1) for ambient monitoring are listed in table H.2, which also shows the constituents that currently (2011) are not on laboratory schedules (LSs) at the USGS National Water Quality Laboratory (NWQL). Many of the HPVs that were prioritized for constituent groups other than Group $\mathrm{H}$ already have analytical methods and would not require additional method development by the start of NAWQA Cycle 3 monitoring. In contrast, more than one-half of the 74 Tier 1 HPV constituents that were prioritized for Group H are not available on current (2011) LSs and would require some degree of method development by the start of NAWQA Cycle 3 monitoring. The Methods Research and Development Program group at the NWQL is examining the feasibility of adding $22 \mathrm{HPVs}$ that are VOCs to LS 2020 (table H.5 at http://pubs.usgs.gov/sir/2012/5218/downloads/ tableH.xlsx) for analysis by purge-and-trap gas chromatography with mass spectrometry (GC/MS) and $21 \mathrm{HPVs}$ that are VOCs to LS 4024 or 4025 (table H.6 at http://pubs.usgs.gov/ sir/2012/5218/downloads/tableH.xlsx) for analysis by heated purge-and-trap GC/MS (Duane S. Wydoski, U.S. Geological Survey, written commun., 2010).

A strategy for determining which analytical method might be appropriate for a given constituent was developed by considering properties such as $\log K_{\text {Ow }}$, base-10 logarithm of vapor pressure $\left(\log p_{\mathrm{L}}^{\mathrm{o}}\right)$ in atmospheres $(\mathrm{atm})$, and base-10 logarithm of Henry's Gas Law constant $(\log H)$ in atmospherecubic meters per mole $\left(\mathrm{atm}-\mathrm{m}^{3} / \mathrm{mol}\right)$, as well as the general relations that exist among such properties. For example, it can be shown that in a plot of $\log p_{\mathrm{L}}^{\mathrm{o}}$ to $\log K_{\mathrm{OW}}$, compounds with a given Henry's Gas Law constant $H$ tend to plot along a line with a slope of -1 . The relevant relation is

$$
\log p_{i, \text { liq }}^{\mathrm{o}}(\mathrm{atm})=\log H_{i}\left(\mathrm{~atm}-\mathrm{m}^{3} / \mathrm{mol}\right)-\log K_{i, \mathrm{ow}}+3.9
$$

The derivation of equation (2) is provided in Appendix H.1. Because compounds that can be purged from water require a certain minimum $H$ value, all "purgeable" compounds plot above the $\log p_{\mathrm{L}}^{\mathrm{o}}: \log K_{\mathrm{OW}}$ line for that $H$ value. For example, MTBE is a compound that is on the cusp of being purgeable at room temperature, and its $H$ value from the Scorecard Web site (http://www.scorecard.org/chemicalprofiles $/ \mathrm{html} / \mathrm{mtbe} . \mathrm{html}$ ) is approximately $(\sim) 6 \times 10^{-4} \mathrm{~atm}-\mathrm{m}^{3} /$ mol at 20-25 degrees Celsius $\left({ }^{\circ} \mathrm{C}\right)$. In contrast, tert-butyl alcohol with $H$ of $\sim 1 \times 10^{-5} \mathrm{~atm}-\mathrm{m}^{3} / \mathrm{mol}$ at $20-25^{\circ} \mathrm{C}$ (http: $/ / w w w$. scorecard.org/chemical-profiles/html/terbutyl_alcohol.html) requires heated purging.

Figure H.2 shows relations between $\log p_{\mathrm{L}}^{\mathrm{o}}(\mathrm{atm})$ and $\log$ $K_{\text {OW }}$ for two subsets of the HPV constituents. A red line for $H=\sim 6 \times 10^{-4} \mathrm{~atm}-\mathrm{m}^{3} / \mathrm{mol}$ at $25^{\circ} \mathrm{C}$ (for example, for MTBE) and an orange line for $H=\sim 1 \times 10^{-5} \mathrm{~atm}-\mathrm{m}^{3} / \mathrm{mol}$ at $25^{\circ} \mathrm{C}$ (for example, for tert-butyl alcohol) are shown in both figures. Constituents plotting above the red line might be analyzed by purge-and-trap GC/MS as in LS 2020, and constituents plotting above the orange line might be analyzed by heated purgeand-trap GC/MS as in LS 4024. It also should be noted that (1) $\log p_{\mathrm{L}}^{\mathrm{o}} \approx-11 \mathrm{~atm}$ is an approximate lower limit for analysis by gas chromatography; and (2) $\log K_{\mathrm{OW}} \approx 4$ can be considered an approximate upper relevance bound for dissolved constituents. In terms of water solubility, compounds with $\log K_{\text {ow }}>$ greater than 4 would not be expected to occur to a substantial extent as dissolved constituents in natural water samples.

In addition to those HPVs that are VOCs and that could be amenable to analysis by purge-and-trap GC/MS or heated purge-and-trap GC/MS, the NWQL has considered method development for the HPVs that are chelates (Duane S.

Wydoski, U.S. Geological Survey, written commun., 2010). For one of the HPVs that is a chelate, namely EDTA (Tier 1), a working method exists at Portland State University with a current method detection limit (MDL) of about 1 microgram per liter $(\mu \mathrm{g} / \mathrm{L})$ (James F. Pankow, Portland State University, written commun., 2010). Efforts are underway to lower this MDL to $0.1 \mu \mathrm{g} / \mathrm{L}$. Work is proceeding at Portland State University to incorporate two other chelate HPVs, namely disodium iminodiacetate and trisodium nitrilotriacetate (both Tier 2) into this method. Implementation of this method by the NWQL would require method validation and approval.

With the addition of any new constituents to current laboratory schedules or with the development of new methods to accommodate high-priority HPVs, a comprehensive field and laboratory blank study will be needed to ensure that the field and laboratory methods do not result in contamination of environmental samples from the materials used in the field or laboratory.

\section{Knowledge and Concerns of High-Production- Volume Chemicals in Water}

The idea of considering production volume as a criterion when selecting constituents for monitoring in the ambient environment is not new; however, the launch by the USEPA and industry trade associations of the HPV Challenge Program (U.S. Environmental Protection Agency, 2011) to collect basic hazard data for HPVs (1998) postdates the start of the NAWQA Program (1992). The defining characteristic of the HPVs as a constituent class is their production or importation into the United States in quantities of 1 million pounds or more per year. The likelihood of any specific HPV entering the environment can be only roughly estimated on the basis of that constituent's end use; however, some HPVs already have manifested themselves in the environment; for example, MTBE has been widely detected by the NAWQA Program (Moran and others, 2005). Literature references documenting occurrence for many of the HPVs are provided in table H.2 (for those in Tier 1) and table H.3 (for those in Tier 2).

Several of the high-priority HPVs that were identified through the NTAS prioritization process for Group H were already included on laboratory schedules used at the USGS 

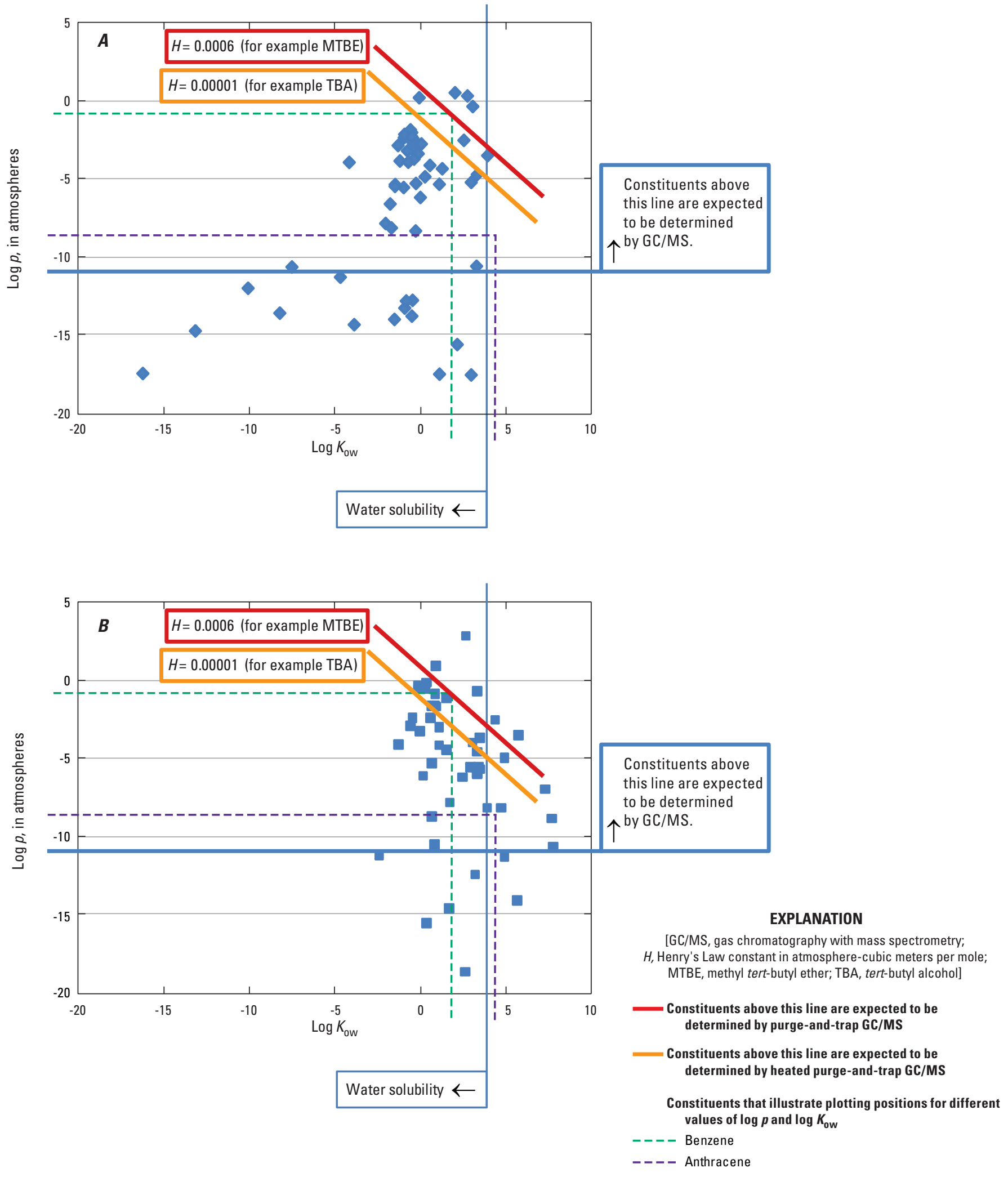

Figure H.2. Relation between vapor pressure $(\log p)$ and $\log \mathrm{K}_{\text {ow }}$ for $A$, 59 high-production-volume chemicals from those ranked 1 to 100 , and $B, 49$ high-production-volume chemicals of human-health or aquatic-life concern from those ranked 101 to 379 , on the basis of equation 1 in the "Supplemental Information $\mathrm{H}^{\text {" section. }}$ 
NWQL or were included in other NTAS constituent groups (table H.1). Nonetheless, several other HPVs were identified by the process used for Group $\mathrm{H}$ that had not been otherwise identified; these constituents represent an opportunity for the NAWQA Program to fill a potential gap in providing monitoring data for these constituents. Because the Tier 1 HPVs include many constituents that are unfamiliar to the water monitoring community, it is useful to list some of these constituents and their uses. The following discussion includes only a dozen of the HPVs that are considered of high priority for monitoring.

Hexamine (CASRN 100-97-0) is a heterocyclic organic compound that is used in the synthesis of plastics (particularly, phenolic resins), adhesives, and pharmaceuticals. Cyclohexanone (CASRN 108-94-1) is a cyclic ketone that is used as a precursor to nylon, through the production of adipic acid. The constituent 4-hydroxy-4-methyl-2-pentanone (CASRN 123-42-2) is a ketone that is used in lacquers and lacquer thinners, and in wood stains and preservatives. The chemical $N, N$-dimethylformamide (CASRN 68-12-2) is an organic solvent used by the petrochemical sector and in the manufacturing of pharmaceuticals, dyes and pigments, polyvinyl chloride, pesticides, and other products. The constituent 1-methoxy-2-propanol (CASRN 107-98-2) is used as a solvent for paints, inks, lacquers, and cleaners, and as an inert ingredient in some pesticides. The chemicals 2-(2-butoxyethoxy)ethanol (CASRN 112-34-5) and 2-(2-methoxyethoxy) ethanol (CASRN 111-77-3) are alkoxy ethers that commonly are used as solvents in paints, dyes, and soaps. Dipropylene glycol monomethyl ether (CASRN 34590-94-8, a mixture of isomers) is another alkoxy ether that is used in paints, coatings, inks, and cleaners. The chemical 1-methyl-2-pyrrolidone (CASRN 872-50-4) is a small lactam molecule that is used as a polar solvent by the petrochemical industry and as an intermediate in the synthesis of pesticides, pharmaceuticals, and artificial textile fibers. The chemical 2 -ethoxyethanol (CASRN $110-80-5)$ is a solvent that is used in some varnish removers, degreasing solutions, and multi-purpose cleaners. EDTA (CASRN 60-00-4) is a chelating agent that is widely used in industry to sequester metal ions from aqueous solutions and in medicine to bind metal ions as therapy for mercury and lead poisoning. Oxirane (CASRN 75-21-8) is a cyclic ether that is used in the synthesis of glycols and other chemicals that are important for the production of antifreeze, brake fluids, plastic bottles, detergents, surfactants, and cosmetics. This partial recitation of HPVs and their uses illustrates the wide variety of chemical structures and properties in this constituent group, which makes these constituents difficult to classify other than as "HPVs."

\section{References for High-Production-Volume Chemicals in Water (Group H)}

Ábalos, Manuela; Bayona, J.M.; and Ventura, Francesc; 1999, Development of a solid-phase microextraction GC-NPD procedure for the determination of free volatile amines in wastewater and sewage-polluted waters: Analytical Chemistry, v. 71 , no. 16 , p. $3,531-3,537$.

Abbasi, Shahryar; Khani, Hossein; Gholivand, M.B.; Naghipour, Ali; Farmany, Abbas; and Abbasi, Freshteh; 2009, A kinetic method for the determination of thiourea by its catalytic effect in micellar media: Spectrochimica Acta, Part A-Molecular and Biomolecular Spectroscopy, v. 72A, no. 2, p. 327-331.

Albaiges, J., Casado, F., and Ventura, F., 1986, Organic indicators of groundwater pollution by a sanitary landfill: Water Research, v. 20, no. 9, p. 1,153-1,159.

Alonso, A., Fernández-Torroba, M.A., Tena, M.T., and Pons, B., 2003, Development and validation of a solid-phase microextraction method for the analysis of volatile organic compounds in groundwater samples: Chromatographia, v. 57 , no. 5-6, p. 369-378.

Biziuk, Merek; Namiesnik, J.; Czerwinski, J.; Gorlo, D.; Makuch, B.; Janicki, W.; Polkowska, Zaneta.; and Wolska, L.; 1996, Occurrence and determination of organic pollutants in tap and surface waters of the Gdansk district: Journal of Chromatography, v. 733, no. 1-2, p. 171-183.

Cao, Xu-N; Li, Jin-Hua; Xu, Hai-Hong; Zhan, Jia-Rong; Lin, Li; Yamamoto, Katsunobu; and Jin, Li-Tong; 2004, Simultaneous determination of aromatic amines by liquid chromatography coupled with carbon nanotubes/poly (3-methylthiophene) modified dual-electrode: Chromatographia, v. 49, no. 3-4, p. $167-172$.

Cappiello, Achille; Famiglini, Giorgio; Palma, Pierangela; Pierini, Elisabetta; Trufelli, Helga; Maggi, Chiara; Manfra, Loredana; and Mannozzi, Michela; 2007, Application of nano-FIA-Direct-EI-MS to determine diethylene glycol in produced formation water discharges and seawater samples: Chemosphere, v. 69, p. 554-560.

Castillo, Monserrat, and Barceló, Damià, 2001, Characterization of organic pollutants in textile wastewaters and landfill leachate by using toxicity-based fractionation methods followed by liquid and gas chromatography coupled to mass spectrometric detection: Analytica Chimica Acta, v. 426, no. 2, p. 253-264.

Clara, Manfred; Scharf, Sigrid; Scheffknecht, Christoph; and Gans, Oliver; 2007, Occurrence of selected surfactants in untreated and treated sewage: Water Research, v. 41, no. 19, p. $4,339-4,348$. 
Clausen, Jay; Robb, Joe; Curry, Diane; and Korte, Nic; 2004, A case study of contaminants on military ranges - Camp Edwards, Massachusetts, USA: Environmental Pollution, v. 129 , no. 1, p. 13-21.

Di Marzio, W.D., Sáenz, M., Alberdi, J., Tortorelli, M., and Silvana, Galassi, 2005, Risk assessment of domestic and industrial effluents unloaded into a freshwater environment: Ecotoxicology and Environmental Safety, v. 61, no. 3, p. 380-391.

Ding, W.-H., and Pei-Chuan, T., 2003, Determination of alkyltrimethylammonium chlorides in river water by gas chromatography/ion trap mass spectrometry with electron impact and chemical ionization: Analytical Chemistry, v. 75, no. 8, p. 1,792-1,797.

Dorgerloh, Ute; Ehrhardt, Ulla; Nehls, Irene; Schmieder, Rosemarie; Walter, Wolfgang; Win, Tin; Hilbert, Sabine; and Mechler, Michaela; 2004, Interlaboratory comparison for the determination of highly volatile halogenated hydrocarbons (VHHC), vinyl chloride (VC) and chlorofluorocarbons (CFC) in groundwater samples: Vom Wasser, v. 102, no. 2 , p. 12-16.

Drzyzga, Oliver, 2003, Diphenylamine and derivatives in the environment-A review: Chemosphere, v. 53, no. 8, p. 809-818.

Dsikowitzky, Larissa; Schwarzbauer, Jan; Kronimus, Alexander; and Littke, Ralf; 2004, The anthropogenic contribution to the organic load of the Lippe River (Germany) — Part I, Qualitative characterisation of low-molecular weight organic compounds: Chemosphere, v. 57 , no. 10, p. 1,2751,288 .

Ellis, D.D., Jone, C.M., Larson, R.A., and Schaeffer, D.J., 1982, Organic constituents of mutagenic secondary effluents from wastewater treatment plants: Archives of Environmental Contamination and Toxicology, v. 11, no. 3, p. 373-382.

Fedonina, V.F., Fedyainov, N.V., and Agapova, S.A., 1981, Determination of $N$-methylpyrrolidinone in river water: Khimiya i Tekhnologiya Vody, v. 3, no. 3, p. 237-240.

Gaca, Jerzy, and Wejnerowska, Grazyna, 2005, Determination of propane chloroderivatives in environmental samples: Analytica Chimica Acta, v. 540, no. 1, p. 55-60.

Godejohann, Markus; Heintz, Lea; Daolio, Cristina; Berset, J.D.; and Muff, Daniel; 2009, Comprehensive non-targeted analysis of contaminated groundwater of a former ammunition destruction site using 1H-NMR and HPLC-SPE-NMR/ TOF-MS: Environmental Science and Technology, v. 43, no. 18 , p. 7,055-7,061.
Hendricks, A.J., Maas-Diepeveen, J.L., Noordsij, A., and van der Gaag, M.A., 1994, Monitoring response of XADconcentrated water in the Rhine delta-A major part of the toxic compounds remains unidentified: Water Research, v. 28, no. 3, p. 581-198.

Hirayama, Yuichi; Ikegami, Hiroshi; Machida, Motoi; and Tatsumoto, Hideki; 2006, Simple and rapid determination of linear alkylbenzene sulfonates by in-tube solid-phase microextraction coupled with liquid chromatography: Journal of Health Science, v. 52, no. 3, p. 228-236.

Inoue, Norikazu; Chida, Chiyoko; Yoshida, Ken-ichi; Koike, Jun-ichi; Chimuro, Mayuko; and Nishimura, Kazuhiko; 2007, Investigation of chemicals in environmental water in Kawasaki City: Kawasaki-shi Kogai Kenkyusho Nenpo, v. 34, p. 35-39.

Jenkins, T.F., Leggett, D.C., Grant, C.L., and Bauer, C.F., 1986, Reversed-phase high-performance liquid chromatographic determination of nitroorganics in munitions wastewater: Analytical Chemistry, v. 58, no. 1, p. 170-175.

Ježová, Věra; Skládal, Jan; Eisner, Aleš; Bajerová, Petra; and Ventura, Karel; 2007, Determination of nitrate esters in water samples comparison of efficiency of solid-phase extraction and solid-phase microextraction: Journal of Chromatography, v. 1174, no. 1-2, p. 13-19.

Jinno, K., Shimizu, T., and Uehara, N., 2007, Determination of hydrophilic organic compounds in river water by GC/MS coupled with solid-phase extraction using activated carbon cartridge: Bunseki Kagaku, v. 56, no. 12, p. 1,141-1,146.

Kadokami, K., 1991, Trace analysis of water-soluble compounds using activated carbon extraction method: PPM, v. 22 , no. 7 , p. $37-43$.

Kadokami, K., Koga, M., and Otsuki, A., 1990, Gas chromatography/mass spectrometric determination of traces of hydrophilic and volatile organic compounds in water after preconcentration with activated carbon: Analytical Sciences, v. 6 , no. 6 , p. 843-849.

Kawamoto, Tatsuhiko; Makihata, Nobuko; Tsuji, Hidetaka; and Teranishi, Kiyoshi; 1999, Annual variation in the concentration levels and frequency of detection of pesticides in water sources in Hyogo prefecture: Journal of Health Science, v. 45, no. 6, p. 401-411.

Kawata, Kuniaki; Ibaraki, Tsuyoshi; Tanabe, Akiko; and Yasuhara, Akio; 2003, Distribution of 1,4-dioxane and N, $\mathrm{N}$-dimethylformamide in river water from Niigata, Japan: Bulletin of Environmental Contamination and Toxicology, v. 70 , no. 5, p. 876-882. 
Kawata, Kuniaki; Ibaraki, Tsuyoshi; Tanabe, Akiko; Yagoh, Hiroaki; Shinoda, Akiko; Suzuki, Hiroshi; and Yasuhara, Akio; 2001, Gas chromatographic-mass spectrometric determination of hydrophilic compounds in environmental water by solid-phase extraction with activated carbon fiber felt: Journal of Chromatography, v. 911, no. 1, p. 75-83.

Kawata, Kuniaki, and Tanabe, Akiko, 2009, Distribution and variation of 1,4-dioxane in water from rivers in Niigata including the Shinano River: Bulletin of Environmental Contamination and Toxicology, v. 82, no. 6, p. 673-677.

Kemmei, Tomoko; Kodama, Shuji; Muramoto, Tatsuya; Fujishima, Hironori; Yamamoto, Atsushi; Inoue, Yoshinori; and Hayakawa, Kazuichi; 2009, Study of solid-phase extraction for the determination of sequestering agents in river water by high-performance liquid chromatography: Journal of Chromatography A, v. 1,216, no. 7, p. 1,1091,114 .

Knepper, T.P., 2003, Synthetic chelating agents and compounds exhibiting complexing properties in the aquatic environment: Trends in Analytical Chemistry, v. 22, no. 10, p. 708-724.

Kolpin, D.W., Barbash, J.E., and Gilliom, R.J., 2000, Pesticides in ground water of the United States, 1992-1996: Ground Water, v. 38, no. 6, p. 858-863.

Koziel, J.A., and Corsi, R.L., 1998, VOC emissions from municipal sewers- - Hot spots: Proceedings, Annual Meeting of the Air and Waste Management Association, 91st, RP104A01/1-RP104A01/14.

Lasa, M., Garcia, R., and Millán, E., 2006, A convenient method for epichlorohydrin determination in water using headspace-solid phase microextraction and gas chromatography: Journal of Chromatographic Science, v. 44, no. 7, p. 438-443.

Lee, H.-B., Peart, T.E., and Svoboda, M.L., 2005, Determination of endocrine-disrupting phenols, acidic pharmaceuticals, and personal-care products in sewage by solid-phase extraction and gas chromatography-mass spectrometry: Journal of Chromatography A, v. 1,094, no. 1-2, p. 122129.

Leets, K., and Raudoja, H., 1979, Determination of the total quantity of formaldehyde and hexamethylenetetramine in wastewater from the manufacture of synthetic citral: Eesti NSV Teaduste Akadeemia Toimetised, Keemia, v. 28, no. 3 , p. 210-211.

Ludvigsen, G.H., and Lode, Olav, 2002, Trends of pesticides in Norwegian streams and rivers (1996-2000): International Journal of Environmental Analytical Chemistry, v. 82, no. 8-9, p. 631-643.
Majzik, E.S., Toth, F., Benke, L., and Kiss, Zs., 2006, SPELC-MS-MS determination of phenoxy acid herbicides in surface and ground water: Chromatographia, v. 63 (Suppl.), S105-S109.

Martínez-Carballo, Elena; Sitka, Andrea; González-Barreiro, Carmen; Kreuzinger, Norbert; Fürhacker, Maria; Scharf, Sigrid; and Gans, Oliver; 2007, Determination of selected quaternary ammonium compounds by liquid chromatography with mass spectrometry-Part I, Application to surface, waste, and indirect discharge water samples in Austria: Environmental Pollution, v. 145, no. 2, p. 489-496.

Merriman, J.C., Anthony, D.H.J., Kraft, J.A., and Wilkinson, R.J., 1991, Rainy River water quality in the vicinity of bleached kraft mills: Chemosphere, v. 23, no. 11-12, p. $1,605-1,615$.

Michalowicz, Jaromir, and Duda, R.O.W., 2005, Analysis of chlorophenols, chlorocatechols, chlorinated methoxyphenols and monoterpenes in communal sewage of Lodz and in the Ner River in 1999-2000: Water, Air, and Soil Pollution, v. 164 , no. $1-4$, p. $205-222$.

Miles, C.J., 2001, Determination of national survey of pesticides analytes in groundwater by liquid chromatography with postcolumn reaction detection: Journal of Chromatography A, v. 592, no. 1-2, p. 283-290.

Miyazaki, Terumi; Kadokami, Kiwao; and Tsukamoto, Hideyuki; 2001, Simultaneous determination of traces of hydrophilic and volatile compounds in water by solid-phase microextraction and GC/MS: Bunseki Kagaku, v. 50, no. 10, p. 685-693.

Monteil-Rivera, Fanny; Beaulieu, Chantale; Deschamps, Stéphane; Paquet, Louise; and Hawari, Jalal; 2004, Determination of explosives in environmental water samples by solid-phase microextraction-liquid chromatography: Journal of Chromatography, v. 1048, no. 2, p. 213-221.

Moran, M.J., Zogorski, J.S., and Squillace, P.J., 2005, MTBE and gasoline hydrocarbons in ground water of the United States: Ground Water, v. 43, no. 4, p. 615-627.

Mrklas, O., Chu, A., and Lunn, S., 2003, Determination of ethanolamine, ethylene glycol and triethylene glycol by ion chromatography for laboratory and field biodegradation studies: Journal of Environmental Monitoring, v. 5, no. 2, p. 336-340.

Nishigaki, A., Kuroiwa, C., and Shibukawa, M., 2004, Characterization and determination of linear alkylbenzenesulfonates in environmental water samples by high-performance liquid chromatography with a hydrophilic polymer column and electrospray ionization mass spectrometric detection: Analytical Sciences, v. 20, no. 1, p. 143-147. 
Nishikawa, Yoshinori, and Okumura, Tameo, 1995, Determination of nitrilotriacetic acid and ethylenediaminetetraacetic acid in environmental samples as their methyl ester derivatives by gas chromatography-mass spectrometry: Journal of Chromatography A, v. 690, no. 1, p. 109-118.

Nomura, Yoko; Ikebukuro, Kazunori; Yokoyama, Kenji; Takeuchi, Toshifumi; Arikawa, Yoshiko; Ohno, Shizue; and Karube, Isao; 1998, Application of a linear alkylbenzene sulfonate biosensor to river water monitoring: Biosensors and Bioelectronics, v. 13, no. 9, p. 1,047-1,053.

Nowack, Bernd, 1997, Determination of phosphonates in natural waters by ion-pair high-performance liquid chromatography: Journal of Chromatography, v. 773, no. 1-2, p. 139-146.

Nowack, Bernd; Kari, F.G.; Hilger, S.U.; and Sigg, Laura; 1996, Determination of dissolved and adsorbed EDTA species in water and sediments by HPLC: Analytical Chemistry, v. 68 , no. 3, p. 561-566.

Nowack, Bernd; Xue, H.-B.; and Sigg, Laura; 1997, Influence of natural and anthropogenic ligands on metal transport during infiltration of river water to groundwater: Environmental Science and Technology, v. 31, no. 3, p. 866-872.

Ochsenbein, Ueli; Zeh, Markus; and Berset, J.D.; 2008, Comparing solid phase extraction and direct injection for the analysis of ultra-trace levels of relevant explosives in lake water and tributaries using liquid chromatography-electrospray tandem mass spectrometry: Chemosphere, v. 72, no. 6, p. 974-980.

Oviedo, Claudia, and Rodríguez, Jaime, 2003, EDTA-The chelating agent under environmental scrutiny: Renewable Resources Laboratory, Universidad de Concepción Casilla 160-C, v. 26, no. 6, p. 901-905.

Parnis, Craig, and Brooks, Peter, 2001, Semi-volatile organic compounds in the Campaspe River system (Victoria, Australia): Water Research, v. 35, no. 8, p. 1,861-1,868.

Patel, Rajmani, and Patel, K.S., 1998, Flow injection determination of anionic surfactants with cationic dyes in water bodies of central India: Analyst, v. 123, no. 8, p. 1,6911,695 .

Paune, F., Caixach, J., Espadaler, I., Om, J., and Rivera, J., 1998, Assessment on the removal of organic chemicals from raw and drinking water at a Llobregat River water works plant using GAC: Water Research, v. 32, no. 11, p. 3,313-3,324.

Paxéus, Nicklas, 1996, Organic pollutants in the effluents of large wastewater treatment plants in Sweden: Water Research, v. 30, no. 5, p. 1,115-1,122.
Paxéus, Nicklas, and Schroeder, H.F., 1996, Screening for non-regulated organic compounds in municipal wastewater in Goteborg, Sweden: Water Science and Technology, v. 33, no. 6 , p. 9-15.

Philippaerts, J., Vanhoof, C., and Vansant, E.F., 1992, Wastewater analysis by purge and trap capillary GC-FTIR spectrometry: Talanta, no. 39, v. 6, p. 681-685.

Pietsch, J., Schmidt, W., Sacher, F., Brauch, H.J., and Worch, E., 1997, Flüssigchromatographische Bestimmung von polaren organischen Stickstoffverbindungen und deren Verhalten im Prozess der Trinkwasseraufbereitung [Liquid chromatographic determination of polar organic nitrogen compounds and their behaviour during drinking water treatment]: Vom Wasser, v. 88, p. 119-135.

Pilipenko, A.T., Milyukin, M.V., Kuzema, A.S., and Tulyupa, F.M., 1988, Use of headspace analysis for determining volatile organic substances in liquid media by combined chromatography-mass spectrometry: Zhurnal Analiticheskoi Khimii, v. 43, no. 1, p. 136-142.

Pirkko-Leena, L., Antti, M., and Rose, M., 2005, Simultaneous determination of DTPA, EDTA, and NTA by capillary electrophoresis after complexation with copper: Analytical and Bioanalytical Chemistry, v. 381, p. 1,264-1,271.

Puig, A., Ormad, P., Roche, P., Sarasa, J., Gimeno, E., and Ovelleiro, J.L., 1996, Wastewater from the manufacture of rubber vulcanization accelerators-Characterization, downstream monitoring and chemical treatment: Journal of Chromatography A, v. 733, no. 1-2, p. 511-522.

Quintana, J.B., and Reemtsma, Thorsten, 2007, Rapid and sensitive determination of ethylenediaminetetraacetic acid and diethylenetriaminepentaacetic acid in water samples by ion-pair reversed-phase liquid chromatography-electrospray tandem mass spectrometry: Journal of Chromatography A, v. 1,145 , no. $1-2$, p. $110-117$.

Rahul, K., and Pradnva, K., 1997, Simultaneous determination of $\varepsilon$-caprolactam and $\varepsilon$-aminocaproic acid by high-performance liquid chromatography: Process Control and Quality, v. 9 , no. $1-3$, p. $31-37$.

Rehorek, Astrid, and Plum, Alexander, 2007, Characterization of sulfonated azo dyes and aromatic amines by pyrolysis gas chromatography/mass spectrometry: Analytical and Bioanalytical Chemistry, v. 388, no. 8, p. 1,653-1,662.

Rudel, R.A., Melly, S.J., Geno, P.W., Sun, Gang, and Brody, J.G., 1998, Identification of alkylphenols and other estrogenic phenolic compounds in wastewater, septage, and groundwater on Cape Cod, Massachusetts: Environmental Science and Technology, v. 32, no. 7, p. 861-869. 
Sacher, Frank; Lenz, Steffen; and Brauch, Heinz-Jürgen; 1997, Analysis of primary and secondary aliphatic amines in waste water and surface water by gas chromatography-mass spectrometry after derivatization with 2,4-dinitrofluorobenzene or benzenesulfonyl chloride: Journal of Chromatography, v. 764 , no. 1 , p. 85-93.

Sacher, Frank; Lochow, Erik; and Brauch, Heinz-Jürgen; 1998, Synthetic organic complexing agents-Analysis and occurrence in surface waters: Vom Wasser, v. 90, p. 31-41.

Sar, S.K., Verma, Chanda, and Pandey, P.K., 2008, Spectrophotometric determination of sodium lauryl sulphate as a prime anionic surfactant and contaminant in central east Chhattisgarh (Durg-Bhilai region): Rasayan Journal of Chemistry, v. 1, no. 2, p. 236-245.

Schwarzbauer, Jan, and Heim, Sabine, 2005, Lipophilic organic contaminants in the Rhine River, Germany: Water Research, v. 39, no. 19, p. 4,735-4,748.

Schwarzbauer, Jan; Heim, Sabine; Brinker, Sabine; and Littke, Ralf; 2002, Occurrence and alteration of organic contaminants in seepage and leakage water from a waste deposit landfill: Water Research, v. 36, no. 9, p. 2,275-2,287.

Semard, Gaëlle; Bruchet, Auguste; Cardinaël, Pascal; and Bouillon, J.P.; 2008, Use of comprehensive two-dimensional gas chromatography for the broad screening of hazardous contaminants in urban wastewaters: Water Science and Technology, v. 57, no. 12 , p. 1,983-1,989.

Shiraishi, H., Yasuhara, A., and Otsuki, Akira; 1984, Unconfirmed organic compounds in polluted river water: Kokuritsu Kogai Kenkyusho Kenkyu Hokoku, v. 58, p. 66-70.

Shiraishi, H., Yasuhara, A., and Otsuki, A., 1982, Analysis of organic pollutants in river waters by mass spectrometry: Kokuritsu Kogai Kenkyusho Kenkyu Hokoku, v. 36, p. 177-195.

Sillanpää, M., Sorvari, J., and Sihvonen, M.L., 1996, Lowlevel determination of EDTA and DTPA in natural waters by gas chromatography: Chromatographia, v. 42, no. 9-10.

Singh, K.P.; Basant, Nikita; Malik, Amrita; Singh, V.K.; and Mohan, Dinesh; 2008, Chemometrics assisted spectrophotometric determination of pyridine in water and wastewater: Analytica Chimica Acta, v. 630, no. 1, p. 10-18.

Soliman, M.A., Pedersen, J.A., and Suffet, I.H., 2004, Rapid gas chromatography-mass spectrometry screening method for human pharmaceuticals, hormones, antioxidants and plasticizers in water: Journal of Chromatography A, v. 1029, no. $1-2$, p. 223-227.
Sparham, Chris; Van Egmond, Roger; O'Connor, Sean; Hastie, Colin; Whelan, Mick; Kanda, Rakesh; and Franklin, Oliver; 2008, Determination of decamethylcyclopentasiloxane in river water and final effluent by headspace gas chromatography/mass spectrometry: Journal of Chromatography, $\mathrm{v}$. 1212, no. 1-2, p. 124-129.

Sree, Usha; Bauer, Heidi; Fuerhacker, Maria; Ellinger, Reinhard; Schmidt, Heidrun; and Puxbaum, Hans; 2000, Hydrocarbons emissions from a municipal wastewater treatment pilot plant in Vienna: Water, Air, and Soil Pollution, v. 124, no. $1-2$, p. 177-186.

Szymanski, A., Wyrwas, B., Szymanowska, M., and Lukaszewski, Z., 2001, Determination of short-chained poly(ethylene glycols) and ethylene glycol in environmental samples: Water Research, v. 35, no. 15, p. 3,599-3,604.

Thruston, A.D., Jr., Richardson, S.D., McGuire, J.M., Collette, T.W., and Trusty, C.D., 1991, Multispectral identification of alkyl and chloroalkyl phosphates from an industrial effluent: Journal of the American Society for Mass Spectrometry, v. 2, no. 5, p. 419-426.

Thurman, E.M., Zimmerman, L.R., Aga, D.S., and Gilliom, R.J., 2001, Regional water-quality analysis of 2,4-D and dicamba in river water using gas chromatography-isotope dilution mass spectrometry: International Journal of Environmental Analytical Chemistry, v. 79, no. 3, p. 185-198.

Trenholm, R.A., Vanderford, B.J., Drewes, J.E., and Snyder, S.A., 2008, Determination of household chemicals using gas chromatography and liquid chromatography with tandem mass spectrometry: Journal of Chromatography A, v. 1,190 , no. $1-2$, p. 253-262.

Tsukamoto, Masakazu, Murata, Yoshiyuki, Tada, Mikiro, and Shimoishi, Yasuaki, 2004, Simple determination of trace amounts of anionic surfactants in river water by spectrophotometry combined with solid-phase extraction: Bioscience, Biotechnology, and Biochemistry, v. 68, no. 4, p. 920-923.

Tsukioka, T., and Murakami, T., 1987, Capillary gas chromatographic-mass spectrometric determination of pyridine bases in environmental samples: Journal of Chromatography, v. 396, p. 319-326.

Tsukioka, T., Ozawa, H., and Murakami, T., 1993, Gas chromatographic-mass spectrometric determination of lower aliphatic tertiary amines in environmental samples: Journal of Chromatography, v. 642, no. 1-2, p. 395-400.

U.S. Food and Drug Administration, 2010, Generally Recognized as Safe (GRAS): accessed February 18, 2011, at http://www.fda.gov/Food/IngredientsPackagingLabeling/ GRAS/ucm2006850.htm. 
U.S. Environmental Protection Agency, 2011, High Production Volume (HPV) Challenge-Basic information: accessed February 18, 2011, at http://www.epa.gov/hpv/pubs/general/ basicinfo.htm.

Van Langenhove, H., Roelstraete, K., Schamp, N., and Houtmeyers, J., 1985, GC-MS identification of odorous volatiles in wastewater: Water Research, v. 19, no. 5, p. 597-603.

Van Stee, L.L.P., Leonards, P.E.G., Vreuls, R.J.J., and Brinkman, U.A.T., 1999, Identification of non-target compounds using gas chromatography with simultaneous atomic emission and mass spectrometric detection (GC-AED/MS) Analysis of municipal wastewater: Cambridge, United Kingdom, Analyst, v. 124, no. 11, p. 1,547-1,552.

Wan, M.T., Kuo, J.-N., McPerson, B., and Pasternak, J., 2006, Agricultural pesticide residues in farm ditches of the Lower Fraser Valley, British Columbia, Canada: Journal of Environmental Science and Health, Part B-Pesticides, Food Contaminants, and Agricultural Wastes, v. 41, no. 5, p. 647-669.

Wang, Chunxia, Wang, Yi, Kiefer, F., Yediler, A., Wang, Zijian, and Kettrup, A., 2003, Ecotoxicological and chemical characterization of selected treatment process effluents of municipal sewage treatment plant: Ecotoxicology and Environmental Safety, v. 56, no. 2, p. 211-217.
Williams, G.M., Smith, B., and Ross, C.A.M., 2001, The migration and degradation of waste organic compounds in groundwater: Organic Geochemistry, v. 19, no. 4-6, p. 531-543.

Wu, Yuqin, Zheng, Hong, Chen, Jinlong, Zhuo, Shujuan, Wang, Lun, Li, Yongxin, and Zhu, Changqing, 2004, Spectrophotometric Method for the direct determination of anionic surfactant sodium dodecyl benzene sulfonate (SDBS) using a hydrophobic near-infrared (NIR) cationic cyanine dye without solvent extraction: Analytical Letters, v. 37 , no. 4 , p. 711-723.

Yasuhara, Akio, Shiraishi, Hiroaki, Tsuji, Masahiko, and Okuno, Toshihide, 1981, Analysis of organic substances in highly polluted river water by mass spectrometry: Environmental Science and Technology, v. 15, no. 5, p. 570-573.

Yasuhara, A., Uno, Y., and Nakasugi, O., 1993, Analysis of chemical components in landfill leachate, Part 3: Kankyo Kagaku, v. 3, no. 3, p. 539-547.

Yasuhara, A., Uno, Y., Nakasugi, O., and Hosomi, M., 1992, Analysis of chemical components in landfill leachate, Part 2: Kankyo Kagaku, v. 2, no. 3, p. 541-546.

You, J., Lao, W., and Wang, G., 1999, Analysis of organic pollutants in sewage by supercritical fluid extraction: Chromatographia, v. 49, no. 7-8, p. 399-405. 


\section{Appendix H.1}

When a chemical constituent $i$ is at partitioning equilibrium between water (wat) and liquid octanol (oct), there is an equality of chemical activities, $a$, in the two liquid phases:

$$
a_{i, \mathrm{wat}}=a_{i, \mathrm{oct}} \text {. }
$$

With the chemical activities expressed on the mole-fraction scale, equation 1 is rewritten using the mole-fraction-scale concentration values $(x)$ and mole-fraction-scale activity coefficients $(\zeta)$ :

$$
x_{i, \text { wat }} \zeta_{i, \text { wat }}=x_{i, \mathrm{oct}} \zeta_{i, \mathrm{oct}}
$$

(Mole-fractions and activity coefficients are usually considered dimensionless.) As an example, if 0.01 mole (mol) of a constituent is present in 1 liter (L) of a water solution, the molar concentration is $0.01 \mathrm{~mol} / \mathrm{L}$. Furthermore, $1 \mathrm{~L}$ of such a solution weighs approximately $(\sim)$ 1,000 grams (g), and most of the molecules are water. The molecular weight (MW) of water is $18 \mathrm{~g} / \mathrm{mol}$, so the liter of solution represents $\sim 55.6 \mathrm{~mol}$, and the mole fraction of the constituent in the solution is $\sim 0.01 / 55.6=1.80 \times 10^{-4}$.

The activity coefficients $\zeta_{i \text {, wat }}$ and $\zeta_{i \text {, oct }}$ are measures of the interactions between a molecule of constituent $i$ and its surrounding solution (water or octanol, respectively) relative to its interactions with itself as a pure liquid. If these interactions are about the same, then $\zeta_{i} \approx 1$. If constituent $i$ is less active in solution than in its pure liquid, then $\zeta_{i}$ is greater than 1 . If constituent $i$ is more active in solution than in its pure liquid, then $\zeta_{i}$ is less than 1 . For most constituents of interest, octanol is relatively similar to pure liquid $i$, so that $\zeta_{\text {oct }}^{i} \approx 1$. This then gives:

$$
\zeta_{\mathrm{wat}}^{i} \approx \frac{x_{i, \mathrm{oct}}}{x_{i, \mathrm{wat}}}
$$

The right-hand side of equation 3 is an octanol-water partition coefficient with concentrations expressed on the mole-fraction scale.

Now, by definition, the conventional octanol-water partition coefficient $K_{\text {ow }}$ gives the ratio of the concentrations, $c$, in octanol and water at equilibrium in units of grams per milliliter $(\mathrm{g} / \mathrm{mL})$ :

$$
K_{i, \mathrm{ow}}=\frac{c_{i, \mathrm{oct}}\left(\frac{\mathrm{g} \text { of } i}{\mathrm{~mL} \text { of oct }}\right)}{c_{i, \mathrm{wat}}\left(\frac{\mathrm{g} \text { of } i}{\mathrm{~mL} \text { of wat }}\right)} .
$$

Noting that the total number of moles in the water phase is approximately given by the number of moles of water, and similarly for the octanol phase, expansion of the right-hand side of equation 3 gives:

$$
\begin{aligned}
& \frac{x_{i, \text { oct }}}{x_{i, \text { wat }}} \approx \frac{\left(c_{i, \text { oct }}\left(\frac{\mathrm{g} \text { of } i}{\mathrm{~mL} \text { of oct }}\right) \times \frac{1}{\mathrm{MW}_{i}(\mathrm{~g} \text { of } i / \mathrm{mol} \text { of } i)} \times \frac{1}{r_{\text {oct }}(\mathrm{mol} \mathrm{of} \mathrm{oct} / \mathrm{mL} \text { of oct })}\right)}{\left(c_{i, \text { wat }}\left(\frac{\mathrm{g} \text { of } i}{\mathrm{~mL} \text { of wat }}\right) \times \frac{1}{\mathrm{MW}_{i}(\mathrm{~g} \text { of } i / \mathrm{mol} \text { of } i)} \times \frac{1}{r_{\text {wat }}(\text { mol of wat } / \mathrm{mL} \mathrm{of} \mathrm{wat})}\right)} \\
& \approx \frac{c_{i, \text { oct }}\left(\frac{\mathrm{g} \text { of } i}{\mathrm{~mL} \text { of oct }}\right) \frac{1}{c_{\text {oct }}(\mathrm{mol} \text { of oct } / \mathrm{mL} \text { of oct })}}{\left.\frac{\mathrm{g} \text { of } i}{\mathrm{~mL} \text { of wat }}\right)} \frac{1}{r_{\text {wat }}(\mathrm{mol} \text { of wat } / \mathrm{mL} \text { of wat })}
\end{aligned}
$$




$$
\approx K_{i, \text { ow }} \frac{r_{\text {wat }}(\mathrm{mol} \text { of wat } / \mathrm{mL} \text { of wat })}{r_{\text {oct }}(\mathrm{mol} \text { of oct } / \mathrm{mL} \text { of oct })},
$$

where $r_{\text {wat }}$ is the ratio of moles of water per milliliter of water, and $r_{\text {oct }}$ is the ratio of moles of octanol of per milliliter of octanol. Equations (3) and (7) can be combined to give:

$$
\zeta_{i, \text { wat }} \approx K_{i, \text { ow }} \frac{r_{\text {wat }}(\mathrm{mol} \text { of wat } / \mathrm{mL} \text { of wat })}{r_{\text {oct }}(\mathrm{mol} \text { of oct } / \mathrm{mL} \text { of oct })} .
$$

Note that based on the densities, $\rho$, of water and octanol,

$$
\begin{gathered}
r_{\text {wat }}(\mathrm{mol} \text { of wat } / \mathrm{mL} \text { of wat })=\frac{\rho_{\text {wat }}(\mathrm{g} \text { of wat } / \mathrm{mL} \text { of wat })}{\mathrm{MW}_{\text {wat }}(\mathrm{g} \text { of wat } / \mathrm{mol} \text { of wat })} \\
r_{\text {oct }}(\mathrm{mol} \text { of oct } / \mathrm{mL} \text { of oct })=\frac{\rho_{\text {oct }}(\mathrm{g} \text { of oct } / \mathrm{mL} \text { of oct })}{\mathrm{MW}_{\text {oct }}(\mathrm{g} \text { of oct } / \mathrm{mol} \text { of oct })} .
\end{gathered}
$$

Equations (8), (9) and (10) can be combined to give:

$$
\zeta_{\text {wat }}^{i} \approx K_{i, \text { ow }} \frac{\left(\frac{\rho_{\text {wat }}(\text { g of wat } / \mathrm{mL} \text { of wat })}{\mathrm{MW}_{\text {wat }}(\mathrm{g} \text { of wat } / \mathrm{mol} \text { of wat })}\right)}{\left(\frac{\rho_{\text {oct }}(\mathrm{g} \text { of oct } / \mathrm{mL} \text { of oct })}{\mathrm{MW}_{\text {oct }}(\mathrm{g} \text { of oct } / \mathrm{mol} \text { of oct })}\right)} .
$$

For the purposes of this derivation, the densities of water and octanol are sufficiently similar, and one can approximate that $\rho_{\text {wat }} \approx \rho_{\text {oct }} \approx 1$, yielding

$$
\zeta_{i, \mathrm{wat}} \approx \frac{\mathrm{MW}_{\mathrm{oct}}}{\mathrm{MW}_{\mathrm{wat}}} K_{i, \mathrm{ow}}=\frac{130}{18} K_{i, \mathrm{ow}} \approx 7 K_{i, \mathrm{ow}}
$$

An expression is needed for $\zeta_{i \text {,wat }}$ and can be obtained by considering the case of solubility (sol) equilibrium between the pure organic compound and water. For this case, $x_{i, \mathrm{oct}} \approx 1$ and $\zeta_{i, \text { wat }} \approx 1$, and equation 2 becomes

$$
x_{i, \mathrm{wat}}^{\mathrm{sol}} \zeta_{i, \mathrm{wat}} \approx 1
$$

so that

$$
\zeta_{i, \text { wat }} \approx 1 / x_{i, \text { wat }}^{\text {sol }}
$$

In general, for any concentration $C_{i}$ in units of mol of $i$ per cubic meter $\left(\mathrm{m}^{3}\right)$ of water,

$$
x_{i, \text { wat }}=\frac{C_{i}\left(\frac{\text { mol of } i}{\mathrm{~m}^{3} \text { of wat }}\right)}{\left(1,000 \frac{\mathrm{L}}{\mathrm{m}^{3} \text { of wat }}\right)\left(1,000 \frac{\mathrm{g} \text { of wat }}{\mathrm{L} \text { of wat }}\right)\left(\frac{1}{\mathrm{MW}_{\text {wat }}(\mathrm{g} \text { of wat } / \mathrm{mol} \text { of wat })}\right)}
$$




$$
=\frac{C_{i}\left(\frac{\text { mol of } i}{\mathrm{~m}^{3} \text { of wat }}\right)}{55,600\left(\frac{\text { mol of wat }}{\mathrm{m}^{3} \text { of wat }}\right)},
$$

which for the case of solubility equilibrium gives:

$$
x_{i, \text { wat }}^{\text {sol }}=\frac{C_{i}^{\text {sol }}\left(\frac{\text { mol of } i}{\mathrm{~m}^{3} \text { of wat }}\right)}{55,600\left(\frac{\text { mol of wat }}{\mathrm{m}^{3} \text { of wat }}\right)}
$$

and so by equation 14

$$
\zeta_{i, \text { wat }}=\frac{1}{x_{i, \text { wat }}^{\text {sol }}}=\frac{55,600\left(\frac{\text { mol of wat }}{\mathrm{m}^{3} \text { of wat }}\right)}{C_{i}^{\text {sol }}\left(\frac{\text { mol of } i}{\mathrm{~m}^{3} \text { of wat }}\right)}
$$

and so

$$
C_{i}^{\text {sol }}\left(\frac{\text { mol of } i}{\mathrm{~m}^{3} \text { of wat }}\right)=\frac{55,600\left(\frac{\text { mol of wat }}{\mathrm{m}^{3} \text { of wat }}\right)}{\zeta_{i, \text { wat }}} .
$$

Now, the Henry's Gas Law constant $H_{i}$ in units of atmospheres (atm)- $\mathrm{m}^{3} / \mathrm{mol}$ relates the gas pressure of $i$ to the corresponding aqueous concentration $C_{i}$ ( $\mathrm{mol}$ of $i / \mathrm{m}^{3}$ of wat):

$$
H_{i}\left(\mathrm{~atm}-\mathrm{m}^{3} / \mathrm{mol}\right)=\frac{p_{i}(\mathrm{~atm})}{C_{i}\left(\frac{\mathrm{mol} \text { of } i}{\mathrm{~m}^{3} \text { of wat }}\right)} .
$$

Henry's Law equilibrium will apply under the particular conditions when the pure compound $i$ is present so that the gasphase pressure $p_{i}=p_{i, \text { iq }}^{\mathrm{o}}(\mathrm{atm})$ (the saturation vapor pressure of pure liquid $i$ ) and the aqueous concentration is at solubility saturation so that $C_{i}=C_{i}^{\text {sol }}$ and thus obtain:

$$
H_{i}\left(\mathrm{~atm}-\mathrm{m}^{3} / \mathrm{mol}\right)=\frac{p_{i, \text { liq }}^{\mathrm{o}}(\mathrm{atm})}{C_{i}^{\mathrm{sol}}\left(\frac{\mathrm{mol} \text { of } i}{\mathrm{~m}^{3} \text { of wat }}\right)} .
$$

Combining equations 19 and 21 gives:

$$
H_{i}\left(\mathrm{~atm}-\mathrm{m}^{3} / \mathrm{mol}\right)=\frac{p_{i, \text { liq }}^{\mathrm{o}}(\mathrm{atm})}{\left[\frac{55,600 \mathrm{~mol} \text { of wat } / \mathrm{m}^{3} \text { of wat }}{\zeta_{i, \text { wat }}}\right]} .
$$


Combining equations 12 and 22 gives:

$$
H_{i}\left(\mathrm{~atm}-\mathrm{m}^{3} / \mathrm{mol}\right)=\frac{p_{i, \text { liq }}^{\mathrm{o}}(\mathrm{atm})}{55,600} 7 K_{i, \mathrm{ow}}
$$

Rearranging equation 23 gives:

$$
p_{i, \text { liq }}^{\text {o }}(\mathrm{atm})=55,600 H_{i} /\left(7 K_{i, \text { ow }}\right)=8,000 H_{i} / K_{i, \text { ow }}
$$

Taking the logarithm of both sides of equation 24 gives:

$$
\log p_{i, \text { liq }}^{\mathrm{o}}(\mathrm{atm})=\log H_{i}\left(\mathrm{~atm}-\mathrm{m}^{3} / \mathrm{mol}\right)-\log K_{i, \mathrm{ow}}+3.9
$$




\title{
Supplemental Information I. \\ Prioritization of Wastewater-Indicator and Industrial Compounds in Water (Group I)
}

By Lisa D. Olsen, Duane S. Wydoski, and Joshua F. Valder

\author{
Abbreviations and Acronyms Used in Supplemental Information I \\ ACToR Aggregated Computational Toxicology Resource (database, USEPA) \\ BHT butylated hydroxytoluene \\ CASRN Chemical Abstracts Service Registry Number ${ }^{\circledR}$ (American Chemical Society) \\ CCL3 Contaminant Candidate List 3 (UESPA) \\ C.I. Colour Index Constitution (Colour Index International) \\ DF detection frequency \\ ECOTOX ECOTOXicology (database, USEPA) \\ GC/MS gas chromatography with mass spectrometry \\ GRAS "Generally Recognized as Safe" list (U.S. Food and Drug Administration) \\ LC/MS/MS high-performance liquid chromatography with tandem mass spectrometry \\ $\log K_{\text {ow }} \quad$ base-10 logarithm of the octanol-water partition coefficient \\ LS laboratory schedule \\ NAWQA National Water-Quality Assessment (USGS) \\ NDMA $\quad N$-nitrosodimethylamine \\ NDPA $\quad N$-nitrosodi- $n$-propylamine \\ NTAS National Target Analyte Strategy (USGS NAWQA) \\ NWQL National Water Quality Laboratory (USGS) \\ PBT persistent, bioaccumulative, and toxic \\ SIM selected-ion monitoring \\ SPE solid-phase extraction \\ USEPA U.S. Environmental Protection Agency \\ USGS U.S. Geological Survey
}


This supplemental information section of the report describes the prioritization of 470 wastewater-indicator and industrial compounds in water (Group I) by the U.S. Geological Survey (USGS) National Target Analyte Strategy (NTAS) work group for national- and regional-scale ambient monitoring in the United States in support of the third cycle (Cycle 3) of the National Water-Quality Assessment (NAWQA) Program. The feasibility of implementing analytical methods for high-priority wastewater-indicator and industrial compounds, and knowledge and concerns of this constituent group, also are described in this section. Constituents evaluated for Group I included those that had been identified on the NTAS lists of human-health and aquatic-life concern, on lists of constituents of regulatory interest, through the scientific literature, and on USGS National Water Quality Laboratory (NWQL) schedules of wastewater-indicator or industrial compounds that could occur in water. They include semivolatile and nonvolatile organic compounds that can enter the environment through wastewater effluent, discharge, air pollution, or combustion, or through the routine use of consumer products.

Group I excludes volatile organic compounds that were evaluated for Group A, except for naphthalene, a semivolatile organic compound that can have poor recoveries with purgeand-trap methods, and 1,4-dioxane, a volatile compound that can have poor performance with unmodified purge-and-trap methods; these constituents were evaluated using the methods described in this supplemental information section, as well as those for Group A (as described in the "Supplemental Information A" section). Group I also excludes constituents evaluated as pesticides in water (Group B1), except for 2,4,6-trichlorophenol, which has nonpesticide uses and was prioritized using the methods described in this supplemental information section. Caffeine was prioritized using methods for Group C (pharmaceuticals and hormones in water or sediment) and Group I with equivalent results. Similarly, perchlorate was considered for Group D (trace elements and other inorganic constituents) and Group I and was prioritized using methods for both groups with equivalent results. Additional Group I constituents that are salts of metals prioritized for Group D were designated as "low priority" (NTAS Tier 3) for Group I because the preferred analytical approach for these constituents is to target the metals rather than their salts. Group I also includes nine constituents that can enter the environment from industrial sources or as disinfection by-products (Group G: disinfection by-products in water); these constituents were prioritized using the methods for both groups (with equivalent outcomes), except for acetaldehyde, which was prioritized using methods for Group G (as described in the "Supplemental Information G" section), and 2-chlorophenol, $N$-nitrosodiphenylamine, $N$-nitrosodi- $n$-propylamine, and $N$-nitrosomorpholine, which are thought to originate predominantly from wastewater or industrial sources and were prioritized using methods for Group I (described in this supplemental information section). In addition, C.I. Pigment Red 53, decamethylcyclopentasiloxane, and nitroglycerin overlapped with Group $\mathrm{H}$ (high-production volume chemicals in water; described in the
"Supplemental Information H" section). These constituents were prioritized using methods for both groups with equivalent results for C.I. Pigment Red 53 and nitroglycerin, but with different results for decamethylcyclopentasiloxane, which was placed into a higher-priority tier for Group I (Tier 2) than would have been decided for Group H (Tier 3) on the basis of additional lines of evidence used for Group I.

Group I also includes many lipophilic organic compounds that were evaluated for sediment (Group F: lipophilic organic compounds in sediment); these overlapping constituents have properties that support their occurrence in filtered water and in sediment. Constituents of potential interest to Groups I and $F$ were evaluated using the base-10 logarithm of its octanolwater partition coefficient $\left(\log K_{\mathrm{OW}}\right)$. Constituents with $\log$ KOW values less than 5 were considered as candidates for Group I because of the potential for these constituents to partition into water. Constituents with $\log K_{\mathrm{OW}}$ values between 5 and 7 were considered as candidates for Group I if there was regulatory interest, monitoring data, or literature evidence supporting their occurrence in filtered water; otherwise, these constituents were considered only for Group F. Constituents with $K_{\mathrm{OW}}$ values in the range of 5 to 7 are less likely to partition into water than into sediment; however, presence in water can occur if a contaminant has recently entered the environment through water or if a contaminant occurs in sediment that is in contact with water (for example, streambed sediment) and a small proportion of its concentration partitions into the water. Constituents with $\log K_{\mathrm{Ow}}$ values of 7 or higher are not expected to occur in filtered water and were not evaluated for Group I. The Group I constituents that overlapped with Group F were evaluated separately for each group with criteria appropriate for each matrix; therefore, a constituent might be prioritized differently for water (Group I) than for sediment (Group F). Constituents in unfiltered (whole or "raw") water can be represented by the combination of priorities for Group I for the aqueous (dissolved) fraction in the water and Group F for the suspended-sediment (particulate) fraction in the water.

\section{Prioritization of Wastewater-Indicator and Industrial Compounds in Water}

This section describes the methods used for prioritization of 470 wastewater-indicator and industrial compounds in water and describes the results and basis of that prioritization. This prioritization was performed using information on constituent occurrence from USGS monitoring studies and the NAWQA Program, information on regulatory benchmarks, toxicity, physical and chemical properties from the U.S. Environmental Protection Agency (USEPA), and information on likelihood of occurrence and reasons for concern from the scientific literature. Constituents evaluated for Group I include compounds that have been analyzed by the USGS on NWQL laboratory schedule (LS) 1383 (priority pollutants in unfiltered water), LS 1433/4433 (wastewater-indicator compounds in filtered/unfiltered water), and LS 2502 (polycyclic aromatic 
hydrocarbons and industrial compounds in sediment), as well as constituents that do not have USGS laboratory schedules. Some constituents can occur in multiple forms, of which one or more forms might be considered more important than the others; as is the case with some sets of isomers and with certain salts and their respective ions (for example, perchlorate ion in comparison to lithium perchlorate or other perchlorate salts). Constituents were prioritized into one of three NTAS prioritization tiers-Tier 1 (high priority for monitoring), Tier 2 (intermediate priority for monitoring), or Tier 3 (low or no priority for monitoring) - using the criteria described in subsequent sections and illustrated in the flow chart (fig. I.1).

\section{Prioritization Methods for Wastewater-Indic ator and Industrial Compounds in Water}

Criteria for prioritization were divided into two categories: likelihood of occurrence and reason for concern. A constituent was required to meet criteria in both categories in order to be assigned to Tier 1 or 2 . Constituents that did not meet the criteria for Tier 1 or 2, or that had evidence of likely nonoccurrence, including those that are intermediates used only in closed systems (limited release, if any), those that have been discontinued or have little documented use in the United States, and those that are unstable in water were placed into Tier 3. In addition, constituents that were on the U.S. Food and Drug Administration's "Generally Recognized As Safe" (GRAS) list (U.S. Food and Drug Administration, 2010) were placed into Tier 3 as having little or no reason for concern.

Likelihood of occurrence (fig. I.1) was determined on the basis of USGS or external monitoring data or from literature sources describing simulated or predicted occurrence. Constituents with detection frequencies of greater than 1 percent were considered for placement into Tiers 1 or 2 , after additional evaluation for reason for concern. Constituents without large sets of monitoring data also could be considered for placement into Tiers 1 or 2, pending additional evaluation for reason for concern, if they were identified in the literature as being likely to occur in the environment. Constituents with detection frequencies of less than 1 percent were assigned to Tier 3 unless other factors warranted assigning them to a higher-priority tier, including consideration of other datasets. A constituent also could be placed into Tier 3 if no evidence was found to support its occurrence in ambient water or if the constituent had evidence of likely nonoccurrence because of chemical instability in water, lack of persistence, or non-release (for example, if the constituent is used only for research in a controlled setting or use has been discontinued in the United States).

Reasons for concern (fig. I.1) included human-health effects, aquatic-life effects (including chronic toxicity to fish), and usefulness as a tracer. Constituents with detection frequencies of 10 percent or higher, or with observed concentrations equal to or greater than a factor of 0.1 of their respective regulatory benchmarks used for drinking-water quality, such as a USEPA Maximum Contaminant Level (U.S. Environmental Protection Agency, 2009a, 2010a) or USGS Health-Based Screening Level, were not required to meet additional criteria for reason for concern and were placed into Tier 1; otherwise, additional factors were considered. Constituents also were placed into Tier 1 if information from the USEPA ACToR (Aggregated Computational Toxicology Resource, http://actor. epa.gov) database or ECOTOXicology (ECOTOX; U.S. Environmental Protection Agency, 2011a) database placed them into a moderate or high NTAS "toxicity bin" or if the chronic value for fish obtained from the USEPA's Persistent, Bioaccumulative, and Toxic Profiles Estimated for Organic Chemicals (PBT Profiler) screening tool (U.S. Environmental Protection Agency, 2011b) was less than 10 milligrams per liter. Constituents also were considered to have reason for concern if they were determined to be useful as a tracer of wastewater, leachate, or spills. Constituents that met criteria for likelihood of occurrence, but had little or no evidence of reason for concern, were placed into Tier 2. Constituents that met criteria for likelihood of occurrence, but were on the U.S. Food and Drug Administration's GRAS list (U.S. Food and Drug Administration, 2010), were placed into Tier 3 on the basis of having little or no reason for concern. Interest in a constituent by regulatory agencies - for example, presence on the USEPA Contaminant Candidate List 3 (CCL3; U.S. Environmental Protection Agency, 2010b) - or the international community was not by itself considered a reason for concern, but was used as a means of identifying constituents to be evaluated further on the basis of human-health effects, aquatic-life effects (including toxicity to fish), or usefulness as a tracer.

The prioritization for the wastewater-indicator and industrial compounds in water took into consideration the lack of occurrence data and benchmarks for many of these constituents; thus, comparisons of concentrations relative to benchmarks were not used as the sole basis for prioritization. Supporting evidence from the aforementioned literature and database sources also was used in assigning constituents to one of the three NTAS tiers. Examples of reasons used to assign constituents to Tiers 1, 2, or 3 for the wastewater-indicators and industrial compounds in water are listed in table I.1 at http:// pubs.usgs.gov/sir/2012/5218/downloads/tableI.xls; reasons for prioritizations are provided for each constituent in tables I.2, I.3, and I.4 at http://pubs.usgs.gov/sir/2012/5218/downloads/ tableI.xls). References used to support the prioritizations are listed in tables I.2, I.3, and I.4 and are provided in the "References Cited" section of this Supplemental Information section.

\section{Results of Prioritization of Wastewater-Indicator and Industrial Compounds in Water}

Of the 470 constituents evaluated for wastewaterindicators and industrial compounds in water, 107 were assigned to Tier 1, 112 were assigned to Tier 2, and 251 were assigned to Tier 3 . Constituents and information to support the 


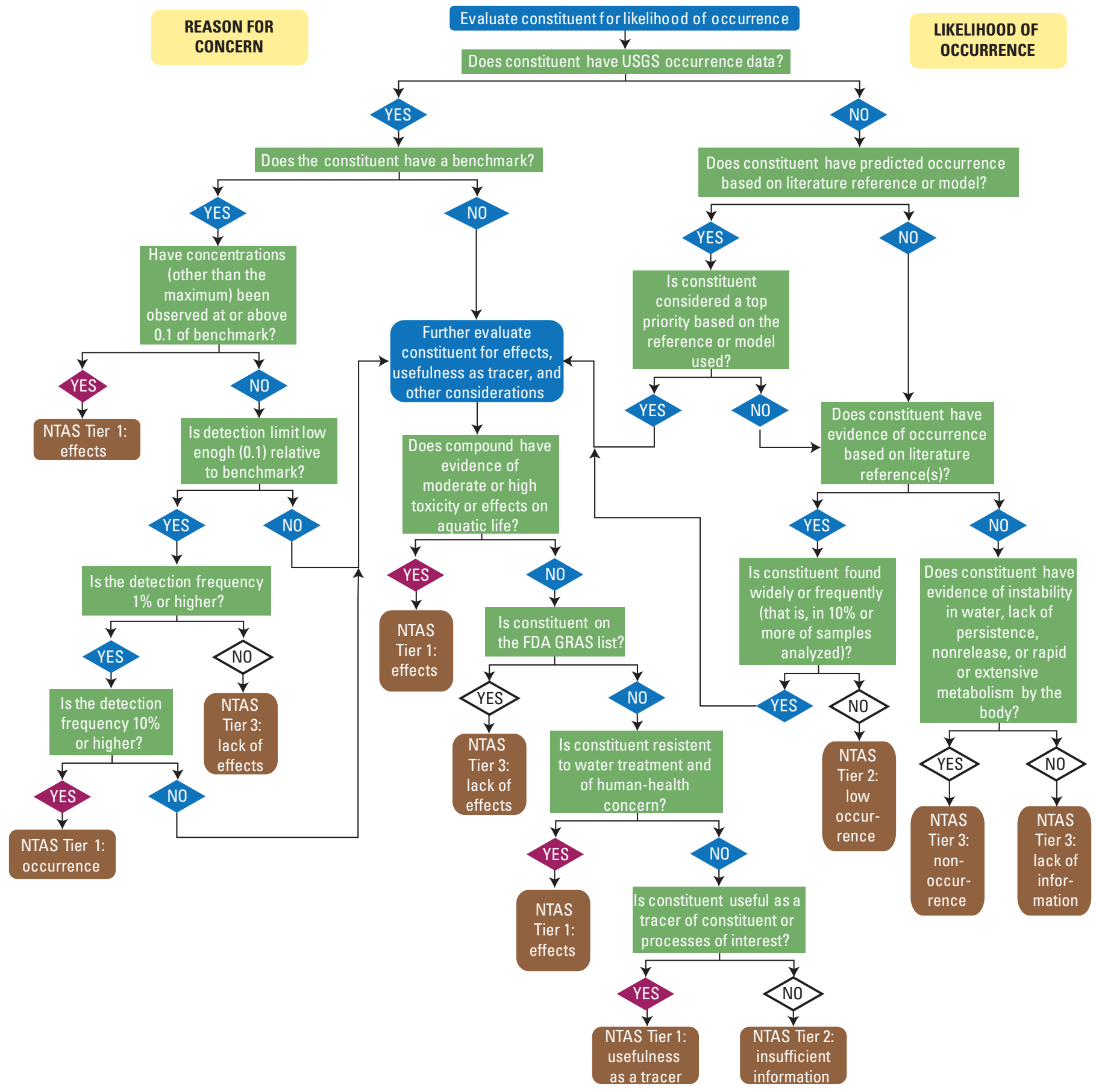

\section{EXPLANATION}

[FDA, U.S. Food and Drug Administration; GRAS, Generally Regarded As Safe: NTAS, National Target Analyte Strategy; \%, percent]
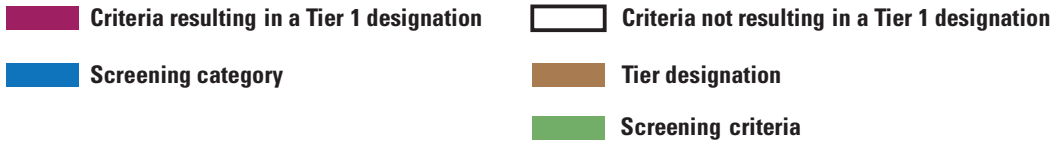

Figure l.1. Flow chart for prioritizing wastewater-indicator and industrial compounds for national- and regional-scale monitoring of water in the United States. 
prioritizations are provided in tables I.2 (Tier 1), I.3 (Tier 2), and I.4 (Tier 3).

\section{Basis for Prioritization of Wastewater-Indicator and Industrial Compounds in Water}

Few sources of national- or regional-scale monitoring data were available for the constituents in Group I. The basis of prioritization for those constituents with monitoring data is described first, followed by the basis for those constituents without monitoring data, which used predicted occurrence from literature sources and physical/chemical properties.

Data from a USGS national reconnaissance of pharmaceuticals and organic wastewater contaminants in the United States (Barnes and others, 2008; Focazio and others, 2008) were used to assist in the prioritization of constituents included in NWQL LS 1433 and in the research methods documented in those publications. Data from this reconnaissance were preferred over other references because the study design did not explicitly target wastewater effluent as have many other studies for wastewater-indicator constituents in water. Data from these publications were reviewed for detection frequency and concentration. Of the 45 constituents evaluated using published monitoring data for LS 1433, 34 were assigned to Tier 1, 7 were assigned to Tier 2, and 4 were assigned to Tier 3. One of the Tier 1 constituents, 4-tert-octylphenol, with a Chemical Abstracts Service Registry Number (CASRN) of 140-66-9, appears in a second entry for the mixture of isomers (CASRNs 140-66-9 and 1806-26-4). The branched isomer (4-tert-octylphenol, CASRN 140-66-9) of this compound is likely to predominate over the linear isomer (4-n-octylphenol, CASRN 1806-26-4) in the environment; however, some laboratory methods cannot resolve the two isomers (Duane S. Wydoski, U.S. Geological Survey, written commun., 2010), so it might be necessary to report the sum of both isomers rather than just the 4-tert-octylphenol.

Additional constituents that were not included in the national reconnaissance were analyzed less systematically for several USGS studies using LS 1383. This dataset included approximately 1,360 environmental samples (Duane $S$. Wydoski, U.S. Geological Survey, written commun., February 2011) collected from 2003 through 2010, although several constituents were not analyzed in all samples and had fewer than 1,360 analyses. Because these data were not collected using a systematic spatially distributed study design, they might not represent the range of conditions that would be observed in a national- or regional-scale monitoring program. For this reason, constituents lacking evidence of occurrence in this dataset were carefully considered for other factors that could justify assigning them to a higher-priority tier. Constituents with detection frequencies greater than 10 percent were assigned to Tier 1 if they had a benchmark or other reason for concern. Constituents with detection frequencies between 1 and 10 percent also were assigned to Tier 1 if the constituent had reason for concern, as described previously. Constituents with detection frequencies greater than 1 percent that did not meet the criteria for reason for concern were assigned to Tier 2 as having some evidence of occurrence in the environment. Constituents with detection frequencies of less than 1 percent were assigned to Tier 3 unless other factors warranted assigning them to a higher-priority tier, including consideration of other datasets or literature sources. Of 45 constituents evaluated on the basis of the LS 1383 data, 33 were assigned to Tier 1, 9 were assigned to Tier 2, and 3 were assigned to Tier 3.

Data from streambed-sediment samples collected by the NAWQA Program from 1,023 sites during 1992-2001, analyzed by using NWQL LS 2502, were used to supplement data from the aforementioned sources because streambed sediment represents a potential source of constituents to the aqueous phase (dissolved in water). Because whole-water sediment composition varies and partitioning between dissolved and adsorbed phases is a dynamic process, it was not possible to use $\log K_{\mathrm{OW}}$ values and detection frequencies to develop correlations with constituents detected with LS 1433 or LS 1383 to predict which LS 2502 constituents are most likely to be found in water. Instead, a semi-quantitative approach was used, using detection frequencies (DFs) for concentrations greater than 50 micrograms per kilogram. The LS 2502 constituents were placed into Tier 1 if the constituent had a DF greater than 1 percent and reason for concern, Tier 2 if the constituent had a DF greater than 1 percent and no known reason for concern, or Tier 3 if the constituent had a DF less than 1 percent. Each constituent that had previously been assigned to a tier using one or more of the criteria presented previously was given the highest-priority tier from all lines of reasoning that were considered (for example, a constituent considered to be Tier 1 based on the LS 2502 data and Tier 2 based on LS 1383 data would be assigned to Tier 1).

Constituents on the USEPA CCL3 were prioritized using the criteria that were used for the other constituents. Of 27 CCL3 constituents evaluated, 22 were assigned to Tier 1 . The other 5 CCL3 constituents were assigned to Tier 3 - benzyl chloride was assigned to Tier 3 because it hydrolyzes rapidly in water to form benzyl alcohol and is not expected to be found in water samples; the four perchlorate salts (ammonium perchlorate, lithium perchlorate, potassium perchlorate, and sodium perchlorate) were assigned to Tier 3 because the preferred analytical approach for these constituents would be as perchlorate, which was assigned to Tier 1 . The decision to place these five constituents into Tier 3 was discussed with USEPA CCL3 staff (Tom Carpenter, U.S. Environmental Protection Agency, Office of Groundwater and Drinking Water, oral commun., April 29, 2010) to ensure that information available from the USEPA that would have led to a different decision had not been overlooked.

Of the 470 constituents considered for prioritization, many had sparse information about environmental occurrence. Compound-by-compound Internet searches, using an Internet search strategy documented in table I.5 at http://pubs.usgs. gov/sir/2012/5218/downloads/tableI.xls, were performed for 
constituents that did not have information from one of the aforementioned sources. The search strategy was used to identify constituents with evidence of likelihood of occurrence, which were then evaluated further for reason for concern for placement into Tiers 1 or 2 . Those with no evidence of likelihood of occurrence were assigned to Tier 3. Each constituent was searched until sufficient references were found to inform whether the constituent is found (or is likely to be found) in the environment (Tier 1 or 2) or the constituent is unlikely to be found in the environment (Tier 3). Searching stopped when one or more references were found for a constituent, so not all search terms were used for all constituents. Unpublished materials sometimes were used to identify reference citations to help target subsequent searches onto published sources. USGS reports, peer-reviewed journal articles, and Government agency databases or Internet sites were favored over nonpublished sources; however, for some constituents, the only information that could be found was contained in non-published sources. These nonpublished sources omitted product marketing literature and were deemed to be credible for the purpose of determining whether a constituent was likely to occur widely in the environment or only in limited areas. Constituents that tend to be rapidly hydrolyzed or that had evidence that release to the environment is unlikely to be substantial (for example, compounds banned or discontinued for use in the United States) were assigned to Tier 3. Salts of compounds that warranted placement into Tier 1 or 2 (for example, salts of trace elements and perchlorate) were assigned to Tier 3 after confirming that the common ion or element had been assigned to the highest-priority tier supported by the combined data for all related compounds. References used to support the prioritization of constituents into Tiers 1, 2, and 3 are provided in tables I.2, I.3, and I.4, respectively.

\section{Feasibility of Implementation for High- Priority Wastewater-Indicator and Industrial Compounds in Water}

Of the 107 constituents in Tier 1 (table I.2), 74 are available on current USGS laboratory schedules (as of 2011) or are in the late stages of method development. Improvements to analytical methods might be needed for a few compounds in order to achieve detection limits sufficiently less than USEPA Maximum Contaminant Limits or other benchmarks. Of the 112 constituents in Tier 2 (table I.3), 24 are available on USGS laboratory schedules or are in method development and could be retained or discontinued, depending upon available resources. Because NAWQA previously has not routinely sampled for wastewater-indicators and industrial compounds, the schedules currently available from the NWQL for these constituents have not been evaluated with respect to NAWQA priorities. Some repackaging of schedules might be needed to accommodate the high-priority constituents in Group I. The 33 Tier 1 constituents without USGS analytical methods, including several CCL3 compounds with little or no monitoring data, warrant method development and validation, to the extent that this is feasible.

The 88 constituents in Tier 2 that do not currently have methods do not warrant method development for the purpose of ambient monitoring; however, these constituents might be reasonable additions for targeted studies that focus on wastewater-indicator or industrial compounds in water and might be of interest to the USGS Toxic Substances Hydrology Program. An additional eight constituents in Tier 3 that are on current laboratory schedules could be dropped from those used for NAWQA monitoring because these constituents have a low likelihood of occurrence in ambient waters or have little or no reason for concern because of their disuse, chemical instability, or lack of human-health or aquatic-life effects. For example, one of these Tier 3 constituents, butylated hydroxytoluene (BHT), is found on the U.S. Food and Drug Administration GRAS list (U.S. Food and Drug Administration, 2010). Similarly, the 24 constituents in Tier 2 on current laboratory schedules could be discontinued from those schedules used for NAWQA monitoring if necessary to conserve resources.

The suitability of analytical methods for wastewater-indicators and industrial compounds in water (Group I) will need to be determined after the Tier 1 and Tier 2 constituent lists have been shared with the NWQL and their Methods Research and Development Program staff. Based on a preliminary scan of the Tier 1 constituents by the NWQL and their Methods Research and Development Program staff, along with their current knowledge of analytical methods, a combination of gas chromatography with mass spectrometry (GC/MS) and highperformance liquid chromatography with tandem mass spectrometry (LC/MS/MS) is the likely approach for many of these constituents. Several of the Tier 1 constituents are included in LS 1433, LS 4433, and LS 1383; however, some constituents in these schedules would need lower detection limits based on current regulatory levels, such as $N$-nitrosodimethylamine (NDMA) and $N$-nitrosodi- $n$-propylamine (NDPA). Many of the Tier 1 constituents in Group I that do not have USGS methods can be determined using GC/MS analysis coupled with isolation using continuous liquid-liquid extraction or solid-phase extraction (SPE). Some of these new constituents that are chemically similar to those on existing NWQL laboratory schedules might be amenable to addition to those schedules. However, some important compound classes, such as organometallics and surfactants, would require development of more substantial methods. Recent advances in analytical technology warrant evaluation in order to meet the regulatory levels and to meet the data-quality objectives of NAWQA Cycle 3; these include using full-scan or selected-ion monitoring (SIM) or large-volume injection for GC/MS-based analytical approaches, and direct aqueous injection for LC/MS/MSbased analytical approaches. Some constituents likely will perform better using LC/MS/MS (compared to GC/MS), and this technique warrants consideration for developing methods for NAWQA Cycle 3.

The NWQL sample capacity is about 3,000 samples per year for analyses in filtered water for LS 1433 (SPE with 
GC/MS; Zaugg and others, 2002). The NWQL sample capacity is about 1,000 to 1,500 samples per year for analyses of whole (unfiltered) water or for analyses requiring continuous liquid-liquid extraction or other complex sample-preparation steps; for example, LS 1383, LS 4433, or comparable methods. Analytical throughput is generally much higher for filtered water samples than for unfiltered water samples because of the additional labor required for the complex extraction steps needed for unfiltered samples. The extraction steps required for unfiltered samples can be more prone to cross-contamination compared to those used for filtered-water samples; the presence of sediment particles can make the extraction apparatus difficult to clean. For these reasons, the NTAS work group recommends that the Group I constituents be analyzed as filtered water samples.

Several Group I constituents overlap with those in Group B2 (pesticides in sediment) and Group F (lipophilic organic constituents in sediment) and are expected to occur in both phases (water and sediment); therefore, the analysis of both water and suspended sediment would be needed to adequately characterize this subset of Group I constituents in the aquatic environment. Unfiltered (whole) water can be represented by the combination of a filtered-water sample and a suspendedsediment sample if the concentration of suspended sediment also is measured. The sediment methods developed for Tier 1 constituents in Groups B2 and F likely will be adequate for the analysis of suspended sediment in water and would complement the methods used for monitoring filtered water samples for Tier 1 constituents in Group I.

\section{Knowledge and Concerns of Wastewater- Indicator and Industrial Compounds in Water}

The USGS is perceived to be a leader in documenting the presence of wastewater-indicator and industrial compounds in the environment. Monitoring for the Tier 1 constituents in Group I, including the CCL3 compounds that are of interest with respect to drinking-water regulation and that have not yet been routinely monitored in ambient water, would be appropriate for NAWQA Cycle 3. In addition, the increasing scarcity of freshwater supplies for household, commercial, agricultural, and industrial use has prompted an increased interest in wastewater recycling and reuse. For example, in 2009, the California State Water Resources Control Board approved a Recycled Water Policy that includes a goal to increase the use of recycled water on the basis of 2002 levels by at least 1 million acre-feet per year by 2020 and by at least 2 million acre-feet per year by 2030 (California State Water Resources Control Board, 2011). Monitoring for the constituents with the highest likelihood of occurrence and reason for concern would provide valuable information about the quality of ambient water resources that could be affected by unintentional leakage of wastewater or by the intentional application of treated wastewater for which the public may have concerns about the efficacy of treatment.
One issue that must be resolved for the Group I constituents is whether whole water will be represented by collecting paired samples of filtered water and corresponding suspendedsediment fraction (preferred) or by collecting a single sample of unfiltered water. It is important for laboratories to know early in their planning process whether they can limit their method development to filtered water and sediment for these constituents or whether unfiltered-water methods also will be needed. For some analytical methods (for example, LC/MS/ MS), the analysis of unfiltered water is impractical or difficult; potentially labor-intensive sample-extraction methods (and equipment-cleaning methods) would need to be developed.

Based on the initial review of data from LS 1433 (wastewater compounds in filtered water), LS 1383 (semivolatile compounds in unfiltered water), and LS 2502 (semivolatile compounds in sediment), some constituents with $\log K_{\text {OW }}$ values greater than 5 , including some with $\log K_{\mathrm{OW}}$ values greater than 6 , frequently have been detected (DF greater than 10 percent) in filtered water, whereas other constituents with low $\log K_{\mathrm{OW}}$ values have been found in the unfiltered water or sediment samples. Thus, some constituents might occur in an environmental matrix other than the one most predicted on the basis of physical and chemical properties. For those constituents that overlap between Group I and Group B2 (pesticides in sediment) or Group F (lipophilic organic constituents in sediment or fish tissue), it is important to monitor the aqueous phase (water) concurrently with the particulate phase (suspended sediment).

For those Group I constituents that tend to also occur in sediment, for the best results in terms of analytical practicality, data quality, and scientific understanding of how these constituents are distributed in the environment, the use of in-field filtration to collect paired samples of filtered water and suspended sediment, is warranted. This approach, coupled with measurement of suspended-sediment concentration in the water, would provide a quantitative measure of constituent occurrence in the aqueous and particulate phases. If the NAWQA Cycle 3 Planning Team adopts this approach, some review and modification of NAWQA field protocols and additional field training likely will be needed.

On the other hand, if the collection and analysis of unfiltered water samples is selected instead of the analysis of paired samples of filtered water and suspended sediment, the NWQL would need to develop additional suites of laboratory methods for unfiltered water to accommodate the varied (and likely uncharacterized) mixtures of water and sediment for those Group I constituents that overlap with Groups B2 and F. Methods for unfiltered water tend to be more labor-intensive and prone to cross-contamination than those for filtered water, and close attention to data-quality would be needed. If this option is selected, laboratory methods for unfiltered water would be needed for the high-priority constituents from Group I, Group B2, and Group F. 


\section{References for Wastewater-Indicator and Industrial Compounds in Water (Group I)}

Abdel-Wahhab, M.A., Hasan, A.M., Aly, S.E., and Mahrous, K.F., 2005, Adsorption of sterigmatocystin by montmorillonite and inhibition of its genotoxicity in the Nile tilapia fish (Oreachromis nilaticus): Mutation Research/Genetic Toxicology and Environmental Mutagenesis, v. 582, no. $1-2$, p. 20-27.

Agency for Toxic Substances and Disease Registry, 1995, Public health assessment for Weldon Spring Ordinance Works: St. Charles County, Missouri, CERCLIS No. MO5210021288, accessed February 18, 2011, at http:// www.atsdr.cdc.gov/HAC/pha/PHA.asp?docid $=871 \& p g=0$.

Agency for Toxic Substances and Disease Registry, 2011, Medical management guidelines for nerve agents-Tabun (GA); sarin (GB); soman (GD); and VX: 24 p., accessed February 25, 2011, at http://www.atsdr.cdc.gov/MHMI/ mmg166.pdf.

Alliance for Environmental Technology, 2012, Section 5, Characterization of risk-Evaluation of the risks associated with the use of chlorine dioxide for the bleaching of pulpScientific progress since 1993: accessed April 26, 2012, at http://www.aet.org/science_of_ecfleco_risk/sap97sec5.html.

Araki, Hiroshi; Tatarazako, Norihisa; Kishi, Katsuyuki; and Kuroda, Ken-ichi; 2000, Evaluation of bioaccumulation potential of 3,4,5-trichloroguaiacol in a zooplankton (Daphnia magna) by pyrolysis-GC/MS in the presence of tetramethylammonium hydroxide (TMAH): Journal of Analytical and Applied Pyrolysis, v. 55, no. 1, p. 69-80.

Audhali, Nadia, and Stevenson, Dennis, 2004, The cycad pages - Cycad toxicity: accessed February 23, 2011, at http://plantnet.rbgsyd.nsw.gov.au/PlantNet/cycad/toxic. html\#poison.

Ayati, B., Ganjidoust, H., and Mir Fattah, M., 2007, Degradation of aromatic compounds using moving bed biofilm reactors: Iranian Journal of Environmental Health Science and Engineering, Iranian Association of Environmental Health (IAEH), v. 4, no. 2, p. 107-112.

Babcock, R.W.; Chen, Wei; Ro, K.S.; Mah, R.A.; and Stenstrom, M.K.; 1993, Enrichment and kinetics of biodegradation of 1-naphthylamine in activated sludge: Applied Microbiology and Biotechnology, v. 39, no. 2, p. 264-269.

Barnes, K.K., Kolpin, D.W., Furlong, E.T., Zaugg, S.D., Meyer, M.T., and Barber, L.B., 2008, A national reconnaissance of pharmaceuticals and other organic wastewater contaminants in the United States-I. Groundwater: Science of the Total Environment, v. 402, p. 192-200.
Bender, D.A., Delzer, G.C., Price, C.V., and Zogorski, J.S., 2009, Occurrence of volatile organic compounds in selected urban streams in the United States, 1995-2003: U.S. Geological Survey Scientific Investigations Report 2009-5203, $87 \mathrm{p}$.

Betts, K.S., 2007, Perfluoroalkyl acids - What is the evidence telling us?: Environmental Health Perspectives, v. 115, no. 5, p. A250-A256.

Bhunia, F., Saha, N.C., and Kaviraj, A., 2000, Toxicity of thiocyanate to fish, plankton, worm, and aquatic ecosystem: Bulletin of Environmental Contamination and Toxicology, v. 64 , no. 2 , p. $197-204$.

Boehncke, A., Kielhorn, J., Könnecker, G., Pohlenz-Michel, C., and Mangelsdorf, I., 2003, 4-Chloroaniline: Geneva, Concise International Chemical Assessment Document No. 48, International Programme on Chemical Safety, World Health Organization, accessed January 11, 2011, at http:// www.who.int/ipcs/publications/cicad/en/cicad48.pdf.

Böhmer, Walter; Rüdel, Heinz; Wenzel, Andrea; and SchröterKermani, Christa; 2004, Retrospective monitoring of triclosan and methyl-triclosan in fish-Results from the German environmental specimen bank: Organohalogen Compounds, v. 66 , p. $1,516-1,521$.

Bonefeld-Jørgensen, E.C.; Long, Manhai; Hofmeister, M.V.; and Vinggaard, A.M.; 2007, Endocrine-disrupting potential of bisphenol A, bisphenol A dimethacrylate, 4- $n$-nonylphenol, and 4-n-Octylphenol in vitro-New data and a brief review: Environmental Health Perspectives, v. 115 (Suppl. 1), p. 69-76.

Boopathy, Ramaraj; Wilson, Marti; and Kulpa, C.F.; 1993, Anaerobic removal of 2,4,6-trinitrotoluene (TNT) under different electron accepting conditions-Laboratory study: Water Environment Research, v. 65, no. 3, p. 271-275.

Bucher, J.R., 1993, NTP technical report on the toxicity studies of 2-chloronitrobenzene (CAS No. 88-73-3) and 4-chloronitrobenzene (CAS No. 100-00-5) administered by inhalation to F344/N rats and B6C3F1 mice: National Toxicology Program, Toxicity Report Series Number 33, 188 p.

Calafat, A.M.; Wong, L.Y.; Ye, Xiaoyun; Reidy, J.A.; and Needham, L.L.; 2008, Concentrations of the sunscreen agent benzophenone-3 in residents of the United StatesNational Health and Nutrition Examination Survey 20032004: Environmental Health Perspectives, v. 116, no. 7, p. 893-897.

California Department of Public Health, 2009, NDMA and other nitrosamines-Drinking water issues: accessed on January 10, 2011, at http://www.cdph.ca.gov/CERTLIC/ DRINKINGWATER/Pages/NDMA.aspx. 
California Environmental Protection Agency, 1998a, Evidence on the carcinogenicity of 2-aminofluorene-Draft: Office of Environmental Health Hazard Assessment, Office of Environmental Health Hazard Assessment, 18 p.

California Environmental Protection Agency, 1998b, Evidence on the carcinogenicity of 4-amino-2-nitrophenol-Draft: Office of Environmental Health Hazard Assessment, Office of Environmental Health Hazard Assessment, 21 p.

California State Water Resources Control Board, 2011, Recycled water policy: accessed August 26, 2011, at http://www. swrcb.ca.gov/water_issues/programs/water_recycling policy/.

Canadian Council of Ministers of the Environment, 1999, Canadian water quality guidelines for the protection of aquatic life - Chlorinated benzenes - 1,2,3,4-Tetrachlorobenzene, in Canadian environmental quality guidelines: Winnipeg, Canada, Canadian Council of Ministers of the Environment, $3 \mathrm{p}$.

Canadian Council of Ministers of the Environment, 2006, Canadian environmental quality guidelines for diisopropanolamine (DIPA) - Water and soil: Winnipeg, Canada, Scientific supporting document, PN 1367, 83 p., accessed January 11, 2011, at http://www.ccme.calassets/pdf/dipa_ ssd_soil_water1.0_e.pdf.

Cary, R., Dobson, Stuart, and Brooke, I., 2000, Phenylhydrazine: Concise International Chemical Assessment Document 19, International Programme on Chemical Safety, World Health Organization, 31 p., accessed April 27, 2012, at http://www.who.int/ipcs/publications/cicad/en/cicad19.pdf.

Centers for Disease Control and Prevention, 2005, Third national report on human exposure to environmental chemicals: Atlanta, Ga., National Center for Environmental Health, NCEH Pub. No. 05-0570, 475 p.

Chemfate, 1994, Syracuse Research Corporation's Environmental Fate Data Bases: Syracuse Research Corporation, Syracuse, N.Y.

Dennis, W.H., Burrows, E.P., and Siggins, B.A., 1983, The environmental fate of 2,4,6-trichloroaniline chemical and physical pathways: Fort Detrick, Md., Army Medical Bioengineering Research and Development Laboratory, $56 \mathrm{p}$.

Dobson, Stuart, and Cabridenc, R., 1990, Tributyltin compounds: Geneva, International Programme on Chemical Safety, World Health Organization, Environmental Health

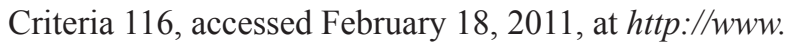
inchem.org/documents/ehc/ehc/ehc116.htm.

Duncan, Brent; Vavricka, Emily; and Morrison, Robert; 2004, A forensic overview of 1,4-dioxane: Environmental Claims Journal, v. 16, no. 1, p. 69-79.
Durkin, P.R., 2008, Fluridone, human health and ecological risk assessment final report: Prepared for the USDA Forest Service, Southern Region, by Syracuse Environmental Research Associates, Inc., SERA TR-052-10-02a, accessed January 11, 2011, at http://www.fs.fed.us/foresthealth/ pesticide/pdfs/0521002a_Fluridone.pdf.

Eastman, 2001, Bulk storage and handling of isobutyronitrile and $n$-butyronitrile: Eastman Chemical Company, Publication GN-415A, 12 p.

Environment Canada, 2003, Follow-up report on five PSL1 substances for which there was insufficient information to conclude whether the substances constitute a danger to the environment-1,2-Dichlorobenezene, 1,4-dichlorobenzene, trichlorobenzene, tetrachlorobenzene, pentachlorobenzene: accessed February 18, 2011, at http://www.ec.gc.cal substances/ese/eng/psap/assessment/PSL1_chlorobenzenes_ followup.pdf.

Environment Canada, 2007, Substance profile for the challenge, (1,1,4,4-tetramethyl-1,4-butanediyl)bis[(1,1-dimethylethyl)peroxide] — CAS No. 78-63-7: accessed February 18,2011, at http://www.ec.gc.ca/substances/ese/eng/ challenge/batch1_78-63-7.cfm.

Environment Canada, 2008a, Proposed risk management approach for 1,2-benzenediol (catechol) - Chemical Abstracts Service (CAS) Registry Number 120-80-9: accessed February 18, 2011, at http://www.ec.gc.cal substances/ese/eng/challenge/batch1/batch1_120-80-9 rm.cfm.

Environment Canada, 2008b, Screening assessment for the challenge-Benzene, 1,3-bis(1-isocyanato-1-methylethyl)(Tetramethyl-m-xylylene diisocyanate) - Chemical Abstracts Service Registry Number 2778-42-9: accessed February 18, 2011, at http://www.ec.gc.ca/substances/ese/ eng/challenge/batch2/batch2_2778-42-9.cfm.

Environment Canada, 2009a, Screening assessment for the challenge-Benzenesulfonamide, $N$-(4-amino-9,10-dihydro3-methoxy-9,10-dioxo-1-anthracenyl)-4-methyl-(disperse red 86) - Chemical Abstracts Service Registry Number 81-68-5: accessed February 18, 2011, at http://www.ec.gc. ca/substances/ese/eng/challenge/batch3/batch3_81-68-5. $c f m$.

Environment Canada, 2009b, Substance profile for the challenge - 2-Propenoic acid, ethyl ester (Ethyl acrylate) Chemical Abstracts Service Registry Number 140-88-5, accessed February 18, 2011, at http://www.ec.gc.cal substances/ese/eng/challenge/batch11/batch11_140-88-5. $c f m$. 
Environment Canada, 2009c, Screening assessment for the challenge-1,2-Benzenedicarboxylic acid, bis(2-methoxyethyl) ester-Chemical Abstracts Service Registry Number 117-82-8: accessed February 23, 2011, at http://www.ec.gc. ca/substances/ese/eng/challenge/batch6/batch6_117-82-8. cfm.

Environment Canada, 2009d, Screening assessment for the challenge-2,7-Naphthalenedisulfonic acid, 4-amino-3[[4'-[(2,4-diaminophenyl)azo][1,1'-biphenyl]-4-yl]azo]5-hydroxy-6-(phenylazo)-, disodium salt (Direct Black 38) - Chemical Abstracts Service Registry Number 193737-7: accessed February 23, 2011, at http://www.ec.gc.cal substances/ese/eng/challenge/batch6/batch6_1937-37-7. cfm.

Environment Canada, 2009e, Screening assessment for the challenge-9,10-Anthracenedione, 1-hydroxy-4-[[4[(methylsulfonyl)oxy]phenyl]amino]- (Disperse Violet 57) - Chemical Abstracts Service Registry Number 1594-08-7: accessed February 23, 2011, at http://www. ec.gc.ca/substances/ese/eng/challenge/batch3/batch3_159408-7.cfm.

Environment Canada, 2009f, Substance profile for the challenge-Hexanoic acid, 2-ethyl- (2-ethyl hexanoic acid)Chemical Abstracts Service Registry Number 149-57-5: accessed February 23, 2011, at http://www.ec.gc.cal substances/ese/eng/challenge/batch11/batch11_149-57-5. cfm.

Environment Canada, 2009g, Screening assessment for the challenge-1-Propanol, 2-methoxy(2-Methoxypropanol)Chemical Abstracts Service Registry Number 1589-47-5: accessed February 23, 2011, at http://www.ec.gc.cal substances/ese/eng/challenge/batch3/batch3_1589-47-5. cfm.

Environment Canada, 2009h, Screening assessment for the challenge - Chemical Abstracts Service Registry Number 64325-78-6, 1154-59-2, 1176-74-5, 70776-86-2, 68443-10-7: accessed February 18, 2011, at http://www. ec.gc.ca/substances/ese/eng/challenge/batch4/batch4_117674-5.cfm.

Environment Canada, 2009i, Screening assessment for the challenge-Phenol, 4,4'- (3H-2,1-benzoxathiol-3-ylidene) bis[2,5-dimethyl-, S,S-dioxide (Xylenol Blue)-Chemical Abstracts Service Registry Number 125-31-5: accessed February 18, 2011, at http://www.ec.gc.ca/substances/ese/ eng/challenge/batch4/batch4_125-31-5_en.pdf.
Environment Canada, 2010a, Draft screening assessment for the challenge-Benzene, 1,3,5-tribromo- (1,3,5-tribromobenzene); 1,2,3,4-tetrachloro-5,6-dimethoxy- (tetrachloroveratrole), Phosphonic acid, [[3,5-bis(1,1-dimethylethyl)4-hydroxyphenyl]methyl]-, monoethyl ester, calcium salt (2:1); Fatty acids, C6-C19-branched,zinc salts (FAZ) Chemical Abstracts Service Registry Number 626-39-1, 944-61-6, 65140-91-2, 68551-44-0: accessed February 18, 2011, at http://www.ec.gc.ca/substances/ese/eng/ challenge/batch8/batch8_944-61-6_en.pdf.

Environment Canada, 2010b, Screening assessment for the challenge-Methanone, bis[4-(dimethylamino)phenyl](Michler's ketone) - Chemical Abstracts Service Registry Number 90-94-8: accessed February 18, 2011, at http:// www.ec.gc.ca/substances/ese/eng/challenge/batch7/ batch7_90-94-8.cfm.

Environment Canada, 2011, Draft screening assessment for the challenge - Guanidine, N,N'-diphenyl- (Diphenylguanidine) - Chemical Abstracts Service Registry Number 102-06-7: accessed February 18, 2011, at http://www.ec.gc. calese-ees/7B3B293F-9127-4B8E-8B4E-D14AB5EAA094/ batch12_102-06-7_en.pdf.

European Chemicals Bureau, 2002, European Union risk assessment report for $o$-anisidine: Austria, Office for Official Publications of the European Communities, accessed April 30, 2012, at http://esis.jrc.ec.europa.eu/doc/risk_ assessment/REPORT/o-anisidinereport025.pdf.

European Chemicals Bureau, 2003, European Union risk assessment report for 1-vinyl-2-pyrrolidone: United Kingdom, accessed February 25, 2011, at http:// esis.jrc.ec.europa.eu/doc/risk_assessment/REPORT/ vinylpyrrolidonereport040.p $\overline{d f}$.

European Chemicals Bureau, 2005, Europoean risk assessment report for 5-tert-butyl-2,4,6-trinitro- $m$-xylene (musk xylene): United Kingdom, accessed February 25, 2011, at http://esis.jrc.ec.europa.eu/doc/risk_assessment/REPORT/ muskxylenereport322.pdf.

European Chemicals Bureau, 2007, TC NES Subgroup on Identification of PBT and VPVP Substances-Results of the Evaluation of the PBT/VPVB Properties of: $\alpha, \alpha, \alpha, 4$-tetrachlorotoluene: EBC-Summary Fact Sheet, PBT Working Group_PBT List No. 25, 10 p., accessed February 18, 2011, at http://esis.jrc.ec.europa.eu/doc/PBT-evaluation/ PBT_sum025_CAS_5216-25-1.pdf.

Federal Register, 1967, Testing consent order on 3,4-dichlorobenzotrifluoride and response to the Interagency Testing Committee: Environmental Protection Agency, 40 CFR Part 799, Tuesday, June 23, 1967, v. 52, no. 120, accessed February 23, 2011, at http://www.epa.gov/oppt/chemtest/pubs/ sun54.pdf. 
Federal Register, 1985, 4-Chlorobenzotrifluoride; Decision not to test: Environmental Protection Agency, Friday, October 18 , v. 50, no. 202, accessed February 23, 2011, at http:// www.epa.gov/oppt/chemtest/pubs/note52.pdf.

Fernandez, Pilar; Alder, A.C.; Suter, M.J.F.; and Giger, Walter; 1996, Determination of the quaternary ammonium surfactants ditallowdimethylammonium in digested sludges and marine sediments by supercritical fluid extraction and liquid chromatography with postcolumn ion-pair formation: Analytical Chemistry, v. 68 , no. 5, p. 921-929.

Focazio, M.J., Kolpin, D.W., Barnes, K.K., Furlong, E.T., Meyer, M.T., Zaugg, S.D., Barber, L.B., and Thurman, E.M., 2008, A national reconnaissance of pharmaceuticals and other organic wastewater contaminants in the United States-II. Untreated drinking water sources: Science of the Total Environment, v. 402, no. 2-3, p. 201-216.

Fries, Elke, and Püttmann, Wilhelm, 2004, Monitoring of the antioxidant BHT and its metabolite BHT-CHO in German river water and ground water: Science of the Total Environment, v. 319, no. 1-3, p. 269-282.

Gharbani, P., Tabatabaii, S.M., and Mehrizad, A., 2008, Removal of Congo red from textile wastewater by ozonation: International Journal of Environmental Science and Technology, v. 5, no. 4, p. 495-500, accessed January 11, 2011, at $h t t p: / / s i d . i r / E n / V E W S S I D / J \_p d f / 92220080408 . p d f$.

Giger, Walter; Schaffner, Christian; and Kohler, H.P.E.; 2006, Benzotriazole and tolyltriazole as aquatic contaminants- 1 . Input and occurrence in rivers and lakes: Environmental Science and Technology, v. 40, no. 23, p. 7,186-7,192.

Goncalves, L.L., Beland, F.A., and Marques, M.M., 2001, Synthesis, characterization, and comparative 32P-postlabeling efficiencies of 2,6-dimethylaniline-DNA adducts: Chemical Research in Toxicology, v. 14, p. 165-174.

Green, C.C., Lochmann, S.E., and Staus, D.L., 2005, Acute toxicity of isopropyl methylphosphonic acid, a breakdown product of sarin, to eggs and fry of golden shiner and channel catfish: Journal of Toxicology and Environmental Health, Part A, v. 68. no. 2, p. 141-149.

Hazardous Substances Data Bank (HSDB), 1994, MEDLARS Online Information Retrieval System, National Library of Medicine.

Health Canada, 1990, Environmental and workplace healthNitrilotriacetic acid (NTA): accessed January 11, 2011, at $h t t p: / / w w w . h c-s c . g c . c a /$ ewh-semt/pubs/water-eau/ nitrilotriacetic_acid/index-eng.php.

Health Canada, 1991, Effluents from pulp mills using bleaching -PSL1: accessed January 11, 2011, at http://www.hc-sc. gc.ca/ewh-semt/pubs/contaminants/psl1-lsp1/pulp_mill_ effluents_pate_blanchie/index_e.html.
Howard, P.H., ed., 1997, Handbook of environmental fate and exposure data for organic chemicals-Solvents 3: New York, Lewis Publishers, v. V, 528 p.

International Agency for Research on Cancer, 2011a, 2-Amino-5-(5-nitro-2-furyl)-1,3,4-thiadiazole: IARC monographs on the evaluation of carcinogenic risks to humans, v. 7, p. 143-146, accessed January 10, 2011, at http:// monographs.iarc.fr/ENG/Monographs/vol7/volume7.pdf

International Agency for Research on Cancer, 2011b, Bis(2chloro-1-methylethyl)ether: IARC monographs on the evaluation of carcinogenic risks to humans, v. 71, p. 1,2751,279, accessed January 10, 2011, at http://monographs. iarc.fr/ENG/Monographs/vol71/mono71-69.pdf.

International Agency for Research on Cancer, 2011c, Catechol: IARC monographs on the evaluation of carcinogenic risks to humans, v. 71, p. 433-451, accessed January 10, 2011, at http://monographs.iarc.fr/ENG/Monographs/vol71/ mono71-18.pdf.

International Agency for Research on Cancer, 2011d, 2-Chloronitrobenzene, 3-chloronitrobenzene, and 4-chloronitrobenzene: IARC monographs on the evaluation of carcinogenic risks to humans, v. 65, p. 263-296, accessed January 10, 2011, at http://monographs.iarc.fr/ENG/Monographs/ vol65/mono65-7.pdf.

International Agency for Research on Cancer, 2011e, 4-Chloro-ortho-toluidine: IARC monographs on the evaluation of carcinogenic risks to humans, v. 77, p. 323-339, accessed January 10, 2011, at http://monographs.iarc.fr/ ENG/Monographs/vol77/mono77-12.pdf.

International Agency for Research on Cancer, 2011f, Cinnamyl anthranilate: IARC monographs on the evaluation of carcinogenic risks to humans, v. 77, p. 177-191, accessed January 10, 2011, at http://monographs.iarc.fr/ENG/ Monographs/vol77/mono77-8.pdf.

International Agency for Research on Cancer, 2011g, 2,4-Diaminoanisole and its salts: IARC monographs on the evaluation of carcinogenic risks to humans, v.79, p. 621645, accessed January 10, 2011, at http://monographs.iarc. fr/ENG/Monographs/vol79/mono79-21.pdf.

International Agency for Research on Cancer, 2011h, 1,2-Diethylhydrazine: IARC monographs on the evaluation of carcinogenic risks to humans, v. 71, p. 1,401-1,404, accessed January 10, 2011, at http://monographs.iarc.fr/ ENG/Monographs/vol71/mono71-91.pdf.

International Agency for Research on Cancer, 2011i, Diisopropyl sulfate: IARC monographs on the evaluation of carcinogenic risks to humans, v. 54, p. 229-235, accessed January 10, 2011, at http://monographs.iarc.fr/ENG/Monographs/ vol54/mono54-10.pdf. 
International Agency for Research on Cancer, 2011j, 2,6-Dimethylaniline (2,6-xylidine): IARC monographs on the evaluation of carcinogenic risks to humans, v. 57, p. 323-335, accessed January 10, 2011, at http://monographs. iarc.fr/ENG/Monographs/vol57/mono57-22.pdf.

International Agency for Research on Cancer, 2011k, Disperse yellow 3: IARC monographs on the evaluation of carcinogenic risks to humans, v. 48, p. 149-159, accessed January 10, 2011, at http://monographs.iarc.fr/ENG/Monographs/ vol48/mono48-14.pdf.

International Agency for Research on Cancer, 20111, Aziridine (ethylenimine): IARC monographs on the evaluation of carcinogenic risks to humans, v. 71, p. 337-344, accessed January 10, 2011 at http://monographs.iarc.fr/ENG/ Monographs/vol71/mono71-12.pdf.

International Agency for Research on Cancer, 2011m, HC Blue No. 1): IARC monographs on the evaluation of carcinogenic risks to humans, v. 57, p. 129-141, accessed January 10, 2011 at http://monographs.iarc.fr/ENG/ Monographs/vol57/mono57-8.pdf.

International Programme on Chemical Safety, 1987, Environmental health criteria 75-Toluene diisocyanates: Geneva, International Programme on Chemical Safety, United Nations Environment Programme, the International Labour Organisation, and the World Health Organization, accessed January 11, 2011, at http://www.inchem.org/documents/ehc/ ehclehc75.htm.

International Programme on Chemical Safety, 1990, Environmental health criteria 110 - Tricresyl phosphate: Geneva, International Programme on Chemical Safety, United Nations Environment Programme, the International Labour Organisation, and the World Health Organization, accessed January 11, 2011, at http://www.inchem.org/documents/ehc/ ehclehc110.htm.

International Programme on Chemical Safety, 1996, Hydroquinone health and safety guide: Geneva, International Programme on Chemical Safety, United Nations Environment Programme, the International Labour Organisation, and the World Health Organization, Health and Safety Guide No. 101, accessed January 11, 2011, at http://www.inchem.org/ documents $/ \mathrm{hsg} / \mathrm{hsg} / \mathrm{hsg} 101 . \mathrm{htm}$.

Irwin, R.J.; Van Mouwerik, Mark; Stevens, Lynette; Seese, M.D.; and Basham, Wendy; 1997a, Environmental contaminants encyclopedia-Benzo (j) fluoranthene (CAS number 205-82-3): Fort Collins, Colo., National Park Service, Water Resources Division, accessed January 11, 2011, at http://www.nature.nps.gov/hazardssafety/toxic/benzojfl.pdf.
Irwin, R.J., Van Mouwerik, Mark, Stevens, Lynette, Seese, M.D., and Basham, Wendy, 1997b, Environmental contaminants encyclopedia-Benzo (e) pyrene (CAS number 192-97-2): Fort Collins, Colo., National Park Service, Water Resources Division, accessed January 11, 2011, at http://www.nature.nps.gov/hazardssafety/toxic/benzoepy.pdf.

Irwin, R.J., Van Mouwerik, Mark, Stevens, Lynette, Seese, M.D., and Basham, Wendy, 1997c, Environmental contaminants encyclopedia-Naphthalene, C3- (C3-naphthalene): Fort Collins, Colo., National Park Service, Water Resources Division, accessed January 11, 2011, at http://www.nature. nps.gov/hazardssafety/toxic/nap_c3.pdf.

Irwin, R.J., Van Mouwerik, Mark, Stevens, Lynette, Seese, M.D., and Basham, Wendy, 1997d, Environmental contaminants encyclopedia-Phenanthrene/anthracene, C1- (C1-phenanthrenes $+\mathrm{C} 1$ anthracenes): Fort Collins, Colo., National Park Service, Water Resources Division, accessed January 11, 2011, at http://www.nature.nps.gov/ hazardssafety/toxic/ph\&an_cl.pdf.

Irwin, R.J., Van Mouwerik, Mark, Stevens, Lynette, Seese, M.D., and Basham, Wendy, 1997e, Environmental contaminants encyclopedia-Dibenzothiophene, C2- (C2-dibenzothiophene): Fort Collins, Colo., National Park Service, Water Resources Division, accessed January 11, 2011, at http://www.nature.nps.gov/hazardssafety/toxic/dibenzc2.pdf.

Kato, Kayoko; Silva, M.J.; Reidy, J.A.; Hurtz, Donald, III; Malek, N.A.; Needham, L.L.; Nakazawa, Hiroyuki; Barr, D.B.; and Calafat, A.M.; 2004, Mono(2-ethyl-5-hydroxyhexyl) phthalate and mono-(2-ethyl-5-oxohexyl) phthalate as biomarkers for human exposure assessment to di-(2-ethylhexyl) phthalate: Environmental Health Perspectives, v. 112 , no. 3, p. 327-330.

Keogh, J.P., 1983, Classical syndromes in occupational medicine-Dimethylaminopropionitrile: Americal Journal of Industrial Medicine, v. 4, no. 3, p. 479-484.

Kielhorn, J., Mangelsdorf, I., and Ziegler-Skylakakis, K., 2008, 2-Butenal: Geneva, International Programme on Chemical Safety, World Health Organization, Concise International Chemical Assessment Document No. 74, p. 1-56, accessed January 11, 2011, at http://www.inchem.org/ documents/cicads/cicads/cicad74.pdf.

Koennecker, G., Mangelsdorf, I., and Wibbertmann, A., 1998, N-Phenyl-1-naphthylamine: Geneva, International Programme on Chemical Safety, World Health Organization, Concise International Chemical Assessment Document No. 9, accessed April 30, 2012, at http://www.inchem.org/ documents/cicads/cicads/cicad9.htm. 
Kolpin, D.W., Furlong, E.T., Meyer, M.T., Thurman, E.M., Zaugg, S.D., Barber, L.B., and Buxton, H.T., 2002, Pharmaceuticals, hormones, and other organic wastewater contaminants in U.S. streams, 1999-2000-A national reconnaissance: Environmental Science and Technology, v. 36, no. 6, p. $1,202-1,211$.

Krasner, S.W.; Westerhoff, Paul; Chen, Baiyang; Rittmann, B.E.; and Amy, Gary; 2009, Occurrence of disinfection byproducts in United States wastewater treatment plant effluents: Environmental Science and Technology, v. 43, no. 21, p. $8,320-8,325$.

Lange, F.T., Schmidt, C.K., and Brauch, H.J., 2007, Perfluorinated surfactants-The perfluoroctanesulfonate (PFOS) substitute perfluorobutanesulfonate (PFBS) increasingly affects the raw water quality of Rhine Waterworks: Gas und Wasserfach Wasser Abwasser, v. 148, no. 7-8, p. 510-516.

Lawrence, S.J., 2009, Occurrence of organic wastewater-indicator compounds in the urban streams of Atlanta, Georgia, 2003-2006: Proceedings of the 2009 Georgia Water Resources Conference, April 27-29, 2009, The University of Georgia.

Lee, K.E., Barber, L.B., Cahill, J.D., Furlong E.T., Kolpin, D.W., Meyer, M.T., and Zaugg, S.D., 2004, Presence and distribution of organic wastewater compounds in wastewater, surface, ground, and drinking waters, Minnesota, 200002: U.S. Geological Survey Scientific Investigations Report 2004-5138, accessed April 30, 2012, at http://water.usgs. gov/pubs/sir/2004/5138/.

Legrini, Omar, Oliveros, Esther, and Braun, A.M., 1993, Photochemical processes for water treatment: Chemical Reviews, v. 93, p. 671-698.

Li, Guirong; Tan, Guanghui; Liu, Yunfu; Wang, Yongsheng; and Liao, Lifu; 2009, A catalytic resonance fluorometry method for determination of hydroquinone and its applications: Analytical Sciences, v. 25, no. 4, p. 493-497.

Li, Kai; Woodward, L.A.; Karu, A.E.; and Li, Q.X.; 2000, Immunochemical detection of polycyclic aromatic hydrocarbons and 1-hydroxypyrene in water and sediment samples: Analytica Chimica Acta, v. 419, no. 1, p. 1-8.

Loganathan, B.G.; Sajwan, K.S.; Sinclair, Ewan; Kurunthachalam, S.K.; and Kannan, Kurunthachalam; 2007, Perfluoroalkyl sulfonates and perfluorocarboxylates in two wastewater treatment facilities in Kentucky and Georgia: Water Research, v. 41, no. 20, p. 4,611-4,620.

Lyman, W.J., Reehl, W.F., and Rosenblatt, D.H., 1990, Handbook of chemical property estimation methods: Washington, D.C., American Chemical Society, p. 15.15-15.29.
Makris, K.C.; Salazar, Jason; Quazi, Shahida; Andra, S.S.; Sarkar, Dibyendu; Bach, S.B.H.; and Datta, Rupali; 2008a, Controlling the fate of roxarsone and inorganic arsenic in poultry litter: Journal of Environmental Quality, v. 37, p. 994-1,009.

Makris. K.C.; Quazi, Shahida; Punamiya, Pravin; Sarkar, Dibyendu; and Datta, Rupali; 2008b, Fate of arsenic in swine waste from concentrated animal feeding operations: Journal of Environmental Quality, v. 37, p. 1,626-1,633.

Martins, A.O., Canalli, V.M., Azevedo, C.M.N., and Pires, Marçal, 2006, Degradation of pararosaniline (CI Basic Red 9 monohydrochloride) dye by ozonation and sonolysis: Dyes and Pigments, v. 68, no. 2-3, p. 227-234.

Masten, S.A., 2004, $n$-Butyl glycidyl ether (BGE) [CAS No. 2426-08-6] - Review of toxicological literature: Research Triangle Park, North Carolina, prepared for the National Toxicology Program, National Institute of Environmental Health Sciences, National Institutes of Health, U.S. Department of Health and Human Services, 56 p., accessed April 30, 2012, at http://ntp.niehs.nih.gov/ntp/htdocs/chem background/exsumpdf/butyl_glycidyl_ether.pdf.

Masten, S.A., 2005, 1,3-Dichloro-2-propanol [CAS No. 96-23-1] — Review of toxicological literature: Research Triangle Park, North Carolina, prepared for the National Toxicology Program, National Institute of Environmental Health Sciences, National Institutes of Health, U.S. Department of Health and Human Services, 74 p., accessed April 30, 2012, at http://ntp.niehs.nih.gov/ntp/htdocs/Chem Background/ExSumPdf/dichloropropanol.pdf.

Mayer, L.P, Dyer, C.A., and Propper, C.R., 2003, Exposure to 4-tert-octylphenol accelerates sexual differentiation and disrupts expression of steroidogenic factor 1 in developing bullfrogs: Environmental Health Perspectives, v. 111, no. 4, p. $557-561$.

McKinney, R.A., Pruell, R.J., and Burgess, R.M., 1999, Ratio of the concentrations of anthraquinone to anthracene in coastal marine sediments: Chemosphere, v. 38 , no. 10, p. $2,415-2,430$.

Monien, B.H.; Müller, Carolin; Engst, Wolfram; Frank, Heinz; Seidel, Albrecht; and Glatt, Hansruedi; 2008, Time course of hepatic 1-methylpyrene DNA adducts in rats determined by isotope dilution LC-MS/MS and 32P-postlabeling: Chemical Research in Toxicology, v. 21, no. 10, p. 2,0172,025 .

Mueller, J.A., Di Toro, D.M., and Maiello, J.A., 1995, Fate of octamethylcyclotetrasiloxane (OMCTS) in the atmosphere and in sewage treatment plants as an estimation of aquatic exposure: Environmental Toxicology and Chemistry, v. 14, no. 10 , p. $1,657-1,666$. 
Munro, N.B., Talmage, S.S., Griffin, G.D., Waters, L.C., Watson, A.P., King, J.F., and Hauschild, Veronique, 1999, The sources, fate, and toxicity of chemical warfare agent degradation products: Environmental Health Perspectives, v. 107 , no. 12 , p. $933-974$.

Nagai, Fumiko; Ushiyama, Keiko; and Kano, Itsu; 1993, DNA cleavage by metabolites of butylated hydroxytoluene: Archives of Toxicology, v. 67, no. 8, p. 552-557.

National Cancer Institute, 1978, Bioassay of 5-nitroacenaphthene for possible carcinogenicity - CAS No. 602-87-9, NCI-CG-TR-118: U.S. Department of Health, Education, and Welfare, Public Health Service, National Institutes of Health, $129 \mathrm{p}$.

National Industrial Chemicals Notification and Assessment Scheme, 2000, 1-Vinyl-2-pyrrolidone: Commonwealth of Australia, Priority Existing Chemical Report No.11, 142 p., accessed on January 11, 2011, at http://www.nicnas.gov.au/ publications/CAR/PEC/PEC11/PEC_11_Full_Report_PDF. pdf.

Oliveros, Esther; Legrini, Omar; Hohl, Mathias; Müller, Thomas; and Braun, A.M.; 1997, Industrial waste water treatment-Large scale development of a light-enhanced Fenton reaction: Chemical Engineering and Processing, v. 36, p. 397-405.

Olson, C.T., and Andersen, M.E., 1983, The acute toxicity of perfluorooctanoic and perfluorodecanoic acids in male rats and the effects on tissue fats: Toxicology and Applied Pharmacology, v. 70, no. 3, p. 362-372.

Olthof, M.R., Hollman, P.C., and Katan, M.B., 2001, Chlorogenic acid and caffeic acid are absorbed in humans: Journal of Nutrition, v. 131, no. 1, p. 66-71.

Ontario Ministry of Environment and Energy, 1994, The acute lethality to rainbow trout of water contaminated by an automobile tire: accessed April 30, 2012, at http://www.archive. org/details/acutelethalityto00ontauoft.

Organisation for Economic Co-operation and Development, 2011, OECD screening information data set (SIDS), SIDS initial assessment profiles: UNEP Publications, accessed February 23, 2011, at http://www.chem.unep.ch/ irptc/Publications/sidsidex/sidsidex.htm for the following constituents: benzyl chloride - CAS No. 100-44-7 (1998), 1-chloro-4-nitrobenzene-CAS No. 100-00-5 (2002), dicyclopentadiene - CAS No. 77-73-6 (2002), hexamethylene diisocyanate-CAS No. 822-06-0 (2001), 2-naphtholCAS No. 135-19-3 (2002), phthalic anhydride - CAS No. 85-44-9 (2005), $p$-toluidine-CAS No. 106-49-0 (2005), and triethylphosphate-CAS No. 78-40-0 (1998).
OSPAR Commission, 2004, Hazardous substances seriesHexamethyldisiloxane (HMDS): 82 p., accessed February 23, 2011, at $h t t p: / / w w w . o s p a r . o r g / d o c u m e n t s / d b a s e /$ publications/p00201_BD\%20on\%20HMDS.pdf.

Ou, L.T., Thomas, J.E., and Jing, W., 1994, Biological and chemical degradation of tetraethyl lead in soil: Bulletin of Environmental Contamination and Toxicology, v. 52, no. 2.

Pamme, Nicole; Steinbach, Klaus; Ensinger, W.J.; and Schmidt, T.D.; 2001, Analysis of polynitrophenols and hexyl by liquid chromatography-mass spectrometry using atmospheric pressure ionisation methods and a volatile ionpairing reagent: Journal of Chromatography A, v. 943, no. 1, p. 47-54.

Pennington, J.C., Thorn, K.A., Hayes, C.A., Porter, B.E., and Kennedy, K.R., 2003, Immobilization of 2,4- and 2,6-dinitrotoluenes in soils and compost: U.S. Army Corps of Engineers, Engineer Reasearch and Development Center, ERDC/EL TR-03-2, 50 p., accessed April 30, 2012, at http://el.erdc.usace.army.mil/elpubs/pdf/trel03-2.pdf.

Plumlee, M.H., Larabee, Jeannine, and Reinhard, Martin, 2008, Perfluorochemicals in water reuse: Chemosphere, v. 72 , no. 10 , p. $1,541-1,547$.

Ponthieu, Marie; Pinel-Raffaitin Pauline; Le Hecho, Isabelle; Mazeas, Laurent; Amouroux, David; Donard, Olivier; and Potin-Gautier, Martine; 2007, Speciation analysis of arsenic in landfill leachate: Water Research, v. 41, no. 14, p. $3,177-3,185$.

Price, O.R., Williams, R.J., Zhang, Zhong, and Egmond, Roger van, 2009, Spatially explicit river catchment modelling of decamethylcyclopentasiloxane [poster] in SETAC Europe 19th Annual Meeting, Protecting ecosystem health-Facing the challenge of a globally changing environment, Gothenburg, Sweden, 31 May-4 June 2009: Brussels, Society of Environmental Toxicology and Chemistry.

Quiñones, Oscar, and Snyder, S.A., 2009, Occurrence of perfluoroalkyl carboxylates and sulfonates in drinking water utilities and related waters from the United States: Environmental Science and Technology, v. 43, no. 24, p. 9,089-9,095.

Radtke, C.W., Gianotto, David, and Roberto, F.F., 2002, Effects of particulate explosives on estimating contamination at a historical explosives testing area: Chemosphere, v. 46, no. 1, p. 3-9.

Renner, Rebecca, 2006, The long and the short of perfluorinated replacements: Environmental Science and Technology, v. 40, no. 1, p. 12-13. 
Russell, L.C., and Fingerman, Milton, 1984, Exposure to the water soluble fraction of crude oil or to naphthalenes alters breathing rates in gulf killifish, Fundulus grandis: Bulletin of Environmental Contamination and Toxicology, v. 32, no. 1, p. 363-367.

Sampathkumar, Krishnaswamy, and Yesudas, Sooraj, 2009, Hair dye poisoning and the developing world: Journal of Emergencies, Trauma and Shock, v. 2, no. 2, p. 129-131.

Sato, Takahiko; Kato, Kenji; Ose, Youki; Nagase, Hisamitsu; and Ishikawa, Tetsuya; 1985, Nitroarenes in Suimon River sediment: Mutation Research, v. 157, no. 2-3, p. 135-143.

Savel'eva, E.I., Radilov, A.S., Kuznetsova, T.A., and Volynets, N.F., 2001, Determination of methylphosphonic acid and its esters as chemical markers of organophosphorus chemical warfare agents: Russian Journal of Applied Chemistry, v. 74 , no. 10 , p. 1,671-1,676.

Silva, M.J., Barr, D.B., Reidy, J.A., Malek, N.A., Hodge, C.C., Caudill, S.P., Brock, J.W., Needham, L.L., and Calafat, A.M., 2004, Urinary levels of seven phthalate metabolites in the U.S. population from the National Health and Nutrition Examination Survey (NHANES) 1999-2000 [published erratum appears in Environmental Health Perspect 2004; 112(5):A270]: Environmental Health Perspectives, v. 112, no. 3 , p. 331-338.

Sitting, Marshall, 2002, Handbook of toxic and hazardous chemicals: Park Ridge, N.J., Noyes Publications, p. 716-717.

Smeds, Annika, and Saukko, Pekka, 2003, Brominated flame retardants and phenolic endocrine disrupters in Finnish human adipose tissue: Chemosphere, v. 53, no. 9, p. 1,123-1,130.

Spectrum Laboratories, 2011a, Spectrum chemical fact sheet-Chemical Abstract Number (CAS \#) 59507: accessed February 23, 2011, at http://www.speclab.com/ compound/c59507.htm.

Spectrum Laboratories, 2011b, Spectrum chemical fact sheet-Chemical Abstract Number (CAS \#) 77474: accessed February 23, 2011, at http://www.speclab.com/ compound/c77474.htm.

Spectrum Laboratories, 2011c, Spectrum chemical fact sheet-Chemical Abstract Number (CAS \#) 108054: accessed February 23, 2011, at http://www.speclab.com/ compound/c108054.htm.

Spectrum Laboratories, 2011d, Spectrum chemical fact sheet-Chemical Abstract Number (CAS \#) 111911: accessed February 23, 2011, at http://www.speclab.com/ compound/c111911.htm.
Spectrum Laboratories, 2011e, Spectrum chemical fact sheet-Chemical Abstract Number (CAS \#) 86306: accessed February 23, 2011, at http://www.speclab.com/ compound/c86306.htm.

Sverdrup, L.E.; Jensen, John; Kelley, A.E.; Krogh, P.H.; and Stenersen, Jørgen; 2002, Effect of eight polycyclic aromatic compounds on the survival and reproduction of Enchytraeus crypticus (Oligochaeta, Clitellata): Environmental Toxicology and Chemsitry, v. 21, p. 109-114.

TenEyck, M.C., and Markee, T.P., 2007, Toxicity of nonylphenol, nonylphenol monoethoxylate, and nonylphenol diethoxylate and mixtures of these compounds to Pimephales promelas (fathead minnow) and Ceriodaphnia dubia: Archives of Environmental Contamination and Toxicology, v. 53, p. 599-606.

Tertuliani, J.S., Alvarez, D.A., Furlong, E.T., Meyer, M.T, Zaugg, S.D., and Koltun, G.F., 2008, Occurrence of organic wastewater compounds in the Tinkers Creek watershed and two other tributaries to the Cuyahoga River, northeast Ohio: U.S. Geological Survey Scientific Investigations Report 2008-5173, 60 p.

Thinakaran, N., Panneerselvam, P., Baskaralingam, P., Elango, D., and Sivanesan, S., 2008, Equilibrium and kinetic studies on the removal of Acid Red 114 from aqueous solutions using activated carbons prepared from seed shells: Journal of Hazardous Materials, v. 158, no. 1, p. 142-150.

Turner Designs, 2001, Application note-Fluorescent tracer dyes: 2 p., accessed June 5, 2012, at http://www. turnerdesigns.com/t2/doc/appnotes/998-5104.pdf.

U.S. Department of Health and Human Services, 1982, Carcinogenesis bioassay of C.I. Disperse Yellow 3 (CAS No. 2832-40-8) in F344/N rats and B6C3F1 mice (feed study): U.S. Department of Health and Human Services, Public Health Service, National Toxicology Program Technical Report Series No. 222, NTP-81-80, 186 p., accessed April 30, 2012, at http://ntp.niehs.nih.gov/ntp/htdocs/lt_rpts/ tr222.pdf.

U.S. Department of Health and Human Services, 1992, Toxicological profile for 2,3-benzofuran: Agency for Toxic Substances and Disease Registry, accessed February 23, 2011, at http://www.atsdr.cdc.gov/toxprofiles/tp25.pdf.

U.S. Department of Health and Human Services, 1994, Toxicological profile for 4,4'-methylenebis(2-chloroaniline) (MBOCA): Atlanta, Ga., Public Health Service, Agency for Toxic Substances and Disease Registry, accessed January 11, 2011, at http://www.atsdr.cdc.gov/ToxProfiles/ tp.asp? id=997\&tid=209. 
U.S. Department of Health and Human Services, 1995a, Public health statement for polycyclic aromatic hydrocarbons (PAHs): Agency for Toxic Substances and Disease Registry, accessed February 23, 2011, at http://www.atsdr.cdc.gov/ phs/phs.asp? $i d=120 \&$ tid $=25$.

U.S. Department of Health and Human Services, 1995b, Toxicological profile for Otto Fuel II and its components: Atlanta, Ga., Public Health Service, Agency for Toxic Substances and Disease Registry, 194 p., accessed February 23, 2011, at http://www.atsdr.cdc.gov/ToxProfiles/tp77.pdf.

U.S. Department of Health and Human Services, 1995c, Toxicological profile for tetryl (2,4,6-trinitrophenyl-N-methylnitramine): Atlanta, Ga., Public Health Service, Agency for Toxic Substances and Disease Registry, 133 p., accessed February 23, 2011, at http://www.atsdr.cdc.gov/ToxProfiles/ tp80.pdf.

U.S. Department of Health and Human Services, 1997, Toxicological profile for hydrazines: Atlanta, Ga., Public Health Service, Agency for Toxic Substances and Disease Registry, 224 p., accessed February 23, 2011, at http://www.atsdr.cdc. gov/toxprofiles/tp100.pdf.

U.S. Department of Health and Human Services, 1999, Toxicological profile for chlorophenols: Atlanta, Ga., Public Health Service, Agency for Toxic Substances and Disease Registry, 260 p., accessed January 10, 2011, at http://www. atsdr.cdc.gov/ToxProfiles/tp107.pdf.

U.S. Department of Health and Human Services, 2001, Profile for di-n-butyl phthalate: Atlanta, Ga., Public Health Service, Agency for Toxic Substances and Disease Registry, 255 p., accessed January 10, 2011, at http://www.atsdr.cdc.gov/ toxprofiles/tp135.pdf.

U.S. Department of Health and Human Services, 2003, Public health statement-Sulfur mustard, CAS\#: 505-60-2: Atlanta, Ga., Public Health Service, Agency for Toxic Substances and Disease Registry, 6 p., accessed January 10, 2011, at http://www.atsdr.cdc.gov/ToxProfiles/tp49-c1-b.pdf.

U.S. Department of Health and Human Services, 2005, Report on carcinogens (11th ed.): U.S. Department of Health and Human Services, Public Health Service, National Toxicology Program, accessed January 11, 2011, at http://ntp.niehs. nih.gov/ntp/roc/toc11.htm.

U.S. Department of Health and Human Services, 2006, Toxicological profile for cyanide: Atlanta, Ga., Public Health Service, Agency for Toxic Substances and Disease Registry, 341 p., accessed January 11, 2011, at http://www.atsdr.cdc. gov/ToxProfiles/tp8.pdf.
U.S. Department of Health and Human Services, 2007, Toxicological profile for acrolein: Atlanta, Ga., Public Health Service, Agency for Toxic Substances and Disease Registry, 227 p., accessed March 15, 2011, at http://www.atsdr.cdc. gov/toxprofiles/tp124.pdf.

U.S. Department of Health and Human Services, 2009, Draft toxicological profile for perfluoroalkyls: Atlanta, Ga., Public Health Service, Agency for Toxic Substances and Disease Registry, 404 p., accessed March 15, 2011, at http://www. atsdr.cdc.gov/ToxProfiles/tp200.pdf.

U.S. Environmental Protection Agency, 1980a, Ambient water quality criteria for 2,4-dimethylphenol: Washington, D.C., U.S. Environmental Protection Agency Office of Water, EPA 440/5-80-044, accessed December 20, 2010, at http://water. epa.gov/scitech/swguidance/standards/upload/2001_10_12_ criteria_ambientwqc_24dimethylphenol80.pdf.

U.S. Environmental Protection Agency, 1980b, Ambient water quality criteria for 2-chlorophenol: Washington, D.C., U.S. Environmental Protection Agency Office of Water, EPA 440/5-80-034, accessed December 20, 2010, at http://water. epa.gov/scitech/swguidance/standards/upload/2001_10_12_ criteria_ambientwqc_2clorophenol80.pdf.

U.S. Environmental Protection Agency, 1985, Health and environmental effects profile for 1,2,3,4,5-penta-bromo6-chlorocyclohexane: Cincinnati, Ohio, Office of Health and Environmental Assessment, Environmental Criteria and Assessment Office, EPA/600/X-85/402, 70 p.

U.S. Environmental Protection Agency, 1990, Health and environmental effects document for trinitrophenylmethylnitramine: Cincinnati, Ohio, Office of Health and Environmental Assessment, Environmental Criteria and Assessment Office, ECAO-CIN-G091.

U.S. Environmental Protection Agency, 1994a, Chemical summary for cyclohexane: U.S. Environmental Protection Agency Office of Pollution Prevention and Toxics EPA 749-F-94-011a, accessed January 11, 2011, at http://www. epa.gov/chemfact/s_cycloh.txt.

U.S. Environmental Protection Agency, 1994b, R.E.D. FACTS_Disodium cyanodithioimidocarbonate (DCDIC): Washington, D.C., U.S. Environmental Protection Agency, EPA 738-F-94-017, accessed January 11, 2011, at http:// www.epa.gov/oppsrrd1/REDs/factsheets/3065fact.pdf.

U.S. Environmental Protection Agency, 2000a, 2-Acetylaminofluorene (53-96-3) — Hazard summary: accessed January 11, 2011, at http://earth1.epa.gov/ttn/atw/hlthef/acetylam. html.

U.S. Environmental Protection Agency, 2000b, 4-Dimethylaminoazobenzene (60-11-7)—Hazard summary: accessed January 11, 2011, at http://earth1.epa.gov/ttn/atw/hlthef/ di-benze.html. 
U.S. Environmental Protection Agency, 2000c, Hexamethylphosphamide (680-31-9)—Hazard summary: accessed January 11, 2011, at http://www.epa.gov/ttn/atw/hlthef/hexapho.html.

U.S. Environmental Protection Agency, 2000d, Methylhydrazine (60-34-4)-Hazard summary: accessed January 11, 2011, at http://earth1.epa.gov/ttn/atw/hlthef/methylhy.html.

U.S. Environmental Protection Agency, 2000e, 4-Nitrobiphenyl (92-93-3) - Hazard summary: accessed January 11, 2011, at http://www.epa.gov/ttn/atw/hlthef/nitrobip.html.

U.S. Environmental Protection Agency, 2002a, Five-year review report-Forest Glen mobile home subdivision site, City of Niagara Falls and Town of Niagara, Niagara County, New York: accessed January 11, 2011, at $h t t p: / / w w w . e p a$. gov/superfund/sites/fiveyear/f02-02012.pdf.

U.S. Environmental Protection Agency, 2002b, Acrylamide and N-methylolacrylamide grouts - Withdrawal of proposed ban: Federal Register Environmental Documents, December 2, 2002, v. 67, no. 231, accessed January 11, 2011, at http://www.epa.gov/EPA-TOX/2002/December/ Day-02/t30470.htm.

U.S. Environmental Protection Agency, 2003a, Reregistration Eligibility Decision (RED) - Di-n-propyl isocinchomeronate (MGK® Repellent 326) (Revised 03/11/05): Washington, D.C., U.S. Environmental Protection Agency, EPA 738-R-03-003, $74 \mathrm{p}$.

U.S. Environmental Protection Agency, 2003b, Ambient aquatic life water quality criteria for tributyltin (TBT) Final: Washington, D.C., U.S. Environmental Protection Agency, EPA 822-R-03-031, 138 p.

U.S. Environmental Protection Agency, 2003c, High Production Volume (HPV) Challenge-Robust summary for 1,5,9-cyclododecatriene: 46 p., accessed February 23, 2011, at http://www.epa.gov/hpv/pubs/summaries/cyclo/c13404rr. $p d f$.

U.S. Environmental Protection Agency, 2003d, Sulfuric acid, diethyl ester (diethyl sulfate; CAS RN 64-67-5)—High Production Volume (HPV) Chemical Challenge Test Plan and Data Review: Prepared by Toxicology/Regulatory Services, Inc., for The Dow Chemical Company, accessed January 11, 2011, at http://www.epa.gov/hpv/pubs/summaries/ slfacdde/c15002tp.pdf.

U.S. Environmental Protection Agency, 2004, Toxics Release Inventory (TRI) Program-2004 TRI national analysis: accessed January 11, 2011, at http://www.epa.gov/tri/ tridata/tri04/data/index.html.
U.S. Environmental Protection Agency, 2005a, Furniture flame retardancy partnership-Environmental profiles of chemical flame-retardant alternative for low-density polyurethane foam: Washington, D.C., U.S. Environmental Protection Agency, EPA 742-R-05-002A and EPA 742-R-05-002B, v. $1-2,153$ p. and 393 p., respectively.

U.S. Environmental Protection Agency, 2005b, Final HPV data summary for benzoyl chloride, CAS No. 98-88-4: 13 p., accessed February 18, 2011, at http://www.epa.gov/hpv/ pubs/summaries/benzchlr/c14969rt.pdf.

U.S. Environmental Protection Agency, 2005c, Cyclohexanol (CAS Number 108-93-0)-USEPA HPV Challenge Program submission (final version): 20 p., accessed February 23,2011 , at $h t t p: / / w w w . e p a . g o v / h p v / p u b s /$ summaries/ cyclohex/c13221rt2.pdf.

U.S. Environmental Protection Agency, 2006a, Reregistration eligibility decision for aliphatic alkyl quaternaries (DDAC): Washington, D.C., U.S. Environmental Protection Agency, EPA 739-R-06-008, 126 p.

U.S. Environmental Protection Agency, 2006b, 4-Vinylcyclohexene-High Production Volume (HPV) Challenge Program submission: accessed February 18, 2011, at http:// www.epa.gov/hpv/pubs/summaries/4vinylhx/c16390.pdf.

U.S. Environmental Protection Agency, 2007, US EPA HPV Challenge Program - Test plan submission-O,O-Diethyl phosphate (CAS No 298-06-6) and O,O-Diethyl dithiophosphate, sodium salt (CAS No 3338-24-7): Submitted by Bayer CropScience LP, accessed January 11, 2011, at http:// www.epa.gov/hpv/pubs/summaries/oodiphos/c14864rt.pdf.

U.S. Environmental Protection Agency, 2008a, Toxics Release Inventory (TRI) Program-TRI 2008 basic data files: accessed January 11, 2011, at http://www.epa.gov/tri/ tridata/tri08/national_analysis/data/indexbasic.html.

U.S. Environmental Protection Agency, 2008b, Drinking water health advisory for 2,4-dinitrotoluene and 2,6-dinitrotoluene: Washington, D.C., U.S. Environmental Protection Agency, EPA 822-R-08-010, 97 p., accessed February 23, 2011, at http://www.epa.gov/ogwdw/ccl/pdfs/reg_ determine2/healthadvisory_ccl2-reg2_dinitrotoluenes.pdf.

U.S. Environmental Protection Agency, 2009a, 2009 Edition of the drinking water standards and health advisories (updated October 2009): U.S. Environmental Protection Agency Office of Water, EPA 822-R-09-011, accessed December 20, 2010, at http://waterepa.gov/action/ advisories/drinking/upload/dwstandards2009.pdf.

U.S. Environmental Protection Agency, 2009b, Region 5 Superfund (SF) - Duell and Gardner Landfill (EPA ID\#

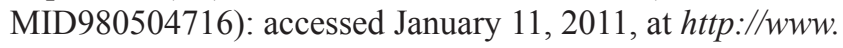
epa.gov/reg5sfun/npl/michigan/MID980504716.html. 
U.S. Environmental Protection Agency, 2010a, National recommended water quality criteria: accessed December 27 , 2010, at http://water.epa.gov/scitech/swguidance/standards/ current/.

U.S. Environmental Protection Agency, 2010b, Contaminant Candidate List 3-CCL3: accessed December 20, 2010, at http://water.epa.gov/scitech/drinkingwater/dws/ccl/ccl3.cfm.

U.S. Environmental Protection Agency, 2011a, ECOTOXicology Database System (version 4.0): U.S. Environmental Protection Agency, Office of Research and Development and the National Health and Environmental Effects Research Laboratory's Mid-Continent Ecology Division, accessed January 5, 2011, at http://www.epa.gov/ecotox/.

U.S. Environmental Protection Agency, 2011b, Persistent, Bioaccumulative, and Toxic Profiles Estimated for Organic Chemicals (PBT Profiler): accessed January 10, 2011, at http://www.pbtprofiler.net/.

U.S. Environmental Protection Agency, 2011c, Integrated Risk Information System-N-Nitrosodiethanolamine (CASRN 1116-54-7): accessed January 10, 2011, at http://www.epa. gov/IRIS/subst/0252.htm.

U.S. Environmental Protection Agency, 2011d, Integrated Risk Information System-Polychlorinated biphenyls (PCBs) (CASRN 1336-36-3): accessed January 10, 2011, at http:// www.epa.gov/IRIS/subst/0294.htm.

U.S. Environmental Protection Agency, 2011e, Technical factsheet on-Dioxin (2,3,7,8-TCDD): accessed on January 10, 2011, at http://www.epa.gov/ogwdw000/pdfs/factsheets/ soc/tech/dioxin.pdf.

U.S. Environmental Protection Agency, 2011f, Basic information about acrylamide in drinking water: accessed on January 10, 2011, at http://water.epa.gov/drink/contaminants/ basicinformation/acrylamide.cfm.

U.S. Environmental Protection Agency, 2011g, Publications details for kinetic-based models for bromate formation in natural waters: National Center for Environmental Research, accessed February 18, 2011, at http://cfpub. epa.gov/ncer_abstracts/index.cfm/fuseaction/display. publications/abstract/915.

U.S. Environmental Protection Agency, 2012, Unregulated Contaminated Monitoring Program: accessed April 26, 2012, at http://water.epa.gov/lawsregs/rulesregs/sdwa/ ucmr/.

U.S. Food and Drug Administration, 2010, Generally Recognized as Safe (GRAS): accessed February 18, 2011, at http://www.fda.gov/Food/IngredientsPackagingLabeling/ GRAS/ucm2006850.htm.
Vincoli, J.W., 1997, Risk management for hazardous chemicals: Boca Raton, Fla., CRC Press, v. 1, 3,136 p.

Walsh, M.E., 1989, Analytical methods for determining nitroguanidine in soil and water: Hanover, N.H., U.S. Army Corps of Engineers Cold Regions Research and Engineering Laboratory, Special Report 89-35, 29 p.

Wang, Rong; Moody, R.P.; Koniecki, Diane; and Zhu, J.P.; 2009, Low molecular weight cyclic volatile methylsiloxanes in cosmetic products sold in Canada-Implication for dermal exposure: Environment International, v. 35, no. 6, p. 900-904.

Whelton, A.J., Jensen, J.L., Richards, T.E., and Valdivia, R.M., 2003, The cyanic threat to potable water: U.S. Army Center for Health Promotion and Preventive Medicine, Proceedings, AWWA Annual Conference and Exposition, Anaheim, Calif., June 14-17, 2003.

Wick, L.Y., and Gschwend, P.M., 1998, Source and chemodynamic behavior of diphenyl sulfone and ortho- and parahydroxybiphenyl in a small lake receiving discharges from an adjacent Superfund site: Environmental Science and Technology, v. 32, no. 9, p. 1,319-1,328.

Wood, A.W., Johnston, B.D., Farrell, A.P., and Kennedy, C.J., 1996, Effects of didecyldimethylammonium chloride (DDAC) on the swimming performance, gill morphology, disease resistance, and biochemistry of rainbow trout (Oncorhynchus mykiss): Canadian Journal of Fisheries and Aquatic Sciences, v. 53, p. 2,424-2,432.

Woodland, C.L., and Maly, E.J., 1997, The effects of tetrachloroguaiacol on the growth, survival, and development of the fathead minnow, Pimephales promelas: Archives of Environmental Contamination and Toxicology, v. 32, no. 4, p. 394-398.

World Health Organization, 2000, Flame retardants-Tris(2butoxyethyl) phosphate, tris (2-ethylhexyl) phosphate and tetrakis (hydroxymethyl) phosphonium salts: World Health Organization, Environmental Health Criteria No. 218, ISBN 92-4-157218-3, 149 p.

Xu, X.B., Nachtman, J.P., Rappaport, S.M., Wei, E.T., Lewis, S., and Burlingame, A.L., 1981, Identification of 2-nitrofluorene in diesel exhaust particulates: Journal of Applied Toxicology, v. 1, no. 3, p. 196-198.

Ye, Xiaoyun, Bishop, A.M., Reidy, J.A., Needham, L.L., and Calafat, A.M., 2006, Parabens as urinary biomarkers of exposure in humans: Environmental Health Perspectives, v. 114 , no. 12 , p. $1,843-1,846$. 
Zaugg, S.D., Smith, S.G., Schroeder, M.P., Barber, L.B., and Burkhardt, M.R., 2002, Methods of analysis by the U.S. Geological Survey National Water Quality LaboratoryDetermination of wastewater compounds by polystyrenedivinylbenzene solid-phase extraction and capillary-column gas chromatography/mass spectrometry: U.S. Geological Survey Water-Resources Investigations Report 01-4186, $37 \mathrm{p}$.
Zhang, Huichun, and Huang, C.H., 2003, Oxidative transformation of triclosan and chlorophene by manganese oxides: Environmental Science and Technology, v. 37, no. 11, p. $2,421-2,430$.

Zhang, Y., Zhu, Y., Wand, S., Zheng, F., Ren, F., Kim, S.J., 2002, Direct determination of 1-hydroxypyrene in fish from coastal water by synchronous fluorimetry: Bulletin of Environmental Contamination and Toxicology, v. 69, no. 4, p. 494-500. 


\section{Supplemental Information J.}

\section{Prioritization of Radionuclides in Water (Group J)}

By Michael R. Rosen, Zoltan Szabo, and Lisa D. Olsen

\section{Abbreviations and Acronyms Used in Supplemental Information J}

$\begin{array}{ll}\text { AMCL } & \text { alternative Maximum Contaminant Level (drinking-water-quality benchmark, USEPA) } \\ \text { CASRN } & \text { Chemical Abstracts Service Registry Number }{ }^{\circledR} \text { (American Chemical Society) } \\ \text { ICP/MS } & \text { inductively coupled plasma with mass spectrometry } \\ \text { L } & \text { liter } \\ \text { MCL } & \text { Maximum Contaminant Level (drinking-water-quality benchmark, USEPA) } \\ \mu \mathrm{g} / \text { L } & \text { microgram per liter } \\ \text { NASQAN } & \text { National Stream Quality Accounting Network (USGS) } \\ \text { NAWQA } & \text { National Water-Quality Assessment (USGS) } \\ \text { NTAS } & \text { National Target Analyte Strategy (USGS NAWQA) } \\ \text { NWIS } & \text { National Water Information System (USGS) } \\ \text { pCi/L } & \text { picocurie per liter } \\ \text { Pb } & \text { lead } \\ \text { Po } & \text { polonium } \\ \text { Ra } & \text { radium } \\ \text { Rn } & \text { radon } \\ \text { Th } & \text { thorium } \\ \text { U } & \text { uranium } \\ \text { UCMR } & \text { Unregulated Contaminant Monitoring Rule (USEPA) } \\ \text { USEPA } & \text { U.S. Environmental Protection Agency } \\ \text { USGS } & \text { U.S. Geological Survey }\end{array}$


This supplemental information section of the report describes the prioritization of 14 radionuclide constituents in water (Group J) by the U.S. Geological Survey (USGS) National Target Analyte Strategy (NTAS) work group for national- and regional-scale ambient monitoring in the United States in support of planning for the third decade (Cycle 3) of the National Water-Quality Assessment (NAWQA) Program. The prioritization in this report addresses only naturally occurring radioactive isotopes because human-made radioactive isotopes typically are associated with known localized point-source releases and are not of high priority for ambient water. The feasibility of implementing analytical methods for high-priority radionuclides, and knowledge and concerns of radionuclides as a constituent group, also are described in this section.

One radionuclide was prioritized for another NTAS constituent group - elemental uranium (U) was prioritized for Group D1 (trace metals and other inorganic constituents in water). However, no constituents overlapped between Group J and Group D1 because the prioritization in Group $\mathrm{J}$ was for the specific isotopes of uranium $\left({ }^{234} \mathrm{U},{ }^{235} \mathrm{U}\right.$, and ${ }^{238} \mathrm{U}$ ) rather than for elemental uranium. Elemental uranium in Group D1, with a Chemical Abstracts Service Registry Number ${ }^{\circledR}$ (CASRN) of 7440-61-1, is a mixture composed predominantly of ${ }^{238} \mathrm{U}$ (typically about 99.7 percent), with lesser amounts of other isotopes. In circumstances in which radionuclides (or their contributions to overall radioactivity) are of interest, it is usually preferable to monitor for specific isotopes; however, occurrence data for elemental uranium can be useful in identifying sites where uranium is present and where monitoring of specific isotopes would likely yield valuable information. The presence of ${ }^{234} \mathrm{U}$ or ${ }^{235} \mathrm{U}$ can contribute to overall radioactivity and can result in activities in water that are greater than benchmarks for human health (table J.1 at http://pubs.usgs.gov/sir/2012/5218/downloads/tableJ.xlsx).

\section{Prioritization of Radionuclides in Water}

This section describes the methods used to prioritize radionuclides in water and the results of the prioritization. USGS monitoring data for nine isotopic radionuclides are available and include data from NAWQA Cycles 1 and 2 for groundwater (table J.1); these include three radium isotopes $\left.{ }^{(224} \mathrm{Ra},{ }^{226} \mathrm{Ra},{ }^{228} \mathrm{Ra}\right)$, three uranium isotopes $\left({ }^{234} \mathrm{U},{ }^{235} \mathrm{U}\right.$, and $\left.{ }^{238} \mathrm{U}\right)$, and one radioisotope each of radon $\left({ }^{222} \mathrm{Rn}\right)$, lead $\left({ }^{210} \mathrm{~Pb}\right)$, and polonium $\left({ }^{210} \mathrm{Po}\right)$. Data also are available for gross alphaparticle activity and gross beta-particle activity (table J.1), which can be used as bulk measures of radioactivity from all radionuclides that emit alpha or beta radioactivity. In addition, elemental uranium was monitored in groundwater $(5,850$ samples) and surface water (4,726 samples) by the NAWQA and National Stream Quality Accounting Network (NASQAN) Programs. Detection frequencies and activities for constituents listed in table J.1 from Ayotte, Gronberg, and Apodaca (2011); Szabo and others (2012); and the USGS National Water
Information System (NWIS; U.S. Geological Survey, 2011a) were considered in prioritizing these nine isotopic radionuclides plus gross alpha-particle activity and gross beta-particle activity in water.

Data also are available for selected radionuclides analyzed for a targeted reconnaissance in 1998 of groundwater sources used for drinking water (Focazio and others, 2001), including ${ }^{210} \mathrm{~Pb},{ }^{210} \mathrm{Po},{ }^{224} \mathrm{Ra},{ }^{226} \mathrm{Ra}$, and ${ }^{228} \mathrm{Ra}$ (99 samples), and 3 thorium isotopes $\left({ }^{228} \mathrm{Th},{ }^{230} \mathrm{Th}\right.$, and $\left.{ }^{232} \mathrm{Th}\right)(33$ samples). Because sufficient national-scale data were available (table J.1) for the radium isotopes, only data for ${ }^{210} \mathrm{Po}$ and ${ }^{210} \mathrm{~Pb}$, and ${ }^{228} \mathrm{Th},{ }^{230} \mathrm{Th}$, and ${ }^{232} \mathrm{Th}$ were used from the 1998 targeted reconnaissance in the prioritization of constituents. Thorium isotopes were only analyzed in the subset of samples with ${ }^{224} \mathrm{Ra}$ activities greater than $4 \mathrm{pCi} / \mathrm{L}$ (Focazio and others, 2001) because thorium is extremely insoluble in water (Cothern and Rebers, 1990) and was not expected to be observed in groundwater samples.

For groundwater, the most frequently sampled isotope (about 4,800 samples) has been ${ }^{222} \mathrm{Rn}$ (table J.1), which occurs as a dissolved gas. Isotopes of radium $\left({ }^{226} \mathrm{Ra}\right.$ and $\left.{ }^{228} \mathrm{Ra}\right)$ were analyzed in about 15 percent of NAWQA groundwater samples (about 1,100 samples). The prioritization of radionuclides was performed using only the monitoring data for groundwater because comparable data for specific isotopes were not available for surface water; however, many of the geochemical processes that can cause radionuclides to occur in groundwater can be relevant for surface water, depending upon stream geochemistry (Zielinski and others, 1997), because of the erosion of radionuclide-containing mineral deposits and inputs of groundwater into gaining streams.

For surface water, samples analyzed for elemental uranium represented more than 400 river sites as part of the NAWQA and NASQAN Programs (fig. J.1), and less than 1 percent had concentrations greater than the U.S. Environmental Protection Agency (USEPA) Maximum Contaminant Level (MCL) of 30 micrograms per liter ( $\mu \mathrm{g} / \mathrm{L}$; U.S. Environmental Protection Agency, 2010). Approximately 27 percent had concentrations greater than or equal to one-tenth of the MCL. Elemental uranium was placed into NTAS Tier 1 (high priority for monitoring) using methods described for Group D1 in the "Supplemental Information D1" section.

\section{Prioritization Methods for Radionuclides in Water}

Radionuclides in water were prioritized by evaluating their potential for occurrence in ambient water and their potential to affect human health. Toxicity was not explicitly considered in the evaluation (that is, benchmark quotients were not used) because all of the radionuclides considered are Class A human carcinogens (U.S. Environmental Protection Agency, 1999a) and occur naturally. Concentrations (activities in picocuries per liter $[\mathrm{pCi} / \mathrm{L}]$ ) from USGS monitoring data were compared to human-health benchmarks promulgated by 


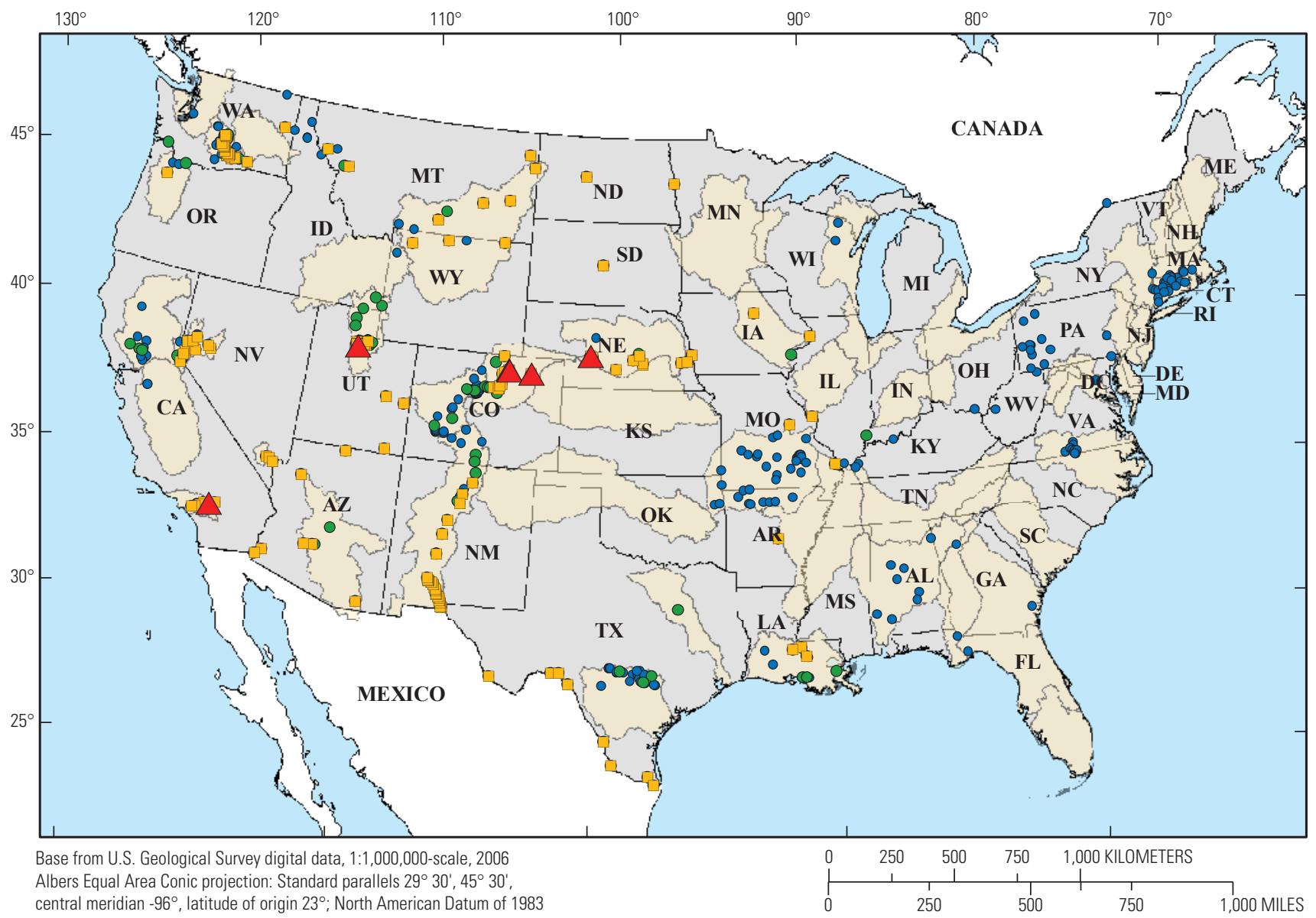

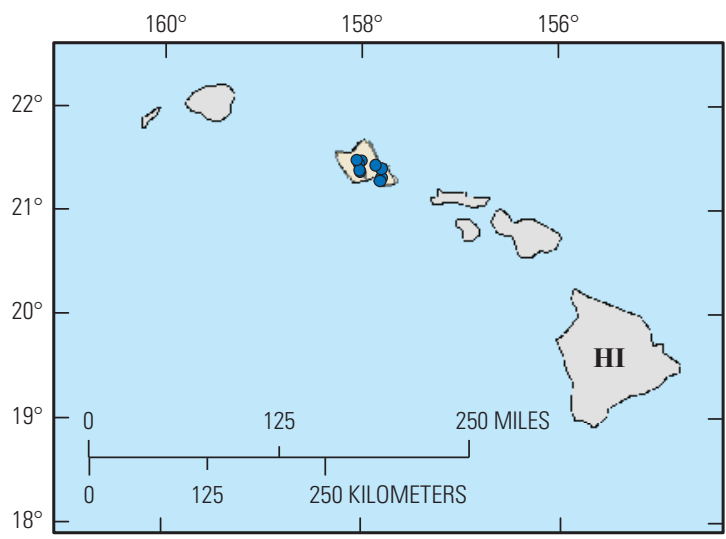

Base from U.S. Geological Survey digital data, 1:1,000,000-scale, 2006 Albers Equal Area Conic projection

Standard parallels $8^{\circ}, 18^{\circ}$, central meridian $-157^{\circ}$

latitiude of origin $13^{\circ}$; North American Datum of 1983

\section{EXPLANATION}

[Data from NAWQA data warehouse; U.S. Geological Survey, 2011b]

$\square$ NAWOA study unit
Uranium concentration in micrograms per liter
$\begin{array}{ll}30 \text { or greater } & \text { ○ } 1 \text { to less than } 3 \\ 3 \text { to less than } 30 & \circ \quad \text { Not detected }\end{array}$

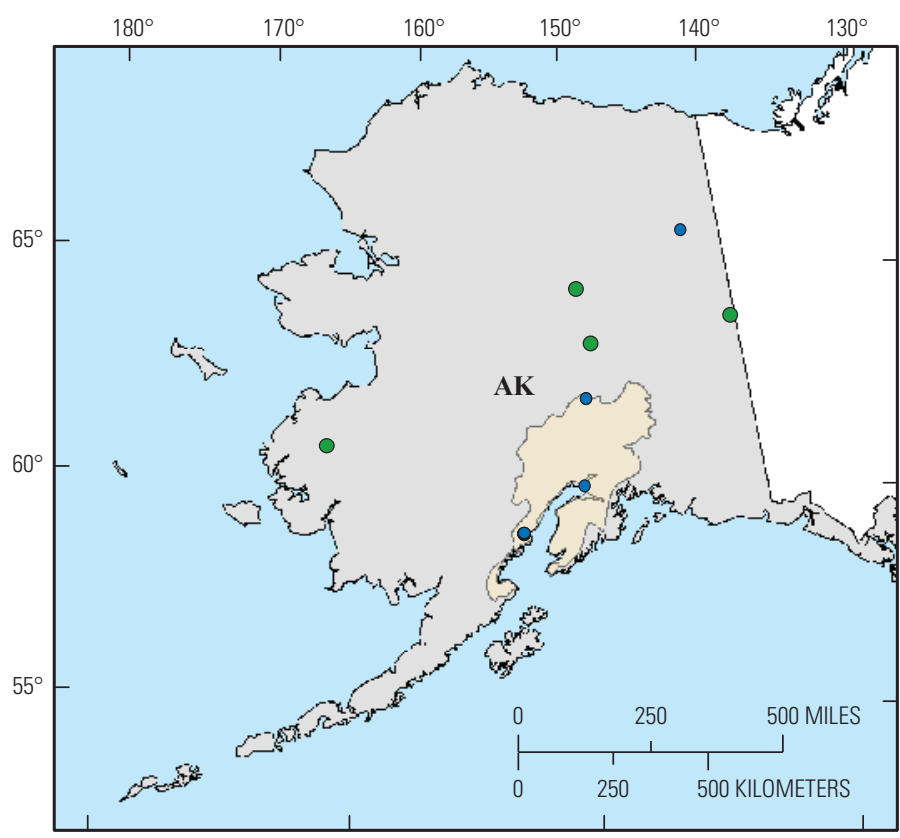

Base from U.S. Geological Survey digital data, 1:1,000,000-scale, 2006 Albers Equal Area Conic projection

Standard parallels $55^{\circ}, 65^{\circ}$, central meridian $-154^{\circ}$ latitiude of origin $50^{\circ}$; North American Datum of 1983

Figure J.1. The distribution of uranium concentrations in surface-water samples at National Water-Quality Assessment (NAWOA) and National Stream Quality Accounting Network (NASQAN) sites in the United States. 
the USEPA and comparable concentrations of human-health concern selected by the NTAS work group (table J.1).

The USEPA Radionuclides Rule, effective December 2003 (U.S. Environmental Protection Agency, 2000a), finalized the MCLs for several radionuclides, some of which have had preliminary regulations (MCLs) since 1976. For gross alpha-particle activity, the MCL of $15 \mathrm{pCi} / \mathrm{L}$ applies to all alpha emitters, minus the alpha activity of uranium isotopes and radon, but including that of ${ }^{226} \mathrm{Ra}$. Almost every laboratory method used for gross alpha-particle activity removes radon from the sample before measurement. Gross alpha-particle and beta-particle activity measurements represent the overall activity of all radionuclides present in a sample over a specified period of time (typically 72 hours or 20 or 30 days). If gross alpha-particle activity is not measured within 72 hours after sample collection, it may underreport the activity resulting from the presence of ${ }^{224} \mathrm{Ra}$; the current MCL for gross alpha-particle activity does not specify a sample holding time (U.S. Environmental Protection Agency, 2010). The MCL for radium of $5 \mathrm{pCi} / \mathrm{L}$ applies to the sum of two isotopes, ${ }^{226} \mathrm{Ra}$ plus ${ }^{228} \mathrm{Ra}$. Activities of $5.0-5.5 \mathrm{pCi} / \mathrm{L}$ for ${ }^{224} \mathrm{Ra}$, although this constituent is not included in the MCL for radium, can result in gross alpha-particle activities of about $15 \mathrm{pCi} / \mathrm{L}$ (the $\mathrm{MCL}$ ) within 36 to 48 hours after sample collection (Szabo and others, 2005); therefore, a benchmark of $5 \mathrm{pCi} / \mathrm{L}$ was selected for ${ }^{224} \mathrm{Ra}$ for purposes of this prioritization (table J.1). A benchmark of $15 \mathrm{pCi} / \mathrm{L}$ for gross beta-particle activity was selected as a screening level for NTAS purposes. Gross beta-particle activity has an MCL of 4 millirem per year (U.S. Environmental Protection Agency, 2000a).

The USEPA Radionuclides Rule also finalized a new MCL of $30 \mu \mathrm{g} / \mathrm{L}$ for uranium, which previously had not been regulated (U.S. Environmental Protection Agency, 2000a). The risk from chemical exposure at $30 \mu \mathrm{g} / \mathrm{L}$ of uranium in drinking water is comparable to the risk from a radiological exposure of $15 \mathrm{pCi} / \mathrm{L}$ of uranium (U.S. Environmental Protection Agency, 2000a), but the chemical analysis for elemental uranium concentration is faster, less expensive, and more widely available than the radiological analysis for the isotopes. If the isotopic composition of uranium has not been determined, a generalized formula can be used to estimate the expected activity on the basis of the mass measurement. If one presumes that the isotopes are present in the natural activity ratios $\left(1: 1\right.$ for $\left.{ }^{238} \mathrm{U}:{ }^{234} \mathrm{U}\right)$, a concentration of $1 \mu \mathrm{g} / \mathrm{L}$ of uranium yields an activity of $0.68 \mathrm{pCi} / \mathrm{L}$; however, in most groundwaters, ${ }^{234} \mathrm{U}$ can become enriched relative to ${ }^{238} \mathrm{U}$ (Osmond and Cowart, 1976), thereby increasing the uranium activity relative to its concentration. Thus, a commonly used activity ratio for ${ }^{238} \mathrm{U}:{ }^{234} \mathrm{U}$ is $1: 1.65$, which yields an activity of $0.9 \mathrm{pCi} / \mathrm{L}$ per $1 \mu \mathrm{g} / \mathrm{L}$ of uranium. This approach can be helpful in comparing gross alpha-particle activity with the MCL by subtracting the activity attributable to uranium. If uranium isotopes are present in ratios outside of the bounds assumed by the generalized formula, a situation that has been documented in nature (Osmond and Cowart, 1976; Gilkeson and Cowart, 1987; Zielinski and others, 1997; Arndt, 2010; Rosen, 2010), it is possible that not all alpha-particle activity will be accounted. In such cases, direct determination of uranium isotopes is needed.

For ${ }^{210} \mathrm{Po}$, the USEPA has determined an activity level of concern on the basis of a lifetime total cancer risk of $10^{-4}$ (1 in 10,000$)$ of $1.1 \mathrm{pCi} / \mathrm{L}$ (U.S. Environmental Protection Agency, 1999a). This level is similar to the MCL for ${ }^{226} \mathrm{Ra}$ plus ${ }^{228} \mathrm{Ra}$ of $5 \mathrm{pCi} / \mathrm{L}$, which assumes a lifetime total cancer risk of $2 \times 10^{-4}$ ( 1 in 20,000). A gross alpha-particle activity MCL of $15 \mathrm{pCi} / \mathrm{L}$ is intended to limit risk from ingestion by presuming a "worst-case" scenario of a water sample with a combination of $5 \mathrm{pCi} / \mathrm{L}$ of ${ }^{226} \mathrm{Ra}, 5 \mathrm{pCi} / \mathrm{L}$ of progeny of ${ }^{226} \mathrm{Ra}$, and $5 \mathrm{pCi} / \mathrm{L}$ of ${ }^{210} \mathrm{Po}$; other combinations of radionuclides, even if emitting alpha-particle activity totaling $15 \mathrm{pCi} / \mathrm{L}$, would carry less risk than this scenario because other radionuclides pose somewhat less ingestion risk. Because no MCL exists for ${ }^{210} \mathrm{Po}$, a benchmark of $5 \mathrm{pCi} / \mathrm{L}$ was used for the NTAS prioritization process (table J.1). Similarly, for the thorium isotopes, which also are alpha-emitters, no USEPA benchmarks were available, so an activity of $5 \mathrm{pCi} / \mathrm{L}$ was selected as a benchmark for the purpose of prioritization.

For ${ }^{210} \mathrm{~Pb}$, a naturally occurring beta-emitter, the MCL for gross beta-particle activity of 4 millirem per year can be exceeded at a concentration of $50 \mathrm{pCi} / \mathrm{L}$, and the USEPA has determined that a concentration of $2.2 \mathrm{pCi} / \mathrm{L}$ for ${ }^{210} \mathrm{~Pb}$ equates to a cancer risk of $10^{-4}$ (U.S. Environmental Protection Agency, 1999a). Because no MCL exists for ${ }^{210} \mathrm{~Pb}$ itself, a benchmark of $5 \mathrm{pCi} / \mathrm{L}$ was used for the NTAS prioritization process (table J.1), and an activity of $2.2 \mathrm{pCi} / \mathrm{L}$ also was used for comparison in the prioritization process.

For radon, the proposed alternative Maximum Contaminant Level (AMCL) was used (table J.1). The proposed MCL $(300 \mathrm{pCi} / \mathrm{L})$ and proposed $\mathrm{AMCL}(4,000 \mathrm{pCi} / \mathrm{L})$ for radon were assigned by the National Research Council (1999) on the basis of risk from both ingestion and inhalation exposure. The proposed AMCL applies to States or water supplies that have developed a multimedia mitigation program to address radon in indoor air (U.S. Environmental Protection Agency, 1999b). Most States or communities with high radon concentrations use the proposed AMCL rather than the proposed MCL. Activities greater than the proposed AMCL of $4,000 \mathrm{pCi} / \mathrm{L}$ were observed in 2.6 percent of NAWQA groundwater samples. By comparison, 64 percent of samples were greater than the proposed MCL of $300 \mathrm{pCi} / \mathrm{L}$.

\section{Results of Prioritization of Radionuclides in Water}

On the basis of the information sources described in the previous subsections, radionuclide activities greater than MCLs or proposed MCLs (or greater than human-health benchmarks for those constituents without MCLs or proposed MCLs) likely would occur for all of the radionuclides except for the thorium isotopes. Therefore, all of the Group J constituents were placed into Tier 1 (high priority), except for the 
thorium isotopes, which were placed into Tier 2 (intermediate priority). In addition, Milvy and Cothern (1989) showed that the risk of cancer mortality for exposure to radionuclides from drinking-water supplies is highest for ${ }^{222} \mathrm{Rn}$, which accounts for 80 percent of the potential mortality risk that can be attributed to radionuclides (primarily as a result of inhalation of the released gas). For a lifetime exposure (70 years), as many as 50,000 potential deaths might be attributable to ${ }^{222} \mathrm{Rn}(700$ annually) on the basis of the assumed risk from the possible exposure. Similarly, natural uranium and radium isotopes $\left({ }^{226} \mathrm{Ra}\right.$ and $\left.{ }^{228} \mathrm{Ra}\right)$ might account for between 100 and 4,000 potential deaths on the basis of the assumed risk from possible exposure over a 70-year lifetime. Therefore, these radionuclides warrant inclusion in Tier 1 to meet NAWQA Cycle 3 objectives related to human health and drinking water and are appropriate for ambient monitoring of water on national and regional scales.

\section{Basis of Prioritization of Radionuclides in Water}

Some of the radionuclide constituents evaluated for Group J are of high priority (Tier 1) because previous monitoring data document their occurrence at concentrations of human-health concern, and others are of high priority because they are likely to occur at concentrations of human-health concern but have relatively little monitoring data. Some of the radionuclides in Tier 1 currently (2011) are monitored in public-supply wells under the Safe Drinking Water Act; however, those radionuclides commonly are bundled within other surrogate measurements (such as gross alpha-particle activity) and, therefore, individual radionuclides have not been widely monitored even though some have MCLs.

New constituents that are of concern because of potential human-health risks (Focazio and others, 2001) are ${ }^{210} \mathrm{~Pb},{ }^{210} \mathrm{Po}$, and ${ }^{224} \mathrm{Ra}$. A major aquifer study in the summer of 2009 in the Mississippi Embayment NAWQA study unit showed that ${ }^{210} \mathrm{Po}$ was detected in 30 percent of samples from wells ( 9 of 30 wells) at low activities (less than $0.12 \mathrm{pCi} / \mathrm{L}$ ) (NAWQA Data Warehouse, U.S. Geological Survey 2011b). These activities were low compared to MCLs for similar radionuclides (for example, $5 \mathrm{pCi} / \mathrm{L}$ for radium) and were observed at the discharge end of the aquifer (near the Gulf of Mexico) where dissolved oxygen is low (fig. J.2). These newly documented ${ }^{210} \mathrm{Po}$ occurrence data are consistent with a current working hypothesis for polonium mobilization under reducing conditions (most likely sulfate-reducing conditions). The ${ }^{210} \mathrm{Po}$ concentrations that were higher than those previously observed might occur in groundwater in locations with strongly reducing conditions. In addition, a sample from one well out of 30 sampled wells had a detectable activity of ${ }^{210} \mathrm{~Pb}(0.2 \mathrm{pCi} / \mathrm{L})$. In the 1998 targeted reconnaissance of groundwater used for drinking-water supply (Focazio and others, 2001), approximately 2 percent of the 99 samples analyzed for ${ }^{210} \mathrm{~Pb}$ had activities greater than $2.2 \mathrm{pCi} / \mathrm{L}$. The radionuclides ${ }^{210} \mathrm{Po}$ and ${ }^{210} \mathrm{~Pb}$ potentially are of regulatory interest and were included in the USEPA's Unregulated Contaminant Monitoring Rule

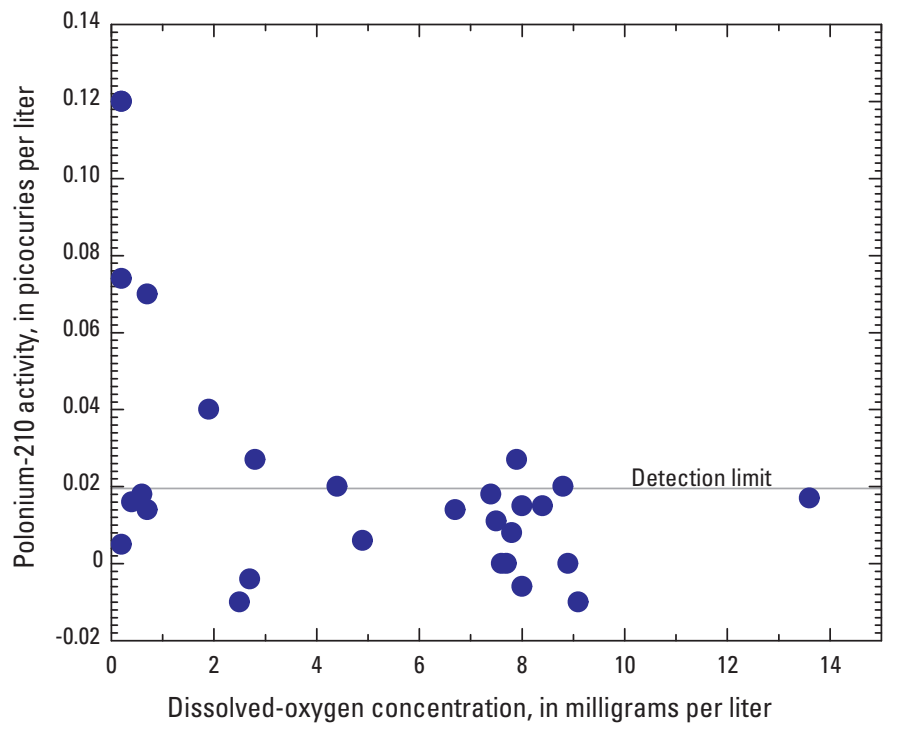

Figure J.2. Comparison of polonium-210 activities and dissolved-oxygen concentrations for National Water-Quality Assessment data collected in the Mississippi Embayment study unit in 2009. Activities less than 0.02 picocurie per liter are less than the detection limit for the analytical method. One sample that did not have a dissolved-oxygen measurement had a polonium-210 activity that was less than the detection limit.

(UCMR) list 3 (U.S. Environmental Protection Agency, 2001). These isotopes are considered to be of human-health concern based on potential ingestion exposure at relatively low activities, although no MCLs have been set.

Similarly, radium isotopes were less than $3 \mathrm{pCi} / \mathrm{L}$ in samples from most of the 30 wells in the Mississippi Embayment study unit, but concentrations of ${ }^{226} \mathrm{Ra}$ plus ${ }^{228} \mathrm{Ra}$ (combined) were greater than the MCL of $5 \mathrm{pCi} / \mathrm{L}$ in 4 of 30 samples (13.3 percent). This frequency of detections greater than the MCL is high in comparison to that documented for the United States as a whole, based on NAWQA monitoring data from Cycles 1 and 2 (table J.1). All the samples with radium activities greater than the MCL were acidic, with $\mathrm{pH}$ values ranging from about 4.0 to 4.5 . The trend was most readily identifiable for ${ }^{226} \mathrm{Ra}$, with activities generally less than $0.2 \mathrm{pCi} / \mathrm{L}$ when $\mathrm{pH}$ was greater than 5 , but with an increase in activity at $\mathrm{pH}$ values less than 5 and the highest activities occurring at $\mathrm{pH}$ values less than 4.5 (fig. J.3). These newly documented radium occurrence data are consistent with a current working hypothesis regarding one of the geochemical conditions for radium mobilization, namely acidic waters (Szabo and others, 2005). Radon was detected in samples from all 30 wells, with more than 25 percent of the samples having activities greater than the proposed MCL of $300 \mathrm{pCi} / \mathrm{L}$; however, no sample had activities greater than the $4,000 \mathrm{pCi} / \mathrm{L}$ proposed AMCL. Radium and gross alpha-particle activity were greater than their MCLs in 3 to 13 percent of samples. (Gross beta-particle activity was measured only in terms of activity and not in terms of tissue exposure in millirems per year as needed to determine MCL exceedance). 


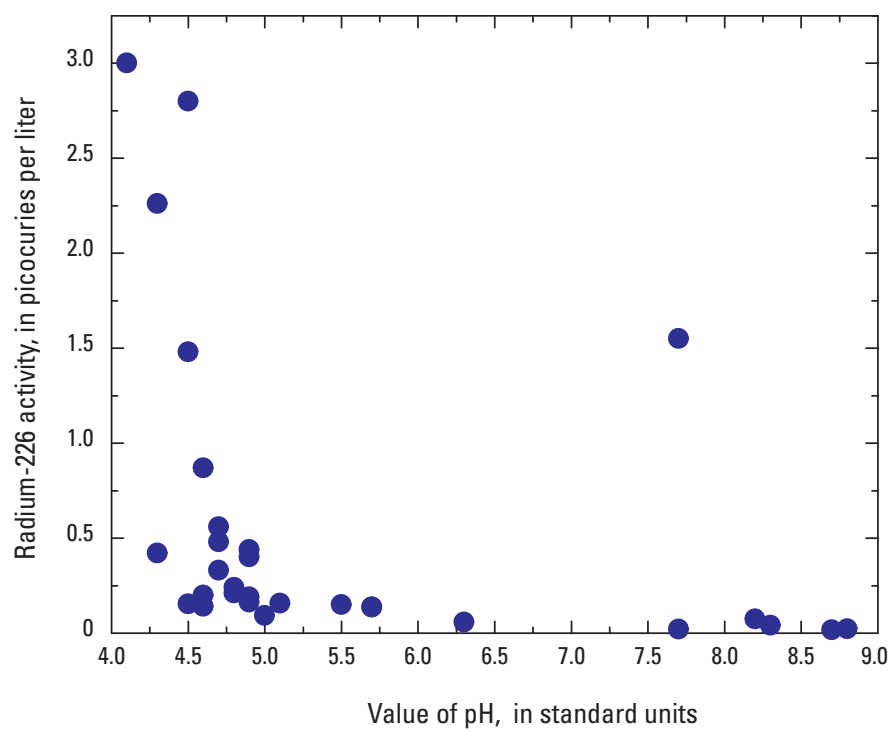

Figure J.3. Relation between radium-226 activity and $\mathrm{pH}$ for groundwater samples collected for the National Water-Quality Assessment Program in the Mississippi Embayment study unit in 2009.

Given the results from this one NAWQA major aquifer study and detection frequencies based on limited national sampling by NAWQA Cycles 1 and 2 and by Focazio and others (2001), all of the Tier 1 constituents, including ${ }^{210} \mathrm{Po}$ and ${ }^{210} \mathrm{~Pb}$, warrant inclusion in future monitoring of ambient groundwater, and possibly surface water. If cost is of concern, historical data coupled with measurements of gross alpha-particle activity, gross beta-particle activity, and elemental uranium could be used to identify those settings that are of highest priority for monitoring for the full suite of radionuclide constituents.

Thorium isotopes $\left({ }^{228} \mathrm{Th},{ }^{230} \mathrm{Th}\right.$, and $\left.{ }^{232} \mathrm{Th}\right)$ were placed into Tier 2 (intermediate priority) because they are practically insoluble and are unlikely to be mobilized in groundwater (Cothern and Rebers, 1990; Focazio and others, 2001). Of the 33 samples collected in the 1998 targeted reconnaissance, for which sites were selected on the basis of known or suspected occurrence of radium $\left({ }^{224} \mathrm{Ra}\right.$ is a member of the ${ }^{232} \mathrm{Th}$ decay series), samples from only one site had activities for ${ }^{228} \mathrm{Th}$, ${ }^{230} \mathrm{Th}$, and ${ }^{232} \mathrm{Th}$ greater than the benchmark of $5 \mathrm{pCi} / \mathrm{L}$ used for the NTAS prioritization (Focazio and others, 2001). Although analyses of thorium isotopes can be useful in the study of the geochemical history and movement of old groundwater (Cuttell and others, 1986), routine monitoring of these constituents in ambient water is not warranted.

\section{Feasibility of Implementation for High-Priority Radionuclides}

Laboratory methods are available for most of the Tier 1 radionuclides (table J.2 at http://pubs.usgs.gov/sir/2012/5218/ downloads/tableJ.xlsx). Current (2011) USGS laboratory methods - uranium by inductively coupled plasma with mass spectrometry (ICP/MS); gross alpha-particle and beta-particle activities by low-background gas-proportional counting; ${ }^{224} \mathrm{Ra}$, ${ }^{226} \mathrm{Ra}$, and ${ }^{228} \mathrm{Ra}$ by alpha-spectrometry, radon de-emanation, and beta-counting, respectively (all after barium sulfate coprecipitation), and ${ }^{222} \mathrm{Rn}$ by liquid scintillation - are suitable for continuation for these previously analyzed constituents because detection limits are less than human-health benchmarks. These methods do not require modification, except perhaps for the method used for ${ }^{224} \mathrm{Ra}$, which has not been approved by the American Society for Testing and Materials (1999) and has had problems with precision, contamination bias, and sensitivity (Duane S. Wydoski, U.S. Geological Survey, written commun., 2010). The gamma spectroscopy technique for ${ }^{224} \mathrm{Ra}$ analysis is an approved standard method by the American Public Health Association (2005).

New constituents (that is, those not previously monitored for the NAWQA Program) placed into Tier 1 are ${ }^{210} \mathrm{Po}$ and ${ }^{210} \mathrm{~Pb}$. Although standard techniques for determining ${ }^{210} \mathrm{Po}$ are adequate, minor improvements are warranted. The radionuclide ${ }^{210} \mathrm{Po}$ is analyzed by alpha spectrometry after spontaneous deposition onto silver disks. Because ${ }^{210} \mathrm{Po}$ is particlereactive, the sample container must be soaked in strong acid to remove any ${ }^{210} \mathrm{Po}$ that could sorb to the container walls and the acid-wash aliquot from the sample bottle combined with the sample before deposition of the ${ }^{210} \mathrm{Po}$ onto the silver disks (Vesterbacka and Ikaheiomenen, 2005). Analysis of ${ }^{210} \mathrm{~Pb}$ is by beta-counting the ingrown isotope of bismuth, ${ }^{210} \mathrm{Bi}$, progeny after separation of the lead from the sample with lead-specific cation-exchange columns or disks that have high specificity for lead in complex matrixes (Woittiez and others, 1995). Beta-counting can result in high imprecision (about or greater than plus or minus 25 percent) and poor quantification at concentrations of environmental interest (at or about $1 \mathrm{pCi} / \mathrm{L}$ ). Isotopes of uranium can be quantified with considerable expense using alpha-spectrometry, but low-cost quantification using ICP/MS may soon be available (Kraemer and others, 2002) and would improve understanding of uranium occurrence and understanding of sources of gross alpha-particle activity.

Improvements in extraction procedures could improve low-level quantification for some of the radioisotopes. For example, the current practice of coprecipitation with barium sulfate limits the effectiveness of alpha spectrometry for analysis of ${ }^{224} \mathrm{Ra}$; approaches have been tested to improve performance of this step, including using ethylenediaminetetraacetic acid as a complexing agent to allow for more complete purification of the sample and precipitation of a more uniform barite crystal (Arndt and West, 2007; Arndt, 2010) or using a bed of previously precipitated microcrystalline barite as the seeding agent for formation of the radium-bearing barite separate (Ganzerli and others, 1999). These improvements could be implemented at commercial laboratories in the future.

Improvements in counting are possible but would require research. Thermal-ionization mass spectrometry has been found to be effective for determination of ${ }^{226} \mathrm{Ra}$ after electroplating (Cohen and O'Nions, 1991), but the technique in its 
current form cannot be used for the other isotopes of radium or for ${ }^{210} \mathrm{Po}$ and ${ }^{210} \mathrm{~Pb}$, although it might work for uranium isotopes. The USGS Geologic Discipline Laboratory in Denver has this instrumentation; however, it has only been used for research to date. Exceptionally low detection limits, possible by this approach, could allow for a lower level of quantification for (at least) ${ }^{226} \mathrm{Ra}$. Alpha-, beta-, or gamma-coincidence counting methods (Moore and Arnold, 1996) are highly accurate, radionuclide-specific, and have low detection limits; however, the equipment used for these methods is expensive and was not available to USGS at the time of the NTAS prioritization effort (2011). Gamma spectroscopy might be used instead of beta counting for beta-emitters ${ }^{228} \mathrm{Ra}$ and ${ }^{210} \mathrm{~Pb}$ if field sample preconcentration methods can be improved (described later in this section); however, the equipment is bulky and samples require long counting times. Perhaps more innovative is the use of alpha spectroscopy of alpha-emitting progeny of the beta-emitter ${ }^{228} \mathrm{Ra}$ and ${ }^{210} \mathrm{~Pb}$, which might substantially improve precision and detection capability (Vesterbacka and Ikaheiomenen, 2005), although drawbacks of this approach are that a long ingrowth time is required and sample preconcentration might be needed.

New constituents ${ }^{210} \mathrm{Po}$ and ${ }^{210} \mathrm{~Pb}$ might require some method development and validation. The National Water Quality Laboratory maintains a contract with a commercial laboratory for analysis of ${ }^{224} \mathrm{Ra},{ }^{210} \mathrm{Po}$, and ${ }^{210} \mathrm{~Pb}$, ensuring adequate analytical capability. Although the methods used by this laboratory have not undergone approval within the USGS (Duane S. Wydoski, U.S. Geological Survey, written commun., 2010), they are standard for the radionuclide-analytical community and can achieve detection limits of $1 \mathrm{pCi} / \mathrm{L}$ (with higher sensitivity possible for individual samples on the basis of composition). Potential improvements would require collaboration with a fully equipped radiochemical laboratory. Recent guidance on the storage and reporting of the results and measurement uncertainty associated with the counting of radioactive decay (McCurdy and others, 2008) for USGS data can be adapted to the expected refinements with the associated field and laboratory methods.

Field collection for the radionuclides requires 1 to 2 liters (L) of water to be filtered and acidified with nitric acid to $\mathrm{pH}$ less than 2 . For short-lived ${ }^{224} \mathrm{Ra}$ and gross alpha- and betaparticle activities, samples are shipped overnight to the laboratory to arrive within 24 hours of collection; these samples must be collected early in the week to allow time to complete the analysis in the same week. Detection limits for the radionuclides are a function of sample volume, so sensitivity can be improved if larger volumes of water can be collected. Several preconcentration methods have been tested that might allow for infield extraction of radionuclides from large volumes of sample (50-200 L), thereby substantially improving detection and quantification capability. One documented approach is the use of manganese-impregnated fibers initially tested by Moore and Reid (1973) that can extract radium with almost 100-percent efficiency from large volumes of water under alkaline oxic conditions; this technique has been used by Eikenberg and others (2001) and Nour and others (2004). Because radium concentrations tend to be lowest in alkaline oxic water (Szabo and dePaul, 1998), this technique could help improve understanding of environmental concentrations specifically in that water type. The efficiency of the manganese coatings is substantially reduced in acidic ( $\mathrm{pH}$ less than 5.5 ) and reducing (dissolved oxygen less than 0.5 milligram per liter) waters; however, radium concentrations tend to be highest under these geochemical conditions (Szabo and Zapecza, 1991; Szabo and others, 2005) under which quantification by standard procedures is less problematic. Similarly, radium-specific extraction discs or lead rhodizonate-coated filters have been tested in laboratory settings but not in the field (Ganzerli and others, 1999).

\section{Knowledge and Concerns of Radionuclides in Water as a Constituent Group}

Uranium isotopes, ${ }^{210} \mathrm{Po},{ }^{210} \mathrm{~Pb},{ }^{226} \mathrm{Ra}$, and ${ }^{224} \mathrm{Ra}$ are established human carcinogens (International Agency for Research on Cancer, 1988), and their presence in drinking water is a cause for concern. Although naturally occurring radionuclides can occur in groundwater at concentrations greater than human-health benchmarks because of weathering and dissolution of minerals, routine monitoring commonly has excluded individual radionuclides because not all have MCLs and analyses are expensive. Consequently, monitoring data for individual radionuclides are sparse, and the understanding of the occurrence and distribution of radionuclides in drinkingwater sources, including groundwater, is incomplete.

Studies have shown natural and human-induced elevated concentrations of uranium in ambient waters in the United States. For example, Spalding and Sackett (1972) showed that uranium concentrations in the Mississippi River watershed system (surface water, drainage canals, and shallow groundwater) have increased from the use of uranium-containing phosphate-based fertilizer throughout the watershed. Hess and others (1985) found elevated concentrations of uranium in public-water supplies from surface water and groundwater in the United States. Snow and Spalding (1994) showed that the North and South Platte Rivers have naturally high uranium concentrations because of weathering of uraniferous rocks within their headwater watershed areas. Ayotte, Gronberg, and Apodaca (2011), Ayotte, Szabo, and others (2011), and DeSimone (2009) identified concentrations greater than MCLs for about 30 percent of samples collected from observation wells for the NAWQA Program and analyzed for trace elements (including uranium) (table J.3 at http://pubs. usgs.gov/sir/2012/5218/downloads/tableJ.xlsx), compared to concentrations greater than MCLs fewer than 5 percent of samples analyzed for volatile organic compounds and pesticides. Uranium concentrations were greater than the MCL in 9 percent of samples collected from wells completed in unconsolidated sand and gravel aquifers and crystalline rock aquifers (Ayotte, Gronberg, and Apodaca, 2011), representing more 
than one-half of the samples analyzed, but not quite one-half of the geographic area studied. Almost 8 percent of samples from wells in the arid parts of the United States had uranium concentrations greater than the MCL, compared to less than 3 percent of the wells in humid areas (Ayotte, Gronberg, and Apodaca, 2011).

Further complicating the issue is that human-induced changes to the redox state of an aquifer can make certain elements and radioactive isotopes more mobile than others (Szabo and Zapecza, 1991; Ayotte, Szabo, and others, 2011). In NAWQA Cycles 1 and 2 monitoring data, uranium concentrations correlated positively with dissolved oxygen concentrations and inversely with iron concentrations, whereas ${ }^{226} \mathrm{Ra}$ correlated inversely with dissolved oxygen concentrations but positively with iron concentrations. The application of uranium-bearing minerals in fertilizers, infiltration or runoff of irrigation water, or degradation of concrete may increase concentrations of radioactive isotopes in shallow groundwater (Spalding and Sackett, 1972; Zielinski and others, 1997; Szabo and others, 2005; Jurgens and others, 2009). Therefore, monitoring of radionuclides could provide an indication of human-induced changes in water quality.

In addition to elemental uranium and gross alpha-particle and beta-particle activity, specific radionuclides could warrant ambient monitoring on a national or regional scale:

- Uranium isotopes tend to be mobile in oxidizing alkaline waters (Szabo and Zapecza, 1991). To date (2010), only one State, California, regulates and requires characterization of uranium isotopes (Wong and others, 1999); for a sample bearing only uranium isotopes, the sum of activities from uranium isotopes should not exceed $15 \mathrm{pCi} / \mathrm{L}$. The presence of uranium isotopes can affect gross alpha-particle activities (Szabo and Zapecza, 1991; Szabo and others, 2007). In some cases, uranium isotopes account for almost all of the gross alpha-particle activity; in other cases, excess gross alpha-particle activity may be attributable to other isotopes, such as radium or polonium (fig. J.4). Measurements of uranium isotopes can be used to assess geochemical conditions in aquifers or to assess the causes of excess gross alpha-particle activity and where it occurs. If enrichment of ${ }^{234} \mathrm{U}$ relative to ${ }^{238} \mathrm{U}$ is not taken into account, a misleading interpretation of the gross alpha-particle activity may be that other isotopes such as radium or polonium are present (when they are not) or that activities are greater than an MCL when, if properly corrected for uranium activity, they are not. The process of alpha recoil (movement of the nucleus in the opposite direction when an alpha particle is emitted) can release ${ }^{234} \mathrm{U}$ directly into waterfilled pore spaces at an enhanced rate relative to dissolution alone for the uranium isotopes (Osmond and Cowart, 1976) resulting in excess ${ }^{234} U$ relative to ${ }^{238} U$ in some groundwaters $\left({ }^{234} \mathrm{U}:{ }^{238} \mathrm{U}\right.$ activity ratio greater than 1). Because the half-life of ${ }^{234} U$ is shorter than that of ${ }^{238} \mathrm{U}$, and its rate of radioactive decay is greater (by nearly a factor of $10^{4}$ ), a very small amount of ${ }^{234} \mathrm{U}$ can result in a substantial increase in the gross alphaparticle activity emitted by uranium in a sample. The excess activity from a small amount of excess ${ }^{234} \mathrm{U}$ can cause substantial variability in the gross alpha-particle activity that might be derived from a quantified "mass" of total uranium because most techniques of mass measurement only effectively measure the mass of the ${ }^{238} \mathrm{U}$ isotope. Analysis by using ICP/MS may become the accepted exception to this analytical issue (Kraemer and others, 2002). The isotopes responsible for "excess" gross alpha-particle activity might be more readily defined if the variations in the isotopic ratios of uranium were known.

- The polonium isotope, ${ }^{210} \mathrm{Po}$, binds to sediment (Balistrieri and others, 1995) but has been found in groundwater at activities greater than $1 \mathrm{pCi} / \mathrm{L}$ (Focazio and others, 2001). Activities of $5 \mathrm{pCi} / \mathrm{L}$ or greater have been reported for samples from wells in California, Florida, Louisiana, Nevada, and Maryland (Harada and others, 1989; LaRock and others, 1996; Seiler, 2011; Seiler and others, 2011). In 2007, the USGS analyzed samples from 25 wells that provide drinking water for human and animal consumption in Lahontan Valley, Nevada (Seiler, 2007); samples from 13 of the wells had ${ }^{210} \mathrm{Po}$ activities greater than $15 \mathrm{pCi} / \mathrm{L}$, and samples from 3 of the wells had activities greater than $60 \mathrm{pCi} / \mathrm{L}$. In 2009, a sample with an activity greater than $170 \mathrm{pCi} / \mathrm{L}$ was collected from a domestic well in the same area (Seiler, 2011). These activities are higher than the World Health Organization drinkingwater guideline of $2.7 \mathrm{pCi} / \mathrm{L}$ (World Health Organization, 2006) and the Canadian Maximum Acceptable Concentration for drinking water of $5.4 \mathrm{pCi} / \mathrm{L}$ (Health Canada, 2010). Polonium occurs as a natural decay product of uranium and radon, which are widespread in aquifers in the United States; thus ${ }^{210}$ Po can occur in groundwater. Geochemical and microbiological studies of ${ }^{210} \mathrm{Po}$ in Florida groundwater indicate that it can be mobilized in sulfate-reducing environments following incorporation into bacterial tissue (Harada and others, 1989; LaRock and others, 1996), and sulfur isotope data indicate that similar processes could be occurring in Lahontan Valley, Nevada (Seiler, 2011). The USEPA has not promulgated drinking-water standards specifically for ${ }^{210} \mathrm{Po}$ (U.S. Environmental Protection Agency, 2000a); however, the USEPA has determined that an activity of $1.1 \mathrm{pCi} / \mathrm{L}$ corresponds to a lifetime total cancer risk of $10^{-4}$ (U.S. Environmental Protection Agency, 2000b). Information on ${ }^{210} \mathrm{Po}$ occurrence is needed by the USEPA to determine whether a specific regulatory standard should be set (U.S. Environmental Protection Agency, 2000b); it is not yet known whether occurrence is widespread enough to justify the monitoring requirements associated with setting a standard. 


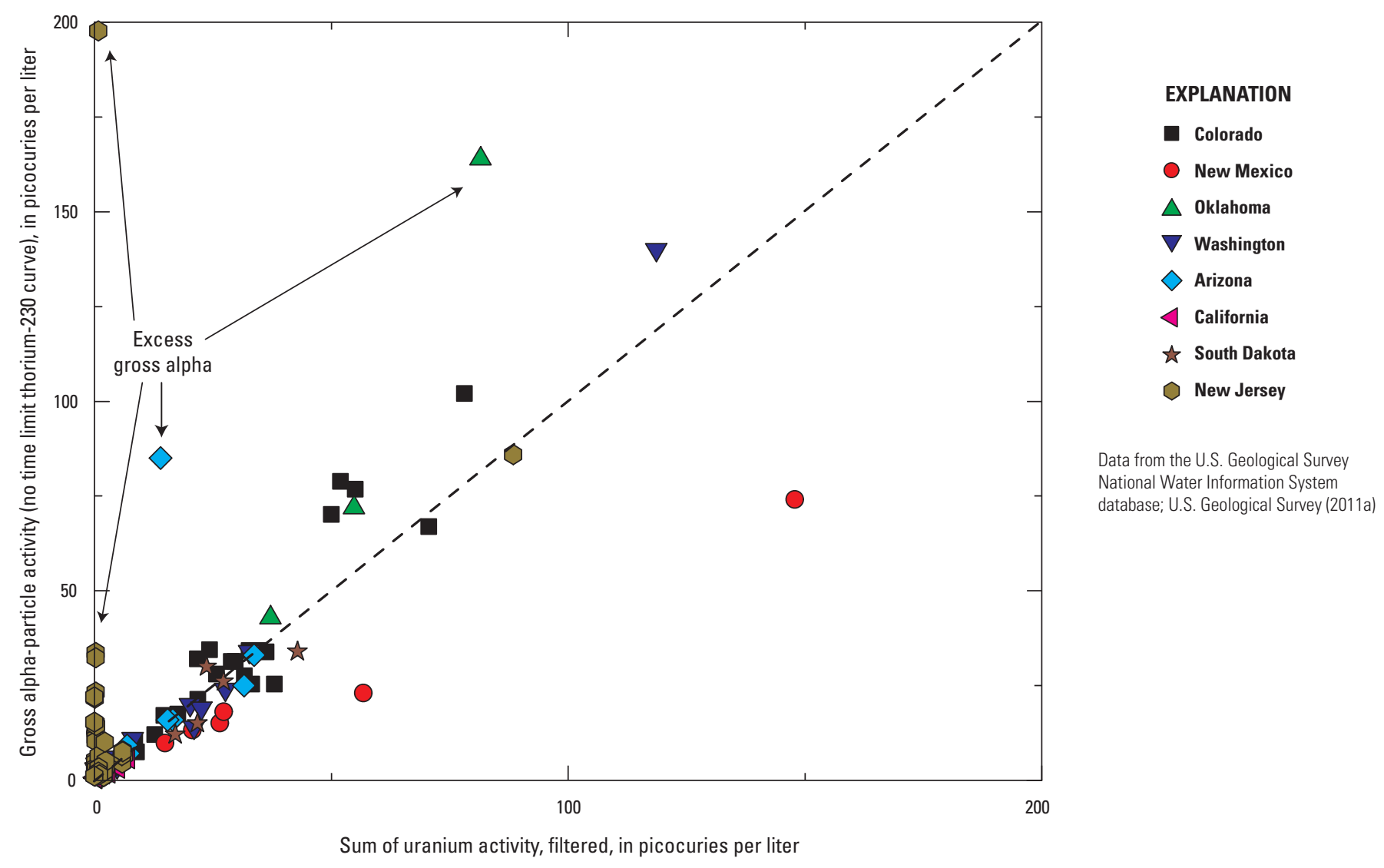

Figure J.4. Correlation between gross alpha-particle activity (unadjusted for uranium acitivity) and the sum of uranium activity.

- Radium is similar to polonium and is mobile in reducing or acidic waters. Its presence can affect gross alpha-particle measurements over time (Szabo and others, 2005, 2007; Arndt and West, 2007; Arndt, 2010). Concentrations of ${ }^{224} \mathrm{Ra}$ can be affected by the physical process of alpha recoil, which can cause slight increases in the concentrations of progeny farther from the original long-lived parent in the decay chain (dePaul and Szabo, 2007; Szabo and others, 2005). Knowledge of radium activities might help identify environments in which reducing geochemical conditions are coupled with radionuclide mobility, and the ratios of radium isotopes might further identify those areas where alpha recoil is prominent. For example, because ${ }^{210} \mathrm{Po}$ is near the end of the ${ }^{238} \mathrm{U}$ decay chain, alpha recoil might be expected to affect ${ }^{210} \mathrm{Po}$ concentrations.

- The lead isotope, ${ }^{210} \mathrm{~Pb}$, sorbs onto aquifer solids (Krishnaswami and others, 1982) and in moderately acidic conditions is less soluble than radium and more difficult to extract from sediment (Paulson, 1997; Centeno and others, 2004; Szabo and others, 2005). In a 1998 targeted reconnaissance of groundwater sources of drinking water (Focazio and others, 2001), 10 percent of 99 samples analyzed for ${ }^{210} \mathrm{~Pb}$ had activities greater than $1 \mathrm{pCi} / \mathrm{L}$, and 2 percent were greater than $2.2 \mathrm{pCi} / \mathrm{L}$, a level that corresponds to a lifetime cancer risk of $10^{-4}$ (U.S. Environmental Protection Agency, 1999a). One sample had a ${ }^{210} \mathrm{~Pb}$ activity greater than $4 \mathrm{pCi} / \mathrm{L}$ (Focazio and others, 2001). The isotope ${ }^{210} \mathrm{~Pb}$ was detected most frequently in the Appalachian Physiographic Province, especially in Connecticut and Pennsylvania. Geochemical mechanisms that control ${ }^{210} \mathrm{~Pb}$ dissolution are not established and warrant additional research. Szabo and others (2005) showed that although ${ }^{224} \mathrm{Ra}$ activities in drinking-water samples from the strongly acidic Kirkwood-Cohansey aquifer system in New Jersey (median pH of 4.8) were larger than expected based on previous analyses of gross alpha-particle activity, the same could not be stated for ${ }^{210} \mathrm{~Pb}$. In 20 samples from community water supplies (Szabo and others, 2005), ${ }^{210} \mathrm{~Pb}$ was detected at activities of about $1 \mathrm{pCi} / \mathrm{L}$ in about one-half of the wells, but activities were less than $2.2 \mathrm{pCi} / \mathrm{L}$ in all samples. The greatest detection frequency of ${ }^{210} \mathrm{~Pb}$ in Finland was in regions with the highest ${ }^{222} \mathrm{Rn}$ activities (Vesterbacka and others, 2005). Correlations of ${ }^{222} \mathrm{Rn}$ with elemental lead have been noted in granitic terranes by Ayotte and others (2007). In groundwater from granitic terranes in New Jersey in areas with high ${ }^{222} \mathrm{Rn}$ activities, one sample had a ${ }^{210} \mathrm{~Pb}$ activity greater than $4 \mathrm{pCi} / \mathrm{L}$ (Zoltan 
Szabo, U.S. Geological Survey, written commun., 2010). Gross beta-particle activity has been analyzed in many USGS studies throughout the Nation but likely would not provide much insight regarding ${ }^{210} \mathrm{~Pb}$ occurrence. Concentrations of naturally occurring potassium isotope ${ }^{40} \mathrm{~K}$ account for most gross beta-particle activity in samples with activities less than $10 \mathrm{pCi} / \mathrm{L}$ (Welch and others, 1995), and ${ }^{228} \mathrm{Ra}$ or progeny of ${ }^{238} \mathrm{U}$ account for most gross beta-particle activity where the activity is greater than $10 \mathrm{pCi} / \mathrm{L}$ or where groundwaters are acidic (Welch and others, 1995; Szabo and others, 2005). Unlike the alpha-particle emissions from ${ }^{224} \mathrm{Ra}$ (and ${ }^{210} \mathrm{Po}$ ), which are extremely energetic and efficiently detected, beta particles from ${ }^{210} \mathrm{~Pb}$ are lower in energy and difficult to detect (Welch and others, 1995). In the absence of other data, areas where ${ }^{210} \mathrm{~Pb}$ could be important might be initially identified by elevated ${ }^{222} \mathrm{Rn}$ as a crude screening mechanism. The USEPA also has not promulgated drinking-water standards for ${ }^{210} \mathrm{~Pb}$, although a proposed standard at $1 \mathrm{pCi} / \mathrm{L}$, assuming a lifetime cancer risk of $5.65 \times 10^{-5}$, has been discussed (U.S. Environmental Protection Agency, 2000a).

- Radon is of human-health concern by way of inhalation and ingestion. The National Research Council (1999) evaluated intake rates, radon fate in the body (biokinetic model), and the fate of decay products to determine a dose-conversion factor (to convert an ingested amount into a radiation dose). Inhalation of radon and its decay products, which can volatilize from drinking water, comprises the major route of residential exposure ( 89 percent), followed by ingestion (11 percent). Because the relation between radon in water and radon volatilized into residential air is approximately an additional $1 \mathrm{pCi} / \mathrm{L}$ of indoor air per $10,000 \mathrm{pCi} / \mathrm{L}$ in water in an "average" home, the proposed AMCL of $4,000 \mathrm{pCi} / \mathrm{L}$ in water would result in an increase of $0.4 \mathrm{pCi} / \mathrm{L}$ in indoor air compared to background concentrations in outdoor air (approximately $0.4 \mathrm{pCi} / \mathrm{L}$ of air). Radon activities collected during NAWQA Cycles 1 and 2 were highest in groundwater samples from the New York and New England crystalline-rock aquifers. The 90th-percentile activity in groundwater samples collected for all of the NAWQA study units (combined) was $1,500 \mathrm{pCi} / \mathrm{L}$, but the 90 th percentile in samples from the crystalline rock aquifers was 8,600 pCi/L (Ayotte, Gronberg, and Apodaca, 2011), which is greater than the proposed AMCL of $4,000 \mathrm{pCi} / \mathrm{L}$. Some groundwater samples collected from the crystalline bedrock aquifers had radon activities greater than $100,000 \mathrm{pCi} / \mathrm{L}$. Radon is an inert gas with a half-life of 3.8 days, so occurrence is indicative of hydrological processes that affect radon activities. In samples from wells completed in several different lithologies, radon activities were shown to correlate with geochemical properties such as redox and pH. In New England, for example, high radon activities commonly occurred in oxic samples with low $\mathrm{pH}$, indicating high groundwater flux (short residence time) (Ayotte, Gronberg, and Apodaca, 2011). Uranium also correlated with radon in the igneous and metamorphic-rock aquifers, but radon correlated with no other elements in this lithology. However, in New York and New England crystallinerock aquifers, radon correlated with lead (Ayotte and others, 2007).

\section{References for Radionuclide Elements in Water (Group J)}

American Public Health Association, 2005, Radium, in Standard methods for the examination of water and wastewater (20th ed.): American Public Health Association, p. 7-29 to 7-42 (section 7500-Ra).

American Society for Testing and Materials, 1999, Annual book of ASTM standards, v. 11.02: Philadelphia, Pa., American Society for Testing and Materials Standards, v. 11.02, p. 240.

Arndt, M.F., 2010, Evaluation of gross alpha and uranium measurements for MCL compliance: Denver, Colo., Water Research Foundation, 225 p.

Arndt, M.F., and West, L.E., 2007, An experimental analysis of some of the factors affecting gross alpha-particle activity with an emphasis on ${ }^{226} \mathrm{Ra}$ and its progeny: Health Physics, v. 92 , p. $148-156$.

Ayotte, J.D., Flanagan, S.M., and Morrow, W.S., 2007, Occurrence of uranium and ${ }^{222}$ radon in glacial and bedrock aquifers in the northern United States, 1993-2003: U.S. Geological Survey Scientific Investigations Report 20075037, 84 p., accessed May 1, 2012, at http://pubs.usgs.gov/ sir/2007/5037/.

Ayotte, J.D., Gronberg, J.M., and Apodaca, L.E, 2011, Trace elements and radon in groundwater across the United States, 1992-2003: U.S. Geological Survey Scientific Investigations Report 2011-5059, 126 p., accessed May 1, 2012, at http://water.usgs.gov/nawqa/trace/pubs/sir2011-5059/.

Ayotte, J.D.; Szabo, Zoltan; Focazio, M.J.; and Eberts, S.M.; 2011, Effects of human-induced alteration of groundwater flow on concentrations of naturally-occurring trace elements at water-supply wells: Applied Geochemistry, v. 26, no. 5, p. $747-762$.

Balistrieri, L.S., Murray, J.W., and Paul, Barbara, 1995, The geochemical cycling of stable $\mathrm{Pb},{ }^{210} \mathrm{~Pb}$, and ${ }^{210} \mathrm{Po}$ in seasonally anoxic Lake Sammamish, Washington, USA: Geochimica et Cosmochimica Acta, v. 59, no. 23, p. 4,845-4,861. 
Centeno, L.M.; Faure, Gunter; Lee, Giehyeon; and Talnagi, J.; 2004, Fractionation of chemical elements including the REEs and ${ }^{226} \mathrm{Ra}$ in stream contaminated with coal-mine effluent: Applied Geochemistry, v. 19, no. 7, p. 1,085-1,095.

Cohen, A.S., and O'Nions, R.K., 1991, Precise determination of fentogram quantities of radium by thermal ionization mass spectrometry: Analytical Chemistry, v. 63, p. 2,7052,706 .

Cothern, R.C., and Rebers, P.A., 1990, Radon, radium and uranium in drinking water: Chelsea, Mich., Lewis Publishers, Inc., 286 p.

Cuttell, J.C., Lloyd, J.W., and Ivanovich, M., 1986, A study of uranium and thorium series isotopes in chalk groundwaters of Lincolnshire, U.K.: Journal of Hydrology, v. 86, p. 353-365.

dePaul, V.T., and Szabo, Zoltan, 2007, Occurrence of radium-224, radium-226, and radium-228 in water from the Vincentown and Wenonah-Mount Laurel aquifers, the Englishtown aquifer system, and the Hornerstown and Red Bank sands, southwestern and south-central New Jersey: U.S. Geological Survey Scientific Investigations Report 2007-5064, 62 p., accessed May 1, 2012, at http://pubs. usgs.gov/sir/2007/5064/.

DeSimone, L.A., 2009, Quality of water from domestic wells in principal aquifers of the United States, 1991-2004: U.S. Geological Survey Scientific Investigations Report 2008-5227, 139 p. (Also available at http://pubs.usgs.gov/ $\operatorname{sir} / 2008 / 5227 /$.)

Eikenberg, Jost; Tricca, Aude; Vezzu, Guido; Bajo, Sixto; Ruethi, Max; and Surbeck, Heintz; 2001, Determination of ${ }^{228} \mathrm{Ra}$, ${ }^{226} \mathrm{Ra}$, and ${ }^{224} \mathrm{Ra}$ in natural water via adsorption on $\mathrm{MnO}_{2}$-coated discs: Journal Environmental Radioactivity, v. 54, p. 109-131.

Focazio, M.J., Szabo, Zoltan, Kraemer, T.F., Mullin, A.H., Barringer, T.H., and dePaul, V.T., 2001, Occurrence of selected radionuclides in ground water used for drinking water in the United States-A targeted reconnaissance survey, 1988: U.S. Geological Survey Water-Resources Investigations Report 00-4273, 40 p. (Also available at http://pubs.usgs.gov/wri/wri004273/.)

Ganzerli, M.T.V., Maggi, Luigino, and Caramella, V.C., 1999, Procedure for analysis of radium in freshwaters by adsorption on basic lead rhodizonate: Analytical Chemistry, v. 71, p., $162-166$.

Gilkeson, R.H., and Cowart, J.B., 1987, Radium, radon, and uranium isotopes in ground water from Cambrian-Ordovician sandstone aquifers in Illinois, in Graves, Barbara, ed., Radon in ground water-Hydrogeologic impact and indoor air contamination: Chelsea, Mich., Lewis Publishers, Inc., p. $403-422$.
Gilliom, R.J.; Barbash, J.E.; Crawford, C.G.; Hamilton, P.A.; Martin, J.D.; Nakagaki, Naomi; Nowell, L.H.; Scott, J.C.; Stackelberg, P.E.; Thelin, G.P.; and Wolock, D.M.; 2006, The quality of our Nation's waters-Pesticides in the Nation's streams and ground water, 1992-2001: U.S. Geological Survey Circular 1291, 172 p. (Also available at http://pubs.usgs.gov/circ/2005/1291/.)

Harada, Koh; Burnett, W.C.; LaRock, P.A.; and Cowart, J.B.; 1989, Polonium in Florida groundwater and its possible relationship to the sulfur cycle and bacteria: Geochimica et Cosmochimica Acta, v. 53, p. 143-150.

Health Canada, 2010, Guidelines for Canadian drinking water quality-Summary table: accessed January 26, 2011, at http://www.hc-sc.gc.ca/ewh-semt/alt formats/hecs-sesc/pdf/ pubs/water-eau/2010-sum_guide-res_recom/sum_guideres_recom-eng.pdf. [Guidelines updated August 2012 at http://www.hc-sc.gc.ca/ewh-semt/pubs/water-eau/2012sum_guide-res_recom/index-eng.php.]

Hess, C.T.; Michel, Jacqueline; Horton, T.R.; Prichard, H.M.; and Coniglio, W.A.; 1985, The occurrence of radioactivity in public water supplies in the United States: Health Physics, v. 48 , no. p. $553-586$.

International Agency for Research on Cancer, 1988, Manmade mineral fibres and radon-Summary of data reported and evaluation (updated January 21, 1998): World Health Organization International Agency for Research on Cancer, IARC Monographs on the Evaluation of Carcinogenic Risks to Humans, v. 43, accessed March 2, 2011, at http:// monographs.iarc.fr/ENG/Monographs/vol43/volume43.pdf.

Jurgens, B.C., Fram, M.S., Belitz, Kenneth, Burow, K.R., and Landon, M.K., 2009, Effects of groundwater development on uranium, Central Valley, California, USA: Ground Water, v. 47 , p. $1-16$.

Kraemer, T.F., Doughten, M.W., and Bullen, T.D., 2002, Use of ICP/MS with ultrasonic nebulizer for routine determination of uranium activity ratios in natural water: Environmental Science and Technology, v. 36, p. 4,899-4,904.

Krishnaswami, S., Graustein, W.C., Turekian, K.K., and Dowd, J.F., 1982, Radium, thorium, and radioactive lead isotopes in groundwaters-Application to the in situ determination of adsorption-desorption rate constants and retardation factors: Water Resources Research, v. 18, no. 6, p. $1,663-1,675$.

LaRock, P., Hyun, J.H., Boutelle, S., Burnett, W.C., and Hull, C.D., 1996, Bacterial mobilization of polonium: Geochimica et Cosmochimica Acta, v. 60, no. 22, p. 4,321-4,328.

McCurdy, D.E., Garbarino, J.R., and Mullin, A.H., 2008, Interpreting and reporting radiological water-quality data: U.S. Geological Survey Techniques and Methods, book 5, chap. B6. 
Milvy, Paul, and Cothern, C.R., 1989, Naturally occurring radionuclides in drinking water-An exercise in risk benefit analysis: Environmental Geochemistry and Health, v. 11, no. 2, p. 63-72.

Moore, W.S., and Arnold, Ralph, 1996, Measurement of ${ }^{223} \mathrm{Ra}$ and ${ }^{224} \mathrm{Ra}$ in coastal waters using a delayed coincidence counter: Journal of Geophysical research, v. 101, p. 1,3211,329 .

Moore, W.S., and Reid, David, 1973, Extraction of radium from natural waters using manganese-impregnated acrylic fibers: Deep Sea Research, v. 23, p. 647-651.

National Research Council, 1999, Risk assessment of radon in drinking water: Washington, D.C., National Academy Press, $296 \mathrm{p}$.

Nour, S., El-Sharkawy, A., Burnett, W.C., and Horwitz, E.P., 2004, Radium-228 determination of natural waters via concentration on manganese dioxide and separation using Diphonix ion exchange resin: Applied Radiation Isotopes, $\mathrm{v}$. 61, p. 1,173-1,178.

Osmond, J.K., and Cowart, J.B., 1976, The theory and uses of natural uranium isotopic variations in hydrology: Atomic Energy Review, v. 14, no. 4, p. 621-679.

Paulson, A.J., 1997, The transport and fate of $\mathrm{Fe}, \mathrm{Mn}, \mathrm{Cu}, \mathrm{Zn}$, $\mathrm{Cd}, \mathrm{Pb}$, and $\mathrm{SO}_{4}$ in a groundwater plume and in downstream surface waters in the Coeur d'Alene Mining District, Idaho, U.S.A.: Applied Geochemistry, v. 12, no. 4, p. 447-464.

Rosen, M.R., 2010, Evaluating the potential occurrence of ${ }^{210} \mathrm{Po}$ in US groundwater using uranium concentrations and gross alpha radioactivity: National Water Quality Monitoring Council, Seventh National Monitoring Conference Program, Denver, Colo., April 25-29, 2010, p. 168, accessed March 15, 2011, at http://acwi.gov/monitoring/ conference/2010/2010_NMC_Program_2010-04-13.pdf.

Seiler, R.L., 2007, Methods and data used to investigate polonium-210 as a source of excess gross-alpha radioactivity in ground water, Churchill County, Nevada: U.S. Geological Survey Open-File Report 2007-1231, 11 p.

Seiler, R.L., 2011, ${ }^{210}$ Po in Nevada groundwater and its relation to gross alpha radioactivity: Ground Water, v. 49, no. 2, p. $160-171$.

Seiler, R.L.; Stillings, L.L.; Cutler, Nichole; Salonen, Laina; and Outola, Iisa; 2011 Biogeochemical factors affecting the presence of ${ }^{210} \mathrm{Po}$ in groundwater: Applied Geochemistry, v. 26 , no. 4 , p. $526-539$.

Snow, D.D., and Spalding, R.F., 1994, Uranium isotopes in the Platte River drainage basin of the North American High Plains Region: Applied Geochemistry, v. 9, no. 3, p. 271-278.
Spalding, R.F., and Sackett, W.M., 1972, Uranium in runoff from the Gulf of Mexico Distributive Province-Anomalous concentrations: Science, v. 175, no. 4022, p. 629-631.

Szabo, Zoltan, and dePaul, V.T., 1998, Dissolved radium-226 and radium-228 in shallow ground water, southern New Jersey: U.S. Geological Survey Fact Sheet FS-062-98, 6 p.

Szabo, Zoltan, and Zapecza, O.S., 1991, Geologic and geochemical factors controlling uranium, radium-226, and radon-222 in ground water, Newark Basin, New Jersey, in Gundersen, L.C.S., and Wanty, R.B., eds., Field studies of radon in rocks, soils, and water: U.S. Geological Survey Bulletin 1971, p. 243-266.

Szabo, Zoltan, dePaul, V.T., Fischer, J.M, Kraemer, T.F., and Jacobsen, Eric, 2012, Occurrence and geochemistry of radium in water from principal drinking-water aquifer systems of the United States: Applied Geochemistry, v. 27, no. 3, p. 729-752.

Szabo, Zoltan, dePaul, V.T., Kraemer, T.F., and Parsa, Bahman, 2005, Occurrence of radium-224, radium-226, and radium-228 in water of the unconfined Kirkwood-Cohansey aquifer system, southern New Jersey: U.S. Geological Survey Scientific Investigations Report 2004-5224, 100 p.

Szabo, Zoltan, Fischer, J.M, dePaul, V.T., Jacobsen, Eric, and Kraemer, T.F., 2007, Change in gross alpha- and betaparticle activity after sample collection as an indicator of the occurrence of radium-224 and uranium in ground water in the western United States, 2004 [abs]: National Ground Water Association Arsenic, Radium, Radon, and Uranium Conference, Charleston, S.C., March 22-23, 2007, p. 3-4.

U.S. Environmental Protection Agency, 1999a, Cancer risk coefficients for environmental exposure to radionuclides: Washington, D.C., U.S. Environmental Protection Agency EPA 402-R-99-001, Federal Guidance Report No. 13.

U.S. Environmental Protection Agency, 1999b, Proposed radon in drinking water rule: Washington, D.C., U.S. Environmental Protection Agency, Technical Fact Sheet EPA 815-F-99-006, 6 p., accessed April 30, 2012, at http://www. epa.gov/ogwdw000/radon/fact10.pdf.

U.S. Environmental Protection Agency, 2000a, National Primary Drinking Water Regulations, Radionuclides, Final Rule: Federal Register, U.S. Code of Federal Regulations, December 7, 2000, v. 65, no. 236, p. 76,708-76,753.

U.S. Environmental Protection Agency, 2000b, Radionuclides notice of data availability-Technical support document: accessed January 25, 2010, at http://www.epa.gov/ogwdw/ radionuclides/pdfs/regulation_radionuclides_rulemaking_ techsupportdoc.pdf. 
U.S. Environmental Protection Agency, 2001, UCMR (1999) list 1 and list 2 chemical analytical methods and quality control manual: U.S. Environmental Protection Agency, Office of Water EPA -815-R-01-028, accessed February 18, 2010, at http://www.epa.gov/ogwdw/ucmr/ucmrl/pdfs/ guidance_ucmr1_qualitycontrol_1999.pdf.

U.S. Environmental Protection Agency, 2010, Drinking water contaminants: accessed December 20, 2010, at http://www. epa.gov/safewater/contaminants/index.html.

U.S. Geological Survey, 2011a, National Water Information System - USGS water data for the Nation [database]: accessed March 15, 2011 at http://waterdata.usgs.gov/nwis/ nwis.

U.S. Geological Suvey, 2011b, USGS National Water Quality Assessment Data Warehouse: accessed March 15, 2011 at http://water.usgs.gov/nawqa/data.

Vesterbacka, Pia, and Ikäheimonen, T.K., 2005, Optimization of ${ }^{210} \mathrm{~Pb}$ determination via spontaneous deposition of ${ }^{210}$ Po on a silver disk: Analytica Chimica Acta, v. 545, p. $252-261$.

Vesterbacka, Pia, Mäkeläinen, I., and Arvela, H., 2005, Natural radioactivity in drinking water in private wells in Finland: Radiation Protection Dosimetry, v. 113, p. 223-232.

Welch, A.H., Szabo, Zoltan, Parkhurst, D.L., VanMetre, P.C., and Mullin, A.H., 1995, Gross-beta activity in ground water-Natural sources and artifacts of sampling and laboratory analysis: Applied Geochemistry, v. 10, no. 5, p. 491-503.
Woittiez, J.R.W., Sloof, J.E., and Kroon, K.J., 1995, Fast, selective, and sensitive methods for the determination of lead-210 in phosphogypsum and phosphate ore: Journal of Radioanalytical and Nuclear Chemistry, v. 194, no. 2, p. 319-329.

Wong, C.T., Okamato, H.S., Milea, A.M., Perera, S.K., and Baumann, F.J., 1999, Isotopic uranium activity ratios in California groundwater: Journal American Water Works Association, v. 91, no. 4, p. 171-185.

World Health Organization, 2006, Guidelines for drinkingwater quality - First addendum to third addition, volume 1, recommendations: accessed October 10, 2007, at http:// www.who.int/water_sanitation_health/dwq/gdwq0506.pdf.

Zielinski, R.A., Asher-Bolinder, A., Meier, A.L., Johnson, C.A., and Szabo, B.J., 1997, Natural or fertilizer-derived uranium in irrigation drainage - A case study in southeastern Colorado, U.S.A.: Applied Geochemistry, v. 12, p. 9-21.

Zogorski, J.S., Carter, J.M., Ivahnenko, Tamara, Lapham, W.W., Moran, M.J., Rowe, B.L., Squillace, P.J., and Toccalino, P.L., 2006, The quality of our Nation's waterVolatile organic compounds in the Nation's ground water and drinking-water supply wells: U.S. Geological Survey Circular 1292, 101 p. (Also available at http://pubs.usgs. gov/circ/circ1292/.) 


\section{Supplemental Information K.}

\section{Constituents Identified as Having Intermediate Priority (Tier 2) or Low or No Priority (Tier 3) for Water or Sediment}

This supplemental information section of the report presents the constituents that were evaluated by the U.S. Geological Survey (USGS) National Target Analyte Strategy (NTAS) work group for national- and regional-scale ambient monitoring in the United States in support of planning for the third decade (Cycle 3) of the National Water-Quality Assessment Program, but were determined to be of intermediate priority (Tier 2) or low or no priority (Tier 3). The 1,460 constituents in table K.1 at http://pubs.usgs.gov/sir/2012/5218/downloads/
tableK.xlsx are not of high priority for monitoring because they are of low or no concern with respect to human health or aquatic life, or they are not expected to be widely found in ambient groundwater, surface water, suspended sediment, or streambed sediment. Constituents that are identified as being of intermediate priority (Tier 2) might be of interest for targeted studies of contaminated sites, such as animal feeding operations, landfills, or wastewater effluent discharge points. 
Publishing support provided by:

Lafayette and Rolla Publishing Service Centers

For more information concerning this publication, contact:

Director, USGS South Dakota Water Science Center

1608 Mt. View Road

Rapid City, South Dakota 57702

(605) 394-3200

http://sd.water.usgs.gov/

Information regarding the National Water-Quality Assessment Program is available at http://water.usgs.gov/nawqa/. 



$$
\text { 遏 }
$$

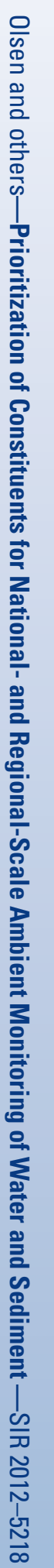

